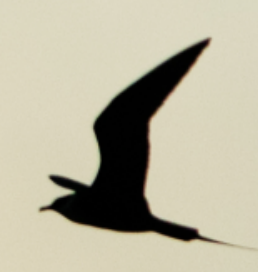

\title{
SEABIRDS LINKING
}

ARCTIC AND OCEAN 


\section{PROPOSITIONS}

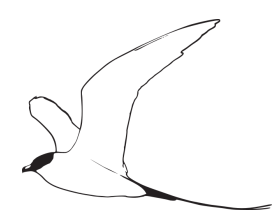

1. Based on existing knowledge, Arctic Skuas show the largest variation in wintering destinations between individuals from a single breeding location of any bird species.

(this thesis)

2. Itinerancy in the non-breeding period, the strategy in which birds move within the wintering area, is a common but understudied phenomenon among migratory birds.

(this thesis)

3. Despite the increased interest in long-term ecological datasets for climate change studies it is extremely difficult to get studies funded for longer than the length of government administrations and funding cycles.

4. Conservation in the high seas requires a global approach both in science and politics.

5. In order to decrease the impacts of single-use consumer plastics, reducing should be heavily prioritized over recycling.

6. Including the period between the last menstruation and conception in the duration of (human) pregnancy is biologically incorrect and confusing.

Propositions belonging to the thesis, entitled

\section{SEABIRDS LINKING ARCTIC AND OCEAN}

Rob S.A. van Bemmelen

Wageningen, 30 October 2019 


\section{Seabirds linking \\ Arctic and ocean}

Rob S. A. van Bemmelen 


\section{THESIS COMMITTEE}

\section{Promotors}

Prof. Dr Ron Ydenberg

Special professor of Fauna Management and Conservation

Wageningen University \& Research

Professor of Behavioural Ecology

Simon Fraser University, Burnaby, Canada

\section{Co-promotors}

Dr Ingrid Tulp

Researcher, Wageningen Marine Research

Wageningen University \& Research

Dr Raymond Klaassen

Researcher, Conservation Ecology Group

University of Groningen

\section{Other members}

Prof. Dr Adriaan Rijnsdorp, Wageningen University \& Research

Prof. Dr Jaap van der Meer, VU Amsterdam

Prof. Dr Bart Nolet, Netherlands Institute for Ecology, Wageningen

Dr Morten Frederiksen, Aarhus University, Denmark

This research was conducted under the auspices of the Graduate School for Production Ecology \& Resource Conservation (PE\&RC). 


\section{Seabirds linking \\ Arctic and ocean}

Rob S. A. van Bemmelen

Thesis

submitted in fulfilment of the requirements for the degree of doctor at Wageningen University

by the authority of the Rector Magnificus

Prof. Dr A.P.J. Mol,

in presence of the

Thesis Committee appointed by the Academic Board

to be defended in public

on Wednesday 30 October 2019

at 11 a.m. in the Aula. 
Rob S.A. van Bemmelen

Seabirds linking Arctic and ocean 280 pages.

PhD thesis, Wageningen University, Wageningen, the Netherlands (2019). With references, with summaries in English and Dutch

ISBN: 978-94-6395-114-2

DOI: https://doi.org/10.18174/499288 


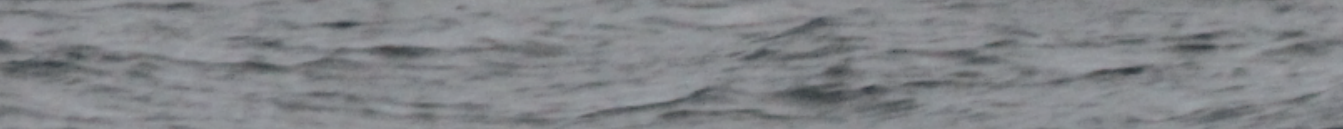

times
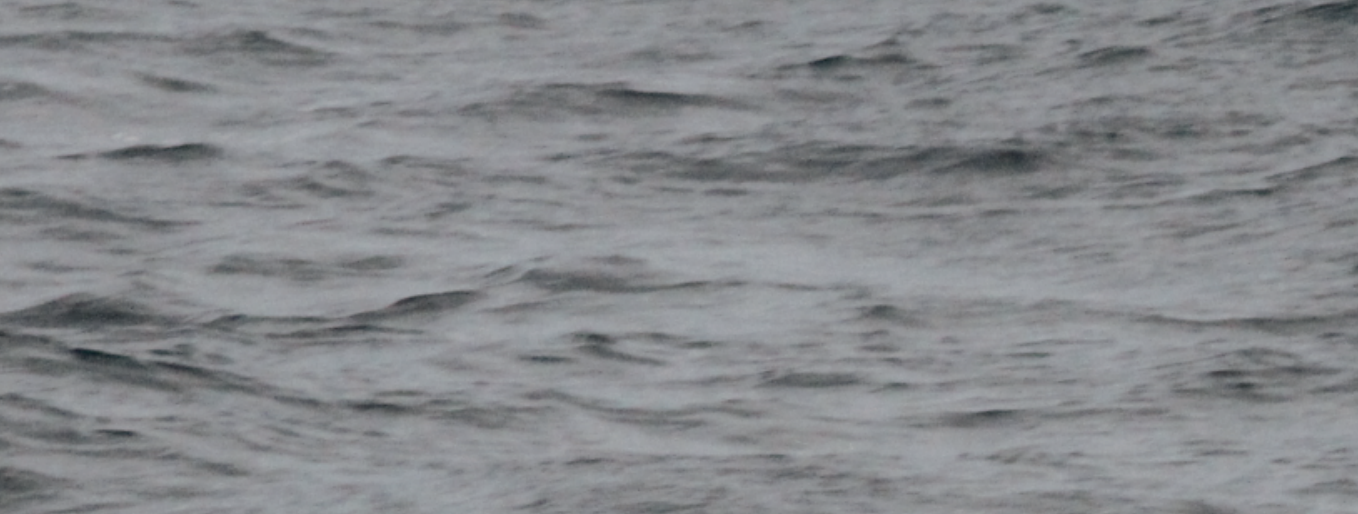

\section{-}
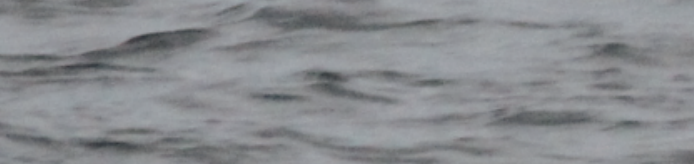

alanom:

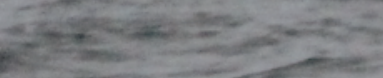

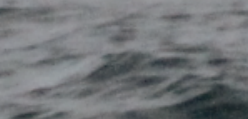

-

-

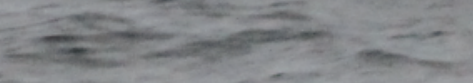

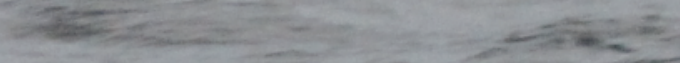

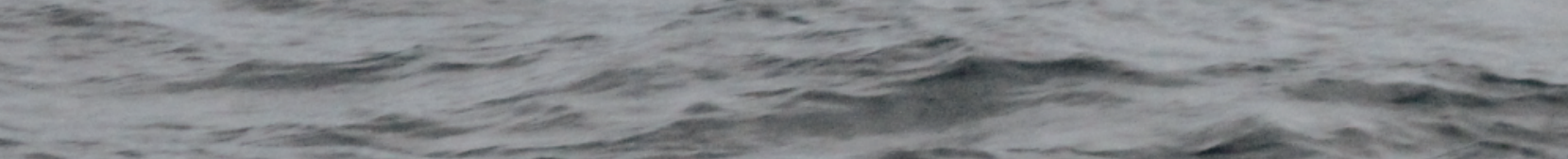
In- -

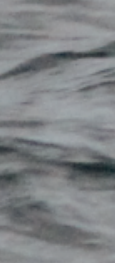
insis.
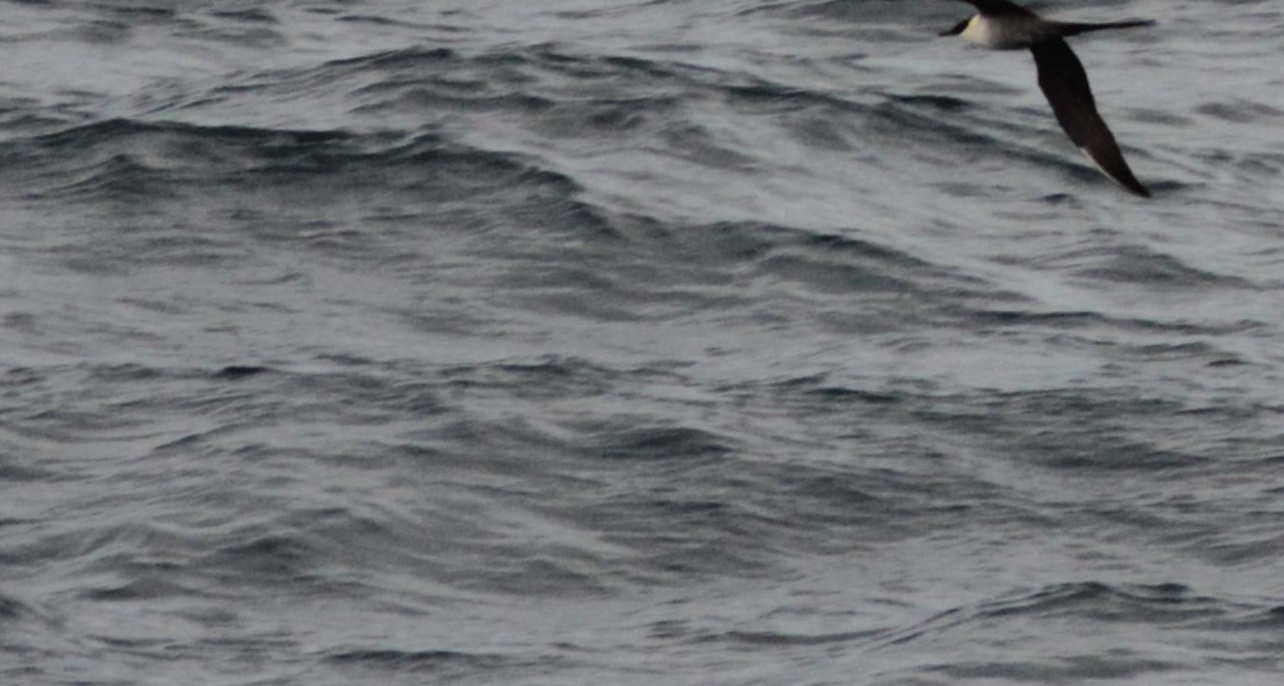

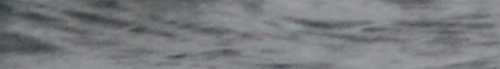
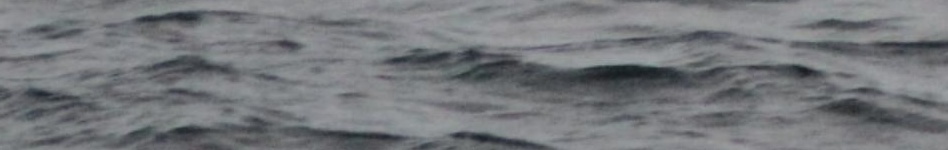

20.

This adult Long-tailed Skua in breeding plumage probably just started its migration to the 


\section{CONTENTS}

Chapter I General introduction 8

Chapter II First geolocator tracks of Swedish red-necked phalaropes reveal the Scandinavia-Arabian Sea connection

Chapter III A migratory divide among red-necked phalaropes in the Western Palearctic reveals contrasting migration and wintering movement strategies

Chapter IV Individual variation in non-breeding movements across hemispheres of Grey Phalaropes

Chapter $\mathrm{V} \quad$ Timing and duration of primary molt in Northern hemisphere skuas and jaegers

Chapter VI Flexibility in otherwise consistent non-breeding movements in a long-distance migratory seabird, the Long-tailed Skua 
Chapter VII Use of distantly and locally acquired resources for egg production under extreme inter-annual variation in food abundance in a long-distance migratory seabird

Chapter VIII Breeding and wintering location drive the annual cycle of a long-distance migratory seabird at an ocean scale

Chapter IX Heavy decline of the largest European Arctic 172 Skua colony: interacting effects of food shortage and predation

Chapter X General discussion

Summary / Samenvatting

References

Author affiliations, List of publications, Acknowledgements / Dankwoord, Author contributions, Biography 


\section{CHAPTER I}

"At first sight it seems remarkable that there is no special work dealing with the birds of an ocean so long and well explored as the North Atlantic. For many of these birds the high sea is their element; and when, as they must, they forsake it to breed, they resort by night to the outermost stacks and loneliest islands as if they grudged even this last link with the shore. Of their habits and lives during the two-thirds of each year when they are not breeding our knowledge is fragmentary and has never been pieced together, not because it is uninteresting but because there are almost insurmountable difficulties to be overcome before completing the picture of the ebb and flow of bird life over so vast an area."

Wynne-Edwards (1935)

The length of the central tail-feathers varies considerable between individual Long-tailed Skuas, is longer in males and may signal the quality of the individual. Ammarnäs, Sweden, 20 June 2016. 


\section{General introduction}

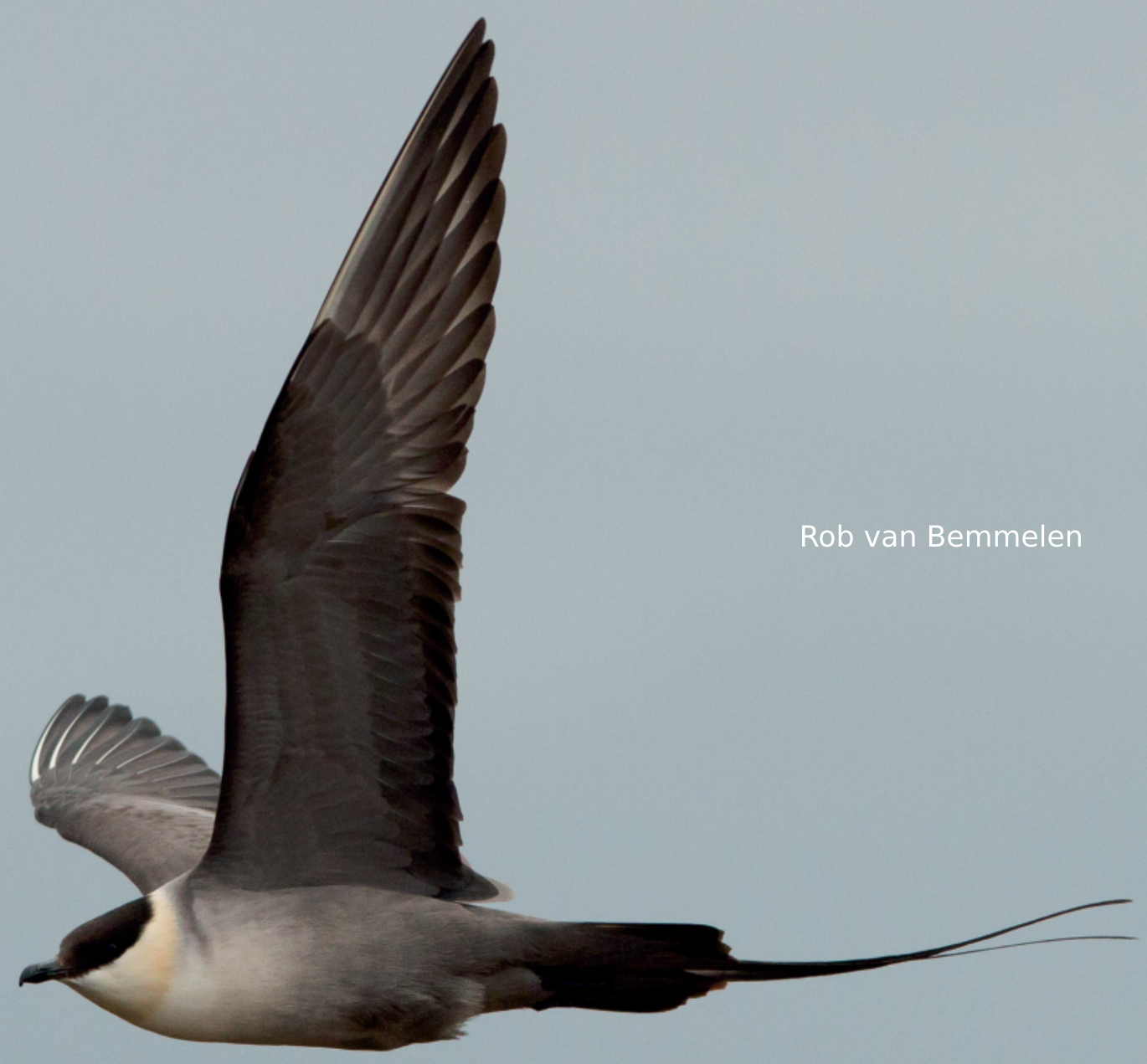


Animal migration - regular, seasonal round-trip movements between a region where reproduction takes place and non-breeding region(s) - is a widespread phenomenon, occurring in many clades of the animal kingdom, including mammals, fish, reptiles and insects, but has been especially extensive studied in birds (MilnerGulland et al. 2011, Dingle 2014). Migration should be favoured over year-round residency whenever it increases individual survival, reproductive success, or both. Among birds breeding in seasonal habitats, migration is generally regarded as a behavioural adaptation to avoid fitness and survival costs of seasonally deteriorating feeding conditions at the breeding site while profiting from favourable feeding conditions at the breeding site and elsewhere (Alerstam et al. 2003, Winger et al. 2018). Other drivers of migration include predation avoidance, reduced parasite loads, reduced competition, or differential habitat requirements for reproduction and survival (Newton 2010). Bird migration involves huge numbers of individuals representing a large biomass, and functionally links areas and species communities that can be many 1000s km apart (Bauer and Hoye 2014). Considering migrants often spent the major part of their annual cycle away from the breeding area, studying migration and wintering ecology is critical for a full understanding of the full life cycle of a species.

Migratory birds need to fit breeding, moult, migration and other important activities within the 365 days of a year. For these activities, individual migrants depend throughout their annual cycle on widely separated areas. These areas may show contrasts in quality of habitat, predation danger, and the potential threats posed by human activities, such as habitat destruction, hunting and (over)fishing (Cury et al. 2011, Croxall et al. 2012, Grémillet et al. 2018). Conditions experienced in any of these areas or periods can lead to mortality within that season, but it can also affect the performance of individuals in subsequent parts of the annual cycle, and ultimately affect individual fitness and population demography (Norris and Marra 2007, Harrison et al. 2011). The occurrence of such 'carry-over' effects in migratory birds is supported by a growing body of evidence (e.g. (Marra et al. 1998, Norris et al. 2004, Sorensen et al. 2009, Catry et al. 2013, Woodworth et al. 2017), and provides a clear impetus to study the full annual cycle of migrants.

In many migratory bird species, individuals return to the same non-breeding area each year (Newton 2010). This strategy has advantages, such as familiarity to foraging areas which may improve efficiency of foraging, and may result in increased survival and body condition (Holmes et al. 1989, Shizuka et al. 2014, Blackburn and Cresswell 2016). In other species, individuals appear more flexible between years in non-breeding area selection (Dias et al. 2011, Van Bemmelen et al. 2017). How such flexibility is advantageous for the individual is not clear, but it is conceivable that flexible individuals are less sensitive to decreases in quality of local habitat, such as those imposed by climate change. Also, flexibility in migration routes and destinations may be advantageous in unpredictable environments (Newton 2010). 
Migration routes and destinations may also differ between individuals of a single population, causing individuals to experience different conditions and selective pressures. In fact, large-scale migration patterns show extraordinary variation in routes, destinations, distances and strategies between and within populations of the same species (Alerstam 1990, Newton 2010). Migratory connectivity measures the extent to which individuals from the same breeding population migrate to a single non-breeding area (strong migratory connectivity) or to different nonbreeding areas (weak migratory connectivity) (Webster et al. 2002). Populations with strong migratory connectivity are thought to be more vulnerable to local threats at any of the sites along their route. As such, the strength of migratory connectivity has been proposed as a demographic metric, like reproductive rates, survival rates, and age ratios, with potentially large consequences for populations and species (Cohen et al. 2018).

In reality, large-scale migration networks are more complex than consisting of only breeding and main non-breeding areas; they also encompass stopover sites used during migration. Although this is acknowledged by Webster et al. (2002), stopover sites are often not considered in studies of migratory connectivity. Likewise, the fact that many species sequentially visit distinct areas during the wintering period ('intra-tropical movements' or 'itinerancy', (Moreau 1972) and how this affects migratory connectivity, has received very little attention (Delmore et al. 2012). Finally, it is not only important where individuals migrate to, but also when they do so. More precisely, the synchrony, phenology, and consistency in area use affect to what extent different individuals or populations are exposed to conditions at a particular site, including aspects as competition and disease transmission (Bauer et al. 2016). Clearly, all these aspects of migratory connectivity have implications for ecology, evolution and conservation.

Migratory bird species are suffering heavier population declines than resident species, suggesting aspects of migratory behaviour renders them particularly vulnerable (Both et al. 2010, Runge et al. 2014). Also seabirds, many of which are migratory, have recently been characterised as "more threatened than other comparable groups of birds" and their conservation status has deteriorated faster over recent decades (Croxall et al. 2012). Their vulnerability is likely related to the fact that seabirds are typically long-lived and slow reproducing species (Weimerskirch 2002), meaning reduction in adult survival or reproductive success has long-lasting effects on population size. Long-distance migratory seabirds breeding in the Arctic may be particularly affected by (human-induced) climate change, considering projected temperature rise is greatest for the Arctic zone (Stocker et al. 2013) while also their non-breeding grounds, productive oceanic habitats, are predicted to change considerably in terms of primary productivity (Hoegh-Guldberg and Bruno 2010). Paradoxically, the mobility of migratory species may lead to contrasting expectations regarding their ability to respond to rapid environmental change, such as altered habitat quality and distribution. On one 
hand, mobile species could be expected to be able to relocate whenever suitable habitat decreases in quality or location. On the other hand, they could be expected to be unable to mitigate the effects of habitat alteration given their tightly scheduled migration itineraries and dependency on multiple, very specific sites (Robinson et al. 2009). Quantifying variation in migration patterns at individual and populations levels is a critical first step to ultimately understand the ability of species to adjust movement patterns to changes in the environment, as selection acts on phenotypic variation (Alerstam 2006, van Noordwijk et al. 2006, Runge et al. 2014).

In this thesis, I aim to reveal the non-breeding movements for a set of four longdistance migrants that breed in the Arctic but winter on the open ocean, and disentangle variation in non-breeding movements at individual, population and species level. Spending most of their time at sea where studying them is challenging and expensive, their non-breeding movements and thus the links between their Arctic breeding area and oceanic non-breeding areas are poorly known. Seabirds evolved into efficient flyers as an adaptation to life at sea (Alerstam 1990). Their migrations rank high among the longest and most spectacular journeys of migratory animals. For example, Arctic Terns Sterna paradisaea migrate back-and-forth between Arctic breeding grounds and Antarctic wintering grounds (Egevang et al. 2010, Fijn et al. 2013), and South Polar Skuas Stercorarius maccormicki breeding on the Antarctic peninsula migrate to the North Atlantic (Kopp et al. 2011). The migration patterns of seabirds are fundamentally different from terrestrial species because they evolved on the ocean, the habitat that represents an ecological barrier to terrestrial species, but is the preferred habitat of seabirds. At the same time, seabirds are bound to terrestrial sites for breeding. While oceans may appear as a uniform habitat, oceans harbour distinct habitats similarly varied as terrestrial habitats (Longhurst 2006) that shape the distribution and movements of seabirds.

Technological advancements in technology to track individual birds are currently revolutionizing our knowledge of migration by supplying detailed individual-level movement and activity data. This applies in particular to seabirds, which are extremely difficult to study outside the breeding period when roaming the world's oceans. Thus, many decades after Wynne-Edwards (1935) asserted that "there are almost insurmountable difficulties to be overcome before completing the picture of the ebb and flow of bird life over so vast an area" (Wynne-Edwards 1935), the extraordinary migrations of seabirds are now started to be revealed at an unprecedented pace and scale (Brooke 2018). The research presented in this thesis rides the wave of this 'golden age of biologging' (Wilmers et al. 2015). 


\section{AIMS AND APPROACH}

This thesis focuses on four species of Arctic-breeding long-distance migratory seabirds: Red-necked Phalarope Phalaropus lobatus and Grey Phalarope $P$ fulicarius, and Long-tailed Skua $S$ longicaudus and Arctic Skua Stercorarius parasiticus (figure 1.1). These species comprise two pairs of sister species (Livezey 2010, Janssen and Mundy 2013). Each species links marine and terrestrial ecosystems - the Arctic breeding grounds/waters with temperate, sub-tropical and tropical marine, nonbreeding habitats. In both marine and tundra ecosystems, they cover different trophic levels (phalaropes low and skuas high). Whereas at sea, phalaropes feed on small planktonic prey (Mercier and Gaskin 1985), skuas are thought to mainly parasitize on terns and other seabirds (Furness 1987). On the tundra, phalaropes feed on arthropods (Cramp and Simmons 1983) and skuas steal fish from other seabirds (kleptoparasitism) or predate on lemmings and chicks and eggs of waders (Andersson and Götmark 1980, de Korte and Wattel 1988).

At the onset of our study, the non-breeding movements of our study species were only roughly known, mostly reconstructed from anecdotal at-sea or coastal sightings in the $20^{\text {th }}$ century. Excerpts from several historical accounts of at-sea observations are included at the title page of part of the chapters. Considering these species spent the greater part of their life out at sea, studying the nonbreeding movements and ecology has been identified as a research priority in all study species (Wiley and Lee 1998, 1999, Rubega et al. 2000, Tracy et al. 2002). Hence, the first aim of this thesis is to describe the non-breeding movement patterns (routes, staging areas, wintering areas and phenology) and migratory connectivity of the study species for populations around the north-eastern North Atlantic. The second aim is to reveal variation within individuals in migration routes, wintering areas and movement strategies in relation to variation between individuals and populations. The third aim is to link non-breeding movements with other activities in the annual cycle: when do they moult their primaries - do they aim to avoid overlap between moult and other activities? Where do they attain fat reserves prior to breeding, to what extent do they use these marine resources for egg production, and how do they time their migration schedules to ensure a timely arrival at the breeding grounds, even when wintering in widely separated areas? Finally, we expand our exploration of individual- and population differences in migration strategies by comparing the two sets of sister species. By drawing similarities and disparities in species-specific movement strategies, individual consistency and migratory connectivity we aim to understand the generality of our findings regarding flexibility in movement strategies.

Capitalizing on international collaboration across 18 breeding sites, the nonbreeding movements of individual seabirds were tracked from breeding grounds between East Greenland and Yamal, Western Siberia to wintering areas across the Atlantic, Mediterranean Sea and the north-west Indian Ocean. Using geolocators 
(also known as light level geolocator, light-level logger or Global Location Sensor, GLS, figure 1.2), individuals were tracked over multiple years, allowing the quantification of variation in movements in both individual- and population levels. Geolocator data was supplemented by primary moult data obtained from photographs to reveal the timing of primary moult in skua species - an important activity during the wintering period. Finally, stable isotope ratios from adult primaries, juvenile feathers and chick down, were used to infer the extent two which Long-tailed Skuas adopt an income or capital breeding strategy.

\section{STUDY SPECIES}

\section{Red-necked Phalarope}

The Red-necked Phalarope is a small, monotypic, wader, about $18-19 \mathrm{~cm}$ in length and a wingspan of $32-41 \mathrm{~cm}$ (Cramp and Simmons 1983, figure 1.1) It starts breeding at an age of one year (Schamel and Tracy 1988) and published longevity record is 9 years (https://euring.org, 2017), although an age of 12 years has been recently recorded in Iceland ( $/ E$ Peteresen pers comm). Females are slightly larger than males. It has a circumpolar breeding distribution in the low- and sub-arctic (figure 1.3), where it nests in freshwater marshes and bogs, usually vegetated with sedges (Walpole et al. 2008).

The Red-necked Phalarope is probably best known for its remarkable breeding system with reversed sex roles, in which females compete for males may attain multiple matings (Whitfield 1990), while males provide parental care to eggs and chicks. Most studies on Red-necked Phalaropes have focused on the evolution and maintenance of this breeding system (Reynolds 1987, Whitfield 1990, Sandercock 1997, Schamel et al. 2004), which is rare amongst birds (Lack 1968). These studies at the breeding sites also produced estimates of natal philopatry and adult breeding site fidelity (Colwell et al. 1988, Schamel and Tracy 1991, Sandercock 1997). The latter varies between 17 to $56 \%$, which corresponds to the variation between sites in year-to-year fluctuations in abundance (Lappo et al. 2012). These fluctuations can make it difficult to detect population trends, and not surprisingly, only few population trends are available. The Red-necked Phalarope populations within a $12.8 \mathrm{~km}^{2}$ survey plot at Ammarnäs, one of our study sites (see below), appeared stable between 1984-1995 (Svensson 2007). Although the Fennoscandian population as a whole appeared stable in 2002-2013 (Lindström et al. 2015), the species has declined in Finland over the past decades (Valkama et al. 2011). Moreover, the species has disappeared as a breeding bird in Ireland, and the small population in Scotland has declined over the last decades (Delany et al. 2009), but increased again in more recent years (Holling and Breeding Birds Panel 2018). No reliable trend information is available for the large Siberian populations (Lappo et al. 2012) or for the Nearctic population (Andres et al. 2012). It should be noted however, that a decline of $>99 \%$ has taken place in the 1980 s at a major stopover 

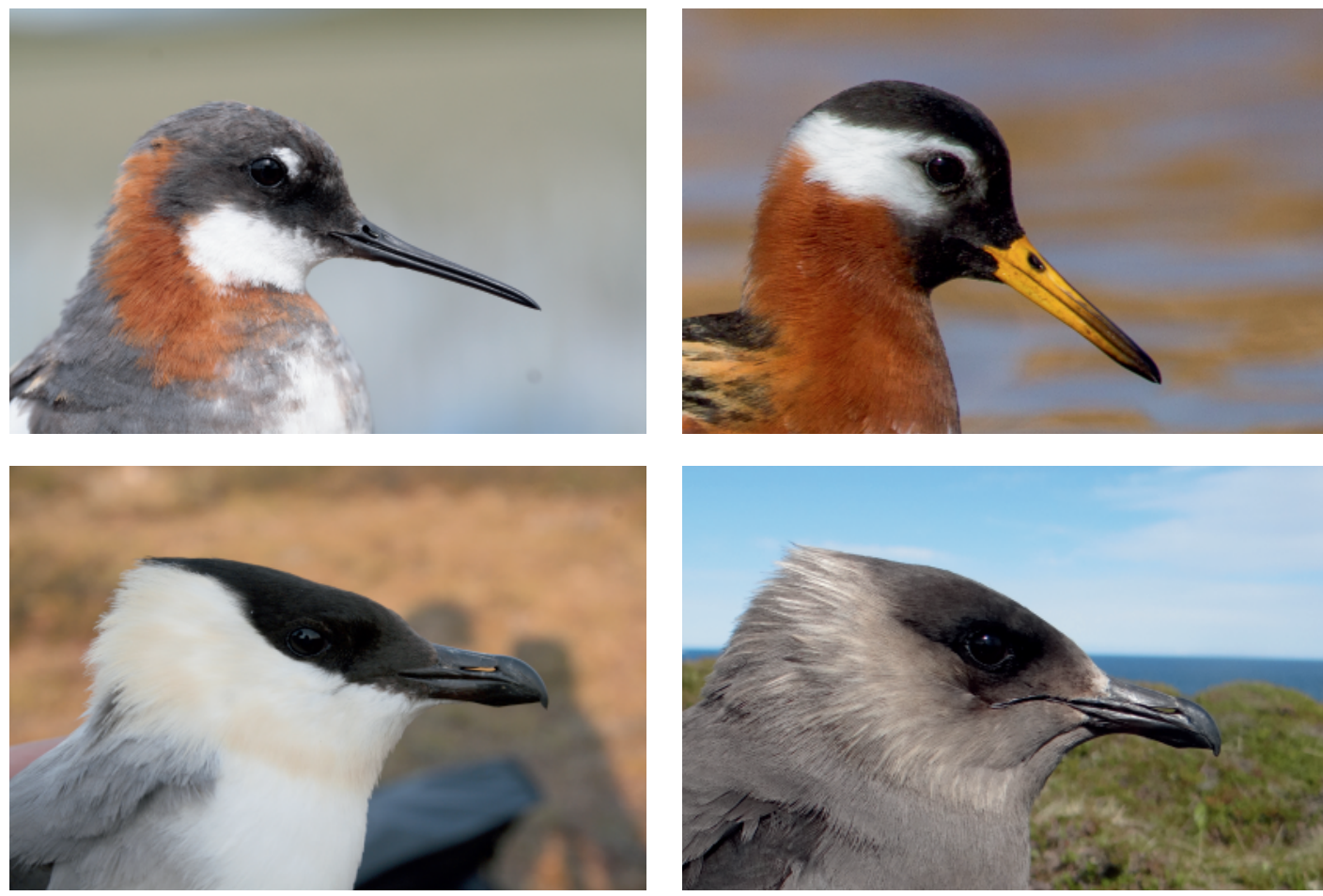

FIGURE 1.1 | Study species: Red-necked Phalarope, Grey Phalarope, Long-tailed Skua and Arctic Skua. Phalaropes depicted here are females; males are usually less brightly coloured. Arctic Skuas come in two colour morphs, of which the dark, melanic morph is depicted here.

in eastern North America, the Bay of Fundy (Nisbet and Veit 2015), but it is unclear whether this represents a population crash or if birds have moved elsewhere.

Red-necked Phalaropes winter in three distinct tropical areas: off the pacific coast of Central and South America, in the Arabian Sea, and in the West Indies (figure 1.3, Cramp and Simmons 1983, BirdLife and HBW 2016). Its ecology during the nonbreeding period is poorly known, as only few studies have been carried out at migration stopovers (Gavrilov et al. 1983, Mercier 1985, Sikora and Zielińksi 2000), and no systematic studies have been carried out in the wintering areas. In North America, migrating Red-necked Phalaropes associate with areas of tidal upwelling and large and persistent coastal or oceanic fronts (Brown and Gaskin 1988, DiGiacomo et al. 2002), where they forage on zooplankton, mainly large copepods (Mercier and Gaskin 1985), or on fish eggs (DiGiacomo et al. 2002). At staging and wintering areas, concentrations of Red-necked Phalaropes can be massive, with up to several 100 000s individuals at single sites (Mörzer-Bruijns and Mörzer-Bruijns 1957, Delany et al. 2009).

\section{Grey Phalarope}

The Grey Phalarope is somewhat larger and more robustly build than the Red- 
necked Phalarope, measuring 20-22 cm in length and a wingspan of 40-44 cm (Cramp and Simmons 1983, figure 1.1) Grey Phalaropes probably start breeding at an age of on year, show site fidelity below 20\% (Schamel and Tracy 1991) and thereby prevent robust estimation of survival rates from ringing data. Females are slightly larger than males. Similar to the Red-necked Phalarope, the Grey Phalaropes' breeding system is characterized by reversed sex roles (Whitfield 1995, Dale et al. 1999). The species breeds at higher latitudes than the Red-necked Phalarope, and its circumpolar range is therefore narrower between Greenland and Taymir (figure 1.3), where densities are generally lower. The most important breeding areas are situated in western Siberia, with densities decreasing both westwards to the Yamal peninsula (Lappo et al. 2012). Small numbers breed in Iceland, Svalbard and Bear Island, whereas the Canadian population is estimated to be much larger; 663000 breeding pairs (Morrison et al. 2006, Delany et al. 2009). In many areas, numbers of Grey Phalaropes fluctuate between years, thereby complicating population estimates (Lappo et al. 2012). Still, Canadian populations

a

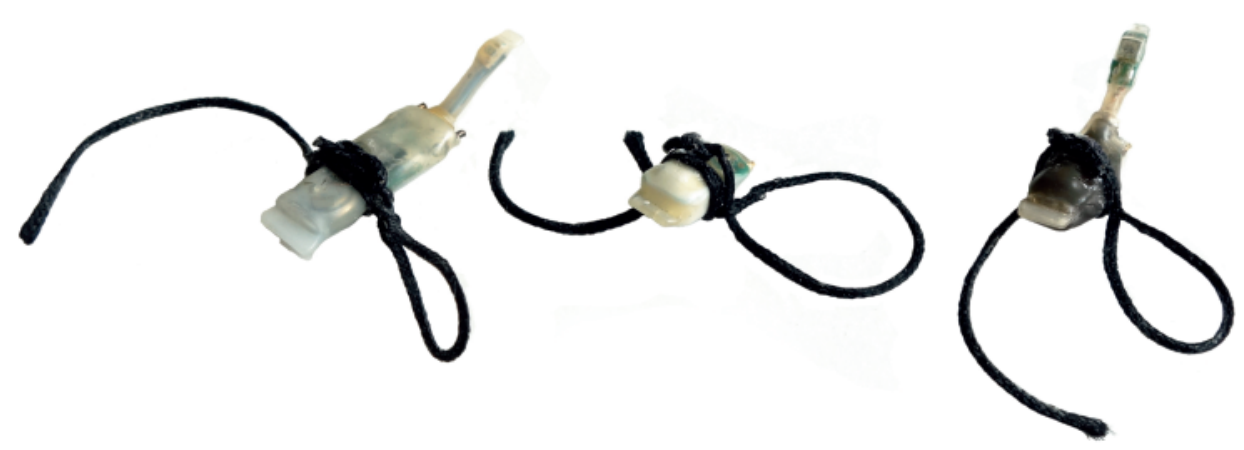

b
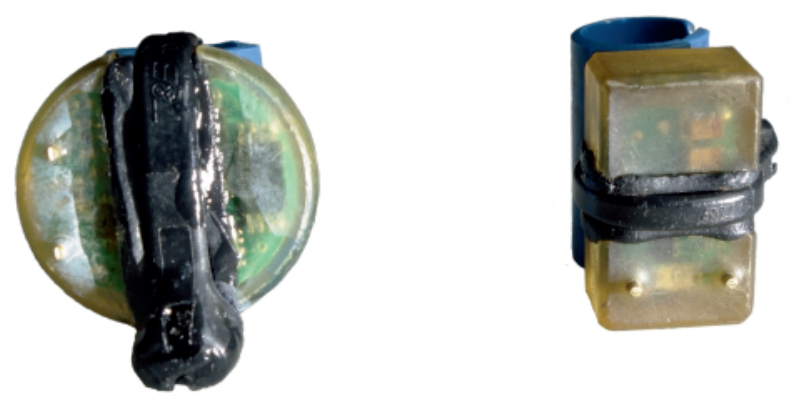

FIGURE 1.2 | Geolocator types used for Red-necked Phalaropes: Mk10 (British Antarctic Survey), used in 2013-2014, and the a modified version of the W65 (Migrate Technology Ltd) without and with stalk used in later years. 

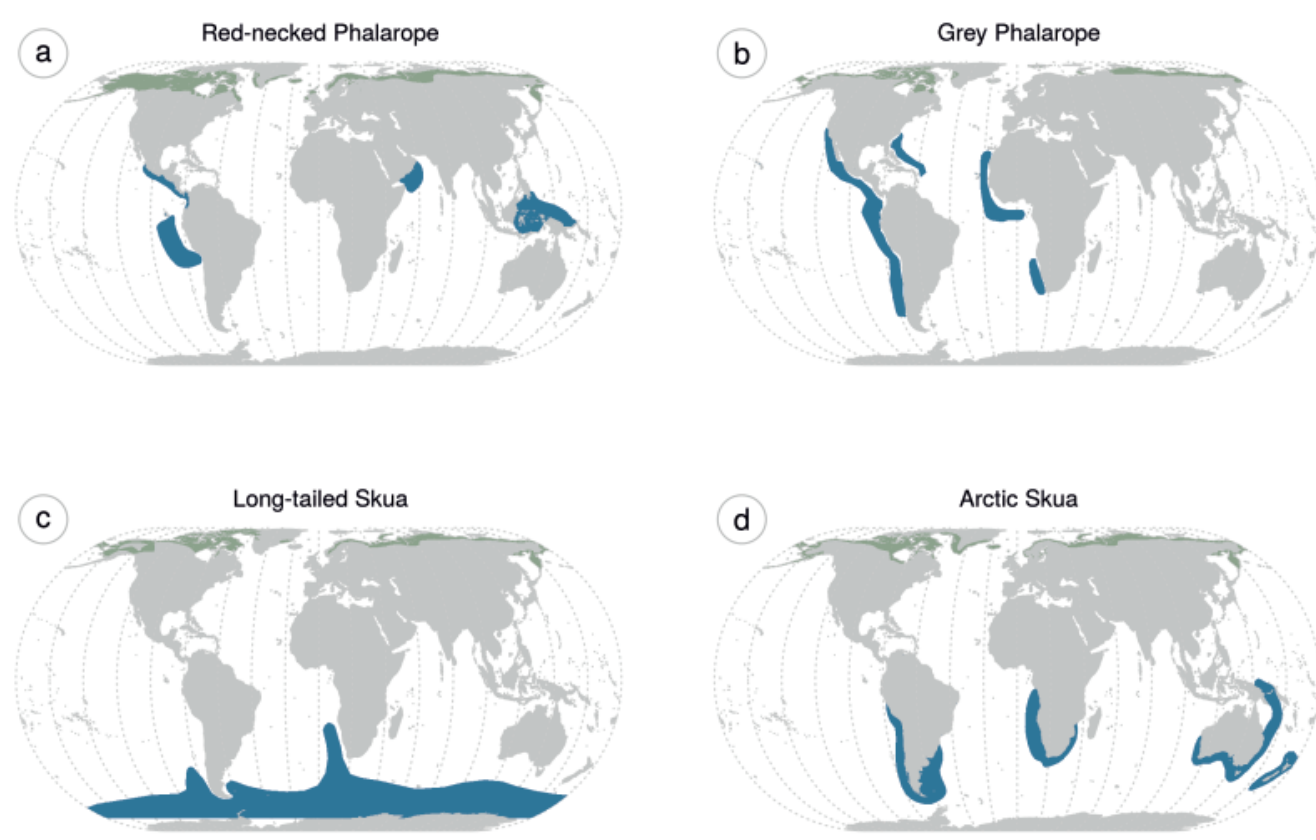

FIGURE 1.3 | Distribution map showing breeding (green) and wintering (blue) areas of the four study species, according to the IUCN species database (accessed 18 October 2018).

are thought to be declining (Morrison et al. 2006, Andres et al. 2012), as well as the tiny Icelandic population (Delany et al. 2009). In contrast, the small population in Svalbard is stable (Henriksen and Hilmo 2015).

Among the three species of phalaropes (Wilson's $P$ tricolor, Red-necked and Grey), Grey Phalarope has the most pelagic lifestyle, occurring inshore during the nonbreeding period only when forced by inclement weather. Partly due to the difficulties to distinguish the Red-necked and Grey Phalaropes in winter plumage, their wintering areas have long been debated (e.g. (Meinertzhagen 1925). In the Pacific, it winters in a wide latitudinal range off the Americas, whereas in the Atlantic it winters mainly in the Canary and Benguela Currents (figure 1.3, (Cramp and Simmons 1983, Delany et al. 2009, BirdLife and HBW 2016). No wintering area is known in the Indian Ocean, although vagrants have been observed.

\section{Long-tailed Skua}

The Long-tailed Skua is the smallest member of the Stercorarius genus, measuring $48-53 \mathrm{~cm}$ in length and a wingspan of 105-117 cm (Cramp and Simmons 1983, figure 1.1) Long-tailed Skuas start breeding at an age of three years, annual survival is probably around 90\% (Andersson 1981), and a published longevity record of 17 years (https://euring.org, 2017) is surpassed by an individual from our 
own study in Ammarnäs of at least 20 years. Females are ca $12 \%$ larger than males (Manning 1964, Furness 1987). Whereas adult Arctic and Pomarine Skua come in two colour morphs, genuine dark morph in adult Long-tailed Skuas seem extremely rare (Irvine 2018, Léandri-Breton et al. 2018). Most if not all claims of dark morph Long-tailed Skuas appear to concern immatures, and it is unclear whether such birds will moult into regular pale morph plumage subsequently (Léandri-Breton et al. 2018). Two subspecies of Long-tailed Skua have been described: the grey-bellied nominate $S$ I longicaudus breeds from Scandinavia eastwards and is replaced by the white-bellied subspecies $S$ I pallescens from eastern Siberia to Svalbard (Manning 1964). Its circumpolar breeding distribution is continuous (figure 1.3) and ranges from mountainous tundra in boreal zones to high arctic tundra in the north. Here, it specialized on rodents (mostly lemmings) (Andersson 1981), although it may feed at sea on fish in areas where no rodents occur, such as Spitsbergen. In comparison with Arctic and Pomarine Skuas, the diet of Long-tailed Skua is more varied, as it is often supplemented by eggs, chicks, berries and arthropods (de Korte and Wattel

\section{Nomenclature}

For three of the four study species, two English names are widely used (table 1.1). The names originating from North-America are currently adopted by three of the four primary world bird species lists (del Hoyo et al. 1996, Clements et al. 2018, Gill, and Donsker 2018), while only the Howard $\&$ Moore checklist (Dickinson and Remsen 2013) uses the names originating from the United Kingdom. A note for Arctic Skua in the IOC list reads: "many prefer 'skua' to German 'jaeger' for three small Stercorarius species" (Gill, and Donsker 2018). In this thesis, I also preferred to use 'skua' for the smaller Stercorarius species, and 'Grey Phalarope' for Phalaropus fulicarius. Only in chapter 4, I adopt the 'North American' nomenclature, following the journal in which this chapter has been published.

Table 1.1 | Nomenclature of the study species.

\begin{tabular}{lll}
\hline Scientific name & United Kingdom & North-America \\
\hline Phalaropus lobatus & Red-necked Phalarope & Red-necked Phalarope \\
Phalaropus fulicarius & Grey Phalarope & Red Phalarope \\
Stercorarius longicaudus & Long-tailed Skua & Long-tailed Jaeger \\
Stercorarius parasiticus & Arctic Skua & Parasitic Jaeger \\
\hline
\end{tabular}


1988). Nevertheless, its reproductive effort and success is tightly linked with rodent abundance and it even foregoes breeding if rodent abundance is low (Maher 1974, Andersson 1981, de Korte 1985). Birds start breeding at an age of three years (de Korte 1985). Long-tailed Skuas lay one or two eggs and seem incapable of incubating more eggs (Andersson 1976).

Populations of Long-tailed Skuas are notoriously difficult to survey, as representative numbers are only present at the breeding grounds very early in the season, or during a (high) lemming peak. Consequently, existing population estimates are highly uncertain and should be interpreted with caution. Population trends are unknown but the species is nevertheless listed as 'least concern' by the International Union for Conservation of Nature, IUCN (BirdLife and HBW 2016). The species is predicted become extinct in the Scandinavian mountain range due to climate change (Huntley et al. 2007).

During the non-breeding season, the Long-tailed Skua is thought to occur further offshore than other skua species (Wynne-Edwards 1935, del Hoyo et al. 1996). Consequently, its main wintering areas have long remained unknown. Areas with higher densities in the Benguela and Falkland Currents were finally described in the 1980s (Lambert 1980, Veit 1985), but as a large part of the individuals in these areas appeared to be immatures to the authors, Furness (1987) argued that these were not the preferred areas by adults. He hypothesized that adults mainly winter in a circumpolar band between $40-50^{\circ} \mathrm{S}$. However, no evidence that this is the case has accumulated since. Only recently, details of its migration routes and wintering area in the Atlantic have been described for populations from Greenland and Svalbard (subspecies S I pallescens) (Sittler et al. 2011, Gilg et al. 2013). Although Long-tailed Skuas on migration and in the wintering areas are observed to kleptoparasitize terns, small gulls and storm-petrels (pers obs, Camphuysen et al. 2013), there are also observations of self-feeding, for example in conjunction with storm-petrels (Campuysen \& van der Meer 2005). Which of the two feeding techniques is more important, and how this changes seasonally and spatially, is unclear.

\section{Arctic Skua}

With a length of $41-46 \mathrm{~cm}$ and a wingspan of $110-125 \mathrm{~cm}$, the Arctic Skua is larger and more powerful than the Long-tailed Skua (Cramp and Simmons 1983, figure 1.1) Arctic Skuas start breeding at an age of three years, although most individuals start later, at an age of four or five years (O'Donald 1983). Survival rates in Scotland were $89 \%$ (Phillips 2001), and the longevity record is 31 years (https://euring.org, 2017). Females are ca 16.5\% larger than males (Furness 1987). The species has a circumpolar breeding distribution in cool temperate to high Arctic zones and is regarded monotypic. A main focus of research on Arctic Skuas has been the evolution and maintenance of its two colour morphs - a pale morph with white underparts and dark grey head-cap, and a melanic morph entirely sooty-grey 
(O'Donald 1983, Furness 1987, Janssen and Mundy 2013). These morphs are not linked to sex, but the ratio between the morphs shows a distinct geographical pattern, with pale morphs dominating at higher latitudes (Kjellen 2000). Its breeding ecology has been mainly studied in Scotland (Furness 1987, Phillips 2001). Like the Long-tailed Skua, Arctic Skuas lay a maximum of two eggs (Furness 1987), but unlike the Long-tailed Skua, it breeds both in loose colonies and as solitary pairs (Andersson and Götmark 1980).

Although the Arctic Skuas is listed as 'least concern' on the IUCN Red List for threatened bird species (BirdLife and HBW 2016), the species has shown rapid declines in large parts of its European breeding range (Frederiksen 2010). For example, Scottish populations have declined by ca $80 \%$ over the past 25 years (Perkins et al. 2018). Declines have also been reported from the Faroe Islands (Bengtson and Bloch 2003), south-west Sweden (Ottosson et al. 2012), mainland Norway (Henriksen and Hilmo 2015), but these declines have been less well documented than those in Scotland. As a result, the species is now listed as 'endangered' on the Faroese, Norwegian and European red lists (BirdLife_International 2015, Henriksen and Hilmo 2015). Declines have been less severe in Svalbard (Henriksen and Hilmo 2015), and the species even appears stable or increasing in the Baltic Sea (Valkama et al. 2011, Ottosson et al. 2012). Reportedly, 5 000-10 000 pairs bred in Iceland in the mid 1990s (Frederiksen 2010), but no recent population or trend estimates are available.

Arctic Skuas are generally regarded as highly dependent on kleptoparasitizing other seabirds, mostly acids, small gulls and terns. This led to the idea the Arctic Skuas would mainly migrate and winter close to the coast, associating with gulls and terns (del Hoyo et al. 1996). Before our study, the species was thought to winter mainly in oceanic areas around South America (Patagonian Shelf), South Africa (Benguela Current) and Australia/New Zealand (figure 1.3, (BirdLife and HBW 2016), with smaller numbers reported from the Caribbean, the Gulf of Mexico and possibly Iberia and north-west Africa (Cramp and Simmons 1983, Wiley and Lee 1999).

\section{STUDY AREAS}

All four species were studied in large international collaborations, covering field sites between eastern Greenland and western Siberia, Russia (table 1.2, figure 1.4). More detailed studies, including aspects of the breeding biology of the study species, were carried out during 2014-2018 at Slettnes, near Gamvik, Norway (Rednecked Phalarope and Arctic Skua) and during 2007-2018 in the Vindelfjällen Nature Reserve, near Ammarnäs, Sweden (Red-necked Phalarope and Long-tailed Skua). Both sites support typical tundra vegetation comprised of heathland (Empetrum nigrum, Vaccinium myrtillus, Betula nana and Salix herbaceae, as well as mosses and lichens), willow shrubs (Salix lapponum), bogs, often lining standing or running 
open water (Carex species and mosses). While Slettnes is a coastal site with an elevation of ca $40 \mathrm{~m}$ asl, Ammarnäs lies a in mountainous well inland. Here, elevation of tundra habitat varies between 800 and $1000 \mathrm{~m}$ asl.

\section{OUTLINE OF THE THESIS}

Chapters 2-4 deal with the two phalarope species, while the skuas feature in chapters 5-9. In chapter 2, we describe the non-breeding movements of four male Red-necked Phalaropes from Ammarnäs, Sweden, to the Arabian Sea. We highlight aspects of their migration strategy and extensive movements within the wintering area. Capitalising on the further increase in available tracks, we extend this view in chapter 3, where the migration and wintering movement strategies of Red-necked Phalaropes from islands in the north-eastern North Atlantic (Greenland, Iceland and Scotland) migrating oversea the northern Humboldt Current in the Pacific are compared with Fennoscandian-Russian populations migrating overland to the Arabian Sea. In chapter 4, we describe the inter- and intra-individual variation in non-breeding movements of Grey Phalaropes breeding in East Greenland and Svalbard, showing that some individuals switch between wintering area ca $6500 \mathrm{~km}$ apart. We then move on to skuas, for which we describe primary moult timing and duration for all four species breeding in the northern hemisphere in chapter $\mathbf{5}$. In chapter 6, we show that Long-tailed Skuas from Greenland, Svalbard and Sweden have similar staging and wintering areas, but show marked between-individual variation in movement patterns. In particular, we show that individual Long-tailed Skuas are generally consistent from year to year in their movement patterns, but can be flexible in the second half of winter, when they are already moving northwards. In chapter 7, we show where they may attain fuel reserves during northbound migration. After arrival in the breeding area, they lose much of these reserves if rodent abundance at the breeding grounds is low. Only a small part of marine resources are used for egg production - the remaining part is formed by terrestrial resources, most likely rodents. Migratory connectivity of Arctic Skuas breeding in the North Atlantic is revealed in chapter 8, where we use the large variation in wintering area at individual and population levels to study migration phenology. European populations of Arctic Skua are in strong decline, and we document the decline of the colony at Slettnes, Norway, in chapter 9. We show that both food shortage and mammalian predation has led to large reproductive failures over four out of five study years, and that the resulting productivity is far below what would be needed for a stable population. Finally, I summarize and compare the findings for all four study species in chapter 10, discuss potential explanations and consequences of the similarities and differences between species, discuss conservation of migratory seabirds during the non-breeding period and suggest directions for future studies. 
TAB LE 1.2 | Study sites within our large collaborative networks. Species names are abbreviated as follows: RNP = Red-necked Phalarope, GP = Grey Phalarope, LTS = Long-tailed Skua, AS = Arctic Skua.

\begin{tabular}{|c|c|c|c|}
\hline Study site & Longitude & Latitude & Species \\
\hline Greenland, Hochstetter Forland & $19^{\circ} 40^{\prime} \mathrm{W}$ & $75^{\circ} 09^{\prime} \mathrm{N}$ & GP, LTS, AS \\
\hline Greenland, Zackenberg & $20^{\circ} 34^{\prime} \mathrm{W}$ & $74^{\circ} 28^{\prime} \mathrm{N}$ & LTS \\
\hline Greenland, Karupelv & $24^{\circ} 00^{\prime} \mathrm{W}$ & $72^{\circ} 50^{\prime} \mathrm{N}$ & LTS, AS \\
\hline Greenland, Constable Pynt & $22^{\circ} 38^{\prime} \mathrm{W}$ & $70^{\circ} 45^{\prime} \mathrm{N}$ & RNP \\
\hline Iceland, Fridland & $21^{\circ} 15^{\prime} \mathrm{W}$ & $63^{\circ} 56^{\prime} \mathrm{N}$ & RNP \\
\hline Iceland, Aðaldalur & $17^{\circ} 04^{\prime} \mathrm{W}$ & $65^{\circ} 51^{\prime} \mathrm{N}$ & RNP \\
\hline Iceland, Hroarstunga & $14^{\circ} 22^{\prime} \mathrm{W}$ & $65^{\circ} 35^{\prime} \mathrm{N}$ & AS \\
\hline Faroe Islands, Fugloy & $19^{\circ} 40^{\prime} \mathrm{W}$ & $75^{\circ} 09^{\prime} \mathrm{N}$ & AS \\
\hline Scotland, Fetlar & $00^{\circ} 52^{\prime} \mathrm{W}$ & $60^{\circ} 36^{\prime} \mathrm{N}$ & RNP \\
\hline Scotland, Fair Isle & $01^{\circ} 31^{\prime} \mathrm{W}$ & $59^{\circ} 37^{\prime} \mathrm{N}$ & AS \\
\hline Sweden, Ammarnäs & $16^{\circ} 01^{\prime} \mathrm{E}$ & $65^{\circ} 59^{\prime} \mathrm{N}$ & RNP, LTS \\
\hline Norway, Brensholmen & $18^{\circ} 01^{\prime} \mathrm{E}$ & $69^{\circ} 35^{\prime} \mathrm{N}$ & AS \\
\hline Norway, Slettnes & $28^{\circ} 12^{\prime} \mathrm{E}$ & $71^{\circ} 05^{\prime} \mathrm{N}$ & RNP, AS \\
\hline Norway, Svalbard, Kongsfjorden & $12^{\circ} 06^{\prime} \mathrm{E}$ & $79^{\circ} 57^{\prime} \mathrm{N}$ & GP, LTS, AS \\
\hline Finland, Enontekiö & $21^{\circ} 16^{\prime} \mathrm{E}$ & $68^{\circ} 58^{\prime} \mathrm{N}$ & RNP \\
\hline Finland, Satakunta & $21^{\circ} 27^{\prime} \mathrm{E}$ & $61^{\circ} 33^{\prime} \mathrm{N}$ & AS \\
\hline Russia, Tobseda & $52^{\circ} 19^{\prime} \mathrm{E}$ & $68^{\circ} 36^{\prime} \mathrm{N}$ & RNP, AS \\
\hline Russia, Erkuta & $69^{\circ} 09^{\prime} \mathrm{E}$ & $68^{\circ} 14^{\prime} \mathrm{N}$ & RNP, LTS, AS \\
\hline
\end{tabular}



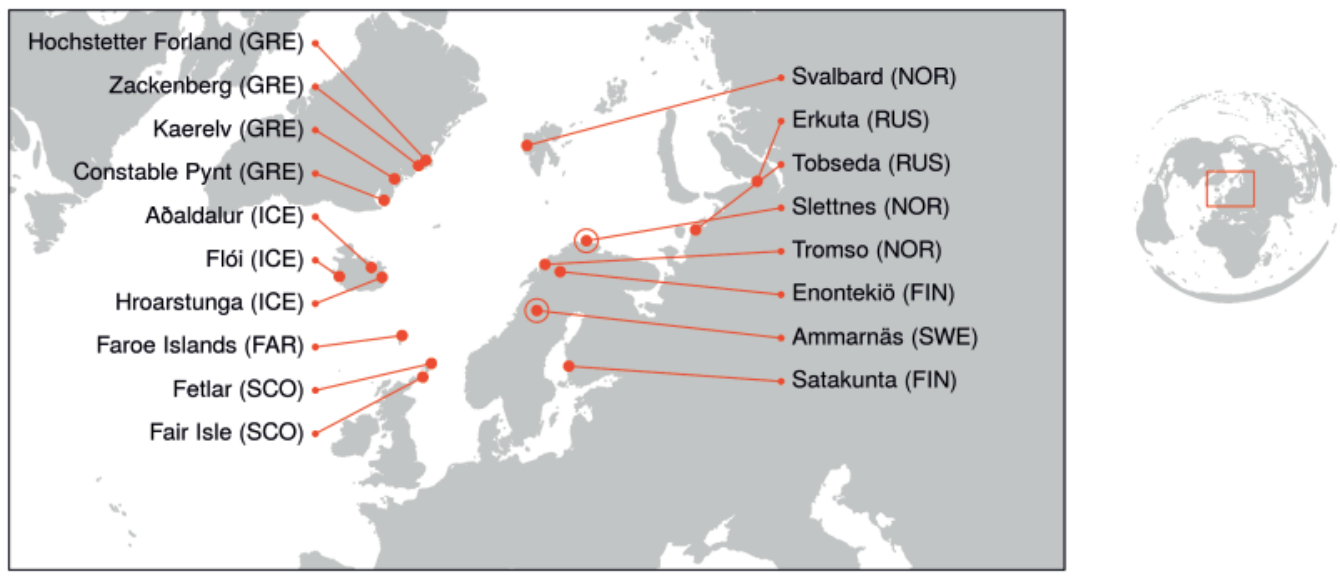

FIGURE 1.4 | Distribution of sites around the northeastern North Atlantic where geolocators were deployed on Red-necked Phalaropes, Grey Phalaropes, Long-tailed Skuas and Arctic Skuas. The two sites where more detailed studies on breeding biology were carried out, Ammarnäs and Slettnes, are circled.

Alpine tundra of the Raurejaure study area, home to many Long-tailed Skua pairs, after most of the snow has melted. Ammarnäs, Sweden, 23 June 2013. 



\section{First geolocator tracks of Swedish red-necked phalaropes reveal the Scandinavia-Arabian Sea connection}

Rob S.A. van Bemmelen, Johannes Hungar, Ingrid Tulp \& Raymond H.G. Klaassen Journal of Avian Biology 47: 295-303 


\section{ABSTRACT}

We studied migration and wintering patterns of a wader with a pelagic lifestyle during the non-breeding period, the Rednecked Phalarope Phalaropus lobatus. Using light-level geolocation, we obtained three full annual tracks and one autumn migration track of male Red-necked Phalaropes caught during breeding in Scandinavia. These tracks confirmed expectations that individuals from the Scandinavian population winter in the Arabian Sea. Migration was accomplished in two to four migration leaps, staging for a few days in the Gulf of Finland (autumn) or the southern Baltic Sea (spring) and for up to a month in or near the Black and Caspian Sea (autumn and spring). In addition, travel speeds suggested that only the flights between the Baltic and Black/Caspian Sea are non-stop, and thus the birds seem to make additional short stops during the other flights. Stopover time in the Black/Caspian Sea is only 8-10 days in spring but up to 36 days in autumn, which is longer than expected if only used for pre-migratory fattening to cover the ca $2000 \mathrm{~km}$ to the Gulf of Oman. After entering the Arabian Sea via the Gulf of Oman, birds dispersed over the entire presumed winter range. Winter movements appear to correspond to the spatio-temporal patterns in primary production linked to seasonally changing monsoon winds. These are not only the first tracks of Scandinavian Red-necked Phalaropes, but also the first seabird tracks in the Arabian Sea, one of the most productive and dynamic marine areas on the planet. 


\section{INTRODUCTION}

The Red-necked Phalarope Phalaropus lobatus is a small wader with an unusual lifestyle, spending the winter out on the ocean like a true seabird - a behaviour only shared with grey phalarope $P$. fulicarius. After a short breeding season in (sub)Arctic tundra, Red-necked Phalaropes migrate to three known main wintering areas: off the Pacific coast of South America, in the Arabian Sea and off the East Indies (Cramp and Simmons 1983). The migration and wintering areas of phalaropes have been much debated in ornithological literature (e.g. (Meinertzhagen 1925, Höhn 1966, Alerstam 1990, Smith et al. 2014). Ringing efforts have thus far provided a fragmented picture of those parts of the migration routes that run over land (e.g. (Höhn 1966, Alerstam 1990, Bakken et al. 2003, Fransson et al. 2008) and have failed to unambiguously link wintering areas to circumpolar breeding areas. A spectacular advancement in the study of migration patterns of phalaropes, is a single geolocator track obtained for a Scottish male Red-necked Phalarope (Smith et al. 2014). This individual crossed the Atlantic and Caribbean to winter in the Pacific. Its westward migration direction contrasts with the assumed migration pattern of the Scandinavian population, for which a small number of ring recoveries in autumn indicates a south-eastern migration direction (Höhn 1966, Schiemann 1977, Alerstam 1990, Bakken et al. 2003, Fransson et al. 2008), strongly suggesting that these birds winter in the Arabian Sea. A south-eastern migration direction is rather unusual among European breeding birds (but see e.g. (Chamberlain et al. 2000, Verkuil et al. 2006, Hedenström et al. 2013) and the idea that Scandinavian Red-necked Phalaropes winter in the Arabian Sea (Höhn 1966, Alerstam 1990, Bakken et al. 2003, Fransson et al. 2008) has never been confirmed. Even less is known about the behaviour of phalaropes during winter, when they are difficult to study due to their pelagic lifestyle. Phalaropes often occur in notably large concentrations during the winter, congregating at shelf edges or other sites with high primary productivity (Schiemann 1986, Brown and Gaskin 1988, Thorne and Read 2013). However, their at-sea winter movements are unknown, i.e. whether they remain at a single site throughout the winter or whether they are itinerant, using several sites (Moreau 1972), as seems to be the more common behaviour among seabirds (Dias et al. 2011, Fijn et al. 2013, Gilg et al. 2013).

Migratory birds have adopted different strategies to trade-off time and energy while bridging long distances (Piersma 1987, Alerstam and Lindström 1990). At the extremes of a continuum, birds make small hops, requiring small amounts of fuel for each hop, or make a single long non-stop flight, requiring accumulation of a substantial amount of fuel prior to the flight. Birds are expected to opt for longer flights when the availability of habitat suitable for refuelling is limited, or when minimizing time rather than energy (Alerstam and Lindström 1990). It is not completely clear what constitutes 'suitable' fuelling habitat for Red-necked Phalaropes migrating ca $5500 \mathrm{~km}$ overland from Scandinavia to the Gulf of Oman, but large congregations of phalaropes have only been reported from a few specific 
saline sites (Cramp and Simmons 1983, Delany et al. 2009). Possibly, Scandinavian Red-necked Phalaropes subdivide their migratory travel in two to three flights, with stopover locations in the Gulf of Bothnia / Gulf of Finland and the Black Sea / Caspian Sea (Schiemann 1977, Cramp and Simmons 1983, Alerstam 1990). Accumulated fat reserves that would enable non-stop flights of about 4300-5100 $\mathrm{km}$ have been reported from the Bay of Fundy, Canada (Mercier 1985), indicating that the species might be able to make long flights. Thus, alternatively, (part of) the Scandinavian Red-necked Phalaropes could also reach the Arabian Sea in a single flight from the breeding area, similar to as for example has been reported for Scandinavian great snipes Gallinago media (Klaassen et al. 2011).

Here, we describe autumn and spring migration patterns of male Scandinavian Rednecked Phalaropes. Specifically, we test the hypotheses that they 1) winter at the Arabian Sea, 2) reach this destination in two or three non-stop flights, and 3) have staging sites at the Black and Caspian Sea and the Baltic region. Furthermore, we describe the behaviour of Red-necked Phalaropes during winter, in particular whether they remain at a single site or are more mobile and exploit several sites.

\section{METHODS}

Ten breeding male Red-necked Phalaropes were captured on the nest using walk-in traps between 17-19 June 2013 in the Vindelfjällen Nature Reserve, near Ammarnäs, Sweden $\left(65^{\circ} 59^{\prime} \mathrm{N}-16^{\circ} 01^{\prime} \mathrm{E}\right)$ and recaptured on 10-24 June 2014 using walk-in traps on the nest or mist-nets away from the nest. Geolocators (Mk10 model, British Antarctic Survey, Cambridge, UK) were back-mounted using leg-loop harnesses (Rappole and Tipton 1991) constructed from $1 \mathrm{~mm}$ wide flat braided shelf-string (British Trust for Ornithology, UK), with a total weight of $1.0 \mathrm{~g}$. In comparison with our dataset of captured males in Ammarnäs $(n=74)$, this extra weight represents $3.7 \%$ of the body mass of the lightest individual $(27.3 \mathrm{~g})$ and $3.1 \%$ of the average weight $(32.5 \mathrm{~g})$.

\section{Data analysis}

After retrieving geolocators, data wasere downloaded from the loggers and processed using BASTrack software (BAS, UK). Further analysis was carried out using the package 'GeoLight' (Lisovski and Hahn 2012) in R 3.1 (R Core Team 2017). Twilight events were identified using the 'threshold method' (Ekstrom 2004) at a light intensity value of 2 . For each track, the corresponding sun angle was selected that resulted in equal latitudes on both sides of equinox periods when birds were stationary (as indicated by longitude, which is not affected by equinox), which was at $-5^{\circ}$ for all individuals. Geolocation provides position estimates with an accuracy \pm SD of about $186 \mathrm{~km}$ (Phillips et al. 2004), with lowest accuracy in latitude estimates close to the equinoxes. Therefore, Llatitude data were deleted from 14 days prior till 18 days after the autumn equinox and 18 days prior till 14 days after 
the spring equinox. To increase accuracy of positions estimates (Phillips et al. 2004), pPositions were smoothed twice following the method of (Pütz 2002).

Departure and arrival at Ammarnäs could not be recorded as this location experiences permanent daylight from late May to early August. For flight speed calculations (see below), we only used the recorded part of the tracks, but for the overall migration distance and overall migration speed between the breeding site and the wintering area we included the distance from Ammarnäs to the first and last position estimate. First or last points often were located just south of the polar circle (see Results), presumably within one day of travelling of/to the breeding site based on a ground speed of $13.3 \mathrm{~m} \mathrm{~s}^{-1}$ (Alerstam and Gudmundsson 1999). Therefore, one day was added to the migration duration. We take the arrival at and departure from oceanic waters as the endpoint of autumn migration and the start of spring migration, respectively.

With two position estimates per day, each migration step is made up of multiple (more or less $12 \mathrm{~h}$ ) segments. For the migration steps between main stopover sites, we calculated ground speed and airspeed for each segment and then took the mean, weighted for the duration of each segment. Segment length was calculated as the great-circle distance between two smoothed position estimates (cf. above). Duration of migration flights was calculated as the time difference between midnight or noon at each position. If the initial or final position was at a staging area, the last twilight event (departure) or the first twilight event (arrival) was used as the start- and end-time of the segment, respectively. For each segment, the ground speed of the bird was calculated by dividing the segment length by segment duration. Although there is uncertainty in the departure and arrival timings of up to half a day, this effects the flight speed only marginally as flight speeds are averaged over larger time periods (cf. Above), in which the shorter departing and arriving segments have less weight in the weighted mean flight speed. For each position estimate and associated time of local midnight or local noon, wind data at 925, 850, 700 and $500 \mathrm{hPa}$ (corresponding to approximately 750, 1500, 3000 and $5000 \mathrm{~m}$ asl) were obtained from the NCEP/NCAR reanalysis project (Kalnay et al. 1996) using the RNCEP package (Kemp et al. 2012). For each segment, the ground speed of the bird was calculated by dividing the segment length by segment duration. Subsequently, airspeed of the bird was calculated by subtracting the wind vector from the track vector. We present resulting airspeeds for $850 \mathrm{hPa}$, considering $1500 \mathrm{~m}$ asl appears a regular flying height for waders (e.g. (Dick et al. 1987), and for a scenario in which individuals selected the most profitable elevation for each segment, i.e. resulting in the lowest airspeed.

For visualisation of monthly positions throughout the winter period (August-May), $50 \%$ home range kernels were calculated using a grid-cell size of $50 \mathrm{~km}$ and a smoothing factor of $50 \mathrm{~km}$, which is similar to the longitude error in geolocator positions reported for other seabirds (Phillips et al. 2004), in the package 
'adehabitatHR' (Calenge 2006), if at least 25 position estimates were available (i.e. not for September and March due to inference by equinoxes). Monthly net ocean primary productivity was obtained from (O'Malley 2016) and is based on the Vertically Generalized Production Model (VGPM) algorithm (Behrenfeld and Falkowski 1997).

Geolocator data has been uploaded to the Movebank data repository (project id 99570338).

\section{RESULTS}

Four out of ten birds fitted with geolocators in 2013 were resighted and subsequently recaptured in 2014. A return rate of $40 \%$ falls within the range of return rates of $17 \%$ to $56 \%$ reported for adults at various locations in Alaska (Colwell et al. 1988, Schamel and Tracy 1991, Sandercock 1997). In all four recaptured individuals, body mass was 1.6-5.4 g higher at recapture in 2014 compared to initial capture in $2013\left(t_{\text {paired }}=-3.652 ; d f=3, p=0.035\right)$. This difference could not be (entirely) attributed to a decrease in body mass over the course of incubationto a seasonal effect, as the dates of recaptures in 2014 were both before and after the capture dates of 2013. Body mass measured in 2013 was slightly higher for individuals recaptured in 2014 than for individuals that were not resighted in $2014(t=-2.476, d f=5.9, p=0.048)$. All four males did aattempted to breeding attempt in 2014 (see below).

Three geolocators contained a full year of data; the fourth contained data up to 3 December 2013. The migration trajectories of all four birds are shown in figure $\mathbf{2 . 1}$ and figure 2.S1, and migration schedules are detailed in table 2.S1. Labels A-D refer to the four tracked individuals and are consistent between all tables, figures and text.

\section{Autumn migration}

All four nests hatched successfully between 21-27 June (table 2.1). First positions outside the breeding area were obtained mid-July. Three birds made short stopovers of 3-6 days at the Gulf of Finland (individuals A and D) or in the eastern Ukraine (individual B) before reaching the Black or Caspian Sea. Individual C apparently arrived directly to the Caspian Sea. Here, birds spent 13-36 days before migrating to the Gulf of Oman or just south of Oman, where they arrived on 11 (B), 13 (C) and 25 August (A) and 6 September (D).

The total autumn migration distance amounted to $5514-6954 \mathrm{~km}$, which was covered in 24-55 days, including 15-35 days spent at stopover sites (table 2.1). Overall migration speed (including stopovers) was $140-230 \mathrm{~km} \mathrm{~d}^{-1}$. 

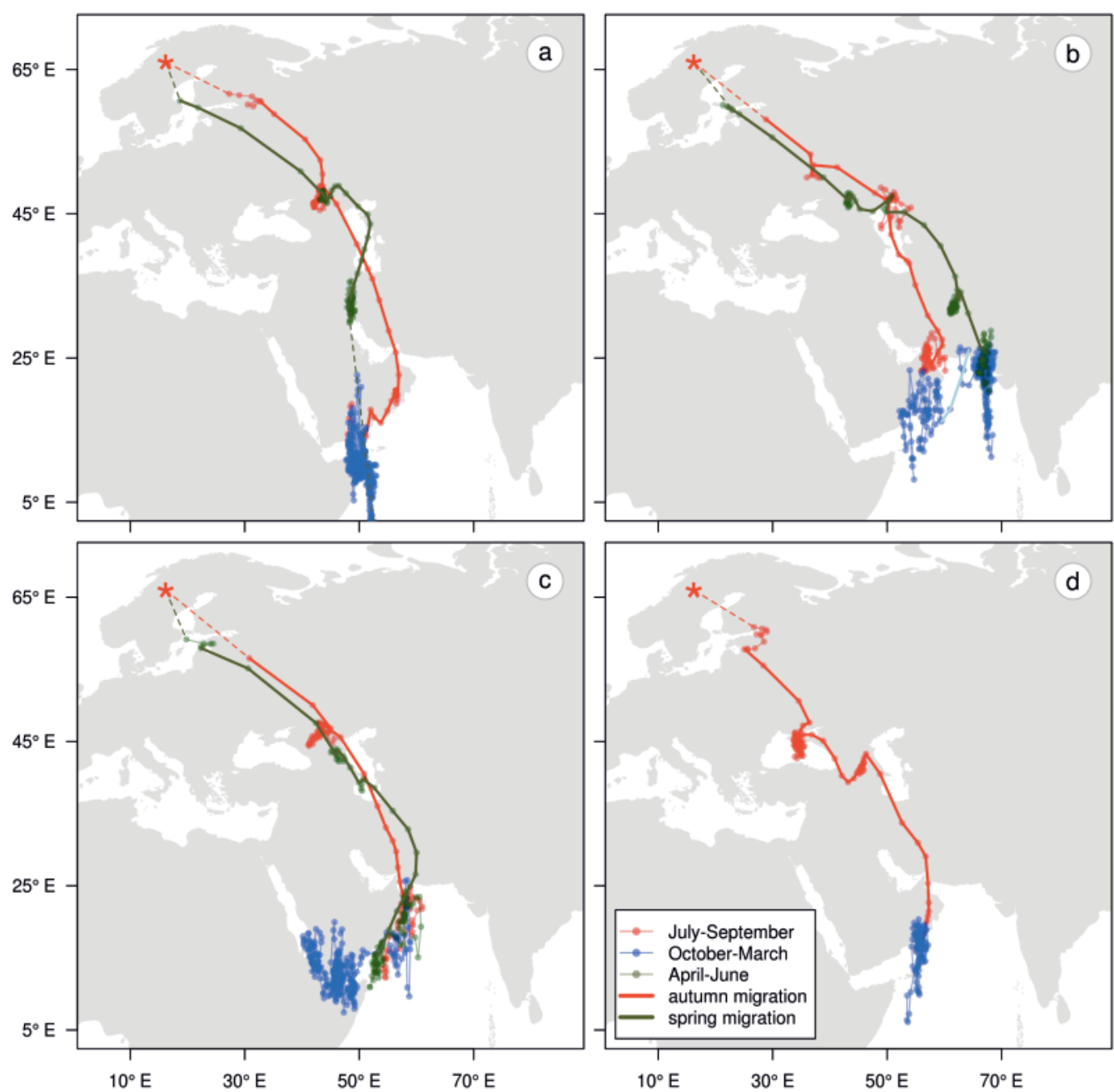

FIGURE 2.1 | Geolocator tracks of four male red-necked phalaropes from Ammarnäs, Swedish Lapland, during 2013-2014. Position estimates are connected by lines; bold lines were used for flight speed calculations and dotted lines from (red) and towards (green) Ammarnäs (indicated by a red star) have not been recorded due to continuous daylight.

\section{Behaviour during wintering}

After arrival in the seas surrounding Oman, birds spread in different directions. After a short stop south of Oman, individual A spent 198 days in the Gulf of Aden before moving to the northern Persian Gulf. Another individual (B) stayed for 27 days in the gulf of Oman before slowly moving south along the Omani coast for 74 days, after which the bird moved east to the seas off Pakistan, where it stayed for 152 days. The third individual (C) stayed for 6 days in the Gulf of Oman before moving south of Oman. After 59 days, the bird moved to the Gulf of Aden for 41 days, spent 33 days in the southern Red Sea, moved back into the Gulf of Aden for 41 days, and 
TABLE 2.1 | Overview of migration duration, distance and speed of four male red-necked phalaropes from Sweden to and from the Arabian Sea. Note that the last part of spring migration is more synchronised than the onset; see results for details.

\begin{tabular}{lcccccccc}
\hline & \multicolumn{3}{c}{ Autumn migration } & & \multicolumn{3}{c}{ Spring migration } \\
\cline { 2 - 4 } Individual & A & B & C & D & & A & B & C \\
\hline Clutch hatching date in 2013 (autumr & 22 Jun & 27 Jun & 21 Jun & 23 Jun & & 2 Jul & - & 4 Jul
\end{tabular}

\section{Migration to/from sea}

\begin{tabular}{|c|c|c|c|c|c|c|c|}
\hline Onset of migration ${ }^{1}$ & 15 Jul & $18 \mathrm{Jul}$ & 15 Jul & 13 Jul & $20 \mathrm{Mar}$ & $23 \mathrm{Apr}$ & 15 May \\
\hline End of migration ${ }^{2}$ & 3 Sep & 11 Aug & 13 Aug & 6 Sep & 25 May & 3 Jun & 4 Jun \\
\hline Total duration (days) & 49 & 24 & 29 & 55 & 65 & 40 & 19 \\
\hline Total cumulative distance $(\mathrm{km})$ & 6939 & 5514 & 5709 & 6954 & $7379^{3}$ & 6345 & 6908 \\
\hline Total migration speed $\left(\mathrm{km} \mathrm{d}^{-1}\right)$ & 142 & 230 & 197 & 126 & 114 & 159 & 364 \\
\hline
\end{tabular}

\section{Stopover duration (d)}

\begin{tabular}{|c|c|c|c|c|c|c|c|}
\hline Baltic Sea, Gulf of Finland or Ukraine ${ }^{4}$ & 3 & 3 & - & 6 & - & 2 & 3 \\
\hline Black Sea and/or Caspian Sea ${ }^{4}$ & 29 & 13 & 23 & 36 & 9 & 10 & 8 \\
\hline Persian Gulf or West Pakistan ${ }^{4}$ & - & - & - & - & 46 & 21 & - \\
\hline Total stopover time & 32 & 16 & 23 & 42 & 55 & 33 & 11 \\
\hline
\end{tabular}

1 in autumn, date at last recorded position minus one day.

2 in spring, date at last recorded position plus one day.

${ }^{3}$ Including the not-recorded flight from the Gulf of Aden to the Persian Gulf ( $2400 \mathrm{~km}$ ).

${ }^{4}$ See table $\mathbf{2 . 5 1}$ for which areas were used by each individual.

finally spent 53 days south of Oman. Winter movements were not recorded for the fourth individual (D): this bird stayed south of Oman until logger failure.

\section{Spring migration}

Departure from the Arabian Sea was commenced in late March to mid-May. Two birds first moved to an intermediate stopover site. The first individual (A) flew approximately $2400 \mathrm{~km}$ from the Gulf of Aden to the northern Persian Gulf, where it stayed for 46 days. Due to the equinox, latitude estimates were unreliable during this period, but the narrow range of longitude estimates $\left(47^{\circ}-53^{\circ} \mathrm{E}\right)$ show that this migration must have been overland. The second individual (B) moved from offshore Pakistan to inland western Pakistan where it stayed for 21 days, before joining the other two individuals at the Caspian Sea in mid-May, where they stayed 8-10 days. 

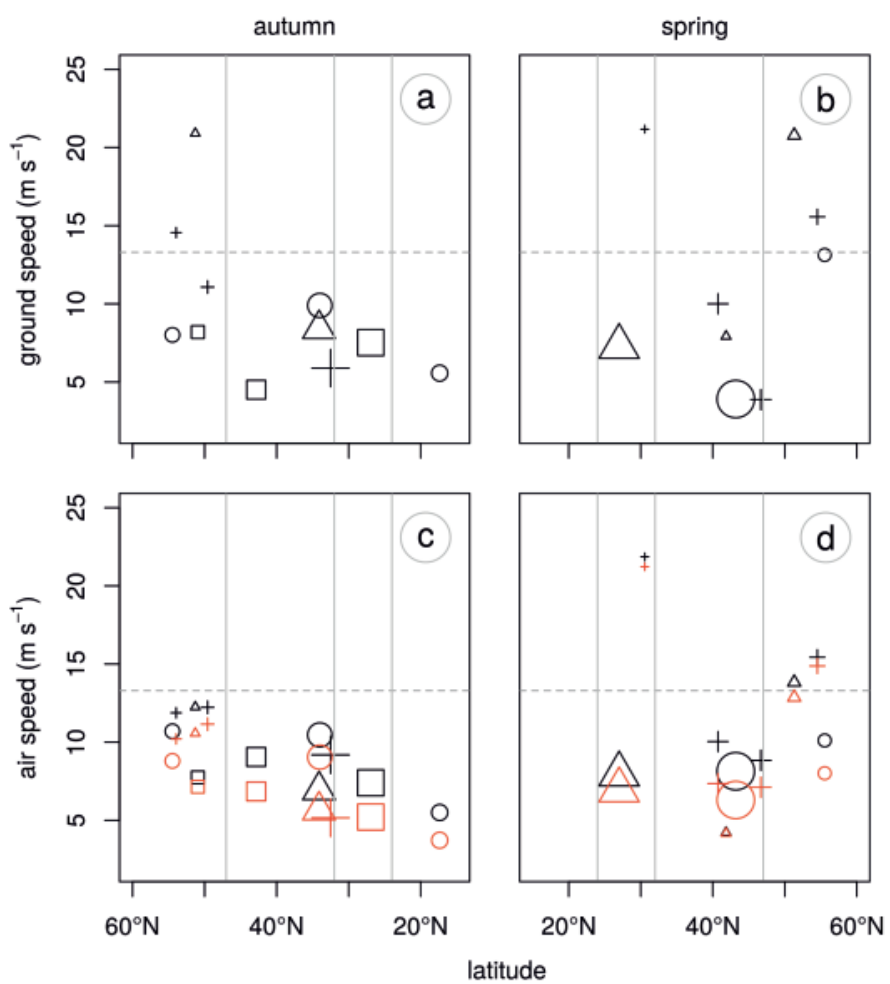

individual

$$
\begin{array}{r}
\circ A \\
+\quad B \\
\triangle C \\
\square D
\end{array}
$$

\section{duration}

- $24 \mathrm{hrs}$

○ $60 \mathrm{hrs}$

$96 \mathrm{hrs}$

( $132 \mathrm{hrs}$

O $168 \mathrm{hrs}$

850 hPa (1500 m asl) most profitable height stopover latitudes

FIGURE 2.2 | Mean ground (a, b) and airspeed (c, d) per migration step of four red-necked phalaropes. Symbol shape relates to the individual and symbol size is proportional to the duration of the migration leg. Airspeeds in case the bird always flies at the most profitable elevation are shown in red. Vertical grey lines roughly indicate the latitude of main stopover areas: Caspian Sea region ( $\left.47^{\circ} \mathrm{NB}\right)$, Western Pakistan and northern Persian Gulf $\left(32^{\circ} \mathrm{NB}\right)$ and the Gulf of Oman $\left(24^{\circ} \mathrm{NB}\right)$. The grey dotted horizontal lines indicate the measured airspeed of $13.3 \mathrm{~m} \mathrm{~s}^{-1}$ based on Alerstam and Gudmundsson (1999).

All three birds then moved to the Baltic Sea, using a trajectory just south of the autumn route. Two individuals ( $B$ and $C$ ) stayed here for 2-3 days, but for individual A only two positions were obtained from this region, suggesting that it more or less directly moved on towards the breeding area that already experiences permanent daylight at this time of the year.

The total spring migration distance amounted to $6345-7379 \mathrm{~km}$ (table 2.1), which was covered in 19-65 days, including total stopover time of 11-55 days. The corresponding overall migration speed (including stopovers) was $114-364 \mathrm{~km} \mathrm{~d}^{-1}$. Variation in the total distance covered, stopover time and migration speed was lower in the last part of the migration (from staging areas the Persian Gulf, from inland western Pakistan and from offshore Oman): a total distance of 4472-6908 $\mathrm{km}$, a duration of 19 days in all three birds, including total stopover time of 8-10 days, and migration speed of 262-364 $\mathrm{km} \mathrm{d}^{-1}$. 
For three individuals (A-C) the nest was found in the 2014 breeding season. Individual D probably was incubating as well, as suggested by consistent bearings when arriving and departing from regular visits to a specific pond for feeding. Two nests hatched successfully on 2 (A) and 4 July (C). Assuming an incubation period of 18 days (Cramp and Simmons 1983), these clutches hadve been laid at 14 and 16 June, respectively. The nest of individual B was found on 13 June but was depredated soon after this date.

\section{Flight speed}

For most migration steps $(75 \%, \mathrm{n}=20)$ mean ground speed (figure 2.2) was lower than the single measurement of airspeed of $13.3 \mathrm{~m} \mathrm{~s}^{-1}$ for Red-necked Phalarope by (Alerstam and Gudmundsson 1999). Ground speeds exceeding $13.3 \mathrm{~m} \mathrm{~s}^{-1}$ were observed only for migration steps shorter than 50 hours. Derived airspeeds at 850 $\mathrm{hPa}$ were on average $10.2 \mathrm{~m} \mathrm{~s}^{-1}(\mathrm{n}=20, \mathrm{sd}=3.9$, range=4.2-21.9). If birds would select the elevation resulting in the lowest airspeed, the average airspeed would be $8.6 \mathrm{~m} \mathrm{~s}^{-1}(\mathrm{n}=20, \mathrm{sd}=4.1$, range=3.7-21.2). Airspeeds were both lower (14/20) and higher $(6 / 20)$ than ground speeds, suggesting that phalaropes experienced tailwinds as well as headwinds, respectively. Only for some migration steps, mostly between the Baltic region and the Caspian Sea region, derived mean airspeeds were equal to the measured airspeed of $13.3 \mathrm{~ms}^{-1}$, suggesting non-stop flights. In most cases the derived airspeed was lower than the measured airspeed, suggesting that the phalaropes did not fly continuously. Assuming a constant airspeed of 13.3 $\mathrm{ms}^{-1}$, birds flew on average for $77 \%(\mathrm{n}=20)$ of the time if flying at $850 \mathrm{hPa}$ or $65 \%$ $(n=20)$ if always flying at the most profitable elevation.

\section{DISCUSSION}

We have presented the first data on movements of individual Scandinavian Rednecked Phalaropes during the non-breeding season, confirming expectations based on ring recoveries (Höhn 1966, Schiemann 1977, Alerstam 1990, Bakken et al. 2003, Fransson et al. 2008) that individuals from this population winter in the Arabian Sea. In agreement with field observation on staging birds, the phalaropes divided the ca 5514-6954 km migrations into two to four leaps, staging for a few days in the Gulf of Finland (autumn) or the southern Baltic Sea (spring) and for up to a month at one or two locations in or near the Black and Caspian Sea (autumn and spring). These results thus confirm the role and importance of these areas as staging sites for Scandinavian Red-necked Phalaropes (Delany et al. 2009).

Previously, overland migration of Red-necked Phalaropes was assumed to be performed 'largely' non-stop (Cramp and Simmons 1983). However, airspeeds from the four individuals tracked in this study were mostly below $13.3 \mathrm{~m} \mathrm{~s}^{-1}$, the single measurement of airspeed for Red-necked Phalarope measured by (Alerstam and Gudmundsson 1999). This suggests that they did not fly continuously, but for about 
$65 \%$ or $77 \%$ of the time, depending on which flight altitude they selected. Although the majority of migration leaps thus likely included short stops, several flights shorter than two days covering up to approximately $2400 \mathrm{~km}$ had calculated airspeeds close to or above $13.3 \mathrm{~m} \mathrm{~s}^{-1}$, indicating these were true non-stop flights. These non-stop flights were mostly in the first or last recorded stage of spring migration, between the stopover in the Caspian Sea region and the Baltic.

Spring staging times in the Caspian Sea region were 8-10 days, which is comparable to estimated staging times for Broad-billed Sandpipers Limicola falcinellus in the Ukraine prior to a presumably non-stop flight to the Scandinavian breeding grounds (Verkuil et al. 2006). Autumn staging duration in the Caspian Sea region was however substantially longer compared to spring in three out of four birds and similar to those reported for Red-necked Phalaropes staging in the Bay of Fundy, Canada. Here, Red-necked Phalaropes accumulate fat loads to ca $40-45 \%$ of lean body mass, which would enable a non-stop flight of up to $5100 \mathrm{~km}$ (Mercier 1985). In autumn, Red-necked Phalaropes staging in the Caspian Sea region would need to 'only' cover approximately $2000 \mathrm{~km}$ to the Gulf of Oman, and would thus need smaller fat reserves compared to their conspecifics staging in eastern Canada. Indeed, both mean and maximum body mass of large numbers of Red-necked Phalaropes captured at inland lakes in Kazakhstan (Gavrilov et al. 1983), were ca 14 g lower than phalaropes staging in the Bay of Fundy (Mercier 1985). Why then do they stop for such long time in the Caspian Sea region on southward migration? Stopover times longer than what seems required for refuelling have also been reported in other studies (Mckinnon et al. 2013), and several potential explanations can be proposed. For example, a longer stopover time might simply be the result of suboptimal feeding conditions, resulting in a lower fattening rate. Alternatively, the birds may postpone departure if feeding conditions are better in the Caspian Sea region than in the Arabian Sea. In addition, birds may stay longer at the Caspian Sea stopover in order to moult, an energetically demanding process. Whereas active primary moult has been reported from Mono Lake, California, USA, a key stopover site for Red-necked Phalaropes following the Pacific Americas flyway (Jehl Jr. 1986), only $1 \%$ of individuals captured in July-September at inland lakes in Kazakhstan showed active moult (Gavrilov et al. 1983). Active moult of body feathers, which is commenced at the breeding grounds, is however reported from all autumn staging sites (Cramp and Simmons 1983, Gavrilov et al. 1983, Jehl Jr. 1986, Eichhorn 2001). Hence moult of body feathers, but probably not primary feathers, may be another function of the stopover in the Caspian Sea region. Clearly, field observations from the Caspian Sea region and the Arabian Sea are needed to verify these ideas.

All individuals entered the Arabian Sea via the Gulf of Oman and then moved into the seas south of Oman, as was hypothesized on the basis of field observations in this region (Mörzer-Bruijns and Mörzer-Bruijns 1957, Bailey 1966). The four individuals we tracked covered the entire proposed wintering range in the Arabian 
Sea, spanning from the Gulf of Aden in the west all along the Somalian coast east to offshore Pakistan (Cramp and Simmons 1983, Alerstam 1990, Delany et al. 2009). This large wintering range is largely the result of the high mobility of individual birds that used different sites.

Tracking studies have shown variation in the extent to which birds are stationary (using only a single site) or mobile ('itinerant', using multiple sites) in winter (Moreau 1972, Guilford et al. 2009, Kristensen et al. 2013, Mckinnon et al. 2013, Trierweiler et al. 2013). Itinerancy may be expected when resources are highly variable in space and time, especially when this occurs in a predictable pattern (Newton 2010). In the Arabian Sea, seasonally shifting monsoon winds drive huge upwelling systems with marked spatio-temporal variation in primary production (Marra and Barber 2005). High primary production occurs in particular at shelf edges, which is where high densities of phalaropes have been reported feeding on zooplankton (Schiemann 1986, Bourne 1991, 1997, Thorne and Read 2013). Location shifts of the three Red-necked Phalaropes tracked over the entire winter coincide with changes in productivity (figure 2.3). For example, individual B switched from the Omani coast to offshore Pakistan after productivity has declined in the former area. Similarly, individual C may have tracked high productivity events at the Omani coast, via the northern Somali coast to the southern Red Sea and back again. It returned to the Omani coast in April, when local primary productivity increased here again. These movements match field observations in winter, the largest numbers being present in the Gulf of Aden north to Salalah, Oman, and in the Gulf of Oman, with only small numbers off the Omani east coast (Mörzer-Bruijns and Mörzer-Bruijns 1957, Bailey 1966). These winter movements of Red-necked Phalaropes may be related to spatio-temporal patterns in primary productivity in a manner similar to the itinerancy reported for migrants wintering in Africa (Moreau 1972, Stach et al. 2012, Trierweiler et al. 2013). In fact, the prolonged stopover times in autumn (see above) and in early spring (at the Persian Gulf and in western Pakistan) obscure the distinction between 'migration' and 'wintering' and may also best be regarded as part an optimal timing of movements relative to optimal local conditions. A formal test of the relationship between the birds' movements and primary production is however problematic given the small sample size, the low spatial resolution of the birds' position estimates and the high spatial heterogeneity in primary production.

To what extent inter-individual differences in winter movements arise due to the individuals' direct responses to current local circumstances or to learned routes in earlier years is yet unclear. Seabirds show an overall tendency for large interindividual variation but small intra-individual variation in route and site fidelity between years (Phillips et al. 2005, Quillfeldt et al. 2010, Guilford et al. 2011, Dias et al. 2013), but see (Dias et al. 2011). Such dispersive movement patterns may be best explained by the recently proposed 'exploration-refinement hypothesis' (Guilford et al. 2011), in which individuals explore large areas and refine their 

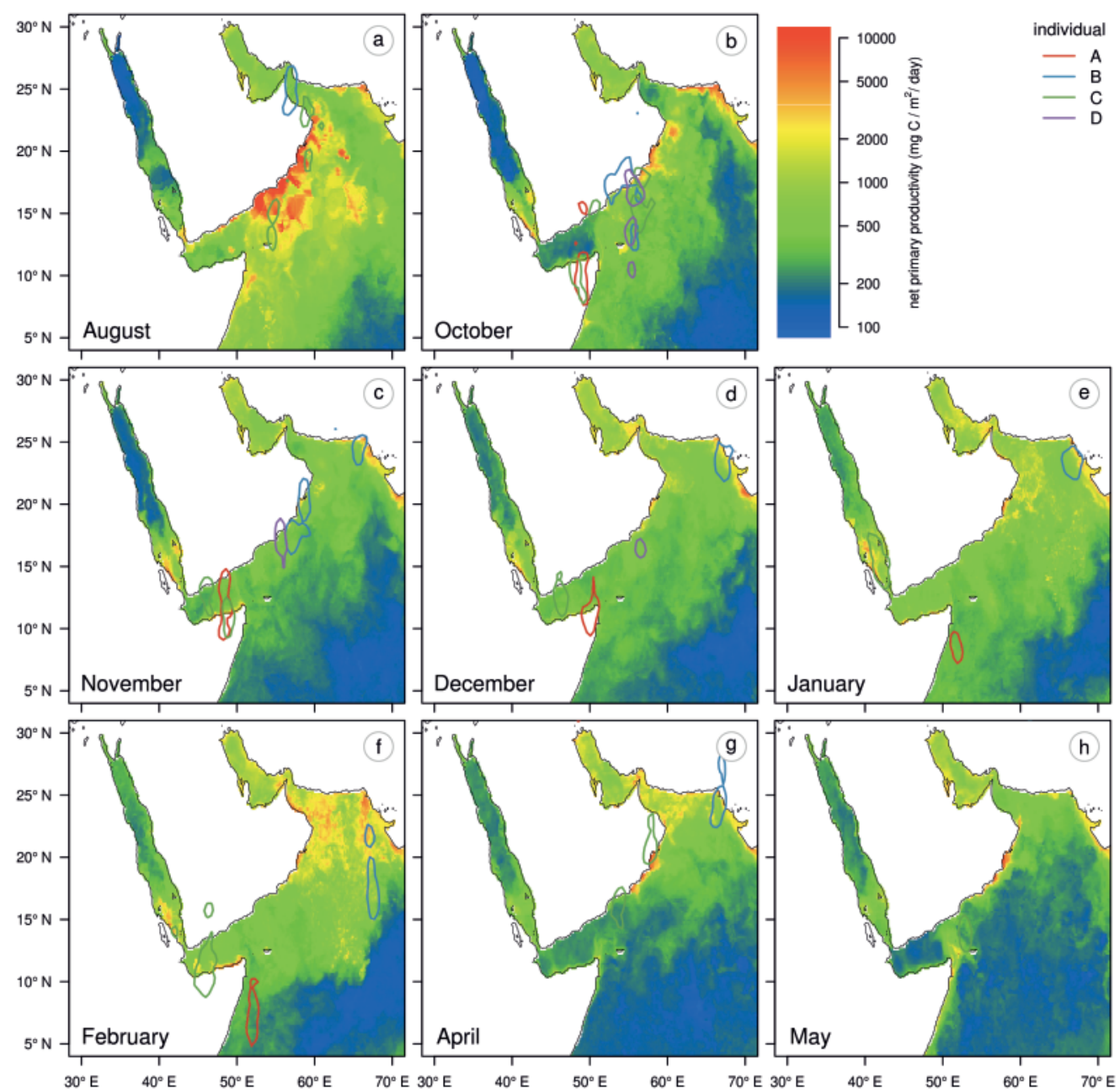

FIGURE 2.3 | Net primary productivity in the Arabian Sea (background) and the outlines of the $50 \%$ home range kernels of four red-necked phalaropes. September and March are left out as the number of position estimates was too low for robust home range kernel estimation.

subsequent movements according to prior experiences. Similar processes may shape the winter movements in Red-necked Phalaropes in the Arabian Sea and repeated tracks from the same individuals, preferably including their first migration cycle, are needed to shed light on this.

Although our sample size is small (four individuals only), the relative consistency in behaviour (destination, stopover use, flight speeds and mobility during winter) suggests the results are representative for the larger population. Still, future studies should test the robustness of our conclusions. 
Tracking studies across a wider range in the Arctic are needed to investigate potential differences in migration strategies among populations using the other two main wintering areas (off the Pacific coast of South America and off the East Indies), but we can now already compare our results to a single male tracked from Scotland to the Pacific and back (Smith et al. 2014). The total migration distance of ca 22 $000 \mathrm{~km}$ of this individual is 1.5-1.9 times the ca $12000-14000 \mathrm{~km}$ covered by the Scandinavian birds. Despite the larger migration distance of the Scottish bird, individuals from both populations may have similar migration speeds: Smith et al. (2014) noted that the 'slow southward progress' suggested regular stops - which, although not substantiated by flight speed calculations - is in line with our findings for Scandinavian Red-necked Phalaropes.

In the current study only males were tracked. It would be interesting to also track females as phalaropes have reversed sex-roles, and thus phalaropes form a good case to test ideas related to sex-specific migration patterns. For example, geolocator tracks could be used to quantify the contribution of three not mutually exclusive proximate causes to the observed earlier arrival of females at the breeding grounds in phalaropes (Reynolds et al. 1986): 1) earlier spring departure from the wintering grounds by females, 2) faster spring migration by females and/or 3) females wintering closer to the breeding grounds.

The Arabian Sea is one of the most productive marine areas on Earth and supports a distinctive but poorly studied avifauna, including several taxa endemic to the area (Bailey 1966). The Red-necked Phalarope is the only seabird abundant in the Arabian Sea that breeds in the Arctic (Bailey 1966) and our study is the first to establish a definitive link with the Scandinavian breeding population. Tracking studies across a wider range in the Arctic are needed to investigate potential differences in migration strategies among populations using the other two main wintering areas. In addition, our study is - to the best of our knowledge - the first to document movement data of individual seabirds in the Arabian Sea and this and future studies are required to understand how Red-necked Phalaropes and other seabirds utilize this rich and dynamic area. 


\section{SUPPLEMENT}

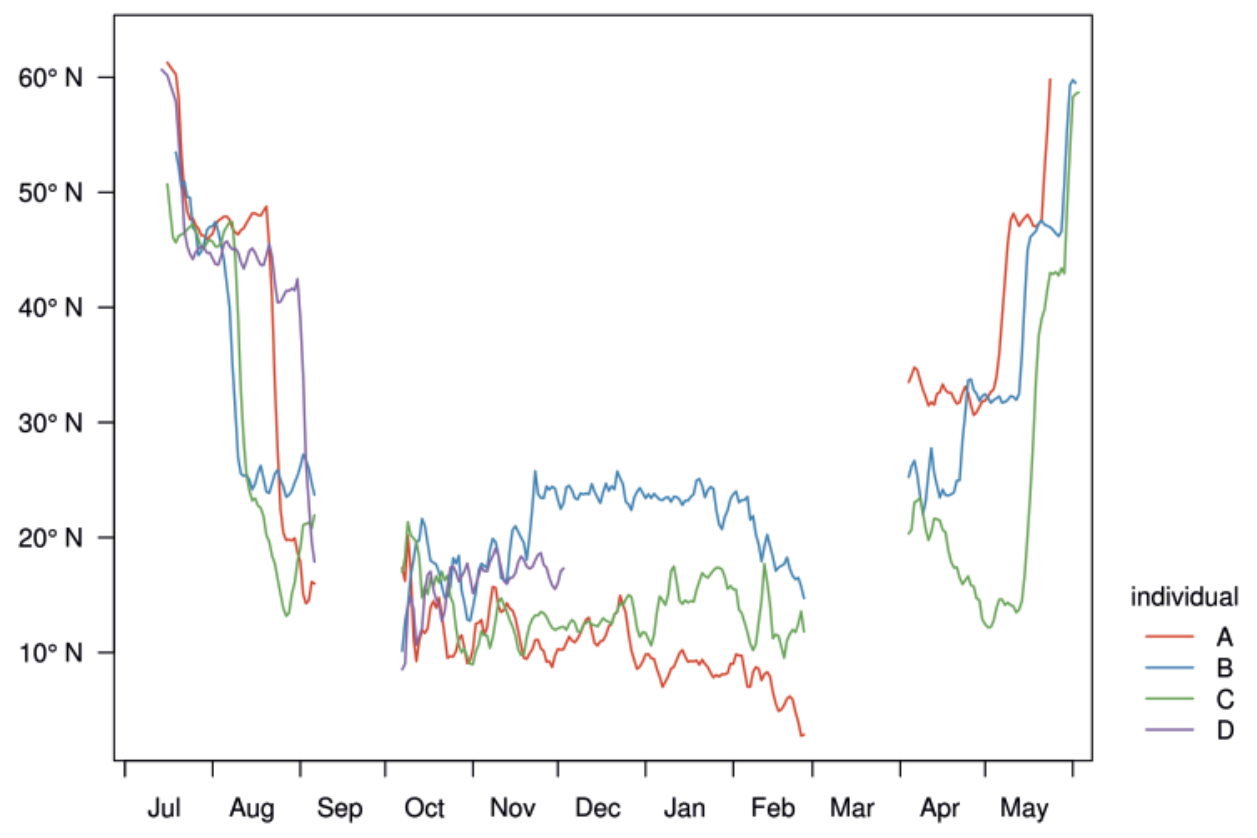

FIGURE 2.S1 | Latitude over time of tracks of four red-necked phalaropes during 2013-2014. 
Table 2.51 | Migration schedules of four male red-necked phalaropes tracked from Sweden during 2013-2014.

\begin{tabular}{|c|c|c|c|c|c|}
\hline Individual & Period & Site & Arrival & Departure & $\begin{array}{c}\text { Stopover } \\
\text { Duration (days) }\end{array}$ \\
\hline \multirow[t]{7}{*}{ A } & A & Gulf of Finland & $16 \mathrm{Jul}$ & $20 \mathrm{Jul}$ & 3 \\
\hline & A & W Caspian Sea & $22 \mathrm{Jul}$ & 21 Aug & 29 \\
\hline & W & South of Oman & 25 Aug & 31 Aug & 5 \\
\hline & w & Gulf of Aden & 3 Sep & $20 \mathrm{Mar}^{1}$ & 198 \\
\hline & w & Persian Gulf & 21 Mar $^{1}$ & 5 May & 46 \\
\hline & $\mathrm{S}$ & W Caspian Sea & 12 May & 22 May & 9 \\
\hline & S & Baltic Sea & 24 May & 24 May & 0 \\
\hline \multirow[t]{9}{*}{ B } & A & Eastern Ukraine & $20 \mathrm{Jul}$ & $23 \mathrm{Jul}$ & 3 \\
\hline & A & E Caspian Sea & $24 \mathrm{Jul}$ & 8 Aug & 13 \\
\hline & w & Gulf of Oman & 11 Aug & 7 Sep $^{1}$ & 27 \\
\hline & W & South of Oman & 8 Sep $^{1}$ & $21 \mathrm{Nov}$ & 74 \\
\hline & w & Off Pakistan & 22 Nov & $23 \mathrm{Apr}$ & 152 \\
\hline & S & Western Pakistan & $24 \mathrm{Apr}$ & 14 May & 21 \\
\hline & S & E Caspian Sea & 16 May & 18 May & 1 \\
\hline & S & W Caspian Sea & 20 May & 29 May & 9 \\
\hline & S & Baltic Sea & 31 May & 2 Jun & 2 \\
\hline \multirow[t]{10}{*}{ C } & A & W Caspian Sea & $17 \mathrm{Jul}$ & 9 Aug & 23 \\
\hline & W & Gulf of Oman & 13 Aug & 19 Aug & 6 \\
\hline & W & South of Oman & $\sim 25$ Aug & 23 Oct & 59 \\
\hline & W & Gulf of Aden & 23 Oct & 3 Jan & 72 \\
\hline & W & S Red Sea & 4 Jan & 6 Feb & 33 \\
\hline & W & Gulf of Aden & $7 \mathrm{Feb}$ & $20 \mathrm{Mar}^{1}$ & 41 \\
\hline & w & S of Oman & $23 \mathrm{Mar}^{1}$ & 15 May & 53 \\
\hline & $\mathrm{s}$ & S Caspian Sea & 20 May & 22 May & 2 \\
\hline & S & W of Caspian Sea & 24 May & 30 May & 6 \\
\hline & $\mathrm{s}$ & Baltic Sea & 31 May & 3 Jun & 3 \\
\hline \multirow[t]{4}{*}{ D } & A & Gulf of Finland & $14 \mathrm{Jul}$ & $20 \mathrm{Jul}$ & 6 \\
\hline & A & Black Sea & $22 \mathrm{Jul}$ & 21 Aug & 29 \\
\hline & A & W Caspian Sea & 25 Aug & $1 \mathrm{Sep}$ & 7 \\
\hline & w & South of Oman & 6 Sep & $N A^{2}$ & $>>87$ \\
\hline
\end{tabular}




\section{ACKNOWLEDGEMENTS}

Vital assistance in the field was provided by Vincent Hin in 2013 and by Tim van der Meer, Guido Keijl and Fons de Meijer in 2014. Martin Green and Åke Lindström (Lund University, Lund, Sweden) provided essential logistical support and the required permits. Geolocators were provided by Thomas Alerstam (Lund University). James Fox (Migrate Technologies Ltd., Cambridge, United Kingdom) kindly downloaded the data from the dead logger. Peter Becker, Götz Eichhorn, Jens Eriksen, Jim de Fouw and Pavel Tomkovich helped with obtaining references. Thanks also to Ron Ydenberg (Wageningen University, the Netherlands). Special thanks go out to Paula Machin and Juan Fernández-Elipe for support during the fieldwork! RvB was funded This work is financed by the Netherlands Organisation for Scientific Research (NWOproject number 866.13.005) and supported by the LUVRE project (www.luvre.org). 


\section{CHAPTER III}

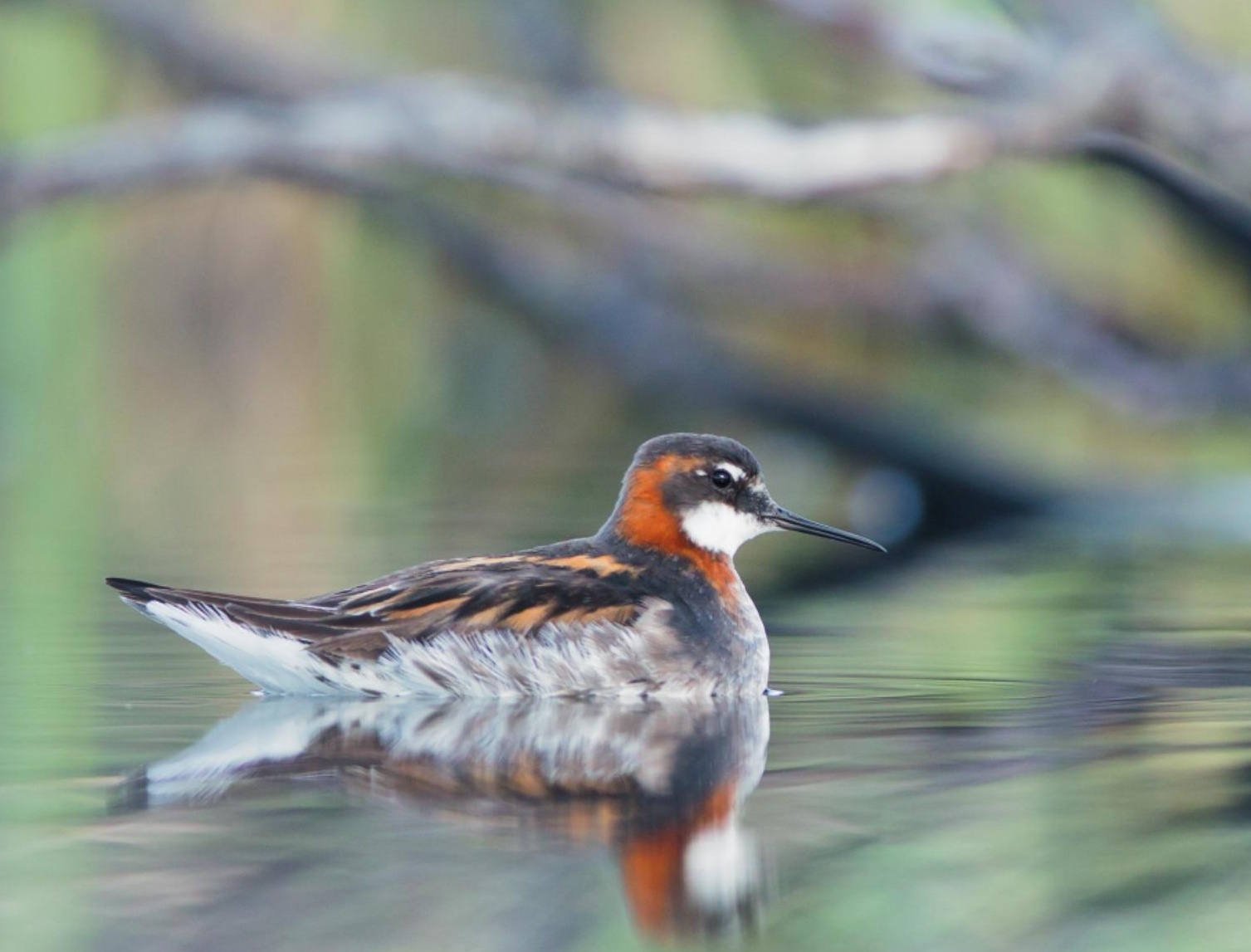

"With their long legs for wading, with narrow lobes instead of broad webbing between their toes, without the slender, narrow wings upon which albatrosses hang through days of storm and stress of weather, phalaropes seem little adapted for pelagic life, and yet here and on the Pacific, hundreds of miles from land, I have seen them in enormous flocks daring wind and water, spending the whole winter out of sight of land, trusting to the floating bounty of the sea for food, and to the buoyancy of their dense plumage and air-filled bodies for safety. I have never seen them in a full storm, but in a half gale, with spray blowing, and every watery hilltop fountaining into ugly lashing foam, I have watched their marvellous seamanship, paddling steadily up wind, able, by some perfected knowledge, to keep in the sliding, shifting valleys and free of the choking spume-drift." 


\section{A migratory divide among red-necked phalaropes in the Western Palearctic reveals contrasting migration and wintering movement strategies}

Rob S.A. van Bemmelen, Yann Kolbeinsson, Raül Ramos, Olivier Gilg, Jose A. Alves, Malcolm Smith, Hans Schekkerman, Aleksi Lehikoinen, Ib Krag Petersen, Böðvar Pórisson, Aleksandr A. Sokolov, Kaisa Välimäki, Tim van der Meer, J. David Okill, Mark Bolton, Børge Moe, Sveinn Are Hanssen, Loïc Bollache, Aevar Petersen, Sverrir Thorstensen, Jacob González-Solís, Raymond H.G. Klaassen \& Ingrid Tulp Frontiers in Ecology \& Evolution 7:31 


\section{ABSTRACT}

Non-breeding movement strategies of migratory birds may be expected to be flexibly adjusted to the distribution and quality of habitat, but few studies compare movement strategies among populations using distinct migration routes and wintering areas. In our study, individual movement strategies of Rednecked Phalaropes Phalaropus lobatus, a long-distance migratory wader which uses saline waters in the nonbreeding period, were studied using light-level geolocators. Results revealed a migratory divide between two populations with distinct migration routes and wintering areas: one breeding in the north-eastern North Atlantic and migrating ca $10000 \mathrm{~km}$ oversea to the tropical eastern Pacific Ocean, and the other breeding in Fennoscandia and Russia migrating ca 6 $000 \mathrm{~km}$ - largely over land - to the Arabian Sea (Indian Ocean). In line with our expectations, the transoceanic migration between the North Atlantic and the Pacific was associated with proportionately longer wings, a more even spread of stopovers in autumn and a higher migration speed in spring compared to the migration between Fennoscandian-Russian breeding grounds and the Arabian Sea. In the wintering period, birds wintering in the Pacific were stationary in roughly a single area, whereas individuals wintering in the Arabian Sea moved extensively between different areas, reflecting differences in spatio-temporal variation in primary productivity between the two wintering areas. Our study is unique in showing how habitat distribution shapes movement strategies over the entire nonbreeding period within a species. 


\section{INTRODUCTION}

Animal movements are strongly linked to habitat and resource availability. For example, during the non-breeding season, migratory birds cover long distances to track spatio-temporal peaks in resource abundance and avoid unfavourable conditions over large spatial scales (Newton 2010, Thorup et al. 2017). Nonbreeding movements may consist of a long-distance migration to wintering areas and movements within the wintering areas, which can cover long distances and - in some species - are carried out by only a portion of the individuals (Trierweiler et al. 2013, Koleček et al. 2018). Components of movement strategy, such as the number of staging sites, the distances between them, and the time spent at each staging site, are thought to be dictated by the availability and relative quality of habitat (Alerstam and Lindström 1990, Gudmundsson et al. 1991). Movement strategies are expected to be flexibly adjusted to habitat availability and quality within the boundaries set by, for example, maximum fattening rates and fuel loads, resulting in different strategies among individuals or populations using different migration routes and wintering areas. Indeed, migration strategies do differ between populations in many species (Buehler and Piersma 2008, Delmore et al. 2012, Alves et al. 2013). At the same time, surprisingly similar migration strategies have been observed in other species, despite geographically distinct migration routes (Fraser et al. 2013, Trierweiler et al. 2014). With so few studies, the extent to which species flexibly adjust large-scale movement strategies to habitat remains poorly understood.

The Red-necked Phalarope Phalaropus lobatus is a small wader which breeds in fresh water ponds in arctic and subarctic tundra. The species is probably best known for its unusual mating system, with reversed sex-roles, where polyandry takes place and the male cares for eggs and chicks (Reynolds et al. 1986). In the non-breeding period, it adopts a pelagic lifestyle in three disjunct areas in tropical oceans: the tropical eastern Pacific, the Arabian Sea, and off the East Indies (Cramp and Simmons 1983). Due to the challenges involved in studying small seabirds at sea, its non-breeding movements remained elusive until recently, when light-level geolocators revealed individual non-breeding movements. Four Swedish males were shown to winter in the Arabian Sea in the north-west Indian Ocean (van Bemmelen et al. 2016), confirming what was already expected based on a small number of ring recoveries (Schiemann 1977). No ring recovery exists for populations breeding on islands in the north-eastern North Atlantic (Scotland, Faroe Islands, Iceland and Greenland), despite substantial ringing efforts (Schiemann 1977, Wernham et al. 2002). Recently, three male Red-necked Phalaropes were tracked from the Scottish breeding area to the northern Humboldt Current in the Pacific (Smith et al. 2014, 2018), suggesting that north-eastern North Atlantic populations migrate westwards after breeding. The migration routes to the Pacific and Arabian Sea differ in distance (respectively ca $11000 \mathrm{~km}$ versus ca $6000 \mathrm{~km}$ one-way; Smith et al. 2014, van Bemmelen et al. 2016), and habitat (mostly oversea versus largely overland), given 
that Red-necked Phalaropes depend on saline waters for staging (Cramp and Simmons 1983, van Bemmelen et al. 2016). In addition, the wintering grounds contrast in spatio-temporal variation in primary productivity, with stable conditions in the Pacific sites but strong fluctuations in the Arabian Sea (Longhurst 2006). The occurrence of two distinct breeding populations of Red-necked Phalarope with divergent migration routes and wintering areas provides a rare opportunity to study how, within a single species, habitat distribution shapes movement strategies over the entire non-breeding period.

A first objective of the current study is to investigate the generality of previous tracking studies (Smith et al. 2014, 2018, van Bemmelen et al. 2016) using nonbreeding movements of Red-necked Phalaropes from nine breeding locations between East-Greenland $\left(22^{\circ} \mathrm{W}\right)$ and Western Siberia $\left(69^{\circ} \mathrm{E}\right)$ recorded by light-level geolocators. Subsequently, both migration strategies and wintering movement strategies are compared between the two routes and wintering areas. Based on optimal migration theory and assuming that suitable feeding conditions are more widespread along the marine western migration route, Red-necked Phalaropes migrating to the Pacific are expected to make shorter flights with more frequent but briefer stopovers on migration to and from the breeding grounds, thereby avoiding the costs of carrying large fuel loads (Alerstam and Lindström 1990). In contrast, Red-necked Phalaropes migrating to the Arabian Sea are expected to show a more direct flight, with few but longer stopovers, as more widely separated saline waters along their route forces them to build up larger fuel loads to cover longer flights (Alerstam and Lindström 1990). Different movement strategies may favour selection towards certain morphological adaptations, such as longer, more pointed, wings for longer migration distances (Alerstam 1990, Leisler and Winkler 2003). Thus, we also tested for morphological variation potentially associated with the two migration strategies. After arrival at the wintering grounds, birds wintering in the Pacific are expected to move only short distances within the wintering grounds ('residency'), given the high and constant primary productivity of the northern Humboldt Current (Chavez and Messié 2009). In contrast, birds wintering in the Arabian Sea are expected to move between several distant areas during the wintering period ('itinerancy'), reflecting large seasonal and spatial variation in primary productivity (Longhurst 2006). In addition to the above, individual consistency between years and the potential effect of sex on migration timing and strategies are explored. We expect females to arrive earlier than males to maximize their potential of obtaining males (Oring and Lank 1982, Reynolds et al. 1986).

\section{MATERIALS AND METHODS}

\section{Catching and geolocator deployments}

Red-necked phalaropes were captured and fitted with geolocators from 2012 to 2017 in Greenland (Constable Pynt: $70^{\circ} 45^{\prime} \mathrm{N}-22^{\circ} 38^{\prime} \mathrm{W}$ ), two sites in Iceland (Flói: 
$63^{\circ} 56^{\prime} \mathrm{N}-21^{\circ} 15^{\prime} \mathrm{W}$ and Adaldalur: $65^{\circ} 51^{\prime} \mathrm{N}-17^{\circ} 04^{\prime} \mathrm{W}$ ), Scotland (Fetlar: $60^{\circ} 36^{\prime} \mathrm{N}-0^{\circ} 52^{\prime} \mathrm{W}$ ), Sweden (Ammarnäs: $65^{\circ} 59^{\prime} \mathrm{N}-16^{\circ} 01^{\prime} \mathrm{E}$ ), Finland (Enontekiö: $68^{\circ} 58^{\prime} \mathrm{N}-21^{\circ} 16^{\prime} \mathrm{E}$ ), Norway (Slettnes: $71^{\circ} 05^{\prime} \mathrm{N}-28^{\circ} 13^{\prime} \mathrm{E}$ ) and two sites in Russia (Tobseda: $68^{\circ} 36^{\prime} \mathrm{N}-52^{\circ} 19^{\prime} \mathrm{E}$; Erkuta: $68^{\circ} 14^{\prime} \mathrm{N}-69^{\circ} 9^{\prime} \mathrm{E}$ ), see figure 3.1. Adults were captured while foraging in tundra ponds using mist nets or on their nests using walk-in traps or spring traps. Different geolocator types and deployment methods were applied because studies in Scotland, Finland and Iceland each began as independent projects before joining the project covering Greenland, Sweden, Norway and Russia. Geolocators were either leg-mounted using a modified darvic ring with flag (Greenland and the first year at Flói, Iceland) or back-mounted using leg-loop harnesses (all other sites and years, Rappole and Tipton 1991). Leg-loops were constructed from $1 \mathrm{~mm}$ silastic tubing (WMQ 60) with an elasticated core (only first study year in Scotland and in Finland) or $1 \mathrm{~mm}$ wide flat braided shelf-string (British Trust for Ornithology, UK). Geolocator models used were the Mk10 model (British Antarctic Survey, Cambridge, UK), (a modified version of) the Intigeo P65A (Migrate Technology Ltd, Cambridge, UK) and the SOI-GDL2 v1.3 in Finland and v2.3 in Scotland (Swiss Ornithological Institute, Sempach, Switzerland), weighing respectively $1.0 \mathrm{~g}, 1.0 \mathrm{~g}$ and $0.7 \mathrm{~g}$. At a mean body mass of $38.3 \mathrm{~g}$ for females $(n=170)$ and $33.4 \mathrm{~g}$ for males $(n=468)$, a geolocator mass of $1 \mathrm{~g}$ represents about $2.6 \%$ of mean body mass in females and $3.0 \%$ in males, or $1.7 \%$ and $2.0 \%$ in case of a geolocator weight of $0.7 \mathrm{~g}$. We are not aware of biases in position estimations inherent to specific geolocator types. The following biometrics were collected: wing length (to the nearest $1.0 \mathrm{~mm}$ ), bill length (to the nearest $0.1 \mathrm{~mm}$ ), total head length (head + bill; to the nearest $1.0 \mathrm{~mm}$ ), tarsus length (to the nearest $1.0 \mathrm{~mm}$ ) and body mass (to the nearest $0.1 \mathrm{~g}$ ). In addition to collecting biometrics for the birds equipped with geolocators, biometrics were obtained from other individuals at the study sites, and also from individuals captured in Iceland (Mývatn: $65^{\circ} 36^{\prime} \mathrm{N}-16^{\circ} 60^{\prime} \mathrm{W}$ and Flatey Island: $65^{\circ} 22^{\prime} \mathrm{N}-22^{\circ} 55^{\prime} \mathrm{W}$ ) and Russia (Medusa Bay: $\left.73^{\circ} 04^{\prime} \mathrm{N}-80^{\circ} 30^{\prime} \mathrm{E}\right)$. Using annual encounter data from 212 individuals with geolocators, we estimated apparent survival $\varphi$ and resighting probability $p$ using Cormack-Jolly-Seber (CJS) models for live encounter data in the 'Rmark' package in $\mathrm{R}$, an interface to the program Mark (Laake 2013). AICc was used to select the best model from a range of CJS models fitted with parameters for $\varphi, p$ and study site either fixed or varying per year. Four CJS models had $\triangle \mathrm{AICC}$ values $<2$, including the simplest model $(\triangle \mathrm{AICC}=0.64)$, which estimated $\mathrm{p}$ at $0.52(\mathrm{Cl}=0.31-0.71)$ and $\varphi$ at $0.32(\mathrm{Cl}=0.23-0.43)$. An apparent survival rate of 0.32 is notably low for a wader species (Méndez et al. 2018) but is within the range of 0.17 to 0.56 reported from sites in Alaska (Colwell et al. 1988, Schamel and Tracy 1991, Sandercock 1997) and likely reflects a low site fidelity rather than survival. Nevertheless, a weak effect of geolocator deployment cannot be ruled out, considering we could not compare against a control group without a geolocator, and knowing that a geolocator attached to a leg flag and weighing $>2.5 \%$ of the body mass led to lower return rates in other small wader species (Weiser et al. 2016). Trapping and tagging Rednecked Phalaropes in Greenland has been approved by the Ministry of Fisheries, 
Hunting and Agriculture (Government of Greenland); in Scotland by the Special Methods Technical Panel of the British Trust for Ornithology and Scottish Natural Heritage; in Finland by the Lapland Centre for Economic Development, Transport and the Environment; in Norway by the Norwegian Food Safety Authority (FOTS ID $6328,7421,8538)$ and in Sweden by the Malmö-Lunds djurförsöksetiska nämnd (M160-11, M470-12).

\section{Geolocator data analysis}

Data were downloaded from retrieved loggers and processed using BASTrack software (BAS, UK) and time was adjusted for clock drift. Twilights events were determined using the 'twilightCalc' function in GeoLight package version 2.0 (Lisovski and Hahn 2012), in R version 3.4 (R Core Team 2017) using a light threshold of two and subsequently checked for errors by plotting the date against time of sunrise or sunset. For a range of potential sun angles (-7 to $2^{\circ}$ ), we plotted (for each track) the position estimates and selected the sun angle that (1) minimized the amplification of latitudinal error close to the equinoxes while (2) resulting in similar latitudes at both sides of the equinox and (3) where positions fitted the shape and position of the oceans and inland seas. Final sun angles were between -5.5 to $-5.0^{\circ}$ for BAS loggers, -5.0 to $-3.5^{\circ}$ for Migrate Technology loggers without stalks, -5.5 to $-4.5^{\circ}$ for Migrate Technology loggers with stalks, and $0^{\circ}$ for the Swiss Ornithological Institute loggers.

Stationary periods were delineated based on patterns in time of sunset and sunrise, using the function 'changeLight' from the 'GeoLight' package in R, with a minimum staging duration of 2 days. For each stationary period, the geographical centroid was calculated. For stationary periods with latitudes greatly affected by proximity to the equinox (e.g. resulting in positions in the central Indian Ocean), a latitude was assumed at the coastline north of the original position estimate, which was always in close proximity to other staging locations. Subsequently, stationary periods with geographical centroids closer than $200 \mathrm{~km}$ were joined. Stationary areas with centroids in the Arabian Sea, Persian Gulf or Pacific were defined as the wintering period. Staging areas preceding the wintering period were assigned to the autumn migration and those following the wintering period to spring migration. Departure from and arrival at the breeding area were calculated as the time needed to cover the great-circle distance to the first or last position estimate, respectively, at a speed of $13.3 \mathrm{~m} \mathrm{~s}^{-1}$ (Alerstam and Gudmundsson 1999). Migration distance was measured using the sum of great-circle distances, using the 'rdist.earth' function in the 'fields' package in R, covered from the breeding site via the centroids of each staging site to the centroid of the first (autumn migration) or last (spring migration) wintering area. Similarly, distance travelled during winter was calculated as the great circle distance between staging areas assigned to the winter period. The fat load needed for the initial migratory movement in still air was estimated using the software package Flight v. 1.25 (Pennycuick 2008). For each potential body mass (at increments of $1 \mathrm{~g}$ ), the fat fraction in which the migration simulation finished 
with a lean body mass was estimated by an iterative process. Pennycuick (2008) defined lean body mass as the 'body mass of a bird with zero fat reserves, but not actually starving'. Here, lean body mass was taken to be the minimum weight for each sex in our database, excluding one male of $24 \mathrm{~g}$ and one female of $28.0 \mathrm{~g}$ : $26.0 \mathrm{~g}$ for males $(n=440)$ and $29.3 \mathrm{~g}$ for females $(n=164)$. Note that taking a lower lean body mass results in higher fat fractions and thus larger potential flight ranges. After estimating the body mass required to cover the distance to the first stopover, the time required to fuel for this flight was calculated assuming a fat deposition rate (FDR) of $3.2 \%$ of lean body mass (Sikora and Zielińksi 2000, Lindström 2003). As no FDR values are known for Red-necked Phalaropes at the wintering areas, the sensitivity of migration speed was explored by plotting migration speed for a range of possible FDR values at each wintering ground (figure 3.51). In two individuals migrating in spring from the Pacific to the north-eastern North Atlantic, no stopovers of 2 or more days were identified. In these cases, the first leg was taken as the distance to the centroid of three clustered position estimates off Florida, which is near the first staging area of other individuals following the western route (figure 3.1). Migration duration was taken as the number of days in transit between the breeding and the wintering area, plus the estimated time needed to fuel for the initial leg. Migration speed was calculated as the total migration distance divided by the migration duration.

The following parameters were derived for each track: migration distance, total migration duration (including stopovers and fuelling time for the first leg, see above), distance to the first staging area, length of the longest stopover, number of stopovers, migration speed, and timing of departure from and arrival at both the breeding and wintering area. First, t-tests were used to test whether any of the aforementioned parameters differed between sexes among Swedish birds, the only area with sufficient females to compare sexes (see Results). ANOVAs were then constructed comparing each of the parameters between four 'regions': 'Atlantic' (Greenland, Iceland and Scotland), 'Sweden' (Ammarnäs), 'Norway' (Slettnes), and 'Russia' (Tobseda and Erkuta). A contrast between 'Atlantic' (hereafter referred to as 'western' birds, populations or migration route) and the three other regions (hereafter referred to as 'eastern' birds, populations or migration route) was used to test for differences in migration strategy parameters between the two flyways. The number of stopovers was compared between the flyways using the same contrast structure in a Poisson Generalized Linear Model (GLM). The number of stopovers per unit distance was tested using the same Poisson GLM with the log of the migration distance included as an offset. In addition to the analysis of the geolocator data, body mass measurements from breeding sites were compared in a Linear Mixedeffect Model (LMM) with flyway as the only main effect and site as a random effect, using the nlme package in $\mathrm{R}$ (Pinheiro et al. 2018). From these body mass measurements, maximum flight ranges were estimated using the relationship as derived from Pennycuick's model (see above). For comparison of fuel loads at staging sites, we obtained body mass measurements at the Bay of Fundy, Canada, 
along the western migration route, from Mercier (1985) and from saline lakes in Kazakhstan, along the eastern migration route, from Gavrilov et al. (1983).

To compare winter movement strategies between the two wintering areas, the number of staging areas was compared using a Poisson GLM and the duration of the longest stationary period and the total distance covered within the winter period were compared using ANOVAs with the same contrast structure as used in the analysis of migration characteristics. In addition, we linked phalarope movements to spatio-temporal patterns in food availability. First, net ocean primary productivity for 8-day periods, based on the Vertically Generalized Production Model (VGPM) algorithm (Behrenfeld and Falkowski 1997), were obtained from (O'Malley 2016). Second, a $300 \mathrm{~km}$ wide polygon parallel to the coast was drawn and split into four main areas: 1) northern Humboldt Current to the Pacific coast off Central America, 2) Red Sea via the Gulf of Aden and Oman to Pakistan, 3) Persian Gulf to the Gulf of Oman and 4) East coast of Somalia. Areas were subdivided bins perpendicular to the coast, thus in longitude bins (Arabian Sea) or latitude bins (Pacific), each $100 \mathrm{~km}$ in width. Finally, to test whether tagged individual Rednecked Phalaropes were associated with areas of high primary productivity, for each 8-day period and longitude/latitude bin, the loge of the $95 \%$ quantile of primary productivity values was correlated with the number of staging Red-necked Phalaropes, using Poisson LMMs, with 'area' and 'longitude/latitude bin' as random effects to account for spatial correlation. To test whether wintering movements are directed towards areas with higher primary productivity, or a steeper decline in primary productivity (which could be due to higher grazing intensity by zooplankton), we calculated the difference in primary productivity and its slope between departure from one site and arrival at the next site and tested whether this differed from zero using an intercept-only LMM, with individual as a random effect.

In the Greenlandic bird, the logger was mounted to a leg flag and also recorded submersion in saline water every 3 seconds and summed the number of 'wets' every 10 minutes. This 'wet/dry' data was used to delineate migration flights (Battley and Conklin 2017). Other loggers were back-mounted and only occasionally recorded submersion, and were unsuitable for delineating long flights.

\section{Biometrics}

We tested for differences in morphology between the two populations using biometric data from eleven breeding locations from Greenland to Taymyr, Russia. As females are larger than males (Cramp and Simmons 1983), we built separate LMMs for each sex, comparing wing length, bill length and tarsus length between western and eastern birds, and with 'breeding site' as a random effect. Wings can be longer either due to more pointedness of wings or due to larger body size. In absence of data on pointedness, we took tarsus length as a measure of body size and fitted a model of wing length by flyway and tarsus length. 


\section{RESULTS}

\section{Sample size}

In total, 34 geolocator tracks (each track referring to one year of data between two breeding periods) of 26 individuals were obtained from eastern populations. From the western population, 10 tracks of 8 individuals were obtained. Nine tracks ( 1 from a western bird and 8 from eastern birds) were incomplete due to premature failure or a flat battery of the logger at the wintering areas; 5 of these failures happened in the second year of tracking. Repeated tracks were obtained for 2 western and 7 eastern individuals (see below). To compare movement strategy variables between western and eastern birds, only the first track of each individual was included. Also, the single Finnish bird was excluded as it had much higher variation in estimates of twilights and positions than the other loggers. The final dataset for comparisons of movement strategies thus included 8 full tracks from western birds ( 1 female, 7 males) and 22 full tracks plus 3 autumn migrations from eastern birds (6 females, 19 males).

\section{Migration routes}

The data show two distinct migration routes from Western Palearctic Rednecked Phalaropes (figure 3.1). All Fennoscandian-Russian birds migrated to the Arabian Sea $(n=26$, including the Finnish bird), whereas those breeding at North Atlantic islands wintered in the Pacific; either in the northern Humboldt Current $(n=6)$ or off the westcoast of Central America $(n=2)$.

\section{Sex differences in migration strategy}

Only the Swedish sample contained sufficient females $(n=5)$ and males $(n=7)$ to compare sexes. Between Swedish males and females, no migration strategy variables were significantly different, either during autumn or spring migration. Although the trends in our data comply with the expectation of earlier migration in females, overlap between sexes in timing rendered them non-significant $(p>0.1)$, but females arrived nearsignificantly earlier than males at the breeding area $\left(t_{1,9}=-2.0, p=0.078\right)$. Like the Swedish birds, the single female from Norway fell within the range of values for all migratory strategy variables. She was earlier than most males in the timing of departure from the breeding area, arrival at and departure from the wintering area. However, she arrived later than most Norwegian males at the breeding area. Among the western birds, the single female departed from the Icelandic breeding area and arrived at and departed from the wintering area at the same time as the males, but arrived earlier at the breeding area. She performed the migration faster than most but not all males, using four stopovers in autumn and none in spring, resulting in a relatively short autumn migration and the shortest spring migration. Considering that no significant sex-differences in 
TABLE 3.1 | Characteristics of autumn and spring migration of Red-necked Phalaropes migrating between north-eastern North Atlantic breeding areas and the Pacific ('West') and between Fennoscandian-Russian breeding areas and the Arabian Sea ('East'). For the number of stopover/staging sites and the longest stopover/staging period, median and range are given instead of mean $\pm s d$ and range. Statistical significance of difference between western and eastern birds is indicated as N.S. not significant, $* p<0.05, * * p<0.01$ and $* * * p<0.001$.

\begin{tabular}{|c|c|c|c|}
\hline Period & Variable & $\begin{array}{c}\text { West } \\
\text { mean } \pm \text { sd (range) }\end{array}$ & $\begin{array}{c}\text { East } \\
\text { mean } \pm \mathrm{sd} \text { (range) }\end{array}$ \\
\hline \multirow{7}{*}{ 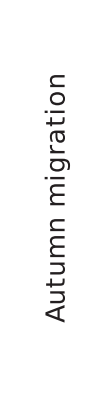 } & Distance $(\mathrm{km})$ & $9238 \pm 900(7559-10269)$ & $6069 \pm 540(5380-7423)$ \\
\hline & Duration (d) & $73.5 \pm 17.2(52-106)$ & $52.9 \pm 12.6(35-75)$ \\
\hline & Number of stopovers $>2 d$ & $4(1-7)$ & $1(1-6)$ \\
\hline & Longest stopover (d) & $11(5-24)$ & $21(7-40)$ \\
\hline & Departure breeding area & $9 \mathrm{Jul} \pm 14.4 \mathrm{~d}(23 \mathrm{Jun}-30 \mathrm{Jul})$ & 19 Jul $\pm 8.7 \mathrm{~d}(4 \mathrm{Jul}-3$ Aug $)$ \\
\hline & Arrival wintering area & 10 Sep \pm 20.6 d (21 Aug-14 Oct) 31 & 1 Aug $\pm 16.2 \mathrm{~d}(10$ Aug-22 Sep) \\
\hline & Sample size & 8 & 25 \\
\hline \multirow{5}{*}{ 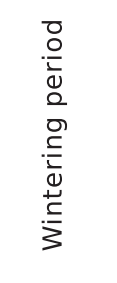 } & Distance $(\mathrm{km})$ & $1549 \pm 1588(0-4302)$ & $4,934 \pm 2,110(1810-9189)$ \\
\hline & Duration (d) & $240.4 \pm 20.0(210-265)$ & $251.0 \pm 16.6(218-282)$ \\
\hline & Number of staging sites & $2.5(1-6)$ & $9(4-13)$ \\
\hline & Longest staging (d) & $172(96-263)$ & $81(40-160)$ \\
\hline & Sample size & 8 & 22 \\
\hline \multirow{7}{*}{ 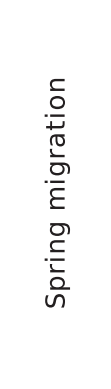 } & Distance (km) & $9103 \mathrm{~km} \pm 821(8163-10188)$ & $5366 \mathrm{~km} \pm 556(4576-6379)$ \\
\hline & Duration $(d)$ & $37.1 \pm 7.8(29-50)$ & $32.5 \pm 7.8(17-54)$ \\
\hline & Number of stopovers $>2 d$ & $1.5(0-5)$ & $2(0-4)$ \\
\hline & Longest stopover (d) & $5(1-9)$ & $6(1-21)$ \\
\hline & Departure wintering area & 8 May \pm 7.9 d (24 Apr-22 May) & 8 May \pm 12.9 d (6 Apr-1 Jun) \\
\hline & Arrival breeding area & 1 Jun \pm 8.8 d (23 May-21 Jun) & 3 Jun $\pm 6.7 \mathrm{~d}$ (22 May-17 Jun) \\
\hline & Sample size & 8 & 22 \\
\hline
\end{tabular}

FIGURE 3.1 | Autumn and spring migration stopovers and wintering areas of individual Rednecked Phalaropes derived from light-level geolocator tracks. Coloured squares show the nine breeding sites (with corresponding sample sizes, i.e., tracked individuals). Dot size represents staging duration. Staging dots are connected by great-circle lines, which do not necessarily represent the exact routes taken. 


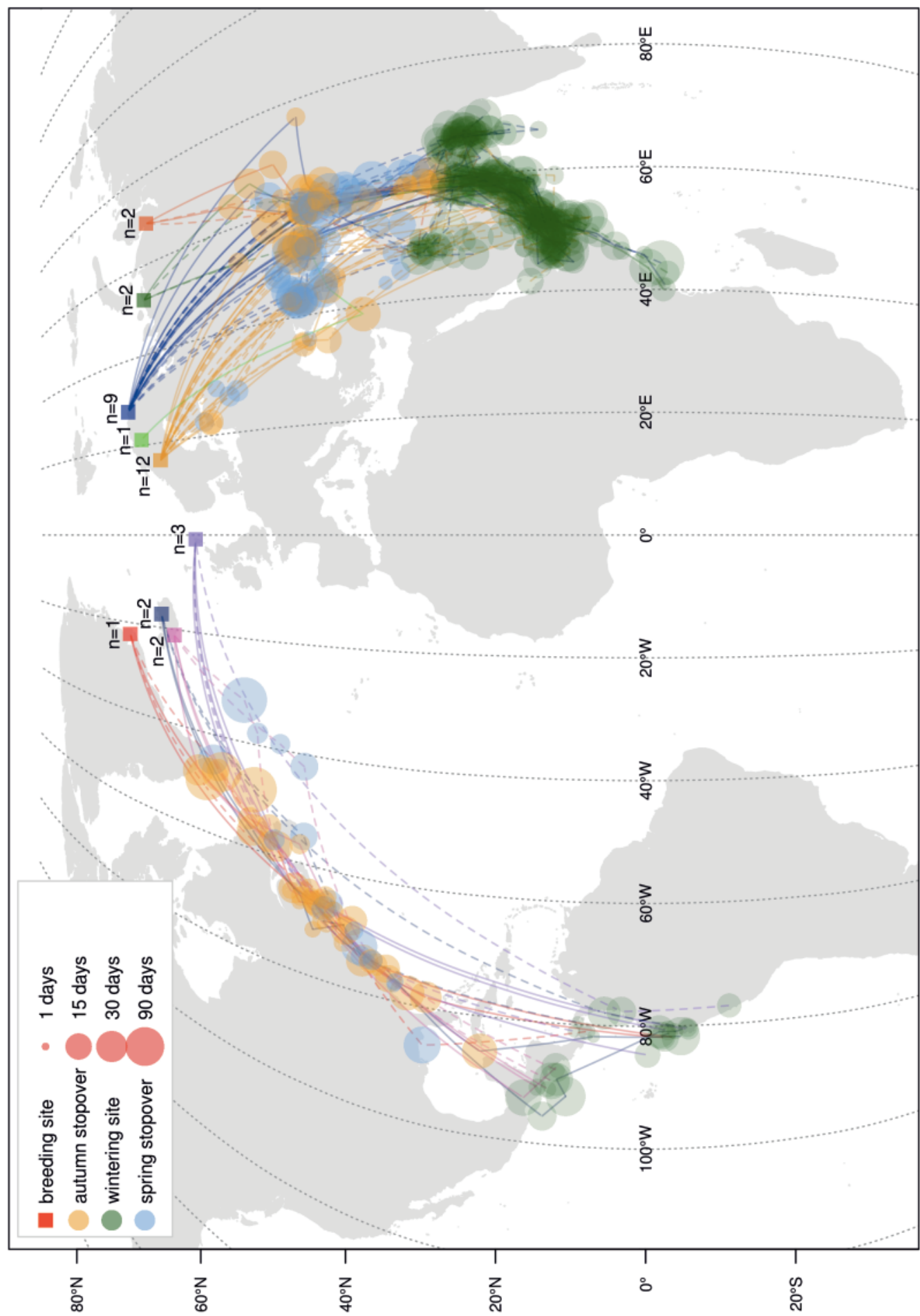



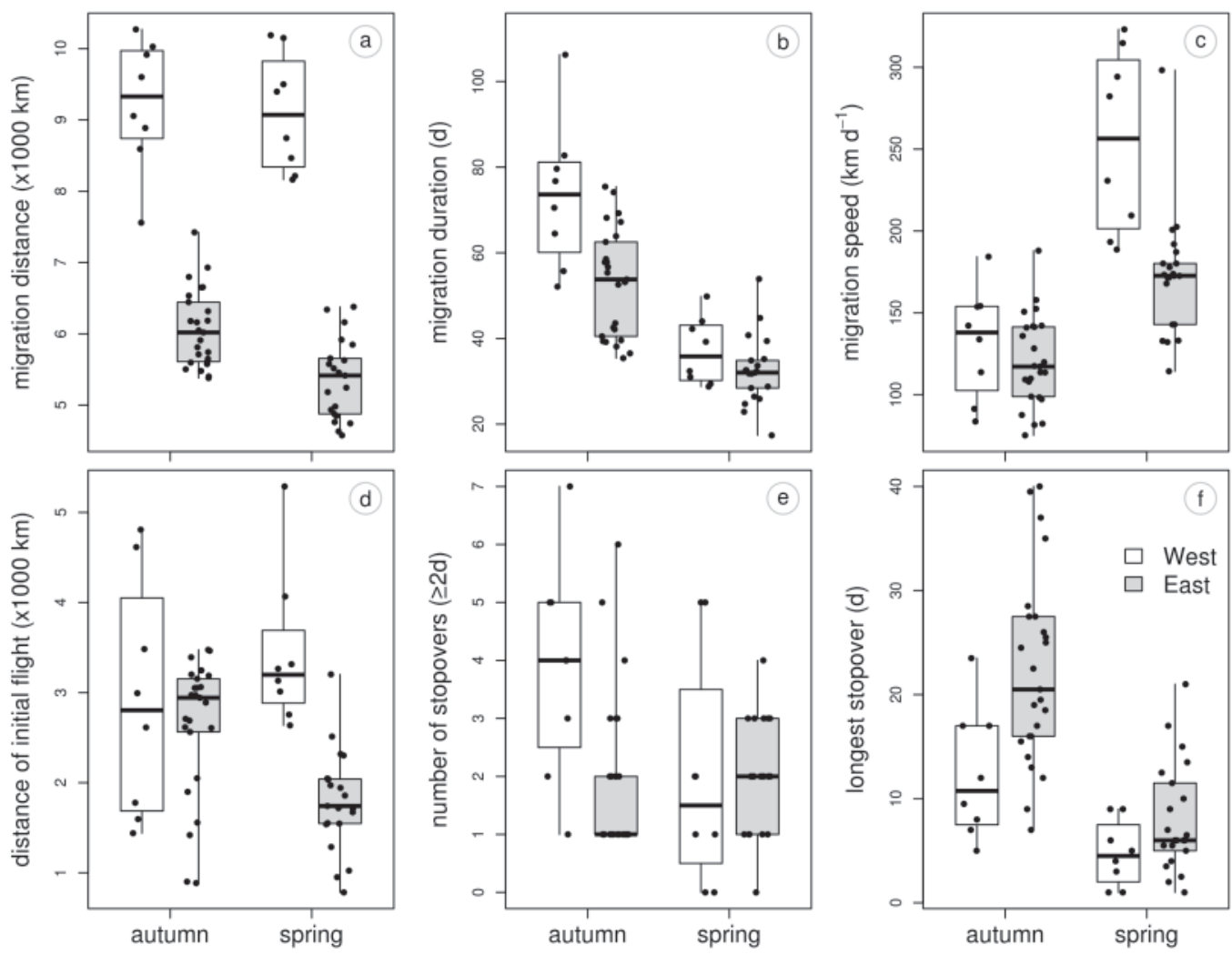

FIGURE 3.2 | Characteristics of autumn and spring migration of Red-necked Phalaropes migrating from breeding sites in Greenland, Iceland and Scotland to the Pacific ('West', white boxplots) or migrating from Fennoscandian-Russian breeding sites to the Arabian Sea ('East', grey boxplots).

migration strategies were detected and the small overall sample size (especially for western birds), no sex-effect was considered in the results we present for subsequent tests comparing western and eastern populations. Nevertheless, analyses were repeated with females excluded to see if the results would change qualitatively.

\section{Autumn migration strategy}

Mean departure time from the breeding grounds was slightly earlier for western than eastern birds $\left(\right.$ mean $_{\text {west }}=9$ July, mean $_{\text {east }}=19$ July, $\mathrm{t}_{3,29}=-2.7, \mathrm{p}=0.012$, table 3.1). However, mean arrival at the wintering grounds did not differ between the two flyways ( mean $_{\text {west }}=10$ September, mean $_{\text {east }}=31$ August, $t_{3,29}=0.9, p=0.400$ ). Migration duration was slightly longer among western birds ( mean $_{\text {west }}=73.5 \mathrm{~d}$, mean $_{\text {east }}=52.9 \mathrm{~d}, \mathrm{t}_{3,29}=3.3, \mathrm{p}=0.002$, figure 3.2 ), while autumn migration distance was 1.5 times longer in western than in eastern birds $\left(\right.$ mean $_{\text {west }}=9238 \mathrm{~km}$, mean $_{\text {east }}=6069 \mathrm{~km}, \mathrm{t}_{3,29}=12.1, \mathrm{p}<0.001$ ). The initial migration leg from the breeding area to the first stopover site was similar in length in western and eastern 

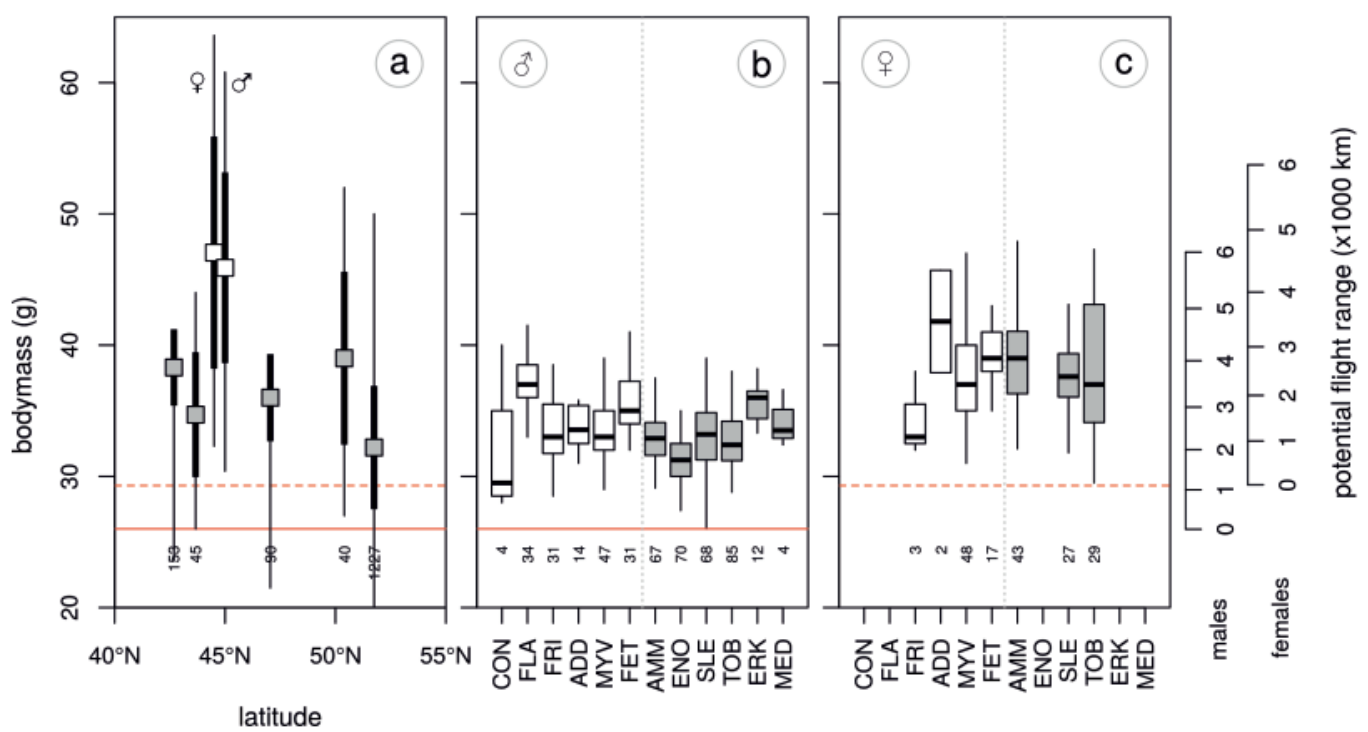

FIGURE 3.3 | Mean body mass obtained from (a) female and male Red-necked Phalaropes at autumn staging areas along the western (white squares, Bay of Fundy, Canada, Mercier 1985), and unsexed birds from the eastern migration route (grey squares, various sites in Kazakhstan, Gavrilov 1983). Thick vertical lines represent $\pm s d$, thin lines are ranges. Body mass of males (b) and females (c) at breeding sites. Western (white boxes) and eastern (grey boxes) populations are divided by a vertical grey dotted line. Whiskers extent to minimum and maximum values. Lean body mass of each sex, as inferred from our sample, are shown by the red horizontal solid (males) and dotted (females) lines. The right axis shows the potential maximum flight range for males and females (see main text). Breeding sites are ordered from West to East, and are abbreviated as follows: $\mathrm{CON}=$ Constable Pynt, Greenland, FLA = Flatey Island, Iceland, FRI = Fridland, Iceland, ADD = Aðaldalur, Iceland, MYV = Myvatn, Iceland, FET = Fetlar, Scotland, AMM = Ammarnäs, Sweden, ENO = Enontekiö, Finland, SLE = Slettnes, Norway, TOB = Tobseda, Russia, ERK = Erkuta, Russia and MED = Medusa Bay, Russia. Numbers below box-plots represent sample sizes.

birds $\left(\right.$ mean $_{\text {west }}=2916 \mathrm{~km}$, mean east $=2638 \mathrm{~km}, \mathrm{t}_{3,29}=1.3, \mathrm{p}=0.218$ ). During autumn migration of both western and eastern birds, the longest stopover occurred at about $45^{\circ} \mathrm{N}$; western birds staged in (the vicinity of) the Bay of Fundy, Canada, whereas eastern birds used areas near the Black Sea, NW and NE of the Caspian Sea, the Aral Sea, and areas in the vicinity of these seas. The longest stopover was shorter in western than in eastern birds (mean $_{\text {west }}=12.4 d, x_{\text {east }}=22.2 d, t_{3,29}=-2.8$, $p=0.008$ ). It should be noted, however, that some birds had several stopovers around $45^{\circ} \mathrm{N}$. If the duration of the stopovers between $40-50^{\circ} \mathrm{N}$ is summed for each bird, western birds stage significantly shorter between these latitudes than eastern birds ( mean $_{\text {west }}=16.2 \mathrm{~d}, \mathrm{x}_{\text {east }}=24.2 \mathrm{~d}, \mathrm{t}_{3,29}=-2.2, \mathrm{p}=0.037$ ). In addition to these long stopovers at around $45^{\circ} \mathrm{N}$, shorter stops were made both before and after the main stopover. Significantly more stopovers were made by western birds than eastern 

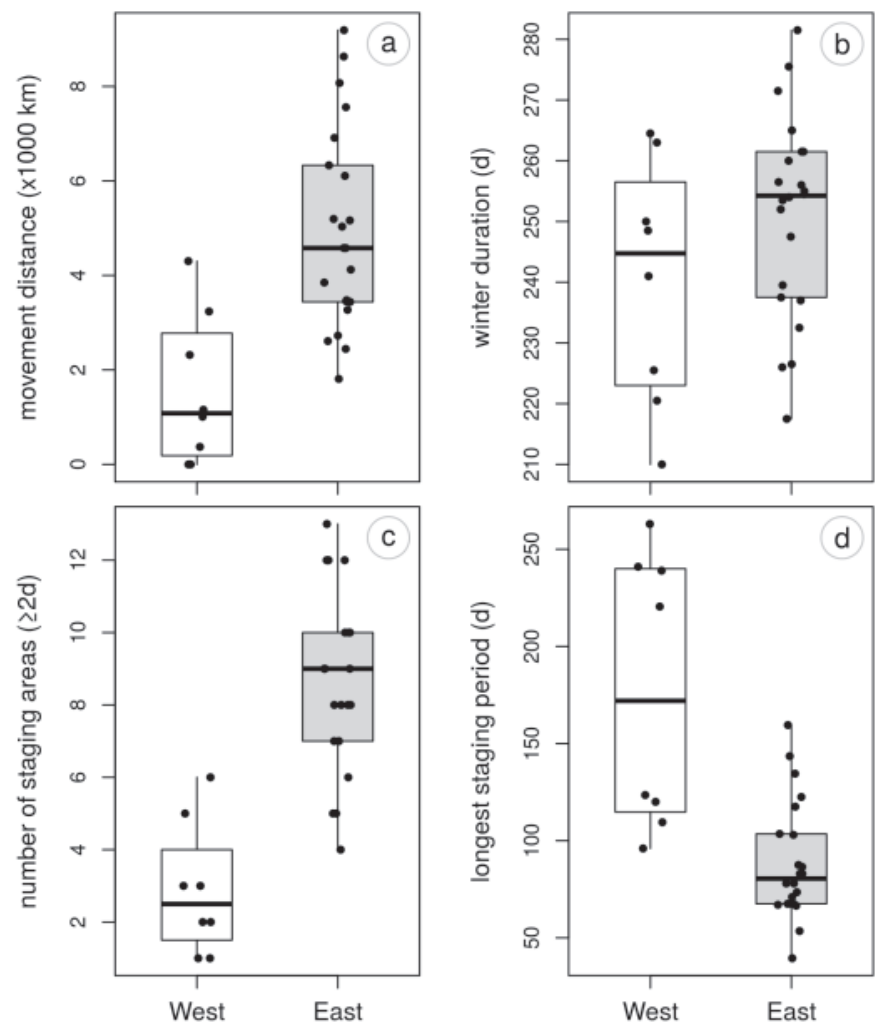

FIGURE 3.4 | (a-d) Characteristics of winter movements of Red-necked Phalaropes wintering in the Pacific ('West', white boxes) and the Arabian Sea ('East', grey boxes).

( mean $_{\text {west }}=3.9$, mean $\left._{\text {east }}=2.0, t_{3,29}=2.6, p=0.010\right)$, but this difference disappeared when correcting for the migration distance $\left(t_{3,29}=0.7, p=0.468\right)$, indicating that mean migration distance between staging sites was similar between the flyways. The number of days on migration, not classified as staging, was higher among western than eastern birds $\left(\right.$ mean $_{\text {west }}=37.3 \mathrm{~d}$, mean $\left._{\text {east }}=15.5 \mathrm{~d}, \mathrm{z}_{3,29}=5.0, p<0.001\right)$. Overall migration speed was similar between western and eastern birds $\left(\right.$ mean $_{\text {west }}=132 \mathrm{~km} \mathrm{~d}^{-1}$, mean east $\left.=120 \mathrm{~km} \mathrm{~d}^{-1}, t_{3,29}=1.4, \mathrm{p}=0.165\right)$. FDR before departure from the breeding grounds effected slower migration speeds, but this effect levelled off at higher migration speeds. In addition, FDR had little effect on differences in migration speed between the two populations: only when FDR would be much lower in eastern breeding areas than in western breeding areas, would the populations differ in migration speed (figure 3.51). Qualitatively identical results were found when excluding females from the autumn migration analysis, except that both breeding departure timing $\left(t_{3,20}=-2.0, p=0.062\right)$ and number of stopovers were near-significantly different between eastern and western birds $\left(z_{3,20}=1.7\right.$, $\mathrm{p}=0.096)$. 


\section{Maximum range of first autumn leg}

The distance from the breeding area to the first stopover was similar in western and eastern birds (see above) and consistent with body mass measurements from the breeding grounds, which were not significantly different between the areas for both males $\left(\mathrm{t}_{10,455}=1.4, \mathrm{p}=0.195\right)$ and females $\left(\mathrm{t}_{5,162}=-0.5, \mathrm{p}=0.644\right)$. Predicted flight range for model-based averages of body mass are $2532 \mathrm{~km}$ for western and 2642 $\mathrm{km}$ for eastern males and $4260 \mathrm{~km}$ for western and $3928 \mathrm{~km}$ for eastern females. Repeating this for the $75 \%$ quantile body mass per flyway translates into $3214 \mathrm{~km}$ for western and $2675 \mathrm{~km}$ for eastern males, and $3033 \mathrm{~km}$ for western and $3300 \mathrm{~km}$ for eastern females. Similarly, flight range for individuals with maximum body mass was predicted to be $4573 \mathrm{~km}$ for western and $5036 \mathrm{~km}$ for eastern males, and 4646 $\mathrm{km}$ for western and $5036 \mathrm{~km}$ for eastern females (figure 3.3). Flight ranges predicted for mean and $75 \%$ quantile body mass were similar to the ranges inferred from our geolocator data, but flight range estimates based on maximum body mass were higher than our longest recorded first legs (figure 3.2).

\section{Spring migration strategy}

Departure time from the wintering grounds did not differ between the two wintering areas $\left(\right.$ mean $_{\text {west }}=8$ May, mean ${ }_{\text {east }}=8$ May1, $\left.\mathrm{t}_{3,26}=0.7, \mathrm{p}=0.511\right)$, and arrival at the breeding grounds was also similar between western and eastern birds $\left(\right.$ mean $_{\text {west }}=1$ June, mean $_{\text {east }}=3$ June, $t_{3,26}=-1.1, p=0.293$, table 3.1). Like in autumn, spring migration distance was ca 1.7 times longer in western birds as compared to eastern birds ( mean $_{\text {west }}=9,103 \mathrm{~km}$, mean east $=5,366 \mathrm{~km}, \mathrm{t}_{3,26}=15.3, \mathrm{p}<0.001$, figure 3.2), but migration duration did not differ $\left(\right.$ mean $_{\text {west }}=37 \mathrm{~d}, \mathrm{x}_{\text {east }}=32 \mathrm{~d}, \mathrm{t}_{3,26}=1.5$, $\mathrm{p}=0.147$ ). The migration strategy in spring was similar to the autumn migration strategy, with a main stopover at about $45^{\circ} \mathrm{N}$ (using the same or nearby areas as in autumn). At the main stopovers, western birds staged about as long as eastern birds $\left(\right.$ mean $_{\text {west }}=4.8 \mathrm{~d}$, mean $\left._{\text {east }}=8.0 \mathrm{~d}, \mathrm{t}_{3,26}=-1.3, \mathrm{p}=0.191\right)$. The number of stopovers was not different between western and eastern birds $\left(\operatorname{mean}_{\text {west }}=2.0\right.$, mean $_{\text {east }}=2.0, z_{3,26}=-0.1, p=0.900$ ), but when corrected for migration distance, a near-significant difference emerged $\left(z_{3,26}=-1.9, p=0.063\right)$. Interestingly, two western birds (including the single female) and one eastern male from Slettnes did not stage for as many as 2 or more days anywhere along the spring migration route. Visual inspection of their tracks suggest they staged once (western male), twice (western female) or thrice (eastern male) for 1.5 days, i.e. under the threshold of 2 days used in delineation of staging periods. Nevertheless, no more days between staging areas (i.e., days that were not classified as staging periods) were spent by western birds than eastern birds $\left(\right.$ mean $_{\text {west }}=19.6 \mathrm{~d}$, mean $_{\text {east }}=19.4 \mathrm{~d}$, $z_{3,26}=0.1, p=0.883$ ), but this became significant when correcting for migration distance $\left(z_{3,26}=-2.8, p=0.005\right)$. Thus, western birds covered more distance without stopovers than eastern birds. In spring, their first leg from the wintering grounds was significantly longer than that of eastern birds $\left(\right.$ mean $_{\text {west }}=3304 \mathrm{~km}$, mean $_{\text {east }}=1052 \mathrm{~km}, \mathrm{t}_{3,26}=5.9, \mathrm{p}<0.001$ ). Their overall migration speed was also significantly higher $\left(\right.$ mean $_{\text {west }}=255 \mathrm{~km} \mathrm{~d} \mathrm{~d}^{-1}$, mean $_{\text {east }}=172 \mathrm{~km} \mathrm{~d} \mathrm{~d}^{-1}, \mathrm{t}_{3,26}=4.3$, 
$\mathrm{p}<0.001)$. Particularly the migration speed of western birds was affected by FDR before departure from the wintering grounds (figure 3.S1). FDR had little effect on the difference in migration speed: the difference in migration speed would become non-significant only if FDR would be low in the Pacific wintering area (figure 3.S1). Excluding females from the spring migration analysis led to qualitatively identical results.

Wet/dry data from the Greenlandic bird with the geolocator attached to a leg flag showed that long (>3 hrs) dry periods, assumed to reflect periods in flight, usually started within an hour of sunset and lasted into the morning of the next day (figure 3.52). Hence, this individual migrated mainly at night, but also performed a nonstop flight of $48 \mathrm{~h}$ when crossing the Caribbean in spring. In this individual, the number of flights was much greater than the number of stopovers of two or more days recorded for its migration using the methods outlined above ( 21 flights versus 6 staging periods in autumn 2013, 10 flights versus 2 staging periods in spring 2014 and 21 flights versus 3 staging periods in autumn 2014). Our results suggest that distances between main staging areas were covered by migrating only by night.

\section{Winter movement strategies}

Winter movement strategies differed markedly between birds in the two wintering areas (figures $\mathbf{3 . 1}$ and $\mathbf{3 . 4}$, table 3.1). Birds wintering in the Pacific used fewer sites than those wintering in the Arabian Sea ( $_{\text {mean }}$ west $=2.9$, mean $n_{\text {east }}=8.8, z_{3,26}=-$ 4.926, $\mathrm{p}<0.001)$. Among western birds, the longest staging period was longer $\left(\right.$ mean $_{\text {west }}=240 \mathrm{~d}$, mean $\left.n_{\text {east }}=251 \mathrm{~d}, \mathrm{t}_{3,26}=4.5, \mathrm{p}<0.001\right)$. Their summed great-circle distances between staging areas were shorter $\left(\right.$ mean $_{\text {west }}=1549 \mathrm{~km}$, mean east $=4934$ $\mathrm{km}, \mathrm{t}_{3,26}=-3.8, \mathrm{p}<0.001$ ). Excluding females led to qualitatively identical results. Winter movements of western birds mainly occurred at the start and end of the wintering period, when birds moved between the northern Humboldt Current and areas off central America. In the Arabian Sea, itinerant individuals often arrived at the winter quarters off Oman before moving to either off Pakistan or off Somalia (in particular the Gulf of Aden). Such itinerant individuals shifted location up to several times (4-13), before moving to stage in the Persian Gulf or the Gulf of Oman in early spring. More or less resident individuals in the Arabian Sea staged in the Gulf of Aden, Gulf of Oman or off the coast of Pakistan during the entire winter. In summary, individuals wintering in the Pacific mostly stayed in the same area (residency), whereas individuals wintering in the Arabian Sea showed a larger range of behaviours, from using only a small area to multiple, widely separated areas (itinerancy). Wintering movements appear to correspond to spatio-temporal patterns in ocean primary productivity (figure 3.6). Primary productivity correlated significantly with number of phalaropes both in the Arabian Sea $(z=6.0, p<0.001)$ and in the Pacific $(z=3.0, p=0.003)$. However, we did not find evidence for higher primary productivity at arrival at a new site relative to departure from the previous site $(z=0.9, p=0.369)$, or for higher primary productivity during staging at a new 
site compared to the same period at the previous site $(z=0.5, p=0.607)$.

\section{Repeated tracks}

Data from two years were obtained for one individual from Greenland (male), one from Iceland (male), three from Sweden (females) and three from Norway (one female, two males). In addition, data for three years were obtained for one male from Norway. Halfway along the final track, four loggers failed prematurely: one in late January and three in February. Locations of and time spent at staging and wintering sites appear fairly consistent between years (figure 3.7). Individuals wintering in the Arabian Sea mostly had very similar routes between the same main sites within the wintering period, although some exceptions occurred (for example, figure 3.7f). The number of individuals with repeated tracks was too small for statistical tests of repeatability.

\section{Biometrics}

In both sexes, wings were longer in western populations (females: mean $_{\text {west }}=116.6$

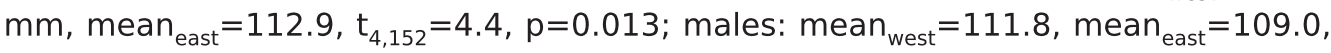
$t_{9,415}=5.1, p<0.001$, figure 3.5). In males, tarsi were longer in western populations; in females, this was only near-significant (females: mean $_{\text {west }}=21.5$, mean $_{\text {east }}=20.4$, $t_{3,111}=3.0, p=0.056$; males: mean $_{\text {west }}=21.4$, mean $_{\text {east }}=20.2, t_{7,297}=9.7, p<0.001$ ). Wings remained significantly longer in western populations in each sex when including tarsus length in the model (females: flyway $t_{3,109}=3.6, p=0.037$; tarsus $t_{3,109}=2.8, p=0.006$; males: flyway $t_{7,294}=4.0, p=0.005$; tarsus: $t_{7,294}=3.2, p=0.002$ ). Bill lengths were not different (females: mean $_{\text {west }}=21.9$, mean $_{\text {east }}=21.4, t_{3,137}=0.7$, $\mathrm{p}=0.511$; males: mean $_{\text {west }}=21.1$, mean $_{\text {east }}=21.0, \mathrm{t}_{7,316}=-0.1, \mathrm{p}=0.914$ ).

\section{DISCUSSION}

Our study demonstrates the existence of two distinct populations of Red-necked Phalaropes within the Western Palearctic: one that breeds in Fennoscandia and Russia and winters in the Arabian Sea (Indian Ocean) and another that breeds on islands in the north-eastern North Atlantic (Greenland, Iceland and Scotland) and winters in the Pacific. The migration route across the Atlantic and into the Pacific was already suggested in part or wholly by earlier authors (Alerstam 1990, Smith et al. 2014), but is now confirmed for birds breeding in Greenland and Iceland. The eastern route to the Arabian Sea was already shown for Swedish males (van Bemmelen et al. 2016), but is now also shown for other Fennoscandian and Russian populations. The contrast in the availability of suitable saline stopover habitat along the two routes and the contrast in spatio-temporal variability in ocean productivity between the two wintering areas provided the rare opportunity to study the effect of non-breeding habitat on large-scale movement strategies within a species. Both autumn and spring migration strategies differed between the oversea route to the Pacific and the overland route to the Arabian Sea. Red-necked phalaropes wintering 

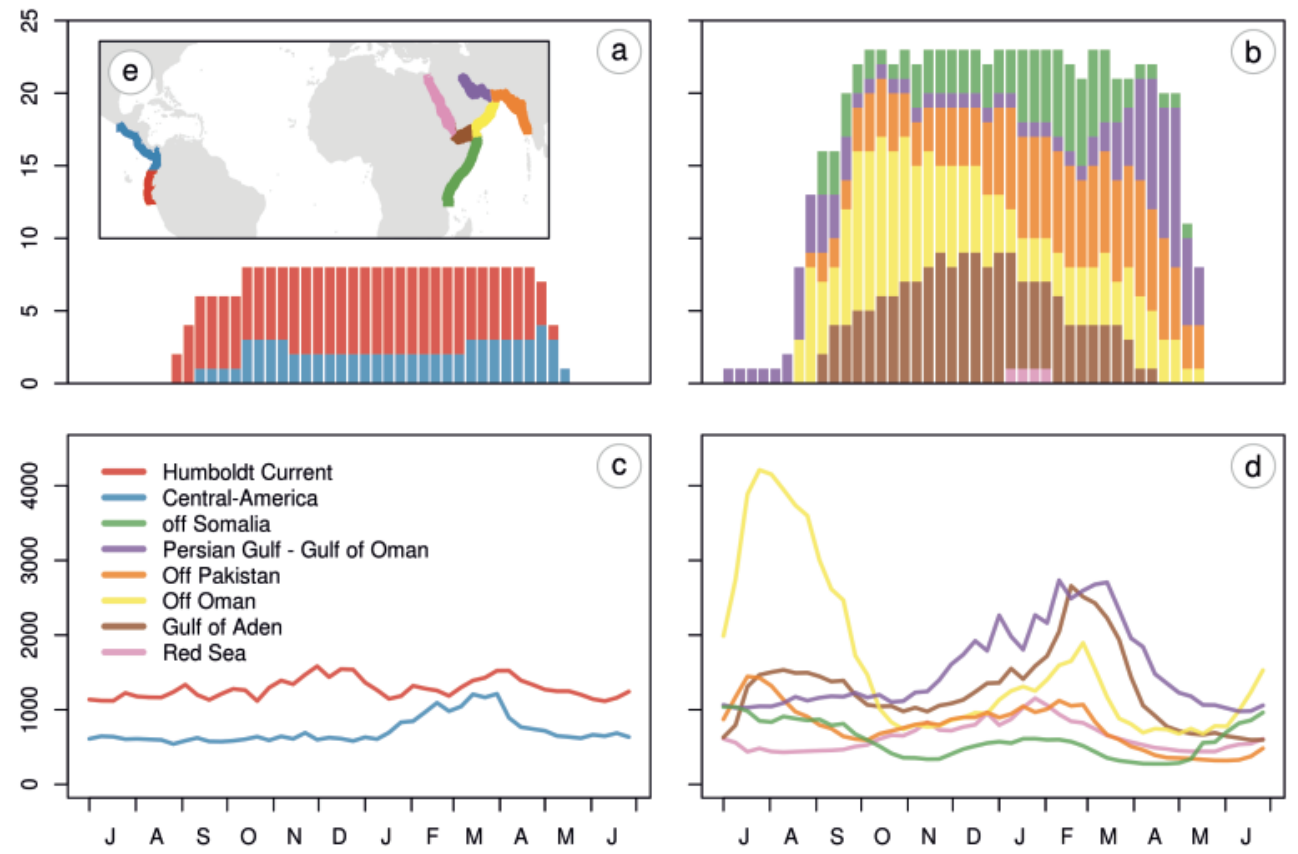

FIGURE 3.5 | Number of tracked Red-necked Phalaropes $(\mathbf{a}, \mathbf{b})$ and mean net primary productivity (c, d) in each of two sectors in the Pacific $(\mathbf{a}, \mathbf{c})$ and six sectors in the Arabian Sea and adjacent areas $(\mathbf{b}, \mathbf{d})$; see $(\mathbf{e})$ for configuration of the sectors.

in the strongly seasonal Arabian Sea moved between several areas whereas those wintering in the non-seasonal eastern Pacific remained roughly in a single area.

The migration of Red-necked Phalaropes migrating oversea to the Pacific was more evenly spread over staging periods along the migration route than those heading overland to the Arabian Sea, which showed a prolonged staging period at about $45^{\circ} \mathrm{N}$. According to optimal migration theory, whenever suitable stopover habitat is abundant, short flights and refuelling periods should be alternated as this minimizes the costs of carrying fuel loads (Alerstam and Lindström 1990)(Alerstam and Lindström 1990). Thus, when habitat is uniformly distributed and of equal quality along the migration route, regular spacing of many stopovers, each visited for a similar time period, is expected. However, variation in quality between potential staging sites can induce skipping behaviour and unequal staging durations (Gudmundsson et al. 1991, Klaassen et al. 2011). In Red-necked Phalaropes following the western migration route, variation in quality of habitat is indicated by the non-uniform distribution of staging periods. Whereas no staging areas were identified in the early and late parts, a prolonged stopover was identified at or near the Bay of Fundy, a well-known staging site where our tagged birds remained for about 12 days, somewhat less than the 15 or 20 days estimated using other methods (Mercier 1985, Hunnewell et al. 2016). Here, staging Red- 

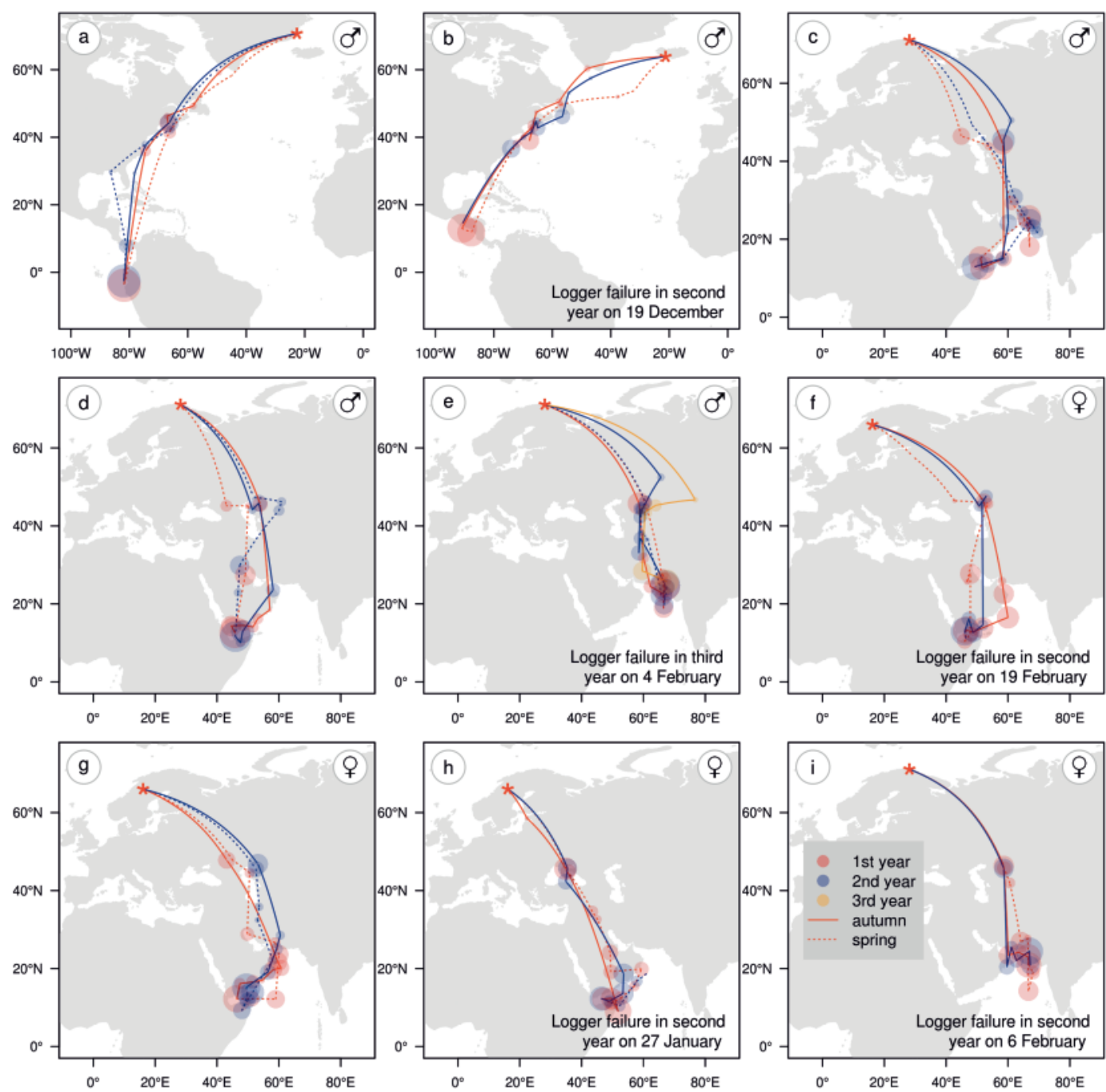

FIGURE 3.6 | Migration stopovers and wintering areas of five males and four female Red-necked Phalaropes tracked over two years from breeding sites in Greenland (a), Iceland (b), Norway (c-e, i) and Sweden (f-h), with breeding sites indicated by red stars. Shaded circles show staging areas in the first (red), second (blue) or third (orange) year of tracking, with circle size proportional to staging duration and staging areas connected by great-circle lines (which do not necessarily represent routes taken) for autumn and early winter (solid lines) and late winter and spring (dotted lines).

necked Phalaropes fatten up considerably more than what would be expected for a strategy of making short flights with several short stops along the western Atlantic coast (figure 3.3, Mercier 1985), indicating a strategy of overloading (Gudmundsson et al. 1991). Despite the high cost of transporting fuel loads, overloading seems a common strategy among waders (Dick et al. 1987, 
Gudmundsson et al. 1991, Alves et al. 2012) and can be expected in timeminimized migrations when fuelling rates at successive stopovers are lower. Overloading at the Bay of Fundy would enable Red-necked Phalaropes to stop and refuel shortly at sites south to Florida and then to rapidly traverse the relatively unproductive waters of the Caribbean Sea, an area where we identified only two short autumn stopovers among all individuals (figure $\mathbf{3 . 1}$ ). In contrast to the western route in autumn, overloading does not seem to occur at the main staging areas along the eastern route, as indicated by body masses obtained in Kazakhstan and the Caspian Sea (figure 3.3, Gavrilov et al. 1983) that seem enough to cover the last stretch to the Arabian Sea. Field observations on fuelling rates at all potential staging sites along the migration route are needed to ultimately understand the migration behaviour in the Red-necked Phalarope.

Migration strategies also differed between the two flyways in spring. A two-day nonstop flight allowed western birds to quickly traverse the unproductive waters of the Caribbean Sea (figure 3.52), after which migration was continued in shorter, mainly nocturnal, flights (Rubega et al. 2000). In contrast, a strategy with several stopovers at scattered wetlands was adopted by eastern individuals to reach the main stopover areas around $45^{\circ} \mathrm{N}$. Spring migrations were also notably fast among Red-necked Phalaropes migrating from the Pacific to the north-eastern North Atlantic, with few or no stops longer than 2 days. A rapid spring migration is usually explained by selection acting at the breeding grounds, e.g. timely arrival at the breeding grounds to compete for mates or territories, or to achieve optimal timing of reproduction relative to seasonal peaks in food abundance (Nilsson et al. 2013). However, as both populations have similar advantages of timely arrival at the breeding grounds, the difference in spring migration speeds is more likely to be explained by differences along the migration route or at the wintering grounds. Explanations for faster speeds may include the occurrence of favourable winds, such as the westerlies prevailing north of the Tropic of Cancer, and potentially higher fuelling rates along the western route between Florida and the Bay of Fundy, than at similar latitudes along the eastern route.

The differences in migration strategies between Red-necked Phalarope populations suggest flexible adjustment of migration strategies within species. In contrast, the migration strategies of thrushes, swallows and raptors showed consistent autumn migration strategies among populations following different routes (Delmore et al. 2012, Fraser et al. 2013, Trierweiler et al. 2014), demonstrating rigid migration strategies, as has been suggested in several other studies on passerines (Irwin and Irwin 2004, Bensch 2009). The effect size of habitat distribution on movement strategies likely depends on the flexibility of habitat requirements for a given species, the absolute degree to which the distribution of suitable habitat differs between compared routes or sites, and the relative quality (fuel rate and predation risk) between sites along each route. Thus, differences in movement strategies are more likely to be detected in diet or habitat specialists, such as the Red Knot 
Calidris canutus (Buehler and Piersma 2008) or the Red-necked Phalarope, than for generalist species for which habitat is more widespread, and more evenly distributed along the migration route. As specialists will have less alternative migration routes and strategies when habitat quality changes, they are required to make larger behavioural adjustments than generalist species, rendering specialists particularly vulnerable. Large-scale tracking studies like ours - in particular of specialist species - is thus critical to understand the potential effect of threats to migrants (Sutherland et al. 2012).

The westward migration route to the Pacific is surprising considering that the migration distance to the Pacific is longer than to the Arabian Sea. The longer migration distance and different migration strategy employed by the western birds may explain why the wings of Red-necked Phalaropes breeding at Greenland, Iceland and Scotland are longer than those of birds breeding in Fennoscandia and Russia. Assuming longer wings are also more pointed, an association between migration distance and wing length is consistent with other studies (Alerstam 1990, Leisler and Winkler 2003, Fiedler 2005, Altizer and Davis 2010), and would be explained by selection for aerodynamically more efficient pointed wings for longer migration. As shown by Minias et al. (2015), wing pointedness is a better predictor for migration strategy among wader species than wing length, but only wing length was measured in our study. That variation in wing length of Red-necked Phalaropes is associated with migration distance is additionally supported by the wing lengths of Canadian populations, which are shorter than our samples from Greenland, Iceland and Scotland and similar to Fennoscandian/Russian Red-necked Phalaropes. The Canadian populations presumably winter in the eastern Pacific and do not have to cross the Atlantic (Reynolds 1987).

Red-necked phalaropes wintering in the Pacific showed only minor movements, whereas most individuals wintering in the Arabian Sea moved around considerably throughout winter (van Bemmelen et al. 2016). Wintering movements have received growing attention in recent years, especially in species wintering in the Neotropics and in Africa (Fraser et al. 2012, Heckscher et al. 2015, Norevik et al. 2019). Also in seabirds, wintering movements occur (Phillips et al. 2005, Hedd et al. 2012, Orben et al. 2015). Although we are not aware of studies contrasting wintering movement strategies between distinct wintering areas in a single species, differences in wintering movement strategies between populations of the same species with overlapping wintering areas have been reported in terrestrial species (Stutchbury et al. 2016, Koleček et al. 2018). Itinerant strategies occurred among Great Reed Warblers Acrocephalus arundinaceus wintering in sub-Saharan nonbreeding sites; with translocations over larger distances by those breeding and wintering further eastwards (Koleček et al. 2018). Wintering movement strategy of Common Swifts Apus apus wintering in Africa appears to correlate with breeding origin, with both Swedish and Dutch birds sharing a major wintering area in the Congo basin, but only Dutch birds vacating this area midwinter to make a round trip 
to south-east Africa (Åkesson et al. 2012, Klaassen et al. 2014). In Red-necked Phalaropes, the occurrence of different wintering movement strategies within the same species suggests flexibility of movement behaviour within the species.

The difference in movement strategies between Red-necked Phalaropes wintering in the Pacific and in the Arabian Sea is consistent with our expectation of how birds should respond to differences in spatio-temporal variation in primary productivity between the two wintering areas. Primary productivity shows only minor seasonal variation in the Pacific (Chavez and Messié 2009), but large spatio-temporal variability driven by monsoon winds in the Arabian Sea (Longhurst 2006). Although phalaropes mainly occupied areas with high primary productivity, movements did not appear to result in higher experienced primary productivity. In Great Reed Warblers and Pallid Swifts Apus pallidus, intra-tropical movement of individuals is explained by improved conditions (inferred from remotely sensed indices of food availability) at destinations in comparison to where they initially staged (Koleček et al. 2018, Norevik et al. 2019). For Red-necked Phalaropes, however, remotely sensed primary productivity may not be a reliable proxy of food availability, as Rednecked Phalaropes feed on zooplankton which may not be directly related to primary productivity (Cramp and Simmons 1983, Brown and Gaskin 1988). Data on distribution and abundance of zooplankton is however scant and scattered in both time and space. A further complication when linking movement to food availability in our study species is the spatial resolution of both the tracking data (which in the case of geolocators deployed on seabirds is ca $185 \mathrm{~km}$; Phillips et al. 2004) and the remotely sensed productivity (cell size of $1 / 6$ a degree, approximately $8 \mathrm{~km}$ in the Arabian Sea). Both spatial resolutions are coarser than the small-scale ephemeral phenomena, such as thermal oceanic fronts, that may be targeted by Red-necked Phalaropes at sea (Haney 1985, Brown and Gaskin 1988).

The large variation between individuals in the number of movements within the Arabian Sea suggests that itinerancy is facultative, as has been shown for several other species wintering in the Neotropics or Africa (Stutchbury et al. 2016, Koleček et al. 2018). At the same time, wintering movement patterns seem consistent within individual Red-necked Phalaropes between years (figure 3.7). High individual consistency in non-breeding movement patterns appears to be widespread among seabirds (Dias et al. 2011, McFarlane Tranquilla et al. 2014, Van Bemmelen et al. 2017) and is hypothesized to develop during an explorative phase in the pre-breeding years (Pulido 2007, Guilford et al. 2011, Senner et al. 2015). If this is the case, then given that the pre-breeding period lasts several years in most seabirds (Weimerskirch 2002), but only one year in Red-necked Phalaropes (Colwell et al. 1988), individuality in itineraries may arise in a single non-breeding season.

Migratory divides can co-occur in areas where multiple species have secondary contact zones after recolonization of northern breeding areas from southern ice age refugia, or in areas that are at similar migration distances from suitable wintering 

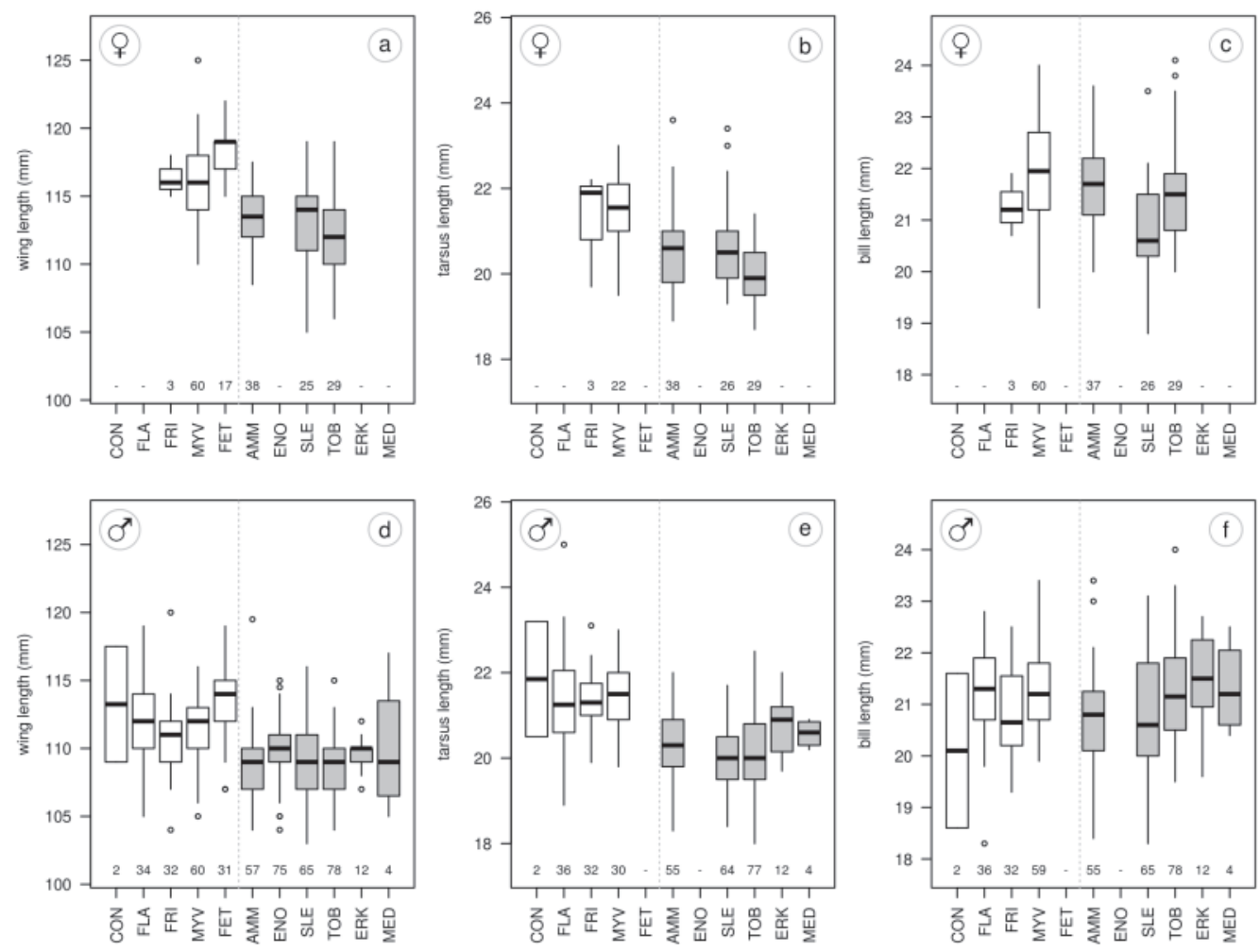

FIGURE 3.7 | Biometrics (wing, tarsus and bill length) for female (a, b, c) and male (d, e, f) Rednecked Phalaropes for western (white boxes) and eastern (grey boxes) breeding sites. Boxes represent $50 \%$ of the values with the median as a horizontal line, and vertical bars extend to $95 \%$ quantiles. For abbreviations of sampling sites, see figure 3.3. Numbers below boxplots show sample sizes.

areas or at locations that present a barrier to migration (Alerstam and Gudmundsson 1999, Newton 2010, Møller et al. 2011). For example, a migratory divide at a longitude of about $100^{\circ} \mathrm{E}$ is shared among many Palearctic birds breeding in the Arctic (Alerstam and Gudmundsson 1999) and central Europe or Scandinavia among European passerines (Møller et al. 2011). Among Nearctic birds, no area with co-occurring migratory divides has been identified, but several species with a circumpolar breeding distribution have a migratory divide in Arctic Canada and/or have evolved into different (sub)species that migrate either within the New World or to the Old World. However, the position of the migratory divide among Western Palearctic Red-necked Phalaropes is not shared with other species. The south-eastward migration of Scandinavian and Russian populations of phalaropes is shared with a small number of species, such as Broad-billed Sandpiper Calidris falcinellus, Little Ringed Plover Charadrius dubius and Red-spotted Bluethroat Luscinia svecica svecica (Verkuil et al. 2006, Hedenström et al. 2013, Lislevand et 
al. 2015), but the westward migration of populations from the north-eastern North Atlantic to the Pacific is unique. The migration route to the Pacific is highly suggestive of a biogeographic legacy, wherein the Nearctic breeding population expanded eastwards while retaining the migration route to the Pacific wintering area. Considering no geographic plumage or biometry variation has been described for the Red-necked Phalarope (Cramp and Simmons 1983), this hypothesis can best be tested in a future population genetic study. Migratory divides delineating the breeding populations migrating to the East Indies are still unknown (Mu et al. 2018) but could be revealed by tracking Red-necked Phalaropes from breeding areas in Siberia and the Nearctic. The divide between birds wintering in the East Indies and eastern Pacific will indicate what part of the Canadian population, besides the populations from the north-eastern North Atlantic, may have been affected by the huge but unexplained population crash observed in the Bay of Fundy in the 1980s (Nisbet and Veit 2015). Siberian and Nearctic breeding populations may migrate oversea as well as overland to the wintering areas in the East Indies and eastern Pacific (Jehl Jr. 1986, Rubega et al. 2000, Mu et al. 2018), providing further opportunities to test the effect of habitat on migration strategies. The observed migration pattern of Western Palearctic birds also raises the question of why Rednecked Phalaropes apparently do not winter in substantial numbers in productive waters in the tropical Atlantic, such as the Canary Current (Camphuysen and van der Meer 2005). Potential explanations for their absence in the Atlantic include a lack of suitable stopover sites along the route to reach these areas, or competition with the larger but ecologically similar Grey Phalarope Phalaropus fulicarius, with which no overlap in wintering area occurs in the Pacific (Cramp and Simmons 1983). Despite being absent from the tropical Atlantic, the differences in both migration strategies and wintering movement strategies between populations indicate adjustment of movement strategies to habitat distribution within the species.

By tracking individual migratory birds from two distinct populations and capitalizing on international collaboration, our study provides a rare demonstration of how habitat distribution shapes large-scale movement strategies over the entire nonbreeding period. The added value to previous studies is that we (1) demonstrate population differences in movement strategies within a species, (2) base our results on tracking data at the individual level, and (3) show that movement strategies are largely consistent within individuals. The individual consistency of movement strategies in adults suggests variation between individuals may best be regarded as the result of developmental plasticity (Drent et al. 2003, Gill et al. 2014). Developmental plasticity may be an important mechanism for population-level adjustments of movement strategies to habitat distribution in the Red-necked Phalarope. Thus, mapping the ontogeny of movement strategies and how individual strategies affect fitness will be key to understanding the origin of flexibility in movement strategies. Understanding flexibility will be important when considering a species' ability to respond to (climate induced) environmental change (Parmesan 
and Yohe 2003, Chen et al. 2011). Given the decline of many populations of longdistance migratory species (Moller et al. 2008, Both et al. 2010), more studies like ours are needed to understand how species characteristics affect the flexible adjustment of movement strategies to habitat availability at individual and population-levels. 


\section{SUPPLEMENT}
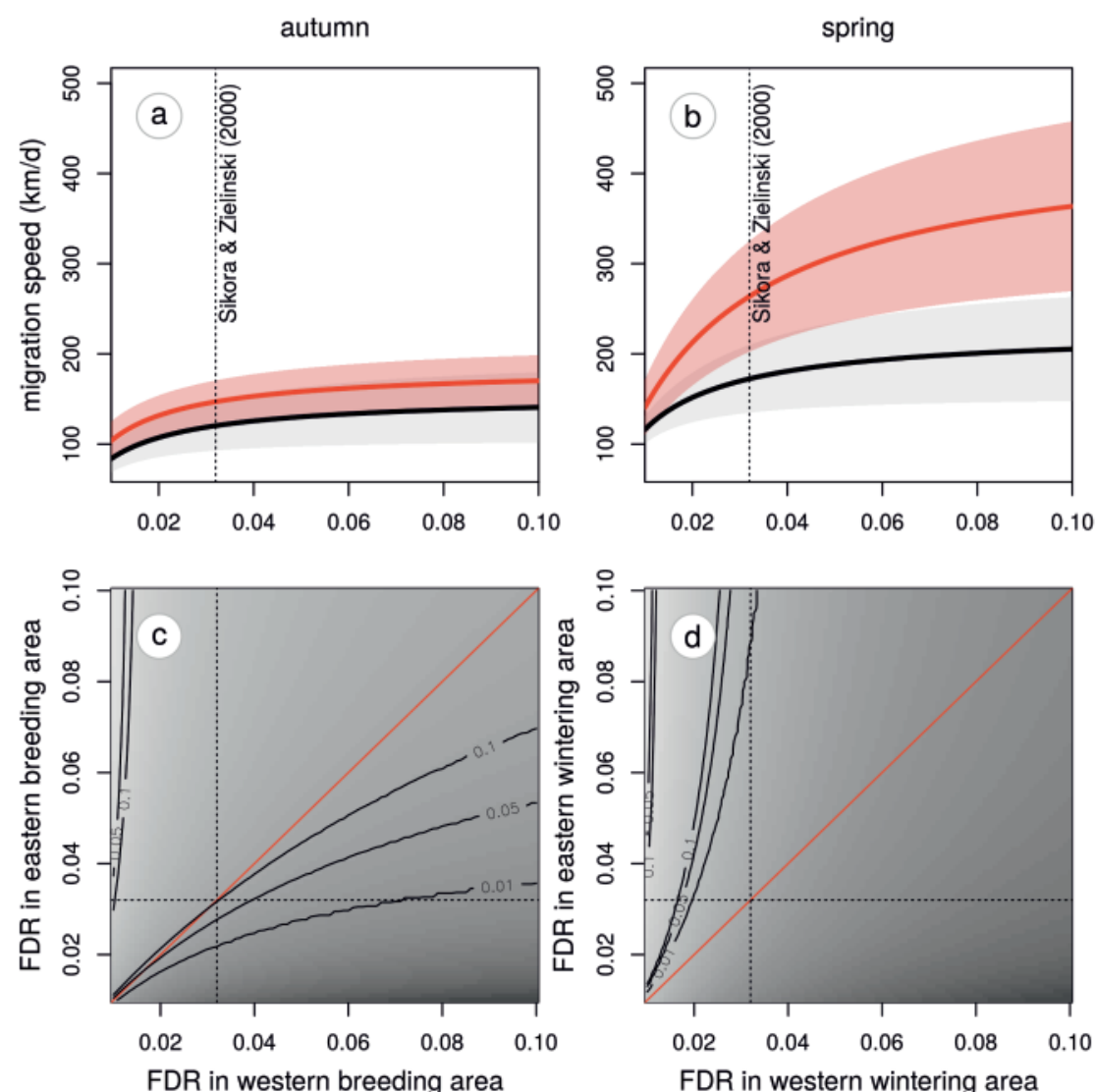

FIGURE 3.S1 | Mean migration speed ( $($ SD) by Red-necked Phalaropes migrating to the northern Humboldt Current (red) and to the Arabian Sea (grey) in autumn (left) and spring (right), as a function of fuel deposition rate (FDR). Vertical dotted lines represent the FDR value of $3.2 \%$ of lean body mass reported by Sikora \& Zielinski (2000). 


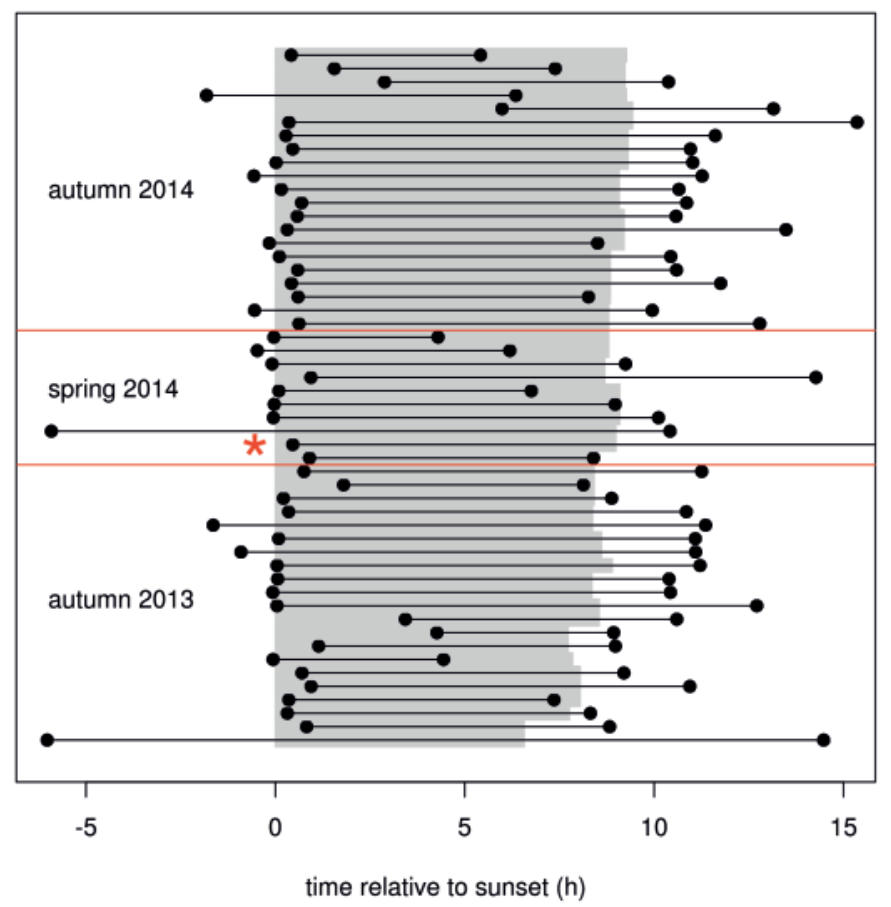

FIGURE 3.S2 | Long flights (>3hrs) by a Red-necked Phalarope during three migrations (delineated by red horizontal lines) between Greenland and the northern Humboldt Current as inferred from wet/dry data. Grey shaded areas represent periods of darkness, based on geolocator light measurements. Staging periods are not excluded. The migration marked with an asterisk lasted for $48 \mathrm{~h}$, thus covering another night. 


\section{ACKNOWLEDGEMENTS}

Our study would not have been possible without the help and enthusiasm of the many fieldworkers. Ammarnäs: Piet Admiraal, Christian Brinkman, Michiel Elderenbosch, Christian Hoefs, Vincent Hin, Johannes Hungar, Guido Keijl, Fons de Meijer, Morrison Pot, Bram Ubels. Also, thanks to Martin Green and Åke Lindström for help in various ways. Erkuta: Jasper Koster, Brigitte Sabard, Vladimir Gilg, Vadim Heuacker. Enontekiö: the Kilpisjärvi waterbird monitoring expedition: Daniel Burgas, Heikki Eriksson, Sara Fraixedas, Sanna Mäkeläinen, Hanna Laakkonen, Petteri Lehikoinen, Mari Pihlajaniemi, Jarkko Santaharju, Jenni Santaharju. Slettnes: Daniel van Denderen, Jan van Dijk, Daan Liefhebber, Maria van Leeuwe, Morrison Pot, Marc van Roomen, Janne Schekkerman, Cees Tesselaar, Rinse van der Vliet. Tobseda: Jasper Koster, Thomas Lameris, Stefan Sand, Kees Schreven. Constable Pynt (part of program "1036 Interactions", supported by the French Polar Institute, IPEV): Brigitte Sabard, Adrian Aebischer, Antoine Dervaux, Eric Buchel, Vadim Heuacker, Mickael Sage, Vladimir Gilg. Fridland (Flói): Verónica Méndez, Camilo Carneiro, Harry Ewing, Einar Gunnlaugsson. Fetlar: George Petrie, Pete Ellis, Phil Harris, Roger Riddington. Francine Mercier kindly provided the raw body mass measurements of phalaropes from her 1980s study in the Bay of Fundy. Thanks to Christoph Mayer and Felix Liechti (Swiss Ornithological Institute) for providing loggers and to Foto Fennica for funding the Finnish loggers. Thanks to Linda McPhee for improving the readability of the manuscript, and to the editor and two anonymous referees for helpful comments that improved the quality of the manuscript.
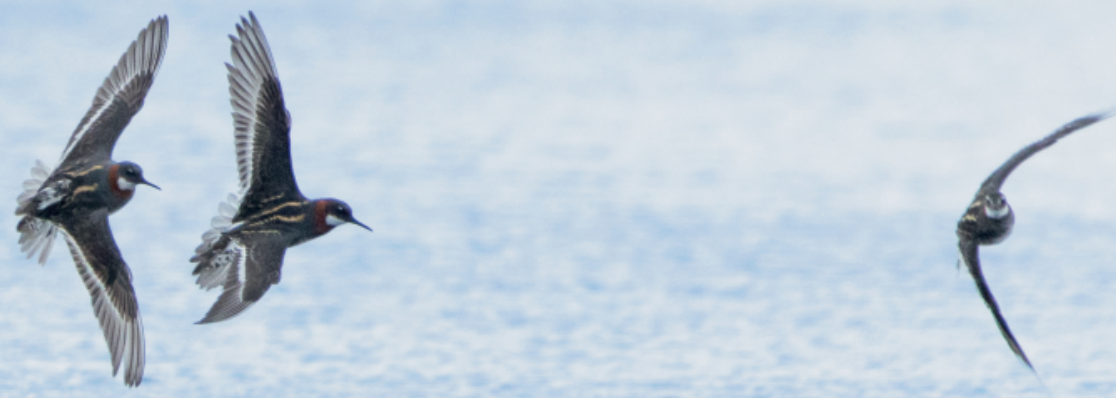

Female Red-necked Phalaropes competing for males: two females (left), one carrying a geolocator, chasing a male. Ammarnäs, Sweden, 18 June 2018. 


\section{CHAPTER IV}
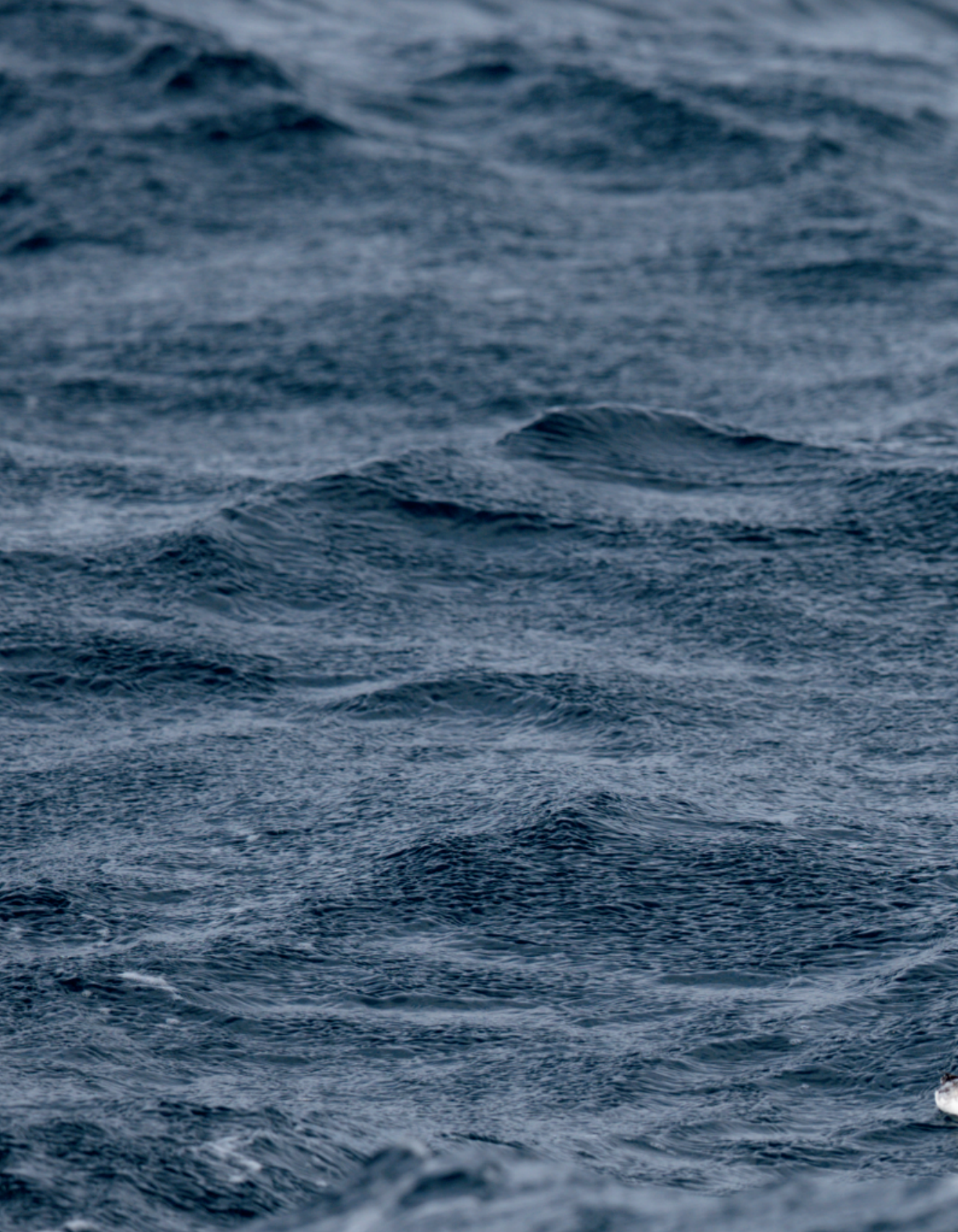

whe $\leq y$

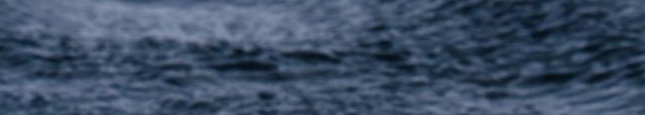

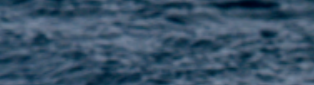
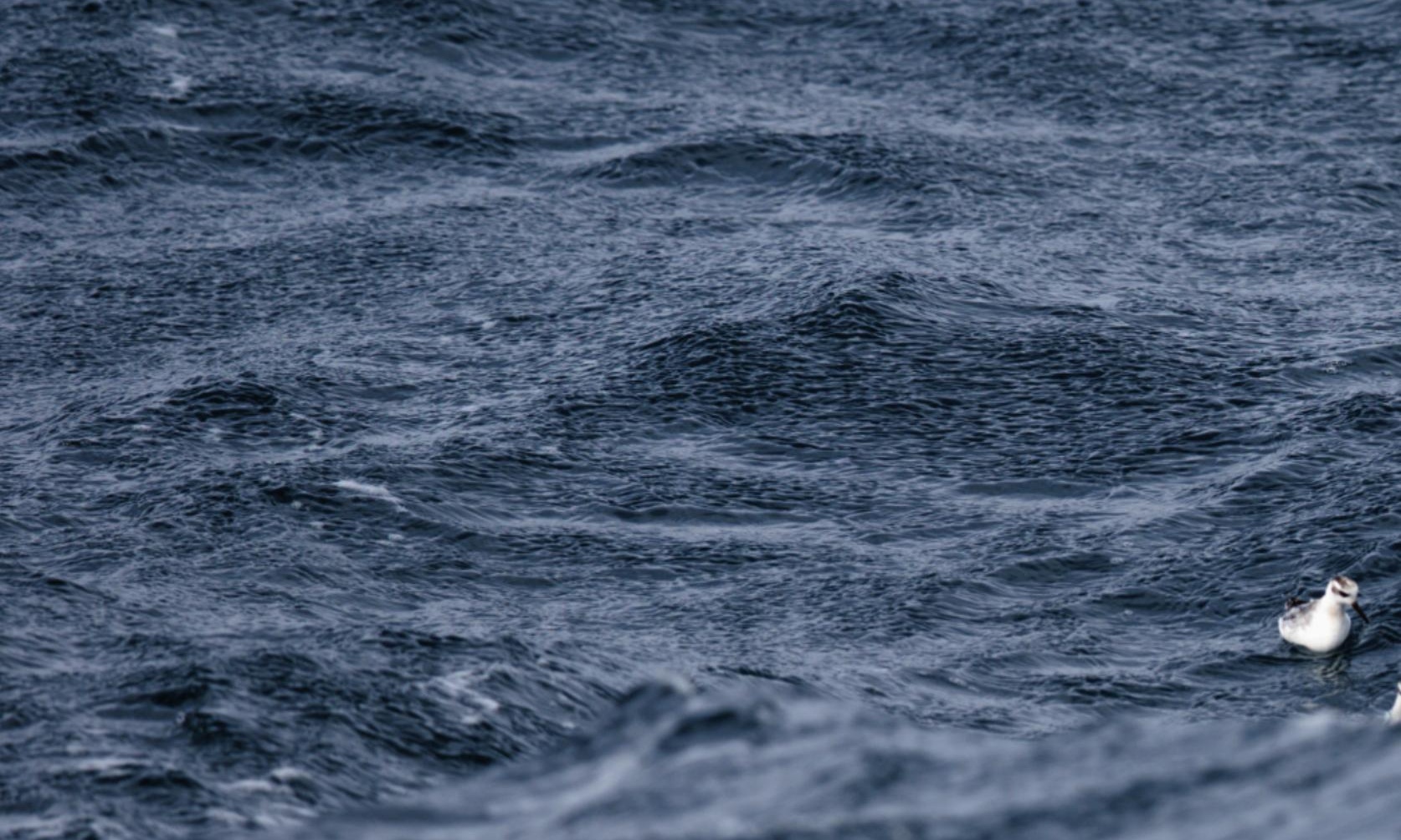

in
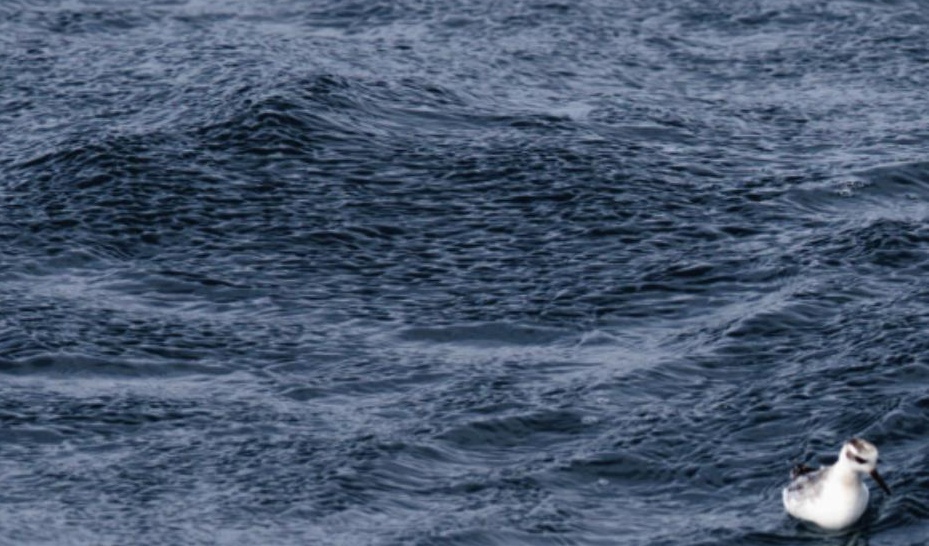


\section{Individual variation in non-breeding movements of Grey Phalaropes across hemispheres

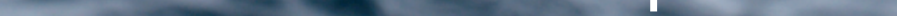
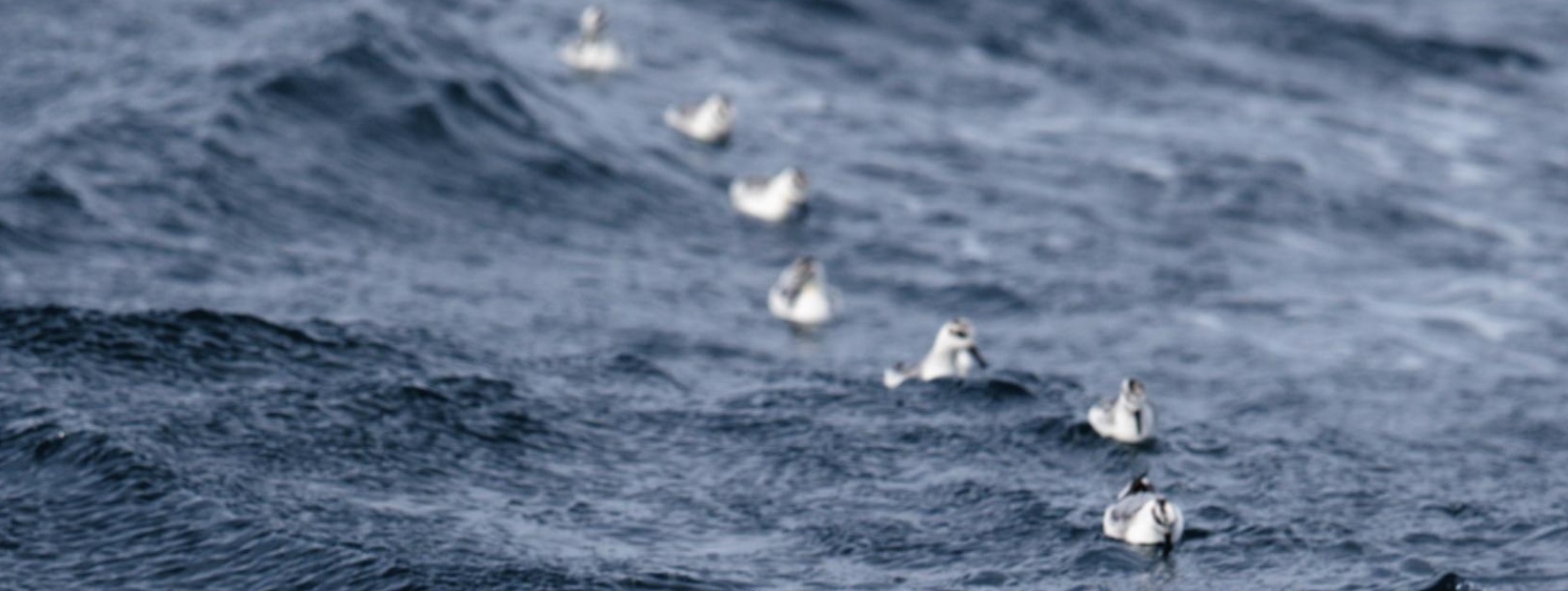

Rob S.A. van Bemmelen, Sveinn Are Hanssen, Olivier of 0 . Ron Porter, Kjell Soot Mork, 6 t Georg Bangjord \& Børge-Moe -

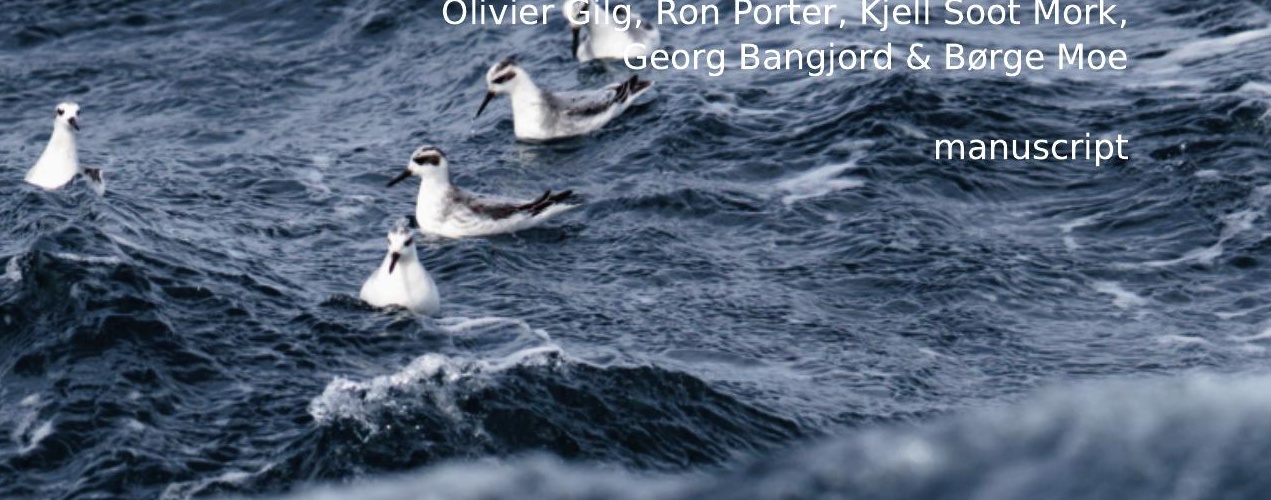




\section{ABSTRACT}

The Grey Phalarope Phalaropus fulicarius is a small wader with an oceanic lifestyle during the entire non-breeding period, making it challenging to study its non-breeding movements. In this study, the migration routes, stopovers, and wintering areas of the Grey Phalaropes are described based on 16 individuals tracked by light-level geolocation from breeding sites in North-east Greenland and Svalbard. Grey Phalaropes wintered in three distinct areas in the northern and southern hemisphere: across a wide longitudinal range at $40^{\circ} \mathrm{N}$ in the North Atlantic, in the upwelling zone of the Canary Current, and in a wide area in the Benguela region. Migration routes and stopovers differed between wintering areas. Within these wintering areas, individuals remained in roughly the same area when wintering in the Canary Current, but moved considerable distances within the two other wintering areas. The amount of wintering movements matches the spatio-temporal variability of the marine environment of these areas. From six individuals tracked over two or three years, three were consistent in use of stopover sites and wintering areas, one varied in movements in the North Atlantic and Canary Current, and two switched wintering sites between the Canary Current and the Benguela region - areas that are approximately $6500 \mathrm{~km}$ apart. 


\section{INTRODUCTION}

Seabirds are well-represented among the species with the most spectacular migrations (Egevang et al. 2010, Hedd et al. 2012). The study of seabird migration has however been challenging due to the difficulties of fieldwork at sea on oceanic scales. Large albatrosses were amongst the first birds to be tracked on their global ocean wanderings using fairly heavy satellite transmitters (Jouventin and Weimerkirch 1990). Thanks to miniaturization of tracking devices, even small seabirds can be tracked during their foraging flights and migrations (Pollet et al. 2019). Weighing about 50-60 g, the Grey Phalarope Phalaropus fulicarius is one of the few seabird species weighing less than $100 \mathrm{~g}$ (Gaston 2004). While most of these small species are Procellariiform or "tube-nose" seabirds, the Grey Phalarope is a small wader (Charadriiformes) with reversed sex-roles that, after leaving its circumpolar breeding areas in the Arctic, become fully pelagic. At sea, Grey Phalaropes congregate at oceanic fronts and upwellings where they feed on zooplankton at or close to the surface (Thorne and Read 2013). Due to their small size, the difficulty of distinguishing Grey from Red-necked Phalarope Phalaropus lobatus in winter plumage and because their movements generally take place well offshore, their migrations and wintering movements have remained elusive (Meinertzhagen 1925, Tracy et al. 2002, Delany et al. 2009). In the Atlantic, the main wintering areas are considered to be the Canary and Guinea Currents off West Africa and the Benguela Current off South-west Africa (Cramp and Simmons 1983, Glutz von Blotzheim and Bauer 1985, Delany et al. 2009), but they are not confined to these areas. Elsewhere in the Atlantic, wintering areas presumed to hold fewer individuals have been noted in the Falkland Current (Alerstam 1990), off eastern North America between approximately $20^{\circ} \mathrm{N}$ and $35^{\circ} \mathrm{N}$ (Lee 1987) and off western Europe (Alerstam 1990). Grey Phalaropes wintering in the Atlantic are thought to originate from breeding areas in eastern Canada, Greenland, Iceland and Svalbard (Lappo et al. 2012), but only a single ring recovery of a bird from Svalbard that was retrieved in France provides support for this (Bakken et al. 2003). Thus, how wintering areas of Grey Phalaropes are connected to breeding populations is still unclear.

Considering the huge latitudinal range of the wintering areas - almost the entire Atlantic - and the narrow latitudinal range of the breeding areas, substantial variation in migration distance must exist. Conceivably, different wintering areas are reached through different migration routes. During autumn migration, congregations of staging Grey Phalaropes in the North-west Atlantic (Orr et al. 1982, Hunnewell et al. 2016) have been suggested to then migrate to West Africa (Alerstam 1990, Delany et al. 2009). This has however not been substantiated with ringing or tracking data and whether these birds also target other areas, such as the Benguela region off South-west Africa, remains unclear. Grey Phalaropes wintering in the Benguela region may also depend on other, yet unknown, stopover sites. 
Whether movements of Grey Phalaropes are confined to the migration periods is unknown. In the closely related Red-necked Phalarope (van Bemmelen et al. 2019), as well as in other seabird species, pronounced movements within the wintering period occur, presumably as a response to seasonal variability in spatial patterns of ocean productivity. Wintering movements are likely to occur in Grey Phalaropes as well, considering their occurrence is associated with ephemeral oceanic phenomena such as fronts between distinct water masses (Brown and Gaskin 1988, Wong et al. 2018).

With the advent of miniaturized tracking devices, in particular geolocators, tracking the non-breeding movements of such small oceanic waders is now feasible (Brown et al. 2017, van Bemmelen et al. 2019). In this study, individual Grey Phalaropes of both sexes were tracked from breeding sites in North-east Greenland and Svalbard, using leg-mounted light-based geolocators. We describe the migration routes and wintering areas, migration strategies, wintering movement strategies, sex differences and, using a set of individuals of which we obtained more than one year of data, individual consistency in routes and destinations.

\section{METHODS}

\section{Study sites and catching}

Grey Phalaropes were captured close to or away from the nest using mist-nets at Adventdalen, Svalbard $\left(16^{\circ} 12^{\prime} \mathrm{E}, 78^{\circ} 12^{\prime} \mathrm{N}\right)$ and Hochstetter Forland, Greenland $\left(19^{\circ} 40^{\prime} \mathrm{W}, 75^{\circ} 09^{\prime} \mathrm{N}\right)$. Geolocators (model W65, Migrate Technology Ltd., Cambridge, United Kingdom) were fitted using a modified darvic leg flag placed on the tibia (Conklin and Battley 2010, Niles et al. 2010, Brown et al. 2017). The total mass of geolocator, leg flag and glue was $0.8 \mathrm{~g}$, representing approximately $1-1.5 \%$ of body mass (Cramp and Simmons 1983). Geolocators sampled ambient light level every minute and recorded the maximum value every 10 minutes. Individuals were sexed using plumage characters (for potential pitfalls using only plumage, see Giroux et al. 2016) and biometrics. In North-east Greenland, geolocators were deployed (on breeding males only) in $2013(n=7), 2014(n=3), 2015(n=4), 2016(n=4)$ and 2017 $(n=1)$ and were retrieved in $2015(n=1)$ and $2016(n=1)$. In Svalbard, geolocators were deployed in $2013(n=9), 2014(n=10)$ and $2016(n=30)$ and were retrieved in $2014(n=3), 2015(n=2), 2016(n=2) 2017(n=3)$ and $2018(n=5)$. Among these, some geolocators failed to download, but data was extracted by the producers: $2016(n=1), 2017(n=1)$ and $2018(n=2)$. Not all individuals that were resighted were also recaptured. Of the birds with geolocators, $26.3 \%(n=19)$ of the individuals in Greenland and $28.6 \%(n=49)$ of the individuals in Svalbard were resighted in at least one later year. These percentages are considerably higher than the $7 \%-14 \%$ return rates reported for ringed individuals in Alaska (Colwell et al. 1988, Schamel and Tracy 1991). Trapping and tagging Grey Phalaropes in Greenland has been approved by the Ministry of Fisheries, Hunting and Agriculture (Government of 
Greenland) and in Svalbard by the Norwegian Food Safety Authority (FOTS ID 6328, $7421,8538)$.

\section{Geolocator data analysis}

After recapture, data were downloaded from the geolocators and processed using the GeoLight package in R 3.4 (Lisovski and Hahn 2012, R Core Team 2017). Twilights were extracted from the light curves at a threshold of 10 Lux. Subsequently, erroneous or unlikely twilights were detected by plotting date versus either time of sunrise and sunset, and removed twilights were replaced by the value of a LOESS (locally estimated scatter plot smoothing) smoother through other twilights. For a range of sun angles (from $-7^{\circ}$ to $-2^{\circ}$, in steps of $0.5^{\circ}$ ), coordinates were calculated and plotted. The sun angle resulting in a close match between latitudes on both sides of each equinox (median $=-4^{\circ}$, range $-6^{\circ}$ to $-3^{\circ}$ ), as well as fitting the coastline of major landmasses around the Atlantic, was selected for the final calculation of positions. Staging periods of two days or more were delineated using the 'changeLight' function, which is based on changes in the timing of sunrise and sunset, and therefore not affected by proximity to the equinoxes. For each staging period, the position was calculated as the median longitude and latitude. As geolocator estimates of latitude become increasingly uncertain in proximity to the equinoxes, median latitudes of staging periods that were clearly affected (which happened when a large part of the staging period fell within about 2 weeks before or after an equinox) were replaced by the mean of the preceding and subsequent staging period. Subsequently, staging periods with median coordinates within 200 $\mathrm{km}$ were combined. As Grey Phalaropes experienced continuous daylight in the breeding area, departure from and arrival at the breeding area could not be observed from positional data and were estimated by assuming a great-circle route from the breeding area to the first (autumn) or last position estimate (spring) at a speed of $19.4 \mathrm{~m} \mathrm{~s}^{-1}$ (Alerstam and Gudmundsson 1999) sustained for $10 \mathrm{~h} \mathrm{~d}^{-1}$ (based on flight activity analysis, see below). The wintering period was defined to include all staging periods spent south of $29^{\circ} \mathrm{S}$ for birds wintering in the Benguela region and south of $26^{\circ} \mathrm{N}$ for birds wintering in the Canary Current. For birds wintering elsewhere in the North Atlantic, the distinction between migration and wintering was less clear. For these birds, the period after crossing $55^{\circ} \mathrm{N}$ in autumn and before crossing $46^{\circ} \mathrm{N}$ in spring was defined as the wintering period. By this definition, first and last staging periods of a non-breeding season are included in migration periods.

Geolocators also tested immersion in saline water every $3 \mathrm{~s}$, storing the sum of positive tests each 10 min period (birds from Svalbard), or every $30 \mathrm{~s}$, storing the number of positive tests saved every hour but capped at a maximum 7 mins (birds from Greenland). In four tracks, wet/dry data was missing due to full memory or logger failure. As the loggers were attached to the tibia and the species is entirely pelagic during the non-breeding period, we assume that (long) dry periods represent flying (Battley and Conklin 2017). The percentage of time loggers were 
July - December
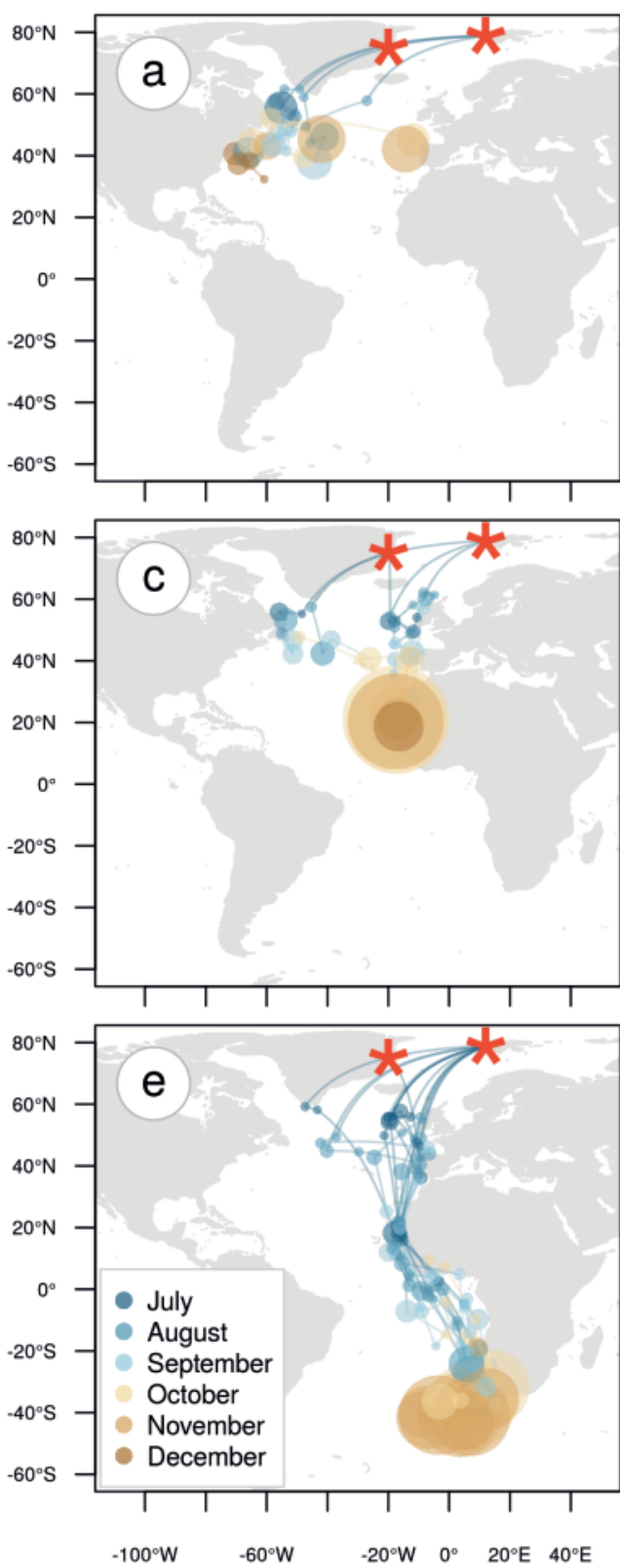

January-June
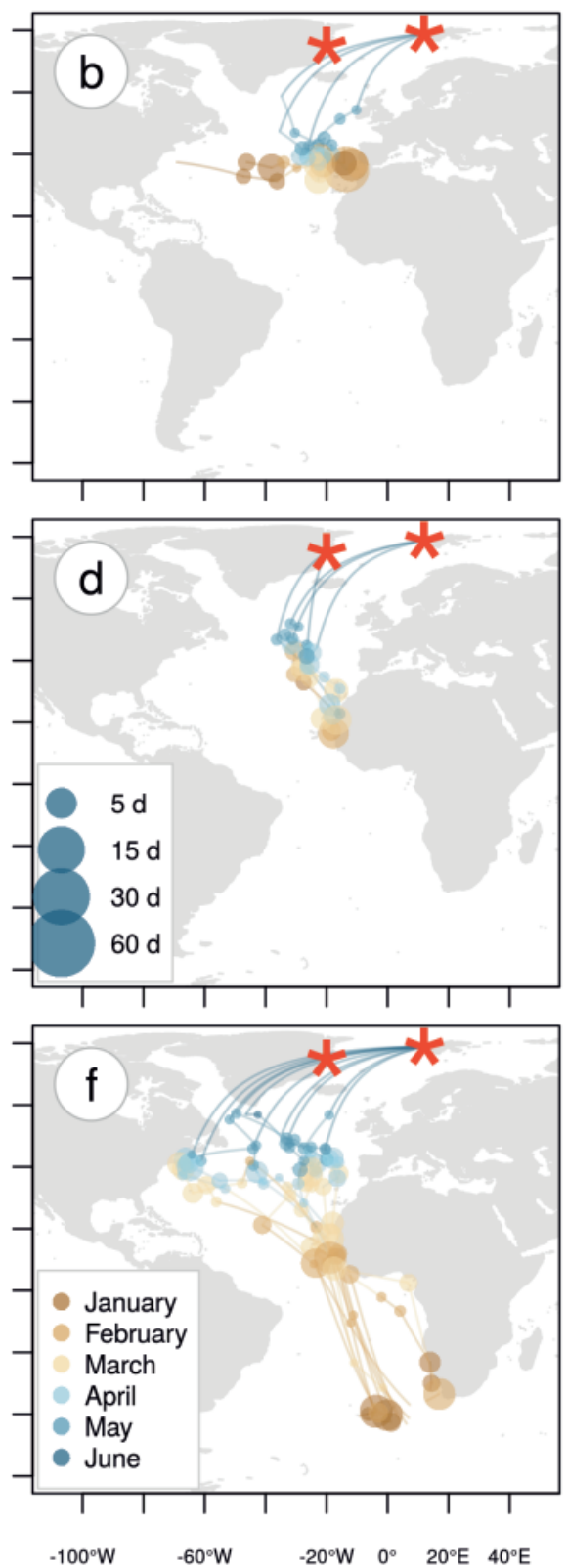

FIGURE 4.1 | Non-breeding movements of Grey Phalaropes tracked from breeding sites (red stars) in North-east Greenland $(n=2)$ and Svalbard $(n=14)$, for birds wintering in the North Atlantic $(\mathbf{a}, \mathbf{b})$, in the Canary Current $(\mathbf{c}, \mathbf{d})$ or in the Benguela region $(\mathbf{e}, \mathbf{f})$. Dots represent staging areas; their size represents the duration of stay and their colour-coding represents the month of arrival. Staging areas are connected by great-circle lines, which do not necessarily represent the routes taken. 

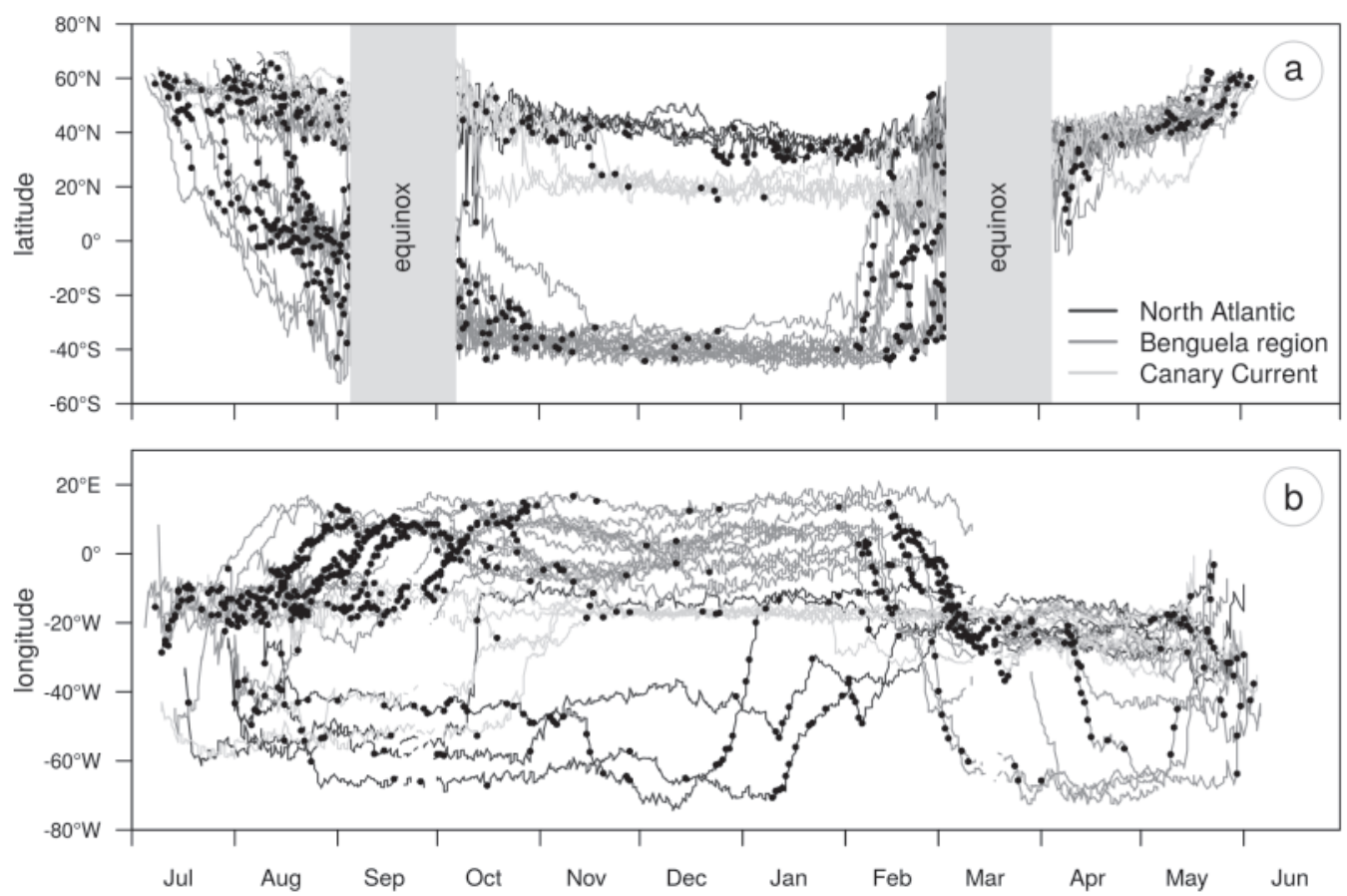

FIGURE 4.2 | Time versus latitude (a) and longitude (b) for tracked Grey Phalaropes wintering in the North Atlantic (blue), Canary Current (green) and Benguela region (orange). Red dots show nights when geolocators were dry more than $80 \%$ of the time. As geolocator estimates of latitude are increasingly uncertain in proximity to the equinoxes (around 20 September and 22 March), these latitudes are shaded. Note the extensive longitudinal movements in mid-winter by birds wintering in the northern hemisphere. Note that wet/dry data is lacking for four tracks.

completely dry was calculated for each day and night. Also, for continuously dry periods of more than $1 \mathrm{~h}$, total duration and timing relative to sunset (as inferred from light measurements, which, at a light threshold of 10 Lux and a sun angle of about $-4^{\circ}$ was slightly before civil twilight) were calculated.

\section{RESULTS}

In total, 23 tracks (movement data between two subsequent breeding seasons) of 16 individuals were obtained. These include 2 males from Greenland, and 5 females and 9 males from Svalbard. Two tracks were obtained for 5 individuals ( 1 male from Greenland, 2 males from Svalbard and 2 females from Svalbard) and three tracks for one individual (a female from Svalbard). From the 23 tracks, 4 were incomplete, as loggers stopped recording in January ( 2 individuals), in May or in November. In 3 of these, failure occurred in the second or third year of tracking. 

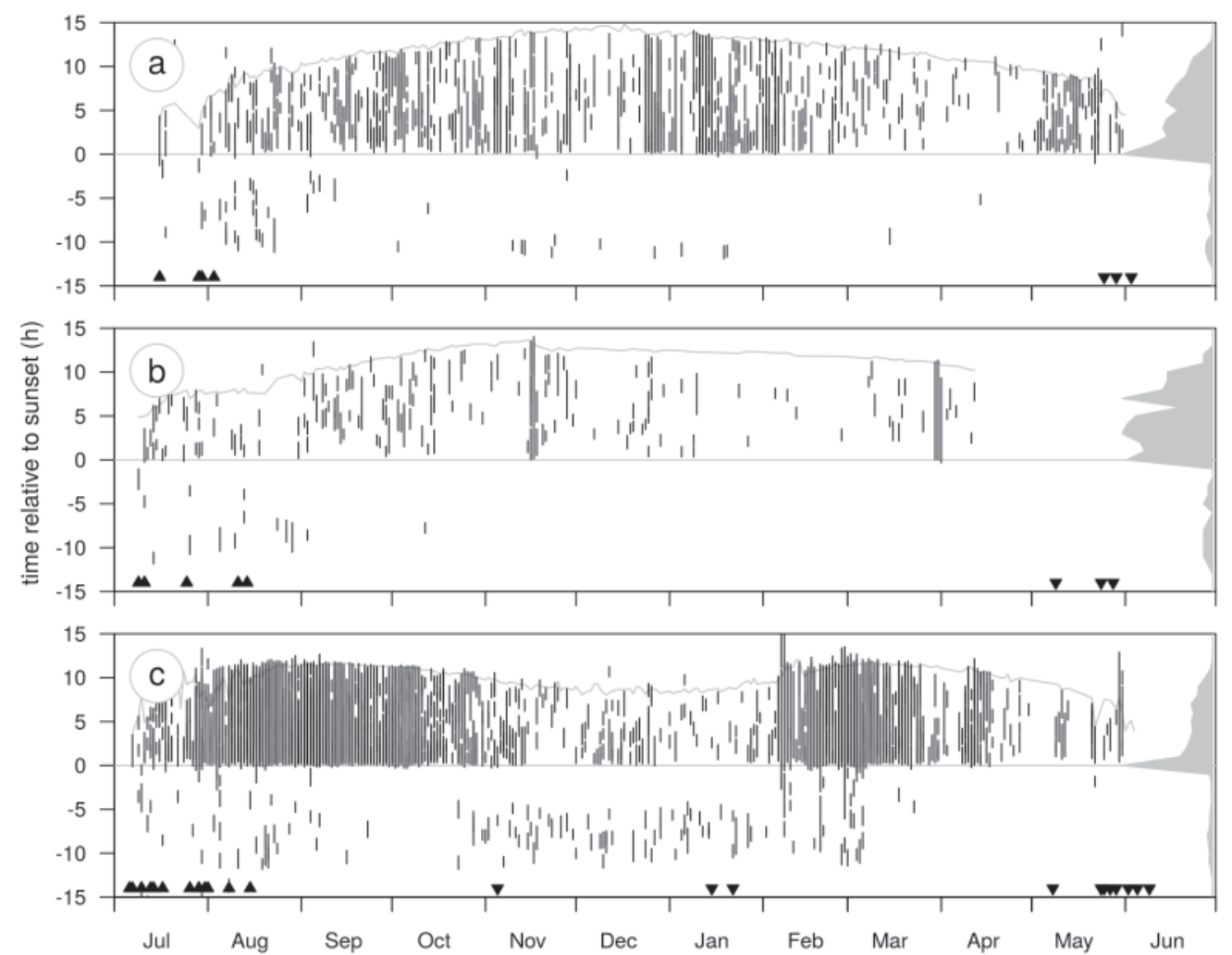

FIGURE 4.3 | Flights longer than $1 \mathrm{~h}$, as inferred from wet/dry records, relative to date ( $\mathrm{x}$-axis) and time of sunset (y-axis), for individuals wintering in the (a) North Atlantic, (b) Canary Current or (c) Benguela region. Each vertical bar represents one flight, dark blue dots indicate the date of the first dark night and pale blue dots indicate the date of the last dark night. Ochre histograms on the right show the distribution of start time of flights relative to sunset. For each wintering area, $y=0$ is the time of sunset and grey curves show the mean time of sunrise for all tracks. Note that data from several individuals overlap.

\section{Wintering areas and migration routes}

Individual Grey Phalaropes from both Greenland and Svalbard dispersed widely over the Atlantic, using wintering areas in a wide area in the North Atlantic from the north-western Atlantic to Iberia and West Africa, and in the South Atlantic from Tristan da Cunha eastwards to the (outer) Benguela Current (figure 4.1). Considering only the first track for each individual, 6 out of 11 males and 1 out of 4 females stayed in the northern hemisphere. Thus, wintering hemisphere was not different between sexes (Fisher's Exact Test: $p=0.308$ ) or from an even distribution among the two hemispheres (Fisher's Exact Test: $p=1.000$ ). More precisely, midwinter positions (December-January), again considering only the first track for each individual, could be classified into three areas: Benguela region off south-west Africa $(n=9)$, Canary Current off west Africa $(n=3)$, or in a broad longitudinal range across at approximately $40^{\circ} \mathrm{N}$ in the North Atlantic $(n=4)$ (figure 4.2). Maximum 

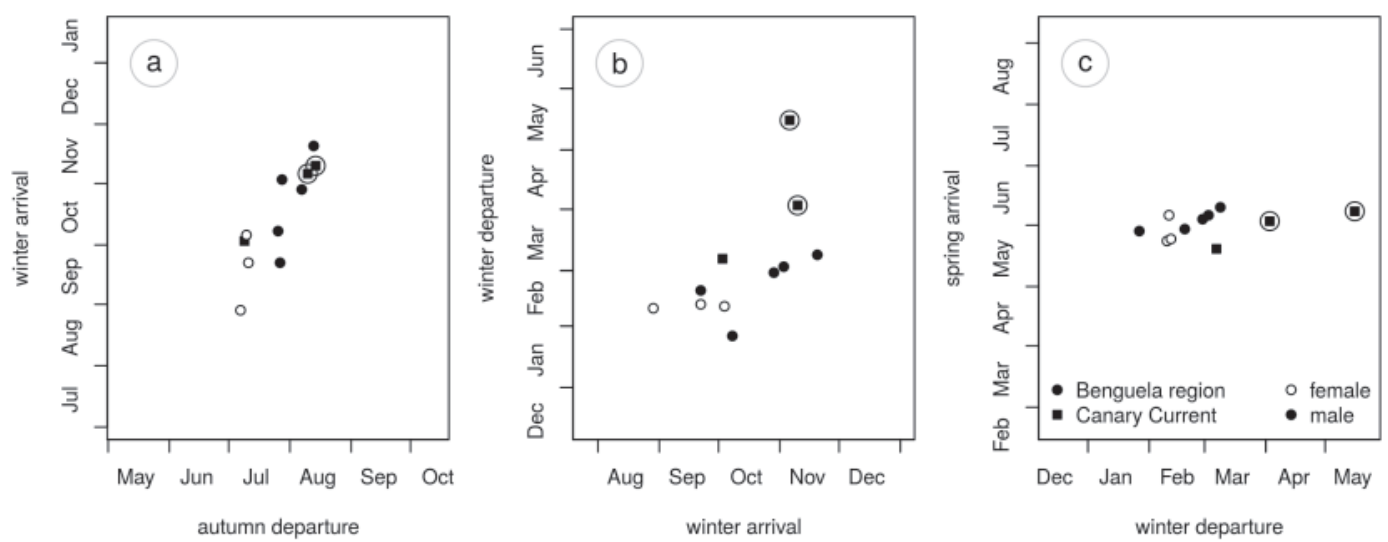

FIGURE 4.4 | lımıng of migratıon of Grey Phalaropes migratıng to the Canary Current and

Benguela region: (a) departure from the breeding area in autumn and arrival at the wintering area; (b) arrival at and departure from the wintering area, and (c) departure from the wintering area and arrival at the breeding area in spring. The two individuals from North-east Greenland are circled.

great-circle distance from the breeding areas were different between wintering areas, with $5696 \pm 353 \mathrm{~km}$ for birds remaining in the North Atlantic; $6481 \pm 507$ $\mathrm{km}$ for those migrating to the Canary Current and $13086 \pm 407 \mathrm{~km}$ for those migrating to the Benguela region $\left(F_{2,13}=578.1, p<0.001\right)$.

Females left the breeding area between 7 and 13 July and males between 9 July and 14 August $(t=-6.4, d f=12.4, p<0.001$, figure 4.3). As birds experienced continuous daylight in and near the breeding area, first position estimates after breeding area departure were on average at $1932 \mathrm{~km}$ (range=760-2845 km, n=16) from the breeding sites. Autumn migration routes were related to wintering area: birds wintering in the northern hemisphere had prolonged stopovers in the Northwest Atlantic (figure 4.1a,b), whereas birds wintering in the Benguela region staged in the (north)eastern Atlantic and in the Canary and Guinea Currents (figure 1e,f). Those wintering in the Canary Current staged both in the north-western and northeastern Atlantic (figure $\mathbf{1 c}, \mathbf{d}$ ). Birds wintering in the North Atlantic moved eastwards between October and February (figure 4.2), to reach an area far offshore between the Azores and Iberia (figure 4.1a,b).

Arrival to the Benguela region was spread over three months, with females arriving between 29 August and 6 October $(n=4)$ and males between 22 September and 20 November $(n=5)$. In the Canary Current, males arrived between 3 October and 9 November $(n=3)$. Among birds wintering in the North Atlantic, the female arrived on 29 August, and the males between 24 August and 20 October $(n=3)$. Arrival to the wintering differed significantly between areas $\left(F_{2,12}=11.6, p=0.001\right)$ and although females were amongst the early arrivals, this was statistically not significant $(F=2.699, p=0.126)$. Females departure from the Benguela region between 10 and 
12 February $(n=3)$; males departed between 27 January and 9 March $(n=5)$. From the Canary Current, the male from Svalbard departed on 7 March and those from Greenland on 3 April and 16 May $(n=3)$. In the Atlantic, the female departed on 15 May and males between 8 and 24 May $(n=3)$. Timing of departure from the wintering areas differed between wintering areas $\left(F_{2,11}=29.4, p<0.001\right)$ and between sexes $\left(F_{1,15}=4.6, p=0.049\right)$. During the wintering period, individuals wintering in the North Atlantic moved between on average 15 sites $(s d=1.3$, range $=13-16, n=4)$, while birds staying in the Canary Current between 3 sites $(s d=1.5$, range $=2-5, n=3)$ and in Benguela region between 4 sites $(s d=1.3$, range $=2-6, n=8$ ). Bearing of these movements showed no clear pattern in time, except for birds wintering in the Benguela region, which moved mainly to the southwest. Within individuals, median distance between sites was on average $640 \mathrm{~km}$ $(\mathrm{sd}=493 \mathrm{~km}$, range $=287-2290 \mathrm{~km}, \mathrm{n}=15)$. Cumulative distances between sites within these areas were $10631 \mathrm{~km}(\mathrm{sd}=1652 \mathrm{~km}$, range=8597-12012 km, $\mathrm{n=4}$ ) in the North Atlantic, $2804 \mathrm{~km}(\mathrm{sd}=1781 \mathrm{~km}$, range=1645-4855 km, $\mathrm{n=3}$ ) in the Canary Current, and $5279 \mathrm{~km}(\mathrm{sd}=2464 \mathrm{~km}$, range=963-9066 km, n=8) in the Benguela region.

In spring, birds that spent the non-breeding period in the northern hemisphere staged in the vicinity of the Azores between March-May (figure 4.1b,d). Birds that spent the non-breeding period in the Benguela region started northbound migration in February or March, staged off West Africa, and arrived at staging areas around $40^{\circ} \mathrm{N}$ in March-April (figure 4.1f). In contrast to the North Atlantic winterers, staging areas around $40^{\circ} \mathrm{N}$ of birds that wintered in the Benguela region were scattered in a wide longitudinal zone between $70^{\circ} \mathrm{W}$ and $10^{\circ} \mathrm{W}$. Irrespective of wintering area, birds migrated northbound in May. The distance from the last position to the breeding site was $2351 \mathrm{~km}$ (range 1575-3678 km, n=15). The two males from North-east Greenland arrived in the breeding area on 3 and 8 June. Females arrived at Svalbard between 24 May and 6 June, and males between 20 May and 10 June.

\section{Flight activity}

Migration flights were performed by night, started at sunset and lasted until about sunrise (figure 4.4). The distribution of flights longer than $1 \mathrm{~h}$ in relation to time of day and season differed as a function of the individuals' wintering areas (figure 4.4), reflecting the spatial and temporal patterns of migration described above. Birds wintering in the North Atlantic performed nocturnal flights throughout the non-breeding period, peaking in mid-winter when migrating to eastern Atlantic (figure 4.2b, 4.4). For birds wintering in the Canary Current, few long flights were detected, with most in autumn. Among birds wintering in the Benguela region, long flights were performed from late-July until late October, reflecting the autumn migration period, and during February to mid-April, reflecting spring migration (figure 4-2-4). 

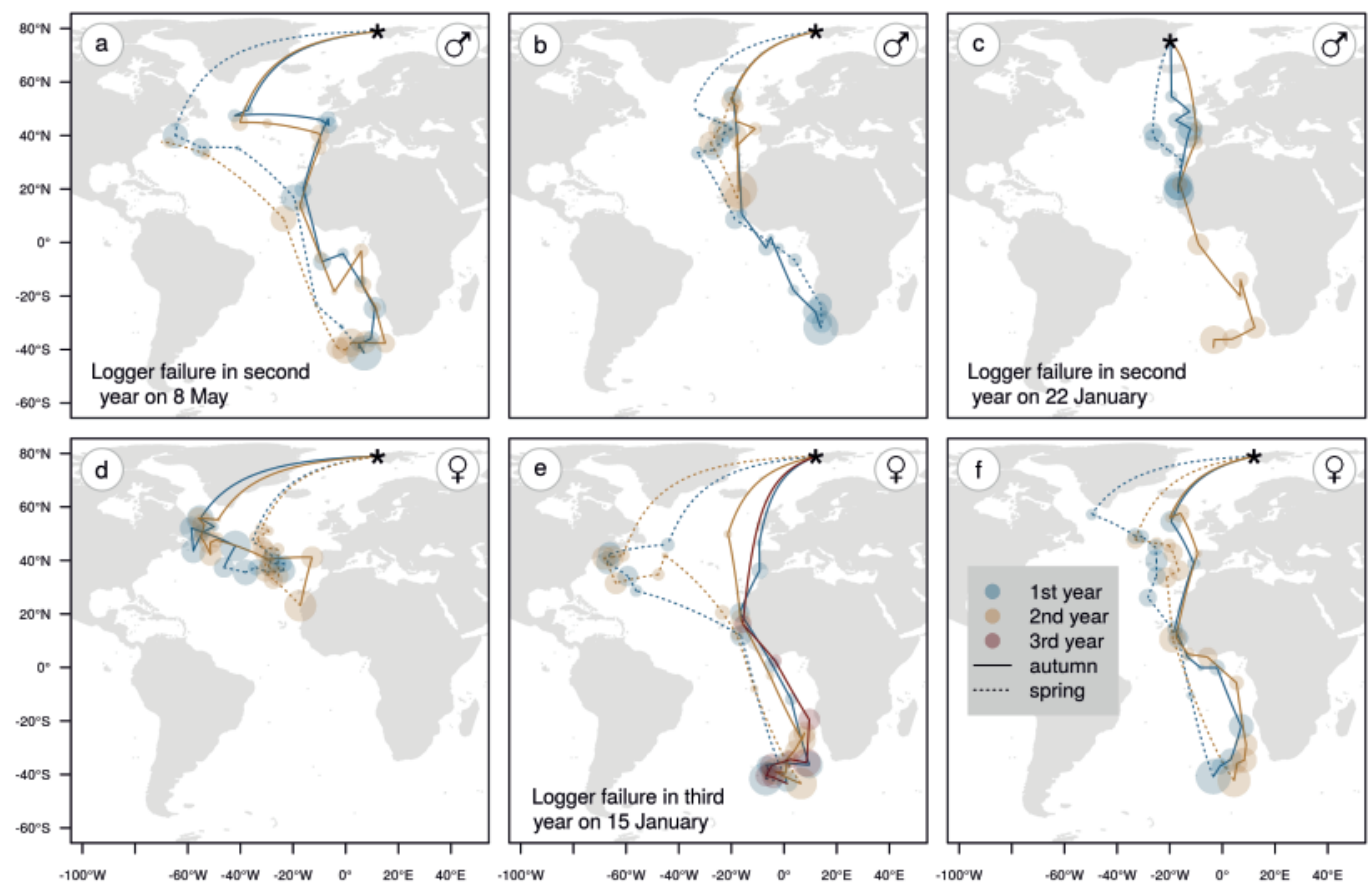

FIGURE 4.5 | Non-breeding movements of six individuals tracked for two or three years. As in figure 4.1, dots show staging areas and their size the duration of stay. Lines are great-circle distances. Note the similarity in routes of individual $\mathbf{a}, \mathbf{e}$ and $\mathbf{f}$, in contrast to the switch in wintering area shown by $\mathbf{b}$ and $\mathbf{c}$, and to a lesser extent by $\mathbf{d}$. Individuals have been tracked over subsequent years, except individual b, which was tracked in 2013-14 and 2016-17.

\section{Individual consistency}

From the six individuals tracked over more than one year, one male and two females from Svalbard followed very similar routes in subsequent years (figure 4.5a, e, f). In contrast to these highly consistent birds, one male from Svalbard and one from Greenland changed their wintering destination between subsequent years from West Africa to South Africa or vice versa (figure 4.5b, c). This represents a distance of ca. $6500 \mathrm{~km}$ between areas at different sides of the equator. One female from Svalbard wintered in the North Atlantic in the first year tracking, but in the Canary Current in the second year (figure 4.5d). Within individuals, timing was mostly similar between years. Difference between years in start of autumn migration ranged between 1 and 7 days in individuals from Svalbard and was 19 days in the Greenland male. Timing of arrival to the wintering area was exactly the same in two individuals (figure $\mathbf{4 . 5 b}, \mathbf{f}$ ), but the difference varied between $32 \mathrm{~d}$ (figure 4.5a), $60 \mathrm{~d}$ (figure 4.5c), $61 \mathrm{~d}$ (figure 4.5e) and $93 \mathrm{~d}$ (figure $3 \mathrm{~d}$ ) in other individuals. Departure from the wintering area was similarly variable: $0 \mathrm{~d}$ (figure 4.5f), $59 \mathrm{~d}$ (figure 4.5b), and $120 \mathrm{~d}$ (figure 4.5d). Timing of arrival in the breeding area differed by $1 \mathrm{~d}$ (figure 4.5d), $3 \mathrm{~d}$ (figure 4.5f) and $18 \mathrm{~d}$ (figure 4.5b). 


\section{DISCUSSION}

In our study, tracked Grey Phalaropes from breeding sites in North-east Greenland and Svalbard roamed widely across the length of the Atlantic, wintering on both sides of the equator in temperate to subtropical waters. Individual wintering areas could be categorized in three regions: across a broad longitudinal range at about $40^{\circ} \mathrm{N}$ in the North Atlantic, in the Canary Current off West Africa, or in the Benguela region of South-west Africa. The importance of the Canary Current and Benguela region as wintering areas is thus confirmed by our results (Stanford 1952, Brown 1979, Delany et al. 2009, Camphuysen et al. 2013). In contrast, wintering of Grey Phalaropes at temperate latitudes in the North Atlantic has been regarded uncommon in literature, whereas a quarter of our tracked individuals follow this strategy. The neglect of this wintering area in literature could be due to the remoteness and lack of at-sea surveys in these areas. Alternatively, considering each of the individuals wintering in the North Atlantic moved considerable distances across the ocean, and at different times, large concentrations of Grey Phalaropes may not occur at any time during the wintering period in the North Atlantic. Is our sample of 16 individuals from North-east Greenland and Iceland representative for the population wintering in the Atlantic? The breeding populations of Svalbard (>1000 pairs, Bangjord et al. 2015) and North-east Greenland (250-500 pairs, Delany et al. 2009) are tiny compared to the bulk of the Atlantic population breeding in arctic Canada, which is estimated at ca. 1000000 pairs (Morrison et al. 2006, Delany et al. 2009). Tracking of Grey Phalaropes from the Canadian population should shed more light on whether these populations differ in their nonbreeding movements. In addition, populations breeding in the Russian Arctic from $50^{\circ} \mathrm{E}$ eastwards are all assumed to migrate to winter in the Pacific (Delany et al. 2009, Lappo et al. 2012), and this still needs to be tested using tracking data.

Both autumn and spring migration routes were associated with wintering areas. Individuals wintering in the Canary Current or Benguela region performed a typical long-distance migration, with quick south- and northbound migration along the east Atlantic to the non-breeding areas. The migrations were performed at night, and flight departure was always around sunset, as is common among waders (Piersma et al. 1990). Nocturnal migration is particularly expected among species that forage visually rather than tactile, as they can optimize diurnal foraging time when avoiding migrating during the day (Alerstam 2009). Indeed, Grey Phalaropes may migrate nocturnally because they are visual foragers (Tracy et al. 2002).

During spring migration, birds that wintered in the Benguela region travelled north via West Africa and migrated over a broad front to staging areas at about $40^{\circ} \mathrm{N}$ across the full width of the North Atlantic. The broad-front migration over the North Atlantic is also observed in Long-tailed Skuas and may be explained by similar wind conditions across the ocean, rendering no route particularly advantageous in terms of wind support (van Bemmelen et al. 2017). However, Grey Phalaropes that 
wintered in the Canary Current all took very similar routes through a narrow strip of staging areas in the central North Atlantic.

In contrast, individuals that remained in the North Atlantic had no clear distinction between a migration and wintering period and roamed from west to east over the course of the autumn and winter, although areas in the Central Atlantic and off Iberia were used for prolonged periods during the winter months. These individuals visited many sites during the non-breeding period, a strategy termed 'itinerancy'. Itinerancy, as opposed to residency - when individuals remain at a single site throughout the wintering period - is widespread among passerines in Africa and the Neotropics (Heckscher et al. 2015, Koleček et al. 2018), but also among seabirds (Fijn et al. 2013, Schultner et al. 2014, van Bemmelen et al. 2017). Itinerancy is usually explained as a response to spatio-temporal variation in resource availability (Moreau 1972) and should therefore differ between wintering areas with contrasting spatio-temporal availability of resources. Indeed, in the closely related Red-necked Phalarope, individuals moved more in wintering areas with pronounced seasonal variability in spatial patterns of ocean productivity (van Bemmelen et al. 2019). Likewise, in Grey Phalaropes, the amount of wintering movements matches the spatio-temporal variability of conditions of three main wintering areas. The Canary Current, where Grey Phalaropes used only few sites within the wintering period, provides fairly stable conditions throughout the wintering period. In contrast, the more oceanic part of the Benguela region, which is at the boundary of the Subtropical Convergence zone of the South Atlantic Current, and the North Atlantic offer more variable environments (Longhurst 2006). In the North Atlantic, Grey Phalaropes feed extensively on large copepods like Calanus finmarchicus (Brown and Gaskin 1988), which shows marked spatial, seasonal and inter-annual variation in abundance (Planque et al. 1997, Conversi et al. 2001). Consistent with these patterns in variability in both the North Atlantic and the Benguela region, Grey Phalaropes moved substantial distances between distinct areas within these wintering areas, but less so in the Canary Current.

Phalaropes are probably best known for their unusual mating system (Lack 1968), with reversed sex-roles, polyandry and male parental care for eggs and chicks (Tracy et al. 2002). Female Grey Phalaropes arrive in the breeding area slightly earlier than or at the same time as males (Schamel and Tracy 1977, Tracy et al. 2002), which is explained by sexual selection for early arrival among the competing sex - i.e. females in the case of phalaropes - to maximize its potential for obtaining mates (Reynolds et al. 1986, Briedis et al. 2019). In our study, sexes did not differ in wintering area selection (Myers 1981) and did not differ in arrival time at the breeding area, which may be caused by the under-representation of females in our sample and limited overall sample size. However, females, who leave parental care for eggs and chicks to males, left the breeding area about a month earlier than males. The earlier timing of females relative to males reoccurs in the time of departure from the wintering area, when females left African wintering areas on 
average a few weeks earlier than males. Whereas the differential timing of autumn migration may be directly understood from the division of parental care, the difference in timing of wintering area departure is larger than what would be expected based on the few days of difference between sexes in arrival at the breeding area.

To what degree are Grey Phalaropes consistent in their non-breeding movement patterns between years? Within our sample of six individuals with more than one track, three individuals were consistent between years, but others showed considerable flexibility in wintering area selection. Among a growing body of studies presenting repeated tracking of individual seabirds, individual consistency between years seems to be the most common strategy (Guilford et al. 2011, Muller et al. 2013, McFarlane Tranquilla et al. 2014). In some seabird species, most individuals were consistent in non-breeding movements between years but some of the individuals switched wintering area. In Cory's Shearwater Calonectris diomedea and Long-tailed Skua Stercorarius longicaudus, for example, some of the individuals changed their non-breeding grounds between years (Dias et al. 2011, van Bemmelen et al. 2017). Whereas Long-tailed Skuas deviated from earlier nonbreeding movements only after they had arrived at or close to the main wintering area (van Bemmelen et al. 2017), Cory's Shearwater appeared to have already made the decision to switch at departure from the breeding colony, thus apparently without any information on the current conditions at each of the non-breeding areas (Dias et al. 2011, Dell'Ariccia et al. 2018). The pattern observed in wintering siteswitching Grey Phalaropes is thus more like the Long-tailed Skuas: they arrived at the wintering area in the Canary Current before deciding whether to continue to the Benguela region. What drives this decision requires a larger sample and is to be investigated in future studies that also take local food and weather conditions into account. 


\section{ACKNOWLEDGEMENTS}

We thank all people who helped in the field. In North-east Greenland, these were Vadim Heuacker, Eric Buchel, Vladimir Gilg and Brigitte Sabard. In Svalbard, these were: Erik Bangjord, Venke Ivarrud and Arild Espelien. RB was funded by the Netherlands Organisation for Scientific Research (project number 866.13.005). Work at Hochstetter Forland by OG and LB was supported by the French Polar Institute, IPEV (program '1036 Interactions') and by the Agence Nationale de la Recherche (program ILETOP ANR-16-CE34-0005). Work in Svalbard was partly financed by Svalbard Environmental Protection Fund and the Fram Centre flagship "Climate Change in Fjord and Coast" (grant nr 2019147470 1152018). Thanks also to Ingrid Tulp; her comments greatly improved the quality of this paper. 


\section{CHAPTER V}

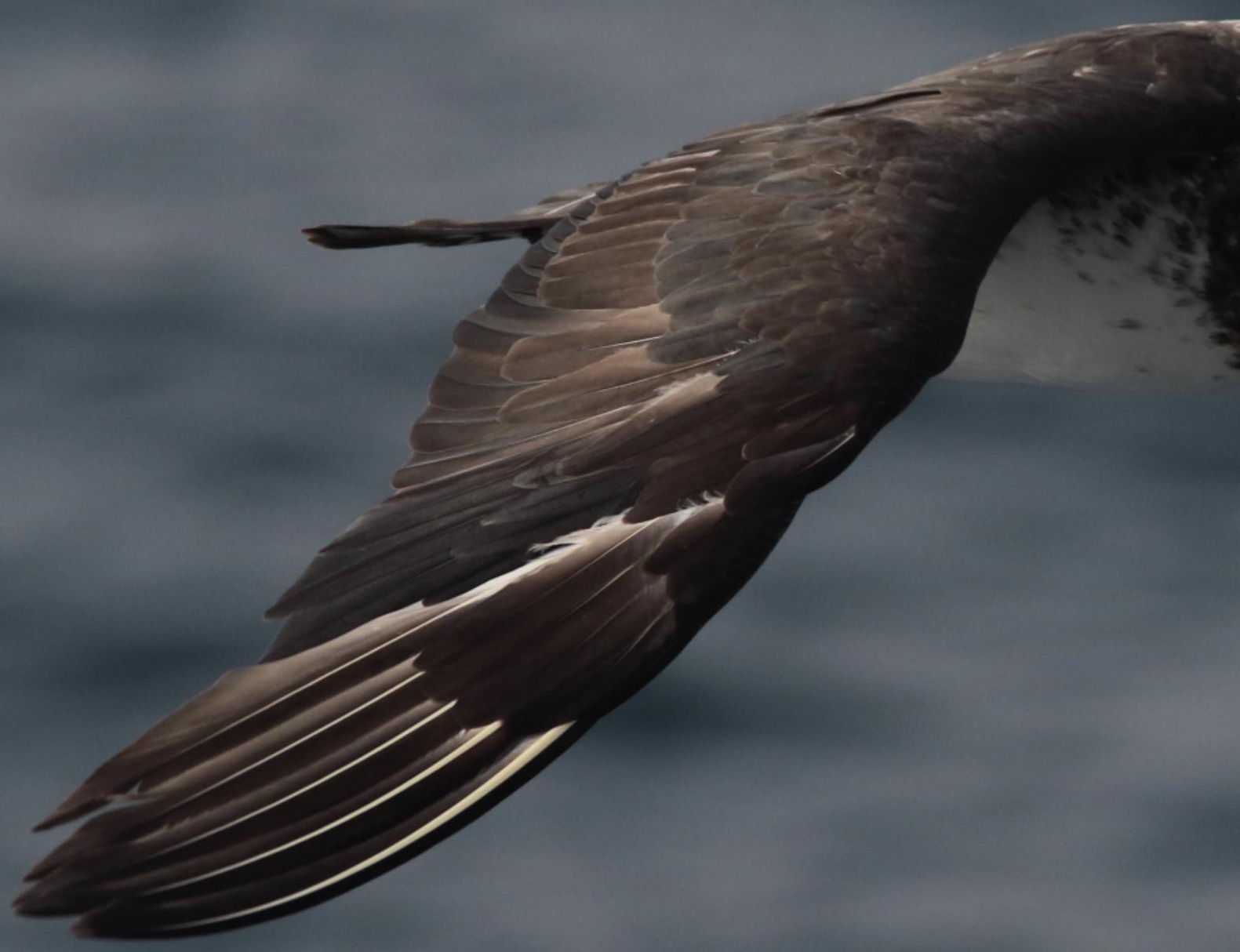

Adult Pomarine Skua off Mauritania, 9 November 2016. 


\section{Timing and duration of primary molt in Northern hemisphere skuas and jaegers}

Rob S.A. van Bemmelen, Rohan H. Clarke, Peter Pyle \& Kees (C.J.) Camphuysen

The Auk 135(4): 1043-1054 


\section{ABSTRACT}

We compared the primary molt of the four species of skuas 58 and jaegers (Stercorariidae) that breed in the northern hemisphere: Long-tailed Stercorarius longicaudus, Parasitic $S$ parasiticus, and Pomarine $S$ pomarinus Jaegers, and Great Skua S skua. We analyzed primary molt data of 1573 individuals of multiple age classes, mostly collected from photographs taken at sea but also from museum specimen and beached individuals. Whereas molt duration generally increased with species' size, molt duration of Parasitic and Pomarine Jaegers was surprisingly similar given their size difference. Larger species were found to start primary molt earlier and show more overlap with post-breeding migration, such that there was complete overlap in Great Skua but no overlap in Long-tailed Jaeger. Within jaeger species, the first primary molt cycle took longer than later molt cycles. We suggest that, unlike birds in their first primary molt cycle, birds in their second or subsequent primary molt cycles are time-constrained to complete primary molt before the onset of pre-breeding long-distance migration. By contrast, molt duration did not differ between age classes of Great Skuas. Adult Great Skuas may have overcome the time constraint by completely overlapping molt and post-breeding migration. Molt-migration overlap is generally rare in birds but may be feasible for Great Skuas due to their shorter migration distance and low migration speed. 


\section{INTRODUCTION}

Primary molt, the replacement of the large remiges attached to the 'hand' of the wing, is one of the major events in the annual cycle of all birds. Several strategies have evolved to fit molt into a birds' annual cycle, generally avoiding temporal overlap with other demanding activities such as breeding and migration (Hedenström 2006). Non-overlap may be achieved by adjusting the timing of molt (e.g. postponing molt until after the most intense period of chick care, or after migration), or by shortening the duration of molt (usually by growing more feathers simultaneously, (Rohwer and Rohwer 2013). Speeding up of molt can lead to decreased flight performance (Hedenström and Sunada 1999) or a lower quality of feathers (Dawson et al. 2000, Serra 2001).

Whereas most variation in molt duration between species is explained by body size, larger species taking longer to molt (Rohwer et al. 2009), molt duration and timing may vary between and within species according to breeding and migration behavior (Lindström et al. 1993a, Serra et al. 1999, Pyle 2008, Dietz et al. 2013). Despite this, few studies quantify differences in molt duration and timing in detail for closely related species or for different groups within species. In seabirds, this is partly due to a lack of primary molt data for many species (Bridge 2006). Studying molt of flight feathers in seabirds is compromised by the fact that the birds disperse over vast expanses of ocean where collection of adequate sample sizes can be difficult. These challenges have been overcome in recent years, now that digital photography has been shown to facilitate molt scoring of flying birds (Keijl 2011, Vieira et al. 2016) and increasing numbers of photos taken during offshore surveys and opportunistic cruises are shared online.

The family of skuas and jaegers (Stercorariidae) comprises seven species. We compared the primary molt of all four species of skuas and jaegers that breed in the northern hemisphere: Long-tailed Stercorarius longicaudus, Parasitic $S$ parasiticus, and Pomarine $S$ pomarinus Jaegers, and Great Skua $S$ skua. Parasitic and Longtailed Jaeger are sister-species, and evidence has been accumulating that Pomarine Jaeger is a sister group of the great skuas (Janssen and Mundy 2017). These species range in body mass from $\sim 300 \mathrm{~g}$ in Long-tailed, $\sim 400 \mathrm{~g}$ in Parasitic and $\sim 700 \mathrm{~g}$ in Pomarine Jaeger to $\sim 1400 \mathrm{~g}$ in Great Skua (Cramp and Simmons 1983). Breeding in the (sub)Arctic and spending the non-breeding period on the oceans, all skuas are migratory, but the distances covered vary considerably between species and individuals. Non-breeding areas vary between $50^{\circ} \mathrm{S}-20^{\circ} \mathrm{N}$ in the smallest species, the Long-tailed Jaeger (Gilg et al. 2013, Van Bemmelen et al. 2017), to $10^{\circ} \mathrm{N}-50^{\circ} \mathrm{N}$ in the largest species, the Great Skua (Furness 1987, Magnusdottir et al. 2012). Migration of Parasitic and Pomarine Jaegers is less well studied, and while Pomarines are thought to winter mainly around $0-20^{\circ} \mathrm{N}$ (albeit with regular occurrence to $\sim 36^{\circ} \mathrm{S}$ off Australia and elsewhere), most Parasitics would mainly migrate to $10^{\circ} \mathrm{S}-50^{\circ} \mathrm{S}$ (Olsen and Larsson 1997, Menkhorst et al. 2017). The timing 
and extent of migration is thought to vary with age and breeding success (Furness 1987). Individuals initially stay out at sea during the boreal summer of their second calendar year and may return to the breeding grounds in their third or fourth calendar years, where they arrive later in the season and remain for a shorter duration than adults (de Korte 1984, Furness 1987). Recruitment to the breeding population occurs after three or more years in the Long-tailed Jaeger (de Korte 1985) and may take even longer in the other species (Furness 1987). The contrasts in body size and migration distance between species, and the contrast in the degree of migratory and breeding behavior between ages within species, allow us to explore the effect of these factors on timing and duration of primary molt. Our expectations can be summarised as follows: (1) larger species will require more time to renew all primaries than smaller species; (2) by starting earlier they will require larger overlap with migration; (3) within a species, populations wintering further south will have a shorter molt duration; and (4) molt duration will decrease with age as time constraints imposed by migration and breeding set in.

\section{METHODS}

Primary molt scores were obtained from several sources. Most were scored from photographs, which were either sourced from the Internet (in particular from online sighting portals), supplied by photographers or taken by the authors. A dataset obtained in the same way and published previously by Newell et al. (2013) was also included, but all molt scores were reassessed by the first author to ascertain uniformity. Only the best visible wing was scored. Photographic records were filtered for duplicates, which could be identified by date and location, molt status, and by individual plumage characters such as the length and shape of the central tail feathers, the amount of barring on the underparts, and the color of the head cap. Additional primary molt data were obtained from tideline corpses on Dutch beaches (Nederlandse Stookolieslachtoffer Onderzoek database), as well as from museum specimens from the California Academy of Sciences, San Francisco, CA (CAS), Museum of Vertebrate Zoology, Berkeley, CA (MVZ) and Western Foundation of Vertebrate Zoology, Camarillo, CA (WFVZ). Finally, we included published molt scores of museum specimen from Stresemann and Stresemann (1966), Lambert (1980), Melville (1983) and de Korte (1985). Individual jaegers were assigned to four age classes (first-cycle, second-cycle, third-cycle or adult) representing primary molt cycles, based on plumage characters and colouration of tarsi as outlined by Howell (2007) and Pyle (2008). In Great Skuas, we only distinguished between firstcycle birds and older birds, as no reliable ageing characters are established to distinguish second-cycle and third-cycle birds from older individuals. Note that the 'adult' class will include an unknown proportion of individuals that did not (yet) recruit to the breeding population, or that skipped or failed breeding in any given year. 
In all four species, primary molt starts at the innermost primary and completes at the outermost primary (Pyle 2008). Molt scores were assigned 0 (old), 1-4 (growing and in pin or $10-33 \%, 33-67 \%$ or $67-99 \%$ grown, respectively) or 5 (new and fully grown) (Ashmole 1962). Feather molt scores of 1 and 2 are usually indistinguishable in photographs (for example, see figure 5.51), as these feathers are clearly dropped but the new feathers are not yet visible beyond the primary coverts. In the case of a single invisible feather, this was scored as 1, whereas two invisible feathers were scored as 1 (outermost) and 2 (innermost). Fully grown primaries collected from birds found dead were cleaned, dried and weighed to the nearest $0.001 \mathrm{~g}$. Using the mean relative mass for each of the ten primary feathers (table 5.1), primary scores were converted into proportion of feather mass grown (PFMG), a molt index that increases approximately linearly over time (Summers et al. 1980). The mean relative mass of each primary reflects the shape of the wing, which shows little variation between individuals or age classes within species, but large differences between species (Dawson 2005). Indeed, the inclusion of several juveniles in our sample (1 Parasitic Jaeger, 2 Pomarine Jaegers and 4 Great Skuas) did not affect our results. Moreover, as relative mass of each primary (numbered p1 to $\mathrm{p} 10$ ) varied on average only $2.5-4.9 \%$ within Parasitic Jaeger, Pomarine Jaeger and Great Skua we consider our single Long-tailed Skua sample to be representative for that species' wing shape.

Mean start date and duration of molt were estimated by modelling PFMG values against day since 1 July (this date falls well outside the primary molt period in most age classes). This was done using likelihood models, referred to as UZ models (Underhill and Zucchini 1988) and implemented in the package 'molt', version 2.0.0 (Erni et al. 2012), within the statistical package $R$, version 3.4.0 (R Core Team 2017). In contrast to other methods, UZ models have specifically been designed to analyse molt data, e.g., dealing with the heteroscedasticity of molt data and biases inherent to regression methods (Summers et al. 1983, Underhill and Zucchini 1988). Only individuals in active primary molt were considered (type 3 data: Underhill and Zucchini 1988). $\mathrm{R}^{2}$-values were obtained from linear models of observed versus fitted values. Age was included in the models as a covariate for molt duration, starting date and standard deviation in starting date. Due to the smaller sample sizes of second-cycle and third-cycle jaegers (table 5.2), we combined these into a single age class (referred to as second/third-cycle). The adult age class was taken as the baseline level, as this class held the largest sample size. Optimization procedures for UZ models are sensitive to starting values (Erni et al. 2012). Therefore, convergence problems for the model of Parasitic Jaeger were solved by providing starting values, based on separate models for each molt cycle, and a standard deviation parameter of 5 days. To estimate the mean feather growth rate of adults, we divided the mean total feather mass by the estimated molt duration.

Considering the effect of non-breeding area latitude on molt timing and duration 
shown in other species (Serra et al. 1999, 2006, Underhill 2003, Pyle 2008), we also explored this by adding the covariate 'latitudinal zone' for onset and duration of molt and comparing their AIC values against models without covariates. We defined three latitudinal zones to investigate the potential effect of (non-breeding area) latitude on molt parameters: North of $35^{\circ} \mathrm{N}$ in the Atlantic (mainly from the North Sea or US east coast) or North of $40^{\circ} \mathrm{N}$ in the Pacific (mainly off the US west coast), from these latitudes south to the equator (mainly California Current and Canary Current), and south of the equator (mainly Australia and the Benguela Current). These latitudinal zones reflect areas where jaegers normally do not spend winter, areas that can be regarded as regular 'northern' non-breeding areas, and regular 'southern' non-breeding areas, respectively (Olsen and Larsson 1997).

The critical assumption of UZ models of a constant rate of change in molt index can be violated by birds that suspend molt (Underhill and Zucchini 1988, Erni et al. 2012). In molt suspension, molt is temporarily halted, to be resumed later. It results when a newer, full-grown feather falls distal to a substantially older feather, with no feathers missing (Pyle 2008, Pyle and Reid 2016, for an example see figure 5.S2). We expect primary molt suspension to mainly take place in birds that start molt when still well north of their non-breeding area, suspend molt during migration and resume after arrival at the main non-breeding area. We therefore explored the effect of exclusion of individuals that - after being 'sampled' - may have suspended primary molt: those that were molting when (still) in the northern latitudinal zone on model parameters.

In order to relate timing and duration of primary molt to migration timing, individual-level timing of departure from the breeding area, arrival at and departure from the non-breeding area and southbound overall migration speed were derived from light-based geolocation data for Parasitic Jaeger and Long-tailed Jaeger. Parasitic Jaegers were captured at Slettnes, Norway $\left(71.0819^{\circ} \mathrm{N}, 28.2102^{\circ} \mathrm{E}\right.$, van Bemmelen et al. in prep), with data spanning three years (2014-2017), and Longtailed Jaegers at Ammarnäs, Sweden $\left(66.0048^{\circ} \mathrm{N}, 16.1842^{\circ} \mathrm{E}\right.$, Van Bemmelen et al. 2017), with data spanning four years (2011-2015). Both datasets were analysed using the same techniques; for details see van Bemmelen et al. (2017). As both datasets span multiple years, we assume year-effects are levelled out. However, mean timing of migration for the Swedish Long-tailed Jaegers may be up to a few weeks earlier than the overall species' average, considering breeding and migration are timed later at higher latitudes (Conklin et al. 2010), and this Swedish population is closer to the southern border of the breeding distribution. The breeding distribution of Parasitic Jaegers extends further south (Olsen and Larsson 1997), with Slettnes taking a central position in the distribution range, and we expect that our sample therefore corresponds reasonably well with the overall species' mean migration timing. For Pomarine Jaeger and Great Skua, approximate migration periods and distances were obtained from literature (Cramp and Simmons 1983, Furness 1987, Higgins and Davies 1996, Olsen and Larsson 1997, Magnusdottir et 
al. 2012) and - with the exception of geolocator data for Great Skuas (Magnusdottir et al. 2012) - are not specific to certain years or sites. We therefore assume they are generalizations over large areas and multiple years.

\section{RESULTS}

\section{Sample size}

A sample of 1573 individuals of Northern Hemisphere breeding Stercorariidae was included in the UZ models, comprising 278 Long-tailed Jaegers, 251 Parasitic Jaegers, 785 Pomarine Jaegers, and 259 Great Skuas. For all species, the largest sample size was represented by the adult age class (69-85\%, table 5.2). Most records were obtained from photographs $(98 \%$ in Long-tailed, $83 \%$ in Parasitic and $86 \%$ in Pomarine jaegers, and $94 \%$ in Great Skua), with the remainder originating from museum specimens except for some beached Great Skuas (3\%).

As UZ models are sensitive to outliers (Erni et al. 2012), some records were removed from the dataset (prior to the above tabulation) as they showed combinations of date and molt score not compatible with any molt cycle. Excluded records were as follows: 1) a first-cycle Long-tailed Jaeger on 9 August 2015 off the

TABLE 5.1 | Mean relative mass per primary (thus summing to 1), sample size and the total mass of all primaries for four species of Stercorariidae as measured from dead specimen. Primaries are numbered distally, with $\mathrm{p} 1$ being the innermost.

\begin{tabular}{ccccc}
\hline Primary & $\begin{array}{c}\text { Long-tailed Jaeger } \\
\text { S longicaudus }\end{array}$ & $\begin{array}{c}\text { Parasitic Jaeger } \\
\text { S parasiticus }\end{array}$ & $\begin{array}{c}\text { Pomarine Jaeger } \\
\text { S pomarinus }\end{array}$ & $\begin{array}{c}\text { Great Skua } \\
\text { S skua }\end{array}$ \\
\hline p1 & 0.034 & 0.035 & 0.039 & 0.045 \\
p2 & 0.041 & 0.043 & 0.046 & 0.053 \\
p3 & 0.05 & 0.055 & 0.056 & 0.063 \\
p4 & 0.063 & 0.068 & 0.07 & 0.077 \\
p5 & 0.08 & 0.084 & 0.085 & 0.091 \\
p6 & 0.098 & 0.103 & 0.103 & 0.106 \\
p7 & 0.121 & 0.121 & 0.119 & 0.117 \\
p8 & 0.143 & 0.14 & 0.141 & 0.133 \\
p9 & 0.168 & 0.163 & 0.159 & 0.151 \\
p10 & 0.202 & 0.189 & 0.181 & 0.163 \\
\hline Mean mass (g) & 2.17 & 3.21 & 5.08 & 7.91 \\
N & 1 & 4 & 4 & 9 \\
\hline
\end{tabular}


Scilly Islands, United Kingdom with growing p8-9 and old p10; 2) an adult Longtailed Jaeger sitting in poor condition on the beach in Mauritania on 7 May 2013 with p9 growing and p10 old; 3) a Long-tailed Jaeger, presumably an adult, reported on 23 September 1981 in New Zealand, with p7 growing and p8-10 old; 4) Longtailed Jaegers picked up moribund in New Zealand during the 1982 ENSO event appeared to have delayed molt (Melville 1983), as has been shown in other seabirds (Guerra et al. 1988, Howell and Corben 2000); 5) an adult Pomarine Jaeger collected on 1 August 1967 at Barrow, Alaska, with p1-4 full-grown, p5 score 4, p6 score 2 and p7-10 old (CAS 68455); and 6) a Pomarine Jaeger on 31 March 2007 from New South Wales, Australia, showing delayed Staffelmauser (see below).

\section{Staffelmauser}

Five first- to second-cycle Pomarine Jaegers showed 'Staffelmauser' (Stresemann and Stresemann 1966; table 5.S1), in which the second molt cycle had commenced before outer-primary replacement during the first molt was finished. Four of these, all collected in Monterey Bay, California (CAS 10932, 10965, 10979, and 11096), were duplicated to be included as both first-cycle and second-cycle birds in the models as their PFMG values were within the range of other first- and second-cycle Pomarine Jaegers. However, a fifth Pomarine Jaeger showing Staffelmauser, photographed off New South Wales, Australia, lagged several

TABLE 5.2 | Number of individuals in active primary molt per age class for four species of Stercorariidae, as used in the UZ models. No reliable plumage characteristics are known for ageing second/third-cycle Great Skuas and these are consequently included in the 'adult' class.

\begin{tabular}{lcccc}
\hline & $\begin{array}{c}\text { Long-tailed Jaeger } \\
\text { S longicaudus }\end{array}$ & $\begin{array}{c}\text { Parasitic Jaeger } \\
\text { S parasiticus }\end{array}$ & $\begin{array}{c}\text { Pomarine Jaeger } \\
\text { S pomarinus }\end{array}$ & $\begin{array}{c}\text { Great Skua } \\
\text { S skua }\end{array}$ \\
\hline Adult & 209 & 175 & 540 & 221 \\
$2^{\text {nd }} 3^{\text {rd }- \text { cycle }}$ & 37 & 53 & 157 & - \\
$1^{\text {st }}$-cycle & 32 & 23 & 88 & 38 \\
Total & $\mathbf{2 7 8}$ & $\mathbf{2 5 1}$ & $\mathbf{7 8 5}$ & $\mathbf{2 5 9}$ \\
\hline
\end{tabular}

FIGURE 5.1 | Progress of molt in adult (black), second/third-cycle (blue) and first-cycle (red) jaegers and Great Skua, expressed as the proportion of feather mass grown (PFMG). Shaded areas represent $95 \% \mathrm{Cl}$. Boxplots above plots of Long-tailed and Parasitic Jaeger show (from left to right) start of southbound migration, arrival at non-breeding grounds and departure from non-breeding grounds as inferred from geolocator data. Approximate timing of migration based on literature is shown by horizontal lines above the plots of Pomarine Jaeger and Great Skua. 

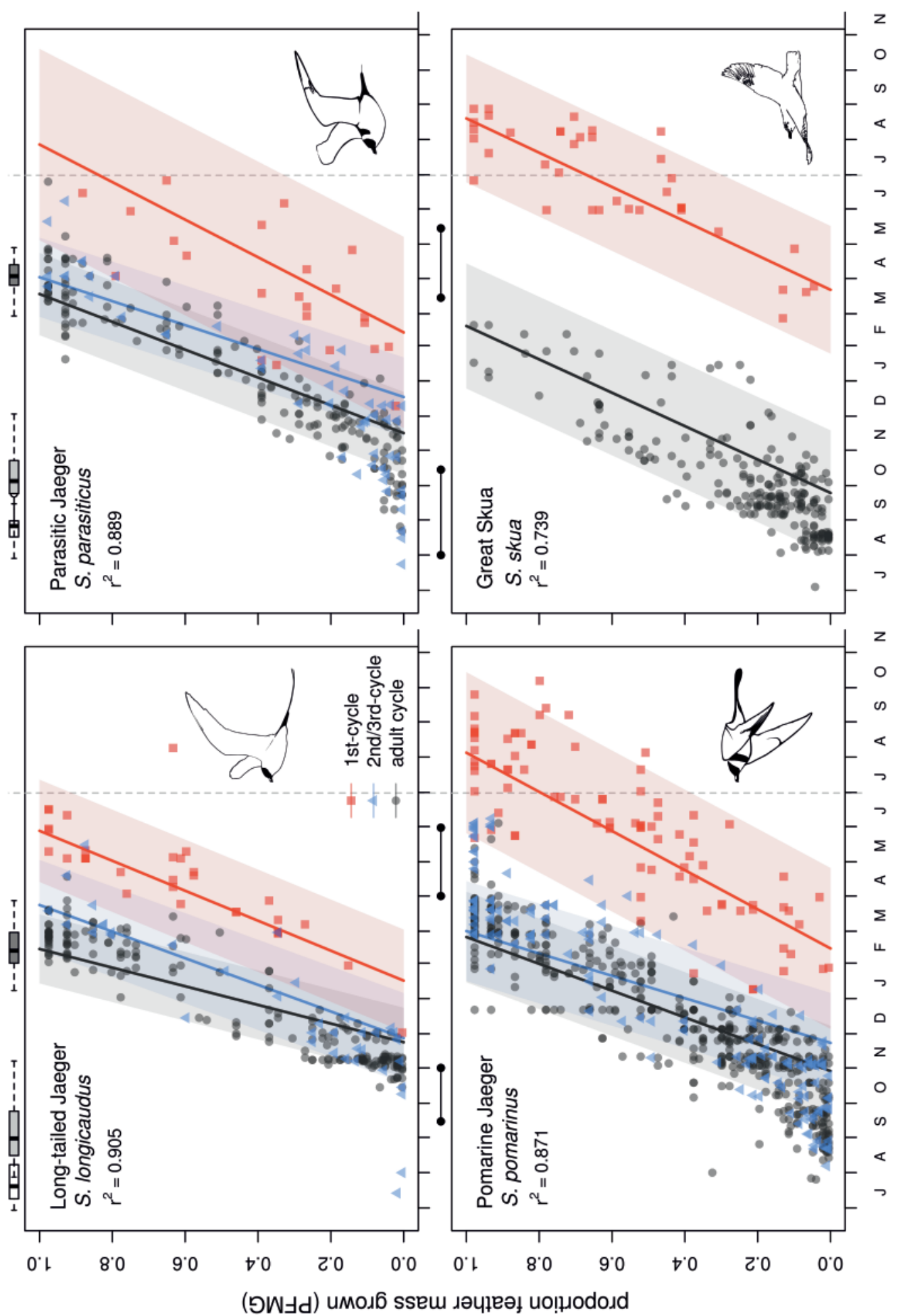
TABLE 5.3 | Model estimates for mean start date and duration of primary molt of four species Stercorariidae. Between brackets, SD values are indicated for the mean start date and SE values for molt duration. See Table 2 for sample size per species and age class. Parameters are missing for second/third-cycle Great Skuas, as no reliable characters are known to distinguish these age classes from older birds.

\begin{tabular}{|c|c|c|c|c|c|}
\hline Age & & $\begin{array}{l}\text { Long-tailed Jaeger } \\
\text { Slongicaudus }\end{array}$ & $\begin{array}{c}\text { Parasitic Jaeger } \\
S \text { parasiticus }\end{array}$ & $\begin{array}{l}\text { Pomarine Jaeger } \\
S \text { pomarinus }\end{array}$ & $\begin{array}{l}\text { Great Skua } \\
\quad \text { S skua }\end{array}$ \\
\hline \multirow[t]{2}{*}{$1^{\text {st }}$-cycle } & Start date & 16 Jan $( \pm 22)$ & 12 Feb $( \pm 42)$ & $13 \mathrm{Feb}( \pm 35)$ & $21 \operatorname{Mar}( \pm 28)$ \\
\hline & Duration (d) & $132( \pm 41)$ & $165( \pm 76)$ & $172( \pm 27)$ & $151( \pm 34)$ \\
\hline \multirow[t]{2}{*}{$2^{\text {nd }} / 3^{\text {rd }}-$ cycle } & Start date & 27 Nov $( \pm 22)$ & 17 Dec $( \pm 42)$ & 23 Nov $( \pm 35)$ & - \\
\hline & Duration (d) & $117( \pm 25)$ & $105( \pm 22)$ & $98( \pm 21)$ & - \\
\hline \multirow[t]{2}{*}{ Adult } & Start date & 23 Nov $( \pm 15)$ & $16 \operatorname{Nov}( \pm 18)$ & 29 Oct $( \pm 20)$ & 24 Sep $( \pm 27)$ \\
\hline & Duration (d) & $82( \pm 10)$ & $122( \pm 8)$ & $118( \pm 6)$ & $147( \pm 16)$ \\
\hline $\mathrm{R}^{2}$-value & & 0.905 & 0.889 & 0.871 & 0.739 \\
\hline
\end{tabular}

months behind in both cycles, and was excluded from the UZ models as it caused errors during model fitting. We did not find examples of Staffelmauser in the other species.

\section{Suspended molt}

Several individuals showed suspended molt. These were three first-cycle (up to p7 or p8 new) and one adult Long-tailed Jaegers (up to p9 new), one adult Parasitic Jaeger (only p1 new), three second-cycle (up to p2, p7 or p8 new) and two adult Pomarine Jaegers (up to p1 and p2 new), and a single adult Great Skua (up to p9 new). We may have missed suspended molt in other records, as the detection depends on the quality of the picture and the difference in age of old and new feathers.

\section{Model results}

All four species display clear temporal patterns in molt timing. In adults, Great Skua showed the longest molt duration and Long-tailed Jaeger the shortest (figures 5.15.2, table 5.3). However, molt duration of Pomarine and Parasitic Jaegers were virtually the same, despite the distinctly larger size of the Pomarine Jaeger. Projected end-dates for adults were 13 February for Long-tailed Jaeger, 18 March for Parasitic Jaeger, 23 February for Pomarine Jaeger and 18 February for Great Skua. The molt of first-cycle birds was well separated in time from the adults, as well as from second/third-cycle birds and this timing difference increased with species' body weight. In the three jaeger species, molt in first-cycle birds took considerably longer than in adults (longer by 50, 43 and 54 days) but was similar in Great Skua 


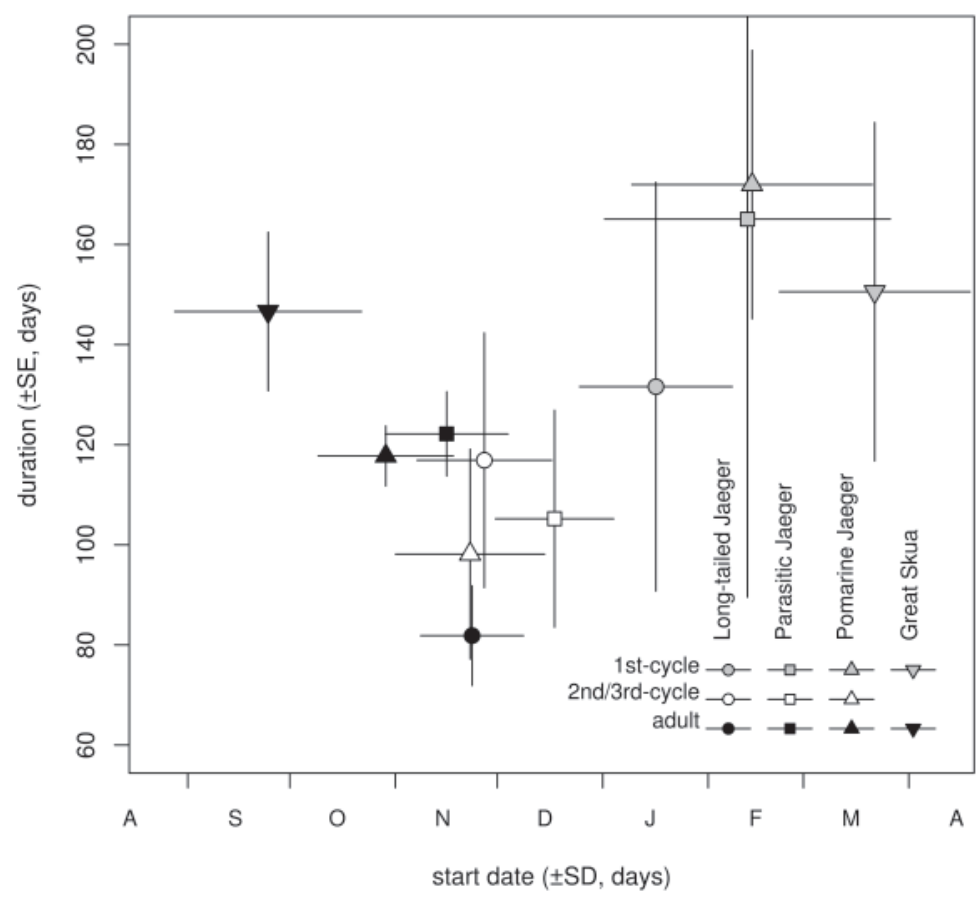

FIGURE 5.2 | Parameter estimates for starting date ( $x$-axis) and molt duration ( $y$-axis, days) for adults, second/third-cycle and first-cycle jaegers and Great Skua. Note that the upper standard error of first-cycle Parasitic Jaeger extends beyond the bounds of the figure.

(longer by 4 days). Duration of molt in second/third-cycle birds was more or less similar to that of adults. The model outputs suggest that second/third-cycle Longtailed Jaeger start at the same time as adults, but have a $35 \mathrm{~d}$ longer molt duration, while second/third-cycle Parasitic and Pomarine Jaegers have a molt duration that is shorter than adults by 17 and $20 \mathrm{~d}$, respectively. All models had very high $\mathrm{R}^{2}$ values.

Adults were the only age class with sufficient data from separate latitudinal zones to test for the effect of latitude. The distribution of records of adults among the three latitudinal zones were as follows, from North to South: 0, 65 and 144 for Longtailed Jaeger, 13, 43 and 119 for Parasitic Jaeger, 22, 275 and 243 for Pomarine Jaeger and 213, 8 and 0 for Great Skua. For all three jaeger species, adding 'latitudinal zone' did not result in large decreases of AIC values (dAIC > 2) compared to UZ models without covariates.

We found no apparent effects relating to Parasitic and Pomarine Jaegers that may have suspended molt after being sampled. Removal of samples from the northern latitudinal zone only had a small effect on molt duration $(<0.4$ d) and on mean 
starting date $(<2$ d) in both species. We could not perform this analysis for Longtailed Jaegers, due to the lack of molting adults in the northern latitudinal zone, or for Great Skua, which largely remain within the latitudinal zone. In addition, we could not repeat this analysis for first-cycle or second/third-cycle datasets, due to smaller sample size.

\section{Migration}

Timing of departure from the breeding areas, arrival at and departure from the nonbreeding areas are indicated for Parasitic and Long-tailed Jaeger by boxplots in figure 5.1. Parasitic and Long-tailed Jaegers travelled on average $273 \mathrm{~km} \mathrm{~d}^{-1}$ ( $\mathrm{n}=$ 29) and $293 \mathrm{~km} \mathrm{~d}^{-1}$, respectively $(\mathrm{n}=60)$. Based on literature, Great Skuas breeding in Scotland complete a migration of $3000-3500 \mathrm{~km}$ to Iberia or NW Africa (based on light-level geolocator data in Magnusdottir et al. 2012), in about two months (Cramp and Simmons 1983, Furness 1987). This suggests they travel approximately $50-60 \mathrm{~km} \mathrm{~d}^{-1}$.

\section{DISCUSSION}

Consistent with our expectations, we found that molt of primaries in the larger Great Skua generally took longer, started earlier, and had a larger temporal overlap with migration than in the three jaeger species. Within jaeger species, differences in molt duration between age-classes suggest time constraints to finish molt before northward migration. Whilst these findings are largely in line with previous publications (Olsen and Larsson 1997, Wiley and Lee 1998, Howell 2007, 2010, Pyle 2008, Pyle and Reid 2016), we provide more precise estimates of molt onset and duration and a uniform data analysis for all four species and identifiable age classes, allowing inter- and intraspecific comparisons.

Molt duration of adult Parasitic and Pomarine Jaegers were surprisingly similar given they differ significantly in body weight (335-470 g versus 542-917 g, respectively, Cramp and Simmons 1983). A longer molt duration in Parasitic Jaeger, to approximate that of Pomarine Jaeger, is difficult to explain. Molt suspension may lead UZ models to overestimate duration of active molt, but models of both species appeared robust to the inclusion of individuals that may have suspended molt after being sampled. Another possible modelling issue would be a poor model fit due to covariance of molt parameters, which is a known problem for type $3 \mathrm{UZ}$ models (Underhill and Zucchini 1988, Erni et al. 2012). Although this was the case in models for both Parasitic $(r=-0.897)$ and Pomarine Jaegers ( $r=-0.912$ ), we can see no reason why this would affect the models for the two species differently.

Alternatively, model results could reflect a true similarity in molt duration between Parasitic and Pomarine Jaeger. Molt duration is determined by both the number of simultaneously growing feathers (molt intensity) and the time required to grow 
individual feathers (growth rate). While total feather mass is clearly larger in Pomarine Jaeger (table 5.1), molt intensity was not different between the two species at any time during primary molt (figure 5.3), suggesting feather growth rate $\left(\mathrm{g} \mathrm{d}^{-1}\right)$ could explain the similar molt durations. Given that feather growth rate increases with body mass among bird species (Rohwer and Rohwer 2013), feather growth rate of Parasitic Jaeger would be expected to be intermediate between Long-tailed and Pomarine Jaeger, but was in fact surprisingly similar to Long-tailed and lower than Pomarine Jaeger (figure 5.3). Thus, Parasitic Jaeger may arrive at a molt duration similar to Pomarine Jaeger by a relatively low feather growth rate. This would be remarkable, given that the predominant strategy for adjusting molt durations among birds is by modifying molt intensity rather than feather growth rate (Rohwer and Rohwer 2013). The benefit of decreasing feather growth rate could be higher feather quality, as shortening molt duration has been shown to decrease feather quality (Dawson et al. 2000, Serra 2001). High feather quality may be especially important in Parasitic Jaeger to avoid feather damage when performing frantic aerial pursuits of terns and other seabirds.

In addition to the effect of body size on molt duration (Rohwer et al. 2009), time costs of migration may have an additive effect leading to shorter molts (De La Hera et al. 2009). This may result from squeezing the molt between breeding and postbreeding migration, but when molt is postponed to the wintering period - as in our study species - shorter molts may result from less time spent at the wintering grounds due to longer migration durations. Although Great Skua indeed has the shortest migration distance and the longest molt duration, the pattern does not hold for jaegers, where the Pomarine Jaeger has the shortest winter period and Long-tailed Jaeger the longest, but molt duration is shorter for the latter. Moreover, we expected any effect of migration distance on molt duration also to be reflected within species, but this was not the case: molt duration in all three jaegers did not differ significantly between areas north and south of the equator.

Previous studies indicated that shorebirds and Procellariiform seabirds that migrate to the tropics or Southern Hemisphere display longer molt durations than in related migratory species or populations of the same species that remain in the Northern Hemisphere (Serra et al. 1999, 2006, Underhill 2003, Pyle 2008). Birds that remain in the Northern Hemisphere appear to be under greater time constraints to complete molt before the onset of winter conditions, with fewer resources, less favorable weather and reduced daylight in which to forage. Our results did not reveal such a latitudinal difference between subtropical areas north and subtropical to temperate areas south of the equator, despite differences in for example day length. Jaegers that remain in northern temperate waters during the non-breeding period (which is uncommon in Pomarine, rare in Parasitic, and extremely rare in Long-tailed Jaeger; Olsen and Larsson 1997), may face time constraints, but our samples from this region were too small to robustly estimate timing and duration of primary molt in these waters. Similarly, it would be interesting to test for a 
difference in molt duration between Great Skuas from this study that probably wintered off Africa and Iberia, with those wintering in the Grand Banks area near Newfoundland, Canada (Magnusdottir et al. 2012).

Among our study species, larger species started molt earlier, thereby creating a temporal overlap of primary molt and southbound migration. Migratory bird species usually molt before or after migration, or divide molt between these periods. In the latter case, molt can be suspended during active migration, meaning no wing surface gap is present. In the smallest Stercorariidae species, the Long-tailed Jaeger, we found neither adults that suspended molt in the inner primaries nor birds of any age class that started primary molt well north of the non-breeding areas that could have suspended molt later on. In Parasitic Jaeger, starting primary molt in northern temperate regions seems an uncommon strategy: only a few of the molting adults in our data were from this region. These were all photographed in September-October and in early molt; one adult from Monterey Bay, California, USA had suspended molt after growing the innermost primary (MVZ 101196). In line with this, Olsen and Larsson (1997) state that $5 \%$ of the Parasitic Jaegers start primary molt in temperate waters. Some of these adults may stay throughout the non-breeding area in northern temperate waters instead of the usual tropical or to southern temperate non-breeding areas. Pomarine Jaegers start post-breeding migration later than Parasitic Jaegers and are commonly encountered in early primary molt off central California. Here, they become much scarcer later in the boreal winter (Briggs et al. 1987), suggesting that birds that have commenced molt move southwards later on. Individuals may then suspend molt at p1 or p2 during migration, as indicated by two adult specimens from Monterey Bay, California, USA (MVZ 17765 and 17800). Thus, both Parasitic and Pomarine Jaeger can suspend molt during southbound migration but whether some individuals migrate with molt gaps remains unknown.

In contrast, our results indicate a complete overlap of migration with primary molt in Great Skuas. Great Skuas start primary molt at or directly after departure from the breeding grounds (Cramp and Simmons 1983, Furness 1987). Data collected at Jan Mayen and included in our study, indicates that, in pairs with chicks close to fledgling, at least one of the partners had dropped the inner primary. Molt then continues during southbound migration. In November/December, when adult Great Skuas are virtually absent from the North Sea (Camphuysen and Leopold 1994, Furness et al. 2006) and have moved further south and west, molt has progressed only halfway. Such an extensive overlap of molt and migration is usually considered to be rare among migratory birds, but less rare among short-distance migrants and species that feed on the wing, such as terns and hirundines (Yuri and Rohwer 1997, Zenatello et al. 2002). It is not clear to what extent other seabird species molt primaries during migration, but at least some albatross species may cover huge distances while actively molting (Croxall et al. 2005). In albatrosses, this may be facilitated by a low molt intensity, thereby minimizing the molt gap and negative 


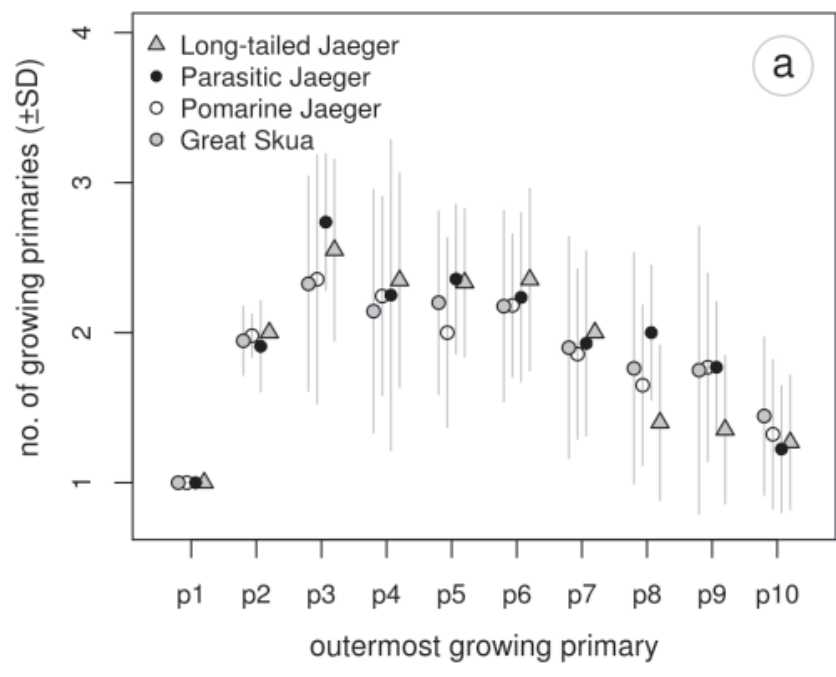

FIGURE 5.3 | (A) Molt intensity (number of primaries growing simultaneously) throughout the molt (upper panel) and (B) deduced mean feather growth rate (lower panel) in adults of four species of Stercorariidae.

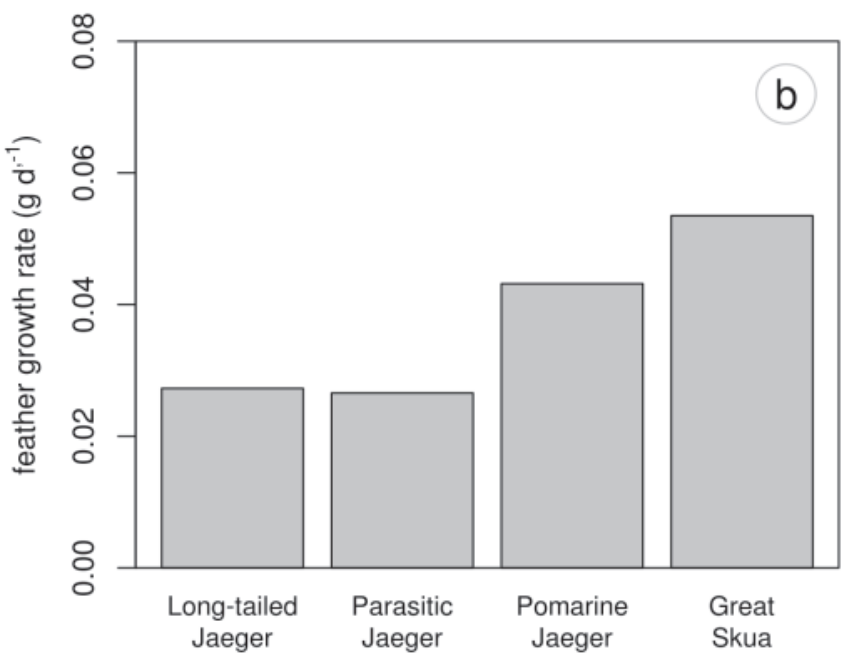

effects on flight performance (Prince et al. 1993). Great Skuas, however, can have substantial molt gaps. Rather, molt-migration overlap in Great Skuas may be facilitated by a short migration distance and low travel speeds. Indeed, whereas Parasitic and Long-tailed Jaegers travel nearly $300 \mathrm{~km} \mathrm{~d}^{-1}$, Great Skuas breeding in Scotland travel at only about $50 \mathrm{~km} \mathrm{~d}^{-1}$. In fact, travel speed in Great Skuas is so low that one could argue they are more or less stationary for most of the time. In addition to travel speeds, high food availability en route may facilitate moltmigration overlap in Great Skuas migrating through productive waters of the North Sea and Gulf of Biscay. In contrast, while migrating between staging in productive areas, jaegers move fast over unproductive subtropical and tropical waters from the central North to the South Atlantic (Van Bemmelen et al. 2017), where molt may need to be postponed or suspended not only due to food limitation. Time 
constraints and the need for waterbird species that remain in the Northern Hemisphere for the non-breeding season to complete molt quicker than species occupying more southerly non-breeding areas might also be affecting the degree to which jaegers and skuas undergo active primary molt during migrations (Pyle 2008).

Although mean starting dates of adults differed by two months, Long-tailed Jaeger, Pomarine Jaeger and Great Skua finished within 10 days of each other, whereas Parasitic Jaeger finished 23 days later. These mean end dates, from late January through early March, are just before the onset of northbound migration as inferred from geolocator data and literature. We found no evidence for molt-migration overlap in the period January-May, in contrast to individuals in active molt during southbound migration at northern temperate latitudes. Our interpretation is therefore that individuals only start northbound migrating once they have finished primary molt. Among migratory birds breeding in the northern hemisphere, migration speed is usually higher during northbound than during southbound migration, indicating a high selection pressure for timely and fast migration (Nilsson et al. 2013). Conceivably, overlap of molt with northbound (pre-breeding) migration entails larger costs than overlap with southbound (post-breeding) migration. For example, the elevated energy requirements (Lindström et al. 1993b) and decreased flight performance (Hedenström and Sunada 1999) of molt may constrain migration speed and lead to later arrival in the breeding area (Gorney and Tov 2001), which can affect breeding performance (Harrison et al. 2011).

The absence of molt-migration overlap during northbound and the (near-)coinciding dates of molt completion and departure from the non-breeding areas (figure 5.1), suggest molt in adults is timed to finish just prior to northbound migration. That this reflects a time constraint is suggested by the ca $50 \mathrm{~d}$ longer molt duration and larger variation in starting dates of first-cycle jaegers compared to adults (Pyle 2008, Howell 2010). Contrary to adults, first-cycle jaegers are not constrained by breeding duties or migration back to the breeding areas. Shorter primary molt duration of adults compared to first-cycle individuals has also been reported in other Arctic breeding long-distance migrant Black-bellied Plovers (Pluvialis sqatarola) and Red Knots (Calidris canutus), in which second-calendar-year individuals do not breed and usually remain on the non-breeding grounds during the boreal summer (Serra et al. 1999, Dietz et al. 2013). In contrast, most secondcalendar year Wood Sandpipers Tringa glareola migrate north directly after an incomplete primary molt on the non-breeding grounds, and this molt takes as long as that of adults (Remisiewicz et al. 2010). An alternative or additional reason for a longer molt duration in first-cycle jaegers may be primary molt suspension, which was observed in some first-cycle Long-tailed Jaegers (Pyle and Reid 2016) and also may explain first-cycle Long-tailed Jaegers in active primary molt in the (late) boreal summer (Wiley and Lee 1998) or even Pomarine Jaegers showing Staffelmauser. Potentially, first-cycle jaegers might suspend primary molt during a - poorly known 
FIGURE 5.S1 | Adult

Pomarine Jaeger

Stercorarius pomarinus in active primary molt, off Mauritania on 11 November 2016. Primary molt was scored as 5542100000 , resulting in a PFMG of 0.171 . Note that p4-5 are invisible and scores for these feathers were inferred.

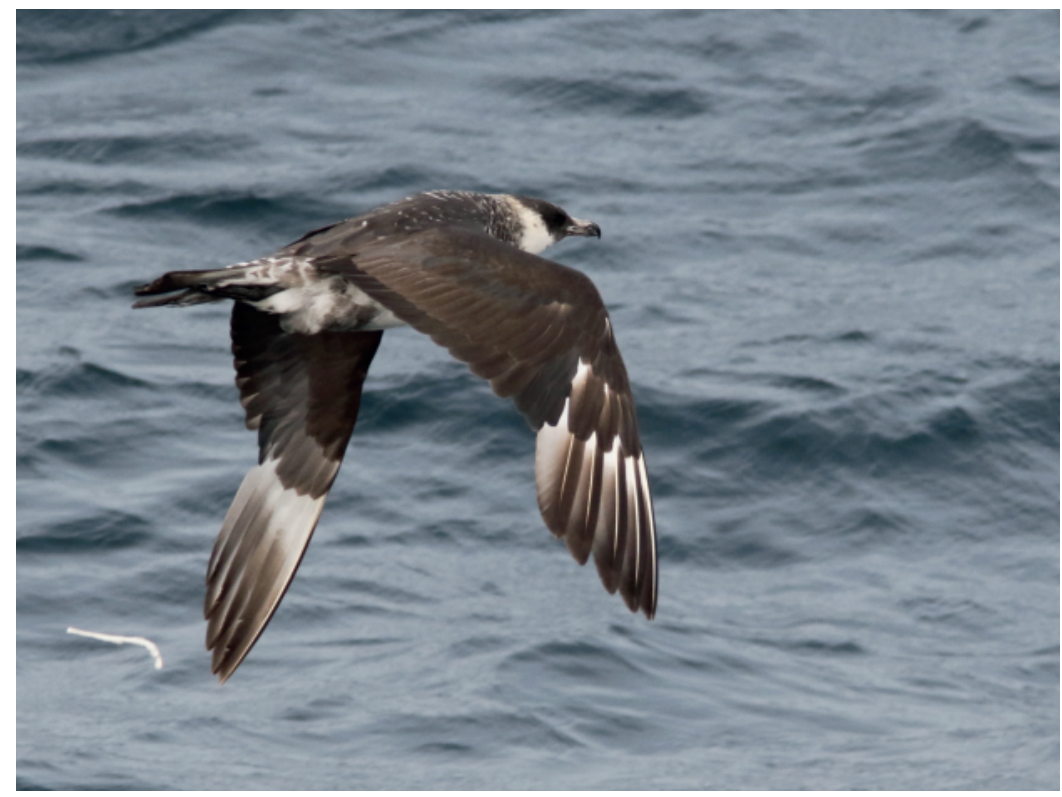

FIGURE 5.S2 Secondcycle Pomarine Jaeger Stercorarius pomarinus that suspended molt after growing $\mathrm{p} 1-2$, off Wollongong NSW, Australia, 23 October 2010.

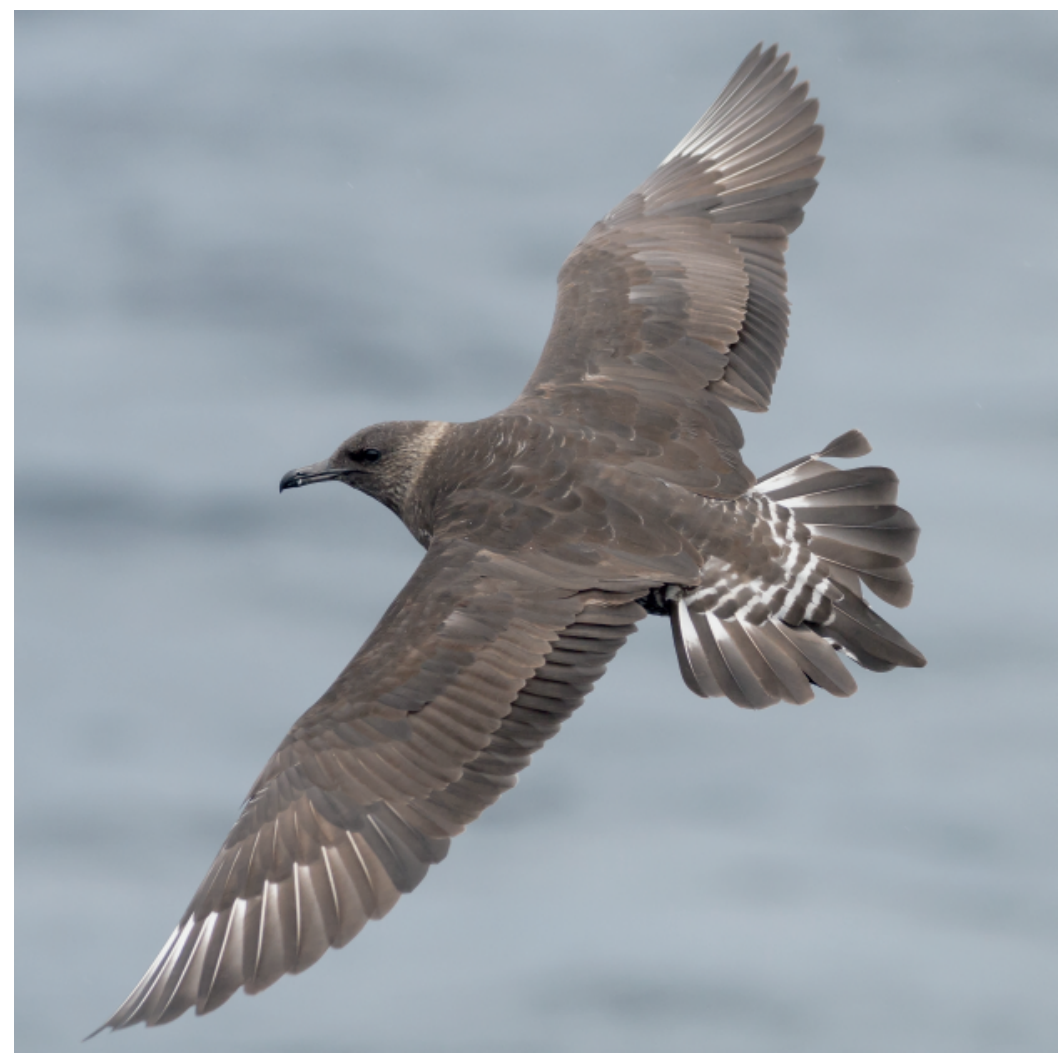


- northbound migration. Their rarity at the breeding areas during the boreal summer suggest that they usually do not migrate all the way to the Arctic (de Korte 1984, van Bemmelen 2010), while during the same period, first-cycle birds appear absent from the Benguela non-breeding areas (Lambert 1980), suggesting most stay in tropical or temperate waters (Howell 2010). Finally, first-cycle jaegers might be constrained by lower foraging success due to lower experience or exclusion from high-quality habitats. However, these options remain speculative until the movements of younger jaegers are uncovered. In contrast to the three jaeger species, molt duration and variation in starting date were virtually equal in firstcycle and older Great Skuas, despite similar contrasts between age classes in breeding and migration as in the jaegers. Adult Great Skuas may have compensated for the time constraint by a greater overlap of molt with southbound migration.

We also expected a longer molt duration for second/third-cycle jaegers than for adults, but our results were inconclusive. We found a longer duration of second/third-cycle birds compared to adults for Long-tailed Jaeger and shorter durations for Parasitic and Pomarine Jaeger. Again, covariance between the parameters for duration and onset of molt may have led to underestimated durations for Parasitic and Pomarine Jaegers. Alternatively, second/third-cycle Parasitic and Pomarine jaegers already face similar time constraints as adults if they are migrating to the northern hemisphere breeding area. However, this should have also been reflected in Long-tailed Jaegers: thrid-calendar-year birds (thus between second- and third-cycle) of this species are regularly recorded at the breeding grounds (de Korte 1984, van Bemmelen 2010).

The molt parameters presented here can inform on when specific primaries are molted, which is critical information for study design and data interpretation when sampling biomarkers from primaries. This applies not only to future studies, but also to re-interpretation of published results. For example, Furness et al. (2006) reported a gradual change through $\mathrm{p} 1$ to $\mathrm{p} 10$ in both $\delta^{15} \mathrm{~N}$ and $\delta^{13} \mathrm{C}$ stable isotopes in Great Skuas and suggested that this reflected a gradual change in diet to lower trophic levels. However, as Great Skuas actively molt during migration, an alternative explanation is that this merely reflects the environmental gradients in stable isotope ratios over which Great Skuas traverse. Indeed, isoscapes published after Furness et al. (2006) show gradients in stable isotope ratios of both elements in near-surface plankton along the Great Skuas' migration route (Graham et al. 2010), which is expected to be reflected in higher trophic levels, including within the growing feathers of top predators such as Great Skuas. As also the smaller species may move during primary molt (Van Bemmelen et al. 2017), we suggest sampling several primaries to obtain biomarker signals along molting locations.

This study is one of only a few that have used digital photographs to obtain avian molt data (Keijl 2011, Conklin and Battley 2012, Vieira et al. 2016). We gathered 
these largely from the Internet. With the increase in popularity of (pelagic) birding, digital photographing, and the ever increasing capacity to share large numbers of observations and images on the Internet, we believe this approach has great potential for the study of molt in other seabird species. There is a clear need for such studies, given the increasing use of biomarkers sampled from flight feathers and other feather tracts, while adequate molt data remain lacking for many species (Bridge 2006, 2011). 


\section{SUPPLEMENT}

TABLE 5.S1 Details of Pomarine Jaegers Stercorarius pomarinus showing Staffelmauser. PFMG values for the first-cycle (the molt wave that has advanced further towards the outer primaries) are calculated by setting new of growing feathers of the second molt cycle (inner primaries) to 5 (fully grown), whereas those grown or growing in the first-cycle are set to 0 (old) to calculate PFMG values for the second-cycle.

\begin{tabular}{cccccc}
\hline Specimen & Date & Location & Molt score & $\begin{array}{c}\text { PFMG } \\
\mathbf{1}^{\text {st }}-\mathbf{c y c l e}\end{array}$ & $\begin{array}{c}\text { PFMG } \\
\mathbf{2}^{\text {nd }}-\mathbf{c y c l e}\end{array}$ \\
\hline CAS-10932 & $01 / 08 / 07$ & Monterey Bay, CA, USA & 2155555554 & 0.977 & 0.011 \\
CAS-10979 & $25 / 09 / 07$ & Monterey Bay, CA, USA & 3155555554 & 0.977 & 0.03 \\
CAS-11096 & $22 / 08 / 07$ & Monterey Bay, CA, USA & 2155555542 & 0.867 & 0.011 \\
CAS-10965 & $22 / 08 / 07$ & Monterey Bay, CA, USA & 1555555554 & 0.997 & 0.005 \\
Suppl. Fig. 2 & $31 / 03 / 07$ & New South Wales, Australia & 5515555420 & 0.701 & 0.092 \\
\hline
\end{tabular}




\section{ACKNOWLEDGEMENTS}

Thanks to the many photographers who were willing to share their photos. Special thanks to Marijke de Boer, Jeff Davies, Bob Flood, Martin Gottschling, Steve Howell, Allan Richardson, Peter Ryan, Raja Stephenson and Andy Williams who provided large numbers of photos and/or helped with additional requests. . Many photographs were found on the Internet, which would not have been possible without the numerous birders sharing their data online and the developers of these portals: www.waarneming.nl, www.observado.org, www.ebird.org, www.birdpix.nl, www.flickr.com and www.birdguides.com and https://macaulaylibrary.org. Pyle thanks curators of the California Academy of Sciences (Maureen Flannery), Museum of Vertebrate Zoology (Carla Cicero) and Western Foundation of Vertebrate Zoology (Adam Searcy and Linnea Hall) for assistance with examining specimens under their care. Thanks to Dick Newell, Steve Howell and Dani López-Velasco for exchanging datasets of Great Skua primary molt scores. Bob Furness kindly answered questions on Great Skuas. Kees Schreven, Sjurdur Hammer and Jannik Hansen increased the sample size for primary weights. Thanks to Paula Machin, Guido Keijl, Ingrid Tulp, Ron Ydenberg and especially Åke Lindström and two anonymous reviewers for helpful comments which have substantially improved this manuscript. This work was funded by the Netherlands Organisation for Scientific Research (project number 866.13.005).

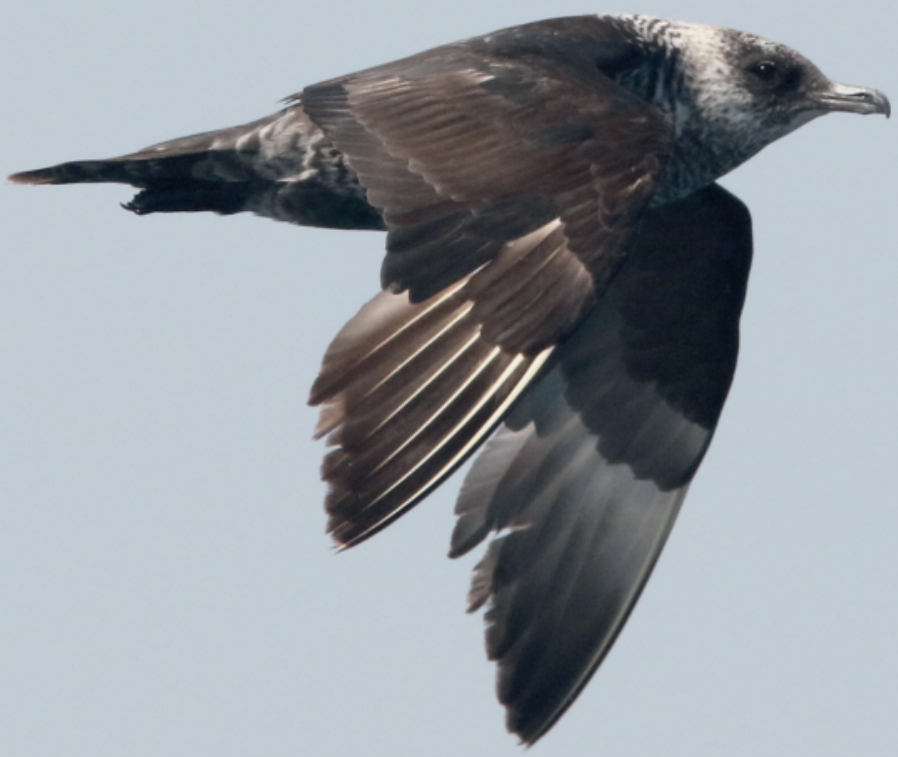

Adult Pomarine Skua in early primary moult, off Mauritania, 9 November 2016. 


\section{CHAPTER VI}

"On a bright day the Long-tailed Jaeger is a graceful sight, buoyed along on light wings with its ten-inch 'Marlinspike' fluttering aft like a pennon in the breeze, and the yellowtinged collar and white belly gleaming in the sunlight. Often in clear weather it sails at a great height, and occasionally soars in wide circles like a buzzard; at other times it will chase and scrap with its companions or any bird at hand, swooping and swerving and turning on its back as if it had no joints at all."

Wynne-Edwards (1935)

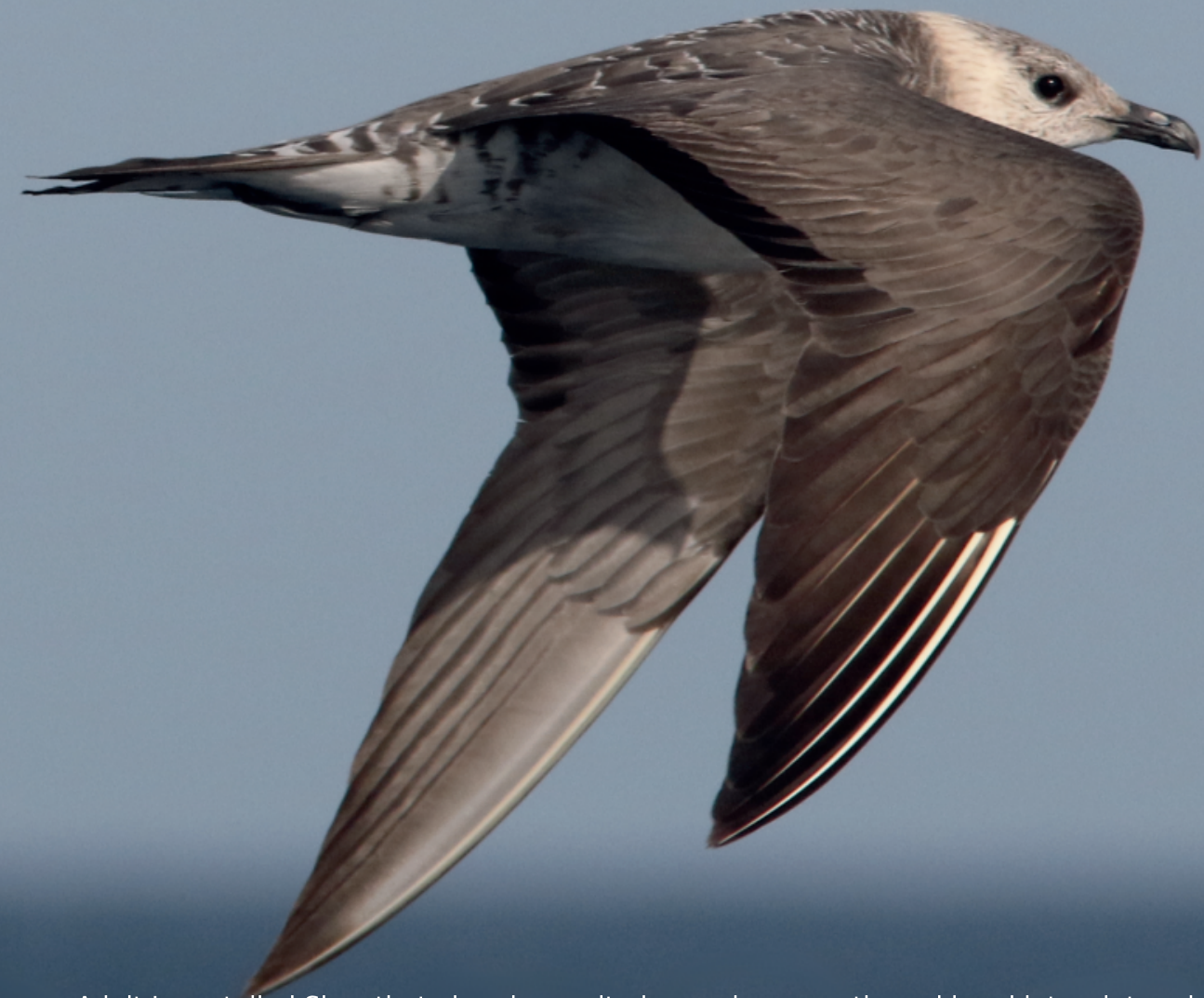

Adult Long-tailed Skua that already moulted scapulars, mantle and head into winter plumage and recently started primary moult, off Mauritania, 9 November 2016. 


\section{Flexibility in otherwise consistent non-breeding movements of a long-distance migratory seabird, the Long-tailed Skua}

Rob van Bemmelen, Børge Moe, Sveinn Are Hanssen, Niels Martin Schmidt, Jannik Hansen, Johannes Lang, Benoît Sittler, Loïc Bollache, Ingrid Tulp, Raymond Klaassen \& Olivier Gilg

Marine Ecology Progress Series 578: 197-211 


\section{ABSTRACT}

Quantifying within- and between-individual variation in animal migration strategies is a first step to our understanding of the ability of migrants to adjust to changes in the environment. We studied consistency (or, conversely, flexibility) in movement patterns at large $(>1000 \mathrm{~km})$ to meso scale (100$1000 \mathrm{~km}$ ) during the non-breeding season of the Long-tailed Skua Stercorarius longicaudus, a long-distance migratory Arctic seabird, using light-based geolocation. We obtained 97 annual tracks of 38 individuals and quantied similarity between routes. Overall, tracks of the same individual were generally within about $200-300 \mathrm{~km}$ of their previous years' route, and more similar than tracks of different individuals. Some flexibility was observed during migration, but individuals were faithful to their staging areas in the North Atlantic and in Benguela Current off Namibia and South Africa. Over the course of the winter, an increasing number of individuals started to deviate - up to $5200 \mathrm{~km} \mathrm{-} \mathrm{from}$ previous' years route. Intriguingly, individuals could be highly consistent between two consecutive years and flexible between other years. Site-shifts in late winter seem to reflect responses to local conditions, but what promotes this larger flexibility remains unclear and requires further study. Our results show that individual Long-tailed Skuas are generally consistent in their itineraries, but can show considerable flexibility in some years. The flexibility in itineraries suggests that Long-tailed Skuas are able to adjust to environmental change, but the mechanisms leading to the observed withinand between-individual variation in movement patterns are still poorly understood.

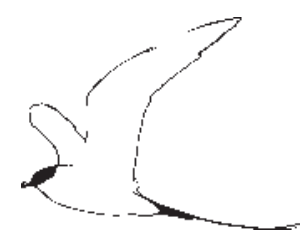




\section{INTRODUCTION}

The ability to track the movements of individual birds throughout multiple annual cycles has fuelled the interest in individual variation in migration and wintering patterns (Phillips et al. 2005, Guilford et al. 2011, Dias et al. 2011, Vardanis et al. 2011). Quantifying variation in movement patterns within- and between-individuals is a critical first step to ultimately understand the ability of populations to adjust their movement patterns to changes in the environment, as selection acts on phenotypic variation (Alerstam 2006, van Noordwijk et al. 2006).

Intriguingly, species vary in their degree of individual consistency (or, conversely, their flexibility) in movement patterns, i.e., the degree to which individuals use the same migration routes or staging areas between years (Guilford et al. 2011, Dias et al. 2011, McFarlane Tranquilla et al. 2014, Vardanis et al. 2016). We are only starting to understand what drives consistency in individual use of staging areas, but it is generally assumed that the spatio-temporal predictability of resources is important (Newton 2010, Trierweiler et al. 2013). Seabirds are an interesting species group in this respect as oceanic areas show large spatio-temporal differences in both availability and predictability of resources (Longhurst 2006, Weimerskirch 2007). While seabirds likely target areas with high productivity for foraging (which can vary in predictability; Weimerskirch 2007), migration routes connecting staging areas are often strongly linked to wind patterns that allow efficient travelling (Felicísimo et al. 2008), and often traverse large areas with low availability and/or predictability of resources. Thus, movement patterns of seabirds during the non-breeding season might consist of a combination of consistent itineraries in periods or areas with high resource availability, and more flexible, nomadic movement patterns in periods or areas with low resource availability, such as areas crossed during migration. A synthesis on how consistency in staging site and migration routes use might vary throughout the non-breeding season is still lacking.

Using light-based geolocation to track individuals, we studied consistency in movement patterns of the Long-tailed Skua Stercorarius longicaudus during the non-breeding season at large $(>1000 \mathrm{~km})$ to meso $(100-1000 \mathrm{~km})$ scales. This longdistance migratory seabird breeds in the sub- to high Arctic. Details of migration routes, stopovers and movements during winter in the southern Atlantic have only recently been revealed (Sittler et al. 2011, Gilg et al. 2013). Gilg et al. (2013) showed that Long-tailed Skuas have a strategy of itinerancy, i.e. visiting multiple places throughout the winter (Moreau 1972). This behaviour is not uncommon among seabirds (Croxall et al. 2005, Hedd et al. 2012, Fijn et al. 2013, van der Winden et al. 2014, Orben et al. 2015) but notably different than a strategy of residency where only a single wintering site is used (Yamamoto et al. 2014, McFarlane Tranquilla et al. 2014). Itinerancy is an interesting strategy in the context of consistency versus flexibility in site use, as it, at least intuitively, leaves more 
possibility for flexibility, even during the winter period.

We quantified variation in individual movement patterns throughout the entire nonbreeding season, thus including migration and winter periods. In particular, we investigated if, where and when movement patterns differ between and within individuals. As Long-tailed Skuas seem to exploit areas with predictable high productivity, e.g. the Benguela Current and the central North Atlantic (Gilg et al. 2013), we expect individuals to revisit the same staging areas, and thus to exhibit high levels of consistency in their itineraries.

Most earlier studies on the consistency of bird migration was based on individuals tracked over two consecutive years (Guilford et al. 2011, Dias et al. 2011, McFarlane Tranquilla et al. 2014). Although this allows partitioning of within- and between-individual variation in behaviour, three or more years of tracking data are needed to study whether individuals vary in their behavioural flexibility (i.e. not the level, but the 'width' of their behavioural response; Dingemanse and Wolf 2013). This idea has, to our best knowledge, not been explored to date, but is needed to understand if and how migrants may cope with environmental change. We tracked individual Long-tailed Skuas for three or more years and investigated whether individual skuas display the same level of consistency or flexibility across years, or can be consistent between some years but flexible between other years.

Our study provides a unique overview of consistency versus flexibility in movement patterns of Long-tailed Skuas at different scales, i.e. from between to within individuals, as measured over multiple years. In addition, we quantified to what extent consistency and flexibility co-occur within the same individual. The idea that an individual may be consistent between some years but flexible between other years has to date, to our best knowledge, not been explored, but is needed to understand if and how migrants may cope with environmental change.

\section{MATERIALS AND METHODS}

\section{Study species, study areas, catching techniques and geolocator deployment}

Two subspecies are recognized in the Long-tailed Skua: the nominate subspecies Stercorarius longicaudus longicaudus breeds from Scandinavia eastwards and is replaced by the white-bellied subspecies $S$. I. pallescens from eastern Siberia to Svalbard (Manning 1964). Gilg et al. (2013) showed that Long-tailed Skuas breeding in Greenland and Svalbard (S.I.pallescens) depart from the breeding areas in late August, migrate via a stopover in the central North Atlantic towards West Africa and arrive at the main wintering grounds off southern Africa between late September and late November. Spring migration commences in March or April, and birds arrive on the breeding grounds in late May/early June. 
Adult Long-tailed Skuas of the nominate subspecies S. I. longicaudus were captured during 2011-2015 in the Vindelfjällen Nature Reserve near Ammarnäs, Sweden $\left(65^{\circ} 59^{\prime} \mathrm{N}-16^{\circ} 01^{\prime} \mathrm{E}\right)$. Adults from the Nearctic subspecies S. I. pallescens were captured during 2010-2015 at Kongsfjorden, Svalbard (79 $\left.57^{\prime} \mathrm{N}-12^{\circ} 6^{\prime} \mathrm{E}\right)$ and three sites in Greenland: Zackenberg $\left(74^{\circ} 28^{\prime} \mathrm{N}-20^{\circ} 34^{\prime} \mathrm{W}\right)$, Karupelv $\left(72^{\circ} 50^{\prime} \mathrm{N}-24^{\circ} 00^{\prime} \mathrm{W}\right)$ and Hochstetter Forland $\left(75^{\circ} 09^{\prime} \mathrm{N}-19^{\circ} 40^{\prime} \mathrm{W}\right)$. Birds were captured on the nest using bow nets or remote-triggered nooses, and away from the nest using hand-held net guns or noose carpets (in a few cases birds were lured by a decoy and playback of the 'long call' - a call used in courtship and territorial disputes). Geolocators of three types (Mk-18L and Mk-18H, produced by British Antarctic Survey, Cambridge, UK, and C65, produced by Migrate Technology Ltd, Cambridge, UK) were legmounted using a darvic ring. The total added weight (geolocator, darvic ring, cable tie, self-amalgamating tape and super glue) amounted ca $2.2 \mathrm{~g}, 2.6 \mathrm{~g}$, and $1.8 \mathrm{~g}$ for the Mk-18L, Mk-18H and C65 types, respectively, which is $0.5-1.2 \%$ of the mean body mass of adult Long-tailed Skuas $(n=129)$. In addition, biometry and a blood sample for DNA sexing were taken. Individuals were sexed using molecular techniques (Fridolfsson and Ellegren 1999). Single tracks from 8 individuals from Greenland and Svalbard have been published earlier (Gilg et al. 2013). The period between two subsequent breeding seasons is referred to as a year; the obtained data in this period is referred to as a track. References to seasons are from a northern hemisphere perspective.

\section{Geolocator data analyses}

After recapture of tagged birds, geolocators were removed and data were downloaded from the geolocators and decompressed using BASTrak (British

TABLE 6.1 | Number of individual Long-tailed Skuas (subspecies S I longicaudus and S I pallescens) tracked over different number of years.

\begin{tabular}{lccc}
\hline No. of years & S. I. longicaudus & S. I. pallescens & Total \\
\hline 1 & 9 & 5 & 14 \\
2 & 1 & 3 & 4 \\
3 & 2 & 4 & 6 \\
4 & 11 & 2 & 13 \\
5 & 0 & 1 & 1 \\
\hline Total (individuals) & 23 & 15 & 38 \\
Total (tracks) & 61 & 36 & 97 \\
\hline
\end{tabular}



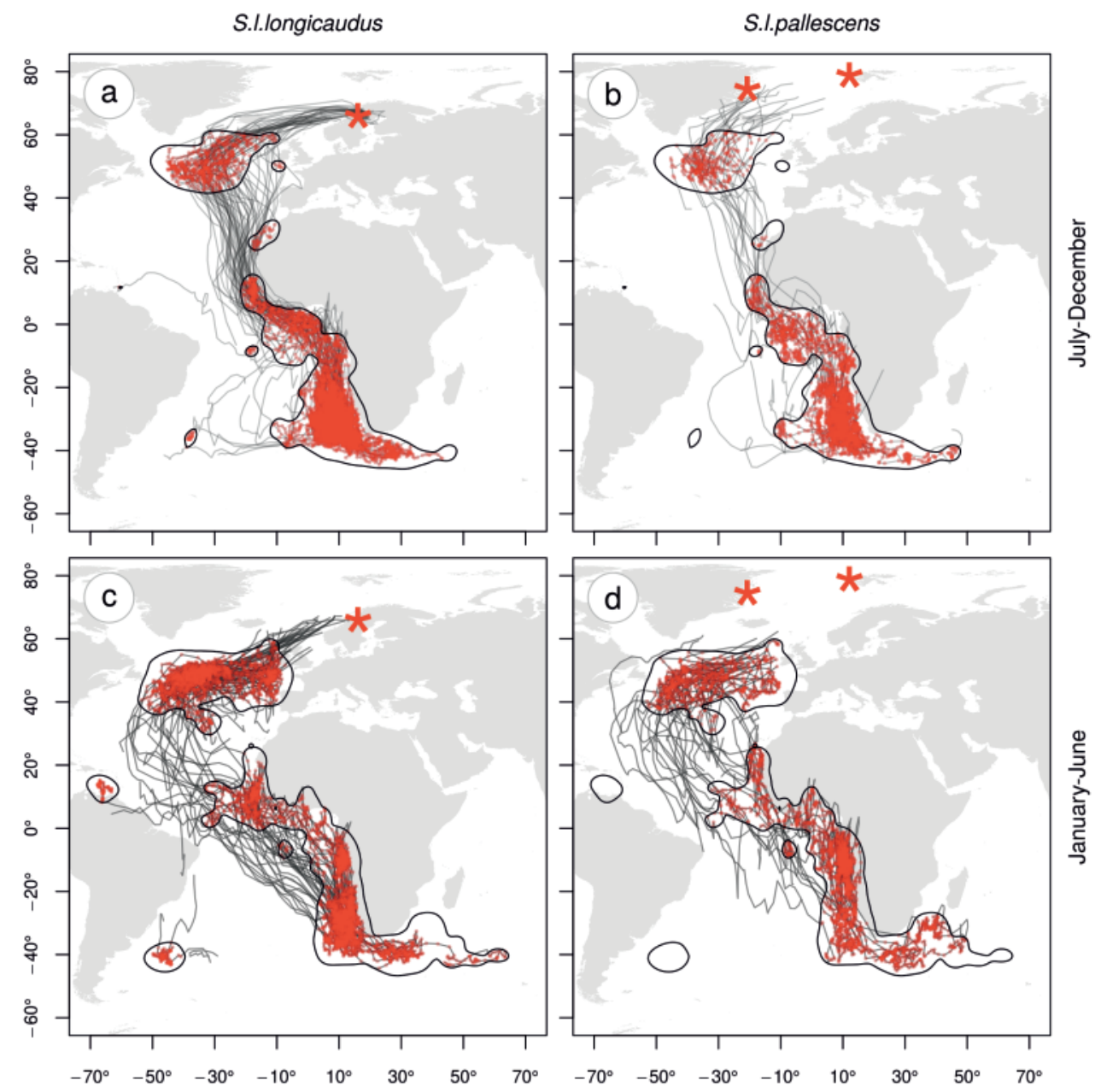

FIGURE 6.1 | Movements of the two subspecies of Long-tailed Skuas, (a, c) S I longicaudus and (b, d) $S$ I pallescens, in $(\mathbf{a}, \mathbf{b})$ in July-December and (c, d) January-June. Red dots indicate staging periods (three or more consecutive days with $<200 \mathrm{~km}$ between daily positions). Black stars indicate the sampled breeding sites for each subspecies. The black outlined polygons indicate $95 \%$ utilization distribution kernels for staging positions of all birds combined. Inaccuracy of geolocator position estimates is generally $\pm 185 \mathrm{~km}$, but is typically larger close to the equinoxes (Phillips et al. 2004).

Antarctic Survey) or IntigeolF software (Migrate Technology Ltd.). The subsequent analysis was entirely carried out using R 3.1.2 (R Core Team 2017) and a set of packages, in particular the $R$ package 'GeoLight' (Lisovski and Hahn 2012). Geolocators recorded ambient light level in arbitrary units (Mk-18L, Mk-18H) or lux (C65) in 1-minute intervals and saved the maximum of these values every 5 minutes. Sun events were calculated unsupervised from light measurements, using 

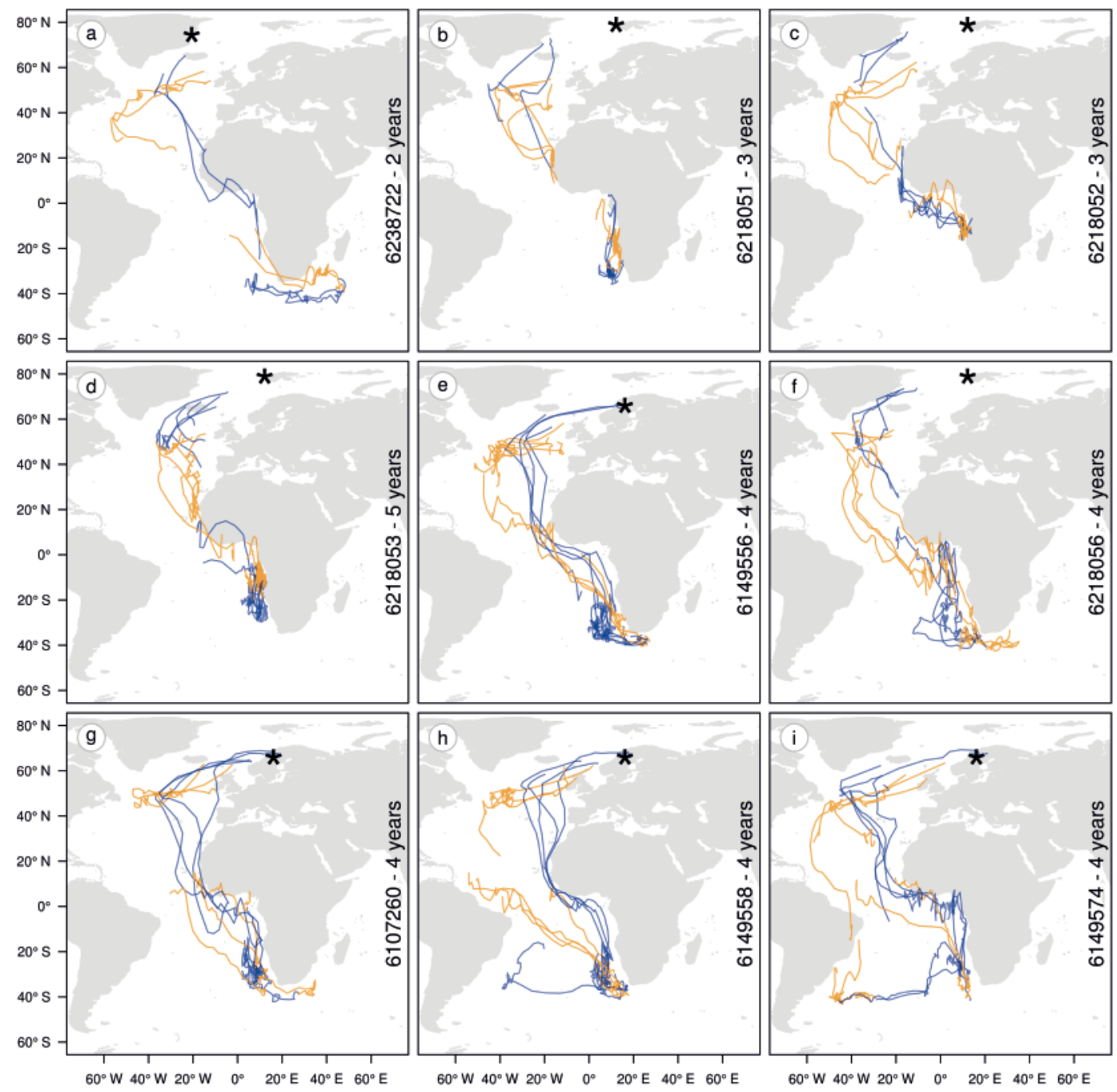

FIGURE 6.2 | Nine examples of geolocator tracks of individual Long-tailed Skuas tracked over multiple years, with July-December shown in blue and January-June in orange. Numbers on the right are ring numbers, $c f$ figure 6.6, and number of years tracked. Black stars indicate the breeding site of each individual. Examples include individuals with high route consistency (a-e) and individuals with more flexibility in their recorded routes $(\mathbf{f}-\mathbf{i})$. The individual shown in $\mathrm{h}$ took a detour along the Falkland Current in one year, while the individual in $\mathbf{i}$ went to the Benguela Current in all four years, but switched mid-winter to the Falkland Current in its second and fourth year of tracking. Inaccuracy of geolocator position estimates is generally $\pm 185 \mathrm{~km}$, but is typically larger close to the equinoxes (Phillips et al. 2004). 
the function 'twilightCalc' and a light threshold value of $10(\mathrm{Mk}-18 \mathrm{H})$ or 2 (C65). Spending the non-breeding season entirely at open sea, light measurement data from the Long-tailed Skuas was generally 'clean', that is, most sun events could automatically be assigned with a relatively low amount of misclassification (due to e.g., shading events). This was checked by visual inspection of plots of date against time of sunrise or sunset, from which unlikely twilight events were identified and removed. For a sequence of potential sun angles, locations were calculated for each noon and midnight. We selected the sun angle resulting in a good fit of location estimates to the shape of the continents and a close match in latitude estimates before and after the equinoxes. Final sun angles for individual loggers ranged from $-1^{\circ}$ to $-3^{\circ}$ for the $\mathrm{Mk}-18 \mathrm{H}$ model and $-4.5^{\circ}$ to $-6.0^{\circ}$ for the $\mathrm{C} 65$ model. Position estimates from light-based geolocation typically have a mean error of $\pm 185 \mathrm{~km}$ for flying seabirds (Phillips et al. 2004), and these errors are especially large in close proximity to the equinoxes. Therefore, positions within 14 days from either side of the equinoxes (20 March and 22 September) were removed. Remaining positions were smoothed by calculating the three-day running mean, using equations in Gilg et al. (2013). All further analyses were based on smoothed positions, with no data around the equinoxes.

\section{Staging areas}

We followed Gilg et al. (2013) in defining staging periods when distance between smoothed positions were smaller than $200 \mathrm{~km}$ for at least three consecutive days. Subsequently, staging areas were identified by creating a $95 \%$ utilization distribution kernel based on staging positions of all individuals, using the 'adehabitatHR' package for R (Calenge 2011). For this, a Lambert azimuthal equalarea projection was used with a grid cell size of $50 \mathrm{~km}$ and a smoothing factor of $200 \mathrm{~km}$. Kernels were estimated for four space/time segments of the data: 1) before 1 January, between $25^{\circ}-60^{\circ} \mathrm{N}, 2$ ) before 1 January, south of $25^{\circ} \mathrm{N}, 3$ ) after 31 December, south of $25^{\circ} \mathrm{N}$ and 4) after 31 December, between $25^{\circ}-60^{\circ} \mathrm{N}$. The split at 1 January is well after arrival to the main wintering areas but before long-distance northward movements (Gilg et al. 2013). The area between $25^{\circ}-60^{\circ} \mathrm{N}$ encompasses the large stopover area in the North Atlantic used by many seabirds, including Long-tailed Skua (Sittler et al. 2011, Gilg et al. 2013). Few positions were obtained north of $60^{\circ} \mathrm{NB}$, in particular for birds breeding at Svalbard or Greenland as they travelled here at times with more or less constant daylight. The area south of $25^{\circ} \mathrm{N}$ contains all wintering areas.

\section{Consistency in movement patterns}

Within- and between-individual consistency was mapped over entire recorded tracks, applying the method used by Guilford et al. (2011) and Dias et al. (2013) to calculate distances between tracks, based on nearest neighbour analysis. For each position estimate in a focal track, we calculated the great-circle distance to the nearest position estimate in another track. The nearest neighbour was selected from the comparison track within a time window. Using a short time window will 
retain effects of different timing (hence can be used to test for route and timing consistency, which is not the topic of the current contribution), whereas a longer time window removes the effect of timing (thus tests for route consistency only). We quantified median within-individual intertrack distances for a range of time windows ( 7 to 121 days, with steps of 6 days) to investigate when the gradual removal of a timing effect on the intertrack distance fades. Next, one time window was selected visually (figure 6.52) and used for the analysis and figures of route consistency. If two tracks follow the same route, intertrack distances from the first track will be biased in the part where the comparison track has missing values due to the equinox. Therefore, if the nearest neighbour of the comparison track is a first or last position on either side of the equinox, this measurement is excluded. In this way, only more or less parallel parts of the tracks are compared, reducing bias due to missing positions during equinoxes. For reasons of interpretability, we only included comparisons of each track with tracks from the previous year.

We studied the resulting intertrack distances in two ways. First, we calculated the overall median intertrack distance per comparison to get an overall measure of track similarity. To allow for greater spatio-temporal resolution and inference of fidelity to staging areas, we also calculated the median intertrack distance per comparison for six 'segments'. Then, median intertrack distances were calculated within the four staging kernels mentioned above. In addition, median intertrack distance was calculated for the southbound (before 1 January) and northbound migration (at or after 1 January) based on all locations that fell outside the staging kernels and south of $50^{\circ} \mathrm{N}$. The resulting values were continuous, non-negative, and right-skewed. Although such data can be modelled using e.g. gamma or inversegaussian error distributions, we log-transformed the data (a variance-stabilizing transformation) to allow the use of a gaussian error distribution, for which routines to calculate Intra-class Correlation Coefficients (ICC or $r$, repeatability) are readily available (Nakagawa and Schielzeth 2010). Bayesian Generalized Linear Mixed Models (GLMMs) were fitted using the package MCMCgImm for R (Hadfield 2010), with 130000 iterations, a burn-in of 30000 iterations and a thinning rate of 100 . As an indication of significance, we provide $\mathrm{P}_{\text {MCMC }}$ values, which are twice the probability that the parameter value is above or below zero. Focal individual in each comparison was included as a random effect to account for pseudo-replication and to assess within- and between-individual variance components. If populations differ in migration routes and destinations, they may inflate between-individual intertrack distances. We therefore first explored whether between-individual and withinindividual intertrack distances differed between subspecies, then compared withinindividual intertrack distances with between-individual intertrack distances of each subspecies.

Second, in order to more precisely illustrate spatio-temporal patterns in within- and between-individual route consistency, we bootstrapped median of intertrack distances 10000 times for each calendar day and, separately, in each $5^{\circ}$ Latitude $x$ 
$5^{\circ}$ Longitude grid cell, with only one track per individual selected in each iteration. We performed this bootstrapping procedure for within-individual and betweenindividual intertrack distances. To illustrate how the spatial pattern in intertrack distances relates to staging areas, we overlaid it with the staging area kernels (see above). With median intertrack distances visualized on a continuous scale, we aided the eye by using a red outline for grid cells with a median intertrack distance of $<500 \mathrm{~km}$.

\section{Individual variation in route flexibility}

To test whether individuals differ between consecutive years in their route flexibility, e.g., whether some individuals are repeatedly flexible and others are repeatedly consistent in their routes or if individuals may be consistent between some years and flexible between others, we calculated Intra-class Correlation Coefficients for within-individual median intertrack distances between tracks from subsequent years (i.e. with only one year difference) using the 'rpt.mcmcLMM' function from the 'rptR' package (Schielzeth and Nakagawa 2013). Note that the term 'repeatability' is used here only to refer to ICC values.

\section{RESULTS}

\section{Sample size}

In Ammarnäs, Sweden, out of 46 geolocators deployed in 2011-2014, 27 (59\%) were retrieved up to 2015. Numbers of retrievals and deployments are 20 out of 30 $(67 \%)$ for Svalbard, 5 out of $14(36 \%)$ for Zackenberg, 2 out of 6 (33\%) for Karupelv and 1 out of $3(33 \%)$ for Hochstetter Forland. Note that some individuals were refitted and recaptured multiple times and that recapturing birds in Sweden and Greenland is hampered by non-breeding years. In total, 97 tracks were obtained from 38 individual Long-tailed Skuas Stercorarius longicaudus, of which 24 individuals were tracked over a period of 2 to 5 years. See table 6.1 for further specification of samples relative to subspecies. Due to logger failure or empty batteries, 14 tracks stopped prematurely between 28 December and 1 May; these were included in the analysis.

\section{General movement patterns}

All tracks are illustrated in figure 6.1, and in an animation in figure 6.S1, while some examples of individual tracks are shown in figure 6.2. No systematic differences in non-breeding movements were detected between the two subspecies. After departure from the breeding areas, Long-tailed Skuas proceeded south-west to stage in the central North Atlantic off Newfoundland. Subsequently, they went south in a relatively narrow corridor to the Canary Current off West Africa. From here, most birds migrated directly to the staging area in the Benguela Current off Namibia and South Africa, whereas 6 individuals (9 tracks) took a westerly loop to approach the Benguela Current from the west. A few proceeded 
further south-east into the Agulhas Current and the Southern Subtropical Convergence. A single individual ( $S$ I longicaudus) went straight west from the Benguela to the Falkland Current in its second and fourth year of tracking (figure 6.2i). Other individuals lingered along the west side of Africa, in particular off Angola. The most northerly winterer was a S I longicaudus wintering in the Canary Current. Northward movements commenced in January-March, and occurred over a broad front, covering a large part of the Atlantic, and included stopovers of varying length off Angola, in the Gulf of Guinea and the Canary Current. After crossing the equator, virtually all birds staged in a large area in the central North Atlantic in April-May (mostly within the North Atlantic Drift Province), which they usually slowly crossed from west to east. Some birds staged for a few days west of Ireland before returning to the breeding grounds.

\section{Route consistency}

Intertrack distances showed a strong seasonal pattern when using a narrow time window for nearest neighbour selection, with large distances in autumn and late winter, and much smaller distances in early winter and spring. Broadening the time window greatly reduced intertrack distances, in particular in autumn (figure 6.52). For example, median within-individual intertrack distance at 15 August was ca 3000 $\mathrm{km}$ for a time window of 7 days, ca $2000 \mathrm{~km}$ for a time window of 30 days and ca $800 \mathrm{~km}$ for a time window of 61 days (figure 6.52). This was mainly caused by the fact that Swedish birds during non-breeding years had earlier autumn migration schedules, but not different migration routes. As the effect of differential timing was largely removed at a time window of 61 days, intertrack distances obtained using this time window were therefore used in subsequent analyses.

Daily median intertrack distances were smaller within individuals than between individuals during almost the entire year (figure 6.3). Between-individual intertrack distances differed between the subspecies and therefore 'subspecies' was included as factor in the models. Note that this does not necessarily indicate different routes and site use between the subspecies - it only reflects a difference in the spread in routes and site use (cf figure 6.1). Overall median intertrack distances were significantly smaller within (model-based, back-transformed posterior mean $(\mu)$ and $95 \%$ credible intervals: mean $=274 \mathrm{~km}, 95 \% \mathrm{Cl}=217-351$ $\mathrm{km}, \mathrm{p}_{\mathrm{MCMC}}<0.001$ ) than between individuals (figure 6.4; longicaudus: mean $=535$ $\mathrm{km}, 95 \% \mathrm{Cl}=347-835 \mathrm{~km}, \mathrm{p}_{\mathrm{MCMC}}<0.001$, pallescens: mean $=928 \mathrm{~km}, 95 \% \mathrm{Cl}=$ 569-1484 km, $\mathrm{p}_{\text {MсмС }}<0.001$ ). This was true also in a model testing the median intertrack distance per segment (figure 6.4; all $\mathrm{p}_{M C M C}<0.001$ ), except for the North Atlantic staging area during southbound migration (for pallescens only; $\mathrm{p}_{\text {MCMC }}$ $=0.370$ ) and northbound migration (for both longicaudus: $\mathrm{p}_{\mathrm{MCMC}}=0.536$, and pallescens: $\mathrm{p}_{\mathrm{MCMC}}=0.020$ ).

Within-individual intertrack distances did not differ between the subspecies and therefore 'subspecies' was not included in the models $\left(p_{\text {MCMC }}=0.448\right)$. Within- 

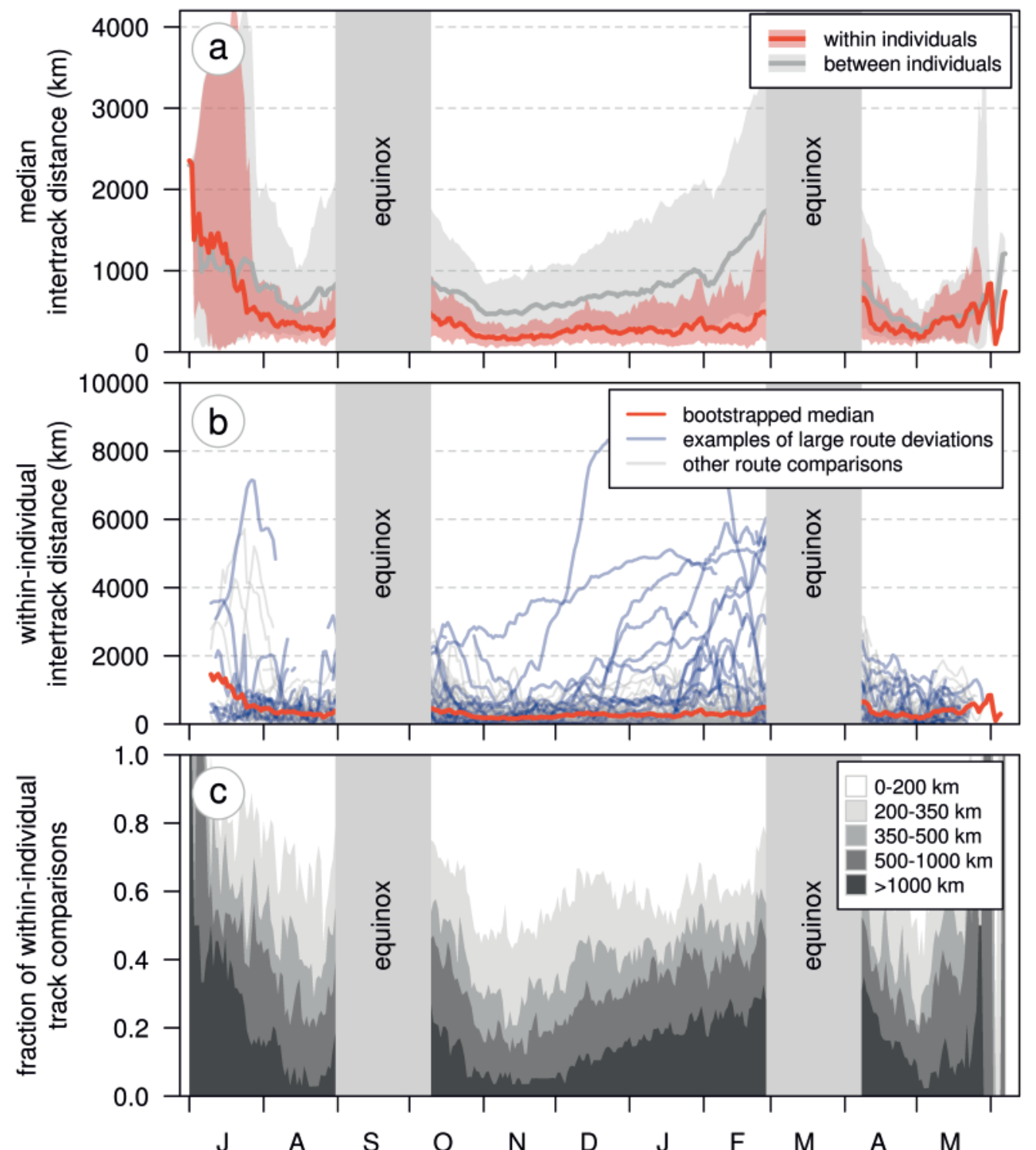

FIGURE 6.3 | Daily route consistency per month. (a) Distribution of bootstrapped median intertrack distances for comparisons within (red) and between (blue) individuals. Shaded areas represent $90 \% \mathrm{Cl}$ of bootstrapped median intertrack distances (red and blue); including their overlap (darker red/blue). (b) Within-individual intertrack distances (orange), highlighting examples of large deviations from previous years' track (blue). The red line shows the bootstrapped median within-individual intertrack distance also shown in a. (c) Graction of tracks with a certain range of intertrack distances. White represents high route consistency $(<200 \mathrm{~km})$; purple reflects large route deviations (>1000 km). 


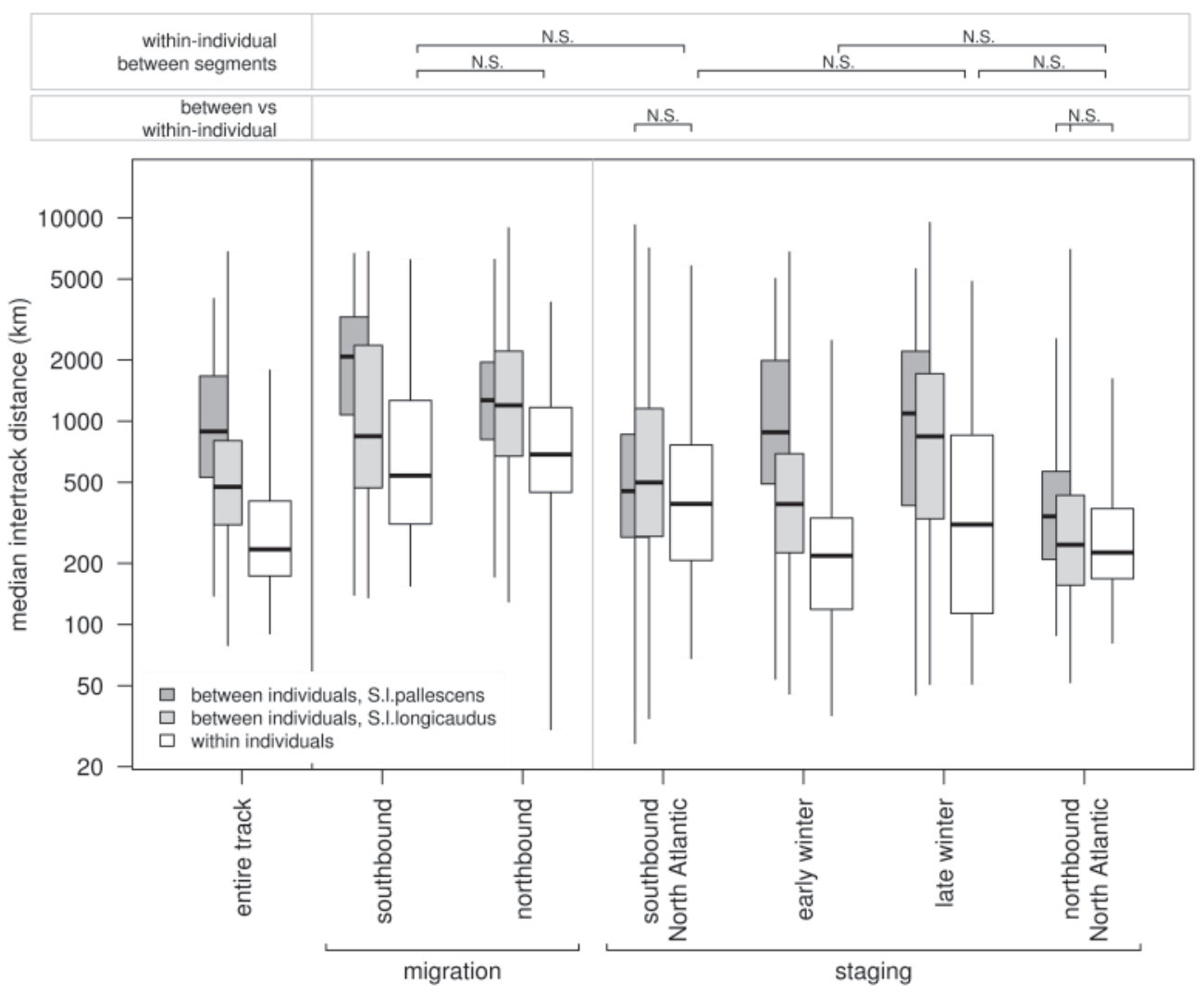

FIGURE 6.4 | Median intertrack distance within individuals Long-tailed Skuas, and between individuals of each subspecies (light/dark grey), calculated for the entire track comparison (left) and six segments (see main text). Note the log-scale of the $y$-axis. Bold horizontal lines represent medians, boxes encompass $50 \%$ of the values and whiskers extend to the most extreme values. Above the figure, only non-significant comparisons are indicated; all other comparisons are significant $\left(\mathrm{p}_{\text {MCMC }}<0.05\right)$.

individual intertrack distance was largest outside staging area kernels during northbound (figure 6.4; $\mu=702 \mathrm{~km}, 95 \% \mathrm{Cl}=500-1026 \mathrm{~km}$ ) and southbound migration (mean $=689 \mathrm{~km}, 95 \% \mathrm{Cl}=524-871 \mathrm{~km}$ ), which were not significantly different $\left(\mathrm{p}_{\text {мсмс }}=0.944\right)$. Within-individual intertrack distances outside staging area kernels were larger than within-individual distances within the staging area kernels (figure 6.4; $\mathrm{p}_{\mathrm{MCMC}}<0.05$ ), except for the comparison between southbound migration and the North Atlantic staging area in autumn $\left(p_{\text {MCMC }}=0.084\right)$. Considering staging kernels, intertrack distances were larger in the North Atlantic staging area during autumn (mean $=414 \mathrm{~km}, 95 \% \mathrm{Cl}=299-610 \mathrm{~km}$ ) than in the staging areas south of $25^{\circ} \mathrm{N}$ during early winter (mean $=278 \mathrm{~km}, \mathrm{Cl}=160-323 \mathrm{~km}$, $\left.\mathrm{p}_{\mathrm{MCMC}}<0.001\right)$ and in the North Atlantic staging area during northbound migration ( mean $\left.=255 \mathrm{~km}, \mathrm{Cl}=175-362 \mathrm{~km}, \mathrm{p}_{\mathrm{MCMC}}=0.018\right)$, but not different in the staging 
areas south of $25^{\circ} \mathrm{N}$ in late winter $\left(\right.$ mean $=347 \mathrm{~km}, 95 \% \mathrm{Cl}=248-479 \mathrm{~km}, \mathrm{p}_{\mathrm{MCMC}}=$ $0.324)$. Intertrack distances in staging areas were smaller during early winter than during late winter $\left(\mathrm{p}_{\mathrm{MCMC}}=0.016\right)$. In figure 6.3a, intertrack distances plotted per day over the entire year (irrespective of location) show that within-individual intertrack distances are smallest and individuals thus especially consistent in space and time in August (medians range from 200-340 km) and late April/early May (when in the North Atlantic staging area; medians range from 170-270 km), and in November (when in the winter quarters; medians range from $160-210 \mathrm{~km}$ ). In the months after November, an increasing part of the individuals diverted from their previous years' route; for example in February, about 40\% deviated more than 500 $\mathrm{km}$ and $20 \%$ more than $1000 \mathrm{~km}$. Within-individual intertrack distance did not differ between years (included as a factor).

Spatial patterns in between-individual intertrack distance reflect largely where individuals aggregate at staging areas, for example in the central North Atlantic and in the Benguela Current, and where migration routes converge, such as for example in the East Atlantic during autumn migration (figure 6.5). In July-December, median intertrack distance was smaller within- than between-individuals in $77 \%$ of the grid cells, with some exceptions scattered mainly in the East Atlantic and west of the Benguela Current. Within-individual intertrack distances in this period were generally smaller than $500 \mathrm{~km}$ in the North Atlantic staging area, in the Benguela and Agulhas Currents, but also in between. Outside these areas, individuals showed lower route consistency. In January-June, $85 \%$ of the grid cells had lower withinthan between-individual median intertrack distance. Uninterrupted areas of withinindividual intertrack distances below $500 \mathrm{~km}$ were apparent again in the same main staging areas (albeit somewhat more restricted). With a few exceptions, intertrack distances were larger outside these areas, in particular between $0^{\circ}-40^{\circ} \mathrm{N}$.

Of those individuals with at least three years of data (thus having two or more sets of intertrack distances), many repeatedly showed intertrack distances around 300 km (figure 6.6). However, several individuals showed small intertrack distances (high consistency) between one or two pairs of years and large intertrack distances (flexibility) between other set(s) of years. Thereby, within-individual variance of overall median intertrack distances was inflated, causing low ICC values ( $r=0.286$, $95 \% \mathrm{Cl}=0.048-0.545)$. The same was found for the parts outside the staging kernels (southbound migration: $r=0.041,95 \% \mathrm{Cl}=0.010-0.209$; northbound migration: $r=0.248,95 \% \mathrm{Cl}=0.029-0.491$ ) and within the staging kernels (southbound, North Atlantic staging area: $r=0.073,95 \% \mathrm{Cl}=0.011-0.318$, early winter/south: $r=0.225,95 \% \mathrm{Cl}=0.025-0.508$; late winter/south: $r=0.178,95 \% \mathrm{Cl}$ $=0.011-0.430$; spring/north: $r=0.205,95 \% \mathrm{Cl}=0.025-0.427$ ). 


\section{DISCUSSION}

We studied consistency of movement patterns at large to meso scales outside the breeding season in a long-distance migratory seabird, the Long-tailed Skua Stercorarius longicaudus, and generally found large between-individual differences and relatively small within-individual variation. As expected, individuals were faithful to main staging areas in southbound and northbound migration (off Newfoundland in the central North Atlantic) and winter destination (the Benguela Current off Namibia and South Africa), where they generally followed their previous years' route within about 200-300 km, while being more flexible during southbound and northbound migration when crossing large areas with low productivity. Surprisingly, over the course of the winter, a minor but increasing part of the individuals started to deviate from their previous' years route. This shows an intriguing combination of general site fidelity and flexibility in subsequent winter movements.

High winter area fidelity has been shown in several seabird species from several families, using both GPS and light-based tracking devices (Phillips et al. 2005, Guilford et al. 2011, Muller et al. 2013, Fifield et al. 2014, Yamamoto et al. 2014, McFarlane Tranquilla et al. 2014). With generally high route consistency within staging areas throughout the winter months, Long-tailed Skuas fit to this pattern, although their movements are often not restricted to a single, well-defined area (i.e. strategy of itinerancy). The generally high route consistency indicates that despite a strategy of itinerancy, similar itineraries are followed from one year to the next, thus although individuals use different staging sites throughout the winter they use the same staging sites in different years. These staging sites are well-known for their high productivity: the Benguela current system, offshore Angola, the Gulf of Guinea, the Canary Current and the recently discovered hotspot for seabirds in the central North Atlantic (Longhurst 2006, Chavez and Messié 2009, Stenhouse et al. 2012, Grecian et al. 2016). This is in line with our expectation that area fidelity is favoured when individuals target areas with predictably high productivity.

However, from late December, an increasing number of individuals deviated from previous' year routes (figure 6.3, 6.6). Much of this variation was due to differences in timing (figure 6.51-S2), but even when controlling for this, about ca $20 \%$ of the tracks deviated more than $1000 \mathrm{~km}$ from the previous route in January (figure 6.3c). In extreme cases, the deviations included a transoceanic flight from the Benguela Current to the Falkland Current (ca $5200 \mathrm{~km}$ ). The ability to switch wintering areas, sometimes at huge spatial scales, has been reported for a small number of seabird species (e.g. up to $7000 \mathrm{~km}$ in Cory's Shearwater Calonectris borealis and $1300 \mathrm{~km}$ in Streaked Shearwater C. leucomelas) (Dias et al. 2011, Yamamoto et al. 2014). One of the Long-tailed Skuas repeated the transoceanic switch even twice (in its second and fourth year of tracking; figure 6.2i, 6.6) using similar routes and destination, indicating this leap was not just an accidental 
displacement by severe weather conditions, but likely based on previous experience. In both years, it made the shift after arrival to its usual winter range, the Benguela Current. The same pattern was observed in other individuals, in which deviations increasingly occurred from late December onwards, i.e. after arrival to the wintering areas. This suggests that individual Long-tailed Skuas check local conditions at a familiar wintering site before deciding where to go during the following months. In contrast, some Cory's Shearwaters directly travelled to a different wintering area than in the previous year, apparently without knowing the conditions at either wintering site (Dias et al. 2011).

Based on individuals with three to five years of tracking data, we conclude that individuals do not show the same degree of consistency between each set of subsequent years. Instead, individuals with dissimilar tracks between two years could have very similar tracks between other years (figure 6.6). This was already hinted at by Dias et al. (2011), who suggested that "each individual may have one (or maybe several) 'preferred' migratory strategies (in terms of route and wintering site), but maintains the capacity to choose alternatives." We can now confirm the intriguing idea of co-occurrence of site fidelity and site-switching within the same individual. In conjunction with the increase in route deviations after arrival at the wintering grounds, this likely indicates that deviations from earlier routes represent individuals' rapid responses to local conditions, for example weather or foraging conditions (including competition) when arriving in the main wintering area.

What determines whether individuals are faithful to their wintering site or shift over small or large distances? While possibly modulated or constrained by intrinsic factors (genetic background, sex, experience, fat reserves), high variation in individual movement patterns likely resultss from declining availability, increased patchiness and decreased predictability of resources (Mueller and Fagan 2008), or deteriorating weather conditions preventing efficient foraging. Dias et al. (2011) explored whether site switches of a small number of individuals could be explained by sex, age, or reproductive success, or by changes in sea surface temperature and chlorophyll a, but found no clear links. Also what exactly caused the movement deviations that we observed in the Long-tailed Skuas in this study remains unclear. At-sea foraging behaviour of Long-tailed Skuas is poorly known, but most authors agree that they probably mostly feed by themselves (e.g., by surface pecking), only rarely kleptoparasitizing other seabirds, as is common in other skua species (Lambert 1980, Cramp and Simmons 1983, Veit 1985, Wiley and Lee 1998). As skuas are unable to dive deep, Long-tailed Skuas likely depend on mechanisms bringing zooplankton or fish at or very close to the surface. Many individuals aggregated in early winter in the southern Benguela current. Here, edges of Agulhas rings (bodies of warm water 'leaking' from the Agulhas retroflection) provide feeding opportunities for seabirds (Camphuysen and van der Meer 2001, Camphuysen 2007), possibly including Long-tailed Skuas (cf Ryan 1989). Whereas the occurrence of Agulhas rings within this large area seems predictable, they 

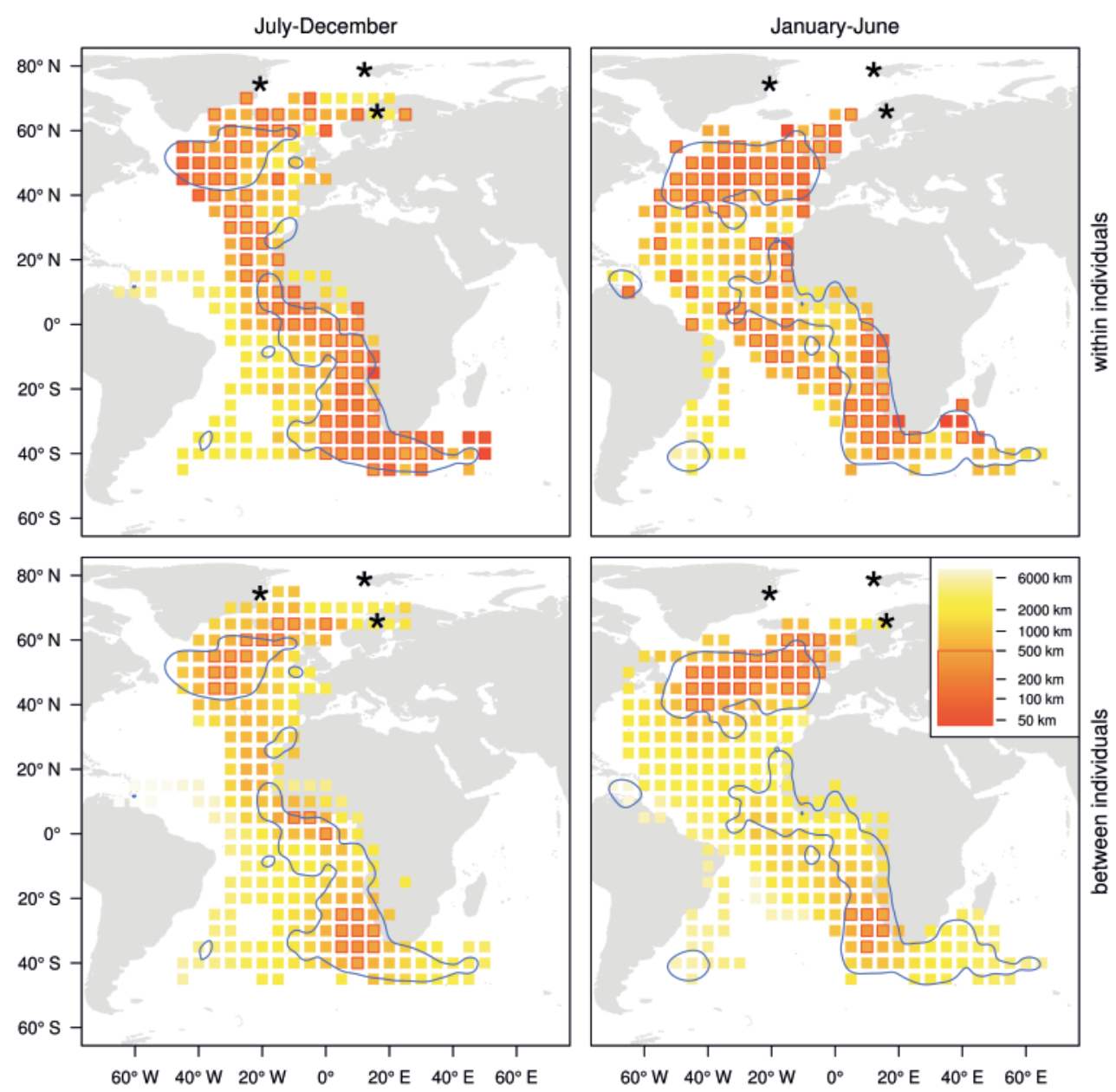

FIGURE 6.5 | Median intertrack distance within individuals (upper panels) and between individuals (lower panels). Emphasis is put on grid cells ( $5^{\circ}$ Latitude $\times 5^{\circ}$ Longitude) with median intertrack distance of less than $500 \mathrm{~km}$ by red outlines. Black stars indicate the breeding locations and blue outlined polygons are $95 \%$ utilization distribution kernels (see figure 6.1). High route consistency is especially achieved in southbound migration both within and outside staging area kernels.

provide localized, slowly moving foraging areas, resulting in irregular patterns in inter-annual variation of ocean productivity (Chavez and Messié 2009)(Chavez \& Messié 2009). In addition, sea surface temperature increases and primary productivity of the western part of the Benguela declines during winter (HardmanMountford et al. 2003, Longhurst 2006, O'Malley 2016). The skuas seem to respond to this by moving south- or eastwards within the Benguela, into the Agulhas or Angola current, or to the Canary Current. Particularly these late-winter movements are consistent between most, but differ between some years and cause the observed increase in within-individual intertrack distance from mid-winter onwards. 
While the onset of these movements may be related to the decrease in productivity, it is unclear what determines the (variation in) flexibility in subsequent destinations. One might argue that flexibility in late-winter movements is promoted by a lower predictability of resources in late winter. Whether this is really the case in our Long-tailed Skua example is questionable; targeted areas include both areas where they may utilize wind-driven upwelling areas along shelf-edges (off Angola and Namibia) and areas with eddies and thermal fronts (Agulhas Retroflection) (Ryan 1989), and such habitats do not seem to be notably less predictable in feeding conditions than for example the Benguela Current during early winter. Future studies should aim to link positional data with (ephemeral) oceanographic features (Tew Kai et al. 2009, Scales et al. 2014), backed up by field studies of atsea feeding behaviour and diet. Examining at what conditions individual movement patterns start to deviate offers a promising opportunity to study movement decisions of seabirds.

In line with our expectations, Long-tailed Skuas showed lower consistency in migration route than in staging area itineraries. Like in many seabird species, migratory routes of Long-tailed Skuas are closely linked to large-scale oceanic wind patterns. They followed routes that provide tail- or sidewinds, except in the second half of southbound migration when using a narrow corridor hugging the contours of western Africa - against the prevailing wind but avoiding an area with stronger headwinds in the central South Atlantic. The same pattern is shown by Sabine's Gulls Xema sabini and part of the Arctic Terns Sterna paradisaea originating from the North Atlantic (Egevang et al. 2010, Stenhouse et al. 2012), but dissimilar to most Cory's Shearwaters which take a westerly roundtrip offering more profitable winds (Felicísimo et al. 2008) - a route taken by only a small number of the Longtailed Skuas in this study. Northbound migration towards the North Atlantic staging area occurred over a much broader front, in particular north of the equator, where birds likely experienced easterly winds over a large area. Despite this difference in longitudinal width of the south- and northbound migration, individuals showed a similar degree of consistency, albeit with large variation, generally staying within $300-1300 \mathrm{~km}$ of their previous years' route. High consistency was observed in particular after departure from the Benguela to the northwest, while more flexibility was shown in the North Atlantic south of the North Atlantic stopover. Higher consistency in northbound than in southbound migration route was also observed in the much shorter migration of Streaked Shearwaters in the western Pacific (Yamamoto et al. 2014).

Error of position estimates from light-based geolocation using the threshold method (Ekstrom 2004) are typically some 100s of kilometres, which precludes us from any conclusions regarding consistency at smaller scales. Inaccuracy of latitude estimates are largest in proximity to the equinoxes (Phillips et al. 2004, Lisovski and Hahn 2012) and could lead to noise in derived measures. Indeed, figure 6.3a shows increased variation in median intertrack distances just before and after each 


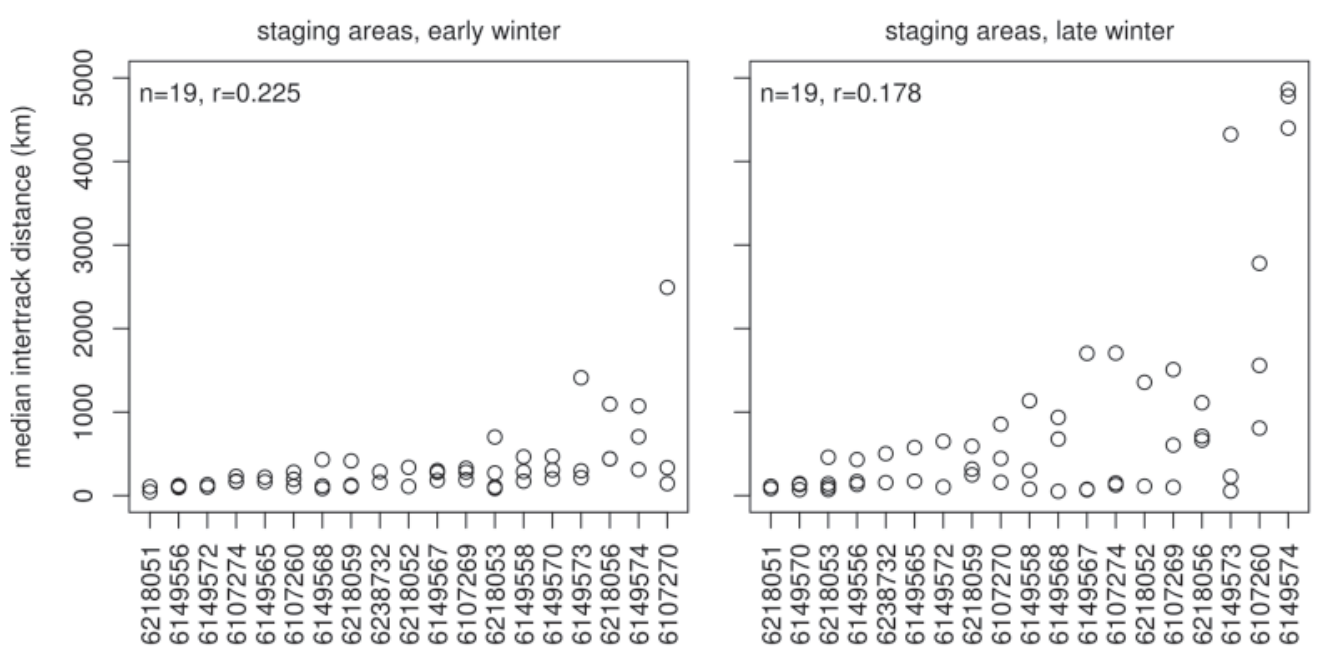

FIGURE 6.6 | Within-individual median intertrack distance in staging areas south of $25^{\circ} \mathrm{N}$ in early winter (left panel) and late winter (right panel) for individuals with at least three tracks, thus at least two sets of intertrack distances ( $x$-axis labels are individual ring numbers). Most individuals stayed within $500 \mathrm{~km}$ of their previous' year route in early winter. Particularly in late winter, some individuals showed large deviations in some years, but not in others. Individual 6149574 (figure

6.2i) switched each year in late winter between two distinct strategies.

equinox, but we do not exclude the possibility of an effect of data gaps around equinoxes. Nevertheless, two arguments suggest that the route consistencies as presented here are conservative and therefore our conclusions robust. First, considering intertrack distances of two identical routes would reflect the combined error of the position estimates of both tracks, most within-individual intertrack distances are remarkably close to the typical error of $\pm 185 \mathrm{~km}$ of single position estimates (Phillips et al. 2004). Second, intertrack distances were calculated as point-to-point measurements. Measuring the distance from each position in a focal track to the line between two closest positions in the comparison track would lead to even smaller distances, in particular if two positions of the comparison track are far apart (e.g. when the bird was migrating).

This study highlights that Long-tailed Skuas show consistency in non-breeding movements, but, at the same time, a fair amount of flexibility during specific parts of the annual cycle, in particular the late winter period. Variation in itineraries between and within individuals suggest that Long-tailed Skuas have the ability to adjust to environmental change. However, as we have a poor understanding about how individual migration patterns arise in the first place, specifically the relative roles of genetic and learning during the ontogeny of individual patterns, and, in addition, to what extent individual migration patterns change over an individuals' lifetime (reversible state effects; Senner et al. 2015), it remains unclear how flexible Long-tailed Skuas really are, and thus how quickly they can respond to 
environmental change. That an individual Long-tailed Skua followed two distinct itineraries that were both repeated in later years (figure 6.2i), strongly suggests extensive spatial memory. This spatial memory may have its origin in explorative movements during early life (Pulido 2007, Guilford et al. 2011, Senner et al. 2015), which would enable Long-tailed Skuas to respond to changes in the distribution of favourable areas relatively quickly, assuming that explorative movements allow for discovery of novel areas. Crucially, the genetic background as well as the occurrence and extent of exploration behaviour in the first years of life and subsequent life stages need to be demonstrated for the far majority of seabirds (but see Kooyman et al. 1996, Weimerskirch et al. 2006, Péron and Grémillet 2013), including Long-tailed Skuas.

\section{SUPPLEMENT}

[https://www.int-res.com/articles/suppl/m578p197_supp/]

FIGURE 5.S1 | Animation of all tracks. Tracks from different years from the same individuals have the same colour. Black stars indicate the three breeding sites. The top panel indicates the date; grey blocks show where positional data is missing due to equinoxes.

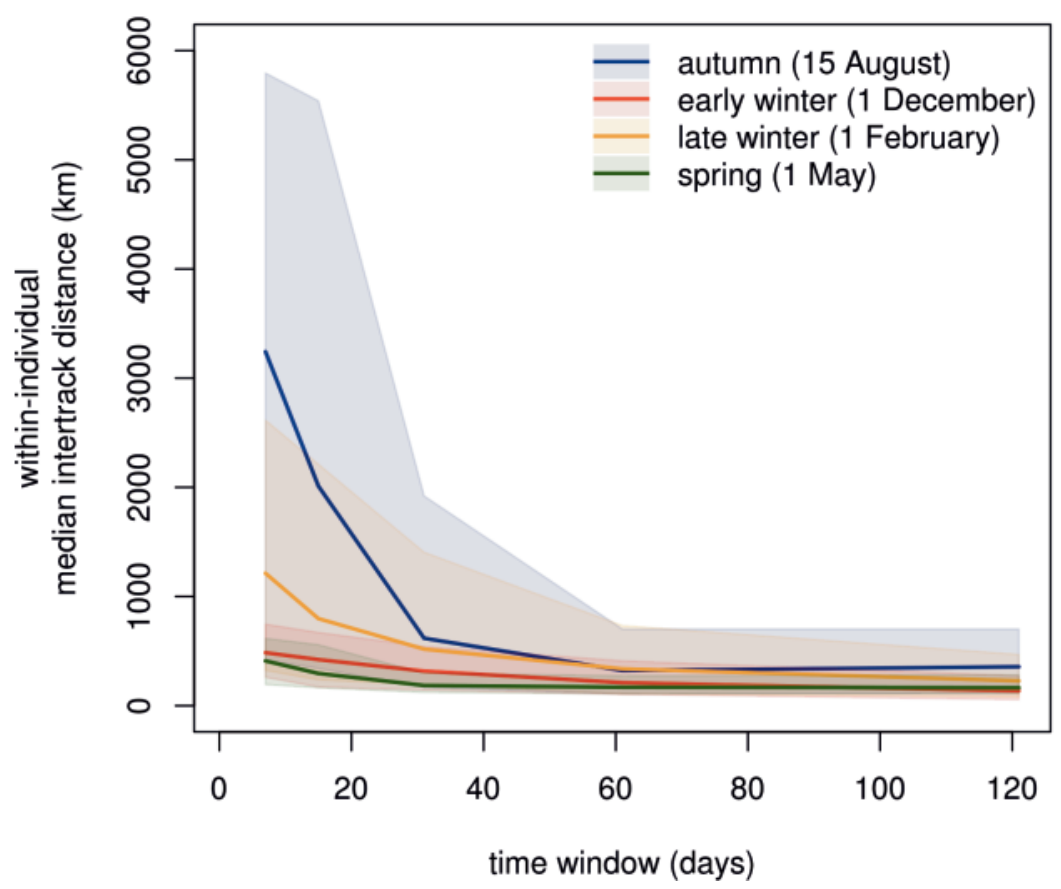

FIGURE 6.S2 | Effect of widening the time window (from 7 to 121 days) on median withinindividual intertrack distances at four example dates. Shaded areas represent $90 \% \mathrm{Cl}$ of bootstrapped medians. Intertrack distances using a time window of 61 days were selected for further analyses. 


\section{ACKNOWLEDGEMENTS}

This study would not have been possible without the huge effort by field crew. Piet Admiraal, Christian Brinkman, Michiel Elderenbosch, Juan Fernández-Elipe, Vincent Hin, Johannes Hungar, Puala Machin and Tim van der Meer assisted in Ammarnäs. Elise Biersma, Nora Bjørnlid, Anette A. Fenstad, Heidi Kilen, Thomas Oudman and Elise Skottene helped in Svalbard. In Greenland, assistance was provided by Antoine Dervaux, Bernhard Frauenberger, Jerome Isambert, Anita Lang, Ines Leonhardt, Mark Nitze at Karupelv, Lars H. Hansen, Jannie Lindebjerg, Jesper Mosbacher, Maria R. Mylius, Palle S. Nielsen and Jeroen Reneerkens at Zackenberg, and Vladimir Gilg, Arne Hegemann, Emmanuelle Pouivé, Brigitte Sabard and Glenn Yannic at Hochstetter Forland. Martin Green and Åke Lindström (Lund University) helped with permits and logistics in Ammarnäs. Aarhus University is thanked for providing logistics at Zackenberg. James Fox (Migrate Technology) and Glen Fowler (Biotrack) produced quality geolocators, provided advice and downloaded data from failed loggers. This study was partially financed by the Netherlands Organisation for Scientific Research (project number 866.13.005), the FRAM - High North Research Centre for Climate and the Environment, Research Council of Norway (Arctic Field Grant), Aage V. Jensen Charity Foundation, the French Polar Institute (Institut Polaire Français Emile Victor - IPEV - programm 1036 'Interactions'), the Groupe de Recherche en Ecologie Arctique and supported by the LUVRE project (www.luvre.org). We thank Judy Shamoun-Baranes, an anonymous reviewer, and the editor, Jacob González-Solís, for their helpful comments. 


\section{CHAPTER VII}

"No bird is more tame and fearless than this skua during the time they have eggs; for they come sailing close over your head when searching for the nest, performing the most beautiful airy gyrations, their long sharp wings and pointed tail giving them a singular and pretty appearance when in the air."

A Long-tailed Skua pair overlooking their territory in a non-breeding year A few days later, these birds will have flocked with other skuas and returned to sea, Ammarnäs, Sweden, 16 Júne 2016 . 


\section{Use of distantly and locally acquired resources for egg production under extreme inter-annual variation in food abundance in a long-distance migratory seabird}

Rob van Bemmelen, Ingrid Tulp, Ron Ydenberg,

Ko de Korte, Jan van Gils \& Marcel Klaassen

Manuscript 


\section{ABSTRACT}

We studied how Long-tailed Skuas Stercorarius longicaudus, a trans-equatorial migratory seabird, use distantly-acquired marine (endogenous) and locally-acquired terrestrial (exogenous) resources for self-maintenance and egg formation in the face of annually varying prey densities on their Arctic breeding grounds. Using light-based geolocation and salt water immersion data, we show that Long-tailed Skuas put on body stores during a 2-month period in the North Atlantic between $40^{\circ} \mathrm{N}$ and $55^{\circ} \mathrm{N}$, before using a 'flyand-forage' strategy to migrate $3000 \mathrm{~km}$ to their breeding area. The rate of mass loss after arrival is related to the local density of terrestrial prey (rodents), with eggs being produced in years with high rodent densities only. Moreover, eggs and clutches are larger in years with higher rodent density. Using stable isotope data of adult, juvenile and chick down feathers, we infer that the increase in egg size can be attributed to larger contributions of locally-acquired terrestrial resources relative to a constant contribution of distantly-acquired marine resources. Our study provides a rare insight into the resource allocation strategy for egg reproduction in a longdistance migratory seabird that is unlikely to be able to predict food availability at the breeding grounds before arrival. 


\section{INTRODUCTION}

How animals allocate resources for reproduction and self-maintenance is key to both life-history and conservation studies. Long-distance migratory birds face annual variability in feeding conditions upon arrival at the breeding grounds which are hard to predict beforehand, especially at greater distance from the breeding area (Bauer et al. 2008). To survive unfavourable feeding conditions upon arrival at the breeding grounds or to start egg laying soon after arrival, migrants can bring body stores deposited on the wintering grounds or at staging areas along the migration route (Drent and Daan 1980, Meijer and Drent 1999). At the other extreme, migrants may arrive with small body stores and rely predominantly on local resources for self-maintenance and egg production (Drent and Daan 1980). Producing eggs from distantly-acquired or from locally-acquired resources are known as 'capital' and 'income' breeding strategies, respectively, and represent the extremes of a continuum, many species adopting an intermediate strategy (Meijer and Drent 1999, Klaassen et al. 2006). The degree to which species follow a capital or income breeding strategy depends largely on body size, as carrying body stores on migration is particularly costly for small birds, but also on if and where fuelling opportunities occur along the migration route (Alerstam and Lindström 1990, Klaassen et al. 2006).

In species with an intermediate breeding strategy, females may not only modify the investment of distantly-acquired versus locally-acquired resources in response to local food abundance, but potentially also their total investment in egg production (figure 7.1). Thus, for example, with increasing local food abundance, females could only vary the relative contribution of distantly- and locally-acquired resources while keeping tot total investment in egg production fixed (' $a$ ' in figure 7.1). Yet, alternatively, females could also invest a fixed amount of distantly-acquired resources, regardless of local feeding conditions, but invest more locally-acquired resources at higher local food abundance, resulting in larger clutches and eggs (' $c$ ' in figure 7.1). Intermediate strategies to these two extremes are also possible (' $b$ ' in figure 7.1). Disentangling these strategies requires measuring absolute investments of distantly-acquired and locally-acquired resources in eggs at different local food abundances.

The Long-tailed Skua Stercorarius longicaudus is a trans-equatorial migratory seabird breeding on Arctic tundra, where it faces extreme annual variations in its prime food source - rodents (Andersson 1976a, de Korte and Wattel 1988). In most breeding areas, its breeding propensity and reproductive success depends on this fluctuating resource, breeding only when rodent densities are above a certain threshold (Andersson 1976a, 1981). Long-tailed Skuas arrive at the breeding grounds with large body stores and enlarged follicles (de Korte 1985). After arrival, pre-laying loss of body mass leads to smaller clutch and egg sizes (de Korte 1985). Although there are costs associated with body stores (Witter and Cuthill 1993), 
considering its strong negative effect on clutch size, mass loss in the pre-laying and incubation period does not appear adaptive, but seems more likely a result of low food abundance.

We studied Long-tailed Skuas in Lapland over a ten-year period with varying rodent densities and used stable isotopes in feathers investments of marine and terrestrial resources in egg production. As Long-tailed Skua is a slow-reproducing and longlived, thus K-selected species, females are expected to prioritize self-maintenance over egg production (Drent and Daan 1980). Therefore, clutch and egg size are predicted to decline with decreasing rodent abundance. Considering enlarged follicles upon arrival indicate eggs are at least partly produced from marine resources (de Korte 1985) and as no other seabirds adopts an entirely capital breeding strategy (Bond and Diamond 2010), Long-tailed Skuas are expected to use both marine and terrestrial resources for egg production. Because Long-tailed Skuas are unlikely to have information on rodent abundance before arriving at the breeding grounds, their absolute contribution of marine resources to egg formation made before arrival is expected to be constant irrespective of rodent abundances with input from terrestrial resources and thus total investment in eggs, to increase with increasing rodent abundance (strategy ' $c$ ', figure 7.1). Combining light-based geolocation and salt water immersion data, foraging activity during spring migration was studied to infer where Long-tailed Skuas may build up the large body stores and the enlarged follicles with which they arrive at the breeding grounds (de Korte 1985). Extensive foraging is expected during the last phase of migration only when Long-tailed Skuas are avoiding the costs of carrying large fuel loads during all of their migration (Alerstam and Lindström 1990).

\section{METHODS}

\section{Fieldwork}

During 2007-2016, Long-tailed Skuas were studied in the Vindelfjällen Nature Reserve, near Ammarnäs, Sweden ( $\left.65^{\circ} 59^{\prime} \mathrm{N}-16^{\circ} 01^{\prime} \mathrm{E}\right)$. In early to mid June, nests were located and clutch size and egg dimensions (width $W$ and length $L$ to the nearest $0.1 \mathrm{~mm}$, using callipers) were recorded. Egg volume was calculated as $L \cdot W^{2} \cdot S$, where $S$ is the shape parameter for which we used 0.509 (Hoyt 1979). We examined the potential effect of increasing measurement error and uncertainty in $S$ by sampling 1000 times from normal distributions of $L, W$ and $S$, using standard deviations for $L$ and $W$ of measurements from 0.1 to $0.8 \mathrm{~mm}$, and for $S$ from 0.02 to 0.08 (Hoyt 1979). The resulting mean coefficient of variation (CV) was $0.6 \%$ for the lowest and $5.6 \%$ for the highest set of standard deviations. To infer relative contributions of marine and terrestrial resources to eggs, we sampled three feather types for isotope analysis: adult feathers, juvenile feathers and chick down. Adult feathers were collected by clipping about 20 barbs from the inner vane at the base of 8th primary (counting outwards) for isotope analysis. Adult feathers are grown at 
a

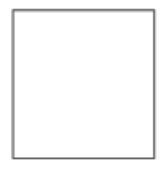

b
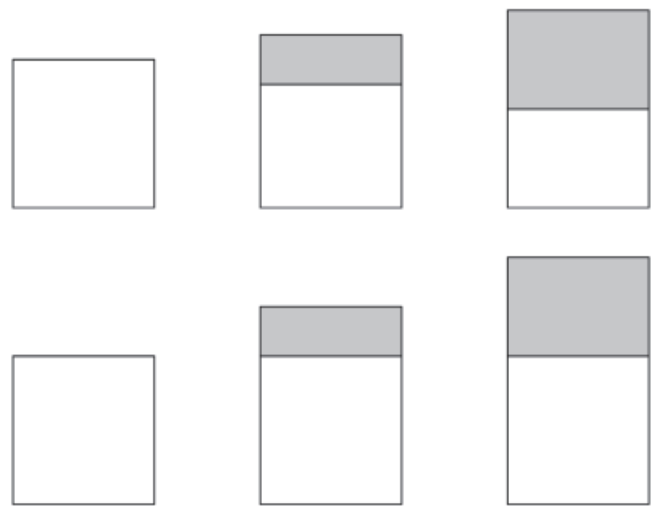

low
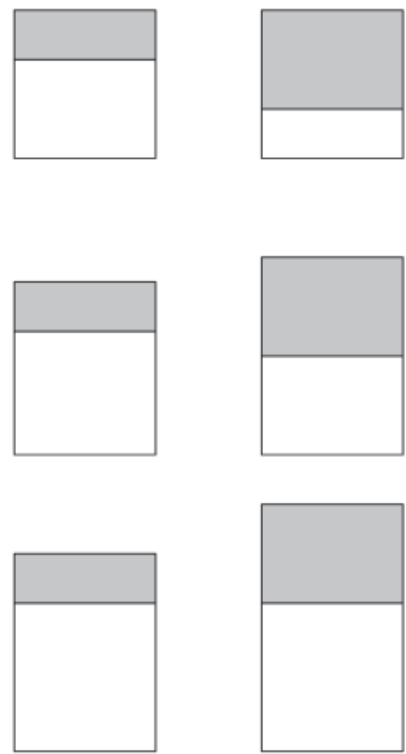

high fixed

total investment

intermediate strategy fixed endogenous investment

local (exogenous)

distant (endogenous)

local food abundance

FIGURE 7.1 | Schematic presentation of how total investment (egg and clutch size) and locallyversus distantly-acquired contributions to egg formation may change as a function of food abundance on the breeding grounds. In a, the total investment is constant, where less distantlyacquired (endogenous) and more locally-acquired (exogenous) resources are invested at higher local food abundance. In c, investment of distantly-acquired resources is constant but investment of locally-acquired resources and therewith also total investment, increases with local food abundance. An intermediate strategy is depicted in $\mathbf{b}$, in which total investment increases (as in $\mathbf{c}$ ), investment of locally-acquired resources increases (as in $\mathbf{c}$ ) and the investment of distantlyacquired resources decreases with local food abundance (as in a). For simplicity, a $100 \%$ contribution of distantly-acquired resources (i.e. a 'capital' breeding strategy) has been assumed as the baseline when local food abundance is low, but any mixed strategy could be used here.

sea and thus reflects isotope ratios from marine resources. Juvenile feathers (wing coverts or scapulars) were sampled from older chicks (>10 days) ad, since grown at the breeding area were taken to reflect terrestrial resources used for egg production (Andersson 1971). Finally, down was collected from recently hatched chicks $(<5$ days old) to reflect the combination of distantly-acquired marine and locallyacquired terrestrial resources into egg production.

To collect feathers and measure body mass (to the nearest $\mathrm{g}$ ), adults were caught on the nest using walk-in traps, bow-nets or snare traps, usually in the second half 
of the incubation period, or away from the nest using a net gun (Edwards and Gilchrist 2011). Ca $30 \mu \mathrm{L}$ blood was collected from the brachial vein for molecular sexing (Fridolfsson and Ellegren 1999). Every bird was equipped with a geolocator (type Mk18-H/Mk4083, manufactured by BAS or Biotrack Ltd., United Kingdom, or type C65, manufactured by Migrate Technologies, United Kingdom), deployed on darvic tarsus rings, and retrieved upon recapture after 1-4 years. Dates of clutch initiation were derived using three methods: 1) the first date at which geolocator light measurements show a distinct periods of $\sim 1 \mathrm{~h}$ darkness, 2) subtracting $24 \mathrm{~d}$ (Cramp and Simmons 1983) from observed hatching dates, 3) hind-casting lay dates using the decline in egg density over time (Furness and Furness 1981).

To supplement our Long-tailed Skua data from 2007 onwards, information on (non)breeding of Long-tailed Skuas in our main study area was obtained for 1995 and 2005-2006 from a territory mapping carried out in a $12.8 \mathrm{~km}^{2}$ survey plot (Svensson 2007). Rodent abundance data for 1995 and 2005-2016 were obtained from the National Environmental Monitoring Program (NEMP) for small rodents run by the Swedish Environmental Protection Agency (Ecke and Hörnfeldt 2018). The method used in this monitoring involves snap-trapping during three nights in mid-late June and three nights in mid-late August along 4-6 approximately $3 \mathrm{~km}$ long altitudinal transects with a total of 35-46 permanent 1-ha trapping plots spaced at intervals of $300 \mathrm{~m}$ along the transects (Ecke et al. 2010). Rodent abundance is expressed as the number of captures per 100 trap-nights (Hörnfeldt 1978, 1994, Ecke et al. 2010). We summed the indices for the three main prey species: Norwegian Lemming Lemmus lemmus, Grey-sided Vole Myodes rufocanus and Field Vole Microtus agrestis. As we were interested in rodent abundance around the time of spring arrival of Long-tailed Skuas, rodent catch indices from late June instead of August were used. In 2008, however, rodents were abundant during egg-laying of Long-tailed Skuas but crashed soon after - before the rodent monitoring in late June. Therefore, the rodent catch index from August 2007 is used for 2008.

\section{Foraging before arrival at the breeding grounds}

Geolocators recorded ambient light every minute and recorded maximum light intensity every five minutes. Time of sunset and sunrise was extracted using the 'twilightCalc' function from the 'GeoLight' package in R (Lisovski and Hahn 2012). By plotting time of sunset and sunrise against date, outliers were detected visually and replaced by a value predicted from a loess smoother. For each annual track, positions were calculated for a range of sun angles $\left(-1^{\circ}\right.$ to $\left.-7^{\circ}\right)$. Subsequently, the sun angle resulting in a close match between positions before and after each equinox, and a good match between the track and the shape of the continents was selected to calculate the final positions. Following Gilg et al. (2013), stationary periods were defined as three subsequent days with daily travelled distances per day of less than $200 \mathrm{~km}$, which is similar to the mean error in geolocator positions of seabirds using the threshold method (Phillips et al. 2004). Geolocators also recorded submersion in saline water every $3 \mathrm{~s}$ and saved the number of 'wets' per 
10 min period. We classified each 10-min period into one of three categories (Dean et al. 2013): a) 'in flight' when wet for $<2 \%$ of the time, b) 'swimming' when wet for $>98 \%$ of the time, or 'foraging' when wet for between $2-89 \%$ of the time. For each day the time spent on each category was calculated. Timing of spring arrival in the breeding area was inferred from this 'wet/dry' data, as the first entirely dry day after 1 January. Subsequently, the fraction of time spent on each activity was calculated per track for between $40^{\circ} \mathrm{N}$ and $55^{\circ} \mathrm{N}$, encompassing the main spring staging area (Gilg et al. 2013, van Bemmelen et al. 2017) and between $55^{\circ} \mathrm{N}$ and arrival in the breeding area.

\section{Stable isotope ratios in feathers}

Carbon $\left(\delta^{13} \mathrm{C}\right)$ and nitrogen $\left(\delta^{15} \mathrm{~N}\right)$ isotope ratios were measured in adult feathers, juvenile feathers and chick down. Before analysis, feathers were rinsed using hexane and methanol and then air dried. Subsequently, 400-1420 $\mu \mathrm{g}$ ( $\mathrm{x}=869 \mu \mathrm{g}$, $\mathrm{sd}=213 \mu \mathrm{g}$ ) of feather material was packed in tin cups and analysed with a Thermo Scientific Flash 2000 Elemental Analyser coupled to a Thermo Scientific Delta V Advantage isotope-ratio mass spectrometer (IRMS) via a Conflo IV interface. Analyses were carried out at the Royal Netherlands Institute for Sea Research (NIOZ), Texel, The Netherlands. Isotope ratios are presented in the usual $\delta$ notation relative to Vienna Pee Dee Belemnite for carbon and air for nitrogen $\delta=\left(R_{\text {sample }} / R_{\text {standard }}\right)-1 \cdot 1000$. Multiple standards with known isotopic composition were analysed throughout each sequence, at the beginning and end and every twelve samples. All isotope values are typically corrected for the difference between the known and measured values for acetanilide, this correction is checked using urea and casein standards. Replicate measurements of standards indicate measurement errors of $\pm 0.14 \%$ o for $\delta^{15} \mathrm{~N}$ and $\pm 0.15 \%$ ofor $\delta^{13} \mathrm{C}(n=48)$.

\section{Statistical analysis}

We tested whether the daily fraction of time devoted to 'foraging', 'swimming' or 'flying' differed between the two areas using binomial Generalized Linear Mixedeffect Models (GLMMs), with individual and track identity as random affects and area as fixed effect. Timing of arrival at the breeding grounds was compared between years by a Likelihood-ratio test between GLMMs with individual as random effect and with or without year as fixed effect. Clutch initiation dates were compared between years using an GLM. As the rodent peak in 2011 was much higher than other peaks, rodent catch indices were $\log _{e}$ transformed to achieve normality and facilitate its use in parametric statistics. Maximum clutch size in Long-tailed Skuas is two (Andersson 1976b), and clutch size was converted into a binomial variable $(0=1$ egg, $1=2$ eggs) and correlated with rodent abundance using a binomial GLM. Similarly, Gaussian GLMs were used with mean egg volume per nest as response and rodent abundance as explanatory variable, and with body mass as response and sex and rodent abundance as explanatory variables.

Bayesian mixing models, as implemented in the 'MixSIAR' in R and using JAGS 
(Plummer 2003, Stock et al. 2018), were used to estimate the proportion of distantly-acquired marine versus locally-acquired terrestrial resource contributions in egg formation, $p$, using carbon $\left(\delta^{13} \mathrm{C}\right)$ and nitrogen $\left(\delta^{15} \mathrm{~N}\right)$ isotope ratios from chick down as 'mixture', and from adult and juvenile feathers as 'sources'. Default uninformative priors, 100000 simulations, a burn-in of 50000 and a thinning interval of 50 were used. Three models were fitted: 1) $p \sim 1$, 2) $p \sim \log _{\mathrm{e}}$ rodent abundance index, and 3) $p \sim$ egg size. In all models, 'year' was included as a random effect. Because of missing egg size measurements, sample size for model 3 was slightly lower $(n=40)$ than for model 1 and $2(n=44)$, the former two models were also fitted with the same sample size as model 3 to enable model comparison based on DIC and WAIC.

Individual-level relative marine and terrestrial investments were derived from a mixing model with only 'individual' as fixed effect. Posterior means of each individual were then multiplied by egg volume to arrive at absolute marine and terrestrial resource investments. Subsequently, absolute investments were compared between years in GLMMs using the same three formulae as above.

\section{RESULTS}

\section{Foraging activity at sea before arrival at the breeding grounds}

Wet/dry data were obtained for 37 spring tracks (including 3 individuals with three tracks and 11 individuals with two tracks) of Long-tailed Skuas breeding in Ammarnäs, with 14 tracks in both 2012 and 2013 (non-breeding years), 1 in 2014 and 8 in 2015 (breeding years). Long-tailed Skuas breeding in Ammarnäs had a main stopover in the North Atlantic roughly between $40^{\circ}$ and $55^{\circ} \mathrm{N}$, but no stopovers were identified between $55^{\circ} \mathrm{N}$ and the breeding area (figure 7.2a). Between $40^{\circ}$ and $55^{\circ} \mathrm{N}$, they spent on average $37 \mathrm{~d}(\mathrm{sd}=16 \mathrm{~d})$, with significantly longer durations in $2013(z=6.5, p<0.001)$ and $2015(z=2.3, p=0.025)$ compared to 2012. The migration from the North Atlantic stopover to the breeding area took on average $6 \mathrm{~d}(\mathrm{sd}=4 \mathrm{~d})$, with the duration in 2012 was significantly longer $(z=-5.5$, $p<0.001$ ) compared to 2012 . Time spent on each activity was significantly different between the North Atlantic stopover and during the last leg of migration to the

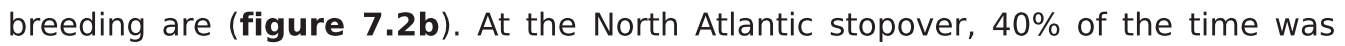
spent 'foraging', 38\% 'swimming' and 22\% 'flying', versus respectively $31 \%$ ( $z=-$ $22.4, p<0.001), 25 \%(z=-26.45, p<0.001)$ and $44 \%(z=55.1, p<0.001)$ on the last leg of migration to the breeding area.

\section{Timing of arrival and clutch initiation}

Long-tailed Skuas arrived at the breeding grounds on average on 20 May ( $s d=5 d$, range $=12-27$ May $)$ and did not differ between years $\left(\chi_{1}^{2}=2.0, p=0.576\right)$ or with rodent abundance $\left(\chi^{2}{ }_{1}=1.8, p=0.179\right)$. Between 2007-2015, clutch initiation dates differed slightly between years $\left(F_{1,145}=1.6, p=0.02\right.$, mean $=1$ June, $s d=5 d, n=147$, 
annual means ranging between 28 May and 2 June), because lay dates were slightly earlier in 2010 than other years $(t=-2.9, p=0.004)$, but did not correlate with rodent abundance $\left(F_{1,145}=1.6, p=0.214\right)$. The period between spring arrival and clutch initiation for females, only known for a small number of individuals in two breeding years, was 12 d in $2014(n=1)$ and 9-14 d in 2015 (mean=12 d, n=4).

\section{Reproductive investment and body mass relative to rodent abundance}

During 2005-2015, the number of Long-tailed Skua nests closely followed a threeyear cycle in rodent abundance. Long-tailed Skuas only bred in years when at least 0.56 rodents were captured per 100 trapping nights; the highest capture index in years without breeding was 0.17 (figure 7.3a). Non-breeding years occurred in 2009, 2012, 2013 and 2016. Among breeding years, more 2-egg clutches were laid $\left(\beta_{\text {rodents }}=0.4, z=2.9, p=0.004\right.$, figure $\left.\mathbf{7 . 3 b}\right)$ and eggs were larger $\left(\beta_{\text {rodents }}=0.9\right.$, $t=4.2, p<0.001$, figure $7.3 c$ ) in years with higher rodent abundance. In addition, both male and female were heavier in such years $\left(\alpha_{\text {intercept }}=303.9, \beta_{\text {rodents }}=7.5\right.$, $t=3.5, p<0.001, \beta_{\text {male }}=-33.0, t=-7.1, p<0.001$, figure 7.3d). Adding an interaction term between sex and rodent abundance did not results in a better model fit $\left(\mathrm{dAIC}_{\mathrm{c}}=-1.61\right)$ and this interaction was non-significant $\left(\beta_{\text {rodents:sex }}=-2.6, t=-0.6\right.$, $\mathrm{p}=0.548)$.
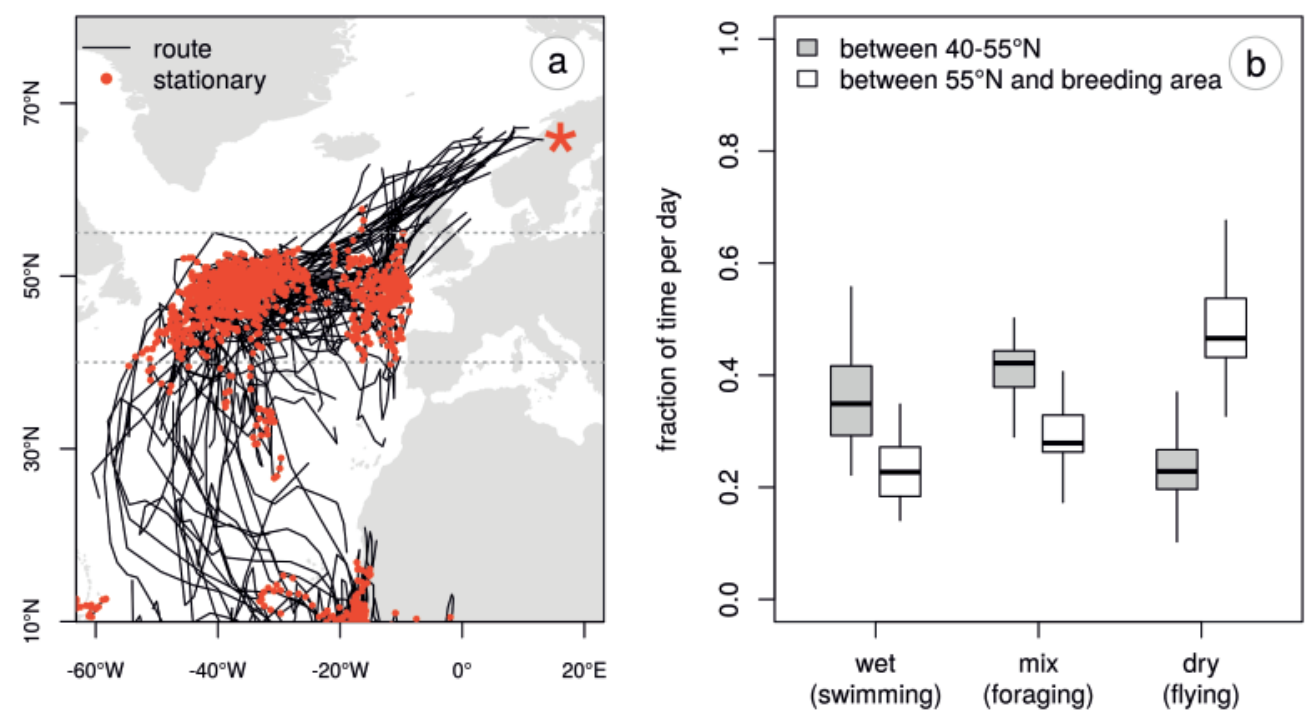

FIGURE 7.2 | Migration route and stopover behaviour (a) and at-sea activity (b) of Long-tailed Skuas before arrival at the breeding grounds. In $\mathbf{a}$, the black lines depict migration routes, the red dots periods of 3 or more days where the birds were stationary and the red asterisk the breeding area. In $\mathbf{b}$, box plots depict the fraction of time the birds spent swimming, foraging and flying during two segments of their migration, when they are between 40-55 $\mathrm{N}$ and when they are closing in on their breeding grounds (i.e. north of $55^{\circ} \mathrm{N}$ ). Behaviours were informed by the geolocators' salt-water sensor. 


\section{Income/capital breeding strategy}

Adult primary feathers showed a stable isotope signature typical for birds foraging in pelagic environments, with high $\delta^{13} \mathrm{C}$ values (mean $=-16.3, \mathrm{sd}=0.9$ ) and $\delta^{15} \mathrm{~N}$ values (mean=14.2, sd=1.0, figure 7.4a, (Ramos et al. 2009). Juvenile feathers showed lower mean $\delta^{13} \mathrm{C}$ (mean=-24.6, $\mathrm{sd}=0.2$ ) and $\delta^{15} \mathrm{~N}($ mean=5.7, $\mathrm{sd}=0.5$ ) values typical for terrestrial tundra environments (Angerbjörn et al. 1994). Chick down showed $\delta^{13} \mathrm{C}$ and $\delta^{15} \mathrm{~N}$ values intermediate between juvenile and adult feathers (figure 7.4a). The relative contributions of marine and terrestrial resources differed between years, with rodent abundance (figure $\mathbf{7 . 4 b}$ ) being a better predictor than egg volume of relative contributions, as indicated by a considerably lower DIC value of the mixing model with rodent abundance compared to the mixing model with egg volume as fixed effect $(d D I C=6.4)$. The difference between the rodent-model and the intercept-only model was slight $(\mathrm{dDIC}=0.4)$, which likely results from the random effect 'year' accounting for much of the interyear variation. Indeed, an intercept-only model without 'year' as random effect had a dDIC of 7.7. Although based on DIC comparisons, the mixing model with rodent abundance as explaining variable was the best model, the posterior distribution for rodent abundance in the model using all data had a credible interval that just included zero, which means no effect cannot be excluded (posterior mean: 0.31, $95 \% \mathrm{Cl}=-0.14-0.69$ ). Individual-level estimates of relative marine versus terrestrial resource contributions to egg production was $9.1 \%$ ( $s d=5.2 \%$, range $=3.6 \%-27.9 \%$, $\mathrm{n}=44)$. Absolute terrestrial resource investment was on average $36.9 \mathrm{~cm}^{3}(\mathrm{n}=38$, $\mathrm{sd}=2.8 \mathrm{~cm}^{3}$, range $=28.6-44.2 \mathrm{~cm}^{3}$ ), whereas absolute marine resource investment was on average $3.7 \mathrm{~cm}^{3}\left(n=38, \mathrm{sd}=1.9 \mathrm{~cm}^{3}\right.$, range $\left.=1.4-11.1 \mathrm{~cm}^{3}\right)$. Whereas absolute marine resource investment did not correlate with rodent abundance $(\beta=0.052, t=0.181, p=0.857)$, absolute terrestrial resource investment showed a positive trend with rodent abundance $(\beta=0.863, t=2.184, p=0.036$, figure 7.4c). Assuming the absolute marine resource investment is spherical, the diameter of this volume is on average $18.9 \mathrm{~mm}(95 \% \mathrm{Cl}=14.6-25.0 \mathrm{~mm}$, figure $\mathbf{7 . 4 d})$, which is larger than the maximum follicle size of $9 \mathrm{~mm}$ reported by Maher (1974) and de Korte (1985).

\section{DISCUSSION}

Breeding propensity of Long-tailed Skuas was tightly linked to rodent abundance, as skuas skipped breeding at low rodent abundance but produced larger clutches and larger eggs at high rodent abundance, consistent with earlier studies in Scandinavia and elsewhere (Maher 1974, Andersson 1981, de Korte 1985, Gilg et al. 2006). That breeding propensity is driven by rodent abundance has also been shown in Canada, where only populations that are subsidized by anthropogenic food are able to breed in years with few lemmings (Julien et al. 2014). In agreement with supplementary feeding experiments in other seabirds (Nager 2006), Long-tailed Skuas did not advance clutch initiation at higher local food abundance. Swedish Long-tailed Skuas 

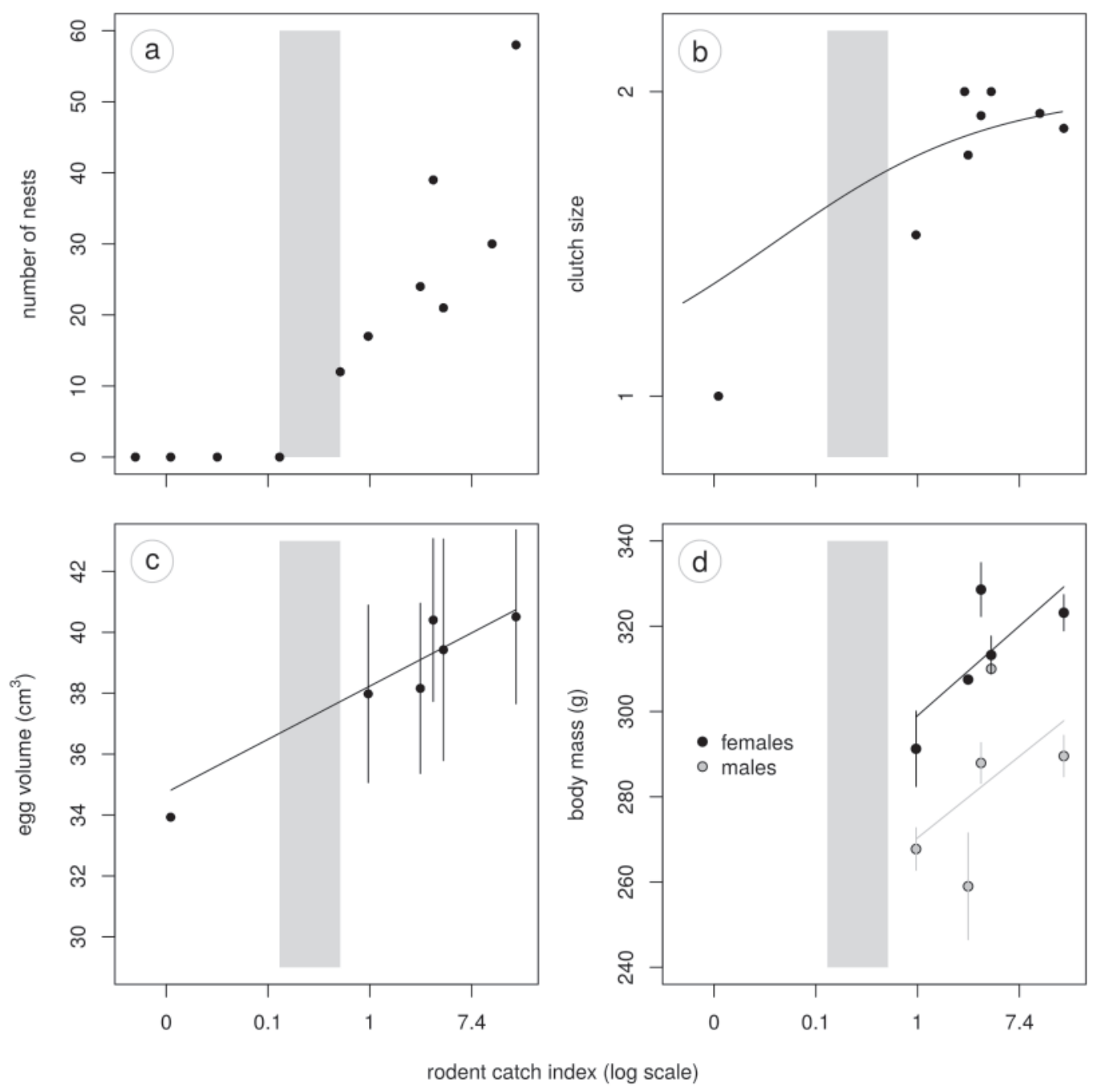

FIGURE 7.3 | Annual number of Long-tailed Skua nests (a), mean clutch size (b), mean egg volume (c) and adult body mass (d) as a function of rodent abundance ( $\log _{\mathrm{e}}$ of rodents captured per 100 trapping nights). Long-tailed Skuas breed only when rodent abundance is above the threshold of 0.17-0.56 rodents captured per 100 trapping nights. Lines show significant regressions. Grey rectangle show the (non-)breeding threshold from $\mathbf{a}$. Error bars in $\mathbf{c}$ and $\mathbf{d}$ are \pm SD.

adopted a mixed breeding strategy, producing eggs from a small ( $~ 9 \%)$ investment of distantly-acquired, marine resource and a large investment of locally-acquired, terrestrial resources. The volume of the largest follicles for birds arriving in Alaska (Maher 1974) and Greenland (de Korte 1985) was substantially smaller the marine resource contribution estimated in our study (figure $\mathbf{7 . 4 d}$ ). The difference in these diameters suggests that investment of marine resources continues after arrival at the breeding grounds. Whereas the volume of the terrestrial resource investment in 
eggs increased between years with higher rodent abundance, the volume of the marine resource contribution was constant with varying rodent abundances, thus indicating strategy ' $c$ ' (figure 7.1).

Our observations on (inter-annual) variation in relative endo- and exogenous contributions in eggs by Long-tailed Skuas differs from what has been proposed in studies of geese and waders. There, larger relative endogenous contributions were explained by a shorter interval between arrival at the breeding grounds and egg laying (Klaassen et al. 2006, Hobson and Jehl 2010, Lameris et al. 2018). In theory, larger contributions of locally-derived resources to egg production in Long-tailed Skuas could have been caused by a longer interval between arrival and clutch initiation. Under this scenario, longer pre-laying periods in the breeding area should result from earlier timing of spring arrival in years with few rodents, as lay dates were very similar between most years. In contrast, our results indicate no difference in spring arrival dates between years. Moreover, whereas geese may be able to predict feeding conditions at the breeding area from their final stopover (Bauer et al. 2008) and can thereby adjust the division of time between the last stopover and the breeding area, Long-tailed Skuas are unlikely to have information of rodent abundance prior to arrival in the breeding area. Thus, variation in the relative contributions to egg production in Long-tailed Skuas is best explained by the effect of rodent density on the investment of terrestrial resources in egg production.

Like terrestrial species (Meijer and Drent 1999, Klaassen et al. 2006) seabirds vary in the degree to which they are income/capital breeders, probably depending largely on migration behaviour (Bond and Diamond 2010). Among migratory seabirds breeding in the Arctic, Sabine's Gull Xema sabini, Arctic Tern Sterna paradisaea and Leach's Storm-petrel Oceanodroma leucorhoa share the longdistance trans-equatorial migration behaviour of Long-tailed Skua (Egevang et al. 2010, Stenhouse et al. 2012, Fijn et al. 2013, Pollet et al. 2019). Whereas Sabine's Gull and Arctic Tern are income breeders ( $1 \%$ endogenous) and spend at most 3 days at North Atlantic stopovers (Day et al. 2001, Bond and Diamond 2010, Stenhouse et al. 2012, Fijn et al. 2013), Leach's Storm-petrel has a mixed strategy ( $\sim 50 \%$ endogenous) and individuals spend about one month in the North Atlantic prior to the breeding season (Bond and Diamond 2010, Pollet et al. 2019). Longtailed Skuas staged much longer - for about two months - in the North Atlantic, while investing only $\sim 10 \%$ endogenous reserves in egg production. Thus, differences between long-distance migratory seabirds in the duration of spring stopovers may predict whether a species adopts an entirely income or a mixed breeding strategy, but appears a poor predictor of the relative contribution of distantly-acquired versus locally-acquired resource contributions to egg production when adopting a mixed breeding strategy.

Seabirds have often been assumed to feed during migration, i.e. a 'fly-and-forage' 

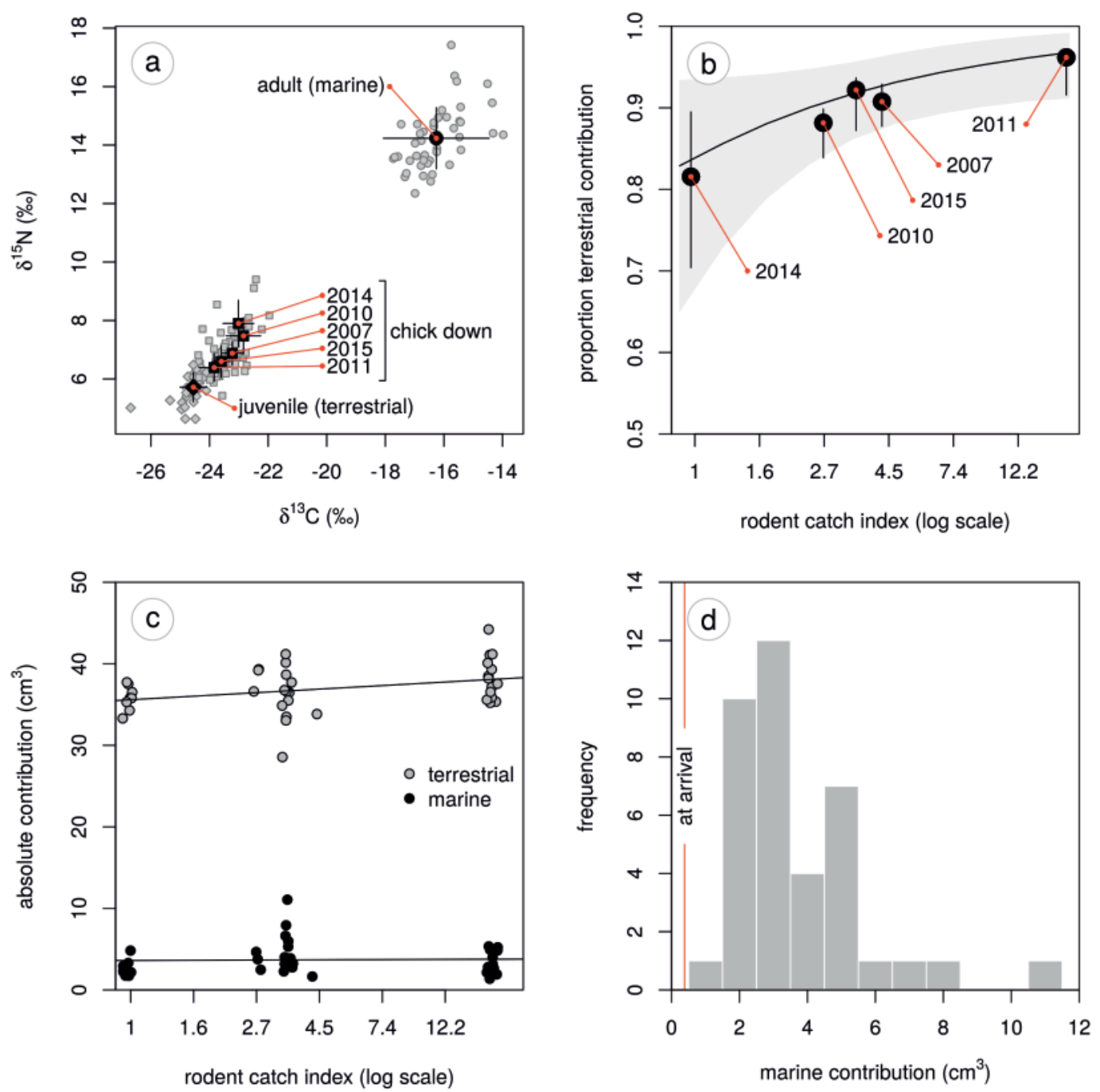

FIGURE 7.4 | (a) Biplot of nitrogen and carbon stable isotope ratios (\%o) of the $8^{\text {th }}$ primary of adults (dots), juvenile feathers (diamonds) and chick down (squares). Overall means for adult and juvenile feathers and annual means for chick down ( \pm SD) are plotted in black. (b) Proportion terrestrial contribution in chick down as a function of rodent abundance. (c) Absolute investment of distantly-acquired, marine (open dots) and locally-acquired terrestrial resources (filled dots) as a function of rodent abundance. The marine contribution is constant irrespective of rodent abundance, whereas the terrestrial contribution increases with rodent abundance. (d) Diameter of the absolute marine investment, assuming this is spherical in shape. Red vertical line shows the volume of the largest follicles $(\varnothing=9 \mathrm{~mm}$ ) of females collected at sea, close to the breeding grounds (Maher 1974, de Korte 1985). 
strategy (Dias et al. 2012), and are known for their energy-efficient flight behaviour (Alerstam 2003) and high migration speeds (Alerstam and Lindström 1990, Dias et al. 2012). Because of these traits, they may differ in fuel accumulation patterns from species with distinct migration and refuelling periods. Indeed, Long-tailed Skuas foraged about one third of their time during the last leg of spring migration, but it seems unlikely that they gained much weight during this ca. $3000 \mathrm{~km}$-long migration accomplished in most years in about a week. Thus, to arrive at the breeding grounds with large body stores (de Korte 1985), Long-tailed Skuas may build up body stores during a long stopover in the North Atlantic and maintain these reserves by fuelling en route. This strategy may seem remarkable, because carrying large body stores on migration is usually costly, especially for small birds (Alerstam and Lindström 1990). However, extra weight may be beneficial by increasing speed when using a wind-assisted flight technique called dynamic soaring (Pennycuick 2008). In skuas, dynamic soaring is used at high wind speeds, whereas a more costly, flapping flight technique is used at lower wind speeds (Olsen and Larsson 1997). The use of dynamic soaring and the absence of high quality foraging areas between the North Atlantic stopover and the breeding area may explain why Long-tailed Skuas carry large body stores during migration.

Considering 1 ) the relatively small marine resource contribution to egg formation, 2 ) the smaller clutch and egg sizes in rodent-poor years, and 3) the considerable lower body mass during incubation in both males and females, the purpose of arriving with large body stores at the breeding grounds is likely to be an insurance against starvation in case of low rodent abundance in the breeding area.

A few uncertainties exist in our approach. First, the adult feathers used to reflect the isotope ratio of the distantly-acquired marine 'source' are grown in the wintering area off South-west Africa (van Bemmelen et al. 2017), thus not in the North Atlantic where body stores and follicles are likely build up. However, feather stable isotope ratios from our Long-tailed Skuas $\left(-16.3 \delta^{13} \mathrm{C}\right.$ and $\left.14.2 \delta^{15} \mathrm{~N}\right)$ are similar to other seabirds in moulting in this region in (late) summer, such as South Polar Skua $\left(-17.3 \delta^{13} \mathrm{C}\right.$ and $13.0 \delta^{15} \mathrm{~N}$, Weimerskirch et al. 2015), Cory's Shearwater $\left(-19.0 \delta^{13} \mathrm{C}\right.$ and $12.0 \delta^{15} \mathrm{~N}$, Paiva et al. 2010, and $-16.0 \delta^{13} \mathrm{C}, 13.0 \delta^{15} \mathrm{~N}$, Roscales et al. 2011), and Sooty Shearwater $\left(-18.9 \delta^{13} \mathrm{C}\right.$ and $12.5 \delta^{15} \mathrm{~N}$, Hedd et al. 2012). Differences among species in stable isotope ratios may be explained by habitat and diet preferences and timing of moult. For example, both carbon and nitrogen isotope ratios of Long-tailed Skuas wintering in the Benguela differ slightly from those of Cory's Shearwaters using roughly the same area $\left(15.5 \delta^{15} \mathrm{~N}\right.$ and $-15.0 \delta^{13} \mathrm{C}$, Catry et al. 2011). Second, as we did not sample eggs but chick down, potential differences in resource contributions between egg component could not be taken into account. For example, marked differences in endogenous contributions to yolk and albumen have been reported for some seabird species (Bond and Diamond 2010). Third, source isotope levels were calculated at the population level, thus ignoring within-clutch correlations and potential effects of individual migration and 
foraging strategies.

Although seabirds are well-represented amongst the most extreme long-distance migrants (Hedd et al. 2012, Fijn et al. 2013), they are poorly represented amongst studies of resource allocation and breeding strategies. Our study provides insights into resource allocation for self-maintenance and reproduction in a long-distance migratory seabird facing extreme variation in its main food source during breeding. Combining multi-year breeding ecology studies, geolocator tracking and analysis of stable isotope ratios in feathers, we showed a strategy of investment of a constant volume of distantly-acquired, marine resources (endogenous) and an increasing volume of locally-derived, terrestrial resources (exogenous) to egg production with increasing local food abundance. In addition, our study reveals the links between area use during the final stage of spring migration and the breeding strategy.

\section{ACKNOWLEDGEMENTS}

Jim de Fouw introduced me to Ammarnäs and came up with the idea to study the breeding strategy of Long-tailed Skuas. Thanks to all who helped in the field: Piet Admiraal, Peter Antkowiak, Christian Brinkman, Pablo Capilla, Michiel Elderenbosch, Juan Fernandez-Elipe, Steve Geelhoed, Vincent Hin, Christian Hoefs, Johannes Hungar, Ferry van der Lans, Paula Machin, Tim van der Meer, Wesley Overman, Morrison Pot and Bram Ubels. Many thanks to Martin Green, Åke Lindström and Sören Svensson for help with logistics and stimulating discussions. Thanks also to the people in the NIOZ isotope lab: Kevin Donkers, Ronald van Bommel and Marcel van der Meer.

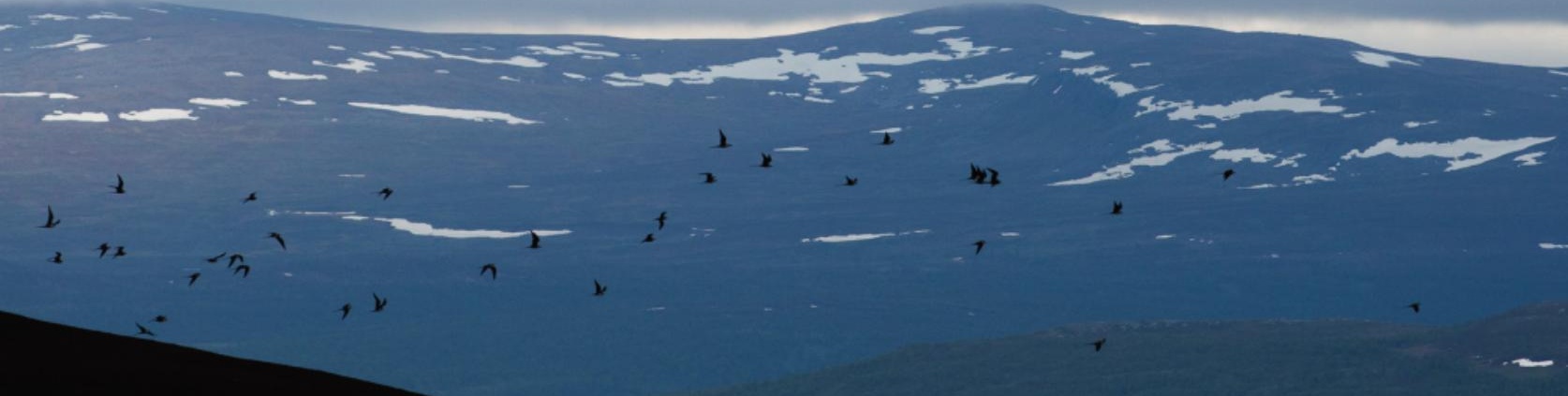

In non-breeding years, flocks of Long-tailed Skuas start to form by mid-June, sometimes amounting to more than 100 individuals, Ammarnäs, Sweden, 16 June 2018. 


\section{CHAPTER VIII}




\section{ABSTRACT}

Annual schedules of migratory birds are strongly driven by

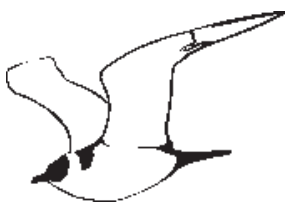
breeding latitude, but the effect of wintering area as a driver of annual schedules is poorly documented. This is due to the rarity of systems with substantial geographic variation in both breeding and wintering areas and mixing of individuals among breeding populations in wintering areas. In our study, the effects of both breeding and wintering location on annual schedules of the Arctic Skua Stercorarius parasiticus were quantified by tracking individuals from multiple breeding sites between East Greenland and Western Siberia to their widely divergent wintering areas across the Atlantic, Mediterranean Sea and Indian Ocean. Beside a strong effect of breeding site on annual schedules, wintering area strongly affected the timing and duration of migration and the duration of the wintering period. Specifically, more distant wintering areas were associated with a substantially longer migration duration and a shorter time at the wintering area. Furthermore, individuals wintering in most distant areas departed earlier towards the breeding than individuals from other wintering areas, but individuals from the farthest wintering area still arrived there with ca. five days delay. Interestingly, higher breeding latitude not only shifted annual schedules but also affected the duration of phases in the annual cycle: spring migrations were faster and the time between arrival at the breeding grounds and clutch initiation shorter than at lower breeding latitudes. These shorter migrations and pre-laying periods suggest that birds breeding in the high Arctic carry body stores from the wintering areas across 60 latitudinal degrees. 


\section{INTRODUCTION}

Long-distance migratory birds need to time their breeding, migrations and wintering periods in a way that maximizes survival and reproduction. Quantifying (variation in) the timing of and links between events across the annual cycle is important for our understanding of how phenology drives life-history variation (Marra et al. 2015). Timing of spring arrival at the breeding grounds is likely under strong selective pressure, as reproductive success usually shows a strong seasonal decline (Kokko 1999), while arriving too early may pose survival costs (Rotics et al. 2018). Variation between individuals in spring arrival timing may be attributable to consistent differences between individuals (Pedersen et al. 2018). For example, individual schedules may differ when wintering in different areas, leading to differences in migration distance and conditions experienced at the wintering grounds and during migration, that may subsequently carry-over to timing of reproduction (Marra et al. 1998, Norris et al. 2004, Tøttrup et al. 2012, Kentie et al. 2017, Lok et al. 2017). As the timing of different parts of the annual cycle are intricately linked (Harrison et al. 2011), whether an individual arrives at the breeding grounds at an optimal time for successful reproduction depends on its ability to optimally time preceding events earlier in the annual cycle, i.e., the migration and wintering periods (Marra et al. 1998, Tøttrup et al. 2012).

Within a species, substantial variation in annual schedules may exist also at population levels. Variation in annual cycle schedules between populations is strongly driven by the optimal time for breeding (for example, along a latitudinal gradient where optimal time for reproduction is generally later at higher latitudes; van der Jeugd et al. 2009, Conklin et al. 2010, Briedis et al. 2016). Despite substantial variation in migration routes and wintering area selection between individuals and populations in many species (Newton 2010), to what extent annual cycle schedules are driven by both breeding and wintering locations is a largely unresolved question in migration ecology (Åkesson et al. 2017). Quantifying the relative effects of breeding and wintering location on annual schedules requires large-scale tracking studies, with substantial geographic variation in breeding and wintering areas and mixing of individuals from different breeding populations in wintering areas. Thus far, a description of such a system has been lacking in the literature.

We studied the ocean-scale migration routes, wintering areas, and phenology of a long-distance migratory seabird, the Arctic Skua Stercorarius parasiticus. This species specializes in kleptoparasitizing other seabirds, most notably terns, small gulls and auks (Furness 1987). The Arctic Skua has a circumpolar breeding distribution ranging from northern temperate to high arctic zones. In the Atlantic, its main wintering areas are thought to span a large (latitudinal) range, from Iberia to Patagonia and South Africa (Furness 1987, Olsen and Larsson 1997), but have never before been investigated using tracking of individuals. Therefore, it is unclear 
whether all wintering areas have been identified, to what degree different breeding populations mix at wintering areas and whether individuals are consistent in their year to year wintering site selection. Full annual cycle tracking of individuals over several years and from multiple breeding sites spanning $19^{\circ}$ in latitude and $89^{\circ}$ in longitude allows us to study, for the first time, the spatial variation in wintering locations of Arctic Skuas and the effects of breeding and wintering locations on temporal organisation of their annual cycle at individual and population levels.

\section{METHODS}

\section{Study area, trapping}

Adult Arctic Skuas were captured and fitted with Global Location Sensor (GLS) loggers (referred to as geolocators hereafter) at eleven breeding sites: North-east

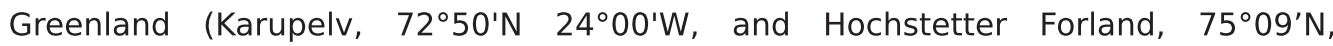
$19^{\circ} 40^{\prime} \mathrm{W}$ ), Iceland (Hroarstunga, $65^{\circ} 35^{\prime} \mathrm{N}, 14^{\circ} 22^{\prime} \mathrm{W}$ ), Faroe Islands (Fugloy, $62^{\circ} 06^{\prime} \mathrm{N}$, $6^{\circ} 52^{\prime} \mathrm{W}$ ), Scotland (Fair Isle, 59 $54^{\prime} \mathrm{N}, 1^{\circ} 63^{\prime} \mathrm{W}$ ), mainland Norway (Brensholmen, $69^{\circ} 35^{\prime} \mathrm{N}, 18^{\circ} 01^{\prime} \mathrm{E}$ and Slettnes, $71^{\circ} 05^{\prime} \mathrm{N}, 28^{\circ} 12^{\prime} \mathrm{E}$ ), Spitsbergen (Kongsfjorden, Svalbard, $79^{\circ} 57^{\prime} \mathrm{N}, 12^{\circ} 06^{\prime} \mathrm{E}$ ), Finland (Satakunta, 61 $33^{\prime} \mathrm{N}, 21^{\circ} 27^{\prime} \mathrm{E}$ ), and Russia (Tobseda, $68^{\circ} 36^{\prime} \mathrm{N}, 52^{\circ} 19^{\prime} \mathrm{E}$, and Erkuta, $68^{\circ} 14^{\prime} \mathrm{N}, 69^{\circ} 09^{\prime} \mathrm{E}$ ). Birds were captured either on the nest using bow nets, tent spring traps or walk-in traps, remove release nooses, or away from the nest using net guns, under appropriate licenses of local or national authorities. Upon recapture of the birds 1-3 years after deployment, geolocators were removed and data downloaded. Catching and deploying Arctic skuas was approved for the following countries by the appropriate licensing authority: North-east Greenland (Government of Greenland, \#C11-31, C12-28, C134(29), C13-11, C14-4(23), C14-16, C15-4(10), C15-14, C16-4(15), C16-20, C173(28), C17-23), Svalbard/Norway (Governor of Svalbard and Norwegian Food Safety Authority, FOTS ID 2086, 3817, 6329, 8538, 15726); Iceland; Faroe Islands (Copenhagen Bird Ringing Centre and The National Museum of the Faroe Islands); Scotland (Special Mark Technical Panel of the British Trust for Ornithology Ringing Committee); Finland (Centre for Economic Development, Transport and the Environment, VARELY/418/07.01/2012) and Russia.

\section{Geolocator specifications}

Several types of geolocators were used: C65, C250 (Migrate Technology, Cambridge, UK), mk9, mk13, mk15, mk18H (British Antarctic Survey, Cambridge, UK) and mk3006 (Biotrack, Wareham, UK). Geolocators measured ambient light in lux (Migrate Technology) or arbitrary units (BAS/Biotrack) every minute and saved the maximum value every 5 minutes. Geolocators were attached to a darvic ring around the tarsus. Length of wing (to the nearest $\mathrm{mm}$ ), head plus bill (to the nearest $0.1 \mathrm{~g}$ ) and tarsus (to the nearest $0.1 \mathrm{~g}$ ) and body mass (to the nearest $\mathrm{g}$ ) were measured. At the Faroe Islands, mainland Norway and Svalbard, ca 30 $\mathrm{LL}$ blood was collected from the brachial vein for DNA-sexing (Fridolfsson and Ellegren 1999). 


\section{Geolocator data processing}

We processed the data per interbreeding period (i.e., one migration cycle, referred to as a 'track' below). Sunrises and sunsets were calculated from light measurements using the function 'twilightCalc' from the R-package 'GeoLight (Lisovski and Hahn 2012) at a light threshold value of 10 (arbitrary light units, BAS/Biotrack models) and 2 (lux, Migrate Technology models). As Arctic Skuas spend the non-breeding period in open habitat (at-sea), light transitions at twilight were only rarely shaded, meaning most automatically assigned twilights had a low amount of misclassification. Remaining outliers (twilights considerably earlier or later than surrounding twilights) were identified visually by plotting date against time of sunset and sunrise and were either replaced by interpolated values using a local regression (LOESS) smoother. Locations were calculated for each noon and midnight for a sequence of potential sun angles, in steps of $0.5^{\circ}$. By visual inspection of the resulting tracks, we selected the sun angle resulting in a good fit of locations to the shape of the continents and a match in latitude estimates before and after each equinox. This resulted in sun angles for individual tracks from $-1^{\circ}$ to $-3^{\circ}$ for BAS/Biotrack loggers and $-4.5^{\circ}$ to $-6.0^{\circ}$ for Migrate Technology loggers. Mean error in position estimates for this method is typically $\pm 185 \mathrm{~km}$ for flying seabirds (Phillips et al. 2004) but can be much larger directly around the equinoxes.

Mid-wintering centroids were calculated as the geographical mean of position estimates from January, as this was the month in which least movement was observed. Based on these centroids, tracks were assigned to one of seven wintering areas: 1) Caribbean Sea, Guiyanan area and Gulf of Mexico and north of Brazil, 2) Patagonian Shelf, 3) Benguela Current west to Tristan da Cuñha, 4) Gulf of Guinea and west towards eastern Brazil, 5) Canary Current and off north-west Africa/lberia, 6) Mediterranean Sea and 7) Indian Ocean and adjacent seas (figure 8.1). For tracks that failed prematurely before January (see below) but that were stationary before logger failure in one of the above-mentioned wintering areas, this area was assumed to be the wintering area. Although assignments were based on positions in January, individuals stayed within the general wintering areas, roughly the boxes shown in figure 8.1, for longer. Timing of arrival at and departure from the wintering area (see below) reflects rapid movement to or away from the wintering area. Migration distance was calculated as the great-circle distance between the wintering centroid and the breeding site.

Considering that the species breeds in the Arctic, we describe the phenology from a northern hemisphere perspective, with, e.g., 'autumn migration' referring to postbreeding migration and 'spring migration' to pre-breeding migration. For each track, we assigned timing of departure from and arrival at the breeding area and arrival at and departure from the wintering area. Timing of movement events were identified by inspecting raw position estimates, in particular longitude data which are also reliably estimated close to equinoxes and give a clear signal of arrival especially when the last segment of migration has a strong westerly or easterly component, 
as was often the case in Arctic Skuas. For birds breeding in areas with continuous daylight (Greenland, Iceland, Norway, Russia), first position estimates (after leaving the zone with continuous daylight) were typically close to the breeding site, but last position estimates (just before entering the zone with continuous daylight) were around $60^{\circ} \mathrm{N}$ and thus well away from the breeding area. To estimate time of departure from or arrival to the breeding area under continuous daylight, we assumed birds travelled at a speed of ca $850 \mathrm{~km} \mathrm{~d}^{-1}$, which has been recorded for the closely related Long-tailed Skua Stercorarius longicaudus (Sittler et al. 2011), between the breeding site and the first or last position estimate. Clutch initiation dates were inferred from light measurements, which in Arctic Skuas, with biparental incubation strategy (O'Donald 1983), are characterized by regularly alternating periods of light and darkness each usually more than an hour in length (Eichhorn et al. 2006). The breeding period was defined as the period from 1 July (as all individuals were in the breeding area at this date) to breeding area departure in the first year plus the period from clutch initiation in the second year to 30 June, and is thus a composite of two breeding seasons.

\section{Statistical analysis}

As a measure of migratory connectivity, the degree to which individuals from the same breeding populations stay together at wintering areas (Webster et al. 2002), we calculated Mantel correlation $\mathrm{R}_{\text {mantel }}$ test using the 'MigConnectivity' package in $R$ (Cohen et al. 2018), using only the first track of each individual. Significance of the Mantel correlation coefficient was assessed by 1000 random permutations. $R_{\text {mantal }}$ values can get negative but are usually between 0 (no correlation between relative positions of individuals in both seasons) and 1 (same configuration of individuals in both seasons), thus with higher values indicating stronger migratory connectivity.

To quantify the consistency of individuals between years in choice of wintering area, inter-centroid distances were measured between subsequent years between

FIGURE 8.1 | Wintering locations of Arctic Skuas from breeding areas between East Greenland and West Siberia. Dots represent centroids of January positions for each track, coloured per wintering area (boxes). Pie charts at breeding sites represent the number of individuals wintering in each of the seven wintering areas. Pie chart sizes correspond to the total number of individuals per breeding site; dark grey boxes show how breeding sites are combined into breeding areas for statistical analyses. Sample sizes next to breeding area pie charts or boxes are number of tracks / number of individuals. Green areas reflect the breeding range. Abbreviations for breeding sites are $A R C=$ Northeast Greenland and Svalbard, NOR = Brensholmen and Slettnes, ICE = Iceland, ATL = Faroe Islands and Fair Isle, FIN = Finland, and for wintering areas are PAT = Patagonian Shelf, BEN = Benguela region, GUL $=$ Gulf of Guinea, CAR $=$ Carib, CAN = Canary Current, MED = Mediterranean Sea. 


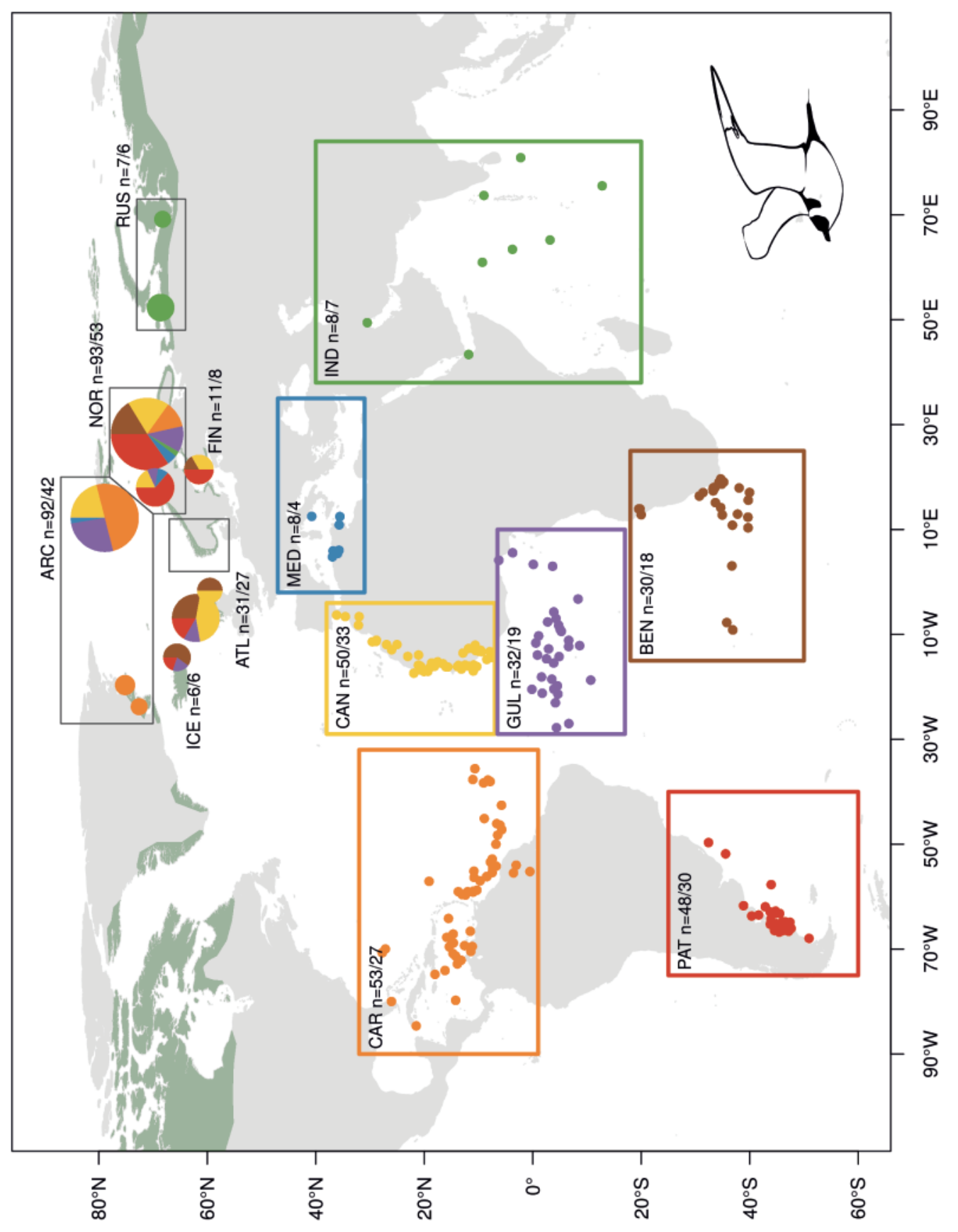


centroids 1 ) of the same individual and 2) of different individuals from the same breeding site. To test whether individuals' centroids were closer, a random distribution was generated by 10000 times randomly re-distributing within- and between-individual labels among a random selection of track-comparisons. In addition, we calculated the frequency in which individuals switched between the seven wintering areas outlined above (figure 8.1).

To estimate the effects of breeding area and wintering area on the timing of each event (breeding area departure, wintering area arrival, wintering area departure, breeding area arrival and clutch initiation, expressed as day since 1 July) and the duration of each intervening period (autumn migration, wintering period, spring migration, pre-laying period and breeding period, expressed in number of days), four Generalized Linear Mixed Models (GLMMs) were constructed with effects of 1 ) breeding area only, 2) wintering area only, 3) both breeding and wintering area and 4) both breeding area and wintering area and their interaction included as categorical variables. Breeding sites with small sample sizes (see below) were grouped with the closest breeding site with similar latitude and mean clutch initiation date: Erkuta was joined with Tobseda (Russia), Scotland with the Faroe Islands ('Atlantic'), Brensholmen with Slettnes (Norway) and both sites in East Greenland with Svalbard ('Arctic'). Because all birds from the two Russian sites and only one bird from Slettnes wintered in the Indian Ocean (see results), the effects of wintering and breeding area for these areas cannot be disentangled. Therefore, we removed all individuals wintering in the Indian Ocean from this analysis, reducing the number of wintering areas to six and the number of breeding areas to five. This also resulted in the loss of one bird from Slettnes which also happened to winter in the Indian Ocean. 'Individual' was included in all models as a random intercept. We used Bayesian GLMMs as implemented in the 'mcmcGLMM' package in R (Hadfield 2010), using 500000 iterations, a burn-in of 3000 and a thinning interval of 10; effective sample sizes was thus ca. 49 700. Default inverse-Wishart priors were used for all models except for breeding area arrival and clutch initiation, in which variance components were small and led to elements of the covariance matrix being estimated at zero. Therefore, for timing of arrival at the breeding area and clutch initiation, we used parameter expanded priors, with a scale parameter of $10^{3}$ (Hadfield 2010). After running, model results were checked for mixing of and autocorrelation within the chains. To compare support between models we used the deviance information criterion (DIC), in which smaller values indicate better model support and models with a $\triangle \mathrm{DIC}$ of 3 or more were considered to have 'considerably less support' (Spiegelhalter et al. 2002). In addition, we present the Akaike model weights $\left(w_{i}\right)$, which is the relative likelihood of each model (Burnham and Anderson 2002). To show partitioning of variation among breeding and wintering area and individuals, variance components were extracted for the fixed effects as well as between and within individuals of a model with both breeding and wintering area. 


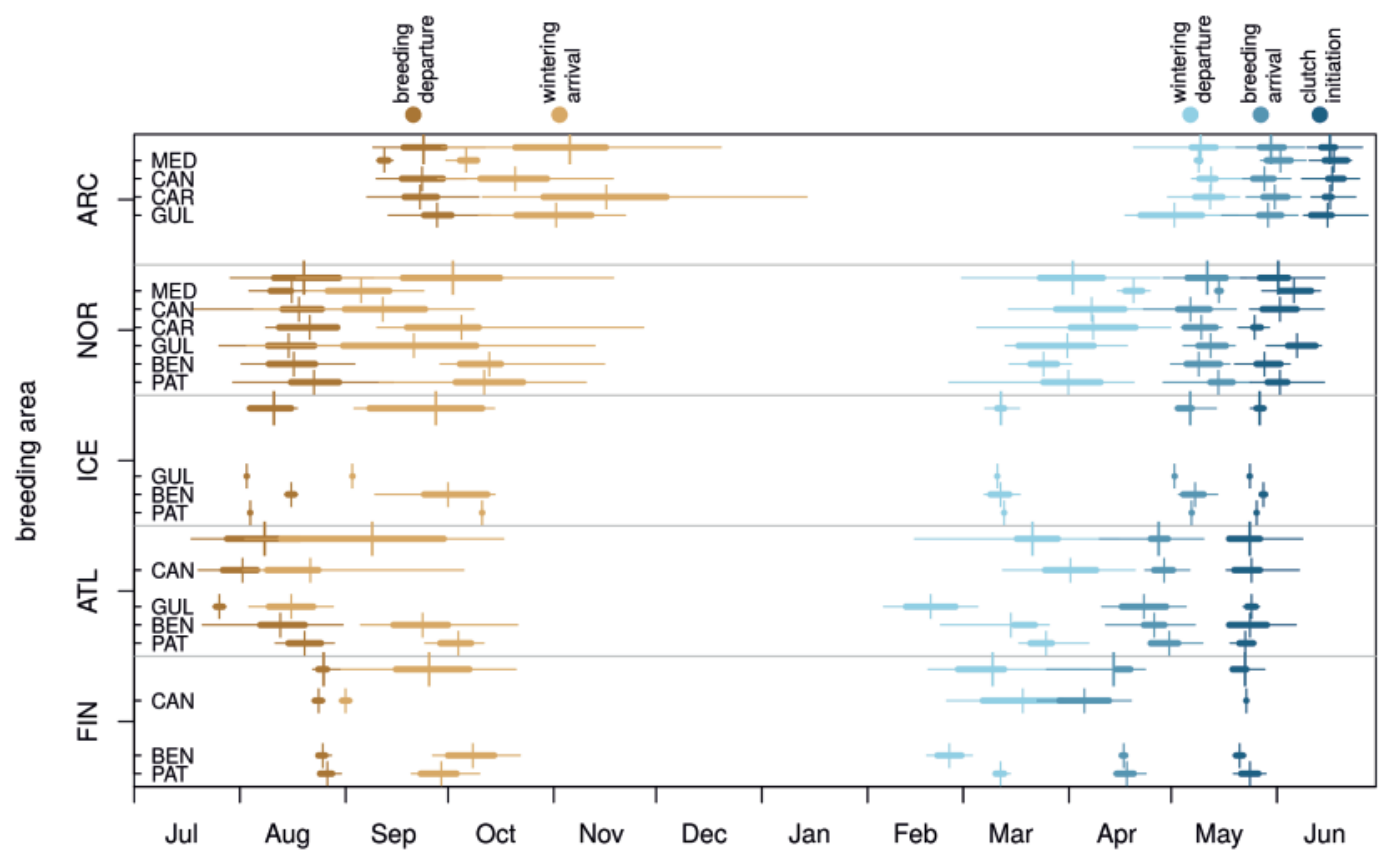

FIGURE 8.2 | Summary of timing data per breeding and wintering area, not corrected for repeated tracks. Vertical lines show the mean, thick horizontal lines show the 25 th and 75 th percentiles and thin horizontal lines extend to the 5th and 95th percentiles. For each breeding area, upper rows show the overall statistics. For abbreviations of breeding and wintering areas, see figure 8.1.

\section{RESULTS}

\section{Sample size}

In total, data for 240 tracks from 142 individuals were obtained, originating from 11 breeding sites (before lumping for statistical analyses). These numbers are specified per breeding site in figure 8.1. In total, 30 individuals were tracked for 2 years, 22 for 3 years and 7 for $4-5$ years. Part of the tracks $(n=43)$ were incomplete due to premature failure of the logger or due to flat batteries. Of all failures $50 \%$ occurred between 9 November and 30 December. About half of the failures $(n=22)$ occurred during the second or later year of tracking.

\section{Migratory connectivity and spatial consistency of individuals}

Individuals from single colonies wintered in widely separated areas (figure 8.1). Largest variation was found among individuals from Slettnes, Norway $(n=43)$, which wintered in each of the seven areas. Variation between individuals was smallest in the small samples from Russian sites, that all wintered in the Indian Ocean $(n=6)$, and from Greenland, that all wintered in the Caribbean area $(n=3)$. Arctic Skuas breeding in Svalbard $(n=38)$ wintered primarily in the Caribbean area $(50 \%)$, and none migrated to the southern wintering areas, the Patagonian Shelf and Benguela 
TABLE 8.1 | Model selection results for (a) timing of migration and clutch initiation and (b) duration of intervening periods as response variables and breeding area and wintering area as a function of breeding and wintering area. Models are compared by $\triangle \mathrm{DICs}$ and Akaike weights $\left(w_{i}\right)$. For each response variable, $\Delta \mathrm{DICS}$ and ${ }_{w i}$ values for the model with highest support is in bold.

\begin{tabular}{|c|c|c|c|c|c|c|c|c|}
\hline \multirow[b]{2}{*}{ response (y) } & \multicolumn{2}{|l|}{$\mathbf{y} \sim$ bre } & $y \sim$ win & \multicolumn{3}{|c|}{$y \sim$ bre + win } & \multicolumn{2}{|c|}{$y \sim$ bre $*$ win } \\
\hline & $\Delta \mathrm{DIC}$ & $w_{i}$ & $\Delta \mathrm{DIC}$ & $w_{i}$ & $\Delta \mathrm{DIC}$ & $w_{i}$ & $\Delta D I C$ & $w_{i}$ \\
\hline \multicolumn{9}{|l|}{ a) timing } \\
\hline breeding departure & 3.7 & 0.13 & 26.8 & 0 & 0 & 0.82 & 5.8 & 0.05 \\
\hline wintering arrival & 17.8 & 0 & 7.8 & 0.01 & 0 & 0.74 & 2.2 & 0.25 \\
\hline wintering departure & 14.5 & 0 & 3.1 & 0.13 & $\mathbf{0}$ & 0.64 & 2.1 & 0.23 \\
\hline breeding arrival & 2.3 & 0.22 & 20.1 & 0 & 0 & 0.69 & 4.1 & 0.09 \\
\hline clutch initiation & 0 & 0.72 & 20.9 & 0 & 1.9 & 0.27 & 8.1 & 0.01 \\
\hline \multicolumn{9}{|l|}{ b) duration } \\
\hline autumn migration & 5.1 & 0.06 & 3 & 0.17 & 0 & 0.74 & 6 & 0.04 \\
\hline wintering period & 10.2 & 0 & 0 & 0.57 & 0.7 & 0.4 & 5.9 & 0.03 \\
\hline spring migration & 4.2 & 0.05 & 0.7 & 0.29 & 0 & 0.41 & 1 & 0.25 \\
\hline pre-breeding period & 2.7 & 0.18 & 9.7 & 0.01 & 0 & 0.7 & 3.6 & 0.12 \\
\hline breeding period & 0 & 0.88 & 21.2 & 0 & 4.2 & 0.11 & 9 & 0.01 \\
\hline
\end{tabular}

Current. In contrast, from other breeding sites, only a small part of the individuals from Norway wintered on the Caribbean area $(9 \%, n=54)$. A considerable part of the individuals breeding in Norway and Finland wintered at the Patagonian Shelf $(41 \%, n=60)$, whereas the Benguela Current $(37 \%)$ and Canary Current $(37 \%$, $\mathrm{n}=27$ ) were the most important wintering areas for birds breeding on the Atlantic islands. Despite the population differences, the considerable degree of mixing of individuals from both the same and from different breeding sites in wintering areas results in a weak migratory connectivity, as is expressed in the $R_{\text {mantel }}$ of 0.21 (credible interval: $0.13-0.30$ ).

During both autumn and spring migration, most birds wintering in the Atlantic staged in a broad area across the central North Atlantic, roughly between $35^{\circ} \mathrm{N}$ and $55^{\circ} \mathrm{N}$ (figure 8.1). Individuals breeding at Svalbard and wintering in the Canary Current, however, skipped this staging area and followed a more eastern route along Western Europe. 


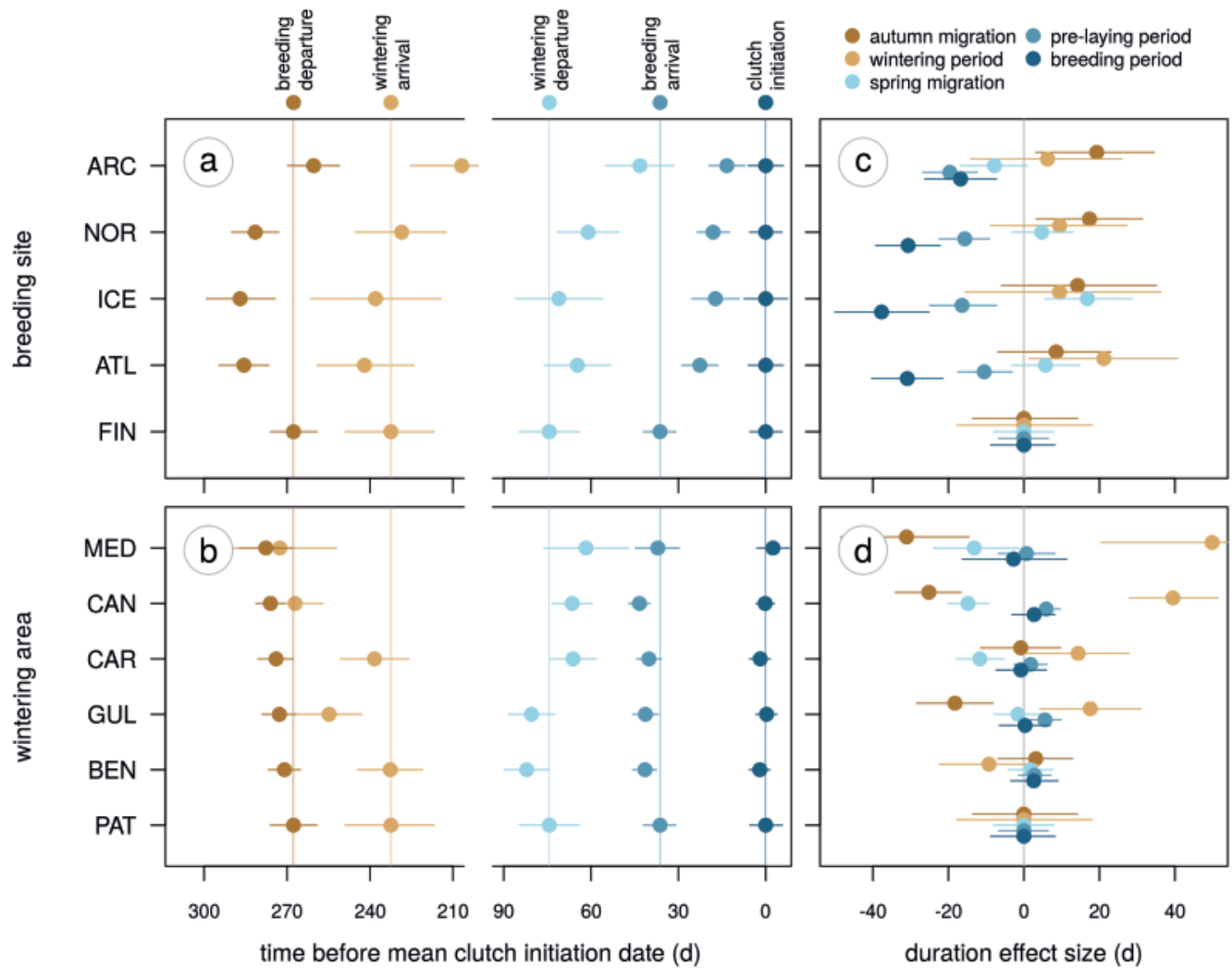

FIGURE 8.3 | Posterior means (with 95\% credible intervals) of models of timing (a, b) and duration (c, d) with breeding site and wintering area as fixed effects. In a, timing of migration events is relative to the intercept for each model (vertical lines) and the posterior mean for clutch initiation date of each breeding site. To clarify, if breeding latitude only shifted annual schedules but not affected durations, all posterior means in a would be at the intercepts and all durations in $\mathbf{b}$ would centre around zero. In $\mathbf{b}$, effect size of wintering areas are relative to the intercepts of each model (vertical lines), which in turn are presented relative to the intercept of clutch initiation date.

Breeding sites $(\mathbf{a}, \mathbf{c})$ are sorted bottom to top according to increasing latitude, which matches with later lay dates. Wintering areas (b, $\mathbf{d})$ are sorted bottom to top according to decreasing migration distance. Note the broken $\mathbf{x}$-axis in $\mathbf{a}$ and $\mathbf{b}$. Effect size of breeding site (c) and wintering area (d) on duration of periods relative to the intercept. In $\mathbf{c}$ and $\mathbf{d}$, colours relate to periods after events in $\mathbf{a}$ and $\mathbf{b}$ with the same colour. For abbreviations of breeding and wintering areas, see figure 8.1.

\section{Individual spatial consistency}

Out of 59 individuals tracked for 2-5 years ( $n=93$ tracks), only two individuals (3.4\%) switched wintering area between years. The first individual, a bird breeding in Brensholmen (Norway), went to the Gulf of Guinea in the first two years of tracking, but wintered in the Canary Current in its third year of tracking. The second individual, breeding in Svalbard, wintered in the Caribbean area in the first year and in the Gulf of Guinea in the second year. All other individuals were consistent in 

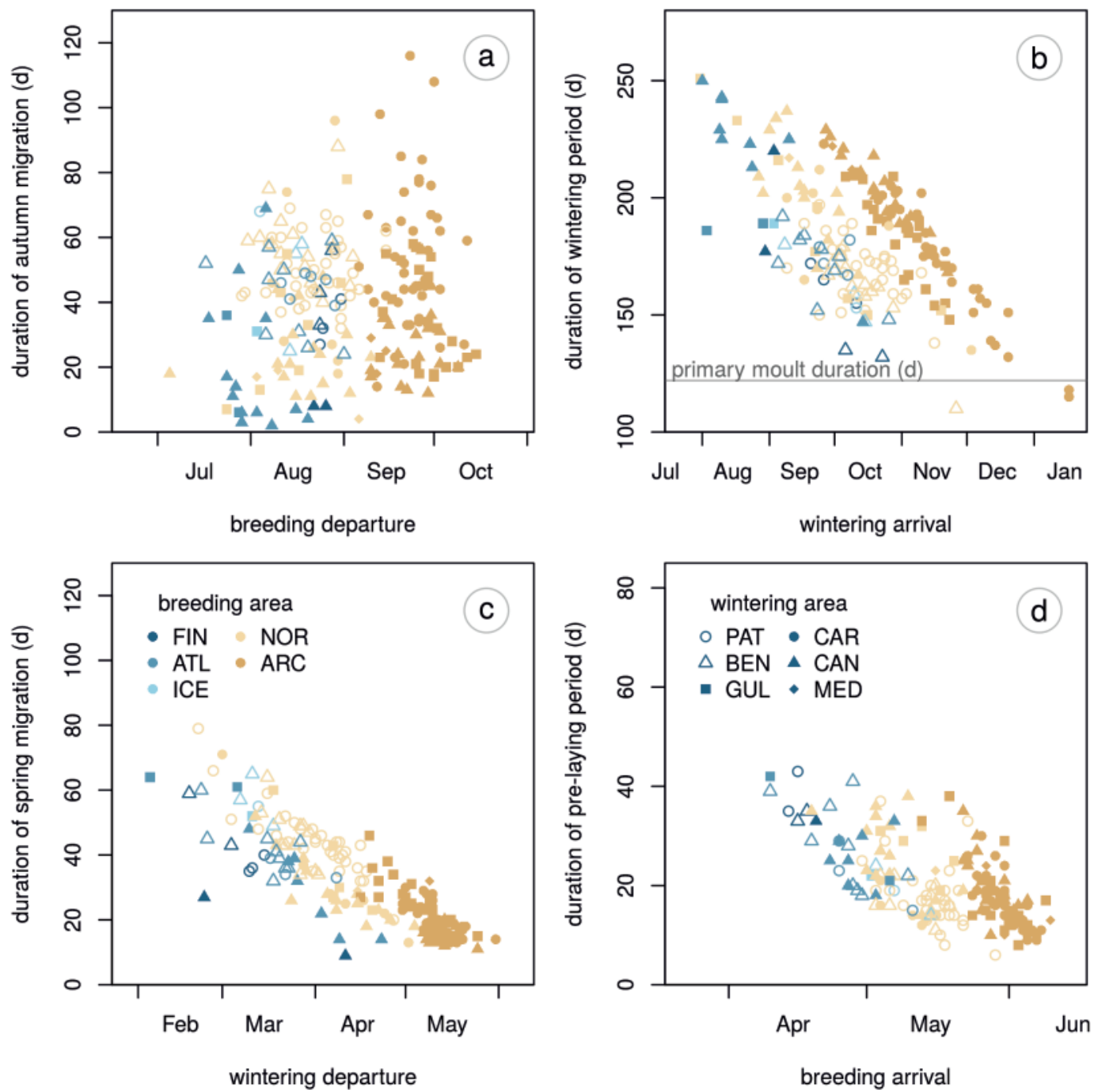

FIGURE 8.4 | Duration of autumn migration (a), wintering period (b), spring migration (c) and the pre-laying period (d) as a function of the timing of their onset. The horizontal grey line in $\mathbf{b}$ reflects the duration of primary moult of $122 \mathrm{~d}$ (van Bemmelen et al 2018). For abbreviations of breeding and wintering areas, see caption of figure 8.1.

their wintering area, which is reflected in smaller distance between wintering centroid distances within individuals $(470 \pm 64 \mathrm{~km})$ than between individuals from the same breeding area $(4486 \pm 488 \mathrm{~km}, \mathrm{p}<0.001)$.

\section{Effect of breeding and wintering location on annual schedules}

Overall, models with both breeding and wintering area had the lowest DIC values and substantially higher Akaike weights than other models for four out of five timing variables and two out of five duration variables (table 8.1). Exceptions to 

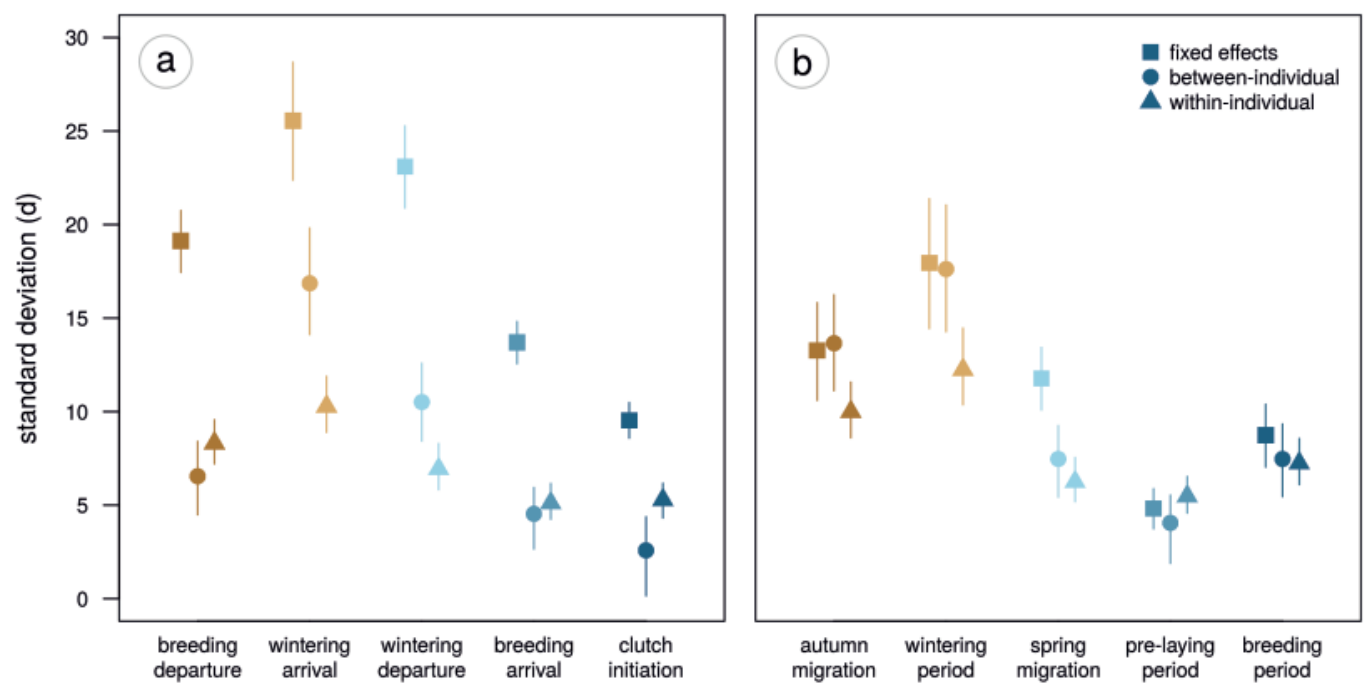

FIGURE 8.5 | Squared posterior means of model standard deviation components of a model with both breeding site and wintering area (a-b): fixed effects, between-individual and within-individual variation for timing of events (a) or duration of periods (b) in the annual cycle of Arctic Skuas.

this were the timing of clutch initiation and the length of the breeding period, which were not or only weakly affected by wintering area, and the duration of the wintering period, on which breeding area had no effect.

Breeding area had a substantial effect on timing of all events in the annual cycle (table 8.1, figure 2, supplement table 8.1), with populations from the northern breeding areas being later in departure from the wintering area, arrival at the breeding area and clutch initiation (figure 8.2). The time spent in the breeding area was similar between most sites, but longer in North-east Greenland/Svalbard, and especially Finland. Birds from Finland as well as from Greenland/Svalbard started autumn migration later than would be expected based on the difference in timing of clutch initiation (figure 8.3a). Duration of autumn migration increased with breeding latitude. Duration of the wintering period showed a similar pattern but was only weakly affected by breeding latitude (table $\mathbf{8 . 1}$, figure 8.3c). Duration of spring migration was longest among birds from Iceland and shortest among birds from Greenland/Svalbard. Overall, spring migration duration declined with later timing, both within and across populations (figure 4). The period between breeding arrival and egg-laying shortened with breeding latitude from ca $34 \mathrm{~d}$ in Finland to ca $14 \mathrm{~d}$ in Svalbard (figure 3c).

Data provide strong support for an additive effect of wintering area next to breeding area, (1) on timing of departure from the breeding area, (2) arrival at and departure from the wintering area (table 8.1, figure 8.3b, supplement table 8.1) and to a lesser extent on (3) timing of arrival at the breeding area (figure 
8.3b, table 8.1, supplement table 8.1). The duration of autumn and spring migration to more southern wintering areas, i.e. farther from the breeding areas, was longer than to more northern wintering areas (figure $\mathbf{8 . 3 d}$ ), and highest support was found for models with only wintering area or wintering and breeding area (table 8.1). The only exception to this pattern was the relatively late timing of arrival to the Caribbean wintering area, ca. $30 \mathrm{~d}$ later than the arrival to the Canary Current, although both are at similar latitudes. The late arrival at the Caribbean wintering area resulted from birds roaming for a long time in the North-west Atlantic before migrating the final leg to the wintering area (figure 2). Wintering period was not or only weakly affected by breeding area. The time between spring arrival and clutch initiation shortened with (latitude of) breeding area, with weak support for a model incorporating both breeding and wintering area over a model with only breeding area. Clutch initiation date appears only weakly affected by wintering area (table 8.1, figure 8.3b). No support was found for an effect of wintering area on time spent at the breeding area.

\section{Individual repeatability and absolute consistency in annual schedules}

Timing of individuals was more variable in autumn migration than in spring migration (figure 8.5). Within-individual variation was largest in the timing of arrival at the wintering area and the duration of the wintering period, and smallest in timing of clutch initiation and the length of the pre-breeding period. Betweenindividual variation and fixed effects variance followed the same pattern as withinindividual variation (figure 8.5).

\section{DISCUSSION}

The study of the relative effects of breeding site and wintering area on annual schedules of migratory birds has previously been hampered by the lack of studies with large spatial variation in wintering area between individuals. Our study species is exceptionally well-suited for studying such large-scale phenology patterns, as Arctic Skuas showed unprecedented variation between individuals - even within breeding sites - in selection of wintering areas separated by thousands of kilometres. Individuals from the best-sampled breeding site (Slettnes, Norway) wintered in all productive areas of the Atlantic between $50^{\circ} \mathrm{S}$ and $30^{\circ} \mathrm{N}$, but also in the Mediterranean Sea and the Persian Gulf, together representing roughly a tenth of the earth's oceanic surface area. The lower variability in choice of wintering area at other breeding sites may reflect smaller sample sizes, notably Russia and Greenland. The variation in wintering area shown by individual Arctic Skuas exceeds the range of wintering location choice in other well-studied long-distance migratory species, such as Cory's Shearwater Calonectris diomedea (Dias et al. 2011), Blacklegged Kittiwake Rissa tridactyla (Frederiksen et al. 2012), Brown Skua Stercorarius antarctica (Phillips et al. 2007, Delord et al. 2017), Tree Swallow Tachycineta bicolor (Gow et al. 2018) and Purple Martin Progne subis (Fraser et al. 2012). It also far 
exceeds the amount of variation shown by a closely related conger species, the Long-tailed Skua Stercorarius longicaudus (van Bemmelen et al. 2017). The oceanscale variation in wintering area selection makes the Arctic Skua ideal for studying the effects of breeding and wintering area on full annual phenology. In our study, both breeding and wintering area affected timing of annual schedules of Arctic Skuas in complex ways (summarized in figure 8.6). Despite distances of many $1000 \mathrm{~s} \mathrm{~km}$ between wintering areas and migrations to the most distant areas taking up to a month longer, timing of spring arrival at the breeding ground as well as clutch initiation were largely synchronized among birds from the same breeding site.

Breeding site had a large effect on the timing of all events in the annual cycle of Arctic Skuas (figure 8.3), with delayed annual schedules of populations breeding at higher latitudes compared to populations from more southern breeding areas. The strong effect of breeding site on annual schedules is consistent with earlier studies on waders and passerines (Conklin et al. 2010, Fraser et al. 2013, Briedis et al. 2016, Gow et al. 2018), and can be explained by selection for optimal timing of reproduction, which is later at higher latitudes (Burr et al. 2016) and affects later stages of the annual cycle through a 'domino effect' (Piersma 1987). Although the duration of incubation and parental care are expected to be similar across latitudes in a single-brood species, departure from the breeding area was not linearly driven by breeding latitude. Compared to sites at intermediate latitudes, onset of autumn migration was later in one of the southernmost breeding areas, Finland, as well as the northernmost breeding area in our sample, Svalbard. A later start of autumn migration may be profitable if feeding conditions are better locally than at stopovers or wintering areas. Indeed, the extended period that Arctic Skuas stay around Svalbard coincides with Black-legged Kittiwakes - an important host species for kleptoparasitizing Arctic Skuas - concentrating here for Capelin Mallotus villosus and other prey species (Reiertsen et al. 2014).

In addition to breeding phenology, also wintering area affected annual schedules. Birds at more distant wintering areas migrated up to ca $30 \mathrm{~d}$ longer in autumn and ca $14 \mathrm{~d}$ longer in spring. Longer migration durations to more distant wintering areas led to later arrival at the wintering grounds and earlier departure from the wintering area. Earlier departure from more distant wintering areas in Arctic Skuas is consistent with studies on other species, such as Northern Gannet Morus bassanus, White Stork Ciconia ciconia and Purple Martin Progne subis (Berthold et al. 2002, Fraser et al. 2013, Fifield et al. 2014). The longer migration duration to more distant wintering sites may not seem surprising, but contrasts with an alternative strategy in which longer migration distances are covered at higher daily travel speeds (REF; RNP paper?). This suggests that migration speed is less flexible than timing in Arctic Skuas, which may be explained by a constrain on fuelling rates at stopovers and en route (Lindström et al. 2019). 
As a consequence of the later arrival at and earlier departure from more distant wintering areas, wintering periods of Arctic Skuas were up to $50 \mathrm{~d}$ shorter in the most distant area compared to the nearest. In Arctic Skuas, the wintering period is used to moult body feathers twice and primary flight feathers once (Olsen and Larsson 1997). In most wintering areas, the wintering period was considerably longer than the time needed for primary moult, which is about $122 \mathrm{~d}$ (van Bemmelen et al. 2018). This left ca 40-130 d for other activities, such as recovering from the preceding breeding season and autumn migration, and fuelling for spring migration. Fuelling for spring migration may overlap temporally with the final part of primary moult, as individuals probably start spring migration quickly after primary moult is finished (van Bemmelen et al. 2018).

Breeding latitude not only shifted the timing of annual schedules, but also affected the duration of key periods within the annual cycle. Most notably, birds breeding at high latitudes had shorter autumn migrations, faster spring migrations and shorter pre-laying periods compared to birds breeding at lower latitudes. Also within breeding populations, later timed spring migrations were shorter (figure 8.4c). While selection for synchronized spring arrival time at the breeding site may explain why later timed spring migrations are shorter, the across-population shortening of spring migrations with later timing indicates an effect of seasonality. Possibly, late-migrating Arctic Skuas may face deteriorating feeding conditions in the North Atlantic stopovers during April to May, when potential host species such as Arctic Terns Sterna paradisaea and Sabine's Gull Xema sabini return to their breeding areas (Egevang et al. 2010, Stenhouse et al. 2012, Fijn et al. 2013).

The more northern, late-migrating Arctic Skuas also had shorter pre-laying periods (for example, $14 \mathrm{~d}$ in Svalbard, $18 \mathrm{~d}$ in Slettnes and $23 \mathrm{~d}$ in the Faroe Islands, similar to values in Furness 1987), suggesting they may rely more on distantlyacquired resources ('endogenous' reserves) for egg production (Hobson et al. 2000). Skuas arrive in the breeding area with large body stores (Belopol'skii 1961, de Korte 1985), which they may build up at the wintering areas or at stopovers. Late-migrating individuals spent little or no time at the North Atlantic stopovers (figure 8.4d) and thus appear to acquire fat reserves in the wintering areas and carry them during spring migration. Carrying large fat reserves on migration is costly and may not be feasible from the furthest wintering areas; this potentially explains why Arctic Skuas breeding in the high Arctic (East Greenland/Svalbard), having the fastest spring migrations and shortest pre-laying periods, do not migrate to the southernmost wintering areas (Patagonian Shelf and Benguela region). Carrying large fat reserves on migration can be advantageous as it increases flight speed when adopting a flight technique called 'dynamic soaring' (Pennycuick 2008), which is what skuas do at high wind speeds (Olsen and Larsson 1997). Furthermore, carrying fat reserves is less costly in larger-bodied birds (Alerstam and Lindström 1990). Interestingly, wing and head lengths as well as body mass increase in Arctic Skuas with breeding latitude (figure 8.S1, table 8.52), thus with 


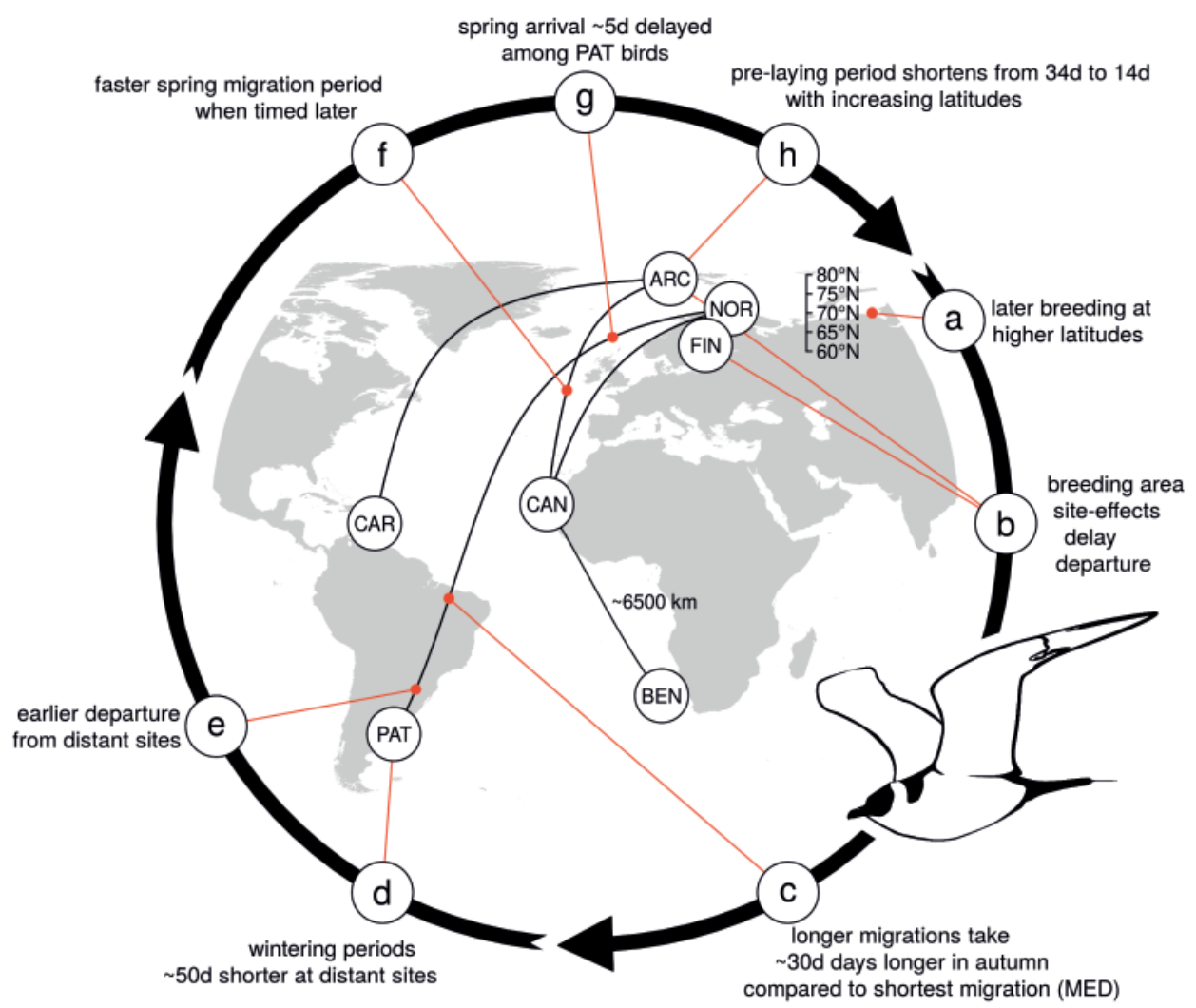

FIGURE 8.6 | Graphic summary of main findings (a-h), in a sequence from clutch initiation (a) through autumn migration (b-c), wintering period (d), spring migration (e-g) to the pre-laying period (h). Four wintering areas and three breeding sites are highlighted as examples. For abbreviations of breeding and wintering areas, see figure 8.1.

later timing of migration, shorter spring migrations, shorter pre-laying periods and presumably a higher dependence on endogenous reserves or egg formation and self-maintenance. Selection for larger body size to reduce the costs of carrying fat reserves during migration provides an alternative hypothesis to explain latitudinal clines in body size, for which usually Bergman's rule is invoked (Meiri and Dayan 2003). Body mass measurements of Arctic Skuas during migration and at arrival in the breeding areas at a range of latitudes are needed to verify whether fat reserves are larger in birds breeding at higher latitudes.

Wintering area selection was not expected to affect timing of spring arrival at the breeding area as later arrival could decrease reproductive success and the potential to obtain territories and mates. Surprisingly, an effect of wintering area on timing of spring arrival is supported by our data, with delayed arrival of ca. $5 \mathrm{~d}$ for birds wintering at the Patagonian Shelf. The Patagonian Shelf is the southernmost and therefore most distant wintering area among our sample of Arctic Skuas, but only marginally further than the Benguela region. The difference in spring arrival timing 
was already manifested at departure from the wintering areas, whereas migration durations between the two areas were similar (figure 8.3). It remains unclear however, why do birds from the Patagonian Shelf not depart earlier.

Later arrival at the breeding grounds of individuals from more distant wintering areas has been reported for several short- to long-distance migrants, including Blackcap Sylvia atricapilla, Great Cormorant Phalacrocorax carbo and Eurasian Spoonbill Platalea leucorodia (Bearhop et al. 2005, Bregnballe et al. 2006, Lok et al. 2017). Whereas in spoonbills the later arrival at the breeding grounds also led to later reproduction and lower reproductive success, wintering area had minimal influence on laying dates in Arctic Skuas, indicating synchronization at breeding sites. Synchronization of clutch initiation at a breeding site may be achieved in several ways. For example, members of pairs established in earlier years may wait for each other, which has been described for Arctic Skuas (Furness 1987). Under this scenario, no assortative mating would occur relative to wintering area despite differences in arrival time (Gunnarsson et al. 2004), and differences in clutch initiation dates would average out between birds from different wintering areas except in pairs with both members wintering in the same area. At Slettnes and Svalbard, several pairs with partners wintering far apart have been observed but sample sizes are currently too small to allow robust estimates of assortative mating. Another potential cause of observed synchrony in lay dates is when latearriving birds are able to produce eggs sooner after arrival, for example by investing a larger amount of distantly-acquired resources into growing follicles (towards a 'capital' strategy on the income-capital axis; Drent and Daan 1980), which would shorten the time to acquire resources for the remaining part of the egg.

Our results demonstrate how both breeding site and wintering area affect annual schedules, leading to different timing of passage through and staging in areas, as well as different lengths of periods spent on breeding, migration and wintering. In particular, our study shows how timing of arrival at and departure from the wintering area depends on migration duration and ultimately leads to synchronized spring arrival time among individuals wintering at sites $1000 \mathrm{~s}$ of $\mathrm{km}$ apart. Given the interdependencies between parts of the annual cycle (Harrison et al. 2011) and differences in mortality rates between seasons (Klaassen et al. 2014, Lok et al. 2015), the variation in annual schedules has the potential to affect survival and reproductive rates. If and how breeding area, wintering area, and the concomitant annual schedules affect survival and reproductive rates in Arctic Skuas is to be investigated in future studies. 


\section{SUPPLEMENT}

Table S1 | Posterior means (with 95\% credible intervals) of Bayesian GLMMs of the timing of events (upper panel) and duration of intervening periods (lower panel) with breeding and wintering area as fixed effects and individual as random effect.

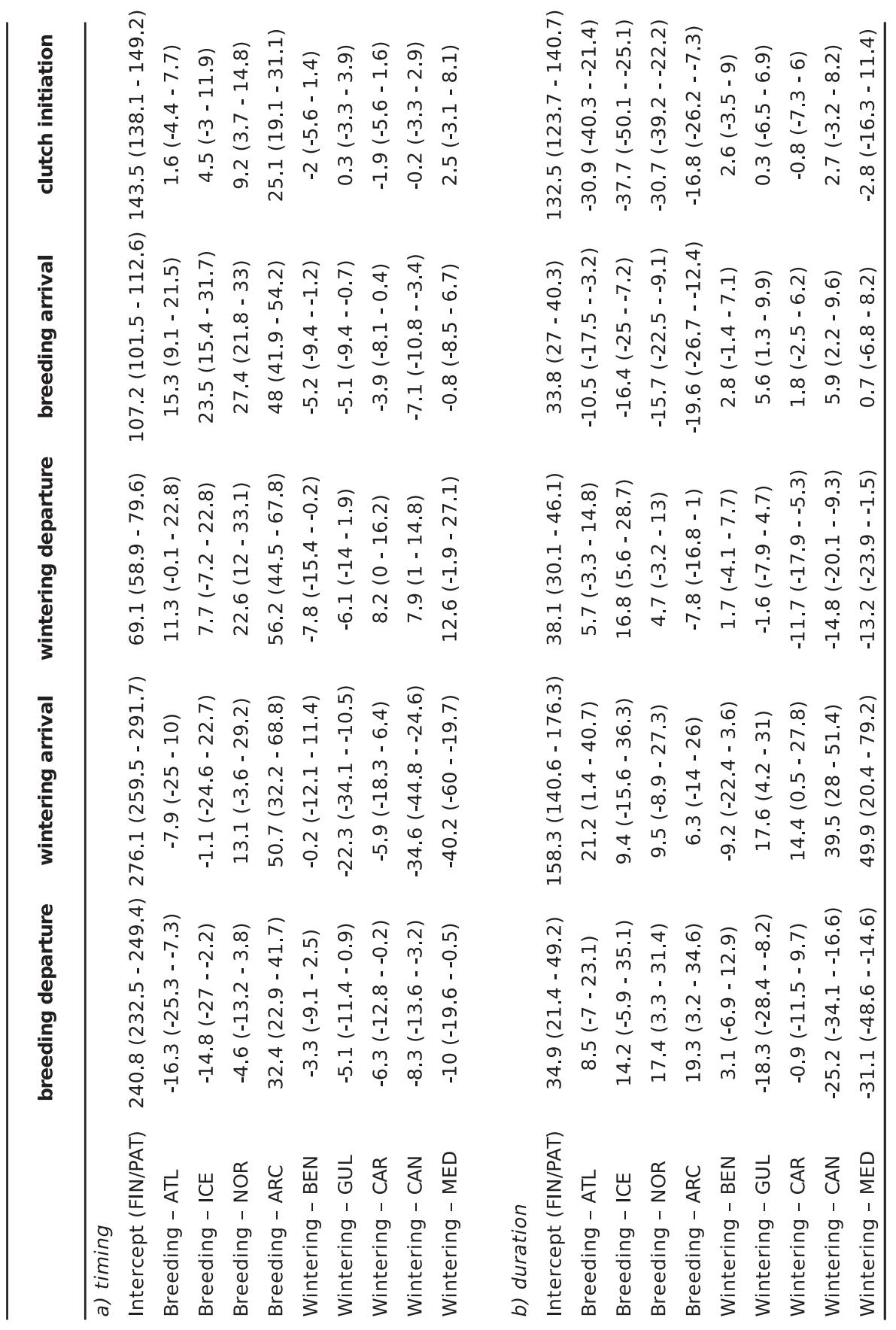




\section{Methods}

To test whether birds from higher breeding latitudes were larger, wing, tarsus and bill lengths and body mass during incubation were each included as response variables in Generalized Linear Mixed-effect Models (GLMMs) using the 'nlme' package in $\mathrm{R}$ (Pinheiro et al. 2018), with breeding latitude and sex as a fixed effects and breeding site as random effect. For each morphometric, all four potential models were compared using AICc using the MuMln package in $\mathrm{R}$ (Barton 2018). Sex is an important covariate as female Arctic Skuas are on average larger and heavier than males (Phillips and Furness 1997). However, sex was only known for part of the individuals and not yet for the dataset of Faroese birds. Therefore, the current analysis did not include birds from the Faroe Islands, but will be included after processing of the blood samples, and are presented in figure 8.S1 for comparison.

\section{Results}

Females were significantly in larger in wing $(\beta=6.7, d f=312, t=8.6$, $p<0.001)$, tarsus $(\beta=0.9, d f=310, t=4.7, p<0.001)$ and head length $(\beta=1.2$, $\mathrm{df}=308, \mathrm{t}=6.2, \mathrm{p}<0.001)$ and heavier $(\beta=56.7, \mathrm{df}=302, \mathrm{t}=16.3, \mathrm{p}<0.001)$ than males. Indeed, sex was included in the top-ranking models for each morphometric. Breeding latitude correlated positively only with wing length $(\beta=0.9, d f=1, t=17.8, p=0.036)$, but not with tarsus $(\beta=0.08, d f=1, t=0.6$, $p=0.653)$, head length $(\beta=0.08, d f=1, t=1.4, p=0.392)$ or body mass $(\beta=1.9, d f=1, t=1.2, p=0.437)$. AlCc and model weights indicated strong support for models with breeding latitude retained in the model for wing length ( $\mathrm{dAICc}=14.14)$, and also some support in the model for head length ( $d A I C c=1.23$ ) and body mass $(d A I C c=0.66)$, but not for tarsus length, where a model including breeding latitude was second-best at $\mathrm{dAICc}=1.12$, at the cost of a parameter. 

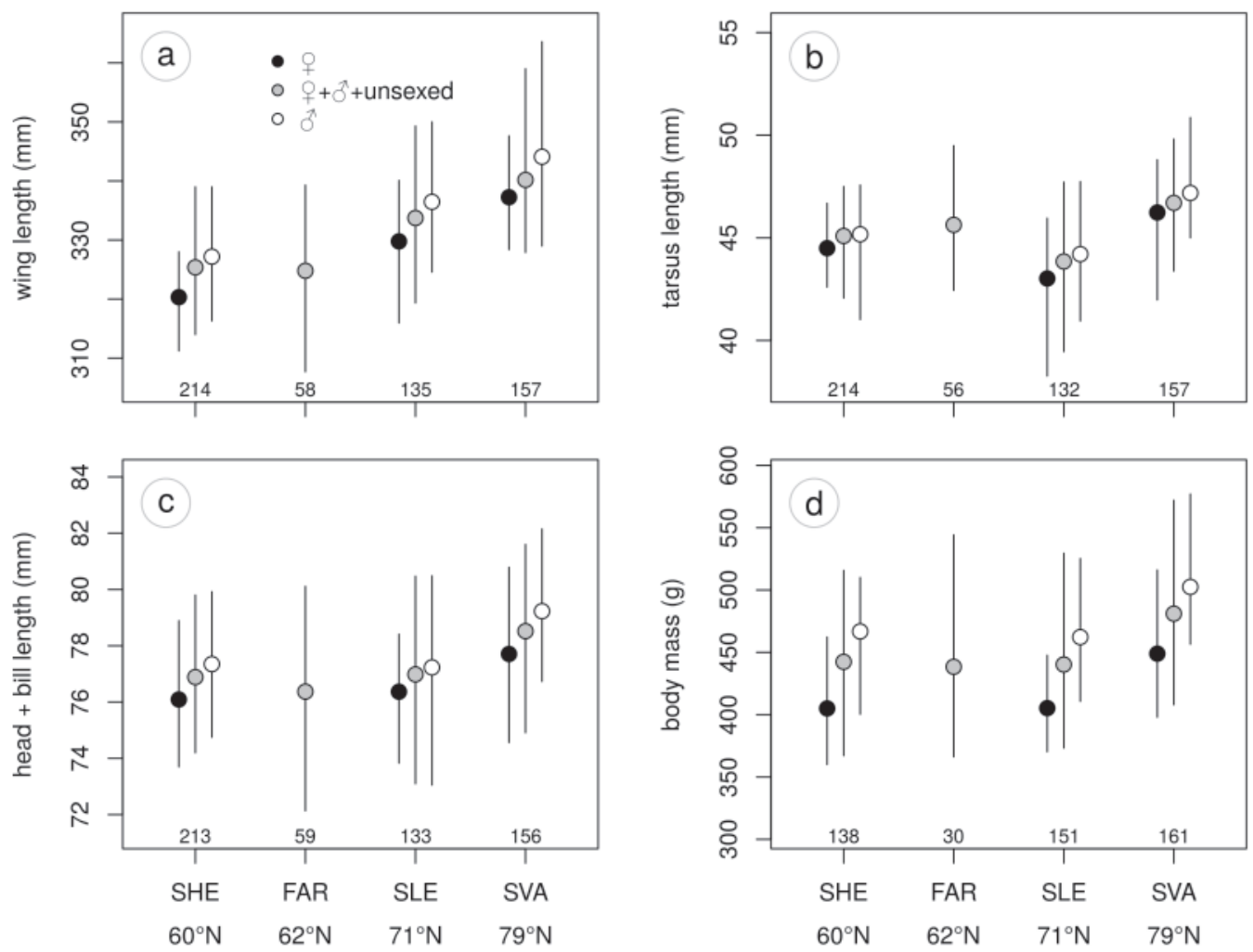

FIGURE 8.S1 | Morphometrics of Arctic Skuas from four breeding sites at increasing latitudes: SHE $=$ Shetland, FAR = Faroe Islands, SLE = Slettnes and SVA = Svalbard. a) Wing length, b) tarsus length, $\mathbf{c}$ ) head plus bill length and $\mathbf{d}$ ) body mass during incubation. For statistical significance of differences, see table 8.52. 


\section{ACKNOWLEDGEMENTS}

This study would not have been possible without the help of many fieldworkers, often investing substantial time and resources. In Slettnes, we were assisted in the field by Geert Aarts, Daniël van Denderen, Jan van Dijk, Maria van Leeuwe, Daan Liefhebber, Morrison Pot, Marc van Roomen, Janne Schekkerman en Rinse van der Vliet. Other help was provided by Cees and Mimi Tesselaar, Barbara Ganther, HansUlrich Rösner, Karl-Birger Strann, Jeanette Hickman, Torstein Johnsrud, Niels Westpahl and Benedicte Færevåg. In Svalbard and Brensholmen, help was provided by Erlend Lorentzen, Elise Biersma, Fokje Schaafsma, Anouk Goedknegt, Oebele Dijk, Maarten Loonen, Anette Fenstad, Elise Skottene, Liv Monica Trondrud, Nora Bjørnlid, Heidi Kilen, Eline Rypdal, Emilly Hill, Melissa Fontenille and Thomas Oudman. Expeditions to Tobseda in 2014-2015 were organized by Thomas Lameris and in 2018 by Götz Eichorn (NIOO-KNAW), and joined by Kees Schreven, Stefan Sand, Jasper Koster and Chiel Boom. In the Faroe Islands, help was provided by Jón Aldará, Leivur Janus Hansen and Anthony Weatherhill; we kindly acknowledge the landowners on Fugloy for permission to work on their property. At Hochsetter

Forland, Adrian Aebischer, Vadim Heuacker, Eric Buchel, Brigitte Sabard and Vladimir Gilg helped with field work. Benoît Sittler organised expeditions to Karupelv Valley where assistance was provided by Anita Lang, Mark Nitze and Felix Norman. In Erkuta, help was provided by Natalia Sokolova, Ivan Fufachev and Stijn Hofhuis. In Finland, Kari Mäntylä and Jukka Nuotio assisted during fieldwork. Support in the field in Scotland was provided by the Fair Isle Bird Observatory. James Fox (Migrate Technology Ltd) and Glen Fowler (Biotrack Ltd) kindly retrieved data from loggers that failed to download. 


\section{FUNDING}

RvB was funded by the Netherlands Organisation for Scientific Research (project number 866.13.005). BM and SAH and work in Svalbard and North Norway (Brensholmen) was financed the Fram Center flagship "Climate Change in Fjord and Coast" (grant nr 2019147470 1152018), as well as the County Governor of Troms and the County Governor of Finnmark. The fieldwork at the Faroe Islands (KS and $\mathrm{SH})$ was financially supported Faroese Research Council and the The National Museum of the Faroe Islands. Work at Hochstetter (led by OG and Loïc Bollache) was funded by the French Polar Institute-IPEV (grant "Interactions-1036") and by the Agence Nationale de la Recherche (program ILETOP ANR-16-CE34-0005). DE was financed by the terrestrial flagship of the Fram Center (project Yamal EcoSystem $\mathrm{nr}$ 362259). Fieldwork in Scotland was funded by a donor programme managed by David Agombar. The Arctic Skua project in Finland was funded by the Kone Foundation (application number 28-1235), The Finnish Cultural Foundation (grant to EM) and the ERC grant no 669609 (EM). 


\section{CHAPTER IX}

1. The Shooi is very far more numerous than its illustrious congener, and is the very sauciest bird in all the sky, not even excepting the Merlins and the Piccatarries. It is not every bird that can enjoy a joke, and the shooi really does seem to appreciate on thoroughly. It is as good as a comedy to witness his outbreak of high spirits, as he suddenly sweeps up high into the air, with a taunting cry, half peacock, half tom-cat, and leaves far behind him the bewildered stranger whom he has befooled hopelessiy of the track of the nests by his admírable-simulation of broken leg, broken wing, and broken prospects in general.

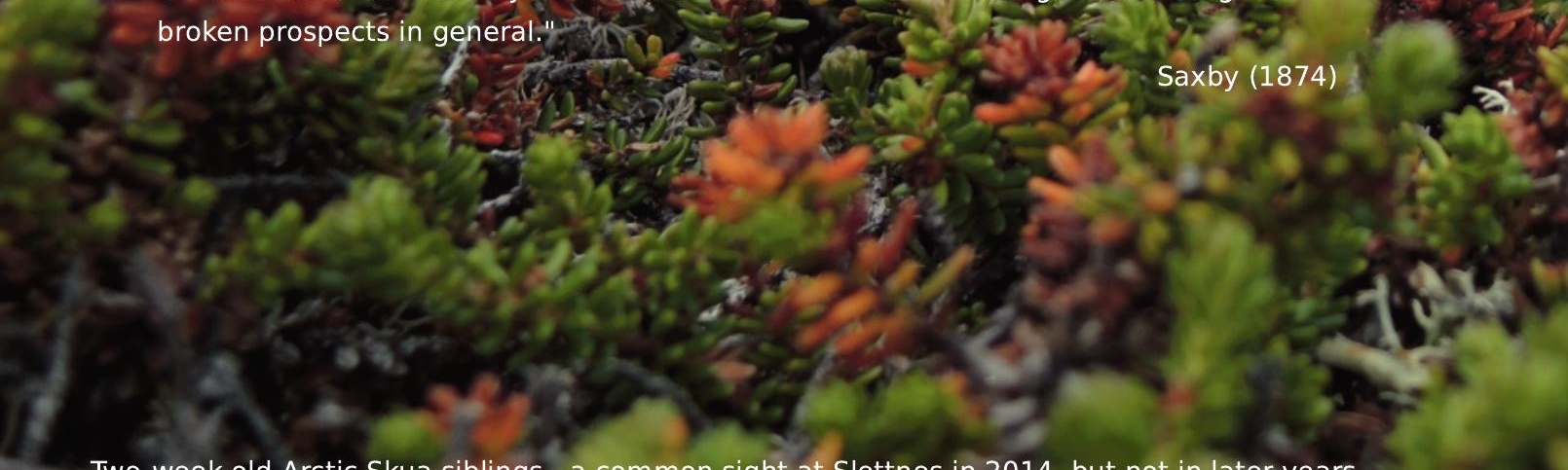

Two-week old Arctic Skua siblings - a common sight at Slettnes in 2014, but not in later years. 


\section{Heavy decline of the largest European Arctic Skua colony: interacting effects of food shortage and predation}

Rob van Bemmelen, Hans Schekkerman, Vincent Hin, Morrison Pot, Kirstin Janssen \& Ingrid Tulp 


\section{ABSTRACT}

Heavy declines of Arctic Skua Stercorarius parasiticus $\int_{1}^{2}$ populations have been reported from large parts of its European breeding range. In this study, we document a dramatic decline in number of breeding pairs of at least $50 \%$ over two decades in the largest European Arctic Skua colony, located at Slettnes in northern Norway. We provide evidence of both bottom-up (food shortage) and top-down (predation) effects on the reproductive investment and hatching success in this colony. Food shortage for three out of five recent study years was suggested by a high percentage of one-egg clutches, small eggs and low adult female body mass. At the same time, nest predation by Red Fox Vulpes vulpes increased during the five-year study, leading to total breeding failures for 2017-2018, despite the sufficient food availability in 2018. Clearly, the reproductive output as observed in recent years is too low to sustain a stable population, even with a high adult survival probability. 


\section{INTRODUCTION}

Seabirds are amongst the most threatened groups of birds with approximately $28 \%$ of all species are globally threatened (Croxall et al. 2012). In Europe, many seabird populations have declined substantially over the past decades, including the Arctic Skua Stercorarius parasiticus. Numbers of Arctic Skuas have been stable around the Baltic Sea at least since the 1980s (Valkama et al. 2011, Ottosson et al. 2012), but heavy declines have been reported from all other areas where reliable population estimates are available (Frederiksen 2010). For example, the species declined by ca $80 \%$ over the last 25 years in Scotland (Eaton et al. 2015, Perkins et al. 2018). Although no trend is known for the large population in Iceland (Skarphéðinsson et al. 2016) or the supposedly very large population of Arctic Skuas across the Russian Arctic and Nearctic, the species is listed as 'least concern' on the IUCN Red List for threatened bird species (BirdLife International 2016). In Europe, however, the Arctic Skua is listed as 'endangered' in the EU27 Red List (BirdLife International 2015). Arctic Skuas are also in decline along the mainland coast of Norway and this population is consequently categorized as 'near threatened' on the Norwegian Red List (Henriksen and Hilmo 2015). Populations appears stable in Svalbard, where the species is still listed as 'least concern' (Henriksen and Hilmo 2015).

Causes of Arctic Skua population declines have been well-studied in Scotland where reduced reproductive success was the main driver (Phillips et al. 1996, Perkins et al. 2018). Arctic Skuas rely on host species for their food provisioning (kleptoparasitism) and the breeding success of both skuas and their hosts is often linked (Furness 1987, Phillips et al. 1996). Indeed, in Scotland, reproductive success of Arctic Skuas was positively linked to the breeding success of Black-legged Kittiwakes Rissa tridactyla, Arctic Terns Sterna paradisaea and auks. In turn, reproductive success of hosts species was strongly impacted by the declining availability of pelagic forage fish, in particular Lesser Sandeel Ammodytes marinus (Phillips et al. 1996, Miles et al. 2015). Reproductive success of Arctic Skuas was also negatively correlated to the abundance of Great Skua Stercorarius skua, a competitor for nest-sites and a predator of eggs and chicks of Arctic Skuas (Dawson et al. 2011). The relative contribution of these bottom-up and top-down effects differed as a function of the size of host species colonies: bottom-up effects were more important at larger host colonies (Perkins et al. 2018). Outside Scotland, potential causes of the declines of Arctic Skuas have remained poorly studied. The relative importance of bottom-up and top-down effects in other areas could be different from the Scottish situation as a function of differences in prey, host and predator communities.

We studied the largest Arctic Skua colony in mainland Europe, located at Slettnes in northern Norway, and document a substantial population decline over the past 20 years. We provide evidence for both bottom-up and top-down effects potentially causing the decline of this colony. Specifically, we use clutch size, egg size, adult 
body mass and time spent at sea during the incubation period to characterize reproductive investment, as a measure of food availability. In addition, we estimate nest survival rates to measure top-down control and deployed nest cameras to identify predators. Finally, we estimated adult survival rates using colour-ring readings and using an age-structured demographic model. We calculate whether the reproductive success during the study period has been sufficient to sustain a stable population.

\section{METHODS}

Fieldwork was carried out at the Arctic Skua colony of Slettnes $\left(71^{\circ} 08^{\prime} \mathrm{N}, 28^{\circ} 21^{\prime} \mathrm{E}\right.$, figure 9.1a) near Gamvik, northern Norway, in two projects run nearly two decades apart. The main aim of the two projects were different and not primarily focussed on documenting the population development. The first project (19971998) focussed on the ecology and evolution of plumage colour morphs (Janssen et al. 2006, Janssen and Mundy 2013), whereas the second project mainly focussed on migration ecology (chapter 8). Neither study focussed on finding every single nest and especially in 2016-2018 most effort was spent in the central part of the study area (main study area in figure 9.1b). To compare number of nests between years, we compare both the colony at large and the main study area that has been intensively studied in all years, and encompasses the overlapping area of the five convex hulls around the nest positions of each year (figure 9.1b). In addition, whole-colony censuses were performed in 2016-2018, by counting the number of territorial pairs in the entire study area during 1-6 July 2016, 4-9 June 2017 and 511 June 2018.

Upon encounter, nest positions were recorded on a topographic map (1997-1998) or using a handheld GPS (2014-2018), the number of eggs was noted and length and width of eggs was measured (to the nearest $0.1 \mathrm{~mm}$ ) using callipers. In 1997 1998, hatching dates were directly observed. In 2014-2018, eggs were floated in lukewarm water to estimate hatching date (Liebezeit et al. 2007). Nests were monitored regularly to register status (incubated, hatched, predated). During nest visits in 2014-2018, the level of aggressive nest defence by the adults was scored on a scale from 0 to 5 , recording whether adults were absent $(0)$, were present without alarming or attacking or even leaving the territory (1), circled above the researcher, but did not dive-bomb (2), dive-bombed (swooped) the researcher, but rarely or never hit (3), dive-bombed frequently and hit occasionally (4) or divebombed frequently and hit on most swoops (5) (Furness 1987). Using the outcome (incubated/hatched or predated) and length of intervals between two nest visits, daily nest survival rates were estimated for each year using a logistic-exposure model (Shaffer 2004). In 2014-2018, adults $\left(\mathrm{n}_{0}=68, \mathrm{n}_{0^{\prime}}=44\right)$ were captured on the nest using bownets or snare traps. Individuals were fitted with a blue two-alpha coded colour-ring on one tarsus and a blue darvic ring with geolocator (weight $2.5 \mathrm{~g}$, 

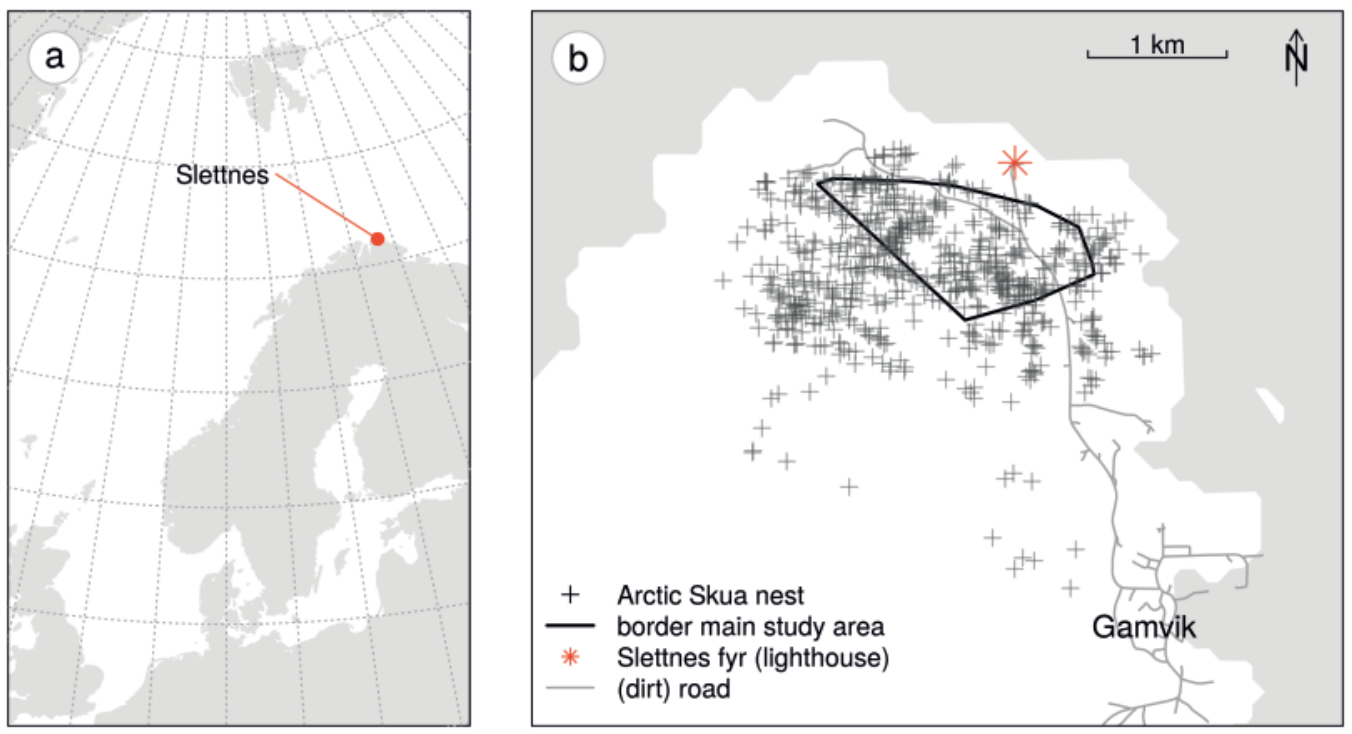

FIGURE 9.1 ( The study area; a) its position in Norway and b) distribution of all nests in 19971998 and 2014-2018 and the delineation of the mean study area, the position of the lighthouse and the dirt road running from the village of Gamvik to the lighthouse and the parking lot west of the lighthouse.

model C250, Migrate Technology Ltd, Cambridge, UK) on the other tarsus, under license provided by the Norwegian Food Safety Authority (FOTS ID 6328, 7421, 8538). Besides recording ambient light every 5 minutes, geolocators also sampled submersion in saline water every 6 seconds and recorded the change of state from wet to dry or dry to wet. Upon recapture and downloading the data, the mean daily duration of 'wets' in June was calculated for each individual and used as an index of time spent (swimming) at sea. More time spent at sea means less time attending the territory; the latter has been shown in Arctic Skuas to be lower in years with low food availability (Phillips et al. 1996). Biometrics were taken, including body mass. Birds were sexed using DNA extracted from blood samples (Fridolfsson and Ellegren 1999).

As an index of Red Fox activity in the area, the daily number of fox encounters per observer was recorded by two independent observers studying Dunlins Calidris alpina in wet areas across the study area. In 2018, we deployed nest cameras (Bushnell Trophy Cam Essential E3) at 9 nests for a total of 46 recording-days to estimate daily nest survival rate and identify predators. Cameras were set to take three pictures at a trigger event, and then wait for 10 seconds before taking another series of pictures. To get an index of fish abundance in the first kilometer offshore of Slettnes, passing or foraging Black-legged Kittiwakes Rissa tridactyla and Arctic Skuas were counted during observations from the Slettnes lighthouse. 
The duration of these observations varied between 5, 10 and 15 minutes, and mean numbers per minute for each of the species were obtained from Poisson Generalized Linear Models (GLMs) with the log of the observation time (in minutes) as an offset and year as a fixed effect.

\section{Adult survival and age-structured demographic model}

Based on encounter histories of adults, adult apparent survival $\varphi_{a}$ and resighting probability $p$ were estimated using Cormack-Jolly-Seber (CJS) models for live encounter data in the 'Rmark' package in $\mathrm{R}$, an interface to the program Mark (Laake 2013). Considering that survival rates are generally high among seabirds while it is common to forego breeding (Weimerskirch 2002), we fitted a model with a fixed value of $\varphi_{a}$ while allowing $p$ to vary with year. Because of parameter confounding between $\varphi_{a}$ and $p$ of the last year, Rmark sets $p$ of the last year to 1 by default, but this is an unlikely outcome given the tendency of seabirds to regularly forego breeding. The high value of $p$ subsequently results in relatively low parameter estimates for $\varphi_{a}$. To address this issue, we first run the model as-is and then re-ran it while fixing $p$ for 2018 at the level of 2017 in the original model.

Estimates of adult apparent survival were used in an age-structured demographic model to estimate 1) whether reproduction during the study years has been sufficient to maintain a stable population and 2 ) the annual reproductive output and number of reproductive years that is required to maintain a stable population. The demographic model sums the expected reproductive contribution over all ages of a female individual that starts to breed at an age of four years (O'Donald 1983). This leads to the expected lifetime reproductive output $\left(R_{0}\right)$, which depends on annual survival probabilities, annual fecundity, and the total number of reproductive years. We assume that annual survival increases linearly from $\varphi_{j}$ during the first year of life to $\varphi_{a}$ at an age of four years, after which it remains constant. From the expression of lifetime reproductive output (appendix A), the fecundity $f_{a}$ that is required for a stable population $\left(R_{0}=1\right)$ is given by:

$$
f_{a}=S_{j}^{-1} \cdot\left(\frac{1-\varphi_{a}}{1-\varphi_{a}^{m}}\right)
$$

where $S_{j}$ depends on both $\varphi_{j}$ and $\varphi_{\mathrm{a}}$ and equals the cumulative survival during the first 4 (non-breeding) years of life, $m$ is the number of reproductive years and annual fecundity $f_{a}$ is expressed as number of female eggs per female. Considerable uncertainty exists in $\varphi_{j}$, as most immatures only start to return to the breeding grounds in their $3^{\text {rd }}$ calendar-year (Furness 1987). Therefore, we varied the value of $\varphi_{j}$ between 0.5 and 0.8 and $m$ between 1 and 20 , while retaining $\varphi_{a}$ as estimated for the Slettnes population. 


\section{RESULTS}

In 1997 and 1998, respectively 187 and 172 nests were found. Not all nests were located; the estimated number of breeding pairs in the entire colony was about 250. In recent years, excluding known relays, the number of nests found dropped to 96, 82, 43, 42 and 60 in 2014-2018 (figure 9.2a). The decline is also evident when restricting the nest count to the main study area: from 65 and 74 in 1997-1998, to 35, 35, 27, 16 and 28 nests in 2014-2018. Whole-colony censuses for 2016 resulted in 70 attendant pairs in early July, of which only a part actually had a nest (though some pairs unsuccessful in breeding had probably already left the colony). Censuses in early June resulted in 65 attendant pairs in 2017 and 91 in 2018.

\section{Reproductive investment and adult body mass}

In $1997-1998,84 \%$ and $94 \%$ of the pairs that laid eggs produced two eggs, others layed one. This percentage decreased from $75 \%, 70 \%, 72 \%$ in $2014-2016$ to $29 \%$ and $23 \%$ in 2017-2018 (figure 9.2b). In 2018, 12 pairs laid a second clutch after predation of the first; 8 (75\%) of these concerned 1-egg clutches. Egg size differed significantly between years (largest egg in a 2-egg clutch: $F=5.4, p<0.001$; smallest egg in a 2-egg clutch: $F=5.7, p=<0.001$; 1-egg clutches: $F=3.8, p=0.001$ ), but due to large variation, only some between-year comparisons were statistically significant. In 1997, when breeding commenced late due to late snow melt, relatively small eggs were laid compared to 1998 (figure 9.3c). Egg size diminished during 2014-2017 from a similar level as in 1998 to well below that level. In 2018, egg size increased again for the largest egg in 2-egg clutches and for 1-egg clutches. The smallest egg in 2-egg clutches remained small, however. In adult females, body mass differed between years $(F=5.8, p<0.001)$, with significantly lower weights in 2015-2016 compared to 2014, 2017 and 2018 (posthoc Tukey test: $p<0.01$ ). Body mass of adult males also varied between years, but this was not significant $(F=2.1, p=0.103)$. Time spent at sea in June differed between years $(F=49.5, p<0.001)$ and was low in 2014 (10min, $n=30)$ and 2018 (4min, $n=15)$, but higher in 2015-2016 (45min, $n=54 ; 45 \mathrm{~min}, \mathrm{n}=56)$ and even more so in 2017 (144min, $n=29$; figure 9.2f).

\section{Reproductive success and predation}

In 1997-1998, predation of complete clutches was only recorded in $2 \%$ and $1 \%$ of the clutches (figure 9.2d). In 2014, $7 \%$ of the clutches were predated and many young fledged: 109 were ringed at ages up to fledging. Clutch loss went up to $53 \%$ in 2015, 21\% in 2016, and only 2 and 1 chick(s) were found in these years at an age of ca two weeks. Within our study area, not a single egg hatched in 2017 and 2018 (although some chicks were found in 2018 south of our study area; Barbara Ganter pers comm.). In 2018, median time between laying of first egg and predation was 5 days (range $2-21, n=46$ ) and at least 12 pairs initiated a second clutch. Consistent with this, daily nest survival rate went down from 0.99 in 2014 to $0.35,0.53,0.04$ and 0.19 in 2015-2018 (figure 9.2d). In 2014, the only year with a 

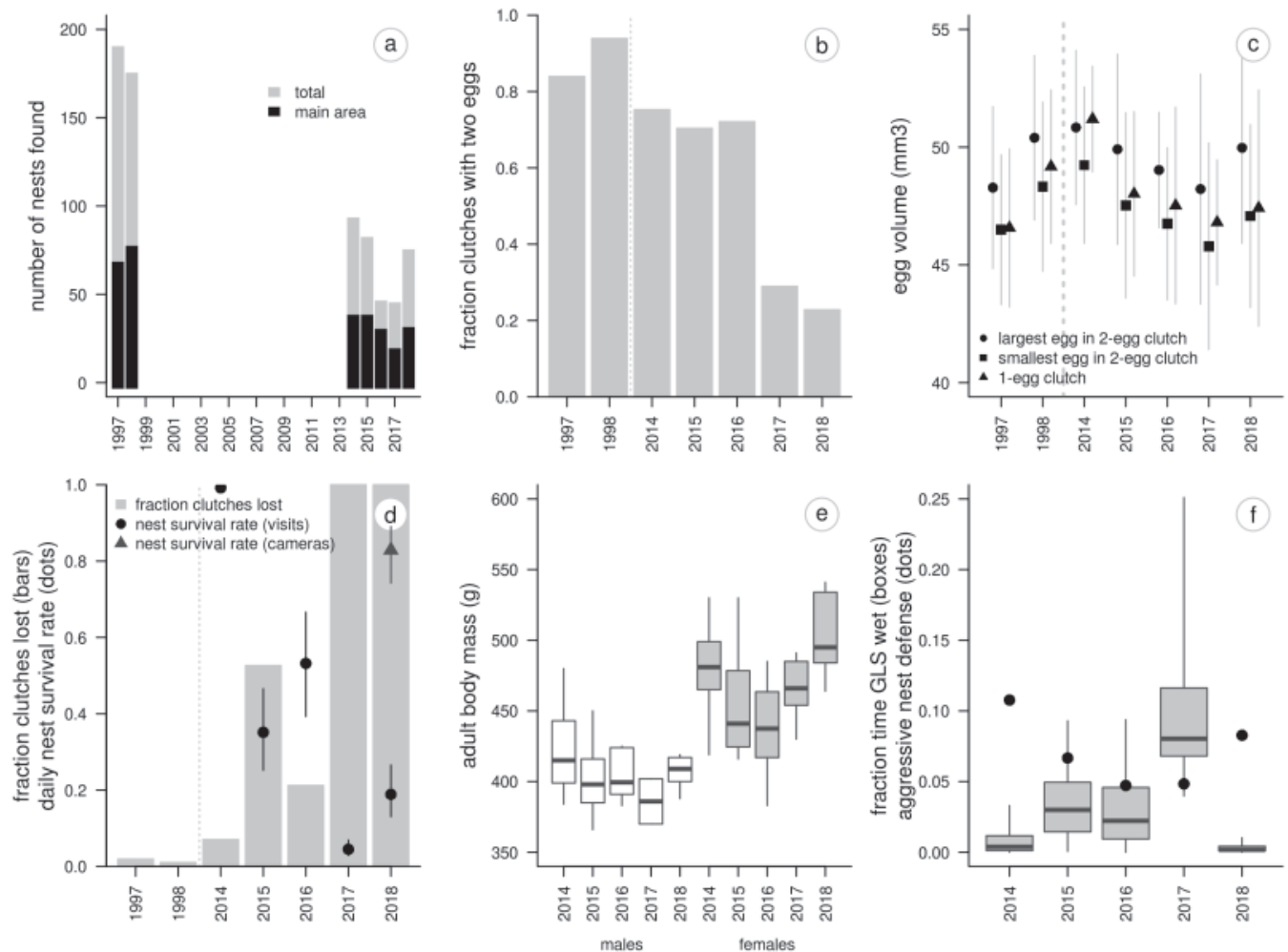

FIGURE 9.2 | The decline of the Artic Skua colony at Slettnes: a) number of nests found in 19971998 and 2014-2018; b) fraction of clutches with only a single egg versus two eggs; c) egg size; d) fraction of clutches that did not hatch (bars), daily nest survival rate based on nest visits (dots) and daily nest survival rate based on nest cameras (triangle); e) body mass during incubation of males (white) and adult females (grey); f) fraction of time when geolocators were submerged in salt water (boxplots) and fraction of nest visits by researchers with skua aggression levels exceeding 2 (dots).

reproductive success clearly above zero, 29 chicks with a body mass of more than $250 \mathrm{~g}$, corresponding to an age of about two weeks (cf (Maher 1974), were found and ringed within the main study area. Of these 29 chicks, 9 were pairs of siblings and 11 were single chicks of which the sibling either died, was not found, or that came from a 1-egg clutch. In a total of 35 nests within this area, 26 chicks were ringed. Assuming all these 26 chicks fledged, fecundity would be 0.41 female offspring per pair.

Aggression levels dropped during 2014-2016 but increased again in 2017-2018 (figure 9.2f). We found no active fox dens in 2014, three in 2015, none in 2016 and one in both 2017 and 2018. A different pattern was found in the number of Red Fox encounters per observer-day, which changed from 0.35 in 2014 ( $n=26), 0.41$ in 

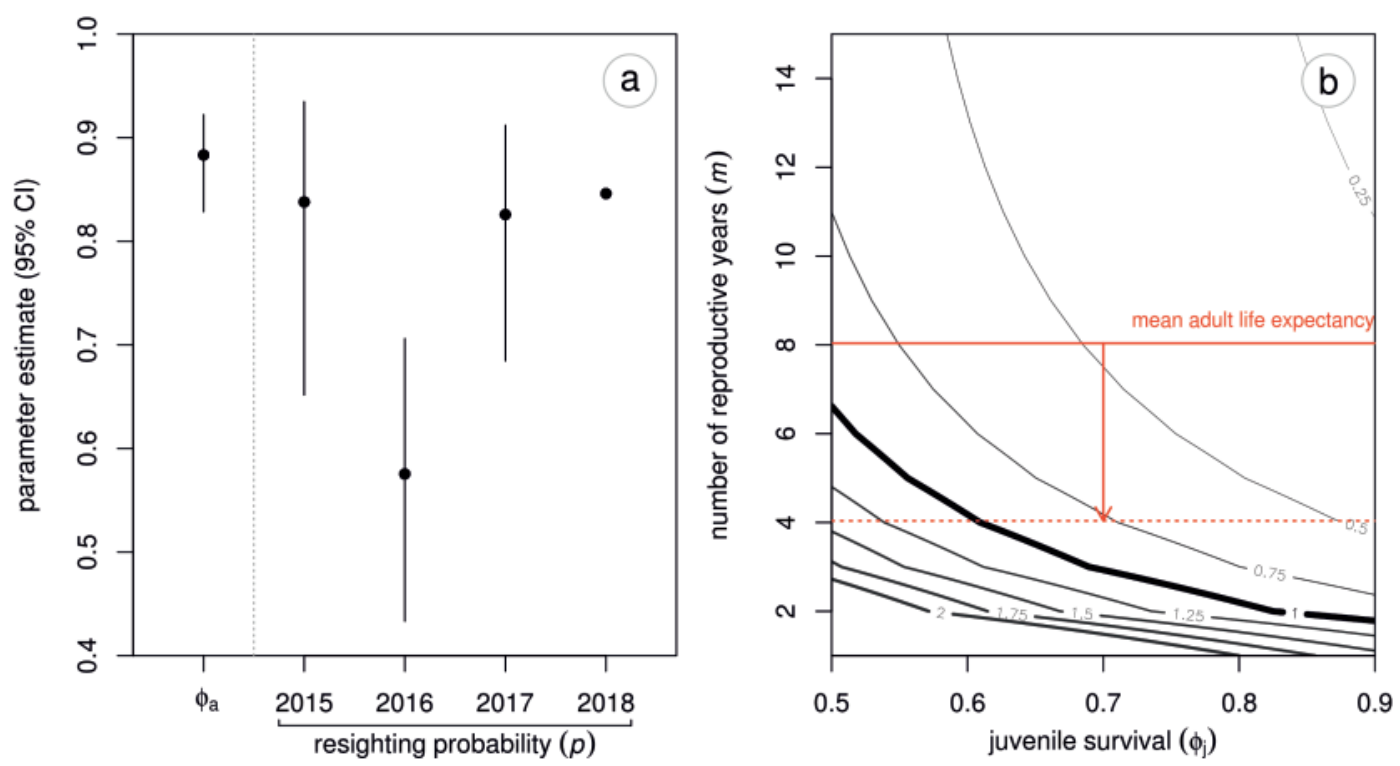

FIGURE 9.3 | Demography of Arctic Skuas at Slettnes: a) survival $\left(\varphi_{a}\right)$ and annual resighting probabilities $(p)$ of adult Arctic Skuas breeding and $\mathbf{b}$ ) required fecundity for a stable population as a function of juvenile survival $\left(\varphi_{j}\right)$ and fecundity $(f)$. The bold curve indicates a fecundity of one, which is the maximum mean annual fecundity. The horizontal red line shows the mean adult life expectancy (thus the number of years after recruitment at an age of four years). The vertical arrow and dotted horizontal line illustrate how four failed breeding years lead to a much higher required annual fecundity.

$2015(n=32), 0.51$ in $2016(n=35), 0.30$ in $2017(n=40)$ to 0.10 in $2018(n=30)$. During nest camera deployments at nine nests in 2018, six nests were predated and in four cases the predator was photographed and identified as Red Fox. Comparison of photos indicates two individuals were involved (figure 9.4). Based on the camera trap deployments, the estimate of daily nest survival rate was 0.83 , which is much higher than based on all nest visits (see above, and figure 9.2d). Two instances of predation on adult Arctic Skuas were documented. On 9 July 2015, the remains of an adult light morph female were found, $150 \mathrm{~m}$ from its nest. Primary feather shafts were bitten, indicating predation by a mammal. On 24 May 2017, a Red Fox was photographed with a dark morph Arctic Skua (with geolocator) in its snout (Jan Erik Røer pers comm).

\section{Age-structured demographic model}

Annual adult apparent survival rate $\varphi_{a}$ was estimated at 0.883 and a resighting probability $p$, set at 0.846 for 2018 , was estimated respectively at $0.838,0.575$, 0.826 in 2015, 2016 and 2017 (figure 9.3a). The combinations of number of reproductive years and first-year survival probability $\varphi_{j}$ that are required for a stable population is depicted in figure 9.3b. Assuming a value of $\varphi_{j}=0.7$ (cf O'Donald 
1983), the estimated fecundity of 2014 (0.41) would be sufficient to maintain a stable population if the number of reproductive years is ca 11 years or more. However, the expected mean lifespan after reaching adulthood $\left(-1 / \log \left(\varphi_{a}\right)\right)$ is only 8 years, which requires an annual fecundity of 0.48 to maintain a stable population. Fecundity was even lower - (close to) zero - in 2015-2018. In case 4 out of 8 potential reproductive years fail, and again assuming $\varphi_{j}=0.7$, annual fecundity in the remaining 4 years needs to be raised from 0.48 to 0.77 to maintain a stable population (figure $\mathbf{9 . 3 b}$ ).

\section{DISCUSSION}

With approximately 250 breeding pairs in the late 1990s, the Arctic Skua colony at Slettnes was the largest in Europe (cf Anker-Nilssen et al. 2000, Mitchell et al. 2004). Since then, the colony at Slettnes more than halved in size over the two decades between 1997 and 2018. This substantial decline is in line with declines reported elsewhere from its European breeding range (Eaton et al. 2015, Perkins et al. 2018). In Norway, declines in Arctic Skua populations have been reported in particular from the southern and western parts of the country. Population changes from the northern regions of Norway have not been documented in detail (Henriksen and Hilmo 2015). Hence, our study fills an important knowledge gap by showing a heavy decline in the largest Arctic Skua colony of Europe.

In three out of five study years (2015-2017), the low body mass of adult females, small egg sizes, a large proportion of one-egg clutches and more time spent at sea suggest a poor local food situation for the Arctic Skuas. The food situation seemed better in 2014 and 2018, when body mass of adult females was higher, eggs were larger and less time was spent at sea (figure 9.2). In 2014, over 1000 pairs of Arctic Terns bred within the perimeter of the Arctic Skua colony, of which many successfully fledged chicks. A sign of a good food situation in 2018 was provided by the many relays following clutch predation (see below). Also, in this year we observed almost daily foraging associations of hundreds to thousands of Herring Gulls Larus argentatus and Kittiwakes Rissa tridactyla in the first few km offshore of the colony, in which Arctic Skuas were frequently seen foraging as well. No or only very few such associations were seen in 2015-17 (figure 9.5b). A more indirect index of fish abundance in nearshore waters may be provided by sightings of feeding large cetaceans within visible range from the Slettnes shoreline, which were regular in both 2014 (Minke Whales Balaenoptera acutorostrata and Humpback whales Megaptera novaeangliae) and 2018 (mostly Minke Whales, and some Fin Whales Balaenoptera physalus, Humpback whales and White-beaked Dolphins Lagenorhynchus albirostris), but not in 2015-2017. Finally, stock estimates for the Barents Sea of Capelin Mallotus villosus, a pelagic fish species of great importance to many seabirds, are consistent with this pattern; abundance was very low in 2015-2016, but higher in 2014, 2017 and 2018 (figure 9.5a, ICES 2018). It should 
be noted, however, that these stock assessments cover a much larger area than the area likely to be covered by Arctic Skuas at Slettnes during breeding and reflect a period after the breeding season of Arctic Skuas, when the bulk of Capelin has moved northwards.

Inconsistent with the above is the large proportion of 1-egg clutches in 2018 despite the good food situation, possibly due to predation during the laying process (about 3 days) or if the nest was found after laying 1 egg and predated before our next visit. In addition, annual fluctuations in body mass of adult males was similar to females, but statistically not significant. Body mass of adult males may be less affected by local food conditions, considering that females incubate more than males and males can therefore forage longer at sea (Furness 1987). This allows males to prioritize their own condition above provisioning the female. Finally, patterns in clutch size and chick survival from Black-legged Kittiwakes and Common Guillemots Uria aalge during 2014-2017 at two localities in Finnmark, Hornøya and Hjelmsøya, both at ca $130 \mathrm{~km}$ from Slettnes, do not align with the pattern observed in Arctic Skuas at Slettnes. For example, the very poor breeding year of kittiwakes at both sites in 2014 is in sharp contrast to the high reproductive success of Arctic Skuas at Slettnes, whereas guillemots at Hornøya had fairly stable fledging success throughout this period (www.seapop.no/en/publications/). These discrepancies suggest that food availability may vary substantially within the province of Finnmark.

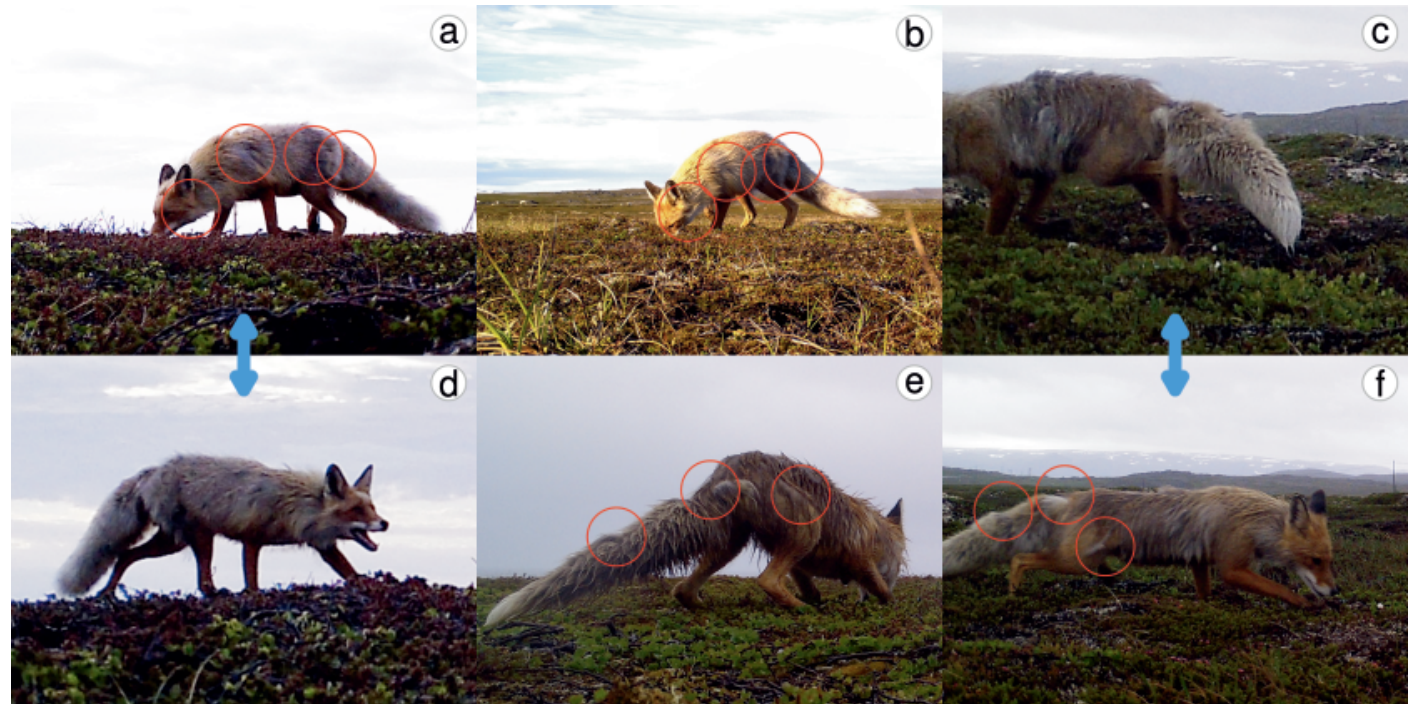

FIGURE 9.4 | Comparison of Red Foxes recorded with nest cameras, with left sides (a-c) and right sides (d-f). Photos (a) and (d) and (c) and (f) refer to the same event, indicated by blue arrows. Red circles highlight individual characteristics supporting our interpretation that these pictures show to individuals: one in $\mathbf{a}, \mathbf{b}$ and $\mathbf{d}$ and the other in $\mathbf{c}$, e and $\mathbf{f}$. Most notable individual characteristic is the indent halfway the tail of the second individual. 
Beside the bottom-up effects mentioned above, top-down effects may also have played a role in the decline of the Arctic Skua colony at Slettnes. Predation caused total reproductive failure in four consecutive years (2015-2018). For 2018, we have direct evidence that Red Fox was the main predator involved. However, we are confident that Red Foxes were also responsible for nest predation in 2015-2017, as this was the only potential predator species that was regularly observed making foraging forays in the colony area. Possibly, the high predation rates may have been indirectly caused by a poor food situation, resulting in a less dense colony (due to lower breeding propensity) and less aggressive nest defence, thus facilitating access to the colony for foxes. However, predation rates were also high in 2018, when the food situation was clearly better. A potential explanation for the contrast between 2018 and 2014, when the food situation was also good and the predation rate was very low, is that individual Red Foxes at Slettnes have specialized in predating Arctic Skua eggs (Rodgers Jr 1987, Panzacchi et al. 2008). An observation consistent with individual specialization is the absence of a clear relation between daily nest survival rates and the number of active Red Fox dens or daily encounter rates of Red Foxes. Also, the fact that only two Red Foxes were recorded by our camera traps in 2018 is in line with this hypothesis but is based on only a small number of predation events and does not exclude the possibility that other foxes were responsible for the predation of other nests.

Has reproductive success been too low to sustain the Arctic Skua population at Slettnes? With an adult survival rate of about 0.883 , a mean of 8 reproductive years and assuming a juvenile survival rate after fledging of 0.70 (O'Donald 1983), the mean annual fecundity should be at least 0.48 female chicks per pair to maintain a stable population. In 2014-2018, fecundity only approached this level in 2014, while (near-) total breeding failures occurred in the other four years. It seems unlikely that this period of failed breeding years be can compensated for, given the regular occurrence of years with poor feeding conditions, negative (indirect) impact of increasing sea temperatures on Capelin abundance (Stige et al. 2010), and the continuing presence of Red Foxes. The number of Red Foxes has increased over the last decades in northern Norway (Killengreen et al. 2011). Winter survival and/or reproduction of Red Foxes may be especially high at Slettnes, as they can feed on marine resources along the coast (Roth 2003), fishery offal in the harbour of Gamvik, and are reportedly being fed by people in Gamvik during the winter months.

Obviously, uncertainty exists in several of the model parameters. Largest uncertainty exists in apparent juvenile survival, as there is neither data to estimate this for the Slettnes colony, nor values reported in literature for other areas. O'Donald (1983) reasoned juvenile survival should be around 0.70 , if the Fair Isle colony would have been stable in his study years. Less uncertainty exists in our estimates of adult apparent survival, which is similar to the 0.886 reported from 1973-1975 at Fair Isle, Scotland (O'Donald 1983) and 0.89 in 1992-1999 at Foula, 

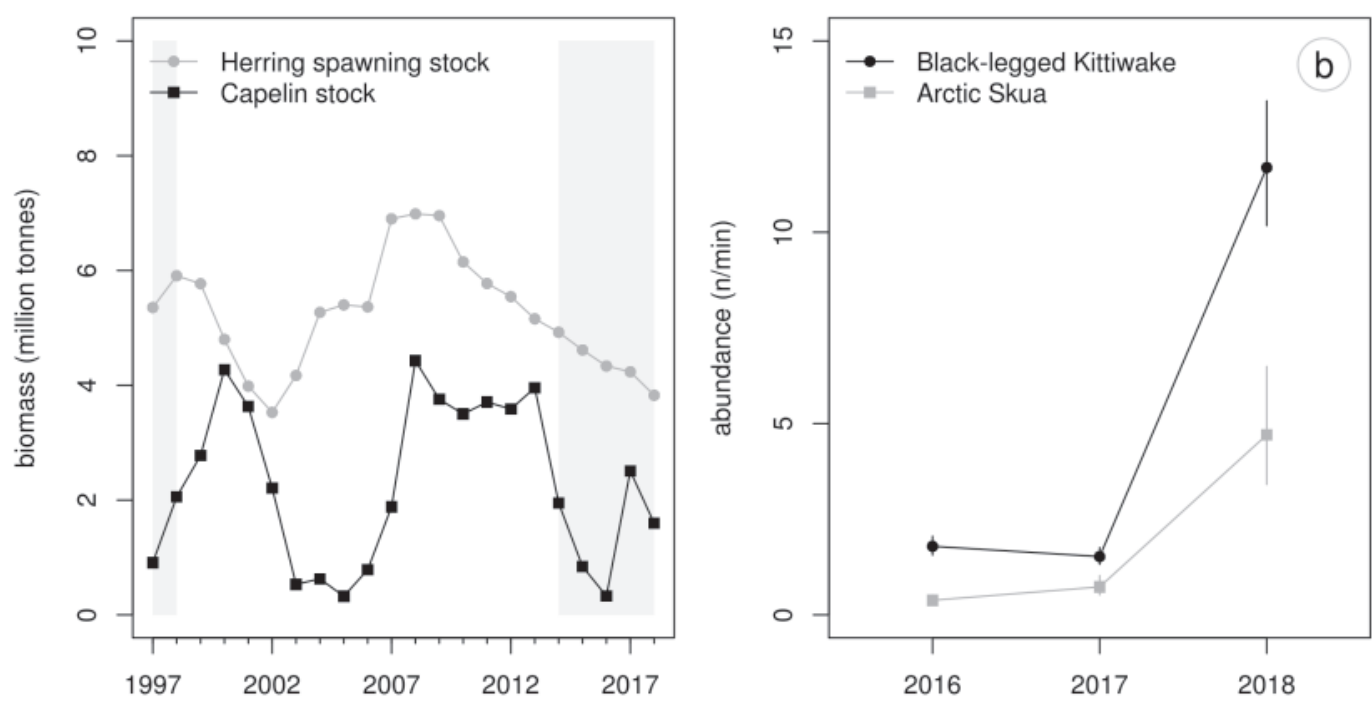

FIGURE 9.5 | Indices of fish abundance: a) biomass of the Capelin Mallotus villosus stock and spring spawning Herring Clupea harengus stock, from ICES (2018a, b), with study periods shaded grey, and b) Black-legged Kittiwake (black) and Arctic Skua (red) numbers per minute as observed from the Slettnes lighthouse in 2016-2018. Error bars show 2.SE of the parameter estimates.

Scotland (Phillips 2001). These adult survival rates appear low for a seabird, which usually have survival rates of 0.90-0.95 (Weimerskirch 2002), and it should be noted that Arctic Skuas were already declining in Scotland in general in the 1990s (Phillips et al. 1996, Perkins et al. 2018). It should also be noted that our estimate of apparent survival is the product of true survival and emigration. Although adult Arctic Skuas show high site fidelity (O'Donald 1983, Furness 1987), we cannot exclude the possibility of emigration to other breeding sites. The same goes for recruiting immatures: they could disperse to other breeding sites. Even if adult survival rates were higher than our data suggest, our conclusion that reproductive success in the Slettnes colony has been too low during 2014-2018 to sustain a stable population, will remain unchanged. A higher adult survival estimate would however permit more failed breeding years before the required fecundity exceeds the maximum of one female chick per pair.

On a large scale, we document a decline of the Arctic Skua colony at Slettnes that is in line with trends observed in other seabirds along the Norwegian coast, including the Arctic Tern and the Black-legged Kittiwake, both important host species for Arctic Skuas (www.seapop.no, Fauchald et al. 2015). The decline in these hosts is mainly attributed to low forage fish stocks, with predation by avian and mammalian predators potentially contributing to population declines (Fauchald et al. 2015). At Slettnes, mammalian predation poses an important threat to the Arctic Skua colony that may prohibit skuas to reproduce even when food is abundant. 


\section{APPENDIX A}

The expected lifetime reproductive output of a female individual $R_{0}$ follows from summing the expected reproductive contribution at each reproductive age:

with $\varphi_{\mathrm{a}}$ the annual survival probability of an individual that will breed the upcoming summer (age 3 years or older), $m$ the number of reproductively active years and $S_{j}$ the survival probability from hatching up to the age at first breeding. We assume that the annual survfüp from the annual first-year survival probability $\varphi_{j}$, to the annual adult survival probability $\varphi_{a}$. The cumulative survival probability during the immature years is then given by:

$$
S_{j}=\prod_{i=0}^{3}\left(\varphi_{j}+i \frac{\left(\varphi_{a}-\varphi_{j}\right)}{3}\right)
$$

Equation (A1) can be simplified to:

$$
\begin{gathered}
R_{0}=S_{j} F_{a} \cdot\left(1+\sum_{i=1}^{m-1} \varphi_{a}^{i}\right) \\
R_{0}=S_{j} F_{a} \cdot \frac{\left(1-\varphi_{a}^{m}\right)}{\left(1-\varphi_{a}\right)}
\end{gathered}
$$

A stable population requires that $R_{0}=1$, which leads to the required fecundity of:

$$
f_{a}=S_{j}^{-1} \cdot\left(\frac{1-\varphi_{a}}{1-\varphi_{a}^{m}}\right)
$$




\section{ACKNOWLEDGEMENTS}

This study would not have been possible without the help of a very motivated field crew: Daniël van Denderen (2014-2015), Jan van Dijk (2014), Daan Liefhebber (2015), Janne Schekkerman $(2014,2016,2017)$, Maria van Leeuwe (2016), Marc van Roomen (2016), Geert Aarts (2017). Thanks also to the people in Gamvik/Slettnes that helped us: Jeanette Hickman, Barbara Ganter, Hans-Ulrich Rösner, Torstein Johnsrud, Niels Westpahl, Benedicte Færevåg, Cees and Mimi Tesselaar. Many thanks to Barbara Ganter and Hans-Ulrich Rösner for sharing their fox encounter data. Thanks to Børge Moe, Sveinn Are Hanssen and Karl-Birger Strann for their help in getting permits.

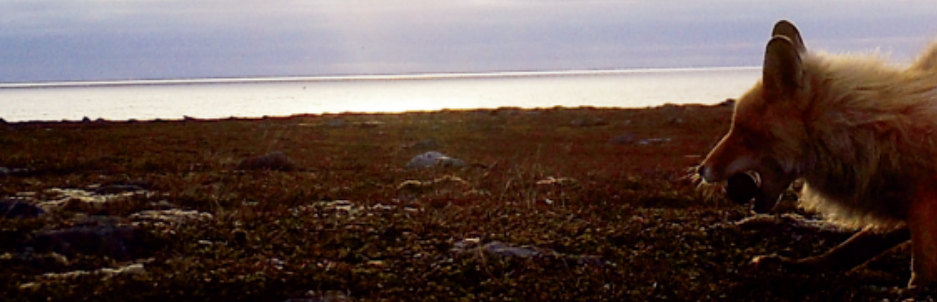

Using camera traps, Red Foxes were caught red-handed predating Arctic Skua eggs. Slettnes, Norway, June 2019. 


\section{CHAPTER $X$}

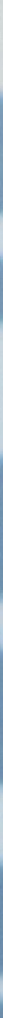

Long-tailed Skua, metal-ringed in 2007, overseeing its territory, Ammarnäs, Swede

2011.

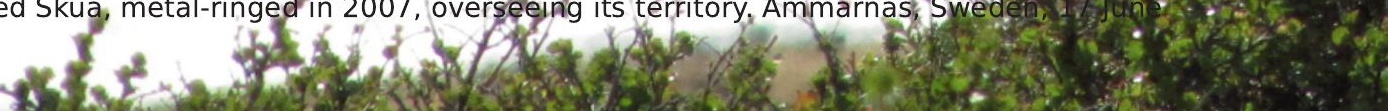




\section{General discussion}

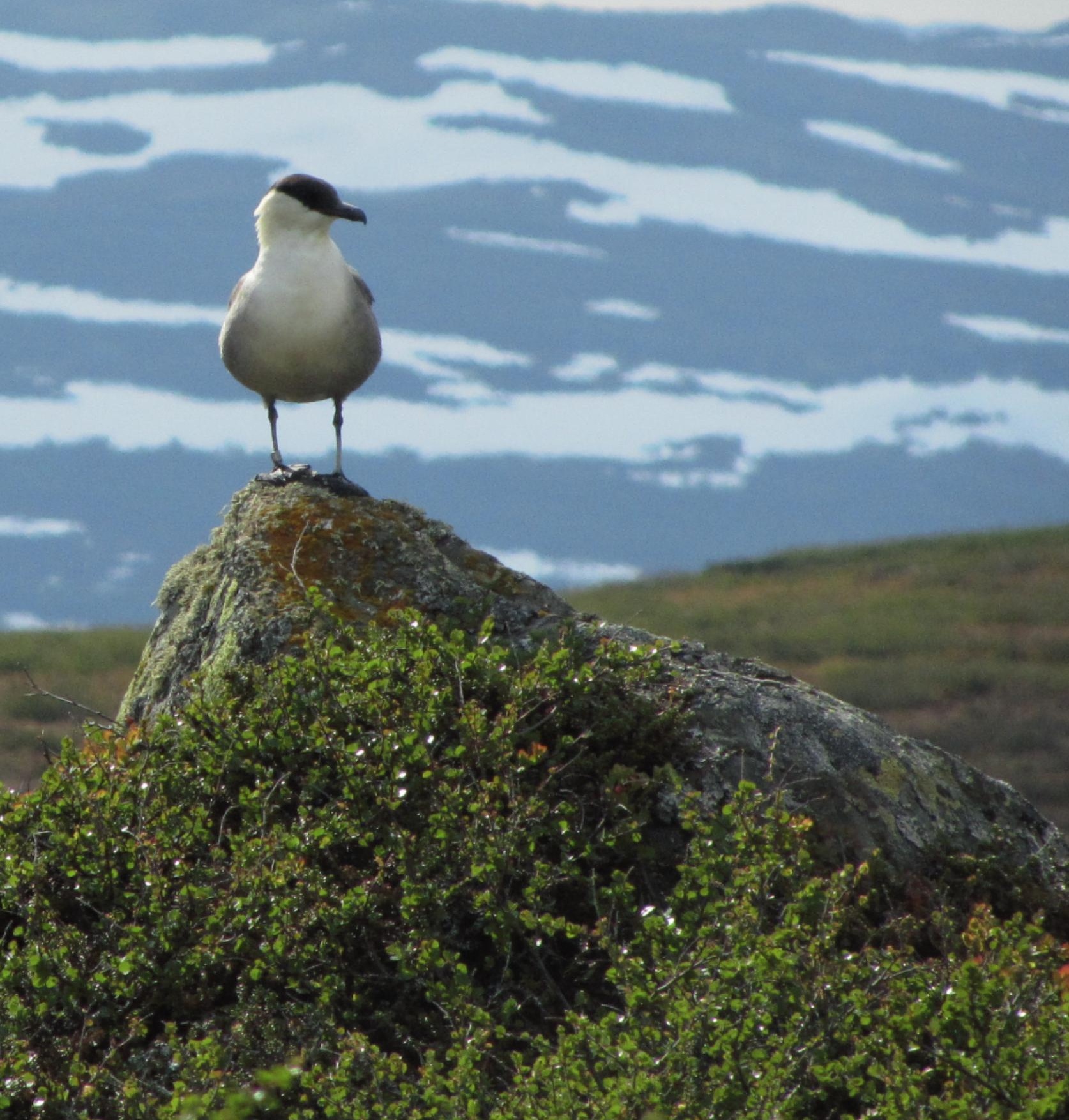


Seabirds are well-represented among the species with the longest and most spectacular migrations in the animal kingdom. Until a few decades ago, much of what was known about seabird migrations and wintering movements was based on land-based sightings or anecdotal at-sea observations. As a result, we had a fragmentary and scattered picture of seabird distribution and migrations in space and time, with no data on individual strategies. With the development of modern tracking techniques, migrations and wintering movements of individual seabirds can now be mapped in great detail. The non-breeding movements of many species are currently being revealed at a fast pace (Brooke 2018).

In chapters 2-4, 6 and 8 of my thesis, the non-breeding movements of four longdistance migratory, Arctic-breeding seabird species are presented: Red-necked Phalarope, Grey Phalarope, Long-tailed Skua and Arctic Skua. By tracking individual birds across the full annual cycle from breeding sites between East Greenland and Russia, a detailed view of the migration patterns of breeding populations across the north-eastern North Atlantic is obtained. In this concluding chapter I will set off by assessing the representativeness of the tracking datasets for the studied populations: did we track enough individuals to represent the tracked populations or the species? Thereafter, potential evolutionary origins of the large-scale migration patterns, similarities and differences in migratory connectivity, individual consistency and degree of itinerancy are discussed for the four study species and compared to other species. Here, the effect of spatio-temporal patterns in primary productivity on itinerancy and individual consistency in site use at the wintering grounds is compared across wintering areas. Finally, potential directions for future studies, conservation of at-sea habitat and whether the studied seabirds will be able to cope with rapid environmental changes are discussed. A section dealing with methods used in additional analyses used in this chapter is included at the end.

The tracking data presented in the thesis, including this final chapter, have been collected by many teams at a large number of field sites (table 1.2, figure 1.4). Collectively, they present a huge effort. Thus, these studies have only been able thanks to the willingness of these teams to collaborate. In this synthesis, I refer to 'we' or 'our' with regard to our efforts and collected tracking data, and to 'l' or 'my' when it comes to matters concerning the work presented.

\section{DID WE TRACK ENOUGH INDIVIDUALS TO INFER THE POPULATIONS' WINTERING DISTRIBUTION?}



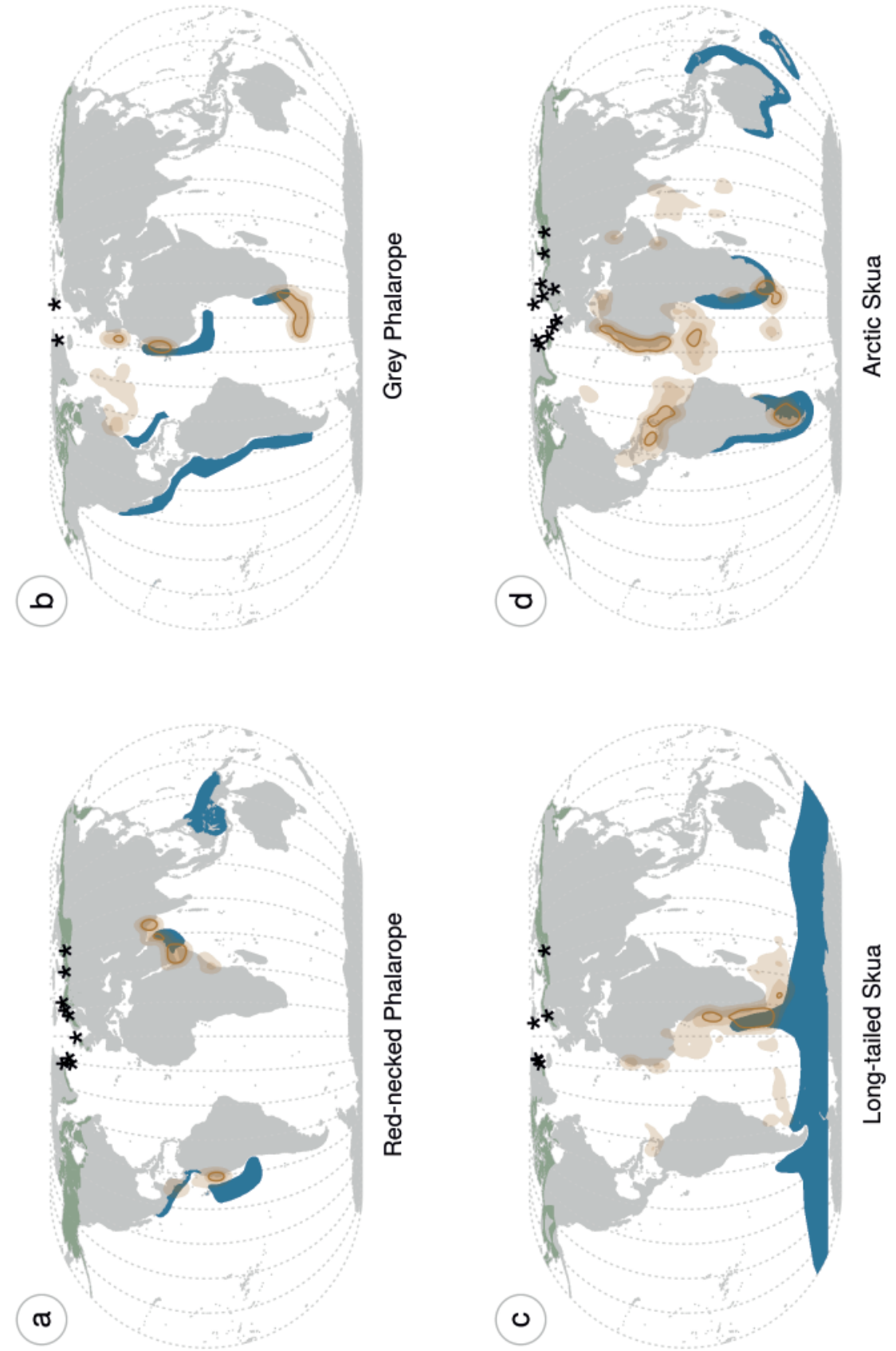

FIGURE 10.1 | Maps showing wintering areas of (a) Red-necked Phalarope, (b) Grey Phalarope, (c) Long-tailed Skua and (d) Arctic Skua, with brown shades indicating 50\% (darkest shade, outlined), 75\% (medium shade) and 95\% (lightest shade) UD kernels, based on geolocator positions in December-January from the first track of each individual. Dark blue areas represent the until recently assumed wintering areas by the IUCN (figure 1.3). Green shading shows the breeding distributions and stars indicate breeding locations from where individuals were tracked. 
TABLE 10.1 | Number of tracked individuals ntracked (including only the first track for each individual and excluding tracks where the geolocator failed before February), the percentage of wintering area surface covered by these tracks Psurface relative to the predicted total wintering area, the number of tracked individuals required nrequired to reveal $90 \%$ of the main wintering distribution (figure 10.2b) and the representativeness percentage PLascelles according to the method by Lascelles et al. (2016) (figure 10.2a).

\begin{tabular}{lcccc}
\hline Species & ntracked & $\boldsymbol{P}_{\text {surface }}$ & $\begin{array}{c}\text { N required for } \\
\mathbf{0 . 9} \cdot \mathbf{a}\end{array}$ & $\boldsymbol{P}_{\text {Lascelles }}$ \\
\hline Red-necked Phalarope & 33 & $87 \%$ & 43 & $83 \%$ \\
Grey Phalarope & 15 & $67 \%$ & 64 & $64 \%$ \\
Long-tailed Skua & 45 & $94 \%$ & 25 & $92 \%$ \\
Arctic Skua & 131 & $88 \%$ & 159 & $91 \%$ \\
\hline
\end{tabular}

The first aim of my study was to map the wintering areas of the different populations of each study species. The number and distribution of the main wintering areas differed between species (figure 10.1). These maps are based on the available tracking data, i.e. the number of recaptured individuals. The question is then: are these maps representative for the wintering areas of the studied populations, or should we have collected more data? I present two measures of representativeness of our datasets, using the shape of the relationship of the number of tracked individuals with 1 ) the percentage of positions that falls within the 50\% UD kernel, the 'inclusion rate' (figure 10.2a, Lascelles et al. 2016) and 2) the surface area of their combined 50\% UD kernels (figure 10.2b). The shape of these relationships depends on the extent of the true wintering distribution, the variation between individuals and the degree to which individuals move during the wintering period (here: November-January). The extent of the wintering distribution is reflected by the asymptote of the curve in figure $\mathbf{1 0 . 2 b}$, which is smallest for Red-necked Phalarope and largest for Arctic Skua. For all study species except Grey Phalarope, our tracking data covers ca $90 \%$ of the predicted main wintering distribution, irrespective of methodology (table 10.1). In the Grey Phalarope, our small sample captured approximately one third of the wide wintering distribution (table 10.1).

Whereas these calculations of representativeness deal with meso-scale variation $(100 \mathrm{~s} \mathrm{~km})$ among (many) tens of tracked individuals, smaller datasets suffice for the identification of large-scale wintering areas (1000s km), such as the Benguela region for Long-tailed Skuas or the Arabian Sea for Fennoscandian-Russian Rednecked Phalaropes. At such large scales, our data likely completely or nearly completely represent the wintering distribution of our study populations well. Even for the most wide-ranging species, the Arctic Skua, additional tracking of individuals 

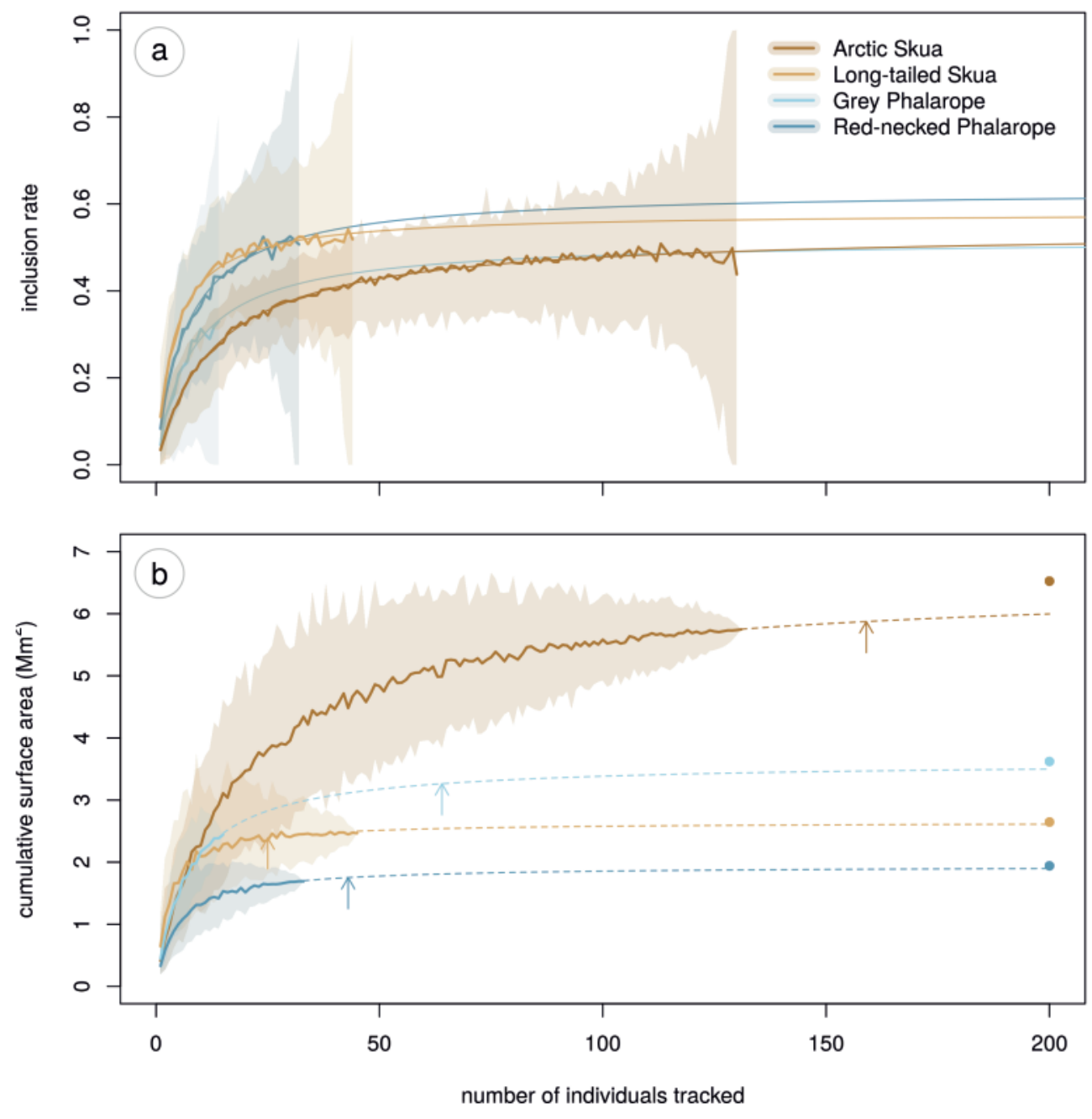

FIGURE 10.2 | Two measures of representativeness of the datasets for their respective populations: (a) inclusion rate in 50\% UD kernels as a function (Lascelles et al. 2016) and (b) diminishing increase in area of the main wintering distribution (50\% UD kernels across individuals) as a function of the number of tracked individuals. In both figures, shaded areas represent $95 \%$ quantiles, based on 100 random samples per potential number of tracked individuals. Dotted lines in $b$ represent fitted functions of the form $s=a \cdot n /(b / n)$; dots at ntracked $=200$ show the asymptote a for each curve, reflecting the estimated extent of the true wintering distribution. Arrows indicate at what ntracked $75 \%$ of a is reached.

from our study populations is unlikely to reveal additional wintering grounds within the Atlantic: our tracking data already covers all areas of medium or high primary productivity.

Although our dataset had a good representativeness of the studied populations, 
wintering areas in the Atlantic that are used by other breeding populations may have been missed or their usage underestimated. For Long-tailed Skua, for example, the Falkland Current has been described as an important wintering area (Veit 1985), while few individuals in our dataset used this area. From the perspective of the wintering area, revealing the migratory divides between breeding populations wintering in the Atlantic and those wintering in the Indian or Pacific Oceans requires expanding our study to breeding areas west- and eastwards.

That brings up the question how representative our datasets are at a global scale? For Red-necked Phalarope, two out of three known wintering areas are covered by our dataset, missing only the one in the East Indies (Cramp and Simmons 1983). For Grey Phalarope, besides the wintering areas in the Atlantic described in chapter 4, the Humboldt Current in the Pacific forms an important wintering area (Hayman et al. 1986). The importance of more northern parts of the Pacific remains to be demonstrated. Wintering areas in the Atlantic of Long-tailed and Arctic Skuas have been described in chapter 6 and 8 . For both skua species, the number, extent and relative importance of wintering areas in the Indian and Pacific Oceans are poorly known, as well as the migration routes to reach them, which may include overland migrations (Higgins and Davies 1996). Indeed, our results for Arctic Skua indicate overland migrations of Russian breeding populations wintering in the Indian Ocean, but movements of individuals from breeding populations from further east, which may winter either in the Indian or the Pacific Ocean, have yet to be tracked.

\section{ORIGIN OF LARGE-SCALE MIGRATION PATTERNS}

In terrestrial bird species, migration patterns often appear to follow routes of breeding range expansion (Newton 2010). A well-known example is provided by Northern Wheatears Oenanthe oenanthe that have expanded westwards to Northeast Canada and eastwards to Alaska while retaining migration routes to wintering grounds in Africa (Bairlein et al. 2012). Among the study species and populations featuring in this thesis, only the migration pattern of Red-necked Phalaropes strongly suggests a biogeographic legacy, in which the westward migration by populations breeding in Greenland, Iceland and Scotland would be explained by eastward expansion of Nearctic breeding populations while retaining the migration route to the eastern Pacific (van Bemmelen et al. 2019, chapter 3). Likewise, Fennoscandian-Russian populations may have retained the migration to the Arabian Sea while expanding westwards into their current breeding distribution (van Bemmelen et al. 2016, 2019, chapters 2-3). This fits a pattern of colonization of Arctic tundra breeding habitat from the western Nearctic and eastern Siberia ('Beringia') upon retreat of ice sheets covering large parts of Arctic Canada, Greenland, Fennoscandia and western Siberia in the last glacial maximum. Long- 
tailed Skuas may have expanded their breeding distribution in the same way, as suggested by the existence of two subspecies of Long-tailed Skuas that reach their extremes around the north-eastern North Atlantic (Manning 1964). In contrast to Red-necked Phalaropes, however, the two Long-tailed Skua subspecies share their main wintering area in the Atlantic, the Benguela region (chapter 6, van Bemmelen et al. 2017), suggesting their migrations into the Atlantic originate from before the last glacial maximum or have only recently evolved. In Arctic Skuas, the largely overland migration of Russian populations to the Indian Ocean suggests a biogeographic legacy from when breeding areas may have been as far south as the Caspian Sea. To get a firmer grip on the role of historic events in shaping current migration patterns in the four study species, a circumpolar expansion of our study of migration patterns in combination with phylogeographic and population genetic studies would be needed.

\section{MIGRATORY CONNECTIVITY AND BETWEEN-INDIVIDUAL VARIATION}

Another aim of my study was to map the migratory connectivity of the studied populations of the study species. Migratory connectivity measures the "extent to which individuals and populations remain together between seasons of the annual cycle" (Cohen et al. 2018), both from the perspective of the breeding areas as well as from the wintering areas (chapter $\mathbf{1}$ ). Migratory connectivity can be viewed at several spatial scales; including the entire distribution of a species, or only subsets of it. Within the Western Palearctic, strong migratory connectivity was found in Rednecked Phalaropes (high $\mathrm{R}_{\text {mantel }}$ ), whereas the other three species had weak migratory connectivity (low Rmantel values, table 10.2). The strong migratory connectivity of Red-necked Phalarope corresponds to its migratory divide between breeding populations from Greenland, Iceland and Scotland and those breeding in Fennoscandia and Russia (van Bemmelen et al. 2019, chapter 3). Within each flyway, migratory connectivity is weak, as individuals from each flyway mix in their corresponding wintering areas. Migratory connectivity of both Grey Phalarope and Long-tailed Skua is characterized by large between-individual variation in wintering area and no marked differences between populations (van Bemmelen et al. 2017, chapters 4 and 6). The migration pattern of Arctic Skua is more complex, with all birds from the small sample from the Russian breeding populations wintering in the Indian Ocean, and many birds from Greenland and Svalbard wintering in the Caribbean area or other areas between $-10^{\circ} \mathrm{S}$ and $20^{\circ} \mathrm{N}$, but not further south. Despite this population structure, the tremendous between-individual variation in wintering area, even within single breeding sites and the overlap between breeding populations, results in a weak migratory connectivity as indicated by low Rmantel values across the dataset as well as within each cluster of breeding sites (table 10.2, chapter 8). 
TABLE 10.2 | Migratory connectivity summary statistics: the mean and $95 \% \mathrm{Cl}$ of the Mantel correlation $R_{m}$ for the entire dataset of each species as well as for clusters within each species.

\begin{tabular}{lc} 
Species & $\boldsymbol{R}_{\boldsymbol{m}}(\mathbf{9 5} \mathbf{9} \mathbf{C l})$ \\
\hline Red-necked Phalarope & $0.66(0.54-0.83)$ \\
Fennoscandia/Russia & $0.10(-0.08-0.30)$ \\
Greenland + Iceland + Scotland & $0.19(-0.08-0.62)$ \\
Grey Phalarope & $0.04(-0.16-0.40)$ \\
Long-tailed Skua & $0.11(-0.05-0.35)$ \\
Fennoscandia + Russia & $0.25(-0.07-0.69)$ \\
Greenland + Svalbard & $0.10(-0.06-0.34)$ \\
Arctic Skua & $0.21(0.13-0.30)$ \\
Greenland + Svalbard & $0.02(-0.12-0.25)$ \\
Norway + Iceland + Faroe Islands + Scotland + Finland & $0.08(0.01-0.18)$ \\
Russia & $-0.06(-0.38-0.35)$
\end{tabular}

\section{INDIVIDUAL CONSISTENCY IN WINTERING AREA CHOICE}

In all study species, individuals were generally consistent between years in wintering area selection, as indicated by high Bhattacharyya's affinity values (figure 10.3) and low intertrack distances (figure 10.4). However, both Grey Phalarope and Long-tailed Skua were more prone to diverge from the previous years' areas and routes than their sister species Red-necked Phalarope and Arctic Skua (chapter 3, 4, 6 and 8). In Grey Phalarope, two out of six individuals switched between wintering sites approximately $6500 \mathrm{~km}$ apart (chapter 4) whereas in Long-tailed Skuas, individuals diverted several $1000 \mathrm{~km}$ from previous routes, mainly after they had arrived at wintering areas that they visited in previous years.

With a growing number of studies reporting on individual consistency, high fidelity to wintering areas appears to be the rule among seabirds (Guilford et al. 2011, Muller et al. 2013, McFarlane Tranquilla et al. 2014, Krietsch et al. 2017), although in some species, a minority of the individuals switch between wintering area from one year to the next (Dias et al. 2011, Yamamoto et al. 2014, Orben et al. 2015). Also among terrestrial bird species, consistency in wintering area selection is usually high (Hjernquist et al. 2009, Vardanis et al. 2011, 2016, Stanley et al. 2012) and examples of terrestrial species site-switching at the spatial scale of what is reported here for Grey Phalarope and Long-tailed Skua are rare (Berthold et al. 2002). 
How individuals' preference for a wintering area arises, as well as the ability of some individuals to switch between wintering areas, is poorly understood. One possibility is that wintering area preference is inherited. Migration direction and distance have been shown to be under genetic control in passerines and brood parasites such as the Common Cuckoo Cuculus canorus, but similar evidence is lacking for other species groups (Pulido 2007). Alternatively or additionally, migration routes and wintering areas may be learned. Individuals may learn through cultural transmission from parents to offspring, such as in geese and cranes (Newton 2010). They may also learn through an associate process, by exploration of potential wintering areas during the first years of life and subsequent settlement in areas where they encountered suitable conditions, as proposed by the 'exploration-refinement' hypothesis (Guilford et al. 2011). Genetic and learning mechanisms are not mutually exclusive; the first migration of juveniles may be partly or largely genetically determined, with individuals improving subsequent migrations through learning (Pulido 2007, Sergio et al. 2014, de Grissac et al. 2016). The relative contributions of inherited versus acquired skills in the first and later migrations may also differ between species (de Grissac et al. 2016). Learning through large-scale explorations by immatures may result in a large spatial memory, allowing individuals to switch between alternative areas depending on local conditions (Phillips et al. 2005, Dias et al. 2011, de Grissac et al. 2016). In the results presented in chapter 6, a large spatial memory was strongly suggested by a Long-tailed Skua that switched between two alternative but each consistently repeated itineraries (van Bemmelen et al. 2017). There is growing empirical evidence of exploratory behaviour in early life, and how this may translate in wintering area preferences among seabirds (Weimerskirch et al. 2006, Dias et al. 2011, Péron and Grémillet 2013, de Grissac et al. 2016), but the degree of genetic control of migration remains to be shown for any long-lived seabirds species.

\section{WINTERING MOVEMENTS: RESIDENCY VERSUS ITINERANCY}

After arrival to the wintering area, migrants either stay in a single area (residency) until spring migration, or move between multiple areas within the wintering area (itinerancy, Moreau 1972). Here, itinerancy is taken to be spatially repeatable across years, and thus distinct from seasonal nomadism, in which individual movements patterns differ between years (Teitelbaum and Mueller 2019). Quantifying itinerancy requires delineating the wintering period, but the distinction between wintering movements and migratory movements is not always clear-cut, for example when individuals slow down during the final part of migration. Such slowing down before arrival may be facilitated when suitable stopover habitat is available - which may be especially likely in seabirds. One possible distinction is to use duration of staging, wherein migratory stopovers are only used for fuelling the next flight and staging periods longer than strictly needed for refuelling would be 

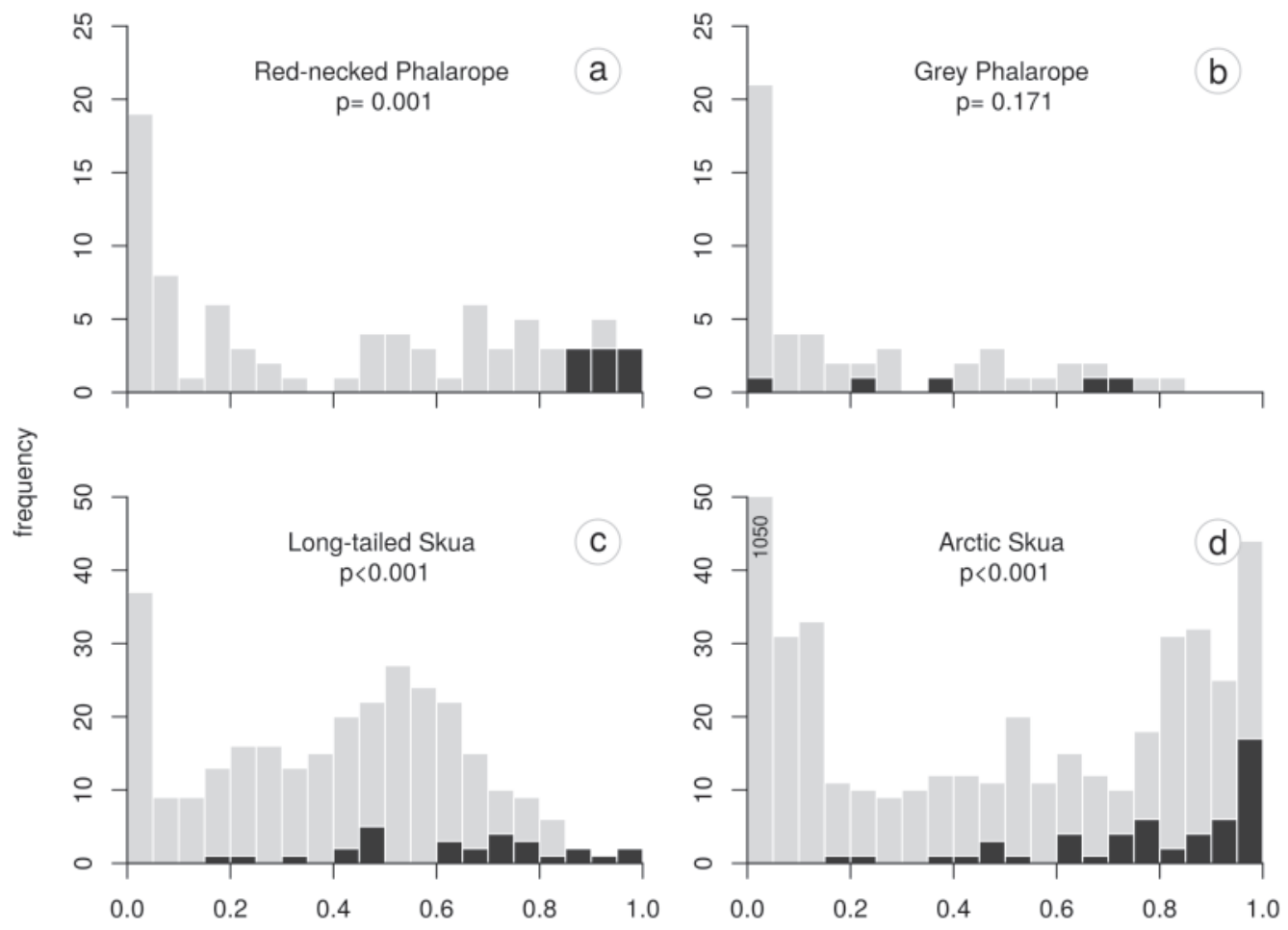

Bhattacharyya's affinity

FIGURE 10.3 | (a-d) Histograms of Bhattacharyya's affinity between 95\% UD kernels of the same individual (black) and different individuals (grey). Higher values represent larger overlap or closer proximity between kernels. Thus, individual consistency in wintering area sites is high in Rednecked Phalaropes, whereas Arctic Skua show some flexibility, and Grey Phalarope and Long-tailed Skua considerable flexibility.

regarded as part of the wintering period (Jones 1995). This mechanistic definition is difficult to implement as it requires knowledge of fuelling rates, which are rarely known. A simplistic but practical approach is to distinguish migration and wintering based on location. For example, all sub-Saharan staging sites are usually regarded as part of the wintering period among Palearctic-African migrants (Moreau 1972). Likewise, staging in marine areas of the Arabian Sea and adjacent waters was taken as the wintering period for Red-necked Phalaropes in chapters 3-4 (van Bemmelen et al. 2016, 2019).

Itinerancy, also referred to as intra-tropical movements in species wintering in the tropics, is increasingly receiving attention, in particular among Nearctic land birds wintering in the Neotropics (Fraser et al. 2012, Stanley et al. 2015) and Palearctic migrants wintering in sub-Saharan Africa (Stach et al. 2012, Kristensen et al. 2013, Trierweiler et al. 2013, Koleček et al. 2018). Itinerancy also occurs among seabird species, such as Sooty Shearwaters Ardenna griseus and Black-legged Kittiwakes 

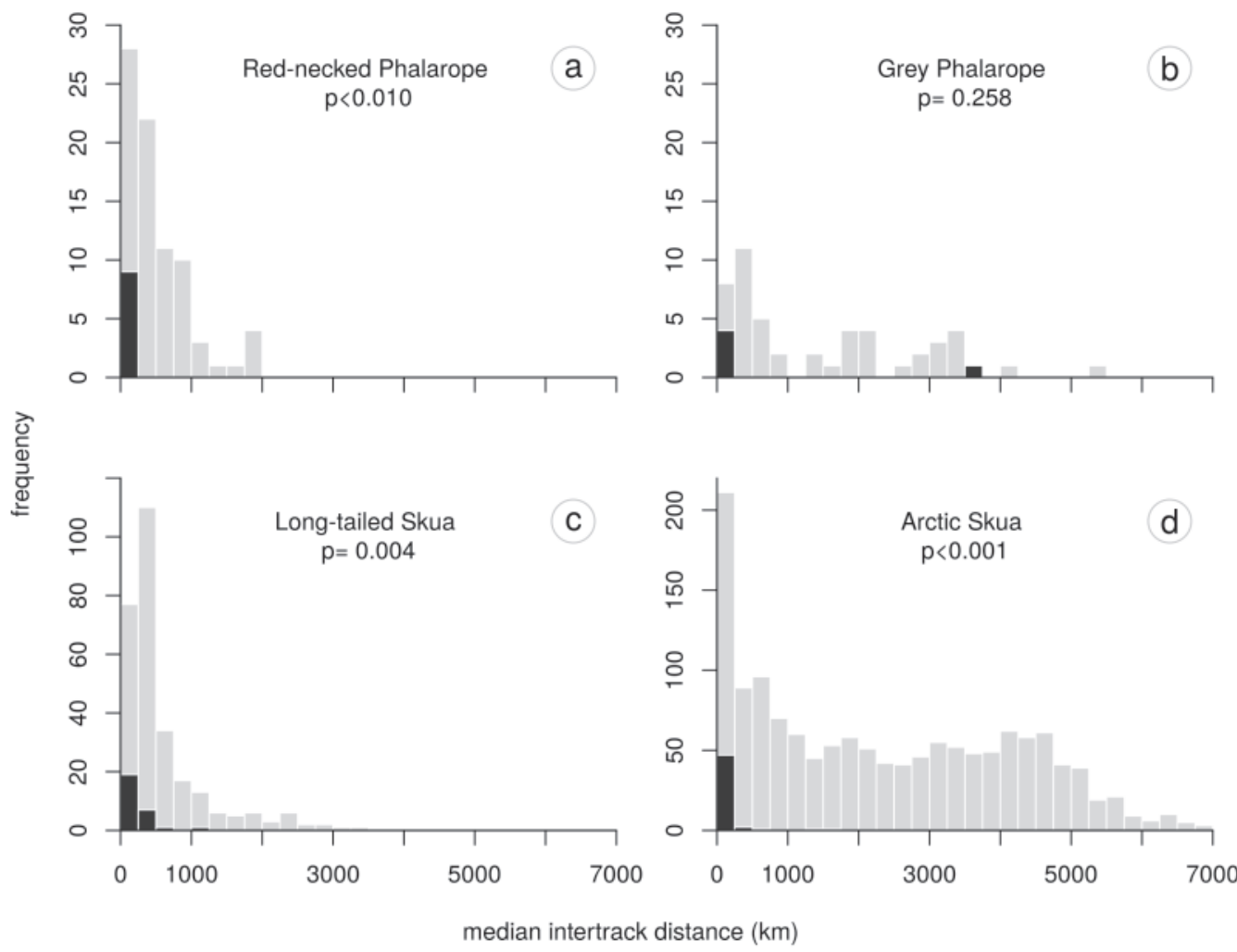

FIGURE 10.4 | (a-d) Histograms of median intertrack distance $(\mathrm{km})$ between tracks of the same individual (black) and of different individuals (grey), showing high individual consistency in all species, with exceptions for Grey Phalarope and Long-tailed Skua.

Rissa tridactyla, but is rarely acknowledged as such (Hedd et al. 2012, Orben et al. 2015). For both seabirds and landbirds, a review of itinerancy, with a quantitative analysis of the occurrence of itinerancy and the associated distances within and between species, as well as the drivers behind itinerancy, is still lacking.

Among the study species, itinerancy occurred in all species but to slightly different degrees. Restricting the staging period to sites where individuals stayed at least 14 d, usually 2-4 and up to 7 areas were visited, with small and non-significant differences between species $(\chi 2=3.4, d f=3, p=0.330$, figure 10.5). The cumulative distance travelled between these sites differed between species $(\chi 2=99.9, \mathrm{df}=6$, $p<0.001)$, with greater distances between sites in Long-tailed Skua $(\beta=0.8, t=2.8$, $p=0.005)$ and Grey Phalarope $(\beta=0.7, t=2.2, p=0.026$, figure 10.5).

What factors shape itinerancy and individual consistency in site use between years during the wintering period? Within the wintering area, the most important driver of movements is likely food availability, which usually varies in space and time 
(Stephens and Krebs 1986). Food availability can differ in abundance, spatial and temporal heterogeneity and predictability (Mueller and Fagan 2008), which in turn are likely to differ between wintering areas of a species. Indeed, the wintering areas of my study species are composed of ocean habitats with different meso-scale spatio-temporal dynamics. For example, wind-driven upwelling systems at shelf edges are predictable in location, whereas bodies of warm water propelled from the Agulhas current into the Atlantic ('Agulhas rings') change position continuously (Longhurst 2006). Thus, species that occupy multiple wintering areas provide the opportunity to study how productivity, spatial and temporal heterogeneity and predictability drive itinerancy and individual consistency. As in chapters $\mathbf{3}$ and $\mathbf{4}$ (van Bemmelen et al. 2019), degree of itinerancy is hypothesized to increase with the spatio-temporal variability of the environment, when they track seasonal shifts in the locations with highest food abundance. Individual consistency in site use between years is hypothesized to increase with predictability of the environment across years (chapter 6, van Bemmelen et al. 2017). Larger inter-annual differences, i.e. unpredictability, in food distribution would lead to non-repeatable itineraries, or 'seasonal nomadism', as site-fidelity would in that case result in individuals ending up in areas with suboptimal food abundance (Teitelbaum and Mueller 2019). Finally, with higher food abundance, birds are expected to move around less and show higher site-fidelity within their wintering area, considering intra- or inter-annual fluctuations in food abundance may stay at profitable levels in areas with high overall productivity. Below, I present an analysis of itinerancy and individual consistency in site use across study species and wintering areas.

Among wintering areas/species combinations, primary productivity correlated with spatial clustering of intra-annual variability (Pearson's product-moment correlation; $r=0.78, d f=15, p<0.001)$ and with the inter-annual variance $(r=0.77, d f=15$, $p<0.001)$. Spatial clustering of intra-annual variability also correlated with the interannual variance $(r=0.79, d f=15,0<0.001)$. Variance Inflation Factors (VIF) for these variables were between 2.2 and 2.5, below levels which are usually regarded as 'severe' amounts of multicollinearity (VIF>10). Yet also moderate VIF levels can impact model output and interpretation in multiple regression (Graham 2003), and the collinearity between the three habitat characteristics means that their relative contributions to explaining variation in itinerancy and site fidelity should therefore be interpreted with caution.

The number of wintering sites, a measure of itinerancy, declined with increasing primary productivity and inter-annual variability of primary productivity (figure 10.6); both were retained in the top-ranked model (table 10.3a). Moreover, the number of wintering sites decreased with spatial clustering of intra-annual variability (figure 10.6), suggesting birds moved less when areas of relatively high productivity remained in the same position. However, spatial clustering of intraannual variability was dropped in the top-ranked model but retained in the secondbest model, which had a marginally lower AIC (table 10.3a). Bhattacharyya's 


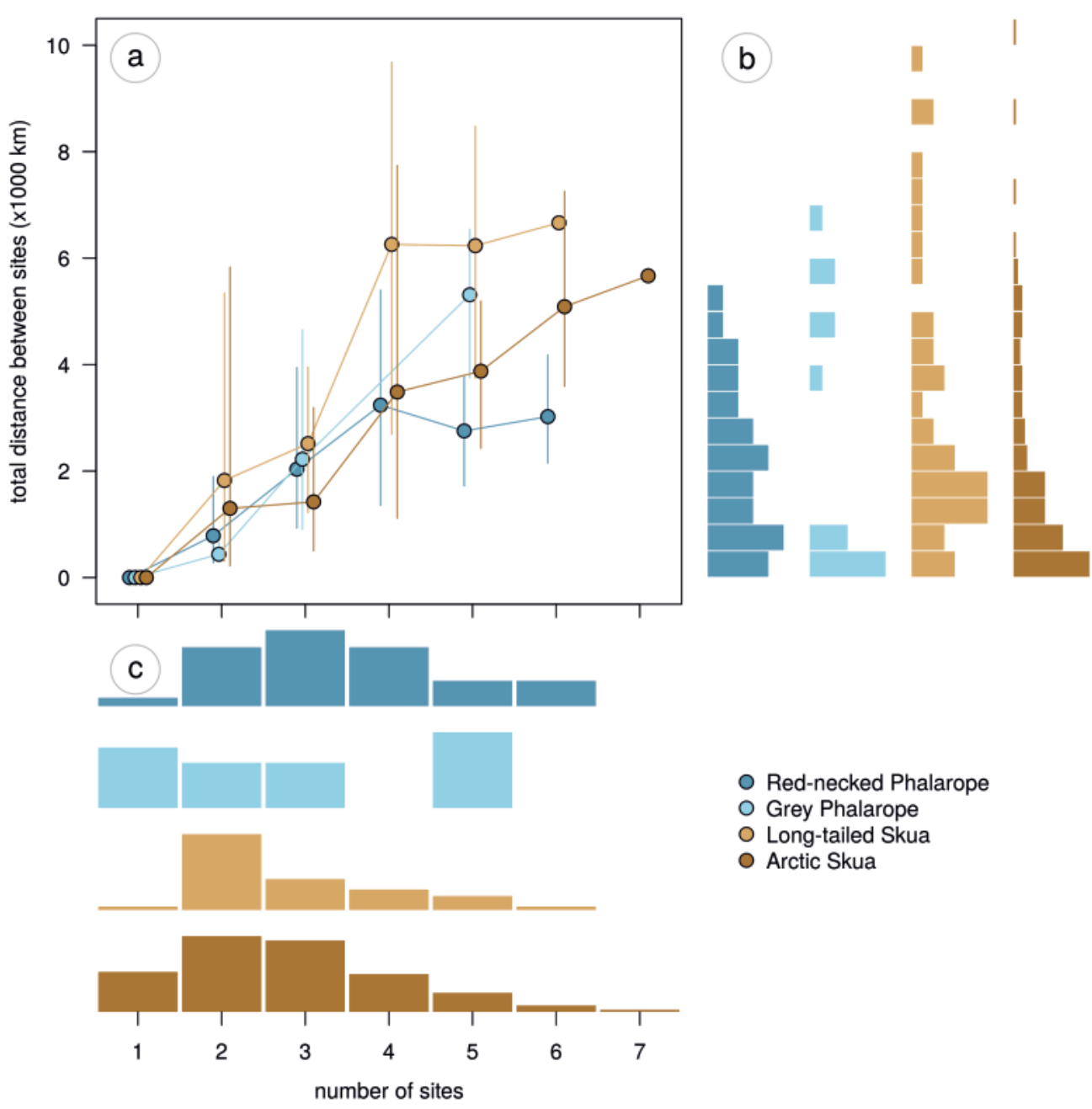

FIGURE 10.5 | Itinerancy in skuas and phalaropes. (a) Cumulative distance travelled within the wintering grounds as a function of the number of wintering sites; $\mathbf{b}$ and $\mathbf{c}$ show the distribution of values at the individual level. In all four species, individuals may use several wintering areas.

Whereas the number of sites was similar between species, the distances between sites was larger in Long-tailed Skua compared to the other study species.

affinities, a measure of individual consistency in site use between years, increased with primary productivity, spatial clustering of intra-annual variability and with inter-annual variability (figure 10.6); all were retained in the top-ranked model (table 10.3b). In summary, in line with my expectations, skuas and phalaropes moved around less and were more consistent in their space use form year to year in areas with high and stable primary productivity. 
TABLE 10.3 | Model selection results (showing the five best models) of a) number of sites (a measure of itinerancy) and b) Bhattacharyya's affinity (a measure of individual consistency in site use between years), as a function of primary productivity, spatial clustering of inter-annual clustering and intra-annual variability. Models are ranked by AICC.

\section{Explanatory variables}

Productivity $\begin{gathered}\text { Intra-annual } \\ \text { clustering }\end{gathered} \quad \begin{gathered}\text { Inter-annual } \\ \text { variability }\end{gathered}$ Species df AICc $\triangle A$ IC weight

a) Number of wintering sites

\begin{tabular}{llllllll}
\hline-0.37 & & 124.9 & + & 6 & 712.7 & 0 & 0.35 \\
-0.3 & -0.16 & 180.5 & + & 7 & 713.6 & 1.64 & 0.23 \\
-0.26 & & 74.97 & & 3 & 715.2 & 2.46 & 0.1 \\
-0.15 & & & 2 & 715.8 & 3.03 & 0.08 \\
-0.17 & & + & 5 & 716.7 & 3.96 & 0.05
\end{tabular}

b) Bhattacharyya's affinity

\begin{tabular}{cccccccc}
\hline 0.12 & 0.12 & -76.09 & + & 8 & -42.5 & 0 & 0.4 \\
0.18 & & -40.53 & + & 7 & -41.1 & 1.34 & 0.21 \\
& 0.19 & -69.15 & + & 7 & -40.9 & 1.61 & 0.18 \\
0.11 & & & + & 6 & -40.3 & 2.18 & 0.14 \\
0.1 & 0.02 & & + & 7 & -38 & 4.45 & 0.04 \\
\hline
\end{tabular}

How animals should move in a resource landscape as a function of internal state, time and safety has been studied extensively, for example in the field of foraging theory (Stephens and Krebs 1986). Because of the difficulties of tracking individual foragers and mapping resource distribution at large spatial scales (100-1000s km), as well as the fact that most tracking studies are site- and species-specific, comparisons of itinerancy and individual consistency in site use between wintering areas of the same species, or across species, have not - as far as I am aware of been carried out in migratory bird species (see also the discussion of chapter $\mathbf{3}$ ). In mammals, however, several studies show how movement types in different species (e.g., nomadism and migration) are driven by differences between areas in environmental seasonality and predictability (Mueller et al. 2011) or within species experiencing large-scale gradients of environmental seasonality and predictability across its range (Singh et al. 2012, Yurkowski et al. 2016). My analysis supports the generality of the links between movement patterns and spatio-temporal dynamics in productivity between species and areas. Therefore, change in productivity and 


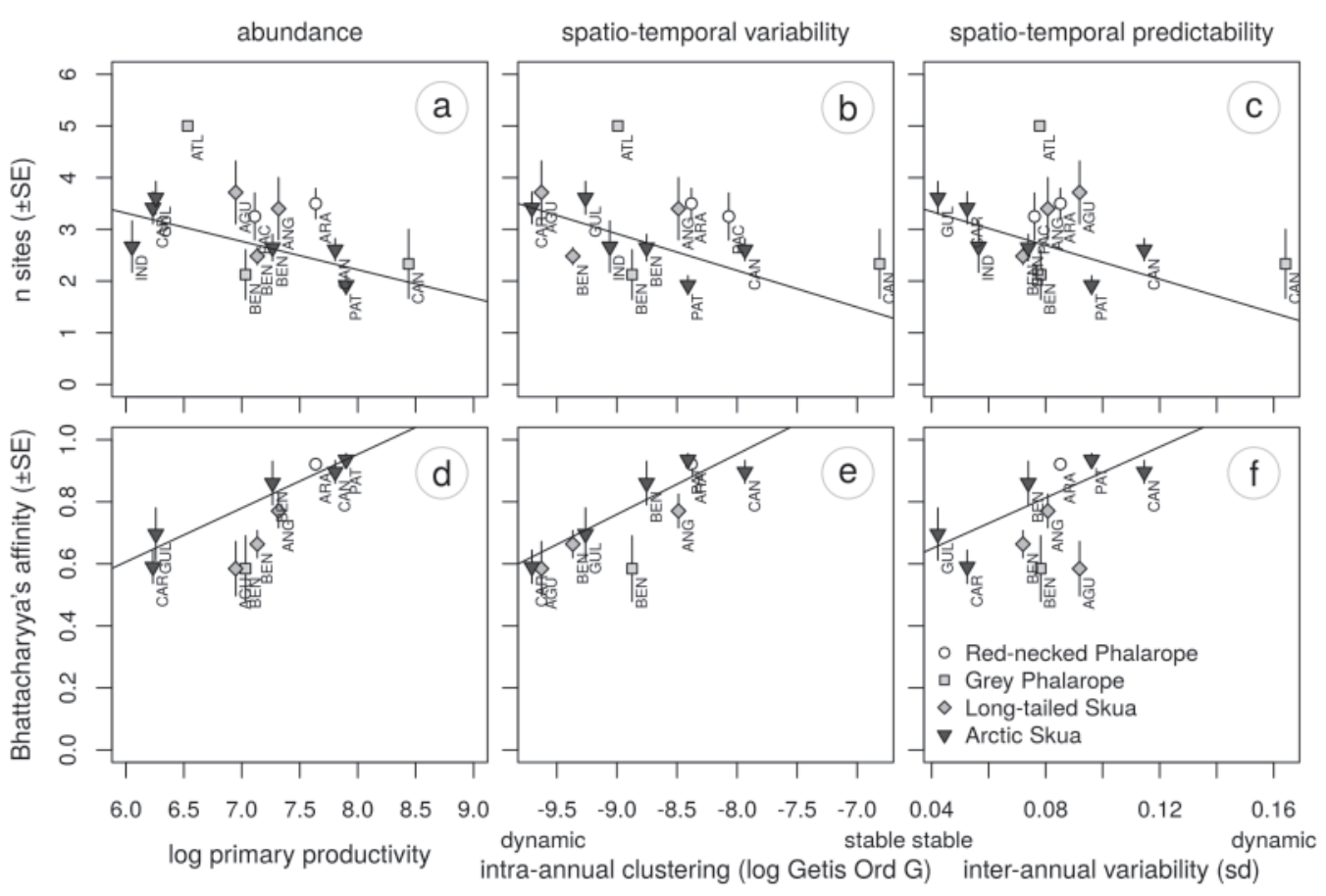

FIGURE 10.6 | Number of wintering sites (a-c), reflecting degree of itinerancy, and Bhattacharyya's affinities (d-f), reflecting individual consistency in site use, as a function of primary productivity (a, d), intra-annual spatial clustering of high primary productivity (b, e) and inter-annual variability $(\mathbf{c}, \mathbf{f})$. Only area-species combinations with three or more samples are shown here. Black lines show simple regression lines for Arctic Skua.

stability of wintering areas due to climate change may well result in different movement strategies.

The above analysis of itinerancy and individual consistency in relation to environmental characteristics could be improved in several respects. First of all, using primary productivity as a proxy for food abundance is obviously a gross simplification, as all study species feed on higher trophic levels; either zooplankton or pelagic fish. Consequently, primary productivity and food abundance for the study species possibly differs in space and time. In addition, sample sizes should ideally be increased, in particular for the two phalarope species, for which only two (Red-necked Phalarope) and three (Grey Phalarope) wintering areas could be included in the analysis of itinerancy and only one area for each species in the analysis of individual consistency. Also, itinerancy of Grey Phalaropes in the North Atlantic was higher compared to other species/areas, while values for other areas fitted fairly well in the general pattern (figure 10.6a-c), suggesting other factors potentially large-scale wind patterns - promote movements in the North Atlantic. Besides wind patterns, another aspect not considered in my analysis is seasonality in predictability. For example, Long-tailed Skuas were shown in chapter 6 to be more flexible between years in site use during the second half of the wintering 
period than during the first half. Thus, individual consistency can fluctuate seasonally, and the analysis presented above can be refined by including site fidelity and predictability of the environment at smaller temporal scales. Finally, future studies should ideally offset the evidence for environmental drivers of itinerancy and individual consistency against alternative potential drivers, such as competition or predation avoidance.

\section{SUGGESTIONS FOR FUTURE STUDIES}

The development of tracking technologies is still ongoing at a rapid pace. At the start of our studies, geolocators were selected because of the benefits of low costs, allowing more individuals to be tracked with a small budget, small size and low weight, allowing even the smallest species to be tagged. However, geolocators have disadvantages compared to other tracking devices that limit what questions can be answered. For example, since geolocators need to be retrieved, results may be biased because only surviving and site-faithful individuals will be sampled. Realtime tracking (e.g. through satellite transmitters) avoids such biases and will also reveal where and when mortality occurs, as well as the level of breeding dispersal (changing of breeding location from year to year) and natal dispersal (from natal area to area of recruitment). In addition, real-time tracking methods usually have higher spatial and temporal resolution, allowing much more detailed study of movements. Tracking devices that do not require recapturing of the individual would be the preferred method to study the ontogeny of movement and of natal dispersal. Natal dispersal distances can be substantial, as shown by Great Skua born in Scotland and breeding at Bear Island and Svalbard (Furness 1987). Realtime tracking has not yet been used on the study species because device weight (phalaropes) and attachment methods (harnesses on skuas, e.g. Thaxter et al. 2016) that were, at the onset of the study, deemed unsuitable for my study species. With further miniaturization of devices and innovations in harness design, real-time tracking will likely be feasible in the near future.

There are large knowledge gaps in the at-sea ecology of the study species during the non-breeding season. In particular, diet composition and the importance of different foraging modes (e.g., kleptoparasitism versus self-feeding in skuas) are poorly known, although at-sea ecology of phalaropes has received limited attention at stopovers (Mercier and Gaskin 1985, Brown and Gaskin 1988, Rubega et al. 2000). Ship-based surveys are vital for our understanding of at-sea ecology of seabirds, because only by direct observation at sea, important information on finescale feeding aggregations, interactions with other species and foraging behaviour can be gathered simultaneously (Camphuysen et al. 2013, chapter 5).

With the non-breeding movements of my study species and populations described, a basis for studying carry-over effects between phases of the annual cycle has been 
laid out. In studies of the effect of wintering area choice on breeding performance, an alternative method to geolocators that avoids the need of and bias towards returning individuals and increasing sample sizes, is to infer wintering area from biomarkers such as stable isotope ratios or trace elements. This would of course require a 'training dataset' with biomarker measurements of birds with known wintering area, i.e. from tracking data. We have built such a training dataset over the past years for both Long-tailed and Arctic Skuas, and in a pilot study using this method on a subset of the Arctic Skua data, wintering area assignments based on carbon and nitrogen stable isotope ratios were correct in $\sim 80 \%$ of the cases (Rypdal 2018). As a next step, carry-over effects of non-breeding conditions on performance in the breeding period can be investigated. Wintering area conditions can be characterized by stress hormone levels in feathers grown in the wintering area (corticosterone, e.g., Bourgeon et al. 2014), by time-budgets (salt-water immersion and movement data) and environmental conditions from geolocator data (sea surface temperature), and from remote sensing (e.g. weather, primary productivity).

Many tracking studies run for one or two years only, which hampers the analysis of individual- or population-level inter-annual variability in timing as a function of environmental conditions. For example, timing of spring arrival at the breeding grounds may be heavily affected by conditions encountered en route (Tøttrup et al. 2012), which only become apparent when individuals are tracked over multiple years. In Arctic species, quantifying flexibility in spring arrival timing is of special interest for predicting the response to effects of climate warming, such as advancing dates of snow melt (Lameris et al. 2018). Insufficient adjustment of timing of spring arrival may lead to a temporal mismatch between the phenology of food availability and the peak in food requirement of offspring (Both and Visser 2001, Ramírez et al. 2016). Our datasets now span multiple years, but are still rather short for robust analyses of inter-annual variability in relation to environmental variables.

A major knowledge gap for all four study species, in particular for conservation studies, is the lack of population trend and demographic data for much of their distribution ranges, notably in the vast Russian tundra areas. Due to this lack, there is a poor understanding of the well-being of the species, even substantial reductions in population sizes may be missed, and the effects of potential threats on population size or demographic rates cannot be assessed. Despite the increased interest in long time series datasets for climate change studies, it remains difficult to get long-term studies funded (Lindenmayer et al. 2012).

\section{CONSERVATION OF SEABIRDS AT SEA}

In Arctic Skuas, the most immediate and visible threats are faced during breeding, 
where low reproductive success is likely the main driver of population declines (chapter 9, Perkins et al. 2018). Likewise, in Long-tailed Skuas, the strong dependency of reproduction on rodent abundances makes them vulnerable to dampening rodent population cycles in the face of climate warming (chapter 7, Kausrud et al. 2008, Barraquand et al. 2014). Being K-selected species, the skuas' life histories combine slow reproduction with high survival rates. Hence, ensuring high adult survival rates by protecting the oceanic non-breeding habitat is, in addition to protecting their breeding habitats, critical to their conservation (Croxall et al. 2012, Runge et al. 2015).

Besides threats from climate change in the breeding areas, such as dampening rodent population cycles that could affect Long-tailed Skuas (Kausrud et al. 2008, Barraquand et al. 2014), changes in insect phenology that could affect phalaropes (Tulp and Schekkerman 2008, van Gils et al. 2016), and changes in fish abundance and distribution that would affect Arctic Skuas (Cury et al. 2011), many oceanic non-breeding habitats have undergone massive changes over the past century, with pollution, overfishing and changing spatial distributions of prey stocks (Cury and Shannon 2004, Rijnsdorp et al. 2009). Although fish stocks are stabilizing in some well-managed areas, stocks continue to decline in others, including areas that are important to seabirds (Worm and Branch 2012). Rapid climate change poses an additional threat, predicting rising ocean temperatures and a concomitant reduction of primary productivity (Moore et al. 2018) which will inevitably affect the food base that seabirds depend on. Spatial mismatch of non-breeding movements and food abundance may mainly impact non-breeding survival, but may also carry-over to reproductive success through lower body condition upon arrival or suboptimal timing. Will seabirds be able to respond to rapid environmental changes in their non-breeding areas?

Migratory animals can respond to changing conditions through adaptive behavioural flexibility or through evolutionary adaptation involving natural selection (Lindström et al. 2014). Both mechanisms require phenotypic variation; either within or between individuals. Variation between breeding populations (chapters 3 and 8), variation between individuals (chapters 2-4, 6, 8), and flexibility at the individual level (chapters $\mathbf{3}, \mathbf{4}, \mathbf{6}, \mathbf{8}$ ) in migration and wintering movement strategies among my study species suggest there is scope for adjustments of migration routes and wintering areas if the distribution of suitable areas changes, but not necessarily when overall food abundance decreases. The relative contributions of individuals and populations to the variation in movement strategies differ between the four study species, with the least variation found in Red-necked Phalarope, greatest between-individual variation in Arctic Skua and largest individual flexibility in Grey Phalarope and Long-tailed Skua. Thus, relatively low individual variation and strong migratory connectivity suggests Red-necked Phalarope would be slowest in responding to rapid changes in the quality and distribution of stopover and wintering habitats, whereas the larger individual 
variation in the other three species suggest more room for adjustment through either developmental plasticity or individual flexibility. However, low individual variation and flexibility, as observed in Red-necked Phalaropes, does not exclude the possibility that they have the ability to can change their movement strategies when pressed.

Also, variation in wintering area selection can potentially buffer populations against deteriorating conditions in part of the wintering areas. In an overview of contemporary changes in migration routes, Sutherland (1998) listed migration routes that appear sub-optimal, suggesting that populations would benefit from changing routes but are apparently hampered to do so. These were all species in which juveniles migrate independently from adults, suggesting a reliance on an innate, genetic programme, whereas no species with culturally transmitted migration routes showed apparently sub-optimal migration routes. This suggests a greater capacity to adjust migration routes to changing conditions among species with culturally transmitted migrations routes.

Do these hypothesized vulnerabilities to rapid climate change match with observed population trends? Population declines have indeed been reported for Red-necked Phalarope at least in Finland (Delany et al. 2009, Valkama et al. 2011). In contrast, although no systematic surveys have been conducted, populations of Grey Phalaropes at Svalbard appear to have increased over the past few decades (Strøm 2006, Delany et al. 2009, Bangjord et al. 2015). No reliable population trend information is available for the Long-tailed Skua. In contrast to the above hypothesis, at least the Scottish and Norwegian populations of Arctic Skuas are rapidly declining, which is thought to be caused by low reproductive output rather than by low adult survival (Perkins et al. 2018, chapter 9).

The huge scale at which seabirds roam and utilize oceans makes conservation of their non-breeding habitats a daunting task (Harrison et al. 2018). The large scale and the fact that foraging areas may shift in location within and between years (e.g. Agulhas rings), call for measures at correspondingly large scales. This is especially complicated as it requires countries, in addition to protecting their own waters, collaborate in protecting international waters (Harrison et al. 2018). By showing which areas are important as stopovers or wintering areas for the study species, this thesis provides important information to inform at-sea conservation plans. Fraser et al. (2018) demonstrated that, if available, the majority of tracking studies are referenced in status assessment reports and recovery plans and may thus help in conservation planning. Moreover, Hays et al. (2019) presented examples of where and how tracking data has been successfully used to inform policy in marine systems. Obviously, the contribution of tracking studies to conservation depends on multiple factors, such as the status of the species, the quality of the tracking data, whether threats are mainly manifested in the breeding or non-breeding period, etc. 
The studies presented in this thesis have already contributed to concrete conservation actions in two instances. First, the Long-tailed Skua tracking data has been used in the delineation of and subsequent proposal for a high-seas Marine Protected Area (MPA) in the North Atlantic: the 'North Atlantic Current and Evlanov Seamount MPA'. Long-tailed Skuas use this area as a stopover in autumn before migrating to the wintering grounds (chapter 6, van Bemmelen et al 2017), and in spring to fuel up to arrive in the breeding area with large body stores (chapter 7 ). In addition to Long-tailed Skuas, Arctic Skuas and Grey Phalaropes, more than two million seabirds, plus many marine mammals and other wildlife, use this area. The proposal for this MPA was put together by Birdlife International and submitted to the Convention for the Protection of the Marine Environment of the North-East Atlantic (OSPAR) committee, and is still under consideration at the time of writing.

Second, the data collected in the Arctic Skua colony at Slettnes (chapter 9) demonstrated the severe effects of predation by Red Foxes, which has led to a greater awareness among governmental and non-governmental organizations and the local community. For example, people living in the nearby village of Gamvik have been discouraged to feed foxes, in the hope that this will decrease (winter) survival rates of foxes. The effectiveness of this and future measures should be demonstrated in the coming years.

\section{CONCLUDING REMARKS}

Close to a century after the study of the distribution of seabirds across the North Atlantic by Vero Copner Wynne-Edwards, despairing over the 'almost insurmountable difficulties to be overcome before completing the picture of the ebb and flow of bird life over so vast an area' (Wynne-Edwards 1935), development of miniature tracking devices has enabled us to study the migrations of four Arctic, long-distance migratory seabirds. Understanding the causes and consequences of their elusive and distant pelagic life, and how that life links with the brief time they spent each year in the Arctic, is highly relevant in this era of rapid environmental change and industrial exploitation of the seas. At the same time, their elusive way of life, happening largely outside our field of vision, adds to the beauty and mystery of seabirds. 


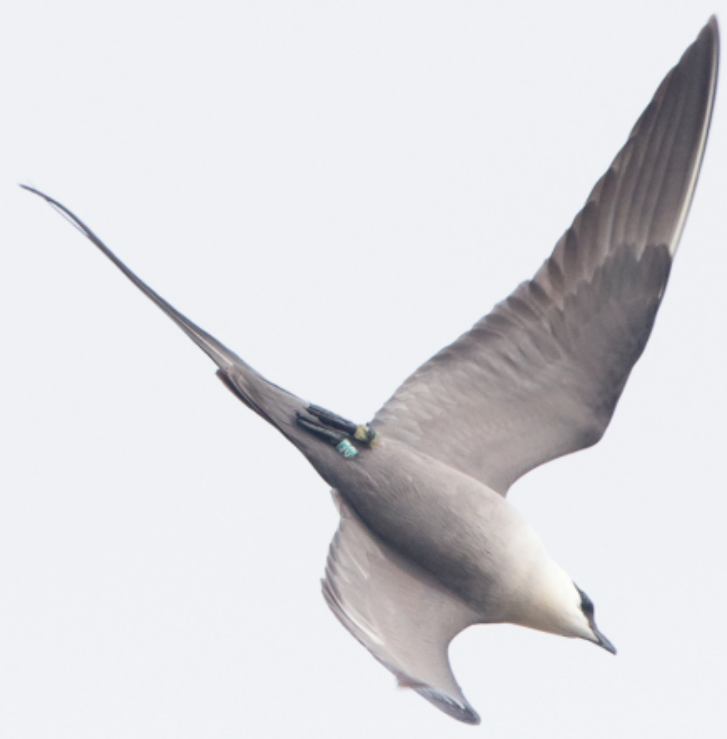

Long-tailed Skua carrying a colour ring ('KF') and geolocator. Ammarnäs, Sweden, 15 June 2018. 


\section{METHODS}

\section{Migratory connectivity}

As a measure of migratory connectivity, Mantel correlations $\left(R_{\text {mantel }}\right)$ were computed for each species using the MigConnectivity package in $\mathrm{R}$ (Ambrosini et al. 2009, Cohen et al. 2018). The Mantel test calculates the correlation between the distance matrix of breeding sites and the distance matrix of wintering sites (or stopover sites).

\section{Representativeness of the data}

To quantify, for each species, the representativeness of our tracking data for the studied populations, I followed two similar approaches. First, I applied the method of Lascelles et al. (2016) that bootstraps $(N=100)$ the percentage of position estimates included in $50 \%$ UD kernels as a function of the number of tracks. Subsequently, a non-linear regression line is fitted to estimate the asymptote; the percentage of positions within the $50 \%$ UD kernel with the full dataset divided by this asymptote is used as a measure for representativeness. Second, I calculated how surface area of the main wintering area saturated as a function of the number of tracked individuals. Positions in December - January from the first track for each individual were selected from complete tracks or tracks in which the logger failed after February. This resulted in 179 position estimates per track, for which $50 \%$ utilization density (UD) kernels were estimated using a fixed smoothing parameter of $185 \mathrm{~km}$, corresponding to the mean error of geolocator position estimates (Phillips et al. 2004). Note that surface area of the $50 \%$ UDs is sensitive to selection of the smoothing parameter and the percentage of UD kernels selected, but by selecting a wide smoothing parameter, $50 \%$ kernels often cover more than $50 \%$ of the position estimates. For each potential number of tracks, UD kernels were resampled 100 times without replacement, measuring the combined surface of the sampled UD kernels. The surface area of the true wintering distribution a, of each species-specific relation between number of tracked individuals $n$ and the cumulative surface area of the $50 \%$ UD kernels $s$ was derived from least-square parameter estimates of the model $s=a \cdot n /(b / n)$. As an indication of how well our data represents the true wintering distribution, combined UD kernel surfaces were divided by a. Finally, the number of tracked individuals required to cover $75 \%$ of a was calculated.

\section{Itinerancy}

Using twilight data from only the first track of each individual, staging periods were delineated using the 'changelight' function from the 'GeoLight' package in $\mathrm{R}$, which detects changes in the moment of sunrise and sunset (Lisovski and Hahn 2012). Only staging periods of at least $14 \mathrm{~d}$ 
were considered. Great-circle distances between staging periods were calculated, and subsequent staging periods with geographical centroids within $200 \mathrm{~km}$ were joined and distances re-calculated.

\section{Individual spatial consistency}

To quantify the degree of spatial consistency, Bhattacharyya's affinity was calculated as a measure of similarity between the 95\% UD kernels of all position estimates between November and February (Fieberg and Kochanny 2005). In addition, intertrack distances were calculated for each trackcomparison. Subsequently, both Bhattacharyya's affinities and median intertrack distances were compared between comparisons of the kernels of the same individual in the two subsequent years against comparisons between individuals from the same breeding site using a randomization procedure with 10000 permutations. In each permutation, all trackcomparisons within individuals and a random selection of betweenindividual comparisons of the same size as the within-individual comparisons were compared. Subsequently, the 'within-individual' and 'between-individual' labels were randomized and the difference of the means of each group calculated. Finally, the number of times the mean difference in the randomized distributions was smaller (Bhattacharyya's affinities) or larger (median intertrack distances) than the observed difference was calculated to assess the statistical significance.

\section{Characterization of wintering areas}

As a proxy of food abundance, remotely sensed primary productivity between 2005 and 2018, with a temporal resolution of 8 d (O'Malley 2016) was extracted from combined $50 \%$ UD kernels of all first tracks of individuals for each species and wintering area. Primary productivity data was first loge transformed and projected using the Eckert IV projection. For each area, metrics for the abundance and inter- and intra-annual spatiotemporal variability were calculated, similar to the methods outlined by (Mueller et al. 2011). For each area, mean productivity was calculated as the average upper $95 \%$ quantile per grid cell $\left(1 / 12^{\circ}\right)$. As a measure of how the most productive patches within a wintering area shift location within a year, first the anomaly in primary productivity was calculated for all grid cells for each $8 \mathrm{~d}$ period and then averaged over all $8 \mathrm{~d}$ periods within a year. Finally, the Getis-Ord G statistic was calculated using the 'spdep' package (Bivand et al. 2013). Getis-Ord G is a measure of spatial clustering of values; with a positive statistic indicating clustering of high values and negative statistic indicating clustering of low values. Thus, when clusters of grid cells have consistently higher primary productivity than other areas, thus indicating low spatio-temporal variation, I expect this to be reflected in high Getis-Ord G statistics. When areas of higher primary productivity occur at different places throughout a season, no such clustering of high 
productivity cells would occur, and the Getis-Ord G would be negative. Resulting Getis-Ord G values were all positive but highly skewed and therefore loge-transformed before analysis. Finally, as a measure of predictability of primary productivity, the variance within each grid cell was calculated for each $8 \mathrm{~d}$ period across years. Subsequently, the spatial average was calculated. Generalized Linear Models (GLMs) with either number of sites (poisson GLMs) or Bhattacharyya's affinities (binomial GLMs) as response variables, and species, mean primary productivity, intra-annual Getis-Ord $G$ and inter-annual Getis-Ord $G$ as response variables. Model selection based on AICc was performed using the MuMIn package (Bartoń 2018).

\section{ACKNOWLEDGEMENTS}

Thanks to all collaborators for allowing me to use their geolocator data for this synthesis. Thanks to Ingrid Tulp, Floor Soudijn and Anieke van Leeuwen for comments and suggestions on an earlier draft.
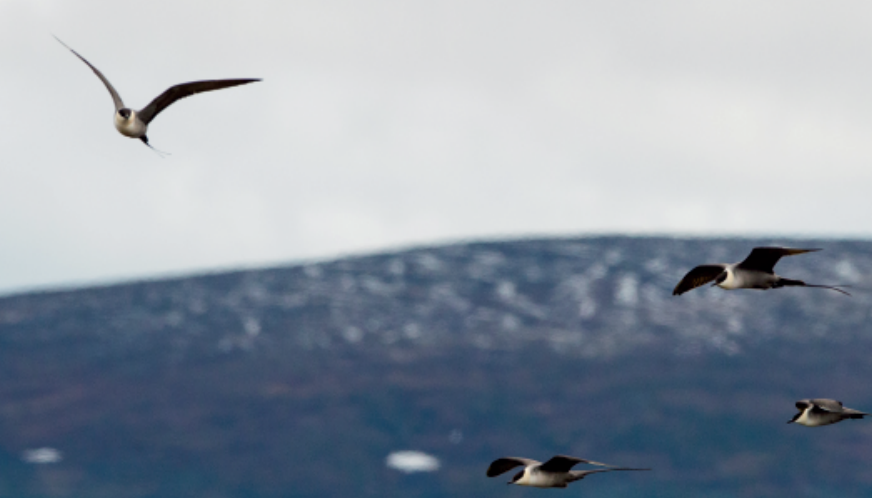


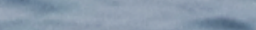
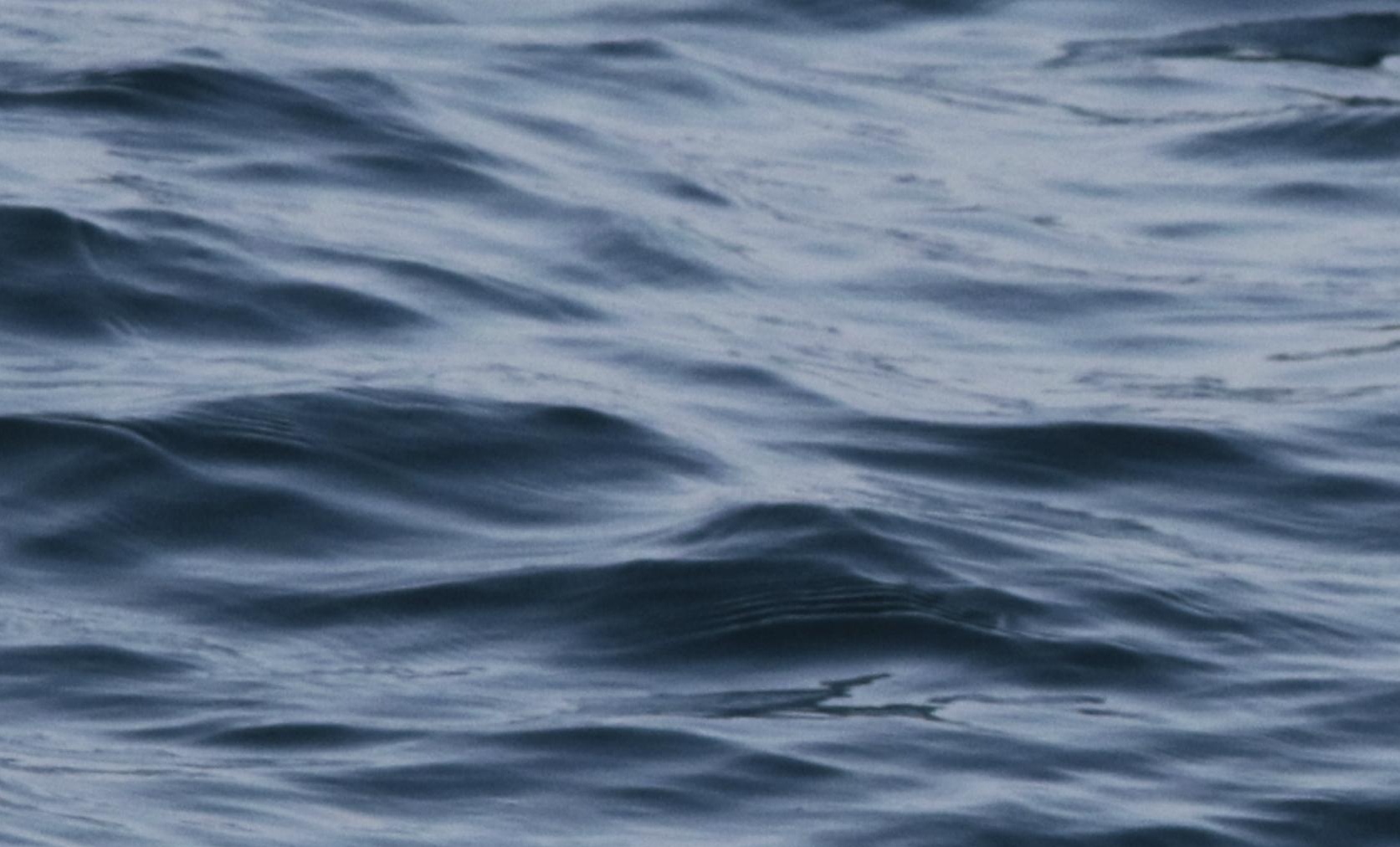

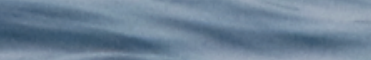
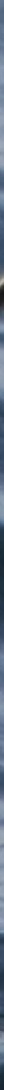

Surface-dipping adult Long-tailed Skua off Mauritania, 3 November 2016. Long-tailed Skuas are regularly seen foraging by themselves, suggesting kleptoparasitism is less important compared with other skuas species. 


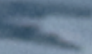

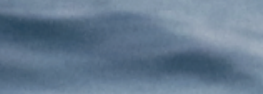

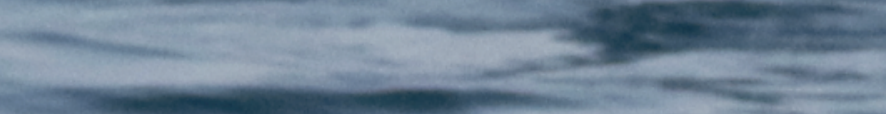

\section{Summary / Samenvatting}

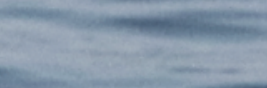

200
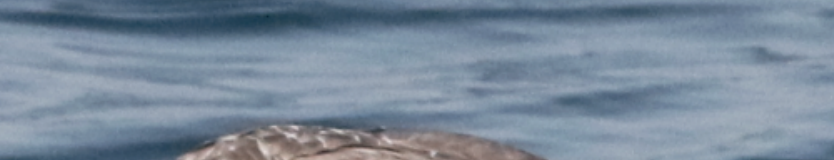

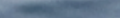

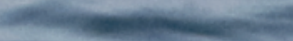
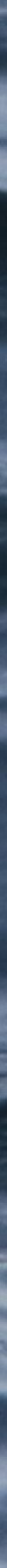


\section{SUMMARY}

Throughout their annual cycle, migratory animals depend on widely separated areas for reproduction, fuelling migration, moulting and wintering. By migrating, animals link these areas. As conditions in one area can affect the behaviour or state of an individual in a next phase of the annual cycle, knowing the area use of migrants is important for understanding potential drivers of individual performance and population dynamics. For many species, however, basic information on their migration route, stopovers and wintering areas is lacking.

Seabirds are well-represented among animals with the longest and most spectacular migrations. Only a few decades ago much of what was known about seabird migrations was based on land-based sightings or anecdotal at-sea observations, providing only a fragmentary and incomplete picture. Since the development and miniaturization of tracking devices, in particular light-based geolocators, details of seabird migrations are revealed at a fast pace. In this thesis, the migrations of a group of long-distance migratory seabirds breeding in Arctic tundra areas around the North-east Atlantic was studied. The main aims are to describe the non-breeding movements of each study species, reveal variation within individuals in migration routes, wintering areas and movement strategies relative to variation between individuals and populations, and link non-breeding movements with other activities in the annual cycle. In international collaborations, individuals were tracked - in some cases over up to five years - using light level geolocators from breeding sites between North-east Greenland and West Siberia.

In chapter 2-3, Red-necked Phalaropes from Fennoscandian and Russian breeding areas were confirmed to migrate to the Arabian Sea in the Indian Ocean - a more or less two-step migration of ca $6000 \mathrm{~km}$, involving a prolonged stopover at around $45^{\circ} \mathrm{N}$ during both autumn and spring migration. In contrast, Red-necked Phalaropes breeding in Greenland, Iceland and Scotland migrated ca $9000 \mathrm{~km}$ westwards to the northern Humboldt Current in the eastern Pacific. The longer migration to the eastern Pacific was associated with longer wings; more pointed wings may reduce flight costs on long migrations. Red-necked Phalaropes following these two flyways face contrasts in availability of saline stopover habitat en route and also in the spatio-temporal variability in upwelling conditions at the two wintering areas, which corresponded to differences in migration strategies as well as wintering movement strategies. Birds wintering in the eastern Pacific migrated generally in more steps and - in spring - at higher speed than those wintering in the Arabian Sea. Moreover, birds wintering in the eastern Pacific stayed at roughly a single site (residency), whereas birds wintering in the Arabian Sea moved considerable distances between sites (itinerancy).

In chapter 4, Grey Phalaropes from North-east Greenland and Iceland were shown to migrate to three broad wintering areas across a wide latitudinal range in the 
Atlantic. These wintering areas were associated with different autumn and spring migration routes and stopover sites, as well as different degrees of movements within each wintering areas. Interestingly, two out of six individuals with more than one year of data switched from one year to the next between wintering areas ca $6500 \mathrm{~km}$ apart, indicating considerable individual flexibility.

Moult (feather replacement) is important for maintaining the main functions of the plumage: insulation and flight. Moult is also energetically demanding and therefore, overlap with other demanding activities, such as breeding and migration, is usually avoided. In chapter 5, start date and duration of primary moult was studied in the four skua species breeding in the northern hemisphere. Among the four skua species, moult was finished at the start of spring migration. Therefore, longer moult durations of the larger species required an earlier start, resulting in temporal overlap with autumn migration. In the most extreme, moult overlapped with the entire autumn migration in Great Skuas. Excluding Great Skuas, the first moult cycle (in $2^{\text {nd }}$ calender-year birds) lasted longer than later moult cycles, which can be attributed to migration limiting the time available for moult in $3^{\text {rd }}$ calendar-year and older birds, but not in $2^{\text {nd }}$ calender-year birds.

Tracking individuals for multiple years allows the investigation of individual consistency in routes and area use. Using geolocator data of Long-tailed Skuas breeding in Greenland and Svalbard (subspecies S I pallescens) and those breeding in Scandinavia (subspecies S I longicaudus), individual consistency in non-breeding movements was quantified in chapter 6. Individuals of both subspecies migrated via a stopover area in the central North Atlantic to winter mainly off South-west Africa, with some individuals venturing into the Indian Ocean. Most individuals closely followed previous years' movement patterns, but during the wintering period, up to ca $20 \%$ of the individuals deviated from earlier routes more than 1000 $\mathrm{km}$. Remarkably, one individual switched mid-winter from the Benguela Current to the Falkland Current in two out of four years, using two distinct itineraries that were both repeated in later years. These results show flexibility in non-breeding movements during a part of the annual cycle, and strongly suggests extensive spatial memory of individual Long-tailed Skuas.

Relying for reproduction on strongly cyclic rodent population sizes, Long-tailed Skuas face large annual variability in feeding conditions upon arrival at the breeding grounds. To survive unfavourable feeding conditions upon arrival at the breeding grounds or to start egg laying soon after arrival, migrants can bring body stores deposited on the wintering grounds or at staging areas along the migration route. In chapter $\mathbf{7}$, the contributions of distantly-acquired, marine resources ('capital') and locally-acquired, terrestrial resources ('income') in egg production were investigated in Lapland, Sweden, during a ten-year period with varying rodent densities, using stable isotope data of adult, juvenile and chick down feathers. With higher rodent density, contributions of locally-acquired terrestrial resources were 
larger whereas the contribution of distantly-acquired marine resources remained constant. Long-tailed Skuas arrive in the breeding area with large body stores, which they likely build up during a prolonged stopover in the central North Atlantic.

Arctic Skuas breeding between East Greenland and the Yamal peninsula (Russia), as shown in chapter 8, range across the entire Atlantic, and also the Mediterranean and Arabian Seas. Within a single colony (Slettnes in northern Norway), the full range of wintering areas occurred, making this species ideal to quantify the relative effects of breeding and wintering area of the timing of migration and breeding. Beside a strong effect of breeding site on annual schedules, wintering area strongly affected the timing and duration of migration and the duration of the wintering period. Specifically, more distant wintering areas were associated with a substantially longer migration duration, a shorter wintering period, and an earlier departure to arrive in time on the breeding area. Breeding latitude not only shifted annual schedules but also affected the duration of phases in the annual cycle: spring migrations were faster and the time between arrival at the breeding grounds and clutch initiation shorter than at lower breeding latitudes. Whereas most Arctic Skuas wintering in the Atlantic used a spring stopover area in the central North Atlantic, time spent here was shorter for individuals that migrated later, with birds migrating from the Canary Current to breed on Svalbard skipping this stopover entirely. These shorter migrations and pre-laying periods suggest that birds breeding in the high Arctic carry body stores from the wintering areas across 60 latitudinal degrees.

Among the four study species, data on population size and trends are lacking or scant. For Arctic Skuas, population trends and their drivers are relatively wellstudied in Scotland, but potential causes of the declines of Arctic Skuas have remained poorly studied elsewhere. In chapter 9, a population decline of ca 50\% over the past two decades is documented for the largest European colony at Slettnes, northern Norway. During five recent study years (2014-2018), both bottom-up (food shortage) and top-down (predation) effects negatively affected the reproductive investment and hatching success in this colony. Food shortage in three out of five recent study years was suggested by a high percentage of one-egg clutches, small eggs and low adult female body mass. At the same time, nest predation by Red Fox Vulpes vulpes increased, leading to total breeding failures in recent years, even when food availability appeared good. Clearly, the reproductive output in the study years was far below levels required to sustain a stable population, even with a high adult survival probability.

In the concluding chapter 10, migration patterns and movements within the wintering areas are compared between the four study species. First, I show that the representativeness of the tracking datasets for the studied populations is generally high. By comparing movement behaviour across species and wintering areas, I show how the degree of itinerancy decrease and individual consistency increases 
with primary productivity and seasonal spatial stability of primary productivity of wintering areas. In the final part of the general discussion, I suggest potential directions for future studies and discuss threats and conservation of seabirds during the non-breeding season, including the question whether the studied seabirds will be able to adjust their non-breeding movements to rapid environmental changes. Considering differences between species in large scale-migration patterns, degree of migratory connectivity and individual flexibility, I argue there is little scope for adjustment in the Red-necked Phalarope, but more scope for adjustment of migration routes and wintering areas to rapid environmental change via developmental plasticity or individual flexibility in the Grey Phalarope, Long-tailed Skua and Arctic Skua.

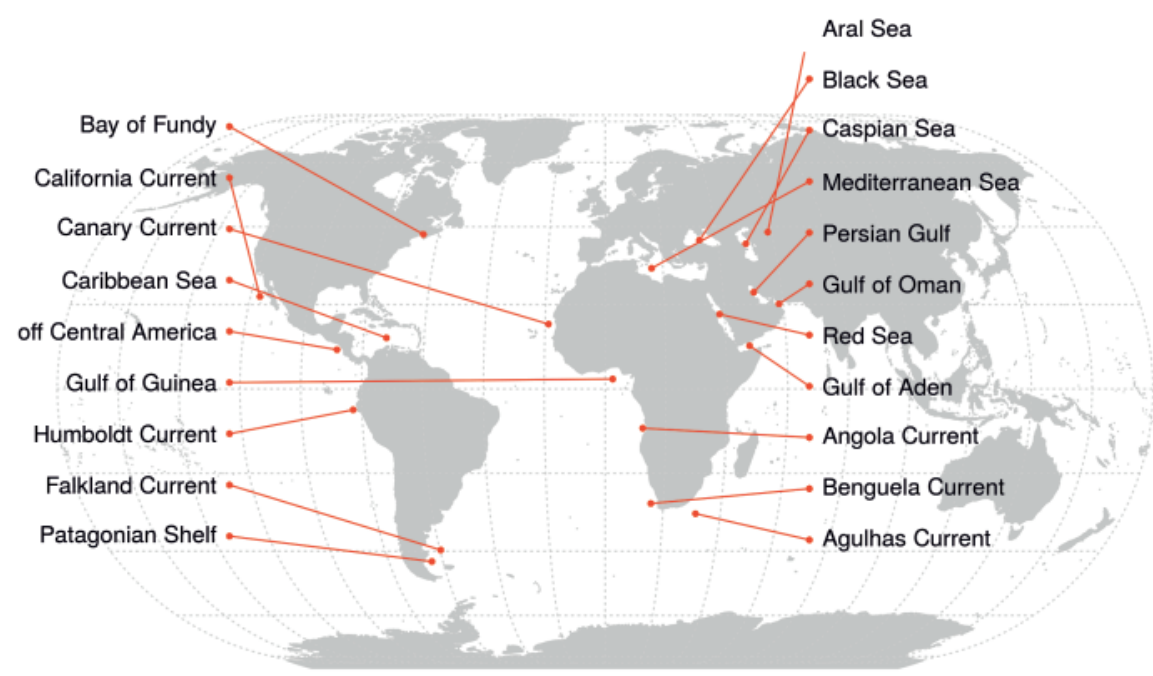

FIGURE 11.1 | Geographic areas referred to in this thesis. 


\section{ZEEVOGELS VERBINDEN DE ARCTIS EN DE OCEAAN}

Trekvogels die jaarlijks migreren tussen broed- en overwinteringsgebieden zijn gedurende hun jaarcyclus afhankelijk van ver uit elkaar liggende gebieden, waar ze broeden, ruien, overwinteren, of rusten en 'bijtanken'. Om een populatie op peil te houden, moeten in al deze gebieden de omstandigheden dusdanig gunstig zijn dat vogels in leven blijven en voldoende nageslacht op de wereld zetten. Wanneer er ergens een kink in de kabel zit, bijvoorbeeld doordat een doortrekgebied ongeschikt wordt door menselijk ingrijpen, voedsel niet voldoende beschikbaar is door klimaatverandering of het broedgebied ongeschikt wordt door de komst van een nieuwe predator, kan dat de populatie in gevaar brengen. Negatieve omstandigheden in één gebied hebben niet altijd directe gevolgen op overleving of reproductie, maar kunnen ook pas later in het jaar voor problemen zorgen. Bijvoorbeeld, mocht een vogel tijdens de trek opgehouden worden door slecht weer of een te lage voedselopname, kan hij te laat aankomen in het broedgebied om nog een territorium of partner van hoge kwaliteit te bemachtigen.

Wanneer trekvogelsoorten bedreigd worden of zich juist uitbreiden, ligt er vaak een sterke focus op mogelijke oorzaken in het broedgebied. Veel trekvogels zijn echter maar drie tot vier maanden per jaar in het broedgebied, en zoals hierboven uitgelegd kunnen oorzaken van voor- of achteruitgang ook buiten het broedgebied liggen. Wil men de voor- of achteruitgang van soorten in het broedgebied begrijpen, dan is het dus in de eerste plaats belangrijk te weten van welke gebieden trekvogels afhankelijk zijn en wat daar mogelijke bedreigingen zijn.

In een tijdsgewricht waarin de druk op de natuur door menselijk handelen enorm is, denk bijvoorbeeld aan klimaatverandering, overbevissing, habitatverlies, is het extra belangrijk om de populatietrends van trekvogels te begrijpen en kwetsbaarheden te signaleren. Of trekvogelsoorten zich kunnen handhaven bij veranderende omstandigheden in de gebieden die ze aandoen, zal grotendeels afhangen van de variatie die ze vertonen in routes, pleisterplaatsen en overwinteringsgebieden. Deze variatie kan op individueel niveau voorkomen, waarbij individuen bij tegenvallende omstandigheden kunnen uitwijken naar plekken met betere omstandigheden. Ook kunnen individuen binnen een populatie onderling verschillen in route en winterbestemming, waardoor het risico binnen de populatie gespreid is. Bij het wegvallen van één overwinteringsgebied zullen de individuen uit andere overwinteringsgebieden nog steeds kunnen overleven. Daarnaast levert variatie in trekroutes en -bestemmingen tussen populaties een vergelijkbare buffer op, hoewel de afzonderlijke populaties juist kwetsbaarder zijn. Het kwantificeren van variatie op het niveau van individuen en populaties vereist het in kaart brengen van individuele routes over meerdere jaren (variatie binnen individuen), van meerdere individuen (variatie tussen individuen) en van meerdere populaties (variatie tussen populaties). Nu studies waarin de trek van individuele vogels in kaart wordt gebracht door middel van zender en loggers steeds langer 
lopen en op meerdere plekken worden geïnitieerd, is er een voorzichtige start gemaakt in het ontrafelen van variatie in trekgedrag op de verschillende niveaus.

Van veel soorten zijn de trekroutes, pleisterplaatsen en overwinteringsgebieden, laat staan de variatie daarin binnen en tussen individuen en populaties, echter niet of slecht bekend. Met name de trekroutes van zeevogels waren - in vergelijking tot veel landvogels - tot voor kort het minst goed onderzocht. Dat komt doordat het leven van zeevogels zich grotendeels op zee afspeelt, ver weg van de bewoonde wereld en dus buiten het zicht van de meeste mensen, in het bijzonder biologen. Tot slechts enkele decennia geleden was de kennis over zeevogeltrek gefragmenteerd en onvolledig doordat deze grotendeels gebaseerd was op waarnemingen vanaf de kust en anekdotische waarnemingen op zee. Sinds de ontwikkeling van steeds kleinere en lichtere zenders en loggers, waarmee bewegingen van individuele dieren tot in detail kunnen worden vastgelegd, worden de geheimen van zeevogelmigraties nu in een hoog tempo blootgelegd.

Dit proefschrift maakt deel uit van deze golf van ontdekkingen. Het beschrijft de trekroutes van vier zeevogelsoorten die broeden op de Arctische toendra rondom de noordoostelijke Atlantische Oceaan en lange afstanden afleggen naar hun oceanische overwinteringsgebieden: de Grauwe en Rosse Franjepoot, en de Kleinste en Kleine Jager. Franjepoten zijn met zo'n 30-60 gram kleine zeevogels die met hun dichte verenpak en gelobde tenen de enige steltlopers die zijn aangepast aan het leven op de de open oceaan. Hier brengen ze de meeste tijd zwemmend door, op zoek naar klein dierlijk voedsel aan het oppervlak: zoöplankton. Jagers zijn sierlijke, krachtige vliegers en verwant aan meeuwen en sterns. Ze staan met name bekend om hun piraterij: ze stelen de door andere zeevogels gevangen vissen, die ze vaak na een wilde achtervolging bemachtigen. Toch bemachtigen Kleinste Jagers ook veel voedsel zelf, zowel op zee als in de broedtijd, wanneer ze op land met name knaagdieren eten, maar ook vogeleieren en -kuikens, insecten en besjes. De in dit proefschrift onderzochte soorten behoren met de Middelste Jager, Vorkstaartmeeuw en Noordse Stern tot een groep Arctische zeevogels met zeer lange migraties. Van de laatste twee soorten waren die migraties recentelijk - in ieder geval voor een klein aantal populaties - in kaart gebracht, maar dat geldt niet voor Middelste Jager (die vanwege logistieke redenen lastig te onderzoeken is) en de in dit proefschrift behandelde soorten.

De belangrijkste doelen van het onderzoek waren 1) het beschrijven van de trekroutes, pleisterplaatsen en overwinteringsgebieden, 2) het kwantificeren van variatie in bewegingen buiten het broedseizoen binnen en tussen individuen en populaties en 3 ) het leggen van verbanden tussen activiteiten in verschillende seizoenen en gebieden. Om deze doelen te bereiken zijn de bewegingen van individuele zeevogels vastgelegd met kleine dataloggers (geolocators), vaak over een periode van meerdere jaren, en vanuit een breed scala aan broedgebieden dat een kwart van de Arctis omvat en begrensd wordt door Noordoost Groenland in het 
westen en Arctisch Rusland in het oosten. Dit was mogelijk dankzij internationale samenwerking van 17 teams uit 10 landen en resulteerde in data van meer dan 224 individuen. Het gebruik van geolocators heeft als voordeel dat ze licht zijn, waardoor ook kleine vogels die weinig gewicht kunnen meesjouwen onderzocht kunnen worden, en dat ze relatief goedkoop zijn, waardoor bij eenzelfde budget meer individuen gevolgd kunnen worden dan wanneer voor duurdere zenders of loggers gekozen zou worden. Nadelen van geolocators zijn dat ze lang niet zo nauwkeurig zijn als GPS zenders of loggers - ze hebben een foutmarge van tientallen tot honderden kilometers - en dat vogels moeten worden teruggevangen om de data te bemachtigen. Of het lukt om ze terug te vangen hangt af van hun overleving, of ze terugkeren naar dezelfde broedplaats, of ze zich nogmaals laten vangen, en of ze broedseizoenen overslaan en onverrichter zake weer vertrekken (zoals vaak gebeurt bij Kleinste Jagers, zie hieronder). In bijna alle hoofdstukken van dit proefschrift staan data van geolocators centraal, aangevuld met gegevens van bijvoorbeeld lichaamsgewicht, het aantal en formaat van eieren, als maat voor de conditie van individuen en hun investering in reproductie. Hieronder bespreek ik de belangrijkste resultaten en conclusies per hoofdstuk. Vaak genoemde gebieden worden weergegeven op het kaartje in figuur 11.1.

In hoofdstukken $\mathbf{2}$ en $\mathbf{3}$ worden de trekroutes van Grauwe Franjepoten onthuld. De resultaten van hoofdstuk 2 bevestigen het vermoeden dat Grauwe Franjepoten die broeden in Fennoscandinavië en Rusland naar de Arabische Zee trekken. Grauwe Franjepoten van Schotland, IJsland en Groenland trokken daarentegen naar de Humboldtstroom in de oostelijke Stille Oceaan. Deze duidelijke scheiding tussen de twee trekwegen ligt in vergelijking met andere soorten op een ongebruikelijke plaats; veel van dergelijke scheidingen liggen op barrières (bijvoorbeeld hoge bergen) of op gelijke afstanden van twee gescheiden overwinteringsgebieden. Beide zijn hier niet van toepassing: Grauwe Franjepoten kunnen gemakkelijk zeeën oversteken en de afstand tot de Stille Oceaan is met ca $9000 \mathrm{~km}$ een stuk groter dan de $6000 \mathrm{~km}$ naar de Arabische Zee. Een aannemelijk scenario van het ontstaan de locatie van de gevonden scheiding tussen de twee Grauwe Franjepootpopulaties, is dat een Nearctische populatie zich naar het oosten heeft uitgebreid, vasthoudend aan het overwinteringsgebied in de Humboldtstroom, terwijl een Euraziatische populatie zich (noord)westwaarts heeft uitgebreid, vasthoudend aan het overwinteringsgebied in de Arabische Zee. Interessant is ook dat de twee trekroutes in een aantal aspecten verschilt die naar verwachting aanpassingen in het trekgedrag van de Grauwe Franjepoten zouden vergen. De westelijke trekroute loopt grotendeels over zee en biedt dus continu geschikt foerageergebied, terwijl de oostelijke route grotendeels over land loopt, met maar een beperkt aantal mogelijke 'tankstations'. Zoals verwacht - omdat gewicht meeslepen kostbaar is maakten vogels op de route naar de Humboldtstroom vaker en korter gebruik van de mogelijkheid om te stoppen tijdens hun najaarstrek en migreerden ze sneller in het voorjaar, dan vogels op de route naar de Arabische Zee die de tocht volbrachten een paar grote 'sprongen'. Ook ontdekten we dat vogels die naar de 
Stille Oceaan trokken langere vleugels hadden dan die naar de Arabische Zee trokken; waarschijnlijk brengen de langere vleugels lagere vliegkosten met zich mee op de langere trektochten. Ook binnen de overwinteringsgebieden zien we verschillen. De voedselsituatie is constanter en voorspelbaarder in de Humboldtstroom dan in de veel meer dynamische Arabische Zee, waar moessonwinden door het jaar heen op steeds weer andere plekken voor voedselrijke situaties zorgen. $\mathrm{Na}$ aankomst in de overwinteringsgebieden verplaatsen vogels in de Arabische Zee zich in de loop van de winter dan ook meerdere malen over enkele honderden kilometers ('itinerancy'), waarschijnlijk in een poging of uit een noodzaak om steeds die voedselrijke plekken op te zoeken en voedselarme situaties te mijden. In de veel stabielere Humboldtstroom was die noodzaak er blijkbaar niet: daar waren vogels min of meer honkvast ('residency') gedurende de winter.

In hoofdstuk 4 komt de migratie van Rosse Franjepoten aan bod. Rosse Franjepoten uit broedgebieden in Noordoost Groenland en Spitsbergen bleken in drie gebieden op de Atlantische Oceaan te overwinteren: de Benguelastroom, de Canarische stroom en een uitgestrekt gebied in de Noord-Atlantische Oceaan, grofweg op de breedtegraad van het Iberisch schiereiland. Terwijl de twee Afrikaanse gebieden al bekend stonden als belangrijke overwinteringsgebieden, was het belang van het gebied in de Noord-Atlantische Oceaan een nieuwe ontdekking, waar maar liefst een kwart van de onderzochte individuen overwinterde. Van zes vogels zijn meerdere jaren gegevens verzameld, waarvan er drie verrassende flexibiliteit lieten zien in hun overwinteringsgebied: twee vogels kozen in één jaar voor de Benguela stroom en in een ander jaar voor de Canarische stroom - gebieden die ongeveer $6500 \mathrm{~km}$ van elkaar verwijderd zijn. Een derde individu gebruikte achtereenvolgens een overwinteringsgebied in de NoordAtlantische Oceaan in de Canarische stroom. De andere drie vogels zochten wel elk jaar hetzelfde overwinteringsgebied op.

Naast bijvoorbeeld broeden en migreren, is de ruiperiode een belangrijke fase tijdens de jaarcyclus van elke (trek)vogel. Rui, het vervangen van oude veren door nieuwe veren, is noodzakelijk voor het behoud van isolatie en vliegvermogen. Omdat rui energetisch kostbaar is, wordt het meestal niet uitgevoerd ten tijde van andere veeleisende activiteiten, zoals migratie en broeden. Uitzonderingen op die regel zijn extra interessant, want waarom combineert de ene soort rui wél met andere activiteiten, maar andere soorten niet? Zeevogels ruien doorgaans grotendeels of geheel op zee, waardoor rui bij zeevogels veel lastiger te bestuderen is dan bij landvogels. Voor veel zeevogelsoorten is er dan ook geen gedetailleerde kennis beschikbaar over de timing en de duur van handpenrui. In hoofdstuk 5 hebben we gebruik gemaakt van de vele foto's die door veel verschillende fotografen gemaakt worden van zeevogels op zee tijdens zeevogeltochten voor vogelaars ('pelagic trips') of vogeltellingen vanaf schepen. Op de foto's is de voortgang van de rui per individu te zien, en op grond van deze gegevens 
bepaalden we de startdatum en de duur van handpenrui voor de vier soorten jagers die op het noordelijk halfrond broeden: Grote, Middelste, Kleine en Kleinste Jager. Hierbij maakten we onderscheid tussen volwassen vogels en - voor zover mogelijk vogels in hun eerste, tweede en derde ruicyclus. Over het algemeen duurt de eerste handpenrui in het leven van een jonge jager beduidend langer dan de volwassen vogels. Het eerste jaar hebben jonge vogels ook meer tijd omdat ze dan nog niet naar de broedgebieden trekken. Pas na de tweede ruicyclus, in hun derde levensjaar, moeten ze op tijd klaar zijn met ruien voor hun eerste noordwaartse trek. De tweede en derde ruicyclus, wanneer ze nog niet broeden maar wel al trekken, loopt zo goed als gelijk met volwassen vogels. Het einde van de rui van volwassen vogels viel in alle vier de soorten samen met het begin van de voorjaarstrek. Omdat grotere soorten langer over de handpenrui doen startten ze eerder, met overlap van handpenrui en najaarsmigratie tot gevolg. Bij de Grote Jager is er zelfs complete overlap: de handpenrui start rond het verlaten van de broedgebieden, gaat door tijdens de trek en wordt in het overwinteringsgebied voltooid. Met de informatie over de startdatum en duur van handpenrui kan biochemische informatie uit handpennen beter worden geïnterpreteerd: nu kan veel nauwkeuriger bepaald worden wanneer een veer is gevormd en, in combinatie met kennis van migratieroutes en -timing, wáár een veer is gevormd. Het gebruik van foto's die grotendeels door vogelaars zijn verzameld voor het bestuderen van rui is een veelbelovende vorm van citizen science.

Door de trek van dezelfde individuen gedurende meerdere jaren te volgen, kan worden bepaald in hoeverre individuen van jaar tot jaar consistent zijn in hun keuze van trekroutes en overwinteringsgebieden. In hoofdstuk 6 is onderzocht hoe consistent individuele Kleinste Jagers zijn die op Groenland en Spitsbergen broeden (ondersoort $S$ I pallescens) en die in Scandinavië broeden (ondersoort $S$ I longicaudus). Individuen van beide ondersoorten trokken via een pleisterplaats in de centrale Noord-Atlantische Oceaan naar overwinteringsgebieden voor de westkust van zuidelijke Afrika, de Benguelastroom. Terwijl de meeste individuen in opeenvolgende jaren dezelfde route volgden en dezelfde gebieden gebruikten, week tot $20 \%$ van de individuen halverwege de overwinteringsperiode meer dan $1000 \mathrm{~km}$ af van de voorgaande route. Een sprekend voorbeeld hiervan is een vogel die in vier jaren eerst steeds naar de Benguelastroom vloog. In het eerste en derde jaar bleef de vogel daar overwinteren, maar in het tweede en vierde jaar verhuisde hij halverwege de overwinteringsperiode van de Benguelastroom naar de Falklandstroom voor de oostkust van Zuid-Amerika. Deze vogel maakte gebruik van twee routes die hij beide herhaalde in latere jaren. Het feit dat er gewisseld wordt tussen strategieën en dat vogels andere gebieden opzoeken in de loop van de winter wijst er op dat Kleinste Jagers een groot ruimtelijk 'geheugen' hebben, waardoor ze bij tegenvallende omstandigheden op hun voorkeursroute gebruik kunnen maken van een of meerdere alternatieven.

Trekvogels kunnen lichaamsreserves voor of tijdens hun migratie opbouwen en 
meenemen naar het broedgebied om na aankomst slechte voedselomstandigheden te kunnen overleven of snel te kunnen beginnen met de eileg. De voedselsituatie in de Arctis kan van jaar op jaar erg variëren. Dat geldt voor Kleinste Jagers zeker, omdat ze voor hun reproductie doorgaans afhankelijk zijn van de beschikbaarheid van knaagdieren (in Scandinavië gaat het hierbij met name Berglemming, Rosgrijze Woelmuis en Aardmuis) die sterke populatiecycli vertonen. Kleinste Jagers komen in de broedgebieden aan met grote lichaamsreserves, die ze in principe zouden kunnen gebruiken om eieren mee aan te leggen, maar in de praktijk gaan ze alleen daadwerkelijk broeden als de knaagdierdichtheden voldoende hoog zijn. In hoofdstuk 7 onderzochten we in hoeverre Kleinste Jagers in Zweeds Lapland de eieren produceren van voedingsstoffen uit meegebrachte lichaamsreserves ('kapitaal') of van in het broedgebied verkregen voedsel ('inkomen'). Uit metingen van ratio's tussen stabiele isotopen van koolstof en stikstof in veren van volwassen vogels (aangelegd op zee), juvenielen (aangelegd op de toendra) en kuikendons (een onbekende mix van opbouw op zee en op de toendra) bleek dat Kleinste Jagers ongeacht de voedselsituatie in elk jaar evenveel van zee meegebrachte voedingsstoffen investeren, maar dit in goede knaagdierjaren meer aanvullen met op de toendra verzameld voedsel dan in slechte jaren. De eieren zijn in die jaren dan ook groter. De lichaamsreserves en de in beginsel al aangelegde eieren waarmee Kleinste Jagers arriveren in het broedgebied worden waarschijnlijk opgebouwd op een pleisterplaats in de centrale Noord-Atlantische Oceaan en dienen waarschijnlijk vooral voor het overleven van voedselschaarste. Het feit dat de jagers een deel van de energie benodigd voor de aanleg van de eieren van elders aanvoeren onderstreept het belang van goede voedselomstandigheden in overwinteringsgebieden en pleisterplaatsen.

De timing van broeden en migratie hangt sterk af van de breedtegraad waarop individuen broeden: hoe noordelijker, hoe later er begonnen wordt met broeden. Wat het optimale moment van eileg is, kan bepaald worden door wanneer er een piek in voedselbeschikbaarheid is, of wanneer een broedgebied beschikbaar is. Het moment van broeden heeft vervolgens gevolgen voor wanneer de najaarstrek kan beginnen, wanneer ze aankomen in het overwinteringsgebied, en vervolgens wanneer ze hier weer moeten vertrekken om op tijd aan te komen in het broedgebied. Het is voorstelbaar dat naast de broedplek ook de overwinteringsplek van belang is voor de timing in de jaarcyclus. In de literatuur is daar nog vrijwel geen aandacht aan besteed. Dit komt doordat er weinig gegevens beschikbaar zijn van soorten waarbij individuen uit eenzelfde broedgebied zich verspreiden over wijd verspreide overwinteringsgebieden. Hoofdstuk 8 beschrijft zo'n systeem voor Kleine Jagers, waarbij de variatie in overwinteringsgebieden enorm bleek. Dit maakt deze soort uitzonderlijk geschikt voor het onderzoeken van het effect van overwinteringsgebied op de timing van de jaarcyclus. Door ook vanuit meerdere broedgebieden (tussen Noordoost Groenland en Yamal, Rusland) de trek van individuen te volgen, konden we zowel het effect van broed- als van overwinteringsgebied onderzoeken. Overwinteringsgebieden van Kleine Jagers 
bleken verspreid over de gehele Atlantische Oceaan, maar ook de Middellandse Zee en de noordwestelijke Indische Oceaan; soms zelfs voor vogels die samen in één kolonie broeden, en zelfs tussen partners van broedparen. Zoals verwacht broedden vogels op hogere breedtegraden later. Met de latere eilegdatum schoof ook de rest van de jaarcyclus op, hoewel het vertrek uit het broedgebied niet helemaal in de pas liep: vogels van de meest zuidelijke (Finland) en noordelijke (Spitsbergen) broedplaatsen vertrokken later dan verwacht, mogelijk als gevolg van een zeer goede voedselsituatie in de herfst. Behalve de breedtegraad van het broedgebied, had ook de breedtegraad van het overwinteringsgebied een sterk effect op migratieschema's: in vergelijking met de meest noordelijke overwinteringsgebieden kostte het ongeveer een maand extra tijd om de meest zuidelijke gebieden te bereiken, waar de vogels ook weer zo'n 20 dagen eerder vandaan vertrokken om op tijd in de broedgebieden te arriveren. De periode in de overwinteringsgebieden was daarmee dus 50 dagen korter dan in de meest noordelijke gebieden, maar nog altijd langer dan ongeveer 120 dagen die nodig zijn voor de handpenrui (zie hoofdstuk 4). De locatie van het broedgebied resulteerde niet alleen in een verschuiving van de timing van het broeden en de trek, maar ook in verschillen in de duur van de tussenliggende periodes. Zo legden de meer noordelijk broedende vogels de voorjaarsmigratie sneller af en was de tijd tussen aankomst in het broedgebied en eileg ook korter. De meeste individuen die in de Atlantische Oceaan overwinterden gebruikten tijdens de voorjaarsmigratie een pleisterplaats in de centrale Noord-Atlantische Oceaan. Hoe later ze aan de voorjaarstrek begonnen, hoe korter ze op deze of andere pleisterplaatsen verbleven. Gezien de snellere, non-stop voorjaarstrek zijn de meest noordelijke broedvogels mogelijk in grotere mate afhankelijk van meegebrachte lichaamsreserves dan vogels van meer zuidelijke broedplaatsen om in goede conditie in de broedgebieden aan te komen. Mogelijk moeten ze de reserves waarmee ze arriveren al (voor een groter deel) in de overwinteringsgebieden opbouwen en meesjouwen tijdens de trek.

Bovengeschetste bevindingen zijn van direct of indirect belang voor populaties omdat ze allemaal consequenties hebben voor de overleving en voortplanting: de timing van de trek, rui en eileg, de reserves waarmee ze in de broedgebieden aankomen. Alleen als individuen overleven en vervolgens voldoende jongen produceren blijft een populatie op peil. Of populaties op peil blijven, dan wel toe- of afnemen, is onduidelijk voor de meeste onderzochte populaties van de in dit proefschrift behandelde soorten, laat staan dat bekend is wat de achterliggende oorzaak van een trend is. Alleen voor Schotse Kleine Jagers is de sterke achteruitgang en de oorzaken daarvan relatief goed bestudeerd, maar in andere broedgebieden, waar aantallen Kleine Jagers ook afnemen, is zowel van de precieze omvang van de afname als van de mogelijke oorzaken zo goed als niets bekend. In hoofdstuk 9 documenteren we een afname van ca $50 \%$ broedparen Kleine Jagers over de afgelopen twee decennia in de grootste kolonie van Europa, in Slettnes, Noorwegen. Gedurende de laatste vijf studiejaren (2014-2018) kwamen er alleen in 2014 jongen groot. De oorzaak daarvan lag in voedselschaarste en predatie. 

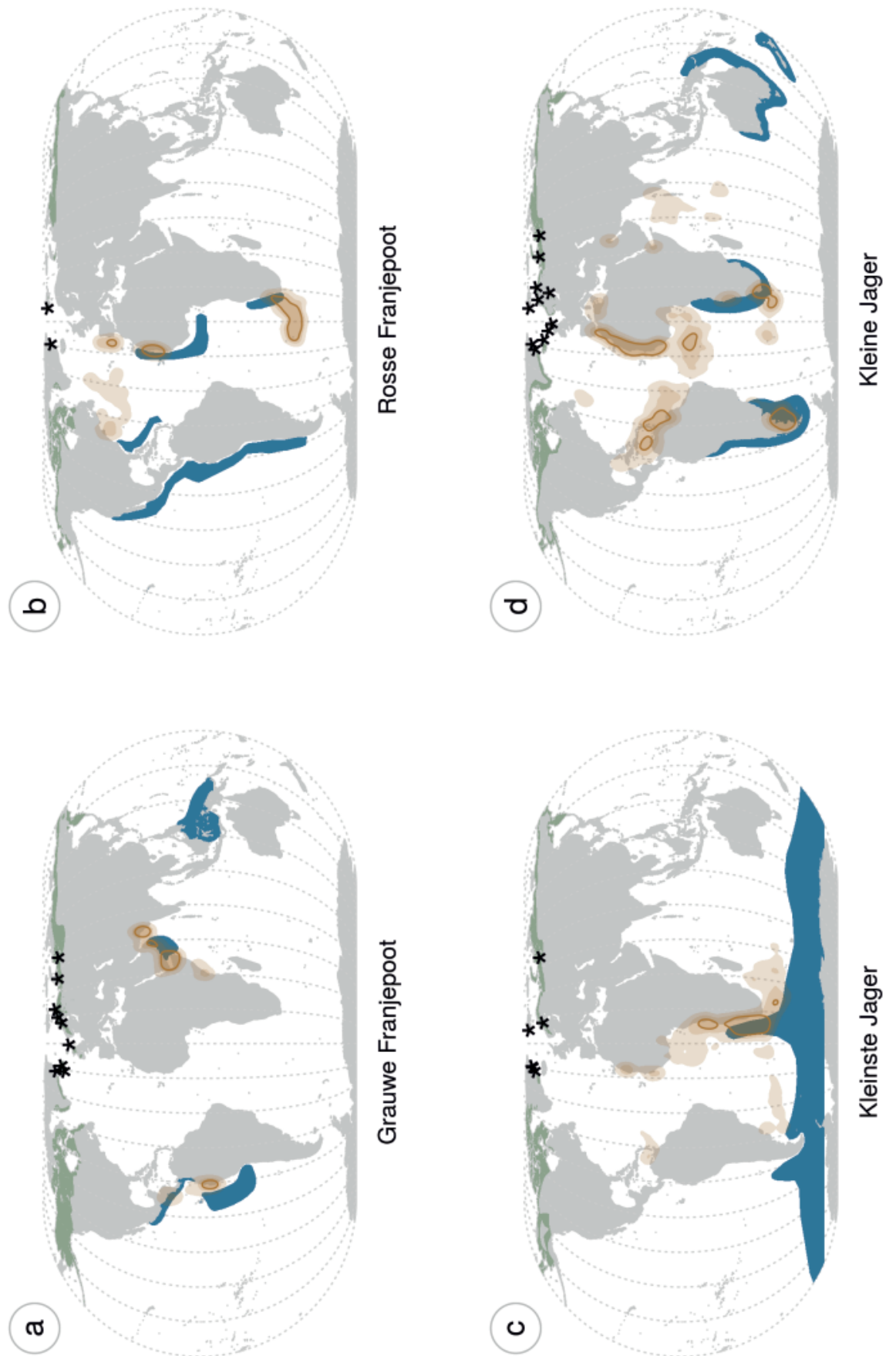

FIGURE 11.2 | (a-d) Per onderzochte soort, een vergelijking van de tot voor kort veronderstelde overwinteringsgebieden (donkerblauw) met de verspreiding op grond van geolocator data (bruin; de drie tinten geven $50 \%, 75 \%$ en $95 \%$ home range kernels weer). Broedgebieden zijn weergegeven in groen; onderzoekslocaties zijn aangegeven met sterretjes. 
Voedselschaarste in drie van de vijf recente jaren werd gesuggereerd door een hoog percentage nesten met slechts één ei (in plaats van het maximum van twee), kleinere eieren en lager lichaamsgewicht van volwassen vrouwtjes dan in de andere twee jaren. Predatie van eieren door Vossen nam gedurende de vijf jaren toe, met als gevolg dat in de laatste jaren geen enkel kuiken in het door ons onderzochte gebied uit het ei kroop, laat staan uitvloog. Dit was zelfs het geval wanneer de voedselsituatie voor de jagers gunstig was, wat mogelijk te verklaren is door Vossen die zich specialiseren op het opsporen van eieren van Kleine Jagers. Het broedsucces was duidelijk véél te laag om de populatie Kleine Jagers op een stabiel niveau te houden, ondanks dat de overleving van volwassen jagers hoog was.

In het laatste hoofdstuk, hoofdstuk 10, worden migratiepatronen en bewegingen binnen het overwinteringsgebied vergeleken tussen de vier bestudeerde soorten. Voor elke soort geldt dat de met geolocators verkregen verspreidingskaarten naast overeenkomsten ook grote verschillen laten zien met tot dan toe veronderstelde verspreiding (figuur 11.2). Sommige gebieden werden niet of nauwelijks erkend als belangrijk overwinteringsgebied (bijvoorbeeld: Rosse Franjepoten in de NoordAtlantische Oceaan en Kleine Jagers in de Golf van Guinea), terwijl andere overwinteringsgebieden niet werden bezocht (bijvoorbeeld: Kleinste Jagers ten zuiden van $40^{\circ} \mathrm{S}$ ). Het is van belang dat duidelijk is in hoeverre de steekproef van geolocatordata groot genoeg is om gefundeerde uitspraken te kunnen doen over dè trekroutes en hèt overwinteringsgebied van een soort. Daarom laat ik eerst zien dat de datasets representatief zijn voor de onderzochte populaties. Daarna behandel ik twee in de hoofdstukken van dit proefschrift terugkerende thema's: in hoeverre individuen zich binnen de overwinteringsperiode verplaatsen en de mate waarin ze van jaar op jaar dezelfde plekken binnen het overwinteringsgebied aandoen. De verwachting was dat zowel het gebruik van meerdere gebieden als de individuele consistentie daarin samenhing met de voedselbeschikbaarheid en in hoeverre deze veranderde in tijd en ruimte door het overwinteringsseizoen heen. We weten helaas weinig over het wintervoedsel van de onderzochte soorten, en daarom gebruikte ik de mate van primaire productie (in hoeverre koolstof wordt vastgelegd door middel van fotosynthese) als maat voor voedselrijkheid, en relateerde deze aan de mate van individuele consistentie en het aantal bezochte plekken binnen ieder overwinteringsgebied per soort en per overwinteringsgebied. Deze vergelijking laat zien dat de mate waarin individuen meerdere gebieden aandoen afneemt en hun consistentie in gebiedsgebruik toeneemt naarmate een overwinteringsgebied een hogere en meer stabiele primaire productie heeft.

In hoeverre kunnen zeevogels hun migratiepatronen en -strategieën aanpassen aan snel veranderende omstandigheden? Omdat de trekroutes van Grauwe Franjepoten een sterke historische oorsprong lijken te hebben, waarin trekroutes en overwinteringsgebieden niet werden verlegd, lijken zij de minste mogelijkheden te hebben tot aanpassing. Rosse Franjepoot, Kleinste Jager en Kleine Jager lijken meer mogelijkheden hebben tot aanpassing van de trekroutes en overwinterings- 
gebieden, omdat bij Rosse Franjepoten en Kleinste Jagers individuen in verschillende jaren alternatieve routes en bestemmingen kozen, en al deze soorten een enorme variatie tussen individuen lieten zien.

De bescherming van zeevogels buiten het broedgebied staat nog in de kinderschoenen. Het is complex doordat vanwege de enorme schaal waarop langeafstandstrekkende zeevogels de oceanen gebruiken, landen niet alleen bereid moeten zijn zeevogels in hun eigen wateren te beschermen, maar ook om gezamenlijk diezelfde zeevogels te beschermen in de wateren die buiten hun jurisprudentie vallen. Eerste stappen daarin worden wel genomen, zoals het aanwijzen van het beschermde gebieden op zee. Zo ligt er een voorstel, deels gebaseerd op geolocator data uit dit proefschrift van Kleinste Jagers, voor een beschermd gebied in de Noord-Atlantische Oceaan waar enkele miljoenen zeevogels gebruik van maken.

In 1935 schreef Vero Copner Wynne-Edwards over acht systematische tellingen van zeevogels, die hij uitvoerde vanaf de veerdienst tussen Montreal, Canada en zuidEngeland. In dit pionierswerk liet hij onder andere voor het eerst zien dat Kleinste Jagers midden over de Atlantische Oceaan trokken. Hoe fascinerend zijn waarnemingen toen al waren, ze bleven toch beperkt in tijd en ruimte. WynneEdwards verzuchtte dat "om de eb en vloed van vogels over zo'n enorm zeeoppervlak in kaart te brengen, er haast onmogelijke hindernissen genomen moeten worden." Nu, vele decennia later, en na meer dan vijf jaar aan deze soorten (13 jaar in het geval van Kleinste Jagers) onderzoek gedaan te hebben, is er een goed beeld van de routes en de timing van migratie over de Atlantische Oceaan van de in dit proefschrift onderzochte soorten. Daarmee is de basis gelegd voor veel meer en dieper gravend onderzoek.

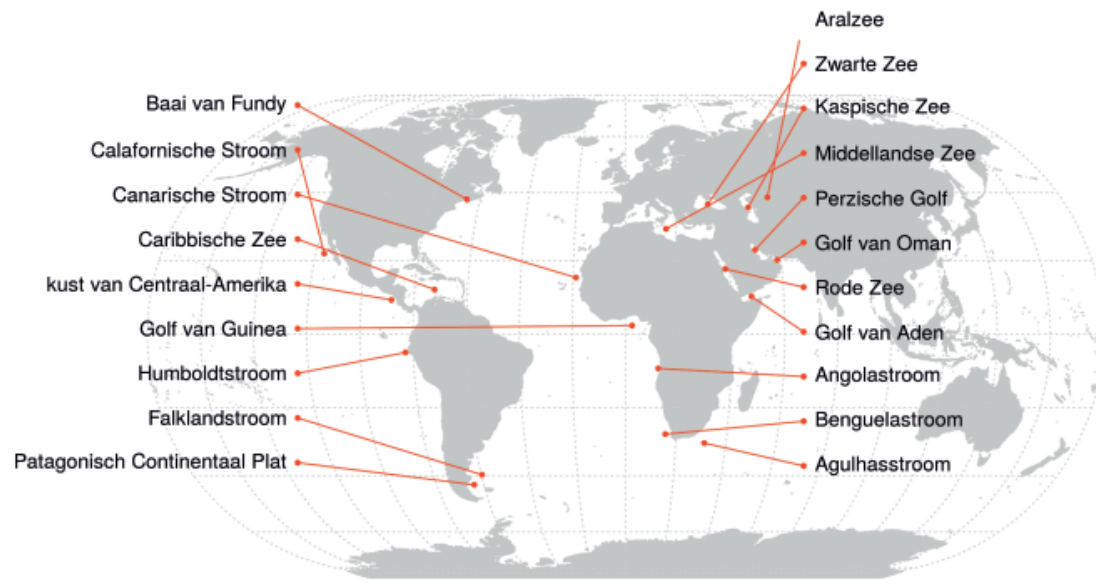

FIGURE 11.3 | Gebieden die in dit proefschrift worden genoemd. Zie figuur 11.1 voor een Engelse versie. 


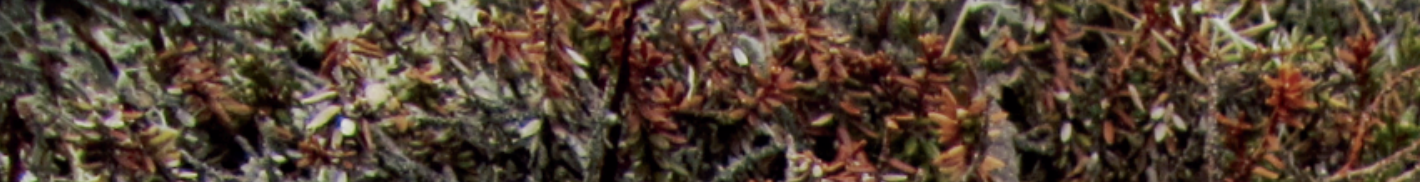

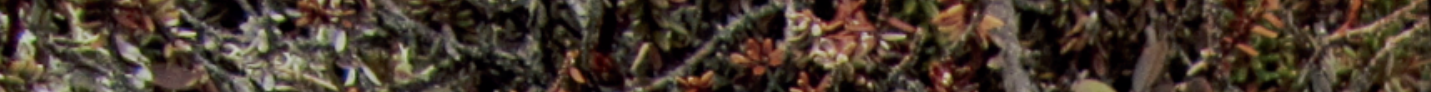

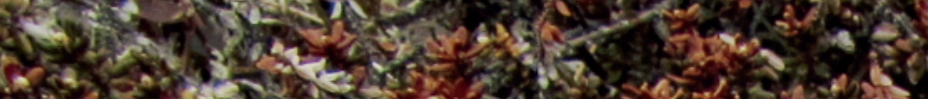

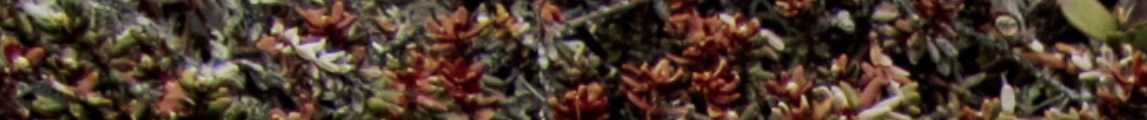

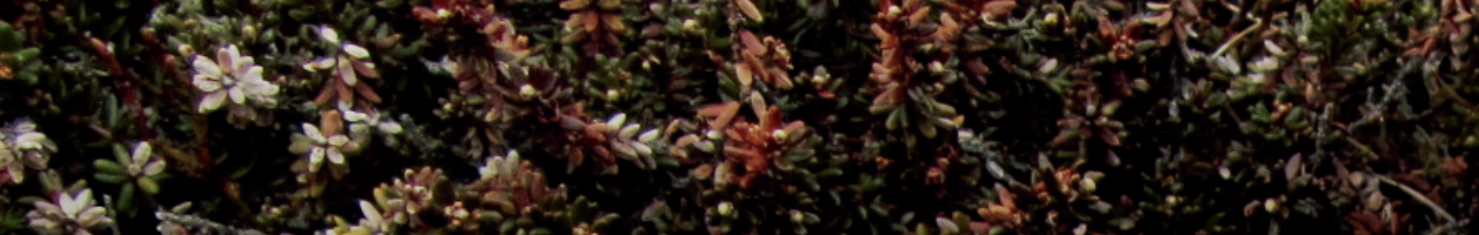
s.

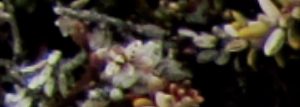

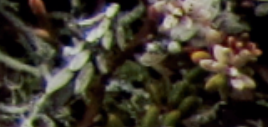

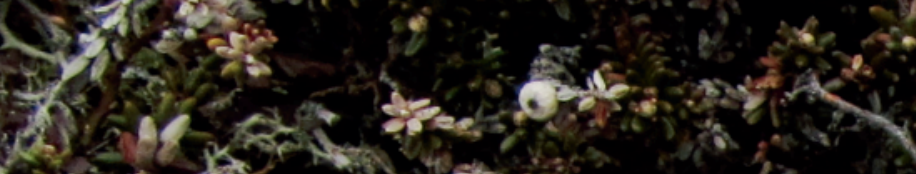
(x)

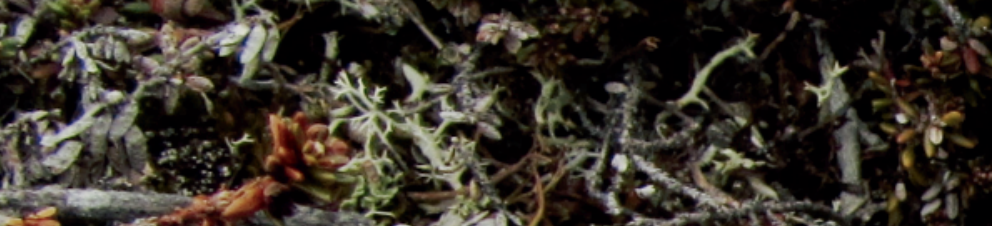

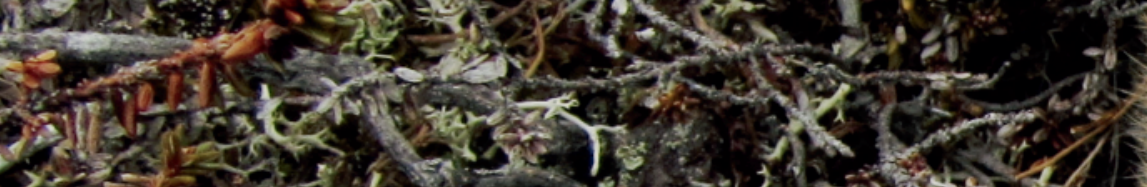
(1)

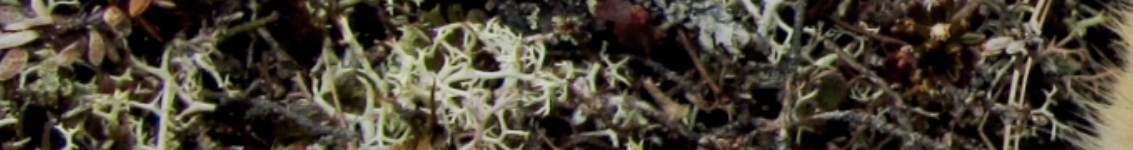
1.2.

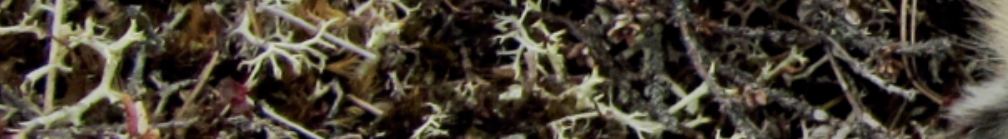
7 . 3 . If

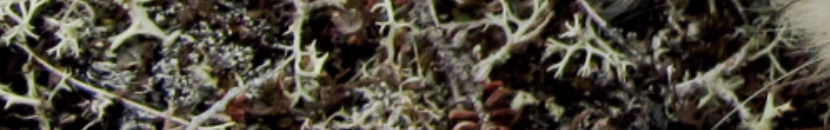
Hon. n. 1.

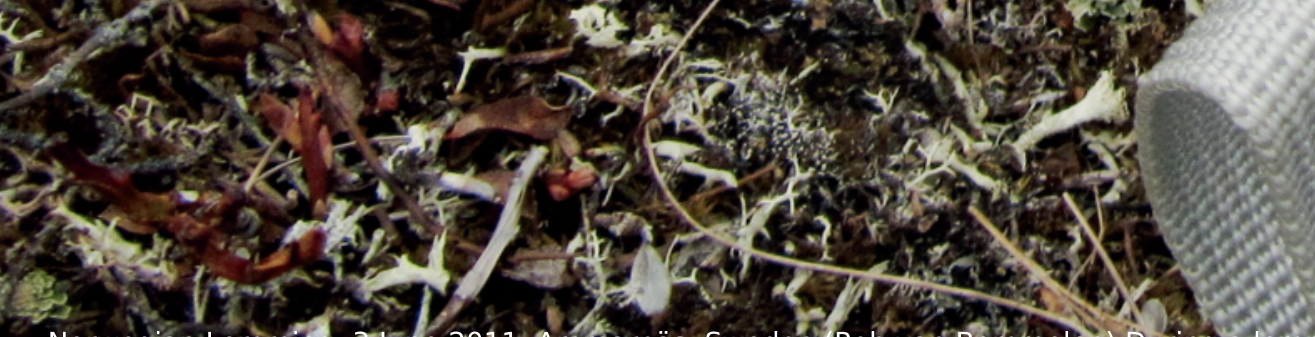
- Norwegian Lemming, 3june 2011, Anmarnäs, Sweden (Rob van Bemmelen) During a lemming-peak individuals can get very aggressive:-

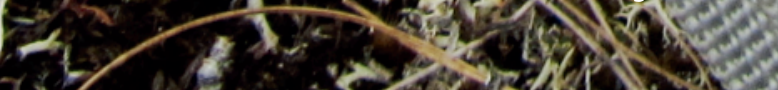


Åkesson, S., Klaassen, R., Holmgren, J., Fox, J. W. and Hedenström, A. 2012. Migration routes and strategies in a highly aerial migrant, the common swift Apus apus, revealed by lightlevel geolocators. - PLoS ONE 7: e41195.

Åkesson, S., llieva, M., Karagicheva, J., Rakhimberdiev, E., Tomotani, B. and Helm, B. 2017. Timing avian long-distance migration: from internal clock mechanisms to global flights. Philosophical Transactions of the Royal Society B: Biological Sciences 372: 20160252.

Alerstam, T. 1990. Bird migration. - Cambridge University Press.

Alerstam, T. 2003. Bird migration speed. - In: Berthold, P. et al. (eds), Avian Migration. Springer, pp. 253-268.

Alerstam, T. 2006. Conflicting evidence about long-distance animal navigation. - Science 313: 791-794.

Alerstam, T. and Lindström, $\AA$. 1990. Optimal bird migration: the relative importance of time, energy and safety. - In: Gwinner, E. (ed), Bird migration: the physiology and ecophysiology. Springer Berlin Heidelberg, pp. 331-351.

Alerstam, T. and Gudmundsson, G. A. 1999. Migration patterns of tundra birds: Tracking radar observations along the Northeast Passage. - Arctic 52: 346-371.

Alerstam, T., Hedenström, A. and Åkesson, S. 2003. Long-distance migration: evolution and determinants. - Oikos 2103: 247-260.

Altizer, S. and Davis, A. K. 2010. Populations of monarch butterflies with different migratory behaviors show divergence in wing morphology. - Evolution 64: 1018-1028.

Alves, J. A., Gunnarsson, T. G., Potts, P. M., Gélinaud, G., Sutherland, W. J. and Gill, J. A. 2012. Overtaking on migration: Does longer distance migration always incur a penalty? - Oikos 121: 464-470.

Alves, J. A., Gunnarsson, T. G., Hayhow, D. B., Appleton, G. F., Potts, P. M., Sutherland, W. J. and Gill, J. A. 2013. Costs, benefits, and fitness consequences of different migratory strategies. - Ecology 94: 11-17.

Ambrosini, R., Møller, A. P. and Saino, N. 2009. A quantitative measure of migratory connectivity. - Journal of Theoretical Biology 257: 203-211.

Andersson, M. 1971. Breeding behaviour of the Long-tailed Skua Stercorarius Iongicaudus (Vieillot). - Ornis Scandinavica 2: 35-54.

Andersson, M. 1976a. Cluth size in the Long-tailed Skuas Stercorarius longicaudus: some field experiments. - Ibis 118: 586-588.

Andersson, M. 1976b. Population ecology of the Long-tailed Skua (Stercorarius longicaudus Vieill.). - Journal of Animal Ecology 45: 537-559.

Andersson, M. 1981. Reproductive tactics of the long-tailed skua Stercorarius longicaudus. Oikos 37: 287-294.

Andersson, M. and Götmark, F. 1980. Social organization and foraging ecology in the arctic skua Stercorarius parasiticus: a test of the food defendability hypothesis. - Oikos 35: 63-71.

Andres, B. A., Smith, P. A., Morrison, R. I. G., Gratto-trevor, C. L., Brown, S. C. and Friis, C. A 2012. Population estimates of North American shorebirds, 2012. - Wader Study Group Bulletin 119: 178-194.

Angerbjörn, A., Hersteinsson, P., Liden, K. and Nelson, E. 1994. Dietary variation in arctic foxes (Alopex lagopus) - An analysis of stable carbon isotopes. - Oecologia 99: 226-232. 
Anker-Nilssen, T., Bakken, V., Strøm, H., Golovkin, A. N., Bianki, V. V. and Tatarinkova, I. P. 2000.

The status of marine birds breeding in the Barents Sea region.

Bailey, R. 1966. The sea-birds of the Southeast coast of Arabia. - Ibis 108: 224-264.

Bairlein, F., Norris, D. R., Nagel, R., Bulte, M., Voigt, C. C., Fox, J., Hussell, D. J. T. and

Schmalijohann, H. 2012. Cross-hemisphere migration of a $25 \mathrm{~g}$ songbird. - Biology letters

8: 505-7.

Bakken, V., Runde, O. and Tjørve, E. 2003. Norsk ringmerkingsatlas. Volum 1. Lommer -

Alkefugler. - Ringmerkingssentralen, Stavanger Museum.

Bangjord, G., Haugskott, T. and Hammer, S. 2015. Svalbard birds - a basic field guide. Longyearbyen Field Biological Society.

Barraquand, F., Høye, T. T., Henden, J. A., Yoccoz, N. G., Gilg, O., Schmidt, N. M., Sittler, B. and Ims, R. a. 2014. Demographic responses of a site-faithful and territorial predator to its fluctuating prey: Long-tailed skuas and arctic lemmings. - Journal of Animal Ecology 83: 375-387.

Bartoń, K. 2018. MuMIn: Multi-Model Inference. R package version 1.42.1.

Battley, P. F. and Conklin, J. R. 2017. Geolocator wetness data accurately detect periods of migratory flight in two species of shorebird. - Wader Study 124: 112-119.

Bauer, S. and Hoye, B. J. 2014. Migratory animals couple biodiversity and ecosystem functioning worldwide. - Science in press.

Bauer, S., Gienapp, P. and Madsen, J. 2008. The relevance of environmental conditions for departure decision changes en route in migrating geese. - Ecology 89: 1953-1960.

Bauer, S., Lisovski, S. and Hahn, S. 2016. Timing is crucial for consequences of migratory connectivity. - Oikos 125: 605-612.

Bearhop, S., Fiedler, W., Furness, R. W., Votier, S. C., Waldron, S., Newton, J., Bowen, G. J., Berthold, P. and Farnsworth, K. 2005. Assortative mating as a mechanism for rapid evolution of a migratory divide. - Science 310: 502-504.

Beebe, C.W. 1924. Galápagos, world's end. New York, London.

Behrenfeld, M. J. and Falkowski, P. G. 1997. Photosynthetic rates derived from satellite-based chlorophyll concentration. - Limnology and Oceanography 42: 1-20.

Belopol'skii, L. O. 1961. Ecology of sea colony birds of the Barents Sea. - Israel Programme for Scientific Translations.

Bengtson, S. and Bloch, D. 2003. The Arctic Skua Stercorarius parasiticus on the Faeroe Islands: abundance and plumage polymorphism. - Dansk Ornitologisk Forenings Tidsskrift 97: 210-220.

Bensch, S. 2009. Is the range size of migratory birds constrained by their migratory program? - Journal of Biogeography 26: 1225-1235.

Berthold, P., van den Bossche, W., Jakubiec, Z., Kaatz, C., Kaatz, M. and Querner, U. 2002. Long-term satellite tracking sheds light upon variable migration strategies of White Storks (Ciconia ciconia). - Journal fur Ornithologie 143: 489-495.

BirdLife and HBW 2016. Phalaropus lobatus, $P$ fulicarius, Stercorarius longicaudus and $S$ parasiticus.

BirdLife International 2015. European Red List of Birds. - Luxembourg: Office for Official Publications of the European Communities.

BirdLife International 2016. Stercorarius parasiticus. - The IUCN Red List of Threatened Species 
2016: e.T22694245A86830238.

Bivand, R. S., Pebesma, E. and Gomez-Rubio, V. 2013. Applied spatial data analysis with R, Second edition. - Springer.

Blackburn, E. and Cresswell, W. 2016. High winter site fidelity in a long-distance migrant: implications for wintering ecology and survival estimates. - Journal of Ornithology 157: 93-108.

Bond, A. L. and Diamond, A. W. 2010. Nutrient allocation for egg production in six Atlantic seabirds. - Canadian Journal of Zoology 88: 1095-1102.

Both, C. and Visser, M. E. 2001. Adjustment to climate change is constrained by arrival date in a long-distance migrant bird. - Nature 411: 296-298.

Both, C., Van Turnhout, C. A. M., Bijlsma, R. G., Siepel, H., Van Strien, A. J. and Foppen, R. P. B. 2010. Avian population consequences of climate change are most severe for longdistance migrants in seasonal habitats. - Proceedings of the Royal Society B: Biological Sciences 277: 1259-1266.

Bourgeon, S., Leat, E. H. K., Magnusdóttir, E., Furness, R. W., Strøm, H., Petersen, A., Gabrielsen, G. W., Hanssen, S. A. and Bustnes, J. O. 2014. Feather corticosterone levels on wintering grounds have no carry-over effects on breeding among three populations of great skuas (Stercorarius skua). - PLoS ONE 9: e100439.

Bourne, W. R. P. 1991. The seabirds of Arabia. - Sea Swallow 40: 4-12.

Bourne, W. R. P. 1997. Phalaropes in the Arabian Sea \& Gulf of Oman. - Oman Bird News 20: 5-6.

Bregnballe, T., Frederiksen, M. and Gregersen, J. 2006. Effects of distance to wintering area on arrival date and breeding performance in Great Cormorants. Ardea: 13: 619-630

Bridge, E. S. 2006. Influences of morphology and behavior on wing-molt strategies in seabirds. - Marine Ornithology 34: 7-19.

Bridge, E. S. 2011. Mind the gaps: what's missing in our understanding of feather molt. - The Condor 113: 1-4.

Briedis, M., Hahn, S., Gustafsson, L., Henshaw, I., Träff, J., Král, M. and Adamík, P. 2016. Breeding latitude leads to different temporal but not spatial organization of the annual cycle in a long-distance migrant. - Journal of Avian Biology 47: 743-748.

Briedis, M., Bauer, S., Adamık, P., Alves, J. A., Costa, J. S., Emmenegger, T., Gustafsson, L., Kole, J., Liechti, F., Meier, C. M., Prochazka, P. and Hahn, S. 2019. A full annual perspective on sex-biased migration timing in long-distance migratory birds. - Proceedings of the Royal Society B: Biological Sciences 286: 20182821.

Briggs, K. T., Tyler, W. B., Lewis, D. B. and Carlson, D. R. 1987. Bird communities at sea off California: 1975 to 1983. - Studies in Avian Biology

Brooke, M. 2018. Far from land: the mysterious lives of seabirds. - Princeton University Press.

Brown, R. G. B. 1979. Seabirds of the Senegal Upwelling and Adjacent Waters. - Ibis 121: 283-292.

Brown, R. G. B. and Gaskin, D. E. 1988. The pelagic ecology of the Grey and Red-necked Phalaropes Phalaropus fulicarius and P. lobatus in the Bay of Fundy, eastern Canada. Ibis 130: 234-250.

Brown, S., Gratto-Trevor, C., Porter, R., Weiser, E. L., Mizrahi, D., Bentzen, R., Boldenow, M., Clay, R., Freeman, S., Giroux, M.-A., Kwon, E., Lank, D. B., Lecomte, N., Liebezeit, J., 
Loverti, V., Rausch, J., Sandercock, B. K., Schulte, S., Smith, P., Taylor, A., Winn, B., Yezerinac, S. and Lanctot, R. B. 2017. Migratory connectivity of Semipalmated Sandpipers and implications for conservation. - Condor 119: 207-224.

Buehler, D. M. and Piersma, T. 2008. Travelling on a budget: predictions and ecological evidence for bottlenecks in the annual cycle of long-distance migrants. - Philosophical Transactions of the Royal Society B: Biological Sciences 363: 247-266.

Burnham, K. P. and Anderson, D. R. 2002. Model selection and multimodel inference : a practical information-theoretic approach. - Springer.

Burr, Z. M., Varpe, Ø., Anker-Nilssen, T., Erikstad, K. E., Barrett, S. D. R. T., Bech, C., Christensen-Dalsgaard, S., Lorentsen, S.-H., Moe, B. and Tone Kristin Reiertsen Hallvard Strøm 2016. Later at higher latitudes: large-scale variability in seabird breeding timing and synchronicity. - Ecosphere 7: 1-12.

Calenge, C. 2006. The package "adehabitat" for the R software: A tool for the analysis of space and habitat use by animals. - Ecological Modelling 197: 516-519.

Calenge, C. 2011. Home Range Estimation in R : the adehabitatHR Package.: 1-60.

Camphuysen, C. J. 2007. Where two oceans meet: Distribution and offshore interactions of great-winged petrels Pterodroma macroptera and Leach's storm petrels Oceanodroma leucorhoa off southern Africa. - Journal of Ornithology 148: 333-346.

Camphuysen, C. J. and Leopold, M. F. 1994. Atlas of Seabirds in the Southern North Sea. IBN/NIOZ/Dutch Seabird Group.

Camphuysen, C. J. and van der Meer, J. 2001. Pelagic distribution, moult and (sub-)specific status of Cory's Shearwaters Calonectris [d.] diomedea/borealis wintering off southern Africa. - Marine Ornithology 29: 89-96.

Camphuysen, C. and van der Meer, J. 2005. Wintering seabirds in West Africa: foraging hotspots off Western Sahara and Mauritania driven by upwelling and fisheries. - African Journal of Marine Science 27: 427-437.

Camphuysen, K. (C. J. ), Verdaat, H. and Kloff, S. 2013. Ship-based seabird and marine mammal surveys off Mauritania, Nov-Dec 2012 - cruise report.

Catry, P., Dias, M. P., Phillips, R. A. and Granadeiro, J. P. 2011. Different means to the same end: Long-distance migrant seabirds from two colonies differ in behaviour, despite common wintering grounds. - PLoS ONE 6: e26079.

Catry, P., Dias, M. P., Phillips, R. A. and Granadeiro, J. 2013. Carry-over effects from breeding modulate the annual cycle of a long-distance migrant: an experimental demonstration. Ecology 94: 1230-1235.

Chamberlain, C. P., Bensch, S., Feng, X., Akesson, S. and Andersson, T. 2000. Stable isotopes examined across a migratory divide in Scandinavian willow warblers (Phylloscopus trochilus trochilus and Phylloscopus trochilus acredula) reflect their African winter quarters. - Proceedings. Biological sciences / The Royal Society 267: 43-48.

Chavez, F. P. and Messié, M. 2009. A comparison of Eastern Boundary Upwelling Ecosystems. Progress in Oceanography 83: 80-96.

Chen, I.-C., Hill, J. K., Ohlemüller, R., Roy, D. B. and Thomas, C. D. 2011. Rapid range shifts of species of climate warming. - Science 333: 1024-1026.

Clements, J. F., Schulenberg, T. S., Iliff, M. J., Roberson, D., Fredericks, T. A., Sullivan, B. L. and Wood, C. L. 2018. The eBird/Clements checklist of birds of the world: v2018. 
Cohen, E. B., Hostetler, J. A., Hallworth, M. T., Rushing, C. S., Sillett, T. S. and Marra, P. P. 2018. Quantifying the strength of migratory connectivity. - Methods in Ecology and Evolution 9: 513-524.

Colwell, M. A., Reynolds, J. D., Gratto, C. L., Schamel, D. and Tracy, D. M. 1988. Phalarope philopatry. - Proceedings International Ornithological Congress 19: 585-593.

Conklin, J. R. and Battley, P. F. 2010. Attachment of geolocators to Bar-tailed Godwits: a tibiamounted method with no survival effects or loss of units. - Wader Study Group Bulletin 117: 56-58.

Conklin, J. R. and Battley, P. F. 2012. Carry-over effects and compensation: Late arrival on nonbreeding grounds affects wing moult but not plumage or schedules of departing bartailed godwits Limosa lapponica baueri. - Journal of Avian Biology 43: 252-263.

Conklin, J. R., Battley, P. F., Potter, M. A. and Fox, J. W. 2010. Breeding latitude drives individual schedules in a trans-hemispheric migrant bird. - Nature communications 1: 67.

Conversi, A., Piontkovski, S. and Hameed, S. 2001. Seasonal and interannual dynamics of Calanus finmarchicus in the Gulf of Maine (Northeastern US shelf) with reference to the North Atlantic Oscillation. - Deep-Sea Research Part II 48: 519-530.

Cramp, S. and Simmons, K. E. L. 1983. Handbook of the Birds of Europe, the Middle East and North Africa, The Birds of the Western Palearctic, Volume III: Waders to Gulls (S Cramp and KEL Simmons, Eds.). - Oxford University Press.

Croxall, J. P., Silk, J. R. D., Phillips, R. A., Afanasyev, V. and Briggs, D. R. 2005. Global circumnavigations: tracking year-round ranges of nonbreeding albatrosses. - Science 307: 249-250.

Croxall, J. P., Butchart, S. H. M., Lascelles, B., Stattersfield, A. J., Sullivan, B., Symes, A. and Taylor, P. 2012. Seabird conservation status, threats and priority actions: a global assessment. - Bird Conservation International 22: 1-34.

Cury, P. and Shannon, L. 2004. Regime shifts in upwelling ecosystems: Observed changes and possible mechanisms in the northern and southern Benguela. - Progress in Oceanography 60: 223-243.

Cury, P. M., Boyd, I. L., Bonhommeau, S., Anker-Nilssen, T., Crawford, R. J. M., Furness, R. W., Mills, J. a., Murphy, E. J., Österblom, H., Paleczny, M., Piatt, J. F., Roux, J.-P., Shannon, L. and Sydeman, W. J. 2011. Global seabird response to forage fish depletion - one-third for the birds. - Science 334: 1703-1706.

Dale, J., Montgomerie, R., Michaud, D. and Boag, P. 1999. Frequency and timing of extrapair fertilisation in the polyandrous red phalarope (Phalaropus fulicarius). - Behavioral Ecology and Sociobiology 46: 50-56.

Dawson, A., Hinsley, S. A., Ferns, P. N., Bonser, R. H. C. and Eccleston, L. 2000. Rate of moult affects feather quality: a mechanism linking current reproductive effort to future survival. - Proceedings of the Royal Society of London. Series B: Biological Sciences 267: 2093-2098.

Dawson, N. M., Macleod, C. D., Smith, M. and Ratcliffe, N. 2011. Interactions with Great Skuas Stercorarius skua as a factor in the long-term decline of an Arctic Skua Stercorarius parasiticus population. - Ibis 153: 143-153.

Day, R. H., Stenhouse, I. J. and Gilchrist, H. G. 2001. Sabine's gull (Xema sabini). - In: The Birds of North America Online. 
de Grissac, S., Börger, L., Guitteaud, A. and Weimerskirch, H. 2016. Contrasting movement strategies among juvenile albatrosses and petrels. - Scientific Reports 6: 26103.

de Korte, J. 1984. Ecology of the Long-Tailed Skua (Stercorarius Longicaudus Vieillot, 1819) at Scoresby Sund, East Greenland. Part two: arrival, site tenacity and departure. - Beaufortia 34: 1-14.

de Korte, J. 1985. Ecology of the Long-Tailed Skua, Stercorarius Longicaudus Vieillot, 1812, at Scoresby Sund, East Greenland. Part Three: Clutch size, Laying Date and Incubation in Relation to Energy Reserves. - Beaufortia 35: 93-127.

de Korte, J. and Wattel, J. 1988. Food and feeding habits of the Long-tailed quite extensively in the breeding areas in Arctic Marine animals. - Ardea 76: 27-41.

De La Hera, I., Díaz, J. A., Pérez-Tris, J. and Luis Tellería, J. 2009. A comparative study of migratory behaviour and body mass as determinants of moult duration in passerines. Journal of Avian Biology 40: 461-465.

Dean, B., Freeman, R., Kirk, H., Leonard, K., Phillips, R. A., Perrins, C. M. and Guilford, T. 2013. Behavioural mapping of a pelagic seabird: combining multiple sensors and a hidden Markov model reveals the distribution of at-sea behaviour. - Journal of the Royal Society, Interface / the Royal Society: 20120570.

del Hoyo, J., Elliott, A. and Sargatal, J. 1996. Handbook of the Birds of the World. Volume 3: Hoatzin to Auks. - Lynx Edicions.

Delany, S., Scott, D., Helmink, A. T. F., Dodman, T., Flink, S., Stroud, D. and Haanstra, L. 2009. An atlas of wader populations in Africa and western Eurasia. - Wetlands International, London.

Delmore, K. E., Fox, J. W. and Irwin, D. E. 2012. Dramatic intraspecific differences in migratory routes, stopover sites and wintering areas, revealed using light-level geolocators. Proceedings. Biological sciences / The Royal Society 279: 4582-9.

Delord, K., Cherel, Y., Barbraud, C., Chastel, O. and Weimerskirch, H. 2017. High variability in migration and wintering strategies of brown skuas (Catharacta antarctica lonnbergi) in the Indian Ocean. - Polar Biology 41: 59-70.

Dias, M. P., Granadeiro, J. P., Phillips, R. A., Alonso, H. and Catry, P. 2011. Breaking the routine: individual Cory's shearwaters shift winter destinations between hemispheres and across ocean basins. - Proceedings. Biological sciences / The Royal Society 278: 1786-1793.

Dias, M. P., Granadeiro, J. P. and Catry, P. 2012. Do seabirds differ from other migrants in their travel arrangements? On route strategies of Cory's Shearwater during its trans-equatorial journey. - PLoS ONE 7: e49376.

Dias, M. P., Granadeiro, J. P. and Catry, P. 2013. Individual variability in the migratory path and stopovers of a long-distance pelagic migrant. - Animal Behaviour 86: 359-364.

Dick, W. J. A., Piersma, T. and Prokosch, P. 1987. Spring migration of the Siberian Knots Calidris canutus canutus: results of a co-operative Wader Study Group project. - Ornis Scand. 18: 5-16.

Dickinson, E. C. and Remsen, J. V. J. 2013. The Howard and Moore Complete Checklist of the Birds of the World. 4th Edition, Vol.1 Non-Passerines. - Aves Press.

Dietz, M. W., Rogers, K. G. and Piersma, T. 2013. When the seasons don't fit: speedy molt as a routine carry-over cost of reproduction. - PLoS ONE

DiGiacomo, P. M., Hamner, W. M., Hamner, P. P. and Caldeira, R. M. A. 2002. Phalaropes feeding 
at a coastal front in Santa Monica Bay, California. - Journal of Marine Systems 37: 199-212.

Dingemanse, N. J. and Wolf, M. 2013. Between-individual differences in behavioural plasticity within populations: Causes and consequences. - Animal Behaviour 85: 1031-1039.

Dingle, H. 2014. Migration. The biology of life on the move. - Oxford University Press.

Drent, R. and Daan, S. 1980. The prudent parent: energetic adjustments in avian breeding. Ardea 68: 225-252.

Drent, R., Both, C., Green, M., Madsen, J. and Piersma, T. 2003. Pay-offs and penalties of competing migratory schedules. - Oikos 103: 274-292.

Eaton, M., Aebischer, N., Brown, A., Hearn, R., Lock, L., Musgrove, A., Noble, D., Stroud, D. and Gregory, R. 2015. Birds of Conservation.Concern 4: the population status of birds in the UK, Channel Islands and Isle of Man. - British Birds 108: 708-746.

Ecke, F. and Hörnfeldt, B. 2018. Miljöövervakning av smågnagare. https://www.slu.se/institutioner/vilt-fisk-miljo/miljoanalys/miljoovervakning-avsmagnagare/.

Ecke, F., Christiansen, P., Rentz, R., Sandström, P., Nilsson, M. and Hörnfeldt, B. 2010. Landscape structure and the long-term decline of the grey-sided vole. - Landscape Ecology 25: 551-560.

Edwards, D. B. and Gilchrist, H. G. 2011. A new means of catching shorebirds: the Super Talon Net Gun. - Wader Study Group Bulletin 118: 134-135.

Egevang, C., Stenhouse, I. J., Phillips, R. A., Petersen, A., Fox, J. W. and Silk, J. R. D. 2010. Tracking of Arctic terns Sterna paradisaea reveals longest animal migration. Proceedings of the National Academy of Sciences of the United States of America 107: 2078-2081.

Eichhorn, G. 2001. Zur Bedeutung der Steppenseen Zentral-Kasachstans als Rastplatz arktischer Watvögel Charadrii, insbesondere zur Rastplatzökologie von Zwergstrandläufer Calidris minuta und Odinshühnchen Phalaropus lobatus.

Eichhorn, G., Afanasyev, V. and Drent, R. H. 2006. Spring stopover routines in Russian Barnacle Geese Branta leucopsis tracked by resightings and geolocation. - Ardea 94: 667-678.

Ekstrom, P. A. 2004. An advance in geolocation by light. - Mem. Natl Inst. Polar Res., Spec. Issue 58: 210-226.

Erni, B., Bonnevie, B. T. and Underhill, L. G. 2012. moult: An R package to analyze moult in birds. - Journal of Statistical Software 52: 1-23.

Fauchald, P., Anker-Nilssen, T., Barrett, R. T., Bust, J. O., Bårdsen, B.-J., Christensen-Dalsgaard, S., Descamps, S., Engen, S., Erikstad, K. E., Hanssen, S. A., Lorentsen, S.-H., Moe, B., Reiertsen, T. K., Strøm, H. and Systad, G. H. 2015. The status and trends of seabirds breeding in Norway and Svalbard.

Felicísimo, Á. M., Muñoz, J. and González-Solis, J. 2008. Ocean surface winds drive dynamics of transoceanic aerial movements. - PLoS ONE 3: 1-7.

Fieberg, J. and Kochanny, C. O. 2005. Quantifying home-range overlap: the importance of the utilization distribution (Lanham, Ed.). - Journal of Wildlife Management 69: 1346-1359.

Fiedler, W. 2005. Ecomorphology of the external flight apparatus of Blackcaps with different migration behavior. - Annals of the New York Academy of Sciences 1046: 253-263. 
Fifield, D. A., Montevecchi, W. A., Garthe, S., Robertson, G. J., Kubetzki, U. and Rail, J.-F. 2014. Migratory tactics and wintering areas of Northern Gannets (Morus bassanus) breeding in North America. - Ornithological Monographs 79: 1-63.

Fijn, R. C., Hiemstra, D., Phillips, R. A. and van der Winden, J. 2013. Arctic Terns Sterna paradisaea from the Netherlands migrate record distances across three oceans to Wilkes Land, East Antarctica. - Ardea 101: 3-12.

Fransson, T., Österblom, H. and Hall-Karlsson, S. 2008. Svensk ringmärkningsatlas. Vol. 2. Naturkistoriska riksmuseet \& Sveriges Ornitologiska Förening.

Fraser, K. C., Stutchbury, B. J. M., Silverio, C., Kramer, P. M., Barrow, J., Newstead, D., Mickle, N., Cousens, B. F., Lee, J. C., Morrison, D. M., Shaheen, T., Mammenga, P., Applegate, K. and Tautin, J. 2012. Continent-wide tracking to determine migratory connectivity and tropical habitat associations of a declining aerial insectivore. - Proceedings of the Royal Society B: Biological Sciences 279: 4901-6.

Fraser, K. C., Silverio, C., Kramer, P., Mickle, N., Aeppli, R. and Stutchbury, B. J. M. 2013. A Trans-Hemispheric Migratory Songbird Does Not Advance Spring Schedules or Increase Migration Rate in Response to Record-Setting Temperatures at Breeding Sites. - PLoS ONE 8: 1-5.

Fraser, K. C., Davies, K. T., Davy, C. M., Ford, A. T., Flockhart, D. T. T. and Martins, E. G. 2018. Tracking the conservation promise of movement ecology. - Frontiers in Ecology and Evolution 6: 150.

Frederiksen, M. 2010. Appendix 1: Seabirds in the North East Atlantic. A review of status, trends and anthropogenic impact. - In: Action plan for seabirds in Western-Nordic areas. Report from a workshop in Malmö, Sweden, 4-5 May 2010. Nordic Council of Ministers, in press.

Frederiksen, M., Moe, B., Daunt, F., Phillips, R. A., Barrett, R. T., Bogdanova, M. I., Boulinier, T., Chardine, J. W., Chastel, O., Chivers, L. S., Christensen-Dalsgaard, S., Clément-Chastel, C., Colhoun, K., Freeman, R., Gaston, A. J., González-Solís, J., Goutte, A., Grémillet, D., Guilford, T., Jensen, G. H., Krasnov, Y., Lorentsen, S. H., Mallory, M. L., Newell, M., Olsen, B., Shaw, D., Steen, H., Strøm, H., Systad, G. H., Thórarinsson, T. L. and Anker-Nilssen, T. 2012. Multicolony tracking reveals the winter distribution of a pelagic seabird on an ocean basin scale. - Diversity and Distributions 18: 530-542.

Fridolfsson, A.-K. and Ellegren, H. 1999. A simple and universal method for molecular sexing of birds. - Journal of Avian Biology 30: 116-121.

Furness, R. W. 1987. The Skuas. - T. \& A.D. Poyser.

Furness, R. W. and Furness, B. L. 1981. A technique for estimating the hatching dates of eggs of unknown laying date. - Ibis 123: 98-102.

Furness, R. W., Crane, J. E., Bearhop, S., Garthe, S., Käkelä, A., Käkelä, R., Kelly, A., Kubetzki, U., Votier, S. C. and Waldron, S. 2006. Techniques to link individual migration patterns of seabirds with diet specialization, condition and breeding performance. - Ardea 94: 631-638.

Gaston, A. J. 2004. Seabirds. A natural history. - Christopher Helm.

Gavrilov, E. I., Jerochov, S. N., Gavrilov, A. E. and Chrokov, V. V. 1983. Über den Herbstzug des Odinswassertreters (Phalaropus lobatus) in Kasachstan. - Die Vogelwarte 32: 103-116.

Gilg, O., Sittler, B., Sabard, B., Hurstel, A., Sané, R., Delattre, P. and Hanski, I. 2006. Functional 
and numerical responses of four lemming predators in high arctic Greenland. - Oikos 113: 193-216.

Gilg, O., Moe, B., Hanssen, S. A., Schmidt, N. M., Sittler, B., Hansen, J., Reneerkens, J., Sabard, B., Chastel, O., Moreau, J., Phillips, R. A., Oudman, T., Biersma, E. M., Fenstad, A. A., Lang, J. and Bollache, L. 2013. Trans-equatorial migration routes, staging sites and wintering areas of a high-Arctic avian predator: the Long-tailed Skua (Stercorarius longicaudus). PLOS ONE 8: e64614.

Gill, F. and Donsker, D. 2018. IOC World Bird List (v8.2).

Gill, J. A., Alves, J. A., Sutherland, W. J., Appleton, G. F., Potts, P. M. and Gunnarsson, T. G. 2014. Why is timing of bird migration advancing when individuals are not? - Proceedings of the Royal Society B: Biological Sciences 281: 20132161.

Giroux, M.-A., Ditlecadet, D., Martin, L. J., Lanctot, R. B. and Lecomte, N. 2016. Sexing a sexrole-reversed species based on plumage: potential challenges in the red phalarope. PeerJ 4: e1989.

Glutz von Blotzheim, U. and Bauer, K. M. 1985. Handbuch der vögel mitteleuropas band 8/i. AULA-Verlag.

Gorney, E. and Tov, Y. Y. 2001. Molt during spring migration: a comparison of four species of raptors. - Journal of Field Ornithology 72: 96-105.

Gow, E. A., Burke, L., Winkler, D. W., Knight, S. M., Bradley, D. W., Clark, R. G., Belisle, M., Berzins, L. L., Blake, T., Bridge, E. S., Dawson, R. D., Dunn, P. O., Garant, D., Holroyd, G., Horn, A. G., Hussell, D. J. T., Lansdorp, O., Laughlin, A. J., Leonard, M. L., Pelletier, F., Shutler, D., Siefferman, L., Taylor, C. M., Trefry, H., Vleck, C. M., Vleck, D., Whittingham, L. A. and Norris, D. R. 2018. A range-wide domino effect and resetting of the annual cycle in a migratory songbird. - Proceedings of the Royal Society B: Biological Sciences 286: 20181916.

Graham, M. H. 2003. Confronting multicollinearity in ecological multiple regression. - Ecology 84: 2809-2815.

Graham, B. S., Koch, P. L., Newsome, S. D., McMahon, K. W. and Aurioles, D. 2010. Using isoscapes to trace the movements and foraging behavior of top predators in oceanic ecosystems. - In: West, J. B. et al. (eds), Isoscapes. Understanding movement, pattern, and process on Earth through isotope mapping. Springer-Verlag, pp. 299-333.

Grecian, W. J., Witt, M. J., Attrill, M. J., Bearhop, S., Becker, P. H., Egevang, C., Furness, R. W. Godley, B. J., González-Solís, J., Grémillet, D., Kopp, M., Lescroël, A., Matthiopoulos, J., Patrick, S. C., Peter, H.-U., Phillips, R. A., Stenhouse, I. J. and Votier, S. C. 2016. Seabird diversity hotspot linked to ocean productivity in the Canary Current Large Marine Ecosystem. - Biology letters 12: 20160024.

Grémillet, D., Ponchon, A., Paleczny, M., Palomares, M.-L. D., Karpouzi, V. and Pauly, D. 2018. Persisting worldwide seabird-fishery competition despite seabird community decline. Current Biology 28: 1-5.

Gudmundsson, G. A., Lindström, Å. and Alerstam, T. 1991. Optimal fat loads and long-distance flights by migrating Knots Calidris canutus, Sanderlings $C$. alba and Turnstones Arenaria interpres. - Ibis 133: 140-152.

Guilford, T., Meade, J., Willis, J., Phillips, R. A., Boyle, D., Roberts, S., Collett, M., Freeman, R. and Perrins, C. M. 2009. Migration and stopover in a small pelagic seabird, the Manx 
shearwater Puffinus puffinus: insights from machine learning. - Proceedings. Biological sciences / The Royal Society 276: 1215-1223.

Guilford, T., Freeman, R., Boyle, D., Dean, B., Kirk, H., Phillips, R. and Perrins, C. 2011. A dispersive migration in the Atlantic Puffin and its implications for migratory navigation. PLoS ONE 6: e21336.

Gunnarsson, T. G., Gill, J. A., Sigurbjörnsson, T. and Sutherland, W. J. 2004. Arrival synchrony in migratory birds. - Nature 431: 646-646.

Hadfield, J. D. 2010. MCMC methods for multi-response generalized linear mixed models: the MCMCgImm R package. - Journal of Statistical Software 33: 1-22.

Haney, J. C. 1985. Wintering phalaropes off the southeastern United States: applications of remote sensing imagery to seabird habitat analysis at oceanic fronts. - Journal of Field Ornithology 56: 321-333.

Hardman-Mountford, N. J., Richardson, A. J., Agenbag, J. J., Hagen, E., Nykjaer, L., Shillington, F. A. and Villacastin, C. 2003. Ocean climate of the South East Atlantic observed from satellite data and wind models. - Progress in Oceanography 59: 181-221.

Harrison, X. a., Blount, J. D., Inger, R., Norris, D. R. and Bearhop, S. 2011. Carry-over effects as drivers of fitness differences in animals. - Journal of Animal Ecology 80: 4-18.

Harrison, A.-L., Costa, D. P., Winship, A. J., Benson, S. R., Bograd, S. J., Antolos, M., Carlisle, A. B., Dewar, H., Dutton, P. H., Jorgensen, S. J., Kohin, S., Mate, B. R., Robinson, P. W., Schaefer, K. M., Shaffer, S. A., Shillinger, G. L., Simmons, S. E., Weng, K. C., Gjerde, K. M. and Block, B. A. 2018. The political biogeography of migratory marine predators. - Nature Ecology \& Evolution 2: 1571-1578.

Hayman, J., Marchant, J. and Prater, T. 1986. Shorebirds. An identification guide to the waders of the world. - Christopher Helm.

Hays, G. C., Bailey, H., Bograd, S. J., Bowen, W. D., Campagna, C., Carmichael, R. H., Casale, P., Chiaradia, A., Costa, D. P., Cuevas, E., Nico de Bruyn, P. J., Dias, M. P., Duarte, C. M., Dunn, D. C., Dutton, P. H., Esteban, N., Friedlaender, A., Goetz, K. T., Godley, B. J., Halpin, P. N., Hamann, M., Hammerschlag, N., Harcourt, R., Harrison, A.-L., Hazen, E. L., Heupel, M. R., Hoyt, E., Humphries, N. E., Kot, C. Y., Lea, J. S. E., Marsh, H., Maxwell, S. M., McMahon, C. R., Notarbartolo di Sciara, G., Palacios, D. M., Phillips, R. A., Righton, D., Schofield, G., Seminoff, J. A., Simpfendorfer, C. A., Sims, D. W., Takahashi, A., Tetley, M. J., Thums, M., Trathan, P. N., Villegas-Amtmann, S., Wells, R. S., Whiting, S. D., Wildermann, N. E. and Sequeira, A. M. M. 2019. Translating marine animal tracking data into conservation policy and management. - Trends in Ecology \& Evolution 34(5): 459-473.

Heckscher, C. M., Halley, M. R. and Stampul, P. M. 2015. Intratropical migration of a NearcticNeotropical migratory songbird (Catharus fuscescens) in South America with implications for migration theory. - Journal of Tropical Ecology 31: 285-289.

Hedd, A., Montevecchi, W. A., Otley, H., Phillips, R. A. and Fifield, D. A. 2012. Trans-equatorial migration and habitat use by sooty shearwaters Puffinus griseus from the South Atlantic during the nonbreeding season. - Marine Ecology Progress Series 449: 277-290.

Hedenström, A. 2006. Scaling of migration and the annual cycle of birds. - Ardea 94: 399-408. Hedenström, A. and Sunada, S. 1999. On the aerodynamics of moult gaps in birds. - Journal of Experimental Biology 202: 67-76.

Hedenström, A., Klaassen, R. H. G. and Åkesson, S. 2013. Migration of the Little Ringed Plover 
Charadrius dubius breeding in South Sweden tracked by geolocators. - Bird Study 60: 466-474.

Henriksen, S. and Hilmo, O. 2015. Norsk rødliste for arter 2015. [Norwegian red list for species 2015].

Hewson, C. M., Thorup, K., Pearce-Higgins, J. W. and Atkinson, P. W. 2016. Population decline is linked to migration route in the Common Cuckoo. - Nature Communications 7: 12296.

Higgins, P. J. and Davies, S. J. J. F. 1996. Handbook of Australian, New Zealand and Antarctic Birds. 3. Snipe to Pigeons. - Oxford University Press.

Hjernquist, M. B., Veen, T., Font, L. and Klaassen, M. 2009. High individual repeatability and population differentiation in stable isotope ratios in winter-grown collared flycatcher Ficedula albicollis feathers. - Journal of Avian Biology 40: 102-107.

Hobson, K. A. and Jehl, J. R. 2010. Arctic waders and the capital-income continuum: Further tests using isotopic contrasts of egg components. - Journal of Avian Biology 41: 565-572.

Hobson, K. A., Sirois, J. and Gloutney, M. L. 2000. Tracing Nutrient Allocation to Reproduction with Stable Isotopes: A Preliminary Investigation Using Colonial Waterbirds of Great Slave Lake. - The Auk 117: 760-774.

Hoegh-Guldberg, O. and Bruno, J. F. 2010. The impact of climate change on the world's marine ecosystems. - Science 328: 1523-1529.

Höhn, E. O. 1966. Ringing (banding) and recoveries of phalaropes: a summary of presently available information. - Bird-Banding 37: 197-200.

Holling, M. and Breeding Birds Panel, R. 2018. Rare breeding birds in the UK in 2016. - British Birds 111: 644-694.

Holmes, R. T., Sherry, T. W. and Reitsma, L. 1989. Population structure, territoriality and overwinter survival of two migrant warbler species in Jamaica. - The Condor 91: 545-561.

Hörnfeldt, B. 1978. Syncronous population fluctuations in voles, small game, owls, and tularemia in nothern Sweden. - Oecologia 32: 141-152.

Hörnfeldt, B. 1994. Delayed density dependence as a determinant of vole cycles. - Ecology 75 : 791-806.

Howell, S. N. G. 2007. Review moult and ageing jaegers (smaller skuas). - Alula: 98-113.

Howell, S. N. G. 2010. Molt in North American birds. - Houghton Mifflin Harcourt.

Hoyt, D. F. 1979. Practical Methods of Estimating Volume and Fresh Weight of Bird Eggs. - The Auk 96: 73-77.

Hunnewell, R. W., Diamond, A. W. and Brown, S. C. 2016. Estimating the migratory stopover abundance of phalaropes in the outer Bay of Fundy, Canada. - Avian Conservation \& Ecology 11(2): 11 .

Huntley, B., Green, R. E., Collingham, Y. C. and Willis, S. G. 2007. A Climatic Atlas of European Breeding Birds. - Lynx Editions.

ICES 2018. Interim report of the Working Group on the Integrated Assessments of the Barents Sea (WGIBAR). WGIBAR 2018 report 9-12 March 2018. Tromso, Norway.: 186.

Irvine, J. L. 2018. Dark adult Long-tailed Skua, Whalsay, Shetland, July 2018. - British Birds 111: 761-764.

Irwin, D. E. and Irwin, J. H. 2004. Siberian migratory divides: the role of seasonal migration in speciation. - In: Greenberg, R. and Marra, P. P. (eds), Birds of two worlds. The ecology and evolution of migration. Smithsonian Institution Press, pp. 27-40. 
Janssen, K. and Mundy, N. I. 2013. Molecular population genetics of the melanic plumage polymorphism in Arctic skuas (Stercorarius parasiticus): Evidence for divergent selection on plumage colour. - Molecular Ecology 22: 4634-4643.

Janssen, K. and Mundy, N. I. 2017. The genetic basis and enigmatic origin of melanic polymorphism in pomarine skuas (Stercorarius pomarinus). - Proceedings of the Royal Society B: Biological Sciences 284: 20171735.

Janssen, K., Erikstad, K. E. and Bensch, S. 2006. Offspring sex ratio allocation in the parasitic jaeger: Selection for pale females and melanic males? - Behavioral Ecology 17: 236-245. Jehl Jr., J. R. 1986. Biology of red-necked phalaropes (Phalaropus lobatus) at the western edge of the Great Basin in fall migration. - Great Basin Naturalist 46: 185-197.

Jiguet, F., Robert, A., Lorrillière, R., Hobson, K. A., Kardynal, K. J., Arlettaz, R., Bairlein, F., Belik, V., Bernardy, P., Copete, J. L., Czajkowski, M. A., Dale, S., Dombrovski, V., Ducros, D., Efrat, R., Elts, J., Ferrand, Y., Marja, R., Minkevicius, S., Olsson, P., Pérez, M., Piha, M., Raković, M., Schmaljohann, H., Seimola, T., Selstam, G., Siblet, J.-P., Skierczyǹski, M., Sokolov, A., Sondell, J. and Moussy, C. 2019. Unravelling migration connectivity reveals unsustainable hunting of the declining ortolan bunting. - Science Advances 5: eaau2642. Jones, P. J. 1995. Migration strategies of Palearctic passerines in Africa. - Israel Journal of Zoology 41: 393-406.

Jouventin, P. and Weimerkirch, H. 1990. Satellite tracking of Wandering albattrosses. - Nature 343: 746-748.

Julien, J.-R., Legagneux, P., Gauthier, G., Morrison, R. I. G., Therrien, J.-F. and Bêty, J. 2014. Contribution of allochthonous resources to breeding in a high-arctic avian predator. Polar Biology 37: 193-203.

Kalnay, E., Kanamitsu, M., Kistler, R., Collins, W., Deaven, D., Gandin, L., Iredell, S., Saha, S., White, G., Zhu, Y., Leetmaa, A., Reynolds, R., Chelliah, M., Ebisuzaki, W., Higgins, W., Janowiak, J., Mo, K., Ropelewski, C., Wang, J., Jenne, R. and Joseph, D. 1996. The NCEP/NCAR 40-Year Reanalysis Project. - Bulletin of the American Meteorological Society 77: 437-471.

Kausrud, K. L., Mysterud, A., Steen, H., Vik, J. O., Østbye, E., Cazelles, B., Framstad, E., Eikeset, A. M., Mysterud, I., Solhøy, T. and Stenseth, N. C. 2008. Linking climate change to lemming cycles. - Nature 456: 93-97.

Keijl, G. O. 2011. Sooty shearwaters Puffinus griseus in the north atlantic - moult studies using digital cameras. - Marine Ornithology 39: 141-142.

Kemp, M. U., Emiel van Loon, E., Shamoun-Baranes, J. and Bouten, W. 2012. RNCEP: Global weather and climate data at your fingertips. - Methods in Ecology and Evolution 3: 65-70.

Kentie, R., Marquez-Ferrando, R., Figuerola, J., Gangoso, L., Hooijmeijer, J. C. E. W., Loonstra, A. H. J., Robin, F., Sarasa, M., Senner, N., Valkema, H., Verhoeven, M. A. and Piersma, T. 2017. Does wintering north or south of the Sahara correlate with timing and breeding performance in black-tailed godwits? - Ecology and Evolution 7: 2812-2820.

Killengreen, S. T., Lecomte, N., Ehrich, D., Schott, T., Yoccoz, N. G. and Ims, R. A. 2011. The importance of marine vs. human-induced subsidies in the maintenance of an expanding mesocarnivore in the arctic tundra. - Journal of Animal Ecology 80: 1049-1060.

Kjellen, N. 2000. Skuas on the Eurasian tundra: relative occurrence of species, ages and colour phases. - Ornis Svecica 10: 71-78. 
Klaassen, M., Abraham, K. F., Jefferies, R. L. and Vrtiska, M. 2006. Factors affecting the site of investment, and the reliance on savings for arctic breeders: the capital-income dichotomy revisited. - Ardea 94: 371-384.

Klaassen, R. H. G., Alerstam, T., Carlsson, P., Fox, J. W. and Lindström, A. 2011. Great flights by great snipes: long and fast non-stop migration over benign habitats. - Biology letters 7: 833-5.

Klaassen, R., Klaassen, H., Berghuis, A., Berghuis, M., Schreven, K., van der Horst, Y., Verkade, H. and Kearsley, L. 2014a. Trekroutes en overwinteringsgebieden van Nederlandse Gierzwaluwen ontrafeld met geolocators. - Limosa 87: 173-181.

Klaassen, R. H. G., Hake, M., Strandberg, R., Koks, B. J., Trierweiler, C., Exo, K.-M., Bairlein, F. and Alerstam, T. 2014b. When and where does mortality occur in migratory birds? Direct evidence from long-term satellite tracking of raptors (G Hays, Ed.). - Journal of Animal Ecology 83: 176-184.

Kokko, H. 1999. Competition for early arrival in migratory birds. - Journal of Animal Ecology 68: 940-950.

Koleček, J., Hahn, S., Emmenegger, T. and Procházka, P. 2018. Intra-tropical movements as a beneficial strategy for Palearctic migratory birds. - Royal Society Open Science 5: 171675.

Kooyman, G., Kooyman, T. G., Horning, M. and Kooyman, C. A. 1996. Penguin dispersal after fledging. - Nature 383: 397.

Kopp, M., Peter, H. U., Mustafa, O., Lisovski, S., Ritz, M. S., Phillips, R. A. and Hahn, S. 2011. South polar skuas from a single breeding population overwinter in different oceans though show similar migration patterns. - Marine Ecology Progress Series 435: 263-267.

Krietsch, J., Hahn, S., Kopp, M., Phillips, R., Peter, H. and Lisovski, S. 2017. Consistent variation in individual migration strategies of brown skuas. - Marine Ecology Progress Series 578: 213-225.

Kristensen, M. W., Tøttrup, A. P. and Thorup, K. 2013. Migration of the Common Redstart (Phoenicurus phoenicurus): a Eurasian songbirds wintering in highly seasonal conditions in the West African Sahel. - The Auk 130: 258-264.

Laake, J. L. 2013. RMark: An R Interface for Analysis of Capture-Recapture Data with MARK. AFSC Processed Rep. 2013-01.

Lack, D. L. 1968. Ecological adaptations for breeding in birds. - Methuen.

Lambert, K. 1980. Ein Überwinterungsgebiet der Falkenraubmöwe, Stercorarius longicaudus Vieill. 1819, vor Südwest- und Südafrika entdeckt. - Beiträge zur Vogelkunde 26: 199-212.

Lameris, T. K., van der Jeugd, H. P., Eichhorn, G., Dokter, A. M., Bouten, W., Boom, M. P., Litvin, K. E., Ens, B. J. and Nolet, B. A. 2018. Arctic Geese Tune Migration to a Warming Climate but Still Suffer from a Phenological Mismatch. - Current Biology 28: 2467-2473.e4.

Lappo, E. P., Tomkovich, P. S. and Syroechkovsky, E. 2012. Atlas of breeding waders in the Russian Arctic. - УФ Офсетная печать.

Lascelles, B. G., Taylor, P. R., Miller, M. G. R., Dias, M. P., Oppel, S., Torres, L., Hedd, A., Le Corre, M., Phillips, R. A., Shaffer, S. A., Weimerskirch, H. and Small, C. 2016. Applying global criteria to tracking data to define important areas for marine conservation ( $P$ Visconti, Ed.). - Diversity and Distributions 22: 422-431. 
Léandri-Breton, D.-J., Jaffré, M. and Bêty, J. 2018. A rare dark morph in the Canadian Arctic raises questions about molting and polymorphism in Long-tailed Jaeger (Stercorarius longicaudus). - The Wilson Journal of Ornithology 130: 337-340.

Lee, D. S. 1987. December Records of Seabirds off North Carolina. - The Wilson Bulletin 99: 116-121.

Leisler, B. and Winkler, H. 2003. Morphological consequences of migration in passerines. - In: Berthold, P. et al. (eds), Avian Migration. Springer-Verlag, pp. 175-186.

Liebezeit, J. R., Smith, P. A., Lanctot, R. B., Schekkerman, H., Tulp, I., Kendall, S. J., Tracy, D. M., Rodrigues, R. J., Meltofte, H., Robinson, J. A., Gratto-Trevor, C., McCaffery, B. J., Morse, J. and Zack, S. W. 2007. Assessing the development of shorebird eggs using the flotation method: Species-specific and generalized regression models. - The Condor 109: 32-47.

Lindenmayer, D. B., Likens, G. E., Andersen, A., Bowman, D., Bull, C. M., Burns, E., Dickman, C. R., Hoffmann, A. A., Keith, D. A., Liddell, M. J., Lowe, A. J., Metcalfe, D. J., Phinn, S. R., Russell-Smith, J., Thurgate, N. and Wardle, G. M. 2012. Value of long-term ecological studies. - Austral Ecology 37: 745-757.

Lindström, Å. 2003. Fuel deposition rates in migrating birds: causes, constraints and consequences. - In: Berthold, P. et al. (eds), Avian Migration. Springer-Verlag Berlin Heidelberg $\mathrm{GmbH}$, pp. 307-320.

Lindström, A., Pearson, D. J., Hasselquist, D., Hedenström, A., Bensch, S. and Åkesson, S. 1993a. The moult of Barred Warblers Sylvia nisoria in Kenya - evidence for a split wingmoult pattern initiated during the birds' first winter. - Ibis 135: 403-409.

Lindström, A., Visser, G. H. and Daan, S. 1993b. The energetic cost of feather synthesis is proportional to basal metabolic rate. - Physiological zoology 66: 490-510.

Lindström, A., Chapman, B. B., Jonzén, N. and Klaassen, M. 2014. Movement and migration in a changing world. - In: Hansson, L.-A. and Akesson, S. (eds), Animal movement across scales. Oxford University Press, pp. 60-89.

Lindström, Å., Green, M., Husby, M., Kålås, J. A. and Lehikoinen, A. 2015. Large-Scale Monitoring of Waders on Their Boreal and Arctic Breeding Grounds in Northern Europe. Ardea 103: 3-15.

Lindström, A.., Alerstam, T. and Hedenström, A. 2019. Faster fuelling is the key to faster migration. - Nature Climate Change 9: 288-289.

Lislevand, T., Chutný, B., Byrkjedal, I., Pavel, V., Briedis, M., Adamik, P. and Hahn, S. 2015. Redspotted Bluethroats Luscinia s. svecica migrate along the Indo-European flyway: a geolocator study. - Bird Study 3657: 1-8.

Lisovski, S. and Hahn, S. 2012. GeoLight - processing and analysing light-based geolocator data in R. - Methods in Ecology and Evolution 3: 1055-1059.

Livezey, B. C. 2010. Phylogenetics of modern shorebirds (Charadriiformes) based on phenotypic evidence: analysis and discussion: CHARADRIIFORMES. - Zoological Journal of the Linnean Society 160: 567-618.

Lok, T., Overdijk, O. and Piersma, T. 2015. The cost of migration: spoonbills suffer higher mortality during trans-Saharan spring migrations only. - Biology Letters 11: 20140944

Lok, T., Veldhoen, L., Overdijk, O., Tinbergen, J. M. and Piersma, T. 2017. An age-dependent fitness cost of migration? Old trans-Saharan migrating spoonbills breed later than those staying in Europe, and late breeders have lower recruitment. - Journal of Animal Ecology 
86: 998-1009.

Longhurst, A. R. 2006. Ecological geography of the sea. - Academic Press.

Magnusdottir, E., Leat, E. H. K., Bourgeon, S., Strøm, H., Petersen, A., Phillips, R. A., Hanssen,

S. A., Bustnes, J. O., Hersteinsson, P. and Furness, R. W. 2012. Wintering areas of Great

Skuas Stercorarius skua breeding in Scotland, Iceland and Norway. - Bird Study 59: 1-9.

Maher, W. J. 1974. Ecology of Pomarine, Parasitic, and Long-Tailed Jaegers in Northern Alaska. Pacific Coast Avifauna 37: 1-148.

Manning, T. H. 1964. Geographical and sexual variation in the Long-Tailed Jaeger Stercorarius longicaudus Vieillot. - Biological Papers of the University of Alaska 7: 1-16.

Marra, J. and Barber, R. T. 2005. Primary productivity in the Arabian Sea: A synthesis of JGOFS data. - Progress in Oceanography 65: 159-175.

Marra, P. P., Hobson, K. A. and Holmes, R. T. 1998. Linking winter and summer events in a migratory bird by using stable-carbon isotopes. - Science 282: 1884-1886.

Marra, P. P., Cohen, E. B., Loss, S. R., Rutter, J. E. and Tonra, C. M. 2015. A call for full annual cycle research in animal ecology. - Biology letters 11: 2015.0552.

McFarlane Tranquilla, L. A., Montevecchi, W. A., Fifield, D. A., Hedd, A., Gaston, A. J., Robertson, G. J. and Phillips, R. A. 2014. Individual winter movement strategies in two species of murre (Uria spp.) in the Northwest Atlantic. - PloS one 9: e90583.

Mckinnon, E. a., Fraser, K. C. and Stutchbury, B. J. M. 2013. New discoveries in landbird migration using geolocators, and a flight plan for the future. - The Auk 130: 211-222.

Meijer, T. and Drent, R. 1999. Re-examination of the capital and income dichotomy in breeding birds. - Ibis 141: 399-414.

Meinertzhagen, R. 1925. The distribution of the phalaropes. - Ibis 67: 325-344.

Meiri, S. and Dayan, T. 2003. On the validity of Bergmann's rule: On the validity of Bergmann's rule. - Journal of Biogeography 30: 331-351.

Melville, D. S. 1983. Long-tailed Skuas Stercorarius longicaudus in New Zealand. - Notornis 32: 51-73.

Méndez, V., Alves, J. A., Gill, J. A. and Gunnarsson, T. G. 2018. Patterns and processes in shorebird survival rates: a global review. - Ibis 160: 723-741.

Menkhorst, P., Rogers, D., Clarke, R., Davies, J., Marsack, P. and Franklin, K. 2017. The Australian Bird Guide. - CSIRO.

Mercier, F. M. 1985. Fat reserves and migration of Red-necked Phalaropes (Phalaropus lobatus) in the Quoddy region, New Brunswick, Canada. - Canadian Journal of Zoology-Revue Canadienne De Zoologie 63: 2810-2816.

Mercier, F. M. and Gaskin, D. E. 1985. Feeding ecology of migrating Red-necked Phalaropes (Phalaropus lobatus) in the Quoddy region, New Brunswick, Canada. - Canadian Journal of Zoology 63: 1062-1067.

Miles, W. T. S., Mavor, R., Riddiford, N. J., Harvey, P. V., Riddington, R., Shaw, D. N., Parnaby, D. and Reid, J. M. 2015. Decline in an Atlantic Puffin Population: Evaluation of Magnitude and Mechanisms. - PLOS ONE 10: e0131527.

Milner-Gulland, E. J., Fryxell, J. M. and Sinclair, A. R. E. 2011. Animal migration: a synthesis. Oxford University Press.

Minias, P., Meissner, W., Włodarczyk, R., Ożarowska, A., Piasecka, A., Kaczmarek, K. and Janiszewski, T. 2015. Wing shape and migration in shorebirds: a comparative study. - Ibis 
157: 528-535.

Mitchell, P. I., Newton, S. F., Ratcliffe, N. and Dunn, T. E. 2004. Seabird populations of Britain and Ireland. - T. \& A.D. Poyser, London.

Moller, A. P., Rubolini, D. and Lehikoinen, E. 2008. Populations of migratory bird species that did not show a phenological response to climate change are declining. - Proceedings of the National Academy of Sciences 105: 16195-16200.

Møller, A. P., Garamszegi, L. Z., Peralta-Sánchez, J. M. and Soler, J. J. 2011. Migratory divides and their consequences for dispersal, population size and parasite-host interactions: Evolutionary consequences of migratory divides. - Journal of Evolutionary Biology 24: 1744-1755.

Moore, J. K., Fu, W., Primeau, F., Britten, G. L., Lindsay, K., Long, M., Doney, S. C., Mahowald, N., Hoffman, F. and Randerson, J. T. 2018. Sustained climate warming drives declining marine biological productivity. - Science 359: 1139-1143.

Moreau, R. E. 1972. The Palearctic-African bird migration system. - Academic Press.

Morrison, R. I. G., Mccaffery, B. J., Gill, R. E., Skagen, S. K., Jones, S. L., Page, G. W., GrattoTrevor, C. L. and Andres, B. A. 2006. Population estimates of North American shorebirds, 2006. - Wader Study Group Bulletin 111: 67 - 85.

Mörzer-Bruijns, W. F. J. and Mörzer-Bruijns, M. F. 1957. Waarnemingen van de Grauwe Franjepoot, Phalaropus lobatus (L.), in de Indische Oceaan. - Ardea 45: 72-84.

Mu, T., Tomkovich, P. S., Loktionov, E. Y., Syroechkovskiy, E. E. and Wilcove, D. S. 2018. Migratory routes of red-necked phalaropes Phalaropus lobatus breeding in southern Chukotka revealed by geolocators. - Journal of Avian Biology 49: 1-6.

Mueller, T. and Fagan, W. F. 2008. Search and navigation in dynamic environments - from individual behaviours to population distributions. - Oikos 117: 654-664.

Mueller, T., Olson, K. A., Dressler, G., Leimgruber, P., Fuller, T. K., Nicolson, C., Novaro, A. J., Bolgeri, M. J., Wattles, D., DeStefano, S., Calabrese, J. M. and Fagan, W. F. 2011. How landscape dynamics link individual- to population-level movement patterns: a multispecies comparison of ungulate relocation data: Population-level movement patterns. - Global Ecology and Biogeography 20: 683-694.

Muller, M., Massa, B. and Dell Omo, G. 2013. Individual consistency and sex differences in migration strategies of Scopolis shearwaters (Calonectris diomedea) despite systematic year differences. - Current Zoology 60: 1-17.

Myers, J. P. 1981. A test of three hypotheses for latitudinal segregation of the sexes in wintering birds. - Canadian Journal of Zoology 59: 1527-1534.

Nager, R. G. 2006. The challenges of making eggs. - Ardea 94: 323-346.

Nakagawa, S. and Schielzeth, H. 2010. Repeatability for Gaussian and non-Gaussian data: A practical guide for biologists. - Biological Reviews 85: 935-956.

Newell, D., Howell, S. N. G. and López-Velasco, D. 2013. South polar and great skuas: the timing of primary moult as an aid to identification. - British Birds 106: 325-346.

Newton, I. 2010. The migration ecology of birds. - Academic Press.

Niles, L. J., Burger, J., Porter, R. R., Dey, A. D., Minton, C. D. T., Gonzalez, P. M., Baker, A. J., Fox, J. W. and Gordon, C. 2010. First results using light level geolocators to track Red Knots in the Western Hemisphere show rapid and long intercontinental flights and new details of migration pathways. - Wader Study Group Bulletin 117: 123-130. 
Nilsson, C., Klaassen, R. H. G. and Alerstam, T. 2013. Differences in speed and duration of bird migration between spring and autumn. - The American naturalist 181: 837-45.

Nisbet, I. C. T. and Veit, R. R. 2015. An explanation for the population crash of red-necked phalaropes Phalaropus lobatus in the Bay of Fundy in the 1980s. - Marine Ornithology 43 : 119-121.

Norevik, G., Boano, G., Hedenström, A., Lardelli, R., Liechti, F. and Åkesson, S. 2019. Highly mobile insectivorous swifts perform multiple intra-tropical migrations to exploit an asynchronous African phenology. - Oikos 128: 640-648.

Norris, D. R. and Marra, P. P. 2007. Seasonal interactions, habitat quality, and population dynamics in migratory birds. - The Condor 109: 535-547.

Norris, D. R., Marra, P. P., Kyser, T. K., Sherry, T. W. and Ratcliffe, L. M. 2004. Tropical winter habitat limits reproductive success on the temperate breeding grounds in a migratory bird. - Proceedings of the Royal Society B: Biological Sciences 271: 59-64.

O'Donald, P. 1983. The Arctic Skua. A study of the ecology and evolution of a seabird. Cambridge University Press.

Olsen, K. M. and Larsson, H. 1997. Skuas \& jaegers. A guide to the skuas and jaegers of the world. - Pica Press.

O'Malley, R. 2016. Ocean productivity. http://www.science.oregonstate.edu/ocean. productivity

Orben, R. A., Paredes, R., Roby, D. D., Irons, D. B. and Shaffer, S. A. 2015. Wintering North Pacific black-legged kittiwakes balance spatial flexibility and consistency. - Movement Ecology 3: 36.

Oring, L. W. and Lank, D. B. 1982. Sexual selection, arrival times, philopatry and site fidelity in the polyandrous spotted sandpiper. - Behavioral Ecology and Sociobiology 10: 185-191.

Orr, C. D., Ward, R. M. P., Williams, N. A. and Brown, R. G. B. 1982. Migration Patterns of Red and Northern Phalaropes in Southwest Davis Strait and in the Northern Labrador Sea. The Wilson Bulletin 94: 303-312.

Ottosson, U., Ottvall, R., Elmberg, R., Green, M., Holmqvist, N., Lindström, A., Nilsson, L., Svensson, M., Svensson, S. and Tjernberg, M. 2012. Fåglarna i Sverige antal och förekomst. - SOF.

Panzacchi, M., Linnell, J. D. C., Odden, J., Odden, M. and Andersen, R. 2008. When a generalist becomes a specialist: patterns of red fox predation on roe deer fawns under contrasting conditions. - Canadian Journal of Zoology 86: 116-126.

Parmesan, C. and Yohe, G. 2003. A globally coherent fingerprint of climate change impacts across natural systems. - Nature 421: 37-42.

Pedersen, L., Jackson, K., Thorup, K. and Tøttrup, A. P. 2018. Full-year tracking suggests endogenous control of migration timing in a long-distance migratory songbird. Behavioral Ecology and Sociobiology 72: 139.

Pennycuick, C. J. 2008. Modelling the flying bird. - Academic Press.

Perkins, A., Ratcliffe, N., Suddaby, D., Ribbands, B., Smith, C., Ellis, P., Meek, E. and Bolton, M. 2018. Combined bottom-up and top-down pressures drive catastrophic population declines of Arctic skuas in Scotland. - Journal of Animal Ecology 87(6): 1573-1586.

Péron, C. and Grémillet, D. 2013. Tracking through life stages: adult, immature and juvenile autumn migration in a long-lived seabird. - PLOS ONE 8: 1-14.

Phillips, R. A. 2001. Stercorarius parasiticus Arctic Skua. - BWP Update 3: 25-41. 
Phillips, R. A., Caldow, R. W. G. and Furness, R. W. 1996. The influence of food availability on the breeding effort and reproductive success of Arctic Skuas Stercorarius parasiticus. Ibis 138: 410-419.

Phillips, R. A., Silk, J. R. D., Croxall, J. P., Afanasyev, V. and Briggs, D. R. 2004. Accuracy of geolocation estimates for flying seabirds. - Marine Ecology Progress Series 266: 265-272.

Phillips, R. A., Silk, J. R. D., Croxall, J. P., Afanasyev, V. and Bennett, J. 2005. Summer distribution and migration of nonbreeding albatrosses: individual consistencies and implications for conservation. - Ecology 86: 2386-2396.

Phillips, R. A., Catry, P., Silk, J. R. D., Bearhop, S., McGill, R., Afanasyev, V. and Strange, I. J. 2007. Movements, winter distribution and activity patterns of Falkland and brown skuas: Insights from loggers and isotopes. - Marine Ecology Progress Series 345: 281-291.

Piersma, T. 1987. Hink, stap of sprong? Reisbeperkingen van arctische steltlopers door voedselzoeken, vetopbouw en vliegsnelheid. - Limosa 60: 185-194.

Piersma, T., Zwarts, L. and Bruggemann, J. H. 1990. Behavioural aspects of the departure of waders before long-distance flights: flocking, vocalizations, flight paths and diurnal timing. - Ardea 78: 157-184.

Pinheiro, J., Bates, D., DebRoy, S., Sarkar, D. and R Core Team 2018. nlme: Linear and Nonlinear Mixed Effects Models. R package version 3.1-137.

Planque, B., Hays, G. C., Ibanez, F. and Gamble, J. C. 1997. Large scale spatial variations in the seasonal abundance of Calanus finmarchicus. - Deep-Sea Research Part I 44: 315-326.

Plummer, M. 2003. JAGS: A Program for Analysis of Bayesian Graphical Models Using Gibbs Sampling. - Proceedings of the 3rd International Workshop on Distributed Statistical Computing (DSC 2003) March 20-22, Vienna, Austria: 10.

Pollet, I. L., Ronconi, R. A., Leonard, M. L. and Shutler, D. 2019. Migration routes and stopover areas of Leach's storm petrel Oceanodroma leucorhoa. - Marine Ornithology 47: 53-63.

Prince, P. a., Rodwell, S., Jones, M. and Rothery, P. 1993. Moult in Black-browed and Greyheaded Albatrosses: Diomedea melanophris and D. chrysostoma. - Ibis 135: 121-131.

Pulido, F. 2007. The genetics and evolution of avian migration. - Bio Science 57: 165-174.

Pütz, K. 2002. Spatial and temporal variability in the foraging areas of breeding King Penguins. - The Condor 104: 528-538.

Pyle, P. 2008. Identification Guide to North American Birds. Part 2. - Slate Creek Press.

Pyle, P. and Reid, M. 2016. Molts and plumages in the Long-tailed and other Jaegers: an “alternate" explanation for nonbreeding plumages? - Western Birds 47: 242-257.

Quillfeldt, P., Voigt, C. C. and Masello, J. F. 2010. Plasticity versus repeatability in seabird migratory behaviour. - Behavioral Ecology and Sociobiology 64: 1157-1164.

R Core Team 2017. R: A Language and Environment for Statistical Computing. - R Foundation for Statistical Computing.

Ramírez, F., Afán, I., Tavecchia, G., Catalán, I. A., Oro, D. and Sanz-Aguilar, A. 2016. Oceanographic drivers and mistiming processes shape breeding success in a seabird. Proceedings of the Royal Society B: Biological Sciences 283: 20152287.

Ramos, R., González-Solís, J. and Ruiz, X. 2009. Linking isotopic and migratory patterns in a pelagic seabird. - Oecologia 160: 97-105.

Rappole, J. H. and Tipton, A. R. 1991. New harness design for attachment of radio transmitters to small passerines. - Journal of Field Ornithology 62: 335-337. 
Reiertsen, T. K., Erikstad, K. E., Anker-Nilssen, T., Barrett, R. T., Boulinier, T., Frederiksen, M., González-Solís, J., Gremillet, D., Johns, D., Moe, B., Ponchon, A., Skern-Mauritzen, M., Sandvik, H. and Yoccoz, N. G. 2014. Prey density in non-breeding areas affects adult survival of black-legged kittiwakes Rissa tridactyla. - Marine Ecology Progress Series 509: 289-302.

Remisiewicz, M., Tree, A. J., Underhill, L. G. and Taylor, P. B. 2010. The path to adult dress: primary moult in second-year Wood Sandpipers Tringa glareola in southern Africa. Wader Study Group Bulletin 117: 35-40.

Reynolds, J. D. 1987. Mating system and nesting biology of the Red-necked Phalarope Phalaropus lobatus: what constrains polyandry? - Ibis 129: 225-242.

Reynolds, J. D., Colwell, M. a. and Cooke, F. 1986. Sexual selection and spring arrival times of red-necked and Wilson's phalaropes. - Behavioral Ecology and Sociobiology 18: 303-310.

Rijnsdorp, A. D., Peck, M. A., Engelhard, G. H., Mollmann, C. and Pinnegar, J. K. 2009. Resolving the effect of climate change on fish populations. - ICES Journal of Marine Science 66: 1570-1583.

Robinson, R. A., Crick, H. Q. P., Learmonth, J. A., Maclean, I. M. D., Thomas, C. D., Bairlein, F., Forchhammer, M. C., Francis, C. M., Gill, J. A., Godley, B. J., Harwood, J., Hays, G. C., Huntley, B., Hutson, A. M., Pierce, G. J., Rehfisch, M. M., Sims, D. W., Begoña Santos, M., Sparks, T. H., Stroud, D. A. and Visser, M. E. 2009. Travelling through a warming world: Climate change and migratory species. - Endangered Species Research 7: 87-99.

Rodgers Jr, J. A. 1987. On the antipredator advantages of coloniality: a word of caution. - The Wilson Bulletin 99: 269-271.

Rohwer, V. G. and Rohwer, S. 2013. How do birds adjust the time required to replace their flight feathers? - The Auk 130: 699-707.

Rohwer, S., Ricklefs, R. E., Rohwer, V. G. and Copple, M. M. 2009. Allometry of the duration of flight feather molt in birds. - PLoS Biology 7: e1000132.

Rotics, S., Kaatz, M., Turjeman, S., Zurell, D., Wikelski, M., Sapir, N., Eggers, U., Fiedler, W., Jeltsch, F. and Nathan, R. 2018. Early arrival at breeding grounds: causes, costs and a trade-off with overwintering latitude. - Journal of Animal Ecology: 1627-1638.

Rubega, M. A., Schamel, D. and Tracy, D. M. 2000. Red-necked Phalarope (Phalaropus lobatus). - The birds of North America online.

Runge, C. A., Martin, T. G., Possingham, H. P., Willis, S. G. and Fuller, R. A. 2014. Conserving mobile species. - Frontiers in Ecology and the Environment 12: 395-402.

Runge, C. A., Watson, J. E. M., Butchart, S. H. M., Hanson, J. O., Possingham, H. P. and Fuller, R. A. 2015. Protected areas and global conservation of migratory birds. - Science 350: 1255-1258.

Ryan, P. G. 1989. The distribution and abundance of Long-tailed Skuas off southern Africa. Ostrich 60: 89-90.

Rypdal, E. 2018. Repeatability in isotopic signatures is linked to consistent individual migration strategies and individual specialization in a long-distance migratory seabird. MSc thesis, NINA, Norway

Sandercock, B. K. 1997. The breeding biology of Red-necked Phalaropes Phalaropus lobatus at Nome, Alaska. - Wader Study Group Bulletin 83: 50-54.

Saxby, H.L. (1874) The birds of Shetland, with observations on their habits, Migration and 
occasional appearance. Edinburgh.

Scales, K. L., Miller, P. I., Embling, C. B., Ingram, S. N., Pirotta, E. and Votier, S. C. 2014. Mesoscale fronts as foraging habitats: composite front mapping reveals oceanographic drivers of habitat use for a pelagic seabird. - Journal of the Royal Society, Interface / the Royal Society 11: 20140679.

Schamel, D. L. and Tracy, D. M. 1977. Polyandry, replacement clutches, and site tenacity in the Red Phalarope (Phalaropus fulicarius) at Barrow, Alaska. - Bird Banding 48: 314-324.

Schamel, D. and Tracy, D. M. 1988. Are yearlings distinguishable from older Red-Necked Phalaropes? - Journal of Field Ornithology 59: 235-238.

Schamel, D. and Tracy, D. M. 1991. Breeding site fidelity and natal philopatry in the sex rolereversed red and red-necked phalaropes. - J. Field Ornithol. 62: 390-398.

Schamel, D., Tracy, D. M. and Lank, D. B. 2004. Male mate choice, male availability and egg production as limitations on polyandry in the red-necked phalarope. - Animal Behaviour 67: 847-853.

Schielzeth, H. and Nakagawa, S. 2013. rptR: Repeatability for Gaussian and non-Gaussian data. R package version 0.6.405/r52.

Schiemann, H. 1977. Beringungsergebnisse Nordeuropäischer Odinshünchen. - Sterna: 73-80.

Schiemann, H. 1986. Red-necked phalaropes Phalaropus lobatus off the coast of Somalia and Kenya. - Scopus 10: 42-44.

Schultner, J., Moe, B., Chastel, O., Tartu, S., Bech, C. and Kitaysky, A. S. 2014. Corticosterone mediates carry-over effects between breeding and migration in the kittiwake Rissa tridactyla. - Marine Ecology Progress Series 496: 125-133.

Senner, N. R., Conklin, J. R. and Piersma, T. 2015. An ontogenetic perspective on individual differences. - Proc. R. Soc. Lond. B 282: 20151050.

Sergio, F., Tanferna, A., De Stephanis, R., Jiménez, L. L., Blas, J., Tavecchia, G., Preatoni, D. and Hiraldo, F. 2014. Individual improvements and selective mortality shape lifelong migratory performance. - Nature 515: 410-413.

Serra, L. 2001. Duration of primary moult affects primary quality in Grey Plovers Pluvialis squatarola. - Journal of Avian Biology 32: 377-380.

Serra, L., Whitelaw, D., Tree, A. and Underhill, L. G. 1999. Moult, mass and migration of Grey Plovers Pluvialis squatarola wintering in South Africa. - Ardea 87: 71-81.

Serra, L., Clark, N. A. and Clark, J. A. 2006. Primary moult, body mass and migration of Grey Plovers Pluvialis squatarola in Britain. - Ibis 148: 292-301.

Shaffer, T. L. 2004. A unified approach to analyzing nest success. - The Auk 121: 526-540.

Shizuka, D., Chaine, A. S., Anderson, J., Johnson, O., Laursen, I. M. and Lyon, B. E. 2014. Across-year social stability shapes network structure in wintering migrant sparrows. Ecology Letters 17: 998-1007.

Sikora, A. and Zielińksi, P. 2000. Autumn migration of the red-necked phalarope in the Visula river mouth during 1983-2000. - Notatki Ornitologiczne 41: 273-282.

Singh, N. J., Börger, L., Dettki, H., Bunnefeld, N. and Ericsson, G. 2012. From migration to nomadism: movement variability in a northern ungulate across its latitudinal range. Ecological Applications 22: 2007-2020.

Sittler, B., Aebischer, A. and Gilg, O. 2011. Post-breeding migration of four Long-tailed Skuas (Stercorarius longicaudus) from North and East Greenland to West Africa. - Journal of 
Ornithology 152: 375-381.

Skarphéðinsson, K. H., Katrínardóttir, B., Guðmundsson, G. A. and Auhage, S. N. V. 2016. Mikilvæg fuglasvæði á Íslandi. - Fjölrit Náttúrufræðistofnunar.

Smith, M., Bolton, M., Okill, D. J., Summers, R. W., Ellis, P., Liechti, F. and Wilson, J. D. 2014. Geolocator tagging reveals Pacific migration of Red-necked Phalarope Phalaropus lobatus breeding in Scotland. - Ibis 156: 870-873.

Smith, M., Bolton, M., Okill, J. D., Harris, P., Petrie, G., Riddington, R. and Wilson, J. D. 2018. Further evidence of transatlantic migration routes and Pacific wintering grounds of Rednecked Phalaropes breeding in Shetland. - British Birds 111: 428-437.

Sorensen, M. C., Hipfner, J. M., Kyser, T. K. and Norris, D. R. 2009. Carry-over effects in a Pacific seabird: Stable isotope evidence that pre-breeding diet quality influences reproductive success. - Journal of Animal Ecology 78: 460-467.

Spiegelhalter, D. J., Best, N. G., Carlin, B. P. and Linde, A. V. D. 2002. Bayesian measures of model complexity and fit. - Journal of the Royal Statistical Society: Series B (Statistical Methodology) 64: 583-639.

Stach, R., Jakobsson, S., Kullberg, C. and Fransson, T. 2012. Geolocators reveal three consecutive wintering areas in the thrush nightingale. - Animal Migration 1: 1-7.

Stanford, W. P. 1952. Winter distribution of the Grey Phalarope Phalaropus fulicarius. - Ibis 95: 483-491.

Stanley, C. Q., MacPherson, M., Fraser, K. C., McKinnon, E. a. and Stutchbury, B. J. M. 2012. Repeat tracking of individual songbirds reveals consistent migration timing but flexibility in route. - PLoS ONE 7: e40688.

Stanley, C. Q., Mckinnon, E. A., Fraser, K. C., Macpherson, M. P., Casbourn, G., Friesen, L., Marra, P. P., Studds, C., Ryder, T. B., Diggs, N. E. and Stutchbury, B. J. M. 2015. Connectivity of wood thrush breeding, wintering, and migration sites based on rangewide tracking. - Conservation Biology 29: 164-174.

Stenhouse, I. J., Egevang, C. and Phillips, R. A. 2012. Trans-equatorial migration, staging sites and wintering area of Sabine's Gulls Larus sabini in the Atlantic Ocean. - Ibis 154: 42-51.

Stephens, D. W. and Krebs, J. R. 1986. Foraging theory. - Princeton University Press.

Stige, L. C., Ottersen, G., Dalpadado, P., Chan, K.-S., Hjermann, D. Ø., Lajus, D. L., Yaragina, N. A. and Stenseth, N. Chr. 2010. Direct and indirect climate forcing in a multi-species marine system. - Proceedings of the Royal Society B: Biological Sciences 277: 3411-3420.

Stock, B. C., Jackson, A. L., Ward, E. J., Parnell, A. C., Phillips, D. L. and Semmens, B. X. 2018. Analyzing mixing systems using a new generation of Bayesian tracer mixing models. PeerJ 6: e5096.

Stocker, T., Qin, D., Plattner, G., Tignor, M., Allen, S., Boschung, J., Nauels, A., Xia, Y., Bex, B. and Midgley, B. 2013. IPCC, 2013: climate change 2013:the physical science basis. Contribution of working group I to the fifth assessment report of the intergovernmental panel on climate change. - Cambridge University Press.

Stresemann, E. and Stresemann, V. 1966. Die Mauser der Vögel. - Journal of Ornithology 107: $1-445$.

Strøm, H. 2006. Birds of Svalbard. - In: Kovacs, K. M. and Lydersen, C. (eds), Birds and Mammals of Svalbard. Norwegian Polar Institute, pp. 86-191.

Stutchbury, B. J. M., Siddiqui, R., Applegate, K., Hvenegaard, G. T., Mammenga, P., Mickle, N., 
Pearman, M., Ray, J. D., Savage, A., Shaheen, T. and Fraser, K. C. 2016. Ecological Causes and Consequences of Intratropical Migration in Temperate-Breeding Migratory Birds. - The American Naturalist 188: S28-S40.

Summers, R. W., Swann, R. L. and Nicoll, M. 1983. The effects of methods on estimates of primary moult duration in the Redshank Tringa totanus. - Bird Study 30: 149-156.

Sutherland, W. J. 1998. Evidence for flexibility and constraint in migration systems. - Journal of Avian Biology 29: 441-446.

Sutherland, W. J., Alves, J. A., Amano, T., Chang, C. H., Davidson, N. C., Max Finlayson, C., Gill, J. A., Gill, R. E., González, P. M., Gunnarsson, T. G., Kleijn, D., Spray, C. J., Székely, T. and Thompson, D. B. A. 2012. A horizon scanning assessment of current and potential future threats to migratory shorebirds. - Ibis 154: 663-679.

Svensson, S. 2007. En inventering av icke-tättingar inom 13 kvadratkilometer lågalpin fjällhed vid Ammarnäs i Lappland 1984-1995. - Ornis Svecica 17: 48-58.

Teitelbaum, C. S. and Mueller, T. 2019. Beyond Migration: Causes and Consequences of Nomadic Animal Movements. - Trends in Ecology \& Evolution 34: 13.

Tew Kai, E., Rossi, V., Sudre, J., Weimerskirch, H., Lopez, C., Hernandez-Garcia, E., Marsac, F. and Garçon, V. 2009. Top marine predators track Lagrangian coherent structures. Proceedings of the National Academy of Sciences of the United States of America 106: 8245-50.

Thaxter, C. B., Ross-Smith, V. H., Clark, J. A., Clark, N. A., Conway, G. J., Masden, E. A., Wade, H. M., Leat, E. H. K., Gear, S. C., Marsh, M., Booth, C., Furness, R. W., Votier, S. C. and Burton, N. H. K. 2016. Contrasting effects of GPS device and harness attachment on adult survival of Lesser Black-backed Gulls Larus fuscus and Great Skuas Stercorarius skua. Ibis 158: 279-290.

Thorne, L. H. and Read, A. J. 2013. Fine-scale biophysical interactions drive prey availability at a migratory stopover site for Phalaropus spp. in the Bay of Fundy, Canada. - Marine Ecology Progress Series 487: 261-273.

Thorup, K., Tøttrup, A. P., Willemoes, M., Klaassen, R. H. G., Strandberg, R., Vega, M. L., Dasari, H. P., Araújo, M. B., Wikelski, M. and Rahbek, C. 2017. Resource tracking within and across continents in long-distance bird migrants. - Science Advances 3: 1-11.

Tøttrup, A. P., Klaassen, R. H. G., Kristensen, M. W., Strandberg, R., Vardanis, Y., Lindström, Å., Rahbek, C., Alerstam, T. and Thorup, K. 2012. Drought in Africa caused delayed arrival of European songbirds. - Science (New York, N.Y.) 338: 1307.

Tracy, D. M., Schamel, D. and Dale, J. 2002. Red Phalarope (Phalaropus fulicarius). - The birds of North America online.

Trierweiler, C., Mullié, W. C., Drent, R. H., Exo, K. M., Komdeur, J., Bairlein, F., Harouna, A., De Bakker, M. and Koks, B. J. 2013. A Palaearctic migratory raptor species tracks shifting prey availability within its wintering range in the Sahel. - Journal of Animal Ecology 82: 107-120.

Trierweiler, C., Klaassen, R. H. G., Drent, R. H., Exo, K.-M., Komdeur, J., Bairlein, F. and Koks, B. J. 2014. Migratory connectivity and population-specific migration routes in a longdistance migratory bird. - Proceedings. Biological sciences / The Royal Society 281: 20132897.

Tulp, I. and Schekkerman, H. 2008. Has prey availability for arctic birds advanced with climate 
change? Hindcasting the abundance of tundra arthropods using weather and seasonal variation. - Arctic 61: 48-60.

Underhill, L. G. 2003. Within ten feathers: primary moult strategies of migratory waders (Charadrii). - In: Avian Migration. pp. 187-197.

Underhill, L. G. and Zucchini, W. 1988. A model for avian primary moult. - Ibis 130: 358-372. Valkama, J., Vepsäläinen, V. and Lehikoinen, A. 2011. The third Finnish breeding bird atlas. Finnish Museum of Natural History and Ministry of Environment.

van Bemmelen, R. 2010. Immature long-tailed skuas Stercorarius longicaudus in Swedish Lapland in 2009. - Ornis Svecica 20: 81-86.

van Bemmelen, R. S. A., Hungar, J., Tulp, I. and Klaassen, R. H. G. 2016. First geolocator tracks of Swedish red-necked phalaropes reveal the Scandinavia-Arabian Sea connection. Journal of Avian Biology 47: 295-303.

van Bemmelen, R., Moe, B., Hanssen, S., Schmidt, N., Hansen, J., Lang, J., Sittler, B., Bollache, L., Tulp, I., Klaassen, R. and Gilg, O. 2017. Flexibility in otherwise consistent non-breeding movements of a long-distance migratory seabird, the long-tailed skua. - Marine Ecology Progress Series 578: 197-211.

van Bemmelen, R. S. A., Clarke, R. H., Pyle, P. and Camphuysen, C. J. 2018. Timing and duration of primary molt in Northern Hemisphere skuas and jaegers. - The Auk 135: 1043-1054.

van Bemmelen, R. S. A., Kolbeinsson, Y., Ramos, R., Gilg, O., Alves, J. A., Smith, M., Schekkerman, H., Lehikoinen, A., Petersen, I. K., Pórisson, B., Sokolov, A., Välimäki, K., van der Meer, T., Okill, D., Bolton, M., Moe, B., Hanssen, S. A., Bollache, L., Petersen, A., Thorstensen, S., González-Solís, J., Klaassen, R. H. G. and Tulp, I. 2019. A migratory divide among red-necked phalaropes in the Western Palearctic reveals contrasting migration and wintering movement strategies. - Front. Ecol. Evol. 7: 86.

van der Jeugd, H. P., Eichhorn, G., Litvin, K. E., Stahl, J., Larsson, K., van der Graaf, A. J. and Drent, R. H. 2009. Keeping up with early springs: rapid range expansion in an avian herbivore incurs a mismatch between reproductive timing and food supply. - Global Change Biology 15: 1057-1071.

van der Winden, J., Fijn, R. C., van Horssen, P. W., Gerristen-Davidse, D. and Piersma, T. 2014. Idiosyncratic migrations of Black Terns (Chlidonias niger): diversity in routes and stopovers. - Waterbirds 37: 162-174.

van Gils, J. A., Lisovski, S., Lok, T., Meissner, W., Ozarowska, A., de Fouw, J., Rakhimberdiev, E., Soloviev, M. Y., Piersma, T. and Klaassen, M. 2016. Body shrinkage due to Arctic warming reduces red knot fitness in tropical wintering range. - Science 352: 819-821.

van Noordwijk, A. J., Pulido, F., Helm, B., Coppack, T., Delingat, J., Dingle, H., Hedenström, A., van der Jeugd, H., Marchetti, C., Nilsson, A. and Pérez-Tris, J. 2006. A framework for the study of genetic variation in migratory behaviour. - Journal of Ornithology 147: 221-233.

Vardanis, Y., Klaassen, R. H. G., Strandberg, R. and Alerstam, T. 2011. Individuality in bird migration: routes and timing. - Biology letters 7: 502-505.

Vardanis, Y., Nilsson, J.-Å., Klaassen, R. H. G., Strandberg, R. and Alerstam, T. 2016. Consistency in long-distance bird migration: contrasting patterns in time and space for two raptors. - Animal Behaviour 113: 177-187.

Veit, R. R. 1985. Long-tailed Jaegers wintering along the Falkland Current. - American Birds 39 : 
873-878.

Verkuil, Y., Van Der Have, T. M., Van Der Winden, J., Keijl, G. O., Ruiters, P. S., Koolhaas, A., Dekinga, A. and Chernichko, I. I. 2006. Fast fuelling but light flight in Broad-billed Sandpipers Limicola falcinellus: Stopover ecology at a final take-off site in spring (Sivash, Ukraine). - Ibis 148: 211-220.

Vieira, B. P., Furness, R. W. and Nager, R. G. 2016. Using field photography to study avian moult. - Ibis in press.

Walpole, B., Nol, E. and Johnston, V. 2008. Breeding habitat preference and nest success of Red-necked Phalaropes on Niglintgak Island, Northwest Territories. - Canadian Journal of Zoology 86: 1346-1357.

Webster, M. S., Marra, P. P., Haig, S. M., Bensch, S. and Holmes, R. T. 2002. Links between worlds: Unraveling migratory connectivity. - Trends in Ecology and Evolution 17: 76-83.

Weimerskirch, H. 2002. Seabird demography and its relationship with the marine environment. - In: Biology of marine birds. pp. 115-135.

Weimerskirch, H. 2007. Are seabirds foraging for unpredictable resources? - Deep-Sea Research Part II: Topical Studies in Oceanography 54: 211-223.

Weimerskirch, H., Åkesson, S. and Pinaud, D. 2006. Postnatal dispersal of wandering albatrosses Diomedea exulans: Implications for the conservation of the species. - Journal of Avian Biology 37: 23-28.

Weiser, E. L., Lanctot, R. B., Brown, S. C., Alves, J. A., Battley, P. F., Bentzen, R., Bêty, J., Bishop, M. A., Boldenow, M., Bollache, L., Casler, B., Christie, M., Coleman, J. T., Conklin, J. R., English, W. B., Gates, H. R., Gilg, O., Giroux, M.-A., Gosbell, K., Hassell, C., Helmericks, J., Johnson, A., Katrínardóttir, B., Koivula, K., Kwon, E., Lamarre, J.-F., Lang, J., Lank, D. B., Lecomte, N., Liebezeit, J., Loverti, V., McKinnon, L., Minton, C., Mizrahi, D., Nol, E., Pakanen, V.-M., Perz, J., Porter, R., Rausch, J., Reneerkens, J., Rönkä, N., Saalfeld, S., Senner, N., Sittler, B., Smith, P. A., Sowl, K., Taylor, A., Ward, D. H., Yezerinac, S. and Sandercock, B. K. 2016. Effects of geolocators on hatching success, return rates, breeding movements, and change in body mass in 16 species of Arctic-breeding shorebirds. - Movement Ecology 4: 12.

Wernham, C., Siriwardena, G. M., Toms, M., Marchant, J., Clark, J. A. and Baillie, S. 2002. The migration atlas: movements of the birds of Britain and Ireland (CV Wernham, MP Toms, JH Marchant, JA Clark, GM Siriwardena, and SR Baillie, Eds.). - T. \& A.D. Poyser, London.

Whitfield, D. P. 1990. Male choice and sperm competition as constraints on polyandry in the red-necked phalarope Phalaropus lobatus. - Behavioral Ecology and Sociobiology 27: 247-254.

Whitfield, D. P. 1995. Behaviour and ecology of a polyandrous population of Grey Phalaropes Phalaropus fulicarius in Iceland. - Journal of Avian Biology 26: 349-352.

Wiley, R. H. and Lee, D. S. 1998. Long-tailed Jaeger (Stercorarius longicaudus). - The birds of North America online.

Wiley, R. H. and Lee, D. S. 1999. Parasitic Jaeger (Stercorarius parasiticus). - The birds of North America online.

Wilmers, C. C., Nickel, B., Bryce, C. M., Smith, J. A., Wheat, R. E. and Yovovich, V. 2015. The golden age of bio-logging: how animal-borne sensors are advancing the frontiers of ecology. - Ecology 96: 1741-1753. 
Winger, B. M., Auteri, G. G., Pegan, T. M. and Weeks, B. C. 2018. A long winter for the Red Queen: rethinking the evolution of seasonal migration. - Biological Reviews 94(3): 737752.

Witter, M. S. and Cuthill, I. C. 1993. The ecological costs of avian fat storage. - Philosophical Transactions of the Royal Society B: Biological Sciences 340: 73-92.

Wong, S. N. P., Ronconi, R. A. and Gjerdrum, C. 2018. Autumn at-sea distribution of phalaropes Phalaropus and other seabirds in the lower Bay of Fundy, Canada. - Marine Ornithology 46: 1-10.

Woodworth, B. K., Wheelwright, N. T., Newman, A. E., Schaub, M. and Norris, D. R. 2017. Winter temperatures limit population growth rate of a migratory songbird. - Nature Communications 8: 1-9.

Worm, B. and Branch, T. A. 2012. The future of fish. - Trends in Ecology \& Evolution 27: 594-599.

Wynne-Edwards, V. C. 1935. On the habits and distribution of birds on the North Atlantic. Proceedings of the Boston Society of Natural History 40: 233-346.

Yamamoto, T., Hoshina, K., Nishizawa, B., Meathrel, C. E., Phillips, R. a. and Watanuki, Y. $2014 a$. Annual and seasonal movements of migrating short-tailed shearwaters reflect environmental variation in sub-Arctic and Arctic waters. - Marine Biology 162: 413-424.

Yamamoto, T., Takahashi, A., Sato, K., Oka, N., Yamamoto, M. and Trathan, P. N. 2014b. Individual consistency in migratory behaviour of a pelagic seabird. - Behaviour 151: 683-701.

Yuri, T. and Rohwer, S. 1997. Molt and migration in the Northern Rough-winged Swallow. - The Auk 114: 249-262.

Yurkowski, D., Semeniuk, C., Harwood, L., Rosing-Asvid, A., Dietz, R., Brown, T., Clackett, S. Grgicak-Mannion, A., Fisk, A. and Ferguson, S. 2016. Influence of sea ice phenology on the movement ecology of ringed seals across their latitudinal range. - Marine Ecology Progress Series 562: 237-250.

Zenatello, M., Serra, L. and Baccetti, N. 2002. Trade-offs among body mass and primary moult patterns in migrating Black Terns Chlidonias niger. - Ardea 90: 411-420. 
A very dark barred morph juvenile Long-tailed Skua. Genuinly dark morph juveniles lack barred feathers and show - at most - pale fringes to coverts. Mauritania, 4 November 2016. 


\section{Author affiliations}

Acknowledgements / Dankwoord Publications Author contributions Biography

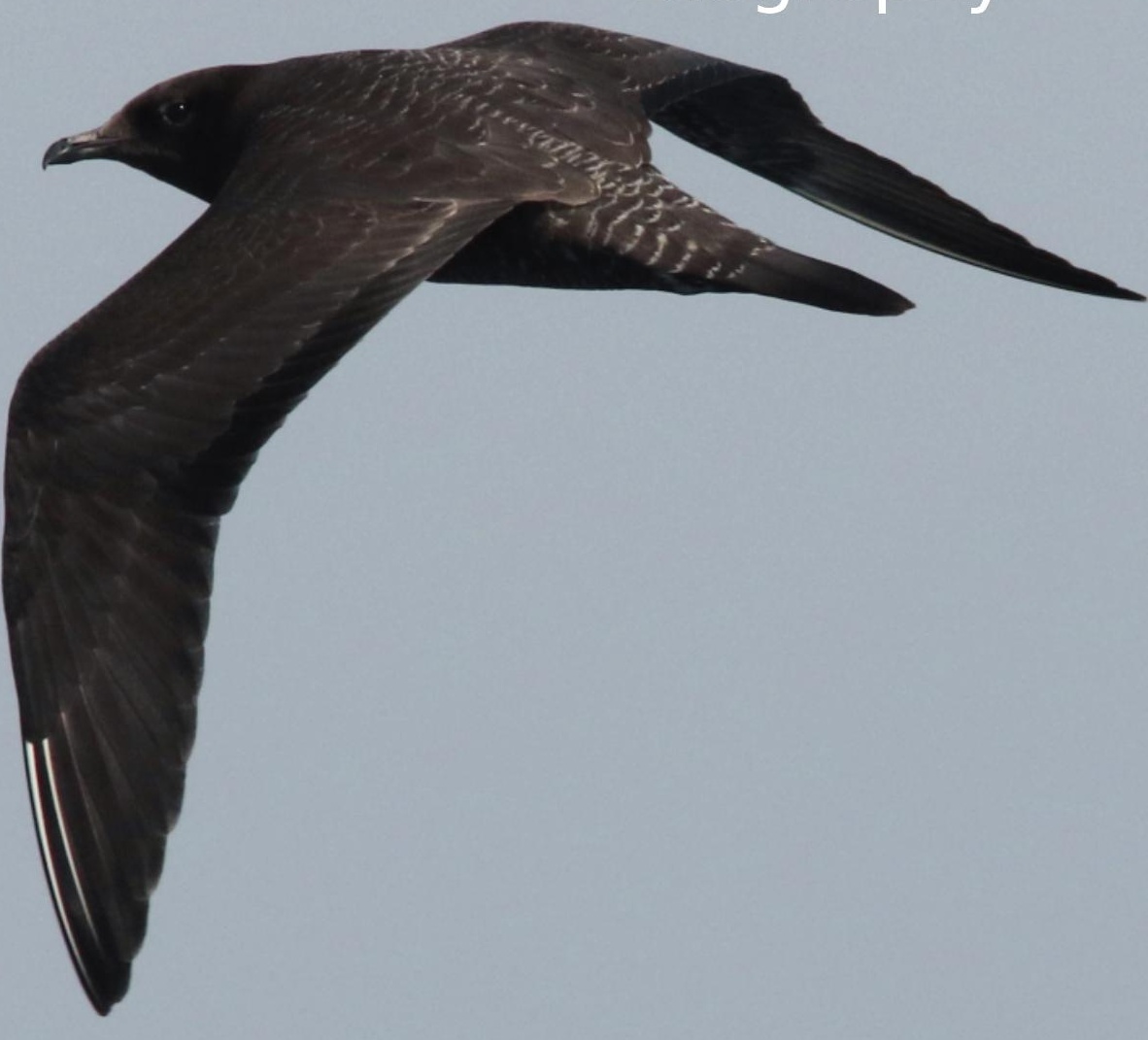




\section{AUTHOR AFFILIATIONS}

\section{Ron Ydenberg \\ Simon Fraser University, Vancouver, \\ Canada}

\section{Ingrid Tulp}

Wageningen Marine Research, IJmuiden, Netherlands

\section{Raymond Klaassen}

University of Groningen, Groningen, Netherlands

\section{Jose Alves}

CESAM, University of Aveiro, Aveiro, Portugal

\section{Georg Bangjord,}

Jonsvatnet, Norway

Loic Bollache

University of Bourgogne, Dijon, France

Mark Bolton

RSPB, Sandy, United Kingdom

John Calladine,

BTO, Stirling, UK

\section{Kees Camphuysen}

NIOZ, Den Burg, Netherlands

Rohan Clarke

Monash University, Clayton, Australia

Dorothee Ehrich,

UiT The Arctic University of Norway,

Tromsø, Norway

\section{Olivier Gilg}

Laboratoire Biogéosciences / University of Bourgogne, Dijon, France

Jan van Gils

NIOZ, Den Burg, Netherlands

Jacob González-Solís

Universitat de Barcelona, Barcelona, Spain

\section{Gunnar Thor Hallgrimsson}

University of Iceland, Reykjavik, Iceland

\section{Sjurdur Hammer}

Environment Agency, Argir, Faroe Islands

\section{Jannik Hansen}

Deptartment for Bioscience, Aarhus

University, Aarhus, Denmark
Sveinn Are Hanssen

NINA, Tromsø, Norway

Sarah Harris,

BTO, Norfolk, UK

Vincent Hin

University of Amsterdam, Netherlands

Liz Humphreys, BTO, Stirling, UK

Johannes Hungar Bonn, Germany

Kirstin Janssen

UiT The Arctic University of Norway, Tromsø, Norway

Marcel Klaassen

Deakin University, Deakin, Australia

Yann Kolbeinsson

Northeast Iceland Nature Research

Centre, Husavik, Iceland

Ko de Korte

Amsterdam, Netherlands

Johannes Lang

University Giessen, Giesen, Germany

Aleksi Lehikoinen

The Helsinki Lab of Ornithology, Helsinki, Finland

Elina Mäntylä

Freie Universität Berlin, Berlin, Germany

Tim van der Meer

Castricum, Netherlands

\section{Børge Moe}

NINA, Trondheim, Norway

David Okill

Trondra, Shetland, United Kingdom

Ib Krag Petersen

Deptartment for Bioscience, Aarhus University, Aarhus, Denmark

Richard Phillips

BAS, NERC, Cambridge, UK

Ron Porter, Ambler, USA

Morrison Pot

Altenburg \& Wymenga, Feanwâlden, Netherlands 
Peter Pyle

California Academy of Sciences,

California, United States

Raül Ramos

Universitat de Barcelona, Barcelona, Spain

\section{Hans Schekkerman}

SOVON, Nijmegen, Netherlands

Niels Martin Schmidt

Deptartment for Bioscience, Aarhus

University, Aarhus, Denmark

\section{Benoit Sittler}

University of Freiburg, Freiburg,

Germany

\section{Kjell Mork Soot,}

Hareid, Norway

\section{Malcolm Smith}

RSPB Scotland, Shetland, United

Kingdom

\section{Katherine Snell}

University of Copenhagen, Copenhagen,

Denmark

\section{Aleksandr Sokolov}

Russian Academy of Sciences,

Labytnangi, Russia

\section{Kaisa Välimäki}

The Helsinki Lab of Ornithology, Helsinki, Finland

\section{Sölvi Rúnar Vignisson}

Soutwest Iceland Nature Research Institute, Iceland

\section{Sverrir Thorstensen,}

Soutwest Iceland Nature Research Institute, Iceland

\section{Böðvar pórisson}

University of Iceland, Bankavegur, Iceland
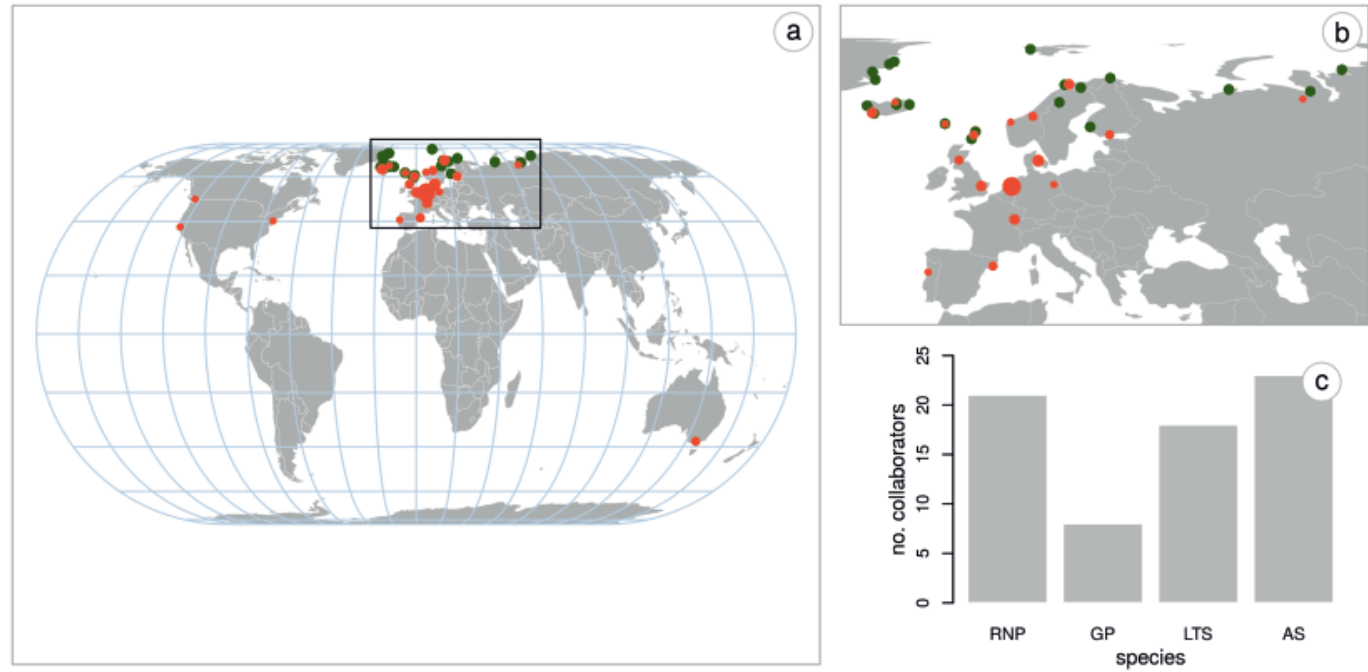

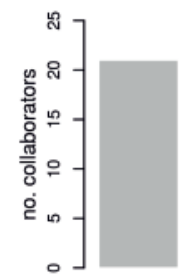

RN

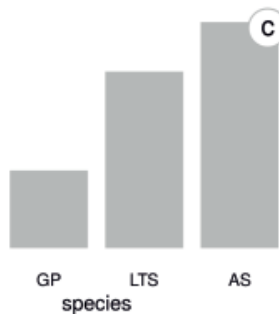

FIGURE 12.1 | a) Geographic distribution of co-authors (red) and field sites (green); the rectangle is enlarged in b. c) Number of co-authors per species. 


\section{PUBLICATIONS}

\section{Peer-reviewed papers}

van Bemmelen RSA, Y Kolbeinsson, R Ramos, O Gilg, M Smith, JA Alves, H Schekkerman, A Lehikoinen, IK Petersen, B pórisson, AA Sokolov, K Välimäki, T van der Meer, JD Okill, M Bolton, B Moe, SA Hanssen, L Bollache, A Petersen, S Thorstensen, J González-Solís, RHG Klaassen \& I Tulp (2019) A migratory divide among red-necked phalaropes in the Western Palearctic reveals contrasting migration and wintering movement strategies. Frontiers in Ecology \& Evolution 7: 86

Baptist MJ, RSA van Bemmelen, MF Leopold, D de Haan, H Flores, B Couperus, S Fassler \& SCV Geelhoed (2019) Self-foraging vs facilitated foraging by Lesser Black-backed Gull (Larus fuscus) at the Frisian Front, the Netherlands. Bulletin of Marine Science 95: 29-43

van Bemmelen RSA, RH Clarke, P Pyle \& CJ Camphuysen 2018. Timing and duration of primary molt in northern hemisphere skuas and jaegers. The Auk 135(4): 1043-1054

van Bemmelen R, B Moe, SA Hanssen, NM Schmidt, J Hansen, J Lang, B Sittler, L Bollache, I Tulp, RHG Klaassen \& O Gilg 2017. Flexibility in otherwise consistent non-breeding movement of a long-distance migratory seabird, the Long-tailed Skua. Marine Ecology Progress Series 578:167-181

Aarts G, AM von Benda-Beckmann, K Lucke, KÖ Sertlek, R van Bemmelen, SCV Geelhoed, S Brasseur, M Scheidat, F-PA Lam, H Slabbekoorn \& R Kirkwood 2016. Harbour porpoise movement strategy affects cumulative number of animals acoustically exposed to underwater explosions. Marine Ecology Progress Series 557: 261-275

Gilles A, S Viquerat, EA Becker, KA Forney, SCV Geelhoed, J Haelters, J Nabe-Nielsen, M Scheidat, U Siebert, S Sveegaard, FM van Beest, R van Bemmelen \& G Aarts. 2016. Seasonal habitat-based density models for a marine top predator, the harbor porpoise, in a dynamic environment. Ecosphere 7:e01367.

van Bemmelen RSA, Hungar J, Tulp I \& RHG Klaassen (2016) First geolocator tracks of Swedish red-necked phalaropes reveal the Scandinavia-Arabian Sea connection. Journal of Avian Biology 47(3): 295-303.

von Benda-Beckmann AM, G Aarts, HÖ Sertlek, K Lucke, WC Verboom, RA Kastelein, DR Ketten, R van Bemmelen, F-PA Lam, RJ Kirkwood \& MA Ainsle (2015). Assessing the impact of underwater clearance of unexploded ordnance on Harbour Porpoises (Phocoena phocoena) in the Southern North Sea. Aquatic Mammals 41(4), 503-523.

Debrot AO, R van Bemmelen \& J Ligon (2015) Bird communities of contrasting secondary habitats of Bonaire, in the arid South-eastern Caribbean. Caribbean Journal of Science 48 : 138-150.

Geelhoed SCV, M Scheidat, RSA van Bemmelen \& G Aarts (2013) Abundance of harbour porpoises (Phocoena phocoena) on the Dutch Continental Shelf, aerial surveys in July 2010-March 2011. Lutra 56(1): 45-57.

van Bemmelen R (2010) Immature Long-tailed Skuas Stercorarius longicaudus in Swedish Lapland in 2009. Ornis Svecica 20: 81-86.

van Bemmelen R \& B Wielstra (2008) Vagrancy of Brünnichs Guillemot in Europe. Seabird 21: 16-31. 


\section{Selected non-peer-reviewed papers}

van Bemmelen RSA, J Lehmhus \& S G Mlodinow (2018) Hybrid Northern Shoveler x Bluewinged Teal on Schiermonnikoog, Netherlands, in May 2014, and identification and WP occurrence. Dutch Birding 40(2): 71-81

van Bemmelen RSA, van Spanje T \& CJ Camphuysen (2017) Olive-backed Pipits and Yellowbrowed Warblers at Cap Blanc peninsula, Mauritania, in November 2016. Dutch Birding 39(2): 103-105

van Bemmelen RSA (2015). Retained barred feathers in adult-summer Long-tailed Jaeger. Dutch Birding 37(2): 92-94.

van Bemmelen RSA, Groenendijk D, Ovaa A \& CDNA (2014) Zeldzame vogels in Nederland in 2012. Limosa 87(4): 216-221.

Wielstra B \& van Bemmelen R (2013) Kortbekzeekoet langs Schiermonnikoog in oktober 2005. Dutch Birding 35(2): 88-99.

Bot S, van Bemmelen RSA, Eggenhuizen T \& Groenendijk D (2012) Invasion of White-headed Long-tailed Tits in The Netherlands in 2010-11: identification. Dutch Birding 34(3): 85-91. van Bemmelen RSA, Eggenhuizen T \& Faveyts W (2012) Invasion of White-headed Long-tailed Tits in The Netherlands in 2010-11: progression, numbers and distribution. Dutch Birding 34(3): 77-84.

Leopold M, van Bemmelen R, Geelhoed S \& Witte R 2012. Alken Alca torda als fanatieke scheepsvolgers. Sula 24(3): 109-120.

van Bemmelen R \& Stegeman L (2011) Pontische Meeuwen Larus cachinnans op de Nederlandse Noordzee. Sula 24(3): 97-108.

Geelhoed S, van Bemmelen R, Keijl G, Leopold M \& Verdaat H (2011) Nieuwe kolonie Drieteenmeeuwen Rissa tridactyla in de zuidelijke Noordzee. Sula 24(1): 27-30. van Bemmelen, R \& Wielstra, B (2005a) Invasie van kleine alken op 23 oktober 2005: kort maar krachtig. Nieuwsbrief NZG 7(1):1-4.

\section{Selected reports and book chapters}

Camphuysen CJ, van Bemmelen R \& T van Spanje (2017) Ship-based seabird and marine mammal surveys off Mauritania, 1-12 November 2016. Royal Netherlands Institute for Sea Research.

Groenendijk, D \& van Bemmelen RSA (2014) Razend mooi, divers en interessant: nachtvlinders. Chapter in: de Raad J \& L Kooistra (eds). Texel is anders. Vereniging Natuurmonumenten.

Leopold MF, van Bemmelen RSA \& AF Zuur (2012) Responses of local birds to the offshore wind farms PAWP and OWEZ off the Dutch mainland coast. IMARES Report C151/12 van Bemmelen R, Bos O \& M Leopold (2012) Vogelwaarden van de Bruine Bank. IMARES report C138/12. 


\section{ACKNOWLEDGEMENTS / DANKWOORD}

Every year in June since 2007, I have been in Ammarnäs to survey and study birds breeding in the most beautiful mountain tundra of the world; specifically Long-tailed Skuas and Red-necked Phalaropes. With a median distance between Long-tailed Skua nests of $766 \mathrm{~m}(n=240)$, fieldwork in Ammarnäs always involved a lot of walking. From 2010 onwards, I logged the distances I walked after crossing the treeline, thus excluding a 45-minute climb to get there, and excluding the times I ran out of batteries or when the GPS failed to record my track for other reasons. In total, I logged nearly 2200 km, with a minimum of 29 km in 2015 (when our daughter Erin was born and I spent only a week with Tim, Michiel and Piet) and a maximum of $615 \mathrm{~km}$ in 2011 (during a major lemming peak, with Christian). However, I did not do this alone. I received plenty of help from others both during fieldwork and when back in 'the office'.

Ingrid, jij bent natuurlijk de eerste die ik hier wil bedanken, want zonder jouw inzet en toewijding had ik misschien nooit het onderzoek in Ammarnäs om kunnen zetten in een PhD. Jij initieerde het onderzoeksvoorstel voor NWO dat uiteindelijk in mijn PhD positie uitmondde, en het was jouw idee om daar ook andere soorten in op te nemen dan Kleinste Jager en Grauwe Franjepoot. Bedankt dat je er altijd was, altijd snel reageerde op allerhande zaken, en mijn (some zeer premature) manuscripten voorzag van altijd zinnige, scherpe commentaren. Bedankt ook voor het vertrouwen dat je in me stelde, ook als stukken (te) lang op zich lieten wachten. Ik ben je vooral veel verschuldigd vanwege de grote investering van tijd en moeite die je stak in het veldwerk te Slettnes. Ik weet dat je het leuk vond om weer in de Arctis te werken, maar het legde ook een druk op je toch al volle tijdsplanning. In Slettnes heb je alle mogelijke uitdagingen van het vangen van jagers en franjepoten ervaren; vogels die zich uit de strik wurmden, kapotte stofzuigerhaspels, het vangen met kippeneieren en het bedenken van alternatieve vangwijzen. Het was heel leuk om in 2018 samen in het veld te zijn, ondanks de soms frustrerende vangpogingen. Sorry dat ik drie jagers met loggers ving op de ochtend na je vertrek... ;) Superleuk dat we nu beiden in Castricum wonen!

Raymond, het mag duidelijk zijn dat jij een grote invloed hebt gehad op de inhoud van deze thesis. Bedankt voor de verhelderende of verwarrende discussies - het was een geruststelling dat ook jij de resultaten van Kleine Jager ingewikkeld en lastig te begrijpen vond... Met name bedankt voor je grote hulp bij het schrijven van de twee Grauwe Franjepoot-papers en het Kleinste Jager-paper. Ook bedankt voor je enthousiasme en je goede ideeën!

Ron, our meetings were few but I always felt inspired by your comments and questions. Thanks for your help and your advice, including the gentle pressure to focus on finishing the thesis instead of including more chapters... 
Dear members of the reading committee, Morten Frederiksen, Bart Nolet, Jaap van der Meer and Adriaan Rijnsdorp, thank you for taking the time and effort to evaluate my thesis. I am looking forward to the defence!

Børge, you were my main partner in crime in our international collaborations, and have played a very important role in many of the chapters of my thesis and hopefully in many more future papers. Thanks for the many discussions, the visits to Trondheim, and the unwavering trust in my (programming and writing) capabilities! Thanks for letting me write up the Grey Phalarope story - it felt weird and exciting at the same time to work on data that I did not collect myself at all. Sveinn Are, thanks for being Børges' partner in crime, and your supportive attitude to whatever I was doing or proposed to do. Looking forward to work with both of you on many more skua projects!

Hans, jouw bijdrage aan dit proefschrift is groot, met name door de investing van je tijd, kennis en grote ervaring in het jaarlijkse veldwerk te Slettnes, maar ook vanwege je input in de papers over Grauwe Franjepoten en Kleine Jagers. We hadden een mooie tijd in Slettnes in 2018! Als ik in Castricum met je over zee kijk moet ik steeds denken aan die fantastische jagers, Kortbekzeekoeten en Dwergvinvissen die we vanaf de vuurtoren zagen. Janne, ook jij heel erg bedankt voor je hulp in het veld te Slettnes!

Olivier, thanks for your hospitality in Francheville - I really enjoyed both visits, and not only because of the good food! Thanks for the wine, the cheese, the frogs and the snails, and of course the discussions and for your trust in me for writing that phalarope paper!

The work in Ammarnäs started in 2007 when Jim de Fouw asked me to join a breeding bird survey and a pilot study to see whether studying Golden Plovers would be feasible. Our conclusion that this was near-impossible was completely ignored by Paula Machin and Juan Fernandez-Elipe, who produced some really nice papers after tough fieldwork in 2009-2013. Master of nest finding Johannes Hungar started working on wader nest predation already a year earlier - in 2008 - and also helped me out in 2015. Johannes, Paula, Juan, thanks for all the nice moments in the station or in the field, during your visits to Texel, Amsterdam and Castricum, and for motivation to climb to Geppejaure or Gelmetje again and again. Ammarnäs has not been the same since you left; I still miss those days!

The fieldwork in Ammarnäs and Slettnes would not have been possible without the effort and enthusiasm of many field assistances. In Ammarnäs, these were: Piet Admiraal (2015), Peter Antkowiak (2016-2019), Christian Brinkman (2011, 2016), Pablo Capilla (2011-2012), Michiel Elderenbosch (2015-2016), Jim de Fouw (2007), Steve Geelhoed (2010), Jonas Hagge (2018), Vincent Hin (2013), Christian Hoefs (2016-2019), Noel Hohenthal (2018) Ferry van de Lans (2008), Tim van der Meer 
(2014-2019), Wesley Overman (2010), Morrison Pot (2017-2019), and Bram Ubels (2016). Therese Flink (2016), Jesper Andersson (2016), Birgith Unterthurner (20172018) and Andrew Barrett (2019) helped out with the artificial nest experiment, part of a circumpolar project on trophic interactions. Tim, Christian and Peter; great to see the birth and development of your project on 'the miracle', the Dotterel. I am sure it will result in many exciting discoveries! Christian, thanks for allowing me to use so many of your amazing photographs! Martin Green and Åke Lindström, I cannot thank you enough for your help and support to carry out the fieldwork in the most beautiful mountain tundra of the world. Martin, thanks for welcoming me and the people I bring in the station, thanks for all the discussions on skuas, plovers, owls, bears, etc, and Wolverines (in my view, you are already way beyond your lifetime sightings quota for the latter species). Åke, thanks for your comments on the first draft of the skua moult paper and the discussions on the phalaropes. Sören Svensson, thanks for the many nice discussions and your interest in Long-tailed Skuas. Goran Paulson, thanks for the many rides to the Raurejaure parking lot in the earlier years, and the music we shared later on. Thanks also to the other bird surveyors and people in the Ammarnäs field station.

Bij het veldwerk in Slettnes werden we geholpen door: Daniel van Denderen (20142015), Jan van Dijk (2014), Maria van Leeuwe (2016), Daan Liefhebber (2014), Marc van Roomen (2016), Morrison Pot (2014), Rinse van der Vliet (2016), Geert Aarts (2017), and of course Janne Schekkerman (2014, 2016, 2017, 2019). Allen bedankt voor jullie enorme hulp! Morrison, het blijft mooi dat je jouw werk in Slettnes hebt kunnen omzetten in een manuscript. Ik hoop van harte dat het je lukt een PhD-plek te bemachtigen! Bij de start van het veldwerk in Slettnes konden we rekenen op Nederlandse hulp ter plaatse: Cees en Minnie Tesselaar. Veel dank voor jullie hulp en het aangename contact. Morrison, Denise en ik zullen de cake van Minnie bij ons vertrek in 2014 niet snel vergeten. Torstein Johnsrud and Jeanette Hickman, thanks for your hospitality in the Slettnes lighthouse. Barbara Ganther and Hans-Ulrich Rösner, it was really nice to share the lighthouse with you in 2018! Thanks for the shared dinners, the discussions, the exchange of fieldnotes and your help with chapter 9 !

Thomas Lameris, bedankt voor het aanbod in 2014 om Grauwe Franjepoten en Kleine Jagers te vangen tijdens de door jou georganiseerde expeditie naar Tobseda! Dank aan Stefan Sand, Kees Schreven en Jasper Koster, die dit vervolgens uitvoerden. Jasper, ik ben nog altijd enorm onder de indruk van de 120+ Grauwe Franjepoten die je ving nadat ik suggereerde om ook 'wat' extra vogels te vangen voor biometrie. Geweldig! Dank ook voor je inzet in Erkuta.

Several of the key chapters in this thesis are the result of international collaborations. Writing these chapters has only been possible because of the willingness to collaborate of all these teams, sharing such valuable and difficult-toobtain geolocator data. Obtaining geolocator data usually involves a huge 
investment in terms of time, money and effort, and the inclusion and sequence of co-authors is 'very bad' at conveying the (relative) amounts of work done by each collaborator and her/his field team members. The first collaboration arose via Børge and Olivier with other members of the interactions teams in Greenland: in particular Johannes Lang, Benoit Sittler, Jannik Hansen and Niels Martin Schmidt. This resulted in chapter 6, shared datasets of Long-tailed and Arctic Skua geolocator data. Thanks for sharing your data, sending me all kinds of feather and plant samples, and for allowing me to join your Interaction meetings in Francheville and Copenhagen! I am sure this collaboration will lead to more papers. The second multi-site collaboration was between the many teams working on Red-necked Phalaropes, and was initiated by Yann Kolbeinsson and Jakob Gonzalez-Solis at the international seabird conference in Cape Town, South Africa. The success of the paper is earned in particularly by the Icelandic teams of Yann and of Jose Alves. Thanks for your patience and the nice collaboration! The final large-scale collaboration is the multi-site study on Arctic Skuas, chapter 8. Kat and Sjurdur, thanks for your efforts at the Faroe Islands and the in our 'skua working group' with Liz Humpreys and Børge. We have gathered a fantastic dataset!

Thanks also to co-authors of my other papers. Marcel Klaassen en Jan van Gils, bedankt voor jullie input in hoofdstuk 7 ! Het verhaal is véél helderder geworden. Nu nog de data van 2019 erbij... Kirstin Jansen, thanks for sharing your 1997/1998 data from Slettnes and for your enthusiasm on skuas! Ko de Korte, bedankt voor je eindeloze interesse in Kleinste Jagers in het algemeen en mijn werk in het bijzonder. Bedankt voor de avonden in Amsterdam en Castricum, waarin we veel meer bespraken dan alleen jagers, en voor je stimulans om samen met Hans-Ulrich Peter een sessie over jagers te organiseren op de World Seabird Conference in Kaapstad. Heel leuk dat je in 2014 een paar dagen met Tim en mij in het veld was in Ammarnäs. Kees Camphuysen, bedankt voor de trips naar Jan Mayen en Mauritanië: twee onvergetelijke reizen! Leuk dat we samen een paper hebben kunnen schrijven (hoofdstuk 4), voor een groot deel op grond van de foto's uit Mauritanië. Wat mij betreft schrijven we minstens nog één paper: over het belang van de WestAfrikaanse wateren voor jagers.

Collega's van Wageningen Marine Research, in het bijzonder Mardik, Meike, Geert, Sophie, Daniël, Michiel, Steve, Hans, Olvin, Joep, Ulrika, Floor en Tobias, bedankt voor de koffie- en lunchpauzes en andere leuke momenten. Mardik, bedankt dat jij me in 2009 'binnenhaalde' bij WMR (toen nog Imares). Wie weet waar ik anders terecht gekomen was? Dankzij jou heb ik veel kunnen varen en met $\mathrm{R}$ kunnen werken. Het was een mooie tijd! Floris Groenendijk, bedankt voor het financieren van de eerste 25 geolocators voor Kleinste Jagers in 2011. De timing hiervan was perfect, want door de enorme lemmingpiek in dat jaar had mijn geolocator project een vliegende start. Herbert Prins, Frank van Langevelde, Gerda Martin en Patricia Meijer van REG/WUR, bedankt voor jullie logistieke hulp! 
Dan zijn er nog allerlei andere mensen die mij hebben geholpen. Maarten Brugge (NIOZ), bedankt dat we een geolocator-attachment-training mochten doen met de Rock Sandpipers. Marcel van der Meer, Jort Ossebaar, Ronald van Bommel en Kevin Donkers (NIOZ), bedankt voor jullie hulp bij de isotoopmetingen.

Buiten het bureau- en veldwerk was er gelukkig ook nog ander vertier dankzij (vogel)matties: Dick, Swen, Niels, Martijn, Kasper, Ben, Wouter, Sander, Hans, Anieke, Floor, Sara, Thomas, Thomas en Jesse, Jeroen \& Michelle \& Frey \& Iris, Fleur \& Machiel \& Magnus, Roeland \& Maaike \& Isa Mimi, Ben \& Marieke \& Toon. Swen! Er moet meer en harder gevogeld worden, zo kan het niet langer! Dick! Wanneer ontdekken we weer eens wat? Roeland, Maaike, Isa Mimi, Ben, Marieke en Toon: C'cum is hot!! Leuk dat jullie hier ook (komen) wonen!

Lieve Yasmin, Vincent en Casper! Wat fijn dat jullie bestaan en ik ook! Ik weet ook niet hoe het anders zou moeten. Dank voor het plezier, het relativeren van allerlei zaken maar in het bijzonder dit proefschrift, en natuurlijk jullie liefde en vriendschap. Yasmin, superbedankt dat je mijn paranimf wil zijn!

Fons en Gré, bedankt voor alle (oppas)hulp - vooral tijdens mijn veldwerk - maar ook daarbuiten. Heel fijn dat jullie nu zo dichtbij wonen en Erin en Sam vaak kunnen zien. Jan, Annet, Ineke en Ed, bedankt! Ineke, bedankt voor je hulp bij saaie (belasting) en leuke (Erin) zaken, en superleuk dat je mijn paranimf wilt zijn! Papa en mama, bedankt dat ik de vrijheid kon genieten om te doen wat ik graag wilde. Bedankt ook voor het vele oppassen op Erin, en nu ook op Sam. Ik weet dat jullie dit niet zouden willen missen, maar zonder deze hulp zouden we thuis toch een logistiek probleem hebben!

Allerliefste Denise, beukenootje, zonder jou was het nooit gelukt om dit proefschrift te maken. Bedankt dat je de vrijheid gaf voor het veldwerk, conferenties en al mijn obsessies. En natuurlijk vooral voor al je liefde! Lieve Erin, nu ik dit boek af heb kan ik eindelijk aan het boek over de Veelvraat beginnen. We gaan ook veel buiten spelen, avonturen beleven, de duinen in, het strand op, tekenen, buitenlands praten en grapjes maken. Sam, wat een geluk dat jij er bent! Zonder jou had ik dit proefschrift nooit ingeleverd. Ik ben superbenieuwd wat we samen gaan meemaken. Denise, Erin en Sam, ik zou jullie heel graag Ammarnäs willen laten zien - maar alleen tijdens een lemmingpiek! 


\section{AUTHOR CONTRIBUTIONS}

Chapter I - I conceived and wrote the general introduction, with feedback from IT, RY and RK.

Chapter II - I collected the data, with help from JH. I also conceived and wrote the paper, with help from RK and IT.

Chapter III - YK and JG-S initiated the collaboration. I, IT, RR and RK conceived the focus of the manuscript. Together with RR, I analysed the data. I also wrote the first draft of the manuscript. All authors collected geolocator and/or biometric data, and provided critical feedback on the manuscript.

Chapter IV - I wrote the manuscript; all authors helped in revising it. All authors except me and RP collected the data.

Chapter V - I conceived the idea, analysed the data and wrote the first draft of the paper. All authors collected data and contributed to writing the paper.

Chapter VI - I conceived the paper and analysed the data. Together with RK, I wrote the first draft of the paper. All authors collected data and contributed to writing the paper.

Chapter VII - I conceived the idea, collected and analysed the data and wrote the first version of the manuscript. All authors contributed to the ms.

Chapter VIII - All authors collected data. I, BM, RK and IT conceived the paper and I wrote the first version of the manuscript.

Chapter IX - All authors collected data. I, IT and HS conceived the paper; VH designed the population model. I analysed the data and wrote the first version of the paper; all authors contributed to writing.

Chapter $\mathrm{X}$ - I conceived and wrote this general discussion, with feedback from IT, RY and RK. 


\section{BIOGRAPHY}

Rob was born in Amsterdam on 25 October 1982 and grew up in Uithoorn, just South of Amsterdam. His interest in animals in general was sparked at a very young age and from an age of 9 years he focussed on birds. Very much interested in bird identification, he authored the mystery bird competition 'Masters of Mystery' in the bimonthly birding magazine Dutch Birding during 2002-2009, together with Dick Groenendijk - his birding mentor from his mid-teens onwards. After this, he became a member of the Dutch rarity committee (CDNA) during 2009-2015.

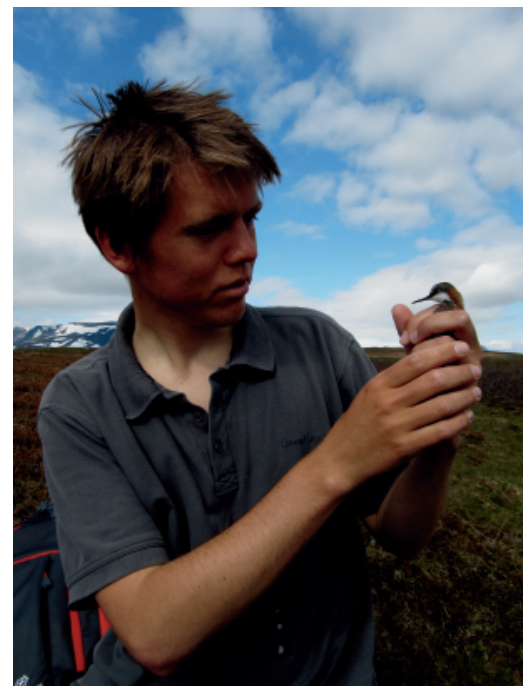

After finishing secondary school in 2001, studying biology at the University of Amsterdam was the logical next step. During his BSc and MSc on Evolutionary Ecology, Rob wrote his BSc thesis on colour polymorphism in damselflies (IBED/UvA), followed by internships on roost site choice of Red Knots (NIOZ) and cold response of plants in the paramó of the Ecuadorian Andes (IBED/UvA). However, his heart was with seabirds. Through a shared interest in (Atlantic) Great Cormorants he came into contact with Mardik Leopold (Imares, now known as WMR), which resulted in a position at Imares as a seabird researcher, starting on the day Rob received his MSc degree in biology in the summer of 2009. The work with Mardik and colleagues mostly involved ship-based surveys of seabirds to study the impact on seabird densities or delineate areas of high conservation value, and of aerial surveys of Harbour Porpoises to estimate population size and distribution in the Dutch sector of the North Sea. Beside allowing Rob to study seabirds, this position also provided plenty of opportunities to develop his R/statistics skills.

Back in 2007, Rob saw his first adult Long-tailed Skuas in Ammarnäs, Swedish Lapland, got hooked to the species and the place, and returned every year in June (except in 2018). Beside the Long-tailed Skua, Robs' attention was drawn to another seabird breeding in the inland mountain tundra surrounding Ammarnäs: the Red-necked Phalarope. The migration ecology of both species was still a black box back then, and Robs' wish was to study them, preferably in the form of a PhD. It was Ingrid Tulp who suggested to submit a research proposal written to the NWO (Ant)Arctic program in 2013, which resulted in the PhD thesis that is in your hands.

\section{Contact details}

email rvanbemmelen@gmail.com

researchgate https://www.researchgate.net/profile/Rob_Van_Bemmelen2 publons https://publons.com/researcher/1173553/rob-van-bemmelen/ 


\section{PE\&RC TRAINING AND EDUCATION STATEMENT}

With the training and education activities listed below the PhD candidate has complied with the requirements set by the C.T. de Wit Graduate School for Production Ecology and Resource Conservation (PE\&RC) which comprises of a minimum total of 32 ECTS ( $=22$ weeks of activities)

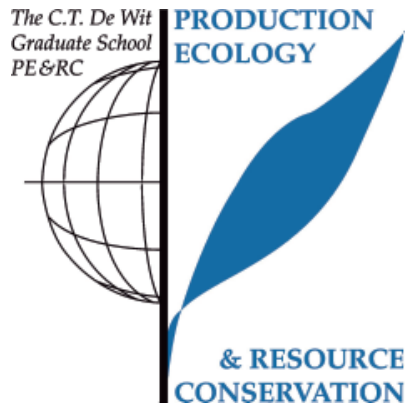

Review of literature (4.5 ECTS)

- Migratory connectivity and carry-over effects in seabirds

Writing of project proposal (4.5 ECTS)

- Migratory connectivity between Arctic breeding grounds and oceanic wintering areas of seabirds (2013)

\section{Post-graduate courses (3 ECTS)}

- Spatial ecology; PE\&RC (2014)

- Introduction to regression models with spatial and temporal correlation using INLA; WMR / Highland Statistics Ltd (2017)

\section{Laboratory training and working visits (3 ECTS)}

- Individual consistency in non-breeding movements of Long-tailed Skuas; NINA, Trondheim, Norway (2014)

- Income/capital breeding Long-tailed Skuas and classification of wintering areas of Arctic Skuas; NIOZ $(2016,2017,2018)$

- Migratory connectivity of Arctic Skuas across the Atlantic; NINA, Trondheim, Norway $(2018,2019)$

Invited review of (unpublished) journal manuscript (9 ECTS)

- Ornis Svecica (2011)

- Journal of Avian Biology (2016)

- Wader Study (2016)

- Journal of Avian Biology (2016)

- Environmental Research Letters (2016)

- Wader Study (2017)

- Marine Ecology Progress Series (2017)

- Journal of Avian Biology (2018)

- Ardea (2018)

Competence strengthening / skills courses (2.5 ECTS)

- Brain training; WGS

- Writing for academic publication; WMR / Linda McPhee 
PE\&RC Annual meetings, seminars and the PE\&RC weekend (2.1 ECTS)

- PE\&RC introduction weekend (2014)

- $\operatorname{NAEM}(2014,2015,2018)$

Discussion groups / local seminars / other scientific meetings (4.5 ECTS)

- Interactions meeting; Dijon, France (2014)

- Interactions meeting; Copenhagen, Denmark (2015)

- EcoDyn meetings; WMR $(2017,2018)$

International symposia, workshops and conferences (9.7 ECTS)

- APECS Polar symposium, Den Haag, the Netherlands (2014)

- World Seabird Conference II; Capetown, South Africa (2015)

- Animal Movement International Symposium: bridging the gap between modelling and tracking data; CanMove, Lund University, Sweden (2016)

- International Wader Study Group conference; Workum, the Netherlands (2018)

Lecturing / Supervision of practicals / tutorials (2.7 ECTS)

- Resource ecology (2016)

- Connectivity and population structuring in sealife; University of Barcelona, Spain (2017)

Supervision of MSC students (6 ECTS)

- Tim van der Meer, UvA: correlates of aggressive nest defense levels in Longtailed Skua

- Morrison Pot, WUR: spatial patterns in reproduction parameters in a colony of Arctic Skuas 
The research described in this thesis was financially supported by the Netherlands Organisation for Scientific Research (project number 866.13.005), the Schure-Beijerinck-Popping Fund (KNAW) and by the LUVRE project (Lund University).

Financial support from Wageningen University and Wageningen Marine Research for printing this thesis is gratefully acknowledged.

Photo credits: Christian Brinkman (6, 15), Denise Hermans (26/27), Christian Hoefs $(6,8 / 9,15,43,44 / 45,73,138 / 139,155,222,225)$, Jasper Koster (156/157, Joe Pender (74/75), Raja Stephenson (109), Jürgen Steudtner (181), Ingrid Tulp (7, 15, 197) and Rob van Bemmelen (5, 6, 15, 25, 92/93, 109, 113, 114/115, 137, 182/183, $199,200 / 201,226 / 227,238 / 239,265,266 / 267)$

Cover photo by Christian Hoefs

Printed by Ridderprint | www.ridderprint.nl. 
